\title{
ESSAYS ON THE INCENTIVES TO FORM INTERNATIONAL AGREEMENTS BETWEEN ASYMMETRIC COUNTRIES
}

by

Natalia Bezmaternykh

Diploma of Candidate of Economic Sciences, Novosibirsk State Agrarian University, Russia, 2009

Specialist Degree in Management, Altai State University, Russia, 2003

Bachelor Degree in Philology, Barnaul State Pedagogical University, Russia, 2004

A dissertation presented to Ryerson University

in partial fulfillment of the

requirements for the degree of

Doctor of Philosophy

in the Program of Economics

Toronto, Ontario, Canada, 2019

(C) Natalia Bezmaternykh, 2019 


\section{Author's Declaration}

I hereby declare that I am the sole author of this dissertation. This is a true copy of the dissertation, including any required final revisions, as accepted by my examiners.

I authorize Ryerson University to lend this dissertation to other institutions or individuals for the purpose of scholarly research.

I further authorize Ryerson University to reproduce this dissertation by photocopying or by

other means, in total or in part, at the request of other institutions or individuals for the purpose of scholarly research.

I understand that my dissertation may be made electronically available to the public. 
Essays on the Incentives to Form International Agreements between Asymmetric Countries

Natalia Bezmaternykh

Doctor of Philosophy, 2019

Department of Economics

Ryerson University

Abstract: International Environmental Agreements suffer from a strong free-riding incentive that generally leads to failure of coalition formation in the economics literature and have been largely unsuccessful in practice. At the same time, preferential trade agreements (PTAs) have increasingly included elements not specifically related to trade, such as domestic policy over the environment, labour, intellectual property, health and investment. One area that has received a great deal of attention is deep agreements is the environment. In this dissertation, we develop three models of asymmetric countries, that include both trade and environmental externalities and study the incentives to form international trade agreements between those asymmetric countries.

First, we develop a two-country, two-good model with cross-border negative spillovers and perfect competition in product markets. We compare shallow (trade only) and deep (trade and environment) trade agreements between those two large asymmetric countries, and we show that deep and shallow trade agreements have different outcomes in terms of world and individual countries welfares, trade specialization and environmental damages.

Next, we develop two three-country, three-goods models, a "competing importers model" and a "competing exporters model", and examine equilibrium agreements and environmental outcomes assuming (i) environmental agreements are negotiated separately, (ii) trade agreements are shallow, and (iii) trade agreements are deep. To examine the stability of endogenous deep and shallow trade 
agreements we set up various three stage games and use coalition-proof Nash equilibria refinement to circumvent the multiplicity of Nash equilibria. Furthermore, in order to examine the differences between shallow and deep trade agreements, we develop extended games where countries can choose between different deep and shallow PTAs and investigate how equilibrium agreements differ based on being deep or shallow. Therefore, in two different models of multiple asymmetric countries, we ask and answer the following questions: (i) how do equilibrium agreements differ when countries choose deep rather than shallow agreements?; (ii) given the choice between deep and shallow trade agreements, would countries prefer to incorporate an environmental clause into their equilibrium trade deal?; and (iii) what are the implications of including non-trade elements in PTAs for the pursuit of global free trade? 


\section{Acknowledgments}

I would like to extend my gratitude to everyone who supported and encouraged me during my $\mathrm{PhD}$ studies.

First, I would like to express my deep and sincere gratitude to my supervisor, Professor Paul Missios for his patience, suggestions and unwavering support throughout my studies and the entire research work. It was my great pleasure to work under his supervision, and I feel extremely privileged to have been his student. Without his guidance, valuable advice, encouragement and persistent help this dissertation would not have been possible.

Also, I am grateful to the members of my advisory committee, Dr. Germãn Pupato and Dr. Halis Murat Yildiz, who dedicated their valuable time and provided me with valuable feedback.

My sincere thanks also goes to the Department of Economics at Ryerson University, Dr. Maurice Roche and Dr. Claustre Bajona, as the chairs of the department, and Dr. Halis Murat Yildiz and Dr. Haomiao Yu, as directors of graduate programs, for creating and maintaining a health research and learning environment.

Finally, I would like to thank people who have encouraged me from the start of this $\mathrm{PhD}$ journey and continuously supported me during it: my family, my husband Oguz Yurekli, and my dearest friend, Sandra Tripone. 
Dedication

To my husband 


\section{Contents}

$\begin{array}{ll}\text { Abstract } & \text { iii }\end{array}$

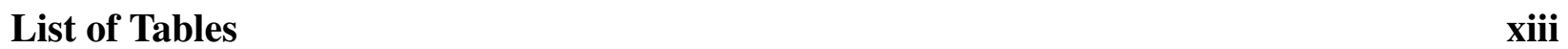

List of Figures $\quad$ xiv

$\begin{array}{ll}\text { List of Appendices } & \text { XV }\end{array}$

1 Introduction $\quad 1$

2 Chapter $2+5$

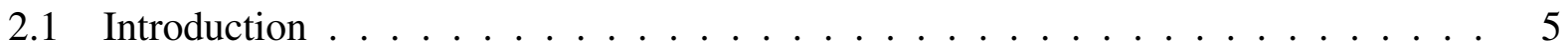

2.2 Overview of the Model . . . . . . . . . . . . . . . . . . . 9

2.3 Optimal Nash Tariffs and Environmental Taxes . . . . . . . . . . . . . . 14

2.4 Environmental Agreement and its Effect on Tariffs, Taxes, Damages, and Welfare

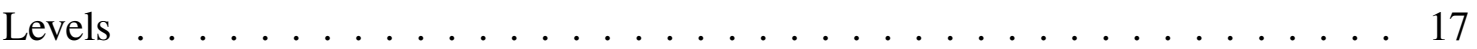

2.5 Local Pollution: Deep and Shallow Trade Agreements . . . . . . . . . . . . . . 20

2.5.1 Deep and Shallow Trade Agreements and their Effect on Taxes and Spe-

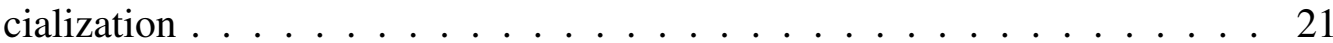

2.5.2 Deep and Shallow Trade Agreements: Welfare Analysis . . . . . . . . . 23

2.6 Global Pollution: Deep and Shallow Trade Agreements . . . . . . . . . . . . . 26

2.6.1 Deep and Shallow Trade Agreements and their Effect on Taxes and Specialization ............................. 27

2.6.2 Deep and Shallow Trade Agreements: Welfare Analysis . . . . . . . . . . 28

2.7 Deep and Shallow Trade Agreements and their Effect on the Environmental Damages 31

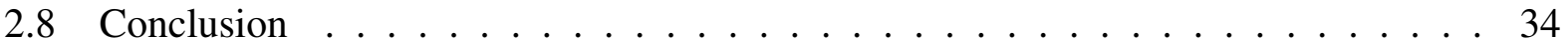

$\begin{array}{llr}3 & \text { Chapter } 3 & 37\end{array}$

3.1 Introduction . . . . . . . . . . . . . . . . . 37 
3.2 The Model . . . . . . . . . . . . . . . . . . . . . . . . . . . 43

3.2.1 Overview of the Model . . . . . . . . . . . . . . . . . . . . . . 43

3.2.2 Optimal Nash Tariffs and Taxes . . . . . . . . . . . . . . . 46

3.3 Environmental and Trade Agreements and their Effects on Tariffs and Taxes . . . . 51

3.3.1 Pure Environmental Agreements . . . . . . . . . . . . . . . . . 51

3.3.2 Shallow Trade Agreements . . . . . . . . . . . . . . . . . . . 55

3.3.2.1 Free Trade Agreements . . . . . . . . . . . . . . . . 55

3.3.2.2 Customs Unions . . . . . . . . . . . . . . . . . . 58

3.3.2.3 Free Trade . . . . . . . . . . . . . . . . . . . . 60

3.3.3 Deep Trade Agreements . . . . . . . . . . . . . . . . . . . . 61

3.3.3.1 Deep Free Trade Agreements . . . . . . . . . . . . . . . . . 61

3.3.3.2 Integrated Customs Unions _ . . . . . . . . . . . . . . 64

3.3.3.3 Integrated Free Trade . . . . . . . . . . . . . . . 65

3.4 Environmental and Trade Agreements and their Effects on Environmental Damages 66

3.4.1 Pure Environmental Agreements . . . . . . . . . . . . . . . . 66

3.4.2 Shallow Trade Agreements . . . . . . . . . . . . . . . . . . . 67

3.4.3 Deep Trade Agreements . . . . . . . . . . . . . . . . . . . . 68

3.5 Endogenous Preferential Environmental and/or Trade Agreements . . . . . . . . 70

3.5.1 Announcements and Strategy Sets . . . . . . . . . . . . . 70

3.5.2 Coalition-Proof Nash Equilibria . . . . . . . . . . . . . . . 71

3.6 Endogenous Environmental Agreements . . . . . . . . . . . . . . . . 72

3.6.1 Pure Environmental Agreements . . . . . . . . . . . . . . . . . 72

3.6.2 Welfare Effects of Various Environmental Agreements in the E Game . . . 73

3.6.3 Announcement Profiles, Associated Environmental Agreements and Nash

Equilibria in the E Game . . . . . . . . . . . . . . . . 74

3.6.4 Coalition-Proof Nash Equilibria in the E Game . . . . . . . . . . 75

3.7 Endogenous Shallow Trade Agreements . . . . . . . . . . . . . . . . . 77 
3.7.1 The Customs Union Game ～. . . . . . . . . . . . . . . . . . . 77

3.7.1.1 Preferential Trade Agreements in the CU Game . . . . . . . 77

3.7.1.2 Welfare Effects of Various Trade Agreements in the CU Game . 78

3.7.1.3 Announcements Profiles, Associated Trade Agreements and Nash

Equilibria in the CU Game . . . . . . . . . . . . . 79

3.7.1.4 Coalition-Proof Nash Equilibria of the CU Game $\ldots \ldots$. . . 80

3.7.2 The Free Trade Agreement Game . . . . . . . . . . . . . . . . 81

3.7.2.1 Preferential Trade Agreements in the FTA Game . . . . . . . . 81

3.7.2.2 Welfare Effects of Various Trade Agreements in the FTA Game . 83

3.7.2.3 Nash Equilibria Announcement Profiles and Associated Trade

Agreements in the FTA Game . . . . . . . . . . . . . . 84

3.7.2.4 Coalition-Proof Nash Equilibria of the FTA Game . . . . . . 85

3.8 Endogenous Deep Trade Agreements . . . . . . . . . . . . . . . . . . . . 87

3.8.1 The Integrated Customs Union Game . . . . . . . . . . . . . . . 87

3.8.1.1 Integrated Customs Unions in the IU Game . . . . . . . . . 87

3.8.1.2 Welfare Effects of Various Trade Agreements in the IU Game . . 89

3.8.1.3 Announcement Profiles, Associated Trade Agreements and Nash

Equilibria in the IU Game . . . . . . . . . . . . . . 990

3.8.1.4 Coalition-Proof Nash Equilibria of the IU Game . . . . . . . . 91

3.8.2 The Integrated Free Trade Agreements Game . . . . . . . . . . . . . 93

3.8.2.1 Integrated FTAs $\ldots \ldots \ldots \ldots$

3.8.2.2 Welfare Effects of Various Deep Trade Agreements in the I Game 95

3.8.2.3 Announcements Profiles, Associated Trade Agreements and Nash

Equilibria in the I Game . . . . . . . . . . . . . . 96

3.8.2.4 Coalition-Proof Nash Equilibria of the I Game . . . . . . . . . 99

3.9 Further Discussion on Shallow versus Deep Integration $\ldots \ldots \ldots 1$

3.9.1 Article XXIV Restriction on External Tariffs . . . . . . . . . . . . 101 
3.9.1.1 Article XXIV Restriction on External Tariffs of Shallow Trade

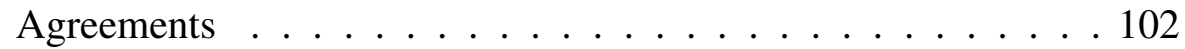

3.9.1.2 Article XXIV Restriction on External Tariffs of Deep Trade Agree-

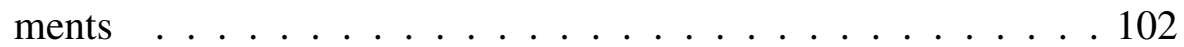

3.9.2 Choice of Deep and Shallow Agreements . . . . . . . . . . . . . 104

3.9.2.1 Shallow Trade Agreements Game . . . . . . . . . . . . . 105

3.9.2.2 Deep Trade Agreements Game . . . . . . . . . . . . . . . . . 107

3.9.2.3 The Choice between Deep and Shallow Customs Unions . . . . 110

3.9.2.4 The Choice between Deep and Shallow FTAs . . . . . . . . . 112

3.10 Conclusion . . . . . . . . . . . . . . . . . 114

$\begin{array}{llr} & \text { Chapter } 4 & 118\end{array}$

4.1 Introduction . . . . . . . . . . . . . . . . . . 118

4.2 The Model: Overview and Optimal Nash Tariffs and Taxes . . . . . . . . . . . 121

4.3 Environmental and Trade Agreements and their Effects on Tariffs and Taxes . . . . 128

4.3.1 Pure Environmental Agreements . . . . . . . . . . . . . . . . 128

4.3.2 Shallow Trade Agreements . . . . . . . . . . . . . . . . . . 130

4.3.2.1 Free Trade Agreements . . . . . . . . . . . . . . . 131

4.3.2.2 Customs Unions . . . . . . . . . . . . . . . 133

4.3.2.3 Free Trade . . . . . . . . . . . . . . . . 136

4.3.3 Deep Trade Agreements . . . . . . . . . . . . . . . 136

4.3.3.1 Deep Tree Trade Agreements . . . . . . . . . . . . . . . . 137

4.3.3.2 Integrated Customs Unions . . . . . . . . . . . . . . . . 139

4.3.3.3 Integrated Free Trade . . . . . . . . . . . . . . . 141

4.4 Environmental and Trade Agreements and their Effects on Environmental Damages 142

4.4.1 Pure Environmental Agreements . . . . . . . . . . . . . . . . . 142

4.4.2 Shallow Trade Agreements . . . . . . . . . . . . . . . . . . . . 144

4.4.3 Deep Trade Agreements . . . . . . . . . . . . . . . . . . 145 
4.5 Endogenous Preferential Environmental and/or Trade Agreements . . . . . . . . . 147

4.5.1 Announcements and Strategy Sets . . . . . . . . . . . . . . 147

4.5.2 Coalition-Proof Nash Equilibria . . . . . . . . . . . . . 148

4.6 Endogenous Environmental Agreements . . . . . . . . . . . . . . . . . 148

4.6.1 Pure Environmental Agreements . . . . . . . . . . . . . . . . . . 148

4.6.2 Welfare Effects of Various Environmental Agreements in the E Game . . . 150

4.6.3 Announcements profiles, Associated Environmental Agreements and Nash

Equilibria in the E Game . . . . . . . . . . . . . . . 151

4.6.4 Coalition-Proof Nash Equilibria of the E game . . . . . . . . . . 152

4.7 Endogenous Shallow Trade Agreements . . . . . . . . . . . . . . . . . 154

4.7.1 The Customs Union Game . . . . . . . . . . . . . . . . . . 154

4.7.1.1 Preferential Trade Agreements in the CU Game . . . . . . . . 154

4.7.1.2 Welfare Effects of Various Trade Agreements in the CU Game . 155

4.7.1.3 Announcement Profiles, Associated Trade Agreements and Nash

Equilibria in the CU Game . . . . . . . . . . . . 156

4.7.1.4 Coalition-Proof Nash Equilibria in the CU Game . . . . . . . . 157

4.7.2 The Free Trade Agreement Game . . . . . . . . . . . . . . . . . 159

4.7.2.1 Preferential Trade Agreements in the FTA Game . . . . . . 159

4.7.2.2 Welfare Effects of Various Trade Agreements in the FTA Game . 160

4.7.2.3 Announcement Profiles, Associated Trade Agreements and Nash

Equilibria in the FTA Game . . . . . . . . . . . 162

4.7.2.4 Coalition-Proof Nash Equilibria of the FTA Game . . . . . . . . 164

4.8 Endogenous Deep Trade Agreements . . . . . . . . . . . . . . . . . . 167

4.8.1 The Integrated Customs Union Game . . . . . . . . . . . . . . 167

4.8.1.1 Integrated Customs Unions In the IU Game . . . . . . . . . . 167

4.8.1.2 Welfare Effects of Various Deep Trade Agreements in the IU

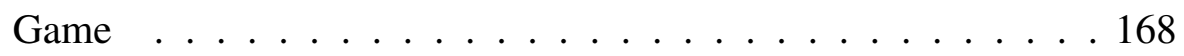


4.8.1.3 Announcement Profiles, Associated Trade Agreements and Nash Equilibria in the IU Game . . . . . . . . . . . . . . 169

4.8.1.4 Coalition-Proof Nash Equilibria in the IU Game . . . . . . . 170

4.8.2 The Integrated Free Trade Agreement Game . . . . . . . . . . . . . . 171

4.8.2.1 Integrated FTAs $\ldots \ldots \ldots \ldots$. . . . . . . . . 171

4.8.2.2 Welfare Effects of Various Deep Trade Agreements in the I Game

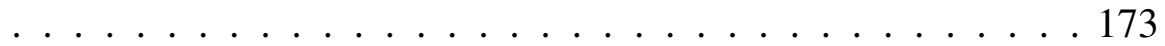

4.8.2.3 Announcement Profiles, Associated Trade Agreements and Nash Equilibria in the I Game . . . . . . . . . . . . 175

4.8.2.4 Coalition-Proof Nash Equilibria of the I Game . . . . . . . 177

4.9 Further Discussion on Shallow versus Deep Integration . . . . . . . . . . . 179

4.9.1 Article XXIV Restriction on External Tariffs . . . . . . . . . . . . . 179

4.9.2 Choice of Deep and Shallow Agreements _ . . . . . . . . . . 180

4.9.2.1 Shallow Trade Agreements Game _. . . . . . . . . . 181

4.9.2.2 Deep Trade Agreements Game . . . . . . . . . . . . . 184

4.9.2.3 The Choice between Deep and Shallow Customs Unions _ . . 188

4.9.2.4 The Choice between Deep and Shallow FTAs _ . . . . . . . 190

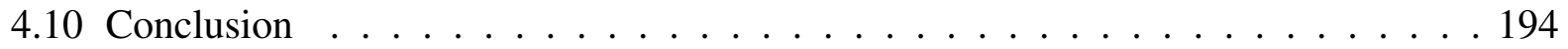

5 Conclusion $\quad 197$

6 Appendices $\quad 203$

$\begin{array}{ll}\text { References } & 330\end{array}$ 


\section{List of Tables}

3.1 The Nash equilibria announcement profiles and the associated environmental agreements in the Egame . . . . . . . . . . . . . . . . . . 74

3.2 The Nash equilibria announcement profiles and the associated trade agreements in the CU game . . . . . . . . . . . . . . . . . . . . . . 79

3.3 The Nash equilibria announcement profiles and the associated trade agreements in the FTA game . . . . . . . . . . . . . . . . . . . . . . 84

3.4 The Nash equilibria announcement profiles and the associated trade agreements in the IU game . . . . . . . . . . . . . . . . . . . . . . . . 90

3.5 The Nash equilibria announcement profiles and the associated trade agreements in the I game . . . . . . . . . . . . . . . . . . . . . . . . . 97

4.1 The Nash equilibria announcement profiles and the associated environmental agreements in the Egame . . . . . . . . . . . . . . . . 151

4.2 The Nash equilibria announcement profiles and the associated trade agreements in

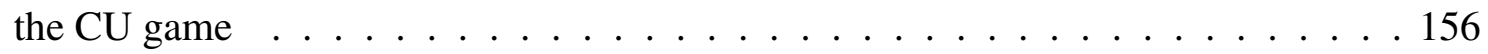

4.3 The Nash equilibria announcement profiles and the associated trade agreements in the FTA game . . . . . . . . . . . . . . . . . . . . 162

4.4 The Nash equilibria announcement profiles and the associated trade agreements in the IU game . . . . . . . . . . . . . . . . . . . . . . . 169

4.5 The Nash equilibria announcement profiles and the associated trade agreements in the I game . . . . . . . . . . . . . . . . . . . . . . . . . . . . . . . .

5.1 Coalition-Proof Nash Equilibria Outcomes in the Case of Local Pollution . . . . . 201

5.2 Coalition-Proof Nash Equilibria Outcomes in the Case of Global Pollution . . . . . 202 


\section{List of Figures}

1.1 Deep and shallow trade agreements, by decade, $1947-2016 \quad \ldots \ldots$. . . . . . . . 2

2.1 The Pattern of Trade $\ldots \ldots \ldots \ldots \ldots \ldots$

2.2 Country a welfare comparison of no agreement $\left(n_{l}\right)$ and environmental agreement $\left(a b_{l}^{e}\right)$ if pollution is local . . . . . . . . . . . . . . . 19

2.3 World and country b welfare comparison of no agreement $\left(n_{g}\right)$ and environmental agreement $\left(a b_{g}^{e}\right)$ if pollution is global . . . . . . . . . . . . 20

2.4 Country a welfare comparison of no agreement $\left(n_{l}\right)$ and shallow trade agreement $\left(a b_{l}^{s}\right)$ if pollution is local . . . . . . . . . . . . . . . . . 24

2.5 Country a welfare comparison of deep trade agreement $\left(a b_{l}^{d}\right)$ and shallow trade

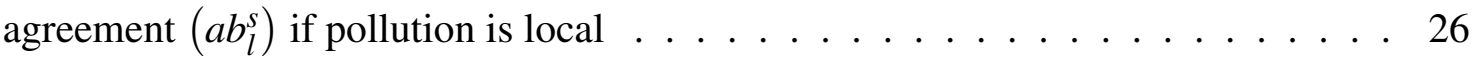

2.6 World welfare comparison of no agreement $\left(n_{g}\right)$ and shallow trade agreement $\left(a b_{g}^{s}\right)$ if pollution is global . . . . . . . . . . . . . . . 30

2.7 Countries welfare comparison of no agreement $\left(n_{g}\right)$ and shallow trade agreement $\left(a b_{g}^{s}\right)$ if pollution is global . . . . . . . . . . . . . . . 30

2.8 World environmental damage comparison of deep trade agreement, $\left(a b_{g}^{d}\right)$, shallow trade agreement, $\left(a b_{g}^{s}\right)$, and no agreement $\left(n_{g}\right)$ if pollution is global . . . . . . 34

3.1 The Pattern of Trade . . . . . . . . . . . . . . . . . . 45

4.1 The Pattern of Trade . . . . . . . . . . . . . . . . . . 124 


\section{List of Appendices}

Appendix of Chapter 3

A. 3.6 The Environmental Agreement Game

A. 3.7.1 The Customs Union Game

A. 3.7.2 The Free Trade Agreement Game

A. 3.8.1 The Integrated Customs Union Game

A. 3.8.2 The Integrated Free Trade Agreements Game

A. 3.9.2.1 Shallow Trade Agreements Game

A. 3 9.2.2 Deep Trade Agreements Game

A. 3.9.2.3 The Choice between Deep and Shallow Customs Unions

A. 3.9.2.4 The Choice between Deep and Shallow FTAs

Appendix of Chapter 4

A. 4.3 Environmental and Trade Agreements and their Effects on Tariffs and Taxes

A. 4.3.1 Pure Environmental Agreements

A. 4.3.2 Shallow Trade Agreements

A. 4.3.3 Deep Trade Agreements

A. 4.4 Environmental and Trade Agreements and their Effects on the Environmental Damages

A. 4.4.1 Pure Environmental Agreements

A. 4.4.2 Shallow Trade Agreements

A. 4.4.3 Deep Trade Agreements

A. 4.6 The Environmental Agreement Game

A. 4.7.1 The Customs Union Game

A. 4.7.2 The Free Trade Agreement Game

A. 4.8.1 The Integrated Customs Union Game

A. 4.8.2 The Integrated Free Trade Agreements Game

A. 4.9.2.1 Shallow Trade Agreements Game

A. 4.9.2.2 Deep Trade Agreements Game 
A. 4.9.2.3 The Choice between Deep and Shallow Customs Unions

A. 4.9.2.4 The Choice between Deep and Shallow FTAs 


\section{Introduction}

The rise in the number of preferential trade agreements (PTAs) has been a major trend in the development of the international trade since the middle of the 20th century. As of June 11, 2019, the number of cumulative notifications of PTAs both in force and inactive has reached 681, and the cumulative number of notifications in force has increased to 467 (counting goods and services separately). ${ }^{1}$ Alongside the growing number of trade agreements in the world, there has been a widespread inclusion of non-trade elements in modern PTAs. As multilateral trade barriers (such as tariffs) have been drastically reduced over time, there has been a shift in focus away from these barriers and to other factors such as domestic policy over the environment, labour, intellectual property, health and investment. As Rodrik(2018) notes, agreements like the TransPacific Partnership (TPP) and the Trans-Atlantic Trade and Investment Partnership(TTIP) can hardly be labelled trade agreements due to the extent of other considerations covered. Also, as it has been pointed out in the recent work of Grossman etal. (2019): “..the trade community has shifted its attention to various non-tariff barriers that leave world markets still far from integrated...'. In this manner, there is a distinction between shallow (trade-only) and deep (trade plus other factors) agreements. Lawrence(1996) writes: "Deeper integration agreements shift the focus from liberalizing barriers that lie at the border to the liberalization or harmonization of barriers and policies that exist "within" or "beyond" the border."

One area that has received a great deal of attention in deep agreements is the environment. Figures 1.1a) and 1.1b) illustrate the increasing number of trade agreements as well as the increasing share of deep trade agreements that included environmental provision by decade, between 1947 and 2016, based on the Trade \& Environment Database/TREND (Morin etal. 2018). This dataset identifies 286 environmental norms (including principles, commitments, and exceptions) in 691 different trade agreements and covers the period of 69 years, between 1947 and 2016. The number of environmental norms in PTAs varies between zero and 137 per one trade agreement. According to other data, $46 \%$ of all current preferential trade agreements contain some environmental laws,

\footnotetext{
${ }^{1}$ https://www.wto.org/index.htm
} 
and provisions on environmental laws are enforceable in 35\% (Limão 2016). Given the increasing predominance of including environmental norms in modern PTAs, we focus on this particular dimension of trade agreements (although any non-trade externality should have similar implications), and investigate the effects of this spread on the stability of trade regimes and counties' welfare gains. Our objective is to investigate how equilibrium agreements differ based on being deep or shallow.

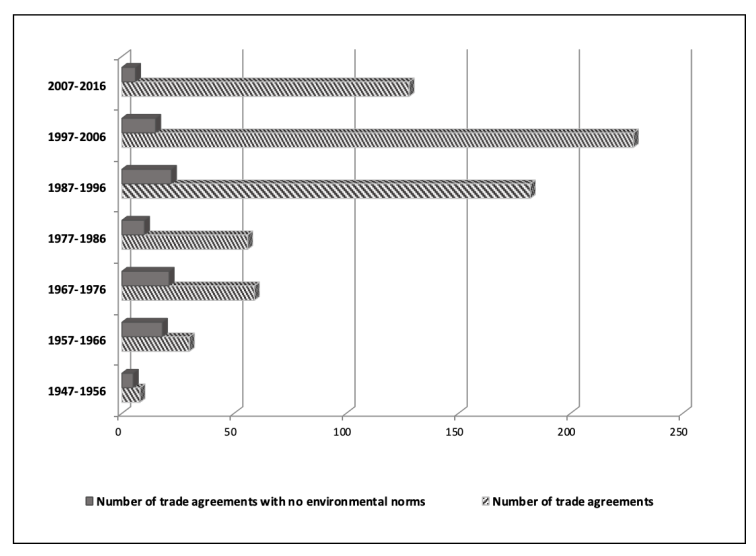

(a) Number of trade agreements and trade agreements with no environmental norms, by decade, 1947-2016

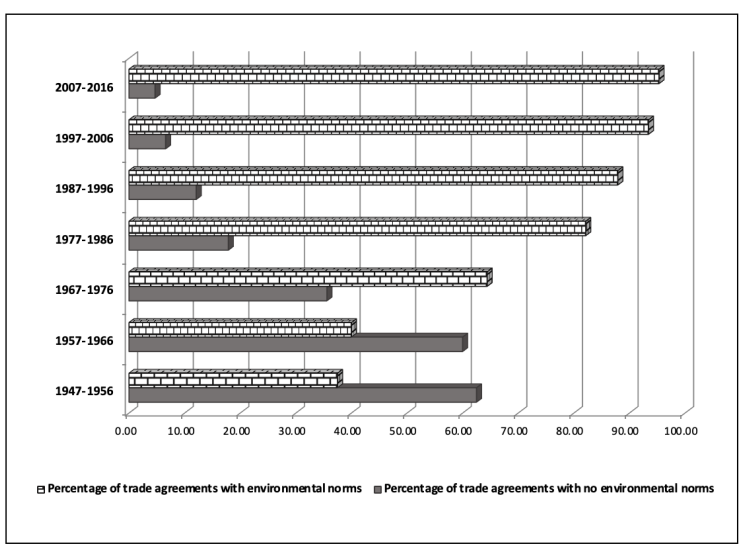

(b) Percentage of trade agreements with and without environmental norms, by decade, 1947-2016

Figure 1.1: Deep and shallow trade agreements, by decade, 1947-2016

Source: Morin etal.(2018) and authors' calculations.

In this dissertation, we develop three models of asymmetric countries, that include both trade (border policies) and environmental externalities (domestic policies), and we study the incentives to form international trade agreements (deep and shallow) between those asymmetric countries. In our models, the difference between shallow and deep trade agreements arises from the nature of the agreement-negotiation process. Shallow trade agreements allow countries negotiate only pure trade deals. Under this type of trade agreements, members lose control over their border policies (import tariff), but keep complete control over their domestic policies (environmental tax). Under deep trade agreements, members have to agree on both border policies and domestic policies. In Chapter 2, we develop a two-country, two-good model with cross-border negative spillovers and perfect competition in product markets, where both countries produce both goods, but each has a 
comparative advantage only in one of them. To create asymmetry across countries, only production of one non-numeraire good is accompanied with a negative per unit production externality, pollution, making this good dirty and the other good clean. The production of the clean good is free of any local taxes in both countries, and the production of the dirty good is subject to a domestic environmental policy. First, we analyze an environmental agreement between those two countries and observe that if pollution is local then the members welfare is always higher under the no agreement scenario and the clean country prefers to stay away from an environment deal with the dirty partner; however, if pollution is global and the level of the per unit production externality is sufficiently high then the clean country is better off in the environmental agreement, but the dirty country prefers to stay away. Furthermore, we compare shallow (trade only) and deep (trade and environment) trade agreements between those two large asymmetric countries, and we show that deep and shallow trade agreements have different outcomes in terms of world and individual countries welfares, trade specialization and environmental damages. With complete flexibility over border policies and domestic instruments, only the dirty country (the one with the comparative advantage in dirty good) will use both instruments, and the clean country (the one with the comparative advantage in clean good) will use border policies exclusively to alter their gains from trade. However, once tariffs are restricted, as in a shallow agreement, both countries will turn to domestic instruments to affect the terms of trade. Our results show that a shallow free trade agreement induces an increase in the level of world and both countries' environmental damages for both levels of transboundary slipovers (local and global levels of pollution), but a deep free trade leads to an increase in environmental damages only in the country with the comparative advantage in the production of the dirty good if pollution is purely local; and indeed induces a decrease in the world and individual country's damages if per unit production externality is sufficiently high and pollution is global. We therefore examine three important questions: (i) how do deep and shallow trade agreements affect countries' choices of domestic policies and their trade specialization given different degrees of transboundary spillovers?; (ii) given the degree of transboundary spillovers, how do deep and shallow trade agreements affect world and individual countries' welfare levels?; 
and (iii) what are the implications of inclusion of the non-trade elements in a shallow trade deal on the world and individual countries environmental damages?

In Chapter 3, we develop a model of multiple asymmetric countries, that includes both trade and environmental externalities. It is a three-country, three-good model with cross-border negative spillovers and perfect competition in product markets, where each country producers all three goods but has a comparative advantage in the production of only one out of three goods. As such, for each good there are two importers and one exporter, or "competing importers". The model we develop in Chapter 4, is also a three-country, three-good model, but here each country has a comparative advantage in the production of two out of three goods. It is a "competing exporters" model. The reason to model both competing importers and competing exporters is that the incentives to form different agreements are not the same between those scenarios, even without deep considerations. Both these models of multiple asymmetric countries enable us to examine the equilibrium agreements and environmental outcomes assuming (i) environmental agreements are negotiated separately, (ii) trade agreements are shallow (trade only), and (iii) trade agreements are deep (trade and environment). Furthermore, in order to examine the differences between shallow and deep trade agreements, we develop extended games where countries can choose between different deep and shallow PTAs. To circumvent the multiplicity of Nash equilibria, we use the equilibrium refinement concept of Coalition-Proof Nash Equilibrium, and show that environment-only agreements, shallow trade agreements and deep trade agreements have very different equilibrium outcomes in terms of membership, welfare and environmental damages, depending on the nature of the pollutant and the type of agreement under consideration. We therefore examine three important questions: (i) how do equilibrium agreements differ when countries choose deep rather than shallow agreements?; (ii) given the choice between deep and shallow trade agreements, would countries prefer to incorporate an environmental clause into their equilibrium trade deal?; and (iii) what are the implications of including non-trade elements in PTAs for the pursuit of global free trade? 


\section{Chapter 2}

\subsection{Introduction}

In the literature, as well as in practice, international trade agreements are often associated with and even criticized for their damaging effect on the environment. Many are concerned with governments incentives to alter their domestic environmental policies in order to affect their firms' competitiveness and thereby increase the gains from trade. The growing number of trade agreements that include different environmental norms illustrates these concerns. In this chapter, we, first, analyze an international environmental agreement, and then compare shallow (trade only) and deep (trade and environment) trade agreements between two large asymmetric countries, and we examine the incentives to form agreements and show that deep and shallow trade agreements have different outcomes in terms of world and individual countries welfares, trade specialization and environmental damages. We develop a two-country, two-good model with cross-border negative spillovers and perfect competition in product markets, where both countries produce both goods, but each has a comparative advantage in only one of them. To create asymmetry across countries but keep the analysis tractable, only production of one non-numeraire good is accompanied with a negative per unit production externality (pollution). Production of the clean good is free of any local taxes in both countries, and production of the dirty good is subject to a domestic environmental policy. Under an environmental agreement, countries loose control over their domestic policies (agree on the level of non-prohibitive environmental tax they levy on their local producers of the dirty good), but members keep control over their border policies (countries are free to set their import tariffs at the individually optimal levels). The difference between shallow and deep trade agreements arises from the nature of the agreement-negotiation process. Under a shallow trade agreement, members agree to eliminate import tariffs, but they are free to set the non-prohibitive environmental tax they levy on their producers of the dirty good at their individually optimal levels. As a result, the level of tax can vary among countries united under a shallow free trade agreement. Contrary to that, under a deep trade agreement, countries have to agree on both eliminating their 
tariffs on each other and the level of environmental tax they levy on their domestic producers of the dirty good. We therefore examine three important questions: (i) how do deep and shallow trade agreements affect countries' choices of domestic policies and their trade specialization given different degrees of transboundary spillovers?; (ii) given the degree of transboundary spillovers, how do deep and shallow trade agreements affect world and individual countries' welfare levels?; and (iii) what are the implications of inclusion of the non-trade elements in a shallow trade deal on the world and individual countries' environmental damages?

Previous work, such as Horn etal.(2010), suggests that given the choice between border policies and domestic instruments, countries will generally apply tariffs and not alter domestic policies to gain a competitive advantage. At the same time, in the presence of restrictions on border policies (if tariffs are constrained), countries will choose to alter their domestic taxes on foreign produced products, as these taxes are perfect substitutes for tariffs. Our model is an adapted version of the perfectly competitive two-country comparative advantage model of Horn et al.(2010). However, in our version, both countries are active in policy and the externality may generate a transboundary effect (local and global pollution). Purely local pollution implies that production of the dirty good affects only the country where the production actually takes place, and purely global pollution implies that both countries get equally affected by the production of the dirty good regardless the location of the producer. Those extensions enable us to gain further insights into countries' choices of whether to use border policies and/or domestic instruments. Our results show that given complete flexibility, for both levels of transboundary spillovers, a country with a comparative advantage in the production of the clean good (the clean country) would choose to alter its border policies and not domestic instruments in order to improve the terms of trade, but a country with a comparative advantage in the production of the dirty good (the dirty country) would use both instruments in order to alter the gains from trade. We now can move to discussing the main questions we ask and answer in this paper.

The first question we ask in this paper is on whether deep and shallow trade agreements affect countries' choices of domestic policies and their trade specialization given different degrees of 
transboundary spillovers and if so, how? Under a shallow trade agreement, countries agree to eliminate the tariffs they impose on imports from each other, but still have full control over their domestic environmental policy. In the no agreement scenario, the dirty country uses both border policy and domestic policy to alter the terms of trade, and the clean country uses its border policy exclusively and sets its environmental tax at the socially optimal level. However, under a shallow FTA, both countries turn to their domestic policies. Our findings here are consistent with Horn etal. (2010), where if border policies are restricted, countries will use domestic instruments to affect the terms of trade. The increase in the tax level imposed by the exporter of the dirty good and the decrease in the tax level imposed by the importer of the dirty good, do not prevent countries from enjoying a deeper specialization on the good they have a comparative advantage in, but those changes in the domestic policies lead to an increased production of the dirty good in both countries and prevent them from enjoying a full specialization, for both local and global levels of spillovers. Under a deep trade agreement, countries lose control over their domestic environmental policies, as well as over their border policies. For both local and global levels of pollution, the formation of a deep free trade agreement induces countries to choose an environmental tax equal to their marginal damages (socially optimal tax). A deep trade agreement leads to a deeper specialization in the world of two large asymmetric countries, and both deep and shallow trade deals increase countries' speciation in their comparative advantage goods relative to the no agreement scenario. The next question we analyze in this paper is how deep and shallow trade agreements affect world and individual countries welfare levels given the degree of transboundary spillovers. As expected, when countries sign a shallow trade agreement, we observe an increase in the world welfare level relative to the no agreement scenario if pollution is purely local. However, contrary to that, when pollution is global, the world welfare under a shallow trade agreement exceeds the no agreement level only if the productivity gap is relatively wide and the per unit production externality is relatively low. Furthermore, even with the zero level of transboundary spillovers, we cannot say that both countries benefit equally from a shallow trade agreement. Not surprisingly, the clean country is better off relative to the no agreement scenario, but the dirty country would sign a shallow 
trade deal only if the productivity gap is relatively wide and the production externality is relatively low. Though we observe that the world welfare under a deep trade agreement exceeds both the no agreement level and a shallow free trade for both local and global levels of pollution, the individual gains of each country vary based on the level of per unit pollution associated with the production of the dirty good and the productivity gap. If pollution is local, then the clean country is better off in a deep trade agreement, and would actually prefer a deep agreement to a shallow one. The dirty country would sign that agreement only if the productivity gap is sufficiently narrow. However, in the case of global pollution, the clean country is interested in adding an environmental clause to a shallow trade deal only if per unit production externality is sufficiently high, and the dirty country likes a deep trade agreement for high level of per unit production externality only if the productivity gap is narrow.

Next, we examine the implications of inclusion of the non-trade elements in a shallow trade deal on the world and individual countries' environmental damages. Our results show that a shallow free trade induces an increase in the level of damages in both countries, and consequently, in the level of world damages as well, for both local and global levels of pollution. This result is consistent with the literature on the subject. Though the formation of a deep trade agreement induces an increase in the world level of damages if pollution is local relative to both no agreement and a shallow trade deal, the dirty country is fully responsible for this increase, and the clean country, on the contrary, exhibits a decrease in the level of damages. A deep trade agreement induces a decrease in the world level of damages relative to both no agreement and shallow free trade if per unit production externality is sufficiently high and the level of negative per unit production externality is global. If pollution is global, then both members of the world are equally affected by the production of the dirty good regardless the location of the producer, and consequently, for this relatively high level of per unit production externality, we observe a decrease in the level of production and damages in both countries. However, if the production externality is relatively low and the productivity gap is sufficiently wide, we then observe an increase in the level of world damages.

Our paper is related to three different and very extensive blocks of literature: the literature on 
shallow trade agreements, the literature on international environmental agreements, and the literature on trade and the environment. The literature on shallow trade agreements is very rich (e.g., Bagwell and Staiger(1997), Bagwell and Staiger(1998), Bond and Syropoulos (1996), Horn etal.(2010), and Missios etal.(2016)). We relate to this literature through our analysis of the effect of a shallow free trade on world and individual countries' welfares. The main body of literature on international environmental agreements concludes that environmental coalitions tend to be small and include only, or primarily, homogeneous countries (e.g., Barrett (1994), Diamantoudi etal. (2018), Ferrara etal. (2011)). Our analysis of deep and shallow trade agreement between two large and asymmetric countries contribute to this literature. The literature on trade and environment primarily analyses the effect of trade liberalization on the environment (e.g., Antweiler etal.(2001), Copeland \& Taylor(1994), Ferrara et al.(2009)), and we relate to this literature through our analysis of the environmental damages under shallow and deep trade agreements. The rest of the chapter has the following structure: section 2.2 provides the overview of the model; section 2.3 analyses optimal Nash tariffs and environmental taxes; section 2.4 covers environmental agreement and its effect on tariffs, taxes, damages, and welfare levels; section 2.5 and section 2.6 explore the effect of deep and shallow trade agreements on countries choices of domestic policies, specialization, and world and individual countries welfare level in the case of global and local negative production externality, respectively; section 2.7 investigates the effect of deep and shallow trade agreements on world and individual countries levels of environmental damages; and section 2.8 concludes the chapter.

\subsection{Overview of the Model}

We consider a two-country world, $j \in[a, b]$. Each country is large and produces three goods: two non-numeraire goods, $k \in[A, B]$, and one numeraire good, $v_{0}$. The production of good $B$, as well as the production of the numeraire good, generates no pollution and considered to be clean. Consequently, the production of these goods is free of any environmental taxes. However, the production of good $A$ generates pollution, and the local producers of this good get taxed in each 
country. Both country $a$ and country $b$ impose a non-prohibitive environmental tax $\left(e_{A}^{j}\right)$ on their domestic producers of this dirty good. Pollution, generated by the local production of the dirty good $A$, may have a transboundary effect. The numeraire good is freely traded, and both nonnumeraire goods, good $A$ and $\operatorname{good} B$, are subject to non-prohibitive import tariffs $\left(t_{k}^{j}\right)$. On the demand side, the representative citizen's utility function is linear in the numeraire good, and it is quadratic and additively separable in the two non-numeraire goods:

$$
U\left(v, v_{0}\right)=u(v)+v_{0}
$$

where $v=\left[v_{A}, v_{B}\right]$ is the consumption vector for the two non-numeraire goods, and $v_{0}$ stands for the consumption of the numeraire good. The demand for good $k$ in country $j$ is given by:

$$
d\left(p_{k}^{j}\right)=\alpha-\beta p_{k}^{j}
$$

To focus on incentives to form agreements, we focus on a single externality and without loss of generality (as long as markets are symmetric) let $\alpha=\beta=1$. As in Hornetal.(2010) and Missios etal.(2010), the only factor of production is labour (l). Labour is employed according to constant-returns-to-scale technology in the production of the numeraire good, and we assume that the supply of labour is large enough in all three countries to always produce that good. Labour is employed in the production of each non-numeraire good according to decreasing-returns-to-scale technology, namely, $x_{k}^{j}=\sqrt{2 \lambda_{k}^{j} l}$, where $\lambda_{k}^{j} \in(0,1)$. $\lambda$ is a productivity parameter: if $\lambda_{k}^{j}=1$, then we say that country $j$ has a comparative advantage in the production of good $k$, and consequently, that country $j$ is a natural exporter of that $\operatorname{good} k$; if $\lambda_{k}^{j}<1$, then we say that country $j$ is a natural importer of good $k$. As a result, the supply of non-numeraire goods in each country $j$ is as follows:

$$
s_{k}^{j}=\lambda_{k}^{j}\left(q_{k}^{j}-e_{k}^{j}\right), \text { where } k=A \quad \text { and } \quad s_{k}^{j}=\lambda_{k}^{j} q_{k}^{j} \text {, where } k=B \text { and } j \in[a, b]
$$


where $q_{k}^{j}$ is the producer's price of good $k$ in country $j$, and $e_{k}^{j}$ is the non-prohibitive environmental tax imposed on the producers of the $\operatorname{dirty} \operatorname{good} A$ in country $j .^{2}$ We assume a symmetric comparative advantage structure, specifically, $\lambda_{A}^{a}=\lambda_{B}^{b}=1$ and $\lambda_{B}^{a}=\lambda_{A}^{b}=\lambda<1$. Under this assumption each of the two countries has a comparative advantage in the production of only one of the two non-numeraire goods, and this good coincides with the identity of the country, and each country has a disadvantage in the production of the other good. Naturally, countries export their comparative advantage good, and import the other good. Goods are freely traded within each country, and we have $q_{B}^{j}=p_{B}^{j}$ and $q_{A}^{j}=p_{A}^{j}-e_{A}^{j}$, where $j \in[a, b]$. However, in the absence of any trade agreement, both countries can impose specific tariffs on the imported non-numeraire goods $\left(t_{k}^{j}\right)$, and under the assumption that countries are large and symmetric in size, we have the following no-arbitrage conditions:

$$
p_{A}^{b}=p_{A}^{a}+t^{b} \text { and } p_{B}^{a}=p_{B}^{b}+t^{a}
$$

where, $t^{b}$ is a specific tariff imposed by country $b$ on the imports of good $A$, and $t^{a}$ is a specific tariff imposed by country $a$ on the imports of good $B$. To simplify the notation, we ignore the exporter's and the good subscripts; each country exports only one good, the good it has a comparative advantage in, and that good is indexed by the same uppercase letter as the identity of the country, see Figure 2.1.

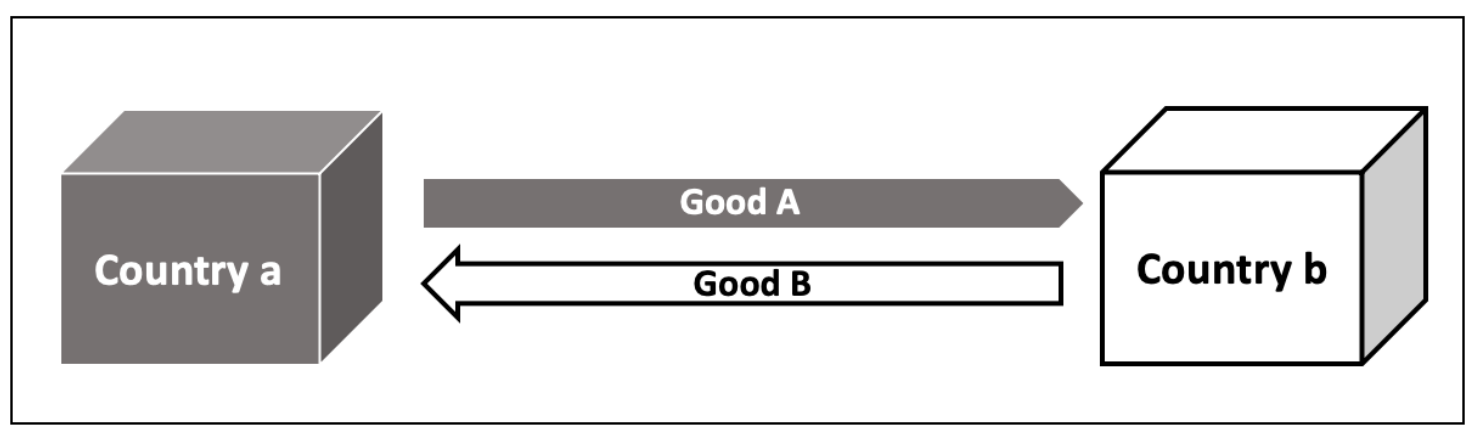

Figure 2.1: The Pattern of Trade

\footnotetext{
${ }^{2}$ Due to term-of-trade considerations, the tariff is not a simple border tax adjustment intended to bridge the gap between local and foreign taxes.
} 
In our model, both countries produce all three goods, but to create asymmetry in incentives across countries, only production of good $A$ generates pollution. Specifically, we assume the following environmental damage function in country $j$ :

$$
\Psi^{a}=\gamma\left(s_{A}^{a}+z \sum_{b} s_{A}^{b}\right) \quad \text { and } \quad \Psi^{b}=\gamma\left(s_{A}^{b}+z \sum_{a} s_{A}^{a}\right)
$$

where $\gamma$ is a per unit production externality, $\gamma \in[0,1]$, and illustrates the degree of pollution generated by the production of the dirty good $A$. The degree of transboundary spillovers is denoted by $z$, and as $z$ approaches 1 , the pollution generated from the production of $\operatorname{good} A$ in country $j$ affects the other country in the same way as it affects the country of production. If $z=0$, then the pollution is purely local, and the production of $A$ affects only the country the good $A$ is actually produced in.

Let $m^{a}\left(p_{B}^{a}\right)=d_{B}^{a}\left(p_{B}^{a}\right)-s_{B}^{a}\left(p_{B}^{a}\right)$ and $m^{b}\left(p_{A}^{b}\right)=d_{A}^{b}\left(p_{A}^{b}\right)-s_{A}^{b}\left(p_{A}^{b}\right)$ be the import demands of country $a$ and country $b$ respectively; and $x^{a}=s_{A}^{a}\left(p_{A}^{a}\right)-d_{A}^{a}\left(p_{A}^{a}\right)$ and $x^{b}=s_{B}^{b}\left(p_{B}^{b}\right)-d_{B}^{b}\left(p_{B}^{b}\right)$ be respectively export supply of country $a$ and export supply of country $b$, then the following are market clearing conditions:

$$
x^{a}=m^{b}\left(p_{A}^{b}\right) \quad \text { and } \quad x^{b}=m^{a}\left(p_{B}^{a}\right)
$$

The equilibrium price of the $\operatorname{dirty} \operatorname{good} A$ in country $a$ and in country $b$ respectfully are:

$$
p_{A}^{a}=\frac{2-t^{b}(1+\lambda)+e_{A}^{a}+\lambda e_{A}^{b}}{\lambda+3} \quad \text { and } \quad p_{A}^{b}=\frac{2\left(1+t^{b}\right)+e_{A}^{a}+\lambda e_{A}^{b}}{\lambda+3}
$$

the equilibrium prices of the clean $\operatorname{good} B$ in countries $b$ and $a$ respectfully are:

$$
p_{B}^{b}=\frac{2-t^{a}(1+\lambda)}{\lambda+3} \quad \text { and } \quad p_{B}^{a}=\frac{2\left(1+t^{a}\right)}{\lambda+3}
$$

Equation (2.7) illustrates the equilibrium price of the dirty good $A$ in the country which has a comparative advantage in the production of that good, country $a$, and in the country which is a 
natural importer of the dirty $\operatorname{good} A$, country $b$. The price of $\operatorname{good} A$ in both countries is positively related to the level of environmental tax faced by the local producers of that good. However, the tax imposed by the exporter of that good has a stronger price effect, depending on the productivity parameter, $\lambda$. An increase in the productivity gap would lead to a decrease in effect which importer's tax has on the price of the dirty good $A$. Equation (2.7) and Equation (2.8) show that the domestic prices of both goods and the tariffs countries face while exporting those goods are inversely related, and the tariffs imposed by those countries and the prices of the goods they import confirm positive relationship.

Given the prices and the market clearing condition, country $b$ 's import of the good $A$ and country $a$ 's import of the $\operatorname{good} B$ respectively are:

$$
m^{b}=x^{a}=\frac{1-(1+\lambda)\left(2 t^{b}+e_{A}^{a}\right)+\lambda\left(2 e_{A}^{b}-1\right)}{\lambda+3} \quad \text { and } \quad m^{a}=x^{b}=\frac{1-2 t^{a}(1+\lambda)+\lambda}{\lambda+3}
$$

World trade in both goods, the dirty good $A$ and the clean good $B$, is decreasing in the tariffs the exporters face, and again, the magnitude of this effect depends on the productivity gap. The increase in the productivity gap between those countries would induce a smaller effect of the tariffs they impose on the good they import. The world trade in the dirty good $A$ is inversely related with the tax faced by the producers in the exporter, and positively related with the tax imposed by the importer of the dirty good $A$.

The production levels of the non-numeraire goods in country $a$ are as follows:

$$
s_{A}^{a}=\frac{2-t^{b}(1+\lambda)-e_{A}^{a}(2+\lambda)+\lambda e_{A}^{b}}{\lambda+3} \text { and } s_{B}^{a}=\frac{2 \lambda\left(1+t^{a}\right)}{\lambda+3}
$$

The production levels of the non-numeraire goods in country $b$ are as follows:

$$
s_{A}^{b}=\frac{\lambda\left(2\left(1+t^{b}\right)-3 e_{A}^{b}+e_{A}^{a}\right)}{\lambda+3} \text { and } s_{B}^{b}=\frac{2-t^{a}(1+\lambda)}{\lambda+3}
$$

Unsurprisingly, equations (2.10) and (2.11) show that the production of comparative advantage goods in respective countries is decreasing in the tariffs producers face while exporting those goods. The production of the dirty $\operatorname{good} A$ in country $a$ is also decreasing in the local environmental tax, and the effect of the change in tax depends on the productivity gap, and the production 
level is increasing in the tax levied by the importer of this good, country $b$, and again, the magnitude depends on the productivity gap. As expected, the production of $\operatorname{good} A$ in country $b$ is increasing in the tariff country $b$ levies on the imports of this good from country $a$. An increase in the tax applied in country $a$ would lead to an increased production of the dirty $\operatorname{good} A$ in country $b$, and the increase in the local tax would decrease the production in country a; however, the effect of the local tax is stronger than the effect of the tax levied by the exporter. We now move to finding non-cooperative tariffs and taxes.

\subsection{Optimal Nash Tariffs and Environmental Taxes}

Country j's welfare is defined as the sum of consumer surplus, producer surplus, tariff revenue, tax revenue on the production of the dirty good $A$, minus environmental damages caused by the production of that dirty good $A$ :

$$
W^{j}=\sum_{k} C S_{k}^{j}\left(p_{k}^{j}\right)+\sum_{k} P S_{k}^{j}\left(p_{k}^{j}\right)+\sum_{j \neq k} t^{j} m^{j}\left(p_{k}^{j}\right)+e_{A}^{j} s_{A}^{j}-\Psi^{j}
$$

where $\sum_{j \neq k} t^{j} m^{j}\left(p_{k}^{j}\right)$ is tariff revenue of country $j$, and $e_{A}^{j} s_{A}^{j}$ is tax revenue of country $j$ over the production of the dirty good $A$. In the absence of any agreement between the countries, each simultaneously chooses its tariff and tax to maximize welfare. The optimal Nash tariffs and environmental taxes are calculated by:

$$
\frac{\partial W^{j}}{\partial t^{j \neq k}}=0 \text { and } \frac{\partial W^{j}}{\partial e_{A}^{j}}=0, \text { where } j \in[a, b] \text {, and } k \in[A, B]
$$

then we have the following reaction functions:

$$
t^{a}(r)=\frac{1}{4} \frac{1-\lambda}{\lambda+2} \text { and } t^{b}(r)=\frac{1}{4} \frac{1-e_{A}^{a}(1+\lambda)^{2}+4 \lambda e_{A}^{b}(2+\lambda)+2 \gamma \lambda(2 z-\lambda)+3 \gamma(z-2 \lambda)+\lambda^{2}(\gamma z-1)}{(\lambda+1)(\lambda+2)}
$$




$$
\begin{gathered}
e_{A}^{a}(r)=\frac{1+2 \lambda e_{A}^{b}-2 t^{b}(1+\lambda)+\lambda^{2} \gamma(1-z)+\lambda \gamma(5-3 z)+6 \gamma-\lambda}{\lambda^{2}+6 \lambda+7} \text { and } \\
e_{A}^{b}(r)=\frac{e_{A}^{a}(1+\lambda)+4 t^{b}(2+\lambda)-3 \gamma(z-\lambda)+\lambda(1-\gamma z)-1}{\lambda^{2}+6 \lambda+7}
\end{gathered}
$$

and those are the relationships between the reaction functions:

$$
\begin{aligned}
& \frac{\partial t^{a}}{\partial t^{b}}=\frac{\partial t^{b}}{\partial t^{a}}=0 \quad \text { and } \quad \frac{\partial t^{a}}{\partial e_{A}^{a}}=\frac{\partial t^{a}}{\partial e_{A}^{b}}=0 \\
& \frac{\partial t^{b}}{\partial e_{A}^{b}}=\frac{\lambda}{\lambda+1}>0 \quad \text { and } \quad \frac{\partial t^{b}}{\partial e_{A}^{a}}=-\frac{1}{4} \frac{\lambda+1}{\lambda+2}<0 \\
& \frac{\partial e_{A}^{a}}{\partial t^{b}}=-\frac{2(\lambda+1)}{\lambda^{2}+6 \lambda+7}<0 \quad \text { and } \quad \frac{\partial e_{A}^{b}}{\partial t^{b}}=\frac{4(\lambda+2)}{5 \lambda+9}>0 \\
& \frac{\partial e_{A}^{a}}{\partial e_{A}^{b}}=\frac{2 \lambda}{\lambda^{2}+6 \lambda+7}>0 \quad \text { and } \quad \frac{\partial e_{A}^{b}}{\partial e_{A}^{a}}=\frac{\lambda+1}{5 \lambda+9}>0
\end{aligned}
$$

Equations (2.16), (2.17), (2.18) and (2.19) illustrate the slopes of the reaction functions. Equation (2.16) shows the independence of the tariffs imposed by country $a$ on its imports of good $B$ and by country $b$ on its imports of good $A$. We also observe that the tariff imposed on the clean $\operatorname{good} B$ by country $a, t^{a}$, is independent from the environmental taxes levied on the producers of the dirty $\operatorname{good} A$ in both countries. The slope of the reaction function between the tariff applied by country $b$ on its imports of the dirty good $A, t^{b}$, and the domestic tax, $e_{A}^{b}$, is positive, and the slope of the reaction function between $t^{b}$ and the foreign tax, $e_{A}^{a}$, is negative, equation (2.17). Furthermore, the local tax has stronger effect on the tariff than the foreign tax does if the productivity gap is relatively narrow, and the change in exporter's tax has a stronger effect of the tariff that exporter faces if the productivity gap is relatively large. ${ }^{3}$ The tariff set by the importer of the $\operatorname{dirty} \operatorname{good} A$, country $b$, and the tax imposed on the local producers in country $a$ are strategic substitutes, and the slope of the reaction function between local taxes and tariffs imposed by the importer, country $b$, is positive, equation (2.18). However, the effect of the change in tariff is higher on the country $b$ 's level of local tax than on the country $a$ 's one. ${ }^{4}$ Equations (2.19) shows that environmental taxes $3\left|\frac{\partial t^{b}}{\partial e_{A}^{b}}\right|>\left|\frac{\partial t^{b}}{\partial e_{A}^{a}}\right|$ if $\lambda$ is sufficiently large and $\left|\frac{\partial t^{b}}{\partial e_{A}^{b}}\right|<\left|\frac{\partial t^{b}}{\partial e_{A}^{a}}\right|$ if $\lambda$ is sufficiently small $4\left|\frac{\partial e_{A}^{a}}{\partial t^{b}}\right|-\left|\frac{\partial e_{A}^{b}}{\partial t^{b}}\right|<0$ 
imposed by country $a$ and country $b$ are strategic complements, but the change in the tax of the natural exporter of this dirty good $A$, country $a$, has a stronger effect on country $b$ 's tax than the change in country $b$ 's tax on the country $a$ 's level of tax. ${ }^{5}$

The equilibrium no agreement tariffs on the clean $\operatorname{good} B$ and on the $\operatorname{dirty} \operatorname{good} A$, and the equilibrium no agreement taxes imposed by both countries on their domestic producers of the dirty good $A$ respectfully are:

$$
\begin{aligned}
& t^{a}\left(n_{l}\right)=t^{a}\left(n_{g}\right)=\frac{1}{4} \frac{1-\lambda}{\lambda+2} ; t^{b}\left(n_{l}\right)=\frac{1}{2} \frac{(\lambda+2)(\lambda-1)(\gamma-1)}{(\lambda+3)(2 \lambda+3)} \text { and } t^{b}\left(n_{g}\right)=\frac{1}{2} \frac{(2-\lambda)-\lambda^{2}(3 \gamma-1)+\gamma(8 \lambda+5)}{(\lambda+3)(2 \lambda+3)} \\
& e_{A}^{b}\left(n_{l}\right)=e_{A}^{b}\left(n_{g}\right)=\gamma ; e_{A}^{a}\left(n_{l}\right)=\frac{1+2 \gamma\left(\lambda^{2}+4\right)+\lambda(10 \gamma-1)}{(\lambda+3)(2 \lambda+3)} \text { and } e_{A}^{a}\left(n_{g}\right)=\frac{(1-\lambda)+\gamma(5 \lambda+7)}{(\lambda+3)(2 \lambda+3)}
\end{aligned}
$$

where $\left(n_{l}\right)$ indicates the no agreement scenario if pollution is local, and $\left(n_{g}\right)$ stands for the absence of any deep and shallow trade agreement between country $a$ and country $b$ if pollution is global. As we can see from equation (2.20), the country with no comparative advantage in the production of the dirty good $A$, country $b$, shows no distortion in the environmental tax from the socially optimal level, $\gamma$, for both local and global levels of pollution. This is consistent with Horn et al.(2010), with complete flexibility countries will use border policies and not domestic instruments to alter the gains of trade ${ }^{6}$. However, it is not true in the other country, country $a$. The level of negative production externality has no effect of the level of tariff on the clean good $B$, and this tariff is negatively related to the productivity parameter, $\lambda$; the increase in the productivity gap would induce an increase the level of tariff country $b$ faces while exporting good $B$ to country $a$. Contrary to that, the level of tariff country $b$ sets on its imports of the dirty good $A$ is greater when pollution is global. The global level of pollution affects both countries equally, and consequently, country $b$ charges a higher tariff to forgo its own production of good $A$. Furthermore, while facing a higher tariff, if pollution is global, country $a$ brings its tax below the no agreement level of local pollution. On one hand, global production externality induces an increase in the level of tariff faced by the

\footnotetext{
$5\left|\frac{\partial e_{A}^{a}}{\partial e_{A}^{b}}\right|-\left|\frac{\partial e_{A}^{b}}{\partial e_{A}^{a}}\right|<0$

${ }^{6}$ Note, that externality is consumption in Horn etal.(2010)
} 
exporters on the dirty good $A$, and on the other hand, the tax burden they bear gets reduced. If pollution is local, then the environmental tax level in the country with the comparative advantage in the production of the dirty good $A$, country $a$, is lower than the environmental tax sets in the importer of this good, country $b$. The local level of negative production externality implies that the importer of the dirty good $A$, country $b$, can benefit from the increased level of consumption of that $\operatorname{good} A$ while enjoying the zero increase in the damages. If pollution is global, then the tax levied in country $a$ exceeds the level of tax charged in country $b$ if productivity gap is relatively large and the production externality, gamma, is relatively low; narrow productivity gap and high level of externality would bring the tax level in country $a$ above its counterpart in country $b$, the importer of this good.

\subsection{Environmental Agreement and its Effect on Tariffs, Taxes, Damages, and Welfare Levels}

In this section, we analyze the effect of an environmental agreement between two large asymmetric countries, the dirty country $a$ and the clean country $b$, on the levels of tariffs, taxes, damages, and welfare gains. When countries sign an environmental agreement, they loose control over their domestic policies, namely, they have to agree on the level of non-prohibited environmental tax they levy on their local producers of the dirty good $A$. In the same time, an environmental agreement allows members to maintain control over their border policies (members set individually optimal tariffs on imports from each other). First, we analyze an environmental agreement between country $a$ and country $b$ if pollution is local, $\left(a b_{l}^{e}\right)$, and then, we analyze an environmental agreement in the case of global pollution, $\left(a b_{g}^{e}\right)$. Members set an environmental tax at a jointly optimal level by solving the following:

$$
\frac{\partial \Sigma^{j} W^{j}\left(a b_{l}^{e}\right)}{\partial e_{A}\left(a b_{l}^{e}\right)}=0, \quad \text { where } j \in[a, b]
$$


Now, we state the following:

Proposition 2.1: An environmental agreement between two large asymmetric countries induces the clean member to raise its tariff on the imports of the dirty good A above the no agreement level but creates no distortion of the tariff on the clean good.

An environmental agreement between two asymmetric countries, country $a$ and country $b$, leads to a jointly optimal level of an environmental tax which is above both individually optimal taxes in respective members in the no agreement scenario, $e_{A}\left(a b_{l}^{e}\right)>e_{A}^{a}\left(n_{l}\right)>e_{A}^{b}\left(n_{l}\right){ }^{7}$ A complementarity of an environmental tax and tariff on the dirty good $A$ levied in the clean country can explain the first half of the above proposition (equation 2.17); both instruments can be used to influence domestic production of the $\operatorname{dirty} \operatorname{good} A$ in the clean country $b$, and as a result, an increased level of an environmental tax would lead to an increased level of tariff in order to protect domestic producers, and an increased tariffs would act as a barrier and, in the same time, would allow the clean country to increase its environmental tax. To prove the second half of the above proposition, we use equation 2.16, which states the independence of taxes set on the domestic producers of the dirty good A and tariffs on the clean good.

LEMMA 2.1: An environmental agreement between two large asymmetric countries induces a decrease in the environmental damages in both members, and consequently, in the world.

An increased level of an environmental tax discourages domestic production of the dirty good $A$ in both members of this environmental deal, $s_{A}^{a}\left(a b_{l}^{e}\right)<s_{A}^{a}\left(n_{l}\right)$ and $s_{A}^{b}\left(a b_{l}^{e}\right)<s_{A}^{b}\left(n_{l}\right)$. Furthermore, an increased tariff imposed on the dirty good $A$ together with an increased local tax in the country with the comparative advantage in the production of the dirty good $A$ lead to a reduction in the international trade of that good, $m^{b}\left(a b_{l}^{e}\right)<m^{b}\left(n_{l}\right)$. As a result, we observe a decrease in the level of environmental damages in both members, and consequently, in the world.

If pollution is local, then a country with a comparative advantage in the production of the clean good would always prefer to stay away from an environmental agreement with the dirty country $a$, and though, the dirty country $a$ is better off in an environmental agreement if the productivity

\footnotetext{
${ }^{7}$ Respective taxes are complements.
} 
gap is sufficiently wide (see Figure 2.2), the world welfare is always lower under an environmental agreement.

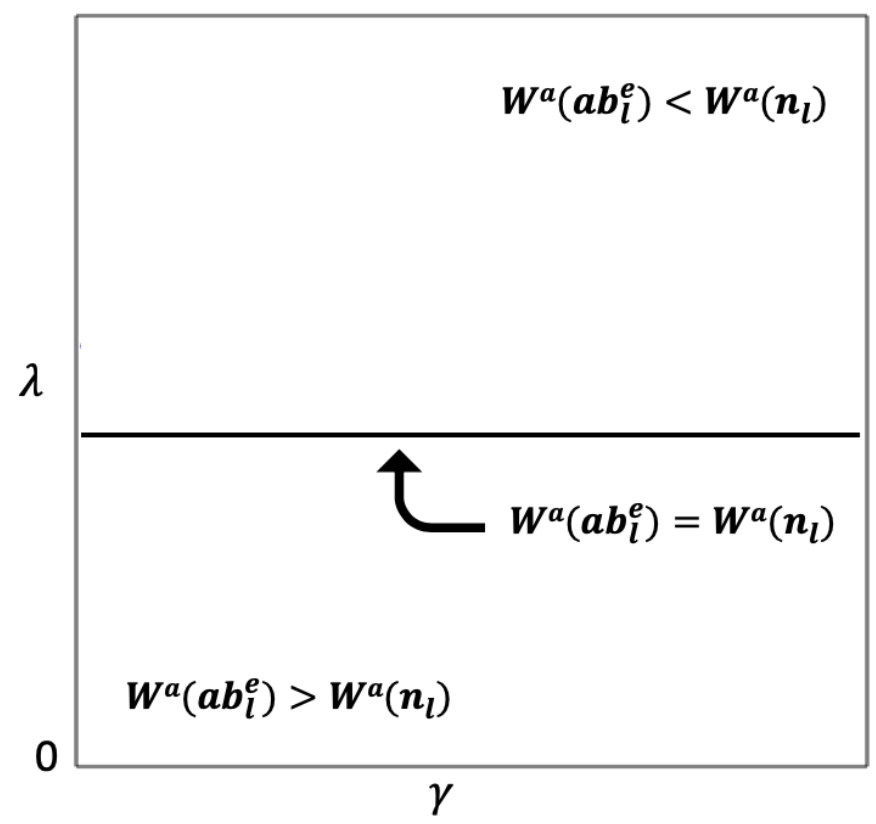

Figure 2.2: Country a welfare comparison of no agreement $\left(n_{l}\right)$ and environmental agreement $\left(a b_{l}^{e}\right)$ if pollution is local

However, contrary to the case of local pollution, when the clean member prefers to stay away from an environmental agreement, if pollution is global, then the dirty country is better off in the no agreement scenario. In the same time, sufficiently high level of negative per unit production externality would encourage the clean member to sign an environmental deal with the dirty country, and that in turn explains an increase in the members welfare if per unit production externality is sufficiently high, see Figure 2.3. 


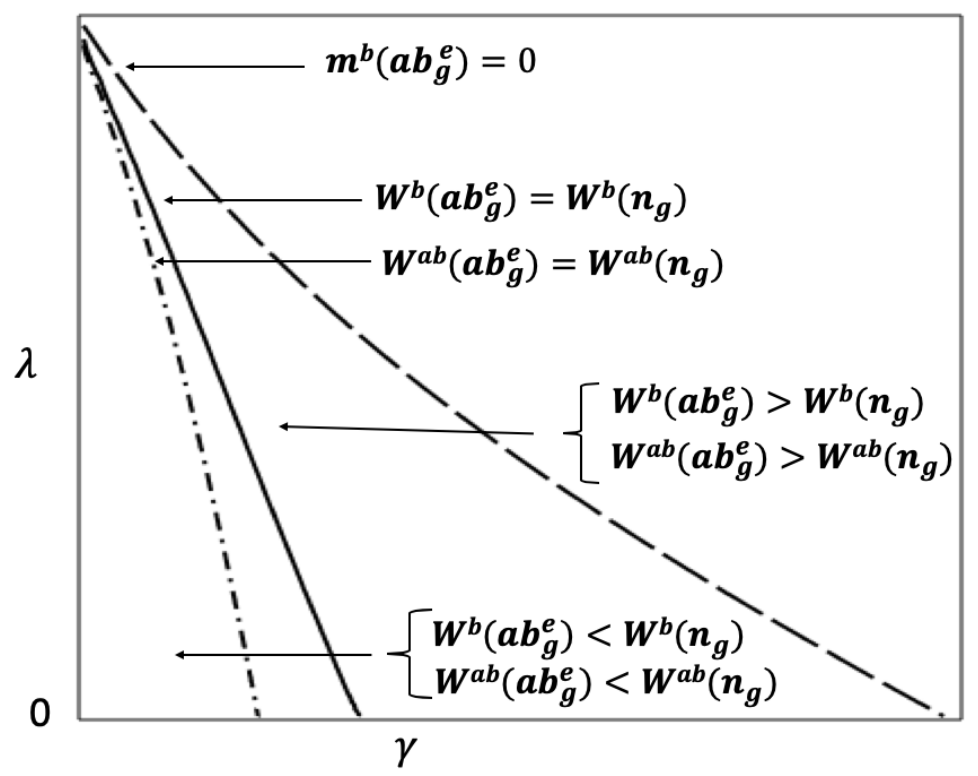

Figure 2.3: World and country b welfare comparison of no agreement $\left(n_{g}\right)$ and environmental agreement $\left(a b_{g}^{e}\right)$ if pollution is global

\subsection{Local Pollution: Deep and Shallow Trade Agreements}

In this section, we analyze two different options, deep and shallow trade agreements, which arise between two large asymmetric countries, country $a$ and country $b$, in the case of local pollution. If pollution is local, then the negative externality associated with the production of the dirty good $A$ has an effect only on the country where the production of that good actually takes place. The other country exhibits no change in its level of damages. (The difference between deep and shallow trade agreements stems from the nature of the agreement-negotiation process. Under a shallow trade agreement, countries agree to eliminate the tariffs they impose on imports from each other, and they still have a full control over their domestic environmental policy, namely, they levy individually optimal levels of environmental tax on their domestic produces of the dirty good A. Alternatively, when countries sign a deep trade agreement, they have to agree on the level of the non-prohibitive environmental tax they impose as well as on the eliminating the trade tariffs on the imports from each other). 


\subsubsection{Deep and Shallow Trade Agreements and their Effect on Taxes and Specialization}

In this subsection, we analyze the effect of deep and shallow trade deals on the level of nonprohibitive environmental tax countries impose on their local producers of the $\operatorname{dirty}$ good $A$ and on their level of specialization. First, we analyze the shallow trade agreement between country $a$ and country $b$, denoted by $\left(a b_{l}^{s}\right)$, and then we evaluate the deep trade agreement, denoted by $\left(a b_{l}^{d}\right)$. Shallow trade agreement members independently set their environmental taxes on the dirty good $A$ by maximizing their utility functions:

$$
\left.\frac{\partial W^{j}\left(a b_{l}^{s}\right)}{\partial e_{A}^{j}\left(a b_{l}^{s}\right)}\right|_{t^{j}\left(a b_{l}^{s}\right)=0}=0 \quad \text { where } j \in[a, b]
$$

Now, we state the following:

Proposition 2.2: A shallow FTA between two large asymmetric countries induces the clean member to lower its environmental tax below the no agreement level but leads to an increase in the environmental tax level imposed by the dirty member of this agreement.

The explanation for the first half of the above proposition lies in the complementarity of the tariff and environmental tax imposed by country $b$ on the imports and production of the $\operatorname{dirty} \operatorname{good} A$, which is illustrated in the equation (2.17). A shallow trade agreement implies that its members eliminate their tariffs on the imports from each other, $t^{b}\left(a b_{l}^{s}\right)=t^{a}\left(a b_{l}^{s}\right)=0$, and consequently, the elimination of the tariff on the dirty good $A$ leads to a decrease in the level of tax levied by country $b$. The second half of the above proposition states that the elimination of the tariff faced by the exporter of that dirty good $A$ leads to an increase in the level of domestic tax faced by the local producers on that good in country $a$. The explanation for that lies in the tariff faced by country $a$ and the tax imposed in country $a$ being strategic substitutes, equation (2.18). As a result, once the tariff is eliminated, country $a$ raises its local tax. Our findings are consistent with Hornetal.(2010), if tariffs are restricted, countries will use domestic instruments to affect the term of trade. The increase in the tax level imposed by the export of the dirty good, country $a$, does not prevent countries from enjoying a deeper specialization on the good they have a comparative 
advantage in, and now, we are ready to state the following:

LEMMA 2.2: A shallow FTA between two large asymmetric countries induces an increase in the production of the clean good B in country $b$ and induces a decrease in the production of that good in country a; the production of the dirty good A increases in both countries.

Once the tariffs are eliminated, countries find it beneficial to increase their specialization in the goods they have a comparative advantage in, and consequently, they increase imports of the goods they do not have a comparative advantage in: $m^{a}\left(s_{l}\right)>m^{a}\left(n_{l}\right)$ and $m^{b}\left(s_{l}\right)>m^{b}\left(n_{l}\right)$. However, though $s_{B}^{a}\left(s_{l}\right)<s_{B}^{a}\left(n_{l}\right)$ and $s_{B}^{b}\left(s_{l}\right)>s_{B}^{b}\left(n_{l}\right)$, we still observe $s_{A}^{j}\left(s_{l}\right)>s_{A}^{i}\left(n_{l}\right)$ where $j \in[a, b]$. The explanation lies in the distortion of the environmental tax level from its socially optimal level in the country with no comparative advantage in the production of the dirty good $A$, country $b$. The elimination of the tariff on the imports of the dirty good $A$ induces a decrease in the tax level the local producers face, and consequently, this reduction makes the production of good $A$ more attractive to the local producers in country $b$. Nethertheless, the increase in the production of the dirty good $A$ in country $a$ still exceeds the increase in country $b$, and that in turn, explains the increase in the export level of the dirty good $A$. Though a shallow trade deal does not lead to a deep specialization of two large asymmetric countries, it still allows countries to benefit from the increased production of their comparative advantage good and an increased import of the good they do not have a comparative advantage in.

Similar to the members of the shallow trade agreement, a deep trade agreement members also eliminate tariffs on the imports from each other, but they also set an environmental tax at a jointly optimal level by solving the following:

$$
\left.\frac{\partial \Sigma^{j} W^{j}\left(a b_{l}^{d}\right)}{\partial e_{A}\left(a b_{l}^{d}\right)}\right|_{t^{j}\left(a b_{l}^{d}\right)=0}=0 \quad \text { where } j \in[a, b]
$$

Now, we state the following:

Proposition 2.3: A deep FTA between two large asymmetric countries induces a socially optimal level of the jointly optimal environmental tax and leads to a deep specialization of its members on their comparative advantage goods. 
When countries add an environmental clause to their trade deal, then the level of the jointly optimal environmental tax on the producers of the dirty $\operatorname{good} A$ is at its socially optimal level. Socially optimal tax level is the lowest level the dirty country $a$ levies on its domestic producers of good $A$, and this level is the highest the clean country $b$ chargers relative to both the no agreement scenario and a shallow trade deal. As a result, we observe a deeper specialization on the comparative advantage goods. Country $b$ 's production of $\operatorname{good} A$ is the lowest relative to both the no agreement and the shallow trade deal, and consequently, the import level is the highest. Under the deep trade agreement, the dirty country $a$ increases the level of production of its comparative advantage good,

$\operatorname{good} A$, while keeping the production of the clean $\operatorname{good} B$ at the shallow agreement level. As a result, we do not observe any increase in the world trade in the clean good $B$. We conclude that, a deep trade agreement between two large asymmetric countries leads to a higher level of specialization than the shallow trade deal does; we observe an increase in the world level of production and trade in the dirty good $A$ relative to the shallow trade agreement. However, both deep and shallow trade deals increase countries specialization on their comparative advantage goods relative to the no agreement scenario.

\subsubsection{Deep and Shallow Trade Agreements: Welfare Analysis}

In this subsection, we examine the effect of deep and shallow trade agreements on world and countries' welfare levels if pollution is local. First, we analyze a shallow trade deal, and then we examine a deep trade agreement. When countries sign a shallow trade agreement, we observe an increase in the world welfare level relative to the no agreement scenario. However, we cannot say that both members benefit equally from this agreement. The clean country is better off in the shallow trade agreement than in the no agreement scenario, but the dirty country $a$ would sign that deal only if productivity gap is relatively wide and production externality is relatively low, as shown in Figure 2.4. Welfare gain from $\left(a b_{l}^{s}\right)$ in dirty country is decreasing in both $\gamma$ and $\lambda$. 


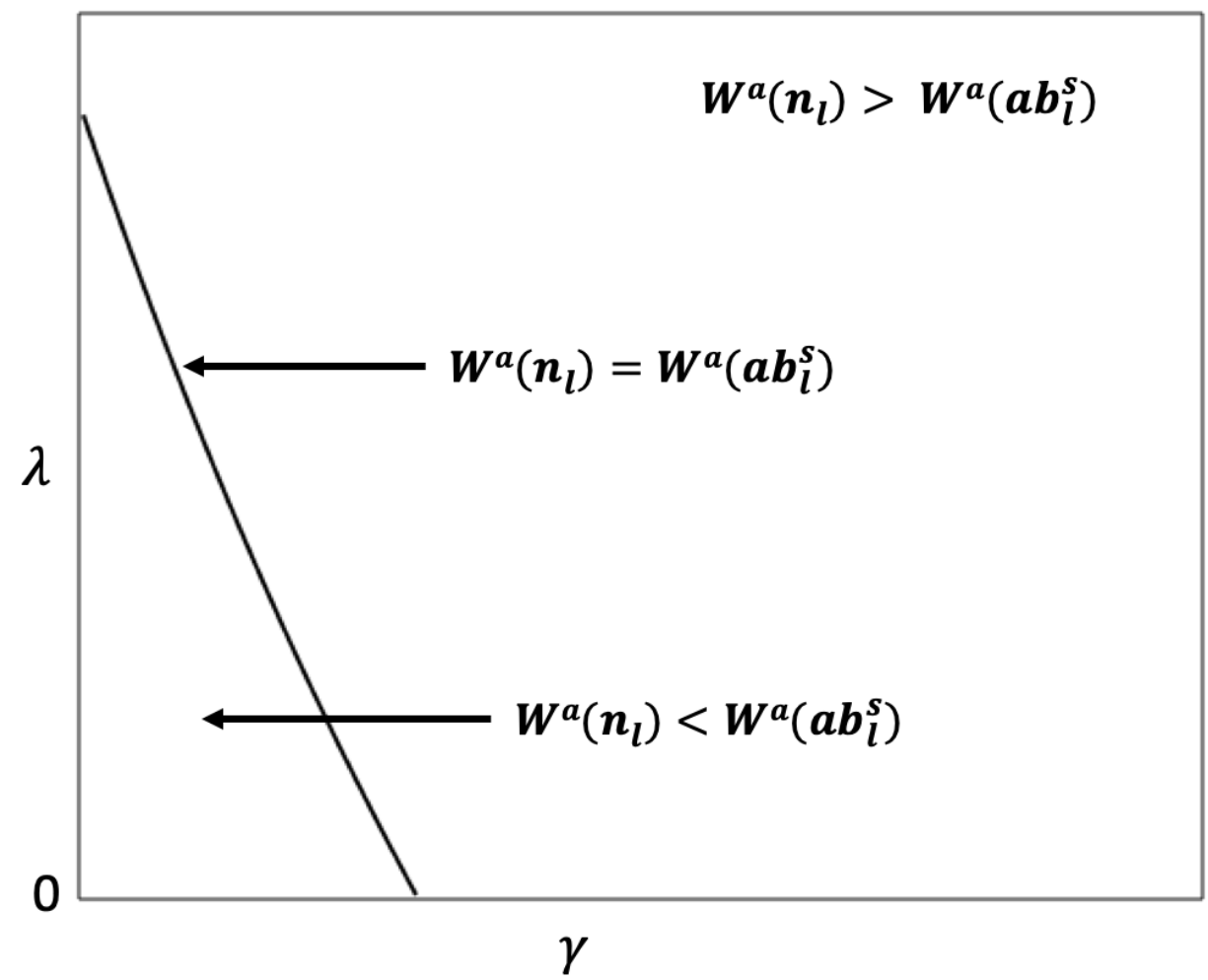

Figure 2.4: Country a welfare comparison of no agreement $\left(n_{l}\right)$ and shallow trade agreement $\left(a b_{l}^{s}\right)$ if pollution is local

In the case of a pure local production externality, the increased production of good $A$ hurts exclusively the country of origin, and that in turn explains positive relationship between the level of per unit production externality, $\gamma$, and country $b$ 's gains from the shallow trade deal. An increase in the level of pollution per unit of production of the dirty good $A$ would make a shallow trade deal even more appealing for the clean country $b$. This country would enjoy the increased level of consumption of the dirty good $A$ without paying the price of an increased pollution. An increase in the productivity gap would also lead to an increased level of gains of country $b$ from this shallow trade deal with country $a$. An increased in productivity parameter, $\lambda$, would decrease the comparative advantage of country $a$ in the production of the dirty good $A$, and consequently, would make the local production in country $b$ more attractive reducing the gains of trade.

A shallow trade agreement reduces the tariffs countries apply on the imports from each other to 
zero, and consequently, leads to an increased level of trade; countries increase the export of their comparative advantage good and increase the import of the good they do not have a comparative advantage in. The increased production of the dirty good $A$ generates a higher level of pollution, and, as a result, decreases the dirty country $a$ 's desire to participate in this agreement. A relatively high level of per unit production externality, $\gamma$, and a narrow productivity gap induce county $a$ 's incentive to stay away from the shallow trade deal with the clean country $b$, as illustrated in Figure 2.4. This incentive grows with an increase in the level of per unit production externality and with the decrease in the productivity gap. Unless the increase on the productivity parameter is accompanied with a decrease in the pollution per unit of production, the dirty country $a$ would prefer to stay away with the shallow trade deal.

When countries add an environmental clause to their trade agreement, then we observe an increase in the world welfare level relative to both the no agreement scenario and the shallow trade deal. Again, the clean country $b$ is better off in the agreement with the dirty country $a$, and would actually prefer a deep agreement to a shallow one. However, the dirty country $a$ would sign that agreement only if the productivity gap is relatively narrow. If the productivity gap is relatively wide, then country $a$ is better off in a shallow trade deal than in a deep one, as shown in Figure 2.5. An increase in the level of per unit production externally would shrink the gains from deep agreement versus shallow one for the clean country $b$, and would increase the gains for the dirty country $a$ only if the productivity gap is relatively narrow. An increase in the level of pollution per unit of production would otherwise increase country $a$ 's gains from this deep trade deal relative to the shallow one. The wider productivity gap increases country $b$ 's incentive to negotiate over the environmental agreement, and country $a$ exhibits similar incentive but only for the relatively high levels of the productivity parameter. The increase in the productivity gap encourages the dirty country $a$ to stay away from the deep trade agreement with the clean country $b$.

Though we observe that the world welfare is the highest under the deep trade agreement, the individual gains of each country varies based on the level of per unit pollution associated with the production of the dirty good $A$ and the productivity gap. The clean country $b$ is better off in a deep 
trade agreement, but the dirty country $a$ would sign it only if the productivity gap is sufficiently narrow.

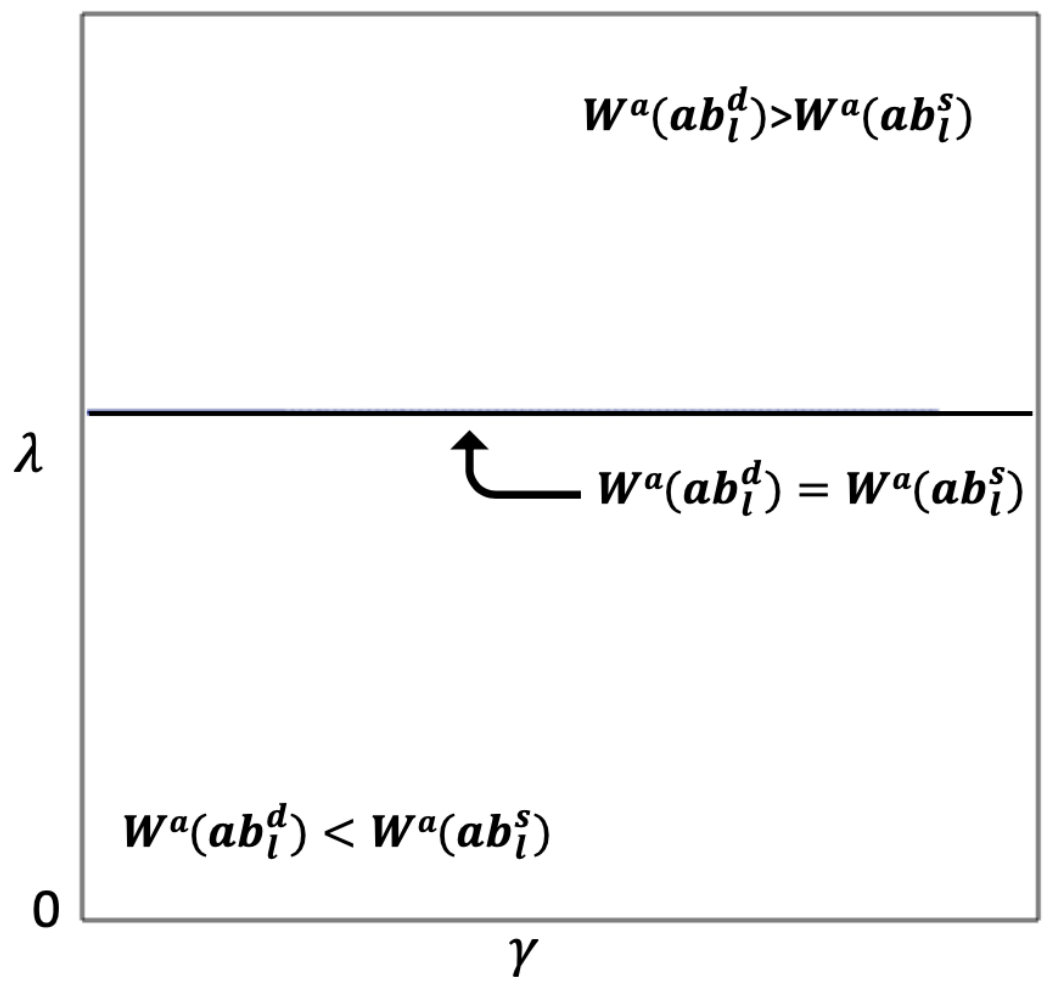

Figure 2.5: Country a welfare comparison of deep trade agreement $\left(a b_{l}^{d}\right)$ and shallow trade agreement $\left(a b_{l}^{s}\right)$ if pollution is local

\subsection{Global Pollution: Deep and Shallow Trade Agreements}

In this part of the paper, we examine deep and shallow trade agreements when negative production externality is global. Global pollution implies that the production of the dirty good $A$ affects both members of the world equally regardless of the country where this production takes place. 


\subsubsection{Deep and Shallow Trade Agreements and their Effect on Taxes and Specialization}

In this subsection, we, first, analyze the effect of a shallow trade agreement, denoted $\left(a b_{g}^{s}\right)$, on the environmental tax on the $\operatorname{dirty} \operatorname{good} A$ in both members and on the level of their specialization, and then, we examine the effect of a deep trade deal, denoted $\left(a b_{g}^{d}\right)$.

Similar to the local pollution case, when pollution is global and countries decide to sign a shallow trade deal, they agree only on eliminating their tariffs on the imports from each other, but they still impose individually optimal levels of the non-prohibitive environmental tax. Again, we observe an increase in the environmental tax levied by country $a$ and a decrease in the level of tax in country $b$ relative to their no agreement levels, and consequently, similar to the local pollution case, these changes in local taxes lead to an increased production of the $\operatorname{dirty} \operatorname{good} A$ in both countries. The inverse relationship between the local tax in country $a$ and the tariff faced by that country, illustrated in the equation (2.18), explains an increase in the level of tax when the tariff is eliminated. Also, an increase in the production, and consequently, export level of the comparative advantage good of country $a$, good $A$, is explained by the elimination of the import tariff under this shallow trade deal. On the other hand, the complementarity of the tax and tariff imposed by the clean country $b$, respectively, on its production and import of the $\operatorname{dirty} \operatorname{good} A$ explain a decrease in the local tax in country $b$, and that in turn explains the increased production of the dirty $\operatorname{good} A$ in country $b$ relative to the no agreement scenario. This shallow trade deal increases the specialization of the clean country $b$ on its comparative advantage good, $\operatorname{good} B: s_{B}^{a}\left(s_{g}\right)<s_{B}^{a}\left(n_{g}\right)$ and $s_{B}^{b}\left(s_{g}\right)<s_{B}^{b}\left(n_{g}\right)$. Though we do observe the increase in the production of the $\operatorname{dirty} \operatorname{good} A$ in both countries, the increase in the production of the dirty good $A$ in country $a$ still exceeds the increase in country $b$. Again, we see that the shallow trade agreement does not lead to a deep specialization of two large asymmetric countries, but it still allows countries to benefit from the

increased production of their comparative advantage good and an increased import of the good they do not have a comparative advantage in.

The members of deep trade agreement eliminate tariffs on the imports from each other, and they also set an environmental tax at a jointly optimal level. Now, we are ready to state the following: 
Proposition 2.4: The formation of a deep free trade agreement induces the members to choose an environmental tax equal to marginal damages.

The negative per unit production externality associated with the production of the dirty good $A$ effects both countries in the same way when pollution is global. In this case, a deep trade agreement induces the members to set the tax at the level at the socially optimal level of $2 \gamma$, which is equal to world marginal damages. This level of tax is the highest the clean county $b$ levies on its local producers of the dirty good $A$ for any size of the productivity gap or per unit production externality. However, this level is the highest for the dirty country $a$ only if the level of per unit production externally is relatively high. The export of the dirty good $A$ decreases in the level of per unit pollution. An increase in per unit production externality, as well as a relatively narrow productivity gap, leads to a lower import demand in country $b$. However, under a deep trade agreement, we also observe a decrease in the local production of the dirty good $A$ in country $b$ for any level of per unit production externally and productivity gap relative to both the no agreement scenario and the shallow trade deal. Based on the above, we conclude that a deep trade agreement also leads to a deeper specialization in the world of two large asymmetric countries if pollution is global, and both deep and shallow trade deals increase countries specialization on their comparative advantage goods relative to the no agreement scenario.

\subsubsection{Deep and Shallow Trade Agreements: Welfare Analysis}

In this subsection, we examine how deep and shallow trade agreements affect world and individual countries' welfare levels if pollution is global. Global pollution implies that both countries get equally affected by the production of the dirty good $A$ regardless the location of the producer. First, we analyze the shallow trade deal, and then we examine the deep trade agreement.

In the case of local pollution, described above, we observe an increase in the world welfare level under shallow trade agreement relative to the no agreement scenario for all levels of the externality and productivity gap. Contrary to that, when pollution is global, the world welfare under shallow 
trade agreement exceeds the no agreement level only if productivity gap is relatively wide and per unit production externality is relatively low, as illustrated in Figure 2.6. As mentioned previously, if pollution is local then the clean country $b$ is better off in a shallow trade deal for any levels of pollution or productivity parameter, but if pollution is global, then the clean member of the world would sign a shallow deal only if productivity gap is large and per unit externality is low (Figure 2.7). The explanation simply lies in the level of spillovers; if pollution is local, then the increased production of the good $A$ in country $a$ had no negative effect on its neighbour, country $b$, and consequently, the clean country demands positive imports of the dirty good $A$ for any level of per unit production externality. However, if pollution is global, then the clean country $b$ bears the cost of the increased production of the dirty $\operatorname{good} A$, and consequently, imports are positive only if per unit production externally is relatively low $\left(m^{b}\left(n_{g}\right)=0\right.$ line in Figure 2.6 and Figure 2.7). The dirty country $a$ would also prefer to stay away from the shallow trade deal if per unit production externality is relatively high and the productivity gap is relatively narrow, as shown in Figure 2.7. This is explained by the negative import demand in country $b$ for the $\operatorname{dirty} \operatorname{good} A$ if per unit pollution is high and productivity gap is narrow. The negative level of import demand limits country $a$ 's ability to benefit from the world specialization on the comparative advantage goods, and consequently, makes any trade deal less desirable. An increase in per unit production externality and/or a decrease in the productivity gap would decrease both countries desire to form a shallow trade deal. If pollution global, then asymmetric countries do not necessarily benefit from a shallow trade agreement, they do so only if per unit pollution is low and the productivity gap is wide. 


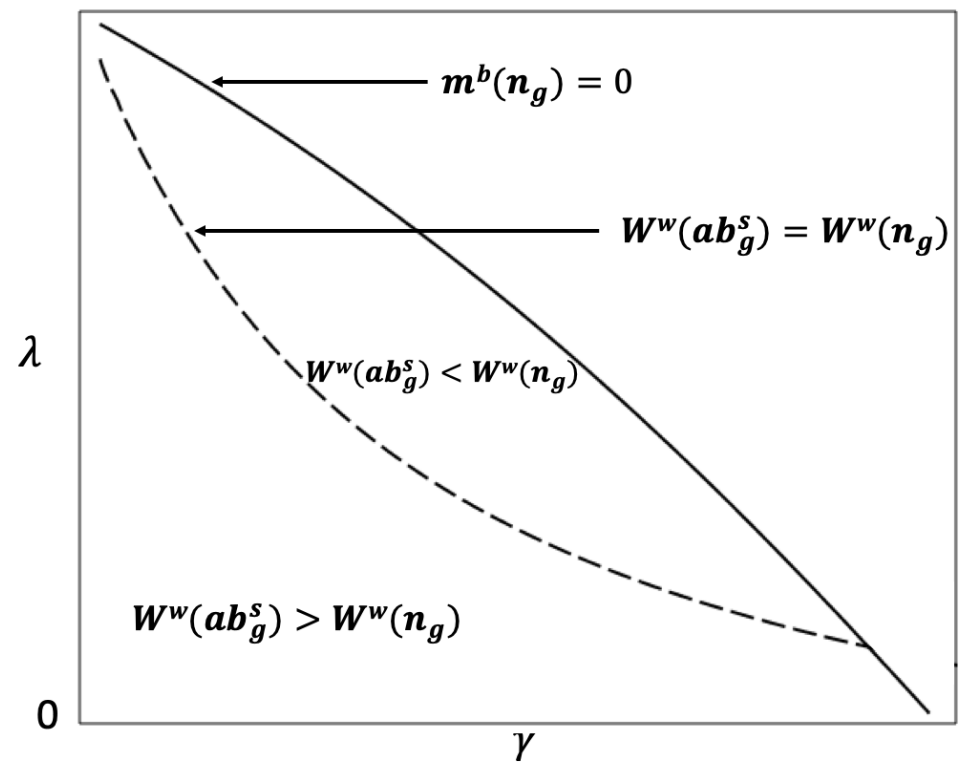

Figure 2.6: World welfare comparison of no agreement $\left(n_{g}\right)$ and shallow trade agreement $\left(a b_{g}^{s}\right)$ if pollution is global

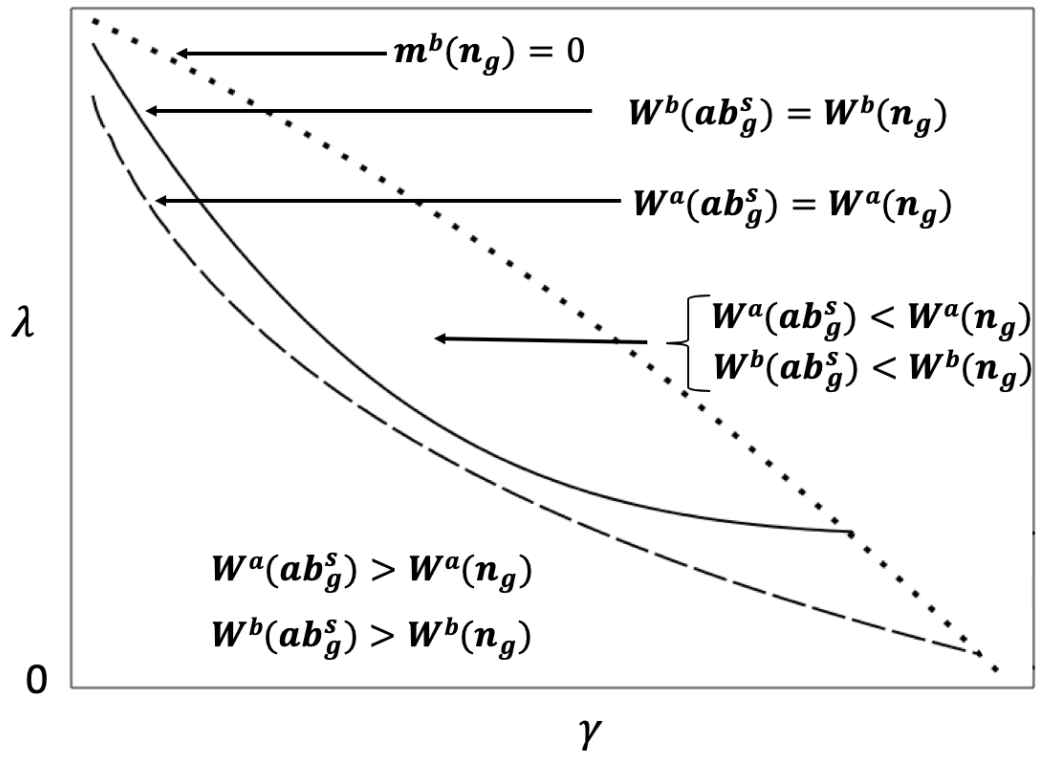

Figure 2.7: Countries welfare comparison of no agreement $\left(n_{g}\right)$ and shallow trade agreement $\left(a b_{g}^{s}\right)$ if pollution is global 
When two large asymmetric countries have to agree on the level of environmental tax they levy on their local producers of the dirty good $A$, as well as on the removing trade tariffs on the imports from each other, then we observe an increase in world welfare level relative to both no agreement and a shallow trade deal. World welfare under deep trade agreement is increasing in productivity parameter for relatively high levels of per unit production externality and decreasing in productivity parameter if per unit pollution is low relative to both no agreement and a shallow trade deal. The increase in the unit production externality would cause an increase in the world value of a deep trade agreement, again relative to both the world with no agreements in it and a shallow free trade. Both a high per unit production externality and a narrow productivity gap would result in higher world welfare level under a deep trade agreement. A high level of per unit production externality makes a shallow trade deal more attractive to the clean member of the world, country $b$, relative to both no agreement and shallow trade deal, and the dirty country $a$ likes a deep trade agreement for high level of per unit production externality only if the productivity gap is relatively narrow. A decrease in productivity gap would, on one hand, make a deep agreement less attractive for country $b$ if production externality is high, and on the other hand, it would make it more attractive for country $a$. The explanation lies in the positive level of export of country a under the shallow trade deal for any level of negative production externality relative to country $a$ 's exports being positive under no agreement only if per unit pollution is relatively low.

Similar to the previous case of local pollution, if pollution is global, we also observe that the world welfare is the highest under a deep free trade agreement, but contrary to the previous case, here, we observe that the dirty country a is also on board with this deal.

\subsection{Deep and Shallow Trade Agreements and their Effect on the Environ- mental Damages}

In this section, we examine the effect of deep and shallow trade agreements on the level of world and individual countries' environmental damages for both local and global levels of negative per unit production externality, pollution. We are ready to state the following: 
Proposition 2.5: Deep and shallow trade agreements have the following effects on the level of world and individual countries environmental damages:

(i) The formation of a shallow free trade agreement induces an increase in the level of damages in both members of the world, and consequently, in the level of world damages as well, for both local and global levels of pollution.

(ii) If pollution is local, though the formation of a deep trade agreement induces an increase in the world level of damages relative to both no agreement and a shallow trade deal, the clean country b exhibits a decrease in the level of damages.

(iii) If pollution is global then a deep trade agreement induces a decrease in the world level of damages relative to both no agreement and shallow free trade if per unit production externality is sufficiently high.

The explanation to part (i) of the above proposition lies in the increased production of the dirty $\operatorname{good} A$ in both members of the world. The removal of the trade tariff leads to increased exports and production of the dirty good $A$ in the country with a comparative advantage in the production of that good, the dirty country $a$, for both local and global pollution. We can say that this effect is fully expected. However, we also observe an increase in the production of the dirty good $A$ in the country with no comparative advantage in this good, the clean country $b$, and again we observe this increase for both levels of pollution, local and global. This can be explained with the complementarity of tariffs and taxes on the local producers of the dirty good $A$ in country $b$. The decrease in the import tariff to zero leads to a decrease in the level of environmental tax, and consequently, makes the production of the dirty good more attractive for the local producers in country $b$. The level of damages is still higher in the country with a comparative advantage relative to the level in the clean country $b$. We can conclude that a shallow trade agreement induces an increase in world pollution relative to the no agreement for any level of productivity parameter and/or negative production externality for both local and global levels of pollution. 
Though the formation of a deep trade agreement, $\left(a b_{l}^{d}\right)$, also leads to an increase in the level of damages in the world if pollution is local, the dirty country $a$ is fully responsible for this increase, Part(ii) Proposition 2.5. In the case of local pollution, the level of world damages under a deep trade agreement exceeds both the no agreement level and a shallow trade deal. However, the level of environmental damages in the clean country $b$ is below the no agreement level. The explanation lies in an increased specialization in both countries on the good they actually have comparative advantage in. We observe a growth in production and export of the dirty good $A$ by country $a$, and consequently, we observe a decrease in the production and an increase in the import demand for the dirty $\operatorname{good} A$ by the clean country $b$.

However, contrary to the local pollution case, the formation of a deep trade agreement, $\left(a b_{g}^{d}\right)$, induces a decrease in the level of world damages relative to both no agreement and a shallow free trade if per unit negative production externally is relatively high; see Figure 2.8. If pollution is global, then both members of the world are equally affected by the production of the dirty good $A$, and consequently, for this relatively high level of per unit production externality, we observe a decrease in the level of production and damages in both countries, the dirty country $a$ and the clean country $b$, relative to both the no agreement and a shallow trade deal. However, if production externality is relatively low and the productivity gap is relatively wide, then we observe an increase in the level of world damages. In this case, both members of the world, the dirty country $a$ and the clean country $b$, increase the production of the dirty $\operatorname{good} A$, and as a result, experience an increase in the level of environmental damages. 


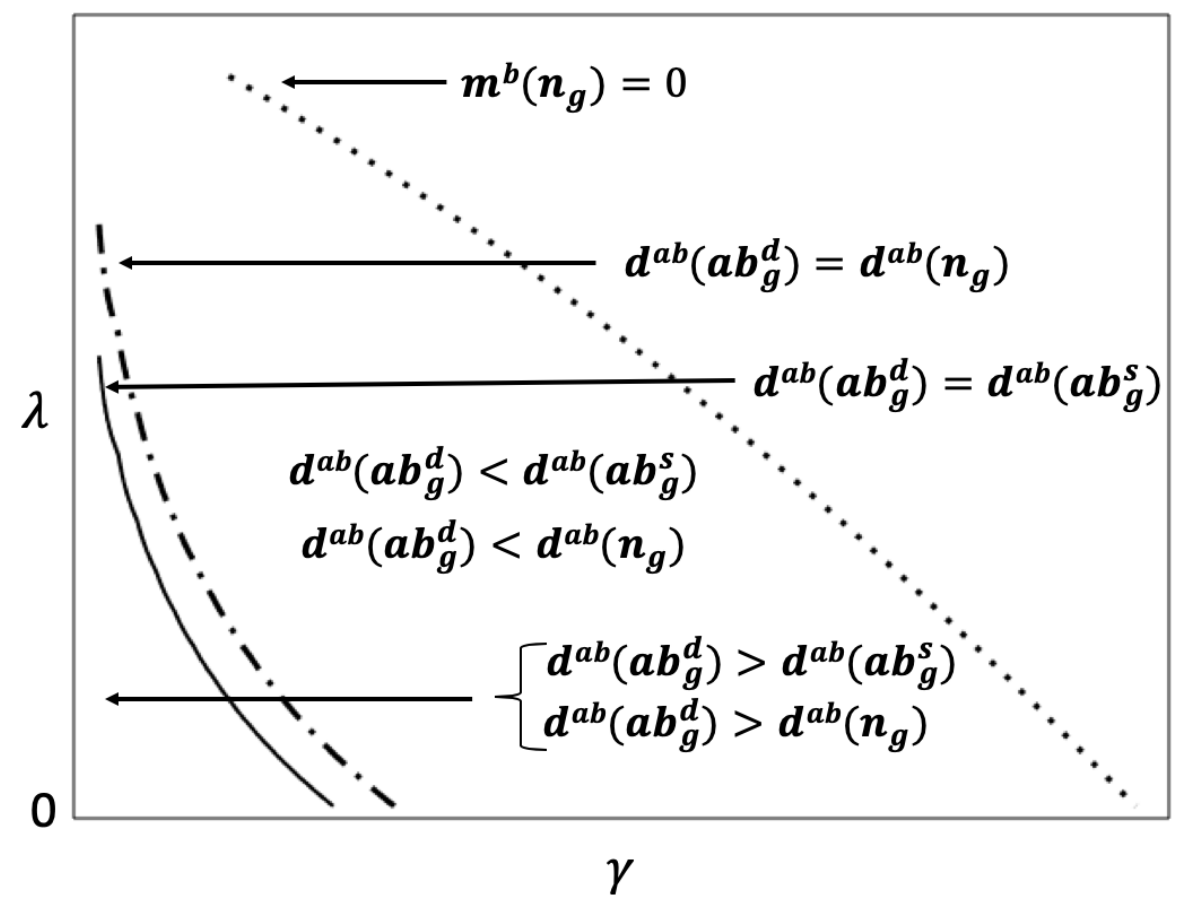

Figure 2.8: World environmental damage comparison of deep trade agreement, $\left(a b_{g}^{d}\right)$, shallow trade agreement, $\left(a b_{g}^{s}\right)$, and no agreement $\left(n_{g}\right)$ if pollution is global

\subsection{Conclusion}

Countries can use both border policies and domestic policies in order to improve their terms-oftrade and increase their gains from trade, and this has received a great deal of attention in both literature and in practice. In this chapter, we have investigated this issue by comparing shallow (trade only) and deep (trade and environment) trade agreements between two large asymmetric countries, and we have shown that deep and shallow trade agreements have different outcomes in terms of world and individual countries welfares, trade specialization and environmental damages. Therefore, we have answered three questions: (i) how do deep and shallow trade agreements affect countries' choices of domestic policies and their trade specialization given different degrees of transboundary spillovers?; (ii) given the degree of transboundary spillovers, how do deep and shallow trade agreements affect world and individual countries' welfare levels?; and (iii) what are 
the implications of inclusion of the non-trade elements in a shallow trade deal on the world and individual countries' environmental damages?

The first question we have answered in this paper is on whether and how deep and shallow trade agreements affect countries choices of domestic policies and their trade specialization given different degrees of transboundary spillovers. Our findings show that with the complete flexibility over both border policies and domestic instruments (under no agreement between countries), only the dirty country would use both border policies and domestic policies to alter the terms of trade, and the clean country will alter its border policies exclusively and set the environmental tax at the socially optimal level. However, under a shallow trade agreement, both countries turn to their domestic policies to manipulate the terms-of-trade. Though those changes in both countries domestic policies do not prevent them from enjoying a deeper specialization on the good they have a comparative advantage in relative to the no agreement scenario, still those changes will lead to an increased production of the dirty good in both countries and prevent them from enjoying a full specialization for both local and global levels of transboundary spillovers. When countries sign a deep trade agreement, they lose control not only over their border policies (as in a shallow trade agreements), but also over their domestic environmental policies as well as, namely, they have agree on the level of environmental tax they levy on their producers of the dirty good. Our results show, that the formation of a deep free trade agreement induces countries to choose an environmental tax equal to marginal damages (socially optimal level) for both local and global levels of pollution. In the world of two large asymmetric countries, a deep trade agreement encourages a deeper specialization of its members on the goods they actually have a comparative advantage in, but still both deep and shallow trade deals increase members specialization relative to the no agreement scenario.

The second question we have analyzed in this paper is how deep and shallow trade agreements affect world and individual countries welfare levels given the degree of transboundary spillovers. Our results show, that given a zero degree of transboundary spillovers, a shallow trade agreement would lead to an increase in the world welfare level relative to the no agreement scenario, and we 
can say that this was fully expected. However, the gains are not the same for both members of a shallow trade deal; the clean country is better off under this deal regardless the level of negative externality and/or productivity parameter, but the country with a comparative advantage in the production of the dirty good is interested in a shallow trade agreement only if productivity gap is sufficiently wide and production externality is sufficiently low. Furthermore, if pollution is global, then a shallow trade agreement would lead to an increased level of world welfare only if the negative per unit production externality is sufficiently low and the productivity gap is sufficiently wide. Contrary to that, our results show that when countries add an environmental clause to their trade deal (sign a deep trade agreement) the world welfare is increased relative to both the no agreement level and a shallow free trade. Again, the countries gains from that agreement depend on the levels of the negative externality and productivity gap. In pollution is local, then the clean country would prefer to coordinate both border policies and domestic policies (sign a deep trade agreement), but the dirty country would prefer to keep control over its domestic policies if productivity gap is sufficiently large. Furthermore, the global pollution, low level of production externally and wide productivity gap would encourage both countries to keep control over their domestic policies.

The next question we answer in this paper is what are the implications of inclusion of the non-trade elements in a shallow trade deal on the world and individual countries environmental damages. Not surprisingly, our results illustrate an increase in the world damages under both shallow and deep trade agreement if pollution is purely local. However, under shallow free trade, both countries exhibit an increase in the level of environmental damages, and under deep free trade, full coordination leads to an increase in the damages only in the country with a comparative advantage in the production of the polluting good. In the case of global pollution, a shallow free trade agreement would increase the level of pollution in both countries, and consequently, in the world, but a deep free trade would indeed induce a decrease in the world level of damages relative to both no agreement and shallow free trade if per unit production externality is sufficiently high. 


\section{Chapter 3}

\subsection{Introduction}

Over the past few decades, the rise in the number of preferential trade agreements (PTAs) has been a major trend in international trade. In the same time, pure international trade agreements have been unsuccessful in practice, and it is well-established in the literature that these agreements suffer from a strong free-riding incentive. Though cooperation is beneficial for all members, a self-exclusion incentive is strong as well as countries benefit form the effort of other countries. Alongside these global trends in trade and the environment, we observe a widespread inclusion of non-trade elements in modern preferential trade agreements, such as domestic policy over the environment, labour, intellectual property, health and investment, and one area that has received a great deal of attention in deep agreements is the environment.

As shown in the two-country model of Horn etal.(2010) on the nature of trade agreements, countries will generally apply tariffs and not alter domestic policies on local firms to gain competitive advantage in the absence of any restrictions. If tariffs are constrained (such as in a PTA), countries will then resort to consumption taxes on foreign produced products, as these taxes are perfect substitutes for tariffs. However, Article III of the WTO prevents differential treatment of foreign products from domestic products (National Treatment). In this situation, countries would then resort to manipulating domestic policies in order to improve their terms-of-trade. In this manner, countries can modify environmental (or health or labour) taxes to gain advantage against foreign competition. Our initial contribution is to formally examine these different cases, and their effects on welfare, in an adapted version of the perfectly competitive two-country comparative advantage model of Horn etal.(2010), but with several extensions: three countries (along the lines of Missios et al.2016), asymmetric countries, active policy in all countries, production (not consumption) externalities, and differential externality effects. Here, each country has a comparative advantage in the production of only one non-numeraire good, and consequently, is a natural exporter of that good, but produces all goods. To simplify the analysis, only one non-numeraire good 
generates a negative (production) externality (the "dirty" good), which may have a transboundary effects on other countries. ${ }^{8}$ We consider two policy instruments: (non-prohibitive) tariffs on imports, and a (non-prohibitive) environmental tax on the domestic producers of the dirty good, and illustrate the optimal policies under each possible trade agreement (and in the absence of any agreement). In addition to the standard tariff complementary of trade agreements, we also investigate the complementary of taxes and tariffs on the production and international trade of the dirty good.

In our model, shallow trade agreements allow countries to negotiate only pure trade deals. Under this type of trade agreements, members are free to set the non-prohibitive environmental tax they levy on their producers of the dirty good at their unilaterally optimal levels. As a result, the level of tax can vary among members of any shallow trade agreement. We analyze two types of shallow PTAs, free trade agreements (FTAs) and customs unions (CUs). As in Bagwell and Staiger(1997), Bond and Syropoulos(1996), and Missios etal.(2016), we observe and explore the effects of the pooled market power of customs unions on the joint external tariff the members levy on their combined imports from the non-member country. As required by article XXIV of the WTO, in any shallow trade agreement, members agree to eliminate tariffs on each other, but FTA members enjoy a higher degree of freedom in setting their individually optimal external tariff on the imports from the non-member, and consequently, each member is free to make a "side deal" with another country (that is, to become a "hub" in a hub-and-spoke situation). Unlike FTA members, members of a customs union impose a jointly optimal tariff on the imports from the outsider by maximizing their joint welfare function. Article XXIV of GATT/WTO requires all PTA members keep their external tariffs on non-member countries no higher than the pre-existing level. In this paper, we examine both cases: first, we ignore this tariff restriction and simply assume that any $\mathrm{CU}$ is free to levy the optimal tariff, and later, we investigate the effect of the restrictions of Article XXIV.

\footnotetext{
${ }^{8}$ As in Horn et al. (2010), we assume a constant externality per unit of production. We also assume with symmetric cross border spillovers in the global pollution case.
} 
Contrary to shallow PTAs, deep trade agreements let their members negotiate both tariffs and taxes. Members of deep FTAs have to agree on both eliminating their tariffs on each other and the level of environmental tax they levy on the domestic producers of the dirty good. In addition to that, members of integrated customs unions (IUs) also agree on a jointly optimal tariff on the imports from the outsider. Similar to shallow customs unions, the combined power of members of an integrated customs union allows them to benefit from the increased terms of trade gain and to raise their common external tariff on the imports from the outsider above the no agreement level. Similar to shallow CUs, we also first ignore the tariff restrictions required according to Article XXIV of the GATT/WTO, and then we examine the effect of these restrictions on the formation of different integrated customs unions.

Following an approach similar to Missios etal.(2016), we also assume that countries are free to choose their shallow or deep PTAs members, as well as their tariffs and environmental tax levels in the absence of any relevant agreement. As a result, deep or shallow preferential trade agreements arise endogenously. First, we restrict countries' sets of announcements to either shallow or deep trade agreements and derive Nash equilibria of five different games of environmental and/or trade liberalization: an environment-only agreement game (E game), a shallow customs union game (CU Game), a shallow free trade agreement game (FTA Game), an integrated (or deep) customs union game (IU Game), and an integrated (or deep) free trade agreement game (I Game). While there is some overlap between the previous literature on (shallow) trade agreements, we extend this analysis by including externalities and domestic policy. Regardless of the nature of trade and/or environmental agreements, the stages of the games are the same: in the first stage, players simultaneously announce the name(s) of the countries with whom they want to form an agreement; in the second stage, given the trade and/or environmental policy regime, countries choose their optimal tariffs and/or environmental taxes they impose on the production of the dirty good; and in the final stage of each game, consumption, production and international trade take place. Countries are free to choose their announcements, and deep or shallow trade agreements can be formed only if partners announce each other. In an environmental agreement game, players announce the names 
of the countries they would like to form pure environmental agreements with. These agreements are free of any trade restrictions. The difference between the shallow CU and a shallow FTA games lies in the nature of two types of preferential trade agreements. In the CU game, a member of a trade union cannot unilaterally decide to sign another agreement with a non-member country. In order to do so, a member would need to get a consent of a current PTA partner (expansion), as members of a trade union impose a jointly optimal tariff on the imports from the outsider. On the contrary, in the FTA game, members levy an individually optimal tariffs on the non-member, and due to that, they are free to form another agreement without any consent of a current PTA member. In the deep customs union (IU) and deep free trade agreement (I) games, each country announces the names of the countries with whom they want to sign a deep trade agreement. Integrated agreements always include an environmental component, namely, members have to agree on the level of tax they levy on their producers of the dirty good.

In order to examine the differences between shallow and deep trade agreements at a deeper level, we develop four extended games: a shallow trade agreements game, where countries can choose between shallow CU and FTA agreements; a deep trade agreements game, where countries can choose between integrated customs unions and integrated FTAs; an extended game with the choice between deep and shallow CUs; and an extended game with the choice between deep and shallow FTAs. In either extended game, for shallow or deep trade agreement to arise, countries profiles should match at two levels, the partner's name(s) and the type of a preferential trade agreement. Looking ahead, we have multiple Nash equilibria in all nine games (five games and four extended games). In this paper, we distinguish any Coalition-Proof Nash Equilibria (CPNE) from the set of Nash Equilibria (NE). Bernheim etal.(1987) argue that "it is natural to assume that players can freely discuss their strategies, but cannot make binding commitments". We follow Missios etal. (2016) and acknowledge that in the present world, countries have the capacity to communicate without having to make binding commitments. Based on that, in our model, we allow countries to discuss possible environmental and/or trade agreements prior to their announcement. We follow the concept of coalition-proof Nash Equilibrium introduced in Bernheim etal.(1987): 
“..,the concept of Coalition-Proof Nash equilibrium, that is designed to capture the notion of an efficient self-enforcing agreement for environments with unlimited, but nonbinding, pre-play communication. An agreement is coalition-proof if and only if it is Pareto efficient within a class of self-enforcing agreements...an agreement is self-enforcing if and only if no proper subset (coalition) of players, taking the action of its complement as fixed, can agree to deviate in a way that makes all of its members better off." Coalition-proof Nash equilibria have to survive all possible self-enforcing coalitional deviations. When we consider whether a particular coalition-proof Nash equilibria holds, we keep the announcement of non-deviating countries unchanged.

In our model, pure environmental agreements as well as either shallow or deep trade agreements arise endogenously. To our knowledge, there is no equilibrium theory on what agreement we should see in this particular situation and how these agreements impact welfares and environments. In this paper, we attempt to narrow this gap by answering three different and equally important questions: (i) how do equilibrium agreements differ when countries choose deep rather than shallow agreements?; (ii) given the choice between deep and shallow trade agreements, would countries prefer to incorporate an environmental clause into their equilibrium trade deal?; and (iii) what are the implications of including non-trade elements in PTAs for the pursuit of global free trade?

The main body of the literature on international environmental agreements exhibits well-known results on free-riding incentives. Though all countries benefit from cooperation, each member has strong incentives to free ride on the coalitional efforts of the others (e.g., Barrett(1994), Diamantoudi etal. (2018), Ferrara etal. (2011)). Environmental coalitions tend to be small and include only, or primarily, homogeneous countries. Our main results are in line with this literature; pure environmental agreements do not arise between asymmetric countries for both local and global levels of pollution. If pollution if global, then pure environmental negotiation yields the coalition-proof Nash equilibria of two symmetric clean countries, and the only dirty country prefers to be an outsider. Furthermore, if the externality exhibits no spillovers, then no agreement is a coalition-proof Nash equilibria. 
Similar to Missios etal.(2016), we also conclude that, in general, customs unions are more coalitionally stable than free trade agreements. As long as the option of a shallow or deep CU is on the table, countries do not end up in either shallow or deep global free trade. In our case of asymmetric countries, though global pollution leads clean countries to desire to form either shallow or deep free trade, the dirty country would never agree to that. The dirty country would rather face a deep or shallow customs union of two symmetric clean countries than be a part of world agreement. Similar to Bagwell and Staiger(1997), Bond and Syropoulos(1996), and Missios etal.(2016) we also observe that customs union members raise their tariff on the imports from the outsider, and the outsider reduces its tariff on the imports from the members relative to the no agreement level, and as in Missios etal.(2016), though the restrictions of Article XXIV prevent members of customs unions from raising their external tariffs on the non-member above the pre-existence level, it does not result in global free trade. However, shallow global free trade survives all coalitional deviations in the FTA game due to the presence of hub-and-spoke trade regimes, even with domestic taxation policy. In this case, though any two countries can benefit from excluding the third one from the agreement, none of the countries would exercise it in equilibrium; the exclusion incentive is still high but the incentive to become a hub is stronger.

The literature on international trade and environment has primarily focussed on the effects of trade liberalization on the environment and welfare (Copeland and Taylor(1994), Antweiler etal.(2001), Ferrara etal.(2009)). We relate to this literature through our analysis of the environmental damages caused by different endogenously formed shallow and deep trade agreements. Our findings show that the equilibrium shallow free trade agreement induces the highest level of pollution. In a free trade world, each country finds it beneficial to increase the specialization of the production of their comparative advantage good and decrease the production of the other two goods, and as a result, we observe the increased amount of goods produced and traded in the world (relative to no agreement). The increased production of the dirty good naturally leads to an increased level of negative externality associated with this production process. We can see that global free trade with no environmental clause attached to it would cause an increase in the environmental damages for 
both local and global levels of pollution. However, if pollution is global, then a fully integrated world is the least polluted. If our asymmetric countries have to agree not only on the removal of the tariffs but also on the environmental tax they levy on their producers of the dirty good, then the environmental tax shows no distortion from its socially optimal no agreement level. ${ }^{9}$

The rest of the chapter has the following structure: section 3.2 sets up the basic model and analyses optimal Nash tariffs and taxes; section 3.3 explores environmental and trade agreements and their effects on tariffs and taxes; section 3.4 investigates environmental and trade agreements and their effects on the environmental damages; section 3.5 reviles announcements and strategy sets and provides the notion of coalition-proof Nash equilibrium; section 3.6 analyses endogenous environmental agreements; section 3.7 analyses endogenous shallow trade agreements; section 3.8 analyses endogenous deep trade agreements; section 3.9 provides further discussion on shallow versus deep integration, Article XXIV restriction and four extended games; section 3.10 concludes the chapter.

\subsection{The Model}

\subsubsection{Overview of the Model}

We consider a perfectly competitive world with three large countries: $j \in[a, b, c]$. Each country producers four goods: three non-numeraire goods, $k \in[A, B, C]$, and one numeraire good, $v_{0}$. The production technology of the numeraire good, as well as the production technology of goods $B$ and $C$, is a clean one. However, the production of $\operatorname{good} A$ generates pollution which may have a transboundary effect on both neighbours. Production of clean goods is free of any taxes in all three countries, and all three countries impose a non-prohibitive environmental tax $\left(e_{A}^{j}\right)$ on the domestic producers of the dirty good $A$. Only the numeraire good is freely traded; all other good are subject to non-prohibitive import tariffs $\left(t_{k}^{j}\right)$. On the demand side, the representative citizen's

\footnotetext{
${ }^{9}$ Socially optimal pollution taxes are higher in the global pollution case due to spillovers.
} 
utility function is linear in the numeraire good, and it is quadratic and additively separable in the three non-numeraire goods:

$$
U\left(v, v_{0}\right)=u(v)+v_{0}
$$

where $v=\left[v_{A}, v_{B}, v_{C}\right]$ is the consumption vector for the three non-numeraire goods, and $v_{0}$ stands for the consumption of the numeraire good. The demand for $\operatorname{good} k$ in country $j$ is given by:

$$
d\left(p_{k}^{j}\right)=\alpha-\beta p_{k}^{j}
$$

Again for simplicity, we assume $\alpha=\beta=1$, without loss of generality as long as demand is the same across markets. On the supply side, as in Horn etal.(2010), labour $(l)$ is the only factor of production. Labour is employed in the production of each non-numeraire good according to DRS (decreasing-returns-to-scale) technology, namely, $x_{k}^{j}=\sqrt{2 \lambda_{k}^{j}} l$, where $\lambda_{k}^{j} \in(0,1] . \lambda$ is a productivity parameter: if $\lambda_{k}^{j}=1$, then we say that country $j$ has a comparative advantage in the production of good $k$, and consequently, that country $j$ is a natural exporter of that $\operatorname{good} k$; if $\lambda_{k}^{j}<1$, then we say that country $j$ is a natural importer of good $k$. We assume that the supply of labour is large enough in all three countries to always produce numeraire good, and this good is produced according to CRS (constant-returns-to-scale) technology. As a result, the equilibrium wage is equal to one, and the supply of non-numeraire $\operatorname{good} k$ in country $j$ is as follows:

$$
s_{k}^{j}=\lambda_{k}^{j}\left(q_{k}^{j}-e_{k}^{j}\right), \text { where } k=A \quad \text { and } \quad s_{k}^{j}=\lambda_{k}^{j} q_{k}^{j} \text {, where } k \in[B, C]
$$

where $q_{k}^{j}$ is the producer's price of $\operatorname{good} k$ in country $j$, and $e_{k}^{j}$ is the non-prohibitive environmental tax imposed on the producers of the $\operatorname{dirty} \operatorname{good} A$ in country $j$. We assume a symmetric comparative advantage structure across all three countries, specifically, $\lambda_{A}^{a}=\lambda_{B}^{b}=\lambda_{C}^{c}=1$ and $\lambda_{B}^{a}=\lambda_{C}^{a}=\lambda_{A}^{b}=$ $\lambda_{C}^{b}=\lambda_{A}^{c}=\lambda_{B}^{c}=\lambda<1$. Under this assumption each country has a comparative advantage in the good that coincides with the identity of the country that exports this good, and each country has a disadvantage in the production of the other two goods and imports them. In this way, we assume that countries are competing importers; each country exports a single good and imports two goods. Due to the absence of any local tariffs (free trade within each country), we have 
$\mathrm{q}_{k}^{j}=p_{k}^{j}$, if $k \in[B, C]$, and $\mathrm{q}_{k}^{j}=p_{k}^{j}-e_{k}^{j}$, if $k=A$. However, all three countries can impose specific tariffs on the imported non-numeraire goods $\left(t_{k}^{j}\right)$, and under the assumption that all three countries are large and symmetric in size, the world price of good $k$ would depend on the tariffs chosen by two importers of that good $k$. We have the following no-arbitrage conditions:

$p_{A}^{b}=p_{A}^{a}+t_{A}^{b} \& p_{A}^{c}=p_{A}^{a}+t_{A}^{c} ; p_{B}^{a}=p_{B}^{b}+t_{B}^{a} \& p_{B}^{c}=p_{B}^{b}+t_{B}^{c} ; p_{C}^{a}=p_{C}^{c}+t_{C}^{a} \& p_{C}^{b}=p_{C}^{c}+t_{C}^{b}$

where, for example, $t_{A}^{b}$ is a specific tariff imposed by country $b$ on the imports of good $A$. To simplify the notation, we ignore the exporter's subscript; each country exports the good it has a comparative advantage in, and that good is indexed by the same uppercase letter as the identity of the country; see Figure 3.1.

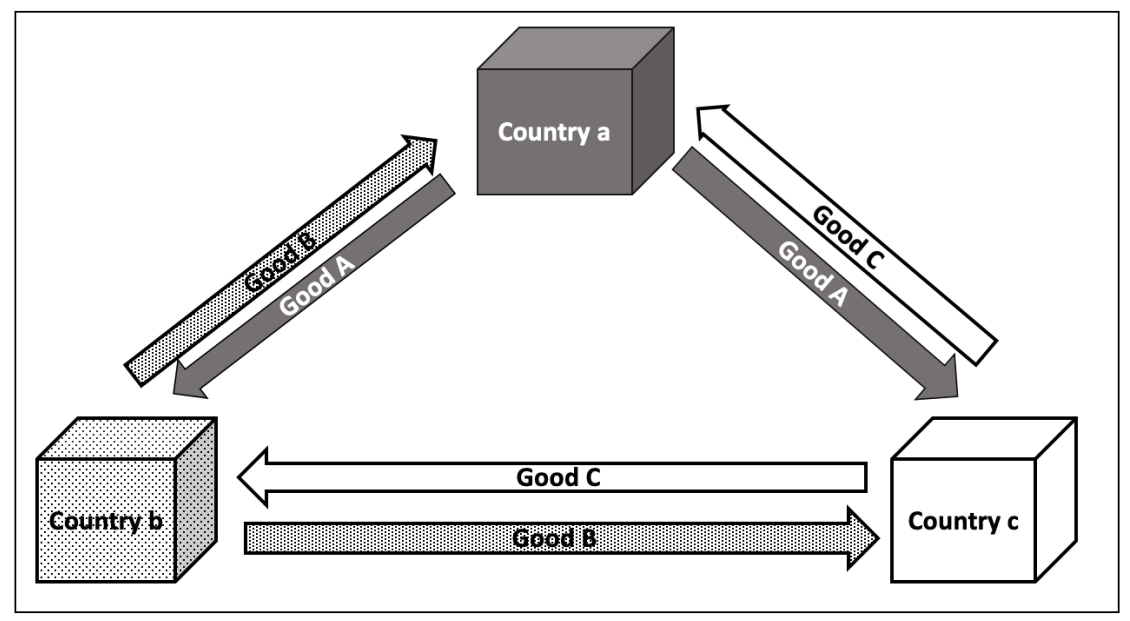

Figure 3.1: The Pattern of Trade

In our model, each country produces all four goods, but only production of good $A$ generates pollution. As in Horn etal. (2010), we assume a constant externality per unit of production, $\gamma$, but potentially with symmetric cross border spillovers. Specifically, we assume the following environmental damage function in country $j$ :

$$
\Psi^{a}=\gamma\left(s_{A}^{a}+z \sum_{j \neq a} s_{A}^{j}\right), \quad \Psi^{b}=\gamma\left(s_{A}^{b}+z \sum_{j \neq b} s_{A}^{j}\right), \quad \Psi^{c}=\gamma\left(s_{A}^{c}+z \sum_{j \neq c} s_{A}^{j}\right)
$$

where $z$ is the degree of transboundary spillovers, $z \in[0,1]$. As $z$ approaches 1 , the pollution generated from the production of $\operatorname{good} A$ in country $j$ affects the two other countries in the same 
way as it affects the country $j$ itself. If $z=0$, then the pollution is purely local, and the production of $A$ affects only the country the good $A$ is actually produced in, and if $z=1$, then pollution is purely global, and the production of $A$ affects all countries equally. To simplify the analysis, we will consider only these two extremes.

Let $m_{k}^{j}\left(p_{k}^{j}\right)=d\left(p_{k}^{j}\right)-s_{k}^{j}\left(p_{k}^{j}\right)$, where $j \neq k$, denote the imports of good $k$ by country $j$. For the convenience, we use good $A$ as an example, and let $m_{A}^{b}\left(p_{A}^{b}\right) \& m_{A}^{c}\left(p_{A}^{c}\right)$ denote the imports of good $A$ by countries $b$ and $c$ respectively:

$$
m_{A}^{b}\left(p_{A}^{b}\right)=d\left(p_{A}^{b}\right)-s_{A}^{b}\left(p_{A}^{b}\right) \quad \text { and } \quad m_{A}^{c}\left(p_{A}^{c}\right)=d\left(p_{A}^{c}\right)-s_{A}^{c}\left(p_{A}^{c}\right)
$$

Let $x_{b}^{a}$ and $x_{c}^{a}$ be the export levels of good $A$ by country $a$ to countries $b$ and $c$ respectively:

$$
x_{b}^{a}=s_{A}^{a}\left(p_{A}^{a}\right)-d\left(p_{A}^{a}\right)-m_{A}^{c}\left(p_{A}^{c}\right) \quad \text { and } \quad x_{c}^{a}=s_{A}^{a}\left(p_{A}^{a}\right)-d\left(p_{A}^{a}\right)-m_{A}^{b}\left(p_{A}^{b}\right)
$$

The following are market clearing conditions for $\operatorname{good} A$ :

$$
x_{b}^{a}=m_{A}^{b}\left(p_{A}^{b}\right) \quad \text { and } \quad x_{c}^{a}=m_{A}^{c}\left(p_{A}^{c}\right)
$$

\subsubsection{Optimal Nash Tariffs and Taxes}

Country $j$ 's welfare is defined as the sum of consumer surplus and producer surplus over all goods, tariff revenue over the two imported non-numeraire goods, tax revenue on the production of a dirty $\operatorname{good} A$, minus environmental damages caused by the production of that dirty $\operatorname{good} A$ :

$$
W^{j}=\sum_{k} C S_{k}^{j}\left(p_{k}^{j}\right)+\sum_{k} P S_{k}^{j}\left(p_{k}^{j}\right)+\sum_{j \neq k} t_{k}^{j} m_{k}^{j}\left(p_{k}^{j}\right)+e_{A}^{j} s_{A}^{j}-\Psi^{j}
$$

where $\sum_{j \neq k} t_{k}^{j} m_{k}^{j}\left(p_{k}^{j}\right)$ is tariff revenue of country $j$, and $e_{A}^{j} s_{A}^{j}$ is tax revenue of country $j$ over the production of the dirty good $A$. In the absence of any environmental and/or trade agreement, each country simultaneously chooses its tariffs and tax to maximize it's individual welfare. We derive optimal no agreement tariffs, following the approach of Feenstra (2004), Broda etal.(2008) and Missios etal.(2016). The optimal tariff on the imports of clean goods using the tariff applied by country $b$ on imports of good $C$ : 


$$
\frac{\partial W^{b}}{\partial t_{C}^{b}}=t_{C}^{b} \frac{\partial m_{C}^{b}}{\partial p_{C}^{b}} \frac{\partial p_{C}^{b}}{\partial t_{C}^{b}}-m_{C}^{b} \frac{\partial p_{C}^{c}}{\partial t_{C}^{b}}=0
$$

while the optimal tariff on imports of the dirty $\operatorname{good} A$ :

$$
\frac{\partial W^{b}}{\partial t_{A}^{b}}=t_{A}^{b} \frac{\partial m_{A}^{b}}{\partial p_{A}^{b}} \frac{\partial p_{A}^{b}}{\partial t_{A}^{b}}+\lambda \frac{\partial p_{A}^{b}}{\partial t_{A}^{b}}\left(e_{A}^{b}-\gamma\right)-m_{A}^{b} \frac{\partial p_{A}^{a}}{\partial t_{A}^{b}}=0
$$

where $\gamma$ is the constant externality per unit of production of a dirty $\operatorname{good} A$.

Countries balance the deadweight loss versus terms-of-trade gains. The first term in equation (3.10) and first two terms in equation (3.11) represent the marginal deadweight loss from the tariff. As the environmental tax approaches its optimal level, $\gamma$, the difference between the efficiency costs of the tariffs levied on the clean and dirty goods approaches zero. If a clean importer of the $\operatorname{dirty} \operatorname{good} A$ does not distort its tax from the socially ideal level, $e_{A}^{j \neq a}=\gamma$, the deadweight loss from the tariff on the imports from either country-partner are exactly the same, so in this case countries maximize the standard difference between terms-of-trade gain and the deadweight loss. If $e_{A}^{j \neq a} \neq \gamma$, however, countries adjust their tariffs to compensate: if a clean country sets its environmental tax on the producers of the dirty good $A$ above the optimal level, it would lead to a reduction in the efficiency cost of the tariff of that dirty good $A$, and if a clean country brings its tax below the ideal level, then the efficiency loss of the tariff would increase. ${ }^{10}$ The magnitude of that difference depends on the productivity parameter, lambda. The second term in both equations above illustrates the terms of trade effect. The terms of trade effect is the amount of imports multiplied by the change in the price of that good in the country with the comparative advantage in the production of the good caused by the change in the tariff.

Equations (3.10) and (3.11) can be re-written as:

$$
\frac{t_{B}^{a}}{p_{B}^{b}}=\frac{m_{B}^{a}}{p_{B}^{b}} \frac{\partial p_{B}^{b}}{\partial t_{B}^{a}}\left[\frac{\partial m_{B}^{a}}{\partial p_{B}^{a}} \frac{\partial p_{B}^{a}}{\partial t_{B}^{a}}\right]^{-1} \quad \text { and } \frac{t_{A}^{b}}{p_{A}^{a}}=\left(\frac{m_{A}^{b}}{p_{A}^{a}} \frac{\partial p_{A}^{a}}{\partial t_{A}^{b}}-\frac{\lambda\left(e_{A}^{b}-\gamma\right)}{p_{A}^{a}}\right)\left[\frac{\partial m_{A}^{b}}{\partial p_{A}^{b}} \frac{\partial p_{A}^{b}}{\partial t_{A}^{b}}\right]^{-1}
$$

To illustrate the relationship between optimal tariffs on clean and dirty goods and the export elasticities of those goods, we use the following market clearing conditions: $m_{A}^{b}=x_{b}^{a}$ and $m_{B}^{a}=x_{a}^{b}$, then $\partial m_{A}^{b} / \partial p_{A}^{b}=\partial x_{b}^{a} / \partial p_{A}^{b}$ and $\partial m_{B}^{a} / \partial p_{B}^{a}=\partial x_{a}^{b} / \partial p_{B}^{a}$.

$$
10 \frac{\partial m_{A}^{b}}{\partial p_{A}^{b}}=-(1+\lambda)<0 \text { and if } e_{A}^{b}<\gamma, \text { then } \lambda \frac{\partial p_{A}^{b}}{\partial t_{A}^{b}}\left(e_{A}^{b}-\gamma\right)<0 / \text { if } e_{A}^{b}>\gamma \text {, then } \lambda \frac{\partial p_{A}^{b}}{\partial t_{A}^{b}}\left(e_{A}^{b}-\gamma\right)>0
$$




$$
\begin{gathered}
\frac{t_{B}^{a}}{p_{B}^{b}}=\frac{1}{\varepsilon_{a}^{b}}=\frac{x_{a}^{b}}{p_{B}^{b}} \frac{\partial p_{B}^{b}}{\partial x_{a}^{b}} \\
\frac{t_{A}^{b}}{p_{A}^{a}}=\frac{1}{\varepsilon_{b}^{a}}-\frac{\lambda\left(e_{A}^{b}-\gamma\right)}{p_{A}^{a}}\left[\frac{\partial m_{A}^{b}}{\partial p_{A}^{b}}\right]^{-1}
\end{gathered}
$$

where $\varepsilon_{a}^{b}$ is the elasticity of export supply curve from country $b$ to country $a$, and $\varepsilon_{b}^{a}$ is the elasticity of export supply curve from country $a$ to country $b$. Equation (3.13) shows that the optimal tariff on a clean good is the inverse of the export price elasticity, and equation (3.14) shows that the optimal tariff on a dirty good is conditional on the environmental tax applied by a clean importer of a dirty good. ${ }^{11}$

The equilibrium price of the dirty $\operatorname{good} A$ in country $a$ and in country $b$ respectfully are:

$$
p_{A}^{a}=\frac{1}{2} \frac{3-(1+\lambda) \sum_{j \neq a} t_{A}^{j}+\lambda \sum_{j \neq a} e_{A}^{j}+e_{A}^{a}}{2+\lambda} ; p_{A}^{b}=\frac{1}{2} \frac{3+(3+\lambda) t_{A}^{b}-(1+\lambda) t_{A}^{c}+\lambda \sum_{j \neq a} e_{A}^{j}+e_{A}^{a}}{2+\lambda}
$$

the equilibrium prices of a clean $\operatorname{good} B$ in countries $b$ and $a$ respectfully are:

$$
p_{B}^{b}=\frac{1}{2} \frac{3-(1+\lambda) \sum_{j \neq b} t_{B}^{j}}{2+\lambda} \quad \text { and } \quad p_{B}^{a}=\frac{1}{2} \frac{3+(3+\lambda) t_{B}^{a}-(1+\lambda) t_{B}^{c}}{2+\lambda}
$$

As we can see from the equations (3.15) and (3.16), the price of the dirty good $A$, in both domestic and export markets, is increasing in the environmental taxes imposed on the production of this good in all three countries. However, the environmental tax in country $a$ has a stronger price effect than the environmental taxes in the other two countries with no comparative advantage in the production of that good. The price of good $A$ in country a is decreasing in the tariffs the country faces in the export markets of the two other countries, $b$ and $c$. Also, the higher the comparative advantage those countries have in the production of $\operatorname{good} A$, the stronger the terms of trade effect on the price of $\operatorname{good} A$. The price of a clean non-numeraire good $B$ in country $b$ is decreasing in the degree of comparative advantage in the production of this good in two other countries, $a$ and $c$; this supply effect is explained by the differences in productivity parameters across countries. As expected, the price of good $A$ in country $b$ and the price of good $B$ in country $a$ are increasing in its tariff and decreasing in its competitor's tariff, and the latter effect is stronger than the former. As in

\footnotetext{
${ }^{11}$ The tariff thus has the standard terms-of-trade component related to the export price elasticity, but also has a border tax adjustment component to account for the gap between foreign taxes and the optimal tax, gamma.
} 
Missios etal.(2016), we can conclude that the pass through from tariffs to local prices in importing countries is incomplete; the domestic price of a good with no comparative advantage does not increase one-to-one with its import tariff and does not decrease one-to-one with its competitor's tariff.

The equilibrium production of the $\operatorname{dirty} \operatorname{good} A$ in country $a$ and $b$ as follows:

$s_{A}^{a}=\frac{3-(1+\lambda) \sum_{j \neq a} t_{A}^{j}+\lambda \sum_{j \neq a} e_{A}^{j}-(3+2 \lambda) e_{A}^{a}}{2(2+\lambda)} \quad$ and $\quad s_{A}^{b}=\lambda \frac{3+(3+\lambda) t_{A}^{b}-(1+\lambda) t_{A}^{c}-(4+\lambda) e_{A}^{b}+e_{A}^{a}+\lambda e_{A}^{c}}{2(2+\lambda)}$

total export levels of countries $a$ and $b$ are as follows:

$x_{b, c}^{a}=\frac{1-(1+\lambda) \sum_{j \neq a} t_{A}^{j}+\lambda \sum_{j \neq a} e_{A}^{j}-(1+\lambda) e_{A}^{a}-\lambda}{\lambda+2} \quad$ and $\quad x_{a, c}^{b}=\frac{1-(1+\lambda) \sum_{j \neq b} t_{B}^{j}-\lambda}{\lambda+2}$

where $x_{b, c}^{a}$ is the export of country $a$, in other words, the volume of trade in $\operatorname{good} A$; and $x_{a, c}^{b}$ is the equilibrium export level of country $b$ to both trading partners, $a$ and $c$. Environmental taxes reduce the production of good $A$ in the countries where it is imposed, and increase the domestic supply of that good in other countries. The local environmental tax has a stronger effect on domestic supply than a foreign tax on the production of the dirty $\operatorname{good} A$. The environmental tax imposed in country $a$ has a stronger effect on the local production of $A$ in $b$ than the same tax set by the country with no comparative advantage in the production of that good, country $c$. The total exports of country $a$ is increasing in the environmental taxes applied in the importers and decreasing in the domestic environmental tax; the latter effect is stronger than the former. As expected, exports are decreasing in the tariffs set by the importers.

The optimal Nash specific tariffs and environmental taxes are calculated by:

$$
\frac{\partial W^{j}}{\partial t_{k}^{j}}=0 \text { and } \frac{\partial W^{j}}{\partial e_{A}^{j}}=0, \text { where } j \in[a, b, c] \text {, and } k \in[A, B, C]
$$

then we have the following relationships between the reaction functions:

$$
\begin{gathered}
\frac{\partial t_{A}^{b}}{\partial t_{A}^{c}}=\frac{\partial t_{A}^{c}}{\partial t_{A}^{b}}=\frac{\partial t_{B}^{a}}{\partial t_{B}^{c}}=\frac{\partial t_{B}^{c}}{\partial t_{B}^{a}}=\frac{\partial t_{C}^{a}}{\partial t_{C}^{b}}=\frac{\partial t_{C}^{b}}{\partial t_{C}^{a}}=\frac{(\lambda+1)^{2}}{(\lambda+3)(3 \lambda+5)}>0 \\
\frac{\partial e_{A}^{a}}{\partial e_{A}^{b}}=\frac{\partial e_{A}^{a}}{\partial e_{A}^{c}}=\frac{\lambda}{2 \lambda^{2}+8 \lambda+7}>0 ; \frac{\partial e_{A}^{b}}{\partial e_{A}^{a}}=\frac{\partial e_{A}^{c}}{\partial e_{A}^{a}}=\frac{\lambda+1}{3 \lambda^{2}+15 \lambda+16}>0 ; \frac{\partial e_{A}^{b}}{\partial e_{A}^{c}}=\frac{\partial e_{A}^{c}}{\partial e_{A}^{b}}=\frac{(\lambda+1) \lambda}{3 \lambda^{2}+15 \lambda+16}>0
\end{gathered}
$$




$$
\frac{\partial t_{A}^{b}}{\partial e_{A}^{b}}=\frac{\partial t_{A}^{c}}{\partial e_{A}^{c}}=\frac{\lambda}{\lambda+1}>0 ; \frac{\partial t_{A}^{b}}{\partial e_{A}^{c}}=\frac{\partial t_{A}^{c}}{\partial e_{A}^{b}}=-\frac{\lambda(\lambda+1)}{(\lambda+3)(3 \lambda+5)}<0 ; \frac{\partial t_{A}^{b}}{\partial e_{A}^{a}}=\frac{\partial t_{A}^{c}}{\partial e_{A}^{a}}=-\frac{\lambda+1}{(\lambda+3)(3 \lambda+5)}<0(3.20)
$$

We have positively sloped reaction functions and observe tariff complementarity on the same good export markets. We consider countries which are competing importers, and consequently, the tariffs they levy on the same good are strategic complements. If one of the countries, country $b$, decreases its tariff on good $A$, then country $a$ would increase exports to country $b$ and decrease exports to country $c$. To keep importing from country $a$, country $c$ would have no choice but decrease its tariff as well. We also observe complementarity of tariffs and environmental taxes on the production of the dirty good $A$ levied in the same country. If a clean country decides to increase the environmental tax on its producers of the dirty good $A$ but keep the tariffs at the prior level or even lower it, it will decrease the ability of the local producers of the dirty good $A$ to compete with imports. This result is very undesirable, and it provides the intuition for why environmental tax and tariffs levied in the same country are strategic complements in our model. However, domestic tariffs and environmental taxes applied in the two other countries are negatively related. Also, the change in the tax level imposed in the country with a comparative advantage in the production of good $A$ has a stronger effect on the tariff on that good than the same tax change in the importer of $\operatorname{good} A$. In the absence of any trade and/or environmental agreements simultaneous solution of the first order conditions gives us the following optimal Nash tariffs and taxes:

$$
\begin{gathered}
t_{B}^{a}(N)=t_{C}^{a}(N)=t_{C}^{b}(N)=t_{B}^{c}(N)=\frac{1}{2} \frac{1-\lambda}{\lambda^{2}+6 \lambda+7} \text { and } \\
t_{A}^{b}(N)=t_{A}^{c}(N)=\frac{1}{4} \frac{3+4 z \gamma \lambda^{2}(\lambda+5.5)+2 \gamma \lambda(\lambda+16 z)+\gamma(\lambda+14 z)-\lambda(2 \lambda+1)-3 \gamma}{(\lambda+2)\left(\lambda^{2}+6 \lambda+6\right)} \\
e_{A}^{a}(N)=\frac{1}{2} \frac{3+2 \gamma \lambda^{3}(1-z)-\gamma \lambda^{2}(14 z-17)+2 \gamma \lambda(19-9 z)-2 \lambda(\lambda+1)+\gamma(21-2 z)}{(\lambda+2)\left(\lambda^{2}+6 \lambda+6\right)} ; e_{A}^{c}(N)=e_{A}^{b}(N)=\gamma
\end{gathered}
$$

where $\gamma$ is the constant externality per unit of production of the dirty good $A$, and $(\mathrm{N})$ indicates no agreement scenario. As we can see from equation (3.22), only country with a comparative advantage in the production of the dirty $\operatorname{good} A$, country $a$, is distorting their environmental tax from the optimal level, $\gamma$. 


\subsection{Environmental and Trade Agreements and their Effects on Tariffs and}

\section{Taxes}

In this section, we first consider various pure environmental agreements: agreements between two clean countries, environmental agreement between one clean and one dirty country, and world environmental agreement. Then, we move to shallow trade agreements: customs unions of two symmetric and two asymmetric countries, bilateral preferential trade agreement between symmetric and asymmetric countries, two different hub-and-spoke agreements, and a free trade world. Finally, we analyze deep trade agreements. The difference between shallow and deep trade agreements arises from the nature of the agreement-negotiation process. Shallow trade agreements let countries negotiate only pure trade deals. In this case, members do not discuss the level of nonprohibitive environmental tax they levy on their producers of the dirty good $A$. Consequently, the level of an environmental tax can vary among members of any shallow trade agreement. Both members and outsiders of any shallow trade deal maximize their individual welfares and set the level of tax accordingly. On the contrary, deep trade agreements let their members negotiate both tariffs and taxes. Members of such kind of agreements have to agree on the level of non-prohibitive environmental tax they set on the domestic producers of the dirty good $A$. However, outsiders of those deep trade agreements are free to choose any level of tax they find optimal.

\subsubsection{Pure Environmental Agreements}

In this subsection, first, we let two clean countries form an environmental agreement, then we describe an environmental agreement between one clean and one dirty country, and finally, we give an account of a world environmental agreement which includes all three countries. In this paper, we examine two levels of externality: purely local, $\theta=l$, and purely global pollution, $\theta=g$.

If two clean countries form a pure environmental agreement, denoted by $\left(b c_{\theta}^{e}\right)$, they agree only on the tax they levy on their domestic producers of the dirty good $A$, and they still impose their indi- 
vidually optimal external tariffs on each other as well as on the non-member country by solving:

$$
\frac{\partial\left(W^{b}\left(b c_{\theta}^{e}\right)+W^{c}\left(b c_{\theta}^{e}\right)\right)}{\partial e_{A}\left(b c_{\theta}^{e}\right)}=0 \text { and } \frac{\partial W^{j}\left(b c_{\theta}^{e}\right)}{\partial t_{k}^{j}\left(b c_{\theta}^{e}\right)}=0 \text { where } j \in[b, c] \text { and } k \in[A, B, C]
$$

Here, the only dirty good is a good $A$, and consequently, the only environmental tax implied by all three countries is on the production of that dirty good $A$. As a result, an environmental agreement between two clean countries would not have any effect on the tariffs imposed on the clean goods by all three countries relative to no agreement level of those tariffs. Also, an environmental agreement between two clean countries would not alter the level of the environmental tax levied by the outsider of this agreements, the dirty country $a$. However, both environmental tax and tariffs which members of this environmental agreement imply on the import from the outsider are subject to change.

$$
\begin{gathered}
t_{A}^{j}\left(b c_{l}^{e}\right)<t_{A}^{j}\left(N_{l}\right) \text { and } t_{A}^{j}\left(b c_{g}^{e}\right)>t_{A}^{j}\left(N_{g}\right) \text { where } j \in[b, c] \\
e_{A}\left(b c_{l}^{e}\right)<e_{A}^{j}\left(N_{l}\right)=\gamma \text { and } e_{A}\left(b c_{g}^{e}\right)>e_{A}^{j}\left(N_{g}\right)=\gamma \text { where } j \in[b, c]
\end{gathered}
$$

Proposition 3.1: An environmental agreement between two clean countries would lead to an increase in the individually optimal tariffs those countries impose on the imports of a dirty good A for sufficiently high levels of spillovers; if pollution is local, then such agreement would cause a decrease in the tariff applied to the imports from the outsider.

The explanation for this lies in the distortion from the ideal tax level in the members of this environmental agreement. If pollution is local, then we observe the decrease in the level of the environmental tax implied by the members, that leads to an increase in the local production of a dirty $\operatorname{good} A$, and consequently to an increase in the damages in those clean countries. The outsider of this agreement keeps the same level of production and export of it's comparative advantage good, the dirty good $A$. Those reasons explain the decrease in the tariffs applied by members on a dirty $\operatorname{good} A$. On the country, if pollution is global, then the environmental tax applied by the members exceeds its optimal level. This leads to a decrease in the local production of a dirty good $A$ and to an increase in tariff imposed by members on the imports from country $a$. We observe the 
decrease in the damages in the clean part of the world, and the outsider of this agreement keeps the level of production and exports at the no agreement level.

If one clean and one dirty country form a pure environmental agreement, denoted by $\left(a b_{\theta}^{e}\right)$, then similar to the previous case, these countries agree only on the tax they levy on their domestic producers of a dirty good $A$, and they still impose their individually optimal external tariffs on each other as well as on the non-member country by solving:

$$
\frac{\partial\left(W^{a}\left(a b_{\theta}^{e}\right)+W^{b}\left(a b_{\theta}^{e}\right)\right)}{\partial e_{A}\left(a b_{\theta}^{e}\right)}=0 \text { and } \frac{\partial W^{j}\left(a b_{\theta}^{e}\right)}{\partial t_{k}^{j}\left(a b_{\theta}^{e}\right)}=0 \text { where } j \in[a, b] \text { and } k \in[A, B, C]
$$

An environmental agreement between one clean and one dirty country would lead to a decrease in the level of the environmental tax levied by the dirty partner, and to an increase in the tax level in the clean member-country if the pollution exhibits local characteristics. Consequently, the reduced tax would increase the production of $A$ in the country with a comparative advantage and decrease its production in the clean partner of this agreement. The outsider of this agreement would decrease its tax relative to the environmental agreement between two clean countries and demand higher imports of a $\operatorname{dirty} \operatorname{good} A$. An environmental agreement between one clean and one dirty country would not distort the tariffs levied on the imports of clean goods. Also, similar to the previous case of the environmental agreement between two clean countries, an environmental agreement between one clean and one dirty country would lead to a decrease in the tariffs on the imports of a dirty good $A$ by both a clean member-country of this agreement and a clean outsider if the pollution exhibits local characteristics.

Proposition 3.2: With a global pollution externality, an environmental agreement between one clean and one dirty country causes the clean outsider and the clean member to reduce their tariffs on the imports of the dirty good.

A clean outsider of this agreement, country $c$, exhibits no distortion of the tax from its ideal level, that brings the environmental tax levied in this country under $\left(a b_{g}^{e}\right)$ to a lower level relative to the agreement between two clean countries, $\left(b c_{g}^{e}\right)$, and consequently, it encourages the increase in the domestic production of a dirty $\operatorname{good} A$ in country $c$ and reduction in the demand for imports. On the other hand, we observe the reduction in the local production of good $A$ in the clean partner of 
this environmental agreement. The explanation for that arises from the increase in the tax level applied on the producers of a dirty good $A$ in a clean partner of this environmental agreement. If pollution is global, then we witness the increase in the level of the environmental tax in both members followed by the decrease in the damages in those countries, and consequently the world damages as well.

Now we let all three countries get into a pure environmental agreement, denoted by $\left(a b c_{\theta}^{e}\right)$. In this case, all countries imply the same environmental tax on their local producers of a dirty good $A$, but they still impose their individually optimal external tariffs on each other by solving:

$$
\frac{\partial \Sigma^{j} W^{j}\left(a b c_{\theta}^{e}\right)}{\partial e_{A}\left(a b c_{\theta}^{e}\right)}=0 \text { and } \frac{\partial W^{j}\left(a b c_{\theta}^{e}\right)}{\partial t_{k}^{j}\left(a b c_{\theta}^{e}\right)}=0 \text { where } j \in[a, b, c] \text { and } k \in[A, B, C]
$$

As expected, an environmental agreement between all three countries would not affect the world tariffs on clean goods, and if pollution is local, then both clean countries would increase their tariffs on the imports from a dirty country $a$.

Proposition 3.3: If pollution is global, then an environmental agreement between all three countries would lead to a decreased tariff on imports from country a in both clean countries.

The explanation lies in the further distortion of the environmental tax from the ideal level in the clean countries. Under a world environmental agreement, both clean countries impose the highest tax on their producers of $\operatorname{good} A$ if the pollution exhibits global characteristics, and consequently, those countries produce the lowest amount of $\operatorname{good} A$ and have the lowest damages as well. This common environmental tax is the highest for the country $a$ as well, which leads to the lowest level of production of this good and the lowest level of damages. Country $a$ is the only one with the comparative advantage in the production of a dirty good $A$, so clean countries still exercise their comparative advantage in the production of either of the two clean goods and enjoy the reduction in the world and local damages. 


\subsubsection{Shallow Trade Agreements}

In this part of the paper, we examine different pure trade agreements. Members agree to eliminate tariffs on each other, but they set individually optimal environmental taxes. We start with shallow bilateral free trade agreements and hub-and-spoke trade regimes, then we consider shallow preferential trade agreements in the form of customs unions, and finally, we examine a free trade.

\subsubsection{Free Trade Agreements}

In this subsection, we consider four types of shallow free trade agreements: an FTA between two clean countries, an FTA between one clean and one dirty country, a hub-and-spoke trade regime with a clean country as a hub, and a hub-and-spoke trade regime with a dirty country as a hub. In any shallow free trade agreement, members agree to eliminate tariffs on each other, but they set individually optimal tariffs on the imports from the outsider, as well as, individually optimal environmental taxes on their producers of the dirty good $A$. First, consider an FTA between the two clean countries, denoted by $\left(b c_{\theta}\right)$. Members independently set their external tariffs and environmental taxes on the $\operatorname{dirty} \operatorname{good} A$ by maximizing their utility functions:

$$
\left.\frac{\partial W^{j}\left(b c_{\theta}\right)}{\partial t_{A}^{j}\left(b c_{\theta}\right)}\right|_{t_{k}^{j}\left(b c_{\theta}\right)=0}=0 \text { and } \frac{\partial W^{j}\left(b c_{\theta}\right)}{\partial e_{A}^{j}\left(b c_{\theta}\right)}=0 \text { where } j \in[b, c] \text { and } k \in[B, C] \text { and } j \neq k
$$

Country $a$ 's maximization problem is the same as under no agreement. An outsider chooses its tariffs and tax to maximize its welfare independently from the two members of this FTA. Bilateral trade agreement between countries $b$ and $c$ does not impact their choice of tariff they impose on the imports from the outsider, country $a: t_{A}^{j}\left(b c_{\theta}\right)=t_{A}^{j}\left(N_{\theta}\right)$ where $j \in[b, c]$. Also, this bilateral trade agreement does not cause any distortion from the no agreement level of environmental taxes of all three countries: $e_{A}^{a}\left(b c_{\theta}\right)=e_{A}^{a}\left(N_{\theta}\right)$ and $e_{A}^{j}\left(b c_{\theta}\right)=e_{A}^{j}\left(N_{\theta}\right)$ where $j \in[b, c]$. However, the outsider of this bilateral trade agreement, country $a$, has to lower its tariffs on the imports from both members:

$$
t_{k}^{a}\left(b c_{\theta}\right)=\frac{1-\lambda}{3 \lambda^{3}-14 \lambda^{2}+15}<t_{k}^{a}\left(N_{\theta}\right), \text { where } k \in[B, C]
$$


If one clean and one dirty country, denoted by $\left(a b_{\theta}\right)$, form a free trade agreement, then similar to the previous case, we observe that members impose their optimal no agreement tariffs on the imports from the outsider, and the outsider has to lower its tariffs on the imports from the members. Now, we can state the following:

Proposition 3.4: Both types of bilateral FTAs (between two clean countries and between one clean and one dirty country) induce the non-member to lower its tariffs on members while it has no effect on the external tariffs of the members.

Though the proposition above states similar results for both bilateral free trade agreements, the logic behind it largely involves examining the differences between them. In the case of bilateral free trade agreement between two symmetric clean players, the results presented in this proposition are very similar to the findings in Missios etal.(2016). The removal of tariffs between two clean countries leads to an increase in the trade between those countries and to the leftward shift of the export supply curves of the members to the outsider. The formation of a bilateral FTA between two clean countries causes an increase in the elasticity of the export supply curves of the members facing an outsider, country $a$ :

$$
\varepsilon_{a}^{j}\left(b c_{\theta}\right)-\varepsilon_{a}^{j}\left(N_{\theta}\right)=\frac{\lambda+1}{1-\lambda}>0, \text { where } j \neq a
$$

Equation(3.30) explains the reason of the reduction in tariffs on clean goods applied by the dirty outsider of this bilateral trade agreement, country $a$, relative to the no agreement level of those tariffs.

Next, we consider a bilateral free trade agreement between one clean and one dirty country. In the previous case, we observed no distortion in the environmental tax from the no agreement level in all three countries; contrary to that, an FTA between asymmetric countries leads to a change in the tax level levied by the members of this agreement. Both members of this agreement would increase their tax on the production of the dirty good $A$ relative to both no agreement and to a two clean countries FTA level if pollution is global. However, if pollution is local, then only a dirty partner of this agreement would raise its tax, and a clean member would actually reduce the environmental tax below the no agreement level. Similar to the previous case, we can see from 
equation (3.20) that the tariffs imposed on the same goods by different competitors for these goods are strategic complements. However, in addition to that, in the case of a bilateral trade agreement between asymmetric countries, we need to consider that tariffs imposed by clean countries on the imports of a dirty good $A$ and the taxes levied on the producers of that good in other countries are strategic substitutes. The reduction of $t_{A}^{b}\left(a b_{\theta}\right)$ to zero causes an increase in the tax levied by the dirty country $a$ on its producers of the dirty good, and consequently, this increase in tax leads to a decrease in the tariff set by the clean outsider of this agreement on the imports from country a. A bilateral free trade agreement between one clean and one dirty country does not cause any distortion in the environmental tax level applied by the outsider of this agreement, $e_{A}^{c}\left(a b_{\theta}\right)=$ $e_{A}^{c}\left(N_{\theta}\right)$, and based on the Equations (3.13) and(3.14), optimal tariffs applied by country $c$ on its imports from the members are the inverse of the export supply elasticity of members to country $c$, and

$$
\varepsilon_{c}^{b}\left(a b_{\theta}\right)-\varepsilon_{c}^{b}\left(N_{\theta}\right)>0 \text { and } \varepsilon_{c}^{a}\left(a b_{\theta}\right)-\varepsilon_{c}^{a}\left(N_{\theta}\right)>0
$$

We can see that both supply curves shift to the left causing the tariffs to be lower than their optimal no agreement levels.

The nature of bilateral FTAs allows their members to impose their individually optimal external tariffs, and consequently, each member is free to make a "side deal" with another country. As a result, hub-and-spoke trade regimes can arise. We have two different hub-and-spoke trade regimes: first, a clean country can assume a role of a hub, and second, a dirty country can act as a hub. Hub trades freely with both spokes, however, spokes still impose individually optimal tariffs on the imports from each other.

Proposition 3.5: Both types of hub-and-spoke trade regimes, with a clean country acting as a hub or with a dirty player assuming a role of a hub, induce spokes to reduce their individual tariffs below the no agreement level.

Each spoke can be seen as an outsider of a bilateral trade agreement between a hub and the other spoke. The removal of tariffs between a hub and the other spoke stimulates trade between those countries and shifts their export supply curves to the left increasing the elasticity of each spoke's 
supply curve facing the other spoke. If one of the clean countries gets to be a hub, then we observe: $\varepsilon_{c}^{a}\left(b_{\theta}^{h}\right)-\varepsilon_{c}^{a}\left(N_{\theta}\right)>0$ and $\varepsilon_{a}^{c}\left(b_{\theta}^{h}\right)-\varepsilon_{a}^{c}\left(N_{\theta}\right)>0$; if a dirty player assumed a role of a hub, then $\varepsilon_{c}^{b}\left(a_{\theta}^{h}\right)-\varepsilon_{c}^{b}\left(N_{\theta}\right)>0$ and $\varepsilon_{b}^{c}\left(a_{\theta}^{h}\right)-\varepsilon_{b}^{c}\left(N_{\theta}\right)>0$.

\subsubsection{Customs Unions}

In this subsection, we consider a different type of preferential trade agreements, customs unions. Unlike FTA members, members of a customs union impose a jointly optimal tariff on the imports from the outsider by maximizing their joint welfare function, and as in any other type of shallow trade agreements, each member still imposes its individually optimal environmental tax. Article XXIV of GATT requires all members of preferential trade agreements keep their external tariffs on non-member countries at least at the level of no agreement tariff (pre-existing level). Members are free to lower their tariffs, but they cannot raise their external tariffs on non-member countries. Initially, we ignore this tariff restriction and simply assume that any customs union is free to levy the optimal tariffs. We examine the effect of the restrictions of Article XXIV in the later sections of this paper.

Two types of customs unions can arise in our model: two symmetric clean countries can form a

customs union and exclude the dirty country, denoted by $\left(b c_{\theta}^{u}\right)$, or one clean and one dirty country can get into a union and exclude the second clean player, denoted by $\left(a b_{\theta}^{u}\right)$. Members of a customs union between two clean countries then solve the following:

$\left.\frac{\partial\left(W^{b}\left(b c_{\theta}^{u}\right)+W^{c}\left(b c_{\theta}^{u}\right)\right)}{\partial t_{A}\left(b c_{\theta}\right)}\right|_{t_{k}^{j}\left(b c_{\theta}\right)=0}=0$ and $\frac{\partial W^{j}\left(b c_{\theta}^{u}\right)}{\partial e_{A}^{j}\left(b c_{\theta}^{u}\right)}=0$ where $j \in[b, c]$ and $k \in[B, C]$ and $j \neq k$

When countries form a customs union, their combined market power exceeds the market power of each individual member of this union, and that allows them to benefit from the increased terms of trade gain, and in turn lets them to raise the tariff on the imports from the outsider above the no agreement level for both local and global levels of pollution: 
$t_{A}\left(b c_{l}^{u}\right)=\frac{1}{16} \frac{9-6 \lambda^{2}-3 \lambda}{(4 \lambda+5)}>t_{A}^{j}\left(N_{l}\right)$ and $t_{A}\left(b c_{g}^{u}\right)=\frac{1}{16} \frac{23-12 \lambda^{2}+\lambda}{(4 \lambda+5)}>t_{A}^{j}\left(N_{g}\right)$ where $j \in[b, c]$

An outsider of a customs union, in the same way as an outsider of a bilateral FTA, has to lower its tariffs on the imports from the members:

$$
t_{k}^{a}\left(b c_{\theta}^{u}\right)=\frac{1-\lambda}{3 \lambda^{2}+14 \lambda+15}<t_{k}^{a}\left(N_{\theta}\right) \text { where } k \in[B, C]
$$

The formation of a customs union between one clean and one dirty country leads to similar results as presented in Equations (3.32)-(3.34) for the formation of a customs union between two clean countries. A clean outsider of this customs union also has to lower its tariffs on imports from either country and face a higher tariff on its exports to the union. As such, our results are very similar to the findings in Missios etat. (2016).

Proposition 3.6: Customs union members raise their tariff on the imports from the outsider, and the outsider reduces its tariff on the imports from the members relative to the no agreement level.

Since members of either customs union demand the same good from the outsider, the total exports of an outsider to the union is larger than its individual exports to each member. As a result, we observe the market power effect. The formation of bilateral free trade agreements does not cause this effect because members of FTAs still act as separate decision-makers, and each member has a power to impose its individually optimal tariff on the imports from the outsider without consulting his FTA partner, and this tariff competition reduces market power. In both customs unions, the elasticity of an outsider's export supply curve is lower than the elasticity of its individual export supply curves to the markets of each member-country: $\varepsilon_{b c u}^{a}\left(b c_{\theta}^{u}\right)-\varepsilon_{j \neq a}^{a}\left(N_{\theta}\right)<0$ and $\varepsilon_{a b u}^{c}\left(a b_{\theta}^{u}\right)-$ $\varepsilon_{j \neq c}^{c}\left(N_{\theta}\right)<0$, and this leads to an increase in the jointly optimal external tariff above no agreement level. The logic we used above to show the reasons for an outsider of a bilateral trade agreement to lower its tariff on the imports from the members thus applies to the case of customs unions as well.

Proposition 3.7: The formation of a customs union between two clean countries induces an outsider to decrease its tax relative to the no agreement level and the bilateral free trade agreement (FTA) does not. 
The intuition behind the above proposition stems from the results illustrated in equation (3.20): the tariffs on a dirty good $A$ and the environmental tax levy on the producers of that good in the only country with a comparative advantage in the production of that good are strategic substitutes. The formation of an FTA does not lead to an increase in the tariffs applied by members on the imports from the outsider, but the formation of a CU does. Consequently, we do not observe any distortion from the no agreement tax level in the outsider of an bilateral FTA, but we observe the reduction in the tax level levied by the dirty outsider of the customs union which includes only clean members.

\subsubsection{Free Trade}

Under shallow global free trade agreement, all three countries eliminate their tariffs on the imports from each other, but members still impose individually optimal environmental taxes on their domestic producers of the dirty good $A$.

Proposition 3.8: The formation of a free trade world induces a dirty country to raise its environmental tax and a clean part of the world to reduce their taxes below the no agreement level.

To explain the logic behind this proposition, we use the results presented in the equation (3.20). In clean countries, taxes and tariffs on the dirty good A are strategic complements, so the removal of the tariffs on imported dirty good leads to a decrease in the tax levy in these clean countries. Environmental tax levy in the only country with a comparative advantage in the production of this good and the tariffs applied by the clean part of the world are strategic substitutes, and the removal

of those tariffs leads to an increase in the level of tax applied by country a on its producers of the dirty good A. We can say, that a dirty country a uses the opportunity provided by the tariff vanishing to increase the tax, keep prices at a reasonable level, and benefit from an increased tax revenue. 


\subsubsection{Deep Trade Agreements}

In this part of the paper, we examine tariffs and taxes under different trade and environmental agreements. Members of deep trade agreements agree not only to eliminate their tariffs on each other, but also on the level of the optimal environmental tax their levy on their producers of the dirty $\operatorname{good} A$. We start with deep bilateral free trade agreements and integrated hub-and-spoke trade regimes, then we consider integrated customs unions, and finally, we examine an integrated free trade.

\subsubsection{Deep Free Trade Agreements}

In this subsection, we examine four types of deep free trade agreements: a deep FTA between two clean countries, a deep FTA between one clean and one dirty country, an integrated hub-and-spoke trade regime with a clean county as a hub, and an integrated hub-and-spoke trade regime with a dirty country as a hub. When countries negotiate shallow free trade agreements, they have to agree only on eliminating their tariffs on each other, and they are still free to set their environmental taxes at the individually optimal levels. However, when countries negotiate deep FTAs, they have to add an environmental clause to it. If two symmetric clean countries form a deep FTA, denoted by $\left(b c_{\theta}^{i}\right)$, they impose zero tariff on imports from each other, they agree on the level of tax they levy on their producers of the dirty $\operatorname{good} A$, and they are still free to impose individually optimal tariffs on the imports from the outsider of this agreement. Under $\left(b c_{\theta}^{i}\right)$, the members solve the following:

$$
\left.\frac{\partial W^{j}\left(b c_{\theta}^{i}\right)}{\partial t_{A}^{j}\left(b c_{\theta}^{i}\right)}\right|_{t_{k}^{j}\left(b c_{\theta}^{i}\right)=0}=0 \text { and } \frac{\partial\left(W^{b}\left(b c_{\theta}^{i}\right)+W^{c}\left(b c_{\theta}^{i}\right)\right)}{\partial e_{A}\left(b c_{\theta}^{i}\right)}=0 \text { where } j \in[b, c] \text { and } k \in[B, C] \text { and } j \neq k \text { (3.36) }
$$

An outsider's maximization problem does not change relative to no agreement. Country $a$ 's choices of tariffs and tax are independent from the decisions taken in the clean part of the world. As we have shown earlier in the paper, a shallow bilateral trade agreement between two clean countries 
does not distort the tariffs members apply on the imports of the dirty good $A$ from the no agreement level, and only the non-member lowers its tariffs on the imports from the clean part of the world. However, in the case of deep trade agreements, both members and the outsider are induced to distort their tariffs on the imports from each other. Now, we can state the following:

Proposition 3.9: A deep bilateral FTA between two clean countries induces the non-member to lower its tariffs on members for both local and global levels of pollution while the external tariffs of the members are reduced below no agreement level only if pollution is local and are increased above the no agreement level if pollution is global.

The formation of either shallow or deep bilateral FTA between two clean countries causes no change in the export supply elasticity of the outsider, but the elasticity of members facing the outsider are subject to change:

$$
\begin{aligned}
& \varepsilon_{j}^{a}\left(b c_{\theta}\right)-\varepsilon_{j}^{a}\left(N_{\theta}\right)=0 \text { and } \varepsilon_{j}^{a}\left(b c_{\theta}^{i}\right)-\varepsilon_{j}^{a}\left(N_{\theta}\right)=0, \text { where } j \neq a \\
& \varepsilon_{a}^{j}\left(b c_{\theta}\right)-\varepsilon_{a}^{j}\left(N_{\theta}\right)>0 \text { and } \varepsilon_{a}^{j}\left(b c_{\theta}^{i}\right)-\varepsilon_{a}^{j}\left(N_{\theta}\right)>0, \text { where } j \neq a
\end{aligned}
$$

Equation(3.38) explains why the non-member, country $a$, lowers its tariffs, but equation(3.37) states that the tariffs based only on export elasticities of the members are supposed to be at the no agreement level. However, contrary to that, we witness a change when clean countries form a deep free trade agreement. The explanation for that lies in the distortion from the efficient tax level in the member countries of this deep bilateral trade agreement. An environmental clause added to a pure trade agreement between two clean countries drives the common tax below the no agreement level (if pollution is local) or brings it above the no agreement level (if pollution exhibits global characteristics). Equation (3.14) shows that if clean countries set their tax above its efficient level, it will cause a decrease in the optimal tariff on the dirty good $A$, and if the clean part of the world brings its tax below the ideal level, the tariffs would go up.

Similar to a shallow bilateral trade agreement between one clean and one dirty country, a deep bilateral trade agreement between those countries, denoted by $\left(a b_{\theta}^{i}\right)$, induces an outsider to lower its tariffs on the imports from both members while it has no effect on the external tariffs of the 
members. The logic behind this is in the change of the export supply elasticity curve of members to the outsider, country $c$ :

$$
\varepsilon_{c}^{b}\left(a b_{\theta}^{i}\right)-\varepsilon_{c}^{b}\left(N_{\theta}\right)>0 \text { and } \varepsilon_{c}^{a}\left(a b_{\theta}^{i}\right)-\varepsilon_{c}^{a}\left(N_{\theta}\right)>0
$$

We can see that both supply curves shift to the left causing the tariffs to be lower than their optimal no agreement levels.

The difference between deep and shallow hub-and-spoke trade regimes lies in the following aspect of a deep trade agreement: when a member of a deep FTA makes a "side deal" with an outsider, they have to agree on the environmental tax as well. In this deep trade agreement game, similar to our finding in shallow trade agreements game, when a dirty country gets to be a hub, both spokes reduce their individual tariffs on the imports from each other below the no agreement level. In this case, each spoke can be viewed as an outsider of a deep bilateral trade agreement between the hub and the other spoke, and similar to that we observe the following: $\varepsilon_{c}^{b}\left(a_{\theta}^{h i}\right)-\varepsilon_{c}^{b}\left(N_{\theta}\right)>0$ and $\varepsilon_{b}^{c}\left(a_{\theta}^{h i}\right)-\varepsilon_{b}^{c}\left(N_{\theta}\right)>0$. However, our finding are different when a clean country assumes the role of a hub in the deep trade agreement game:

Proposition 3.10: The formation of a hub-and-spoke regime with a clean country acting as a hub, induces both spokes to reduce their tariffs only if pollution is global, and if pollution is local only a dirty country reduces its tariff but a clean spoke raises its tariff above the no agreement level.

To prove the above proposition, we need to examine both components of an optimal tariff: elasticities and environmental tax distortions. Based on equation(3.13), the optimal tariff on a clean good is the inverse of the elasticity of a dirty spoke facing a clean one. The removal of the tariff between a dirty country and a hub shifts their supply curves to the left and increases the export elasticity of the dirty good $A$ to a clean spoke: $\varepsilon_{a}^{c}\left(b_{\theta}^{h i}\right)-\varepsilon_{a}^{c}\left(N_{\theta}\right)>0$. However, the formula for the optimal tariff applied by a clean spoke on the imports of the dirty good $A$ is different, and it is as follows:

$$
\frac{t_{A}^{c}}{p_{A}^{a}}\left(b_{\theta}^{h i}\right)=\frac{1}{\varepsilon_{c}^{a}\left(b_{\theta}^{h i}\right)}-\frac{\lambda\left(e_{A}\left(b_{\theta}^{h i}\right)-\gamma\right)}{p_{A}^{a}\left(b_{\theta}^{h i}\right)}\left[\frac{\partial m_{A}^{b}}{\partial p_{A}^{b}}\left(b_{\theta}^{h i}\right)\right]^{-1}
$$

We observe the change in both both components of the above equation: 
(i). $\varepsilon_{c}^{a}\left(b_{l}^{h i}\right)-\varepsilon_{c}^{a}\left(N_{l}\right)<0$ and $\mathrm{e}_{A}\left(b_{l}^{h i}\right)<e_{A}^{c}\left(N_{l}\right)$;

(ii). $\varepsilon_{c}^{a}\left(b_{g}^{h i}\right)-\varepsilon_{c}^{a}\left(N_{g}\right)>0$ and $\mathrm{e}_{A}\left(b_{g}^{h i}\right)>e_{A}^{c}\left(N_{g}\right)$.

This fully explains the increase in the optimal tariff applied by a clean spoke on the imports of the dirty good $A$ if pollution is global, and the decrease in the tariff if pollution is global. If pollution is local, then both the shift of the supply curve and the decrease in the environmental tax level applied by the clean spoke induce it to decrease the tariff. If pollution is global, then both the leftwards shift of the supply curve and the increased tax induce country $c$ to increase its tariff on the imports of the dirty good $A$.

\subsubsection{Integrated Customs Unions}

In this subsection, we examine two different integrated customs unions: an integrated customs union between two clean countries, denoted by $\left(b c_{\theta}^{i u}\right)$, and an integrated customs union between one clean and one dirty country, denoted by $\left(a b_{\theta}^{i u}\right)$. Unlike members of deep FTAs, members of integrated customs unions impose a jointly optimal tariff on the imports from the outsider, and as in any other type of deep trade agreements, a jointly optimal environmental tax. Similar to the subsection on shallow customs unions, here we also ignore the tariff restrictions required according to Article XXIV of the GATT/WTO, and we examine the effect of these restrictions on the formation of integrated customs unions in later sections of this paper.

Members of the integrated customs union between two clean countries solve the following:

$$
\left.\frac{\partial \Sigma^{l} W^{j}\left(b b_{\theta}^{i u}\right)}{\partial t_{A}\left(b c_{\theta}^{i u}\right)}\right|_{t_{k}^{j}\left(b c_{\theta}^{i u}\right)=0}=0 \text { and } \frac{\partial \Sigma^{l} W^{j}\left(b c_{\theta}^{i u}\right)}{\partial e_{A}\left(b c_{\theta}^{i}\right)}=0 \text {, where } j \in[b, c], k \in[B, C] \text { and } j \neq k
$$

Proposition 3.11: Members of the integrated customs unions raise their tariff on the imports from the outsider, and the outsider reduces its tariff on the imports from the members relative to the no agreement level.

The combined power of members of an integrated union allows them to benefit from the increased 
terms of trade gain and to raise their common external tariff on the imports from the outsider above the no agreement level. An outsider of this type of agreement, similar to an outsider of any deep or shallow bilateral FTA, has to lower its tariff on the imports from the members. In both integrated customs unions, the export supply elasticity of an outsider is lower than the export supply elasticity of each member: $\varepsilon_{b c i u}^{a}\left(b c_{\theta}^{i u}\right)-\varepsilon_{j \neq a}^{a}\left(N_{\theta}\right)<0$ and $\varepsilon_{a b i u}^{c}\left(a b_{\theta}^{i u}\right)-\varepsilon_{j \neq c}^{c}\left(N_{\theta}\right)<0$, and this leads to an increase in the jointly optimal external tariff above the no agreement level.

\subsubsection{Integrated Free Trade}

Under integrated free trade agreement, all three countries eliminate their tariffs on the imports from each other and impose jointly optimal environmental tax on their domestic producers of the dirty $\operatorname{good} A$.

Proposition 3.12: The formation of an integrated free trade agreement induces the members to choose an environmental tax equal to marginal damages with both local and global externalities. The production of the dirty good A generates a negative externality, pollution, which may have a transboundary effect on both neighbours. If pollution is pure local, then the transboundary effect is zero, and integrated free trade agreements induces all members to set an environmental tax at its socially optimal level, $\gamma$. With a global externality and symmetric cross border spillovers, the production of the dirty good A affects all three countries equally regardless of the location of the dirty good A producer. In this case, an integrated free trade agreement induces the members to set the tax at the level of $3 \gamma$, which is equal to world marginal damages. 


\subsection{Environmental and Trade Agreements and their Effects on Environ- mental Damages}

In this section, we examine the effect of various environmental and trade agreements on damages. In our model, only production of the good $A$ creates a negative externality, pollution. First, we analyze the effect of different pure environmental agreements on the level of damages, then we examine the effect of various shallow trade agreement, and finally, we consider the effect of deep trade agreements on the environmental damages.

\subsubsection{Pure Environmental Agreements}

In this subsection, we examine the effect on the environmental damages of three different pure environmental agreements: an environmental agreement between two clean countries, an environmental agreement between one clean and one dirty country, and a global environmental agreement. The formation of an environmental agreement between two clean countries actually induces an increase in environmental damages in the clean part of the world, if pollution is local. This illustrates the conflict in setting environmental taxes. Each country would, other things equal, like to lower its tax and give competitive advantage to its firms. As all countries have this incentive, taxes are lowered, but no competitive advantage is gained. In creating an environmental agreement, countries can coordinate and actually raise taxes relative to no agreement when pollution is local. The outsider of this agreement, the dirty country $a$, exhibits no distortion of the environmental damages from the no agreement level. As a result, we observe an increase in the world damages, if pollution is local, relative to the no agreement level. If pollution is global, an environmental agreement between two clean countries leads to a lower level of environmental damages in all three countries, and consequently, in the level of world damages as well. As the pollution externality increases, countries balance total externality effects against competitive advantage. With global pollution free-riding outweighs other factors and non-cooperative taxes set too low.

An environmental agreement between one clean and one dirty country, $\left(a b_{\theta}^{e}\right)$, induces an increase 
in the level of damages in the country with a comparative advantage in the production of the dirty $\operatorname{good} A$ and to a decrease in the environmental damages in both clean countries, if pollution is

local. However, if pollution is global, then the formation of $\left(a b_{g}^{e}\right)$ causes a decrease in the level of environmental damages in all three countries relative to both no agreement level and $\left(b c_{g}^{e}\right)$ level. Now, we can state the following:

Proposition 3.13: The formation of a global environmental agreement induces the highest level of damages if pollution is local, and the lowest level of environmental damages if pollution is global.

If pollution is local, then the transboundary effect of the production of the dirty good $A$ on both neighbours is zero; as a result, the only country with a comparative advantage in the production of that good, country $a$, displays the highest level of production of this good and both clean countries demand the highest levels of imports of the dirty good $A$. Consequently, country $a$ induces an increase in damages, which leads to the highest level of world environmental damages. On the contrary, with a global pollution externality, the formation of a global environmental agreement causes the decrease in the production of the dirty good $A$ in all three countries. Furthermore, sufficiently high level of spillovers leads to a decrease in the import demand for the $\operatorname{dirty} \operatorname{good} A$ in both clean countries. As a result, we observe the lowest level of world environmental damages, if pollution is global.

\subsubsection{Shallow Trade Agreements}

In this subsection, we examine the effect on the environmental damages of various shallow trade agreements: an FTA between two clean countries, an FTA between one clean and one dirty country, two different hub-and-spoke trade regimes, a CU between two clean countries, a CU between one clean and one dirty country, and a free trade.

The formation of a bilateral free trade agreement between two clean countries causes no distortion from the no agreement level of environmental damages for both local and global externalities in all 
three countries, and consequently, in the world. Contrary to that, the formation of an FTA between one clean and one dirty country leads to an increase in the environmental damages in all three countries for both levels of spillovers. It can be explained by an increase in the demand for the dirty $\operatorname{good} A$ in the members of this union, and a decrease in the import demand by the outsider of this agreement. A customs union between two clean countries induces a decrease in the level of environmental damages for both global and local externalities below the no agreement level in all three countries. Both hub-and-spoke trade regime with a clean country as a hub and shallow customs union between one clean and one dirty country lead to the $\left(a b_{\theta}\right)$ level of environmental damages. However, a hub-and-spoke trade regime with a dirty country as a hub induces the highest level of environmental damages as well as a free trade world, and now we can state the following:

Proposition 3.14: Free trade induces the highest level of pollution.

In a free trade world each country finds it beneficial to increase the specialization in a production of a comparative advantage good and decrease the production of the other two goods, and as a result, we observe the increased amount of goods produced and traded in the world: $S_{A}^{a}\left(N_{\theta}\right)<S_{A}^{a}\left(a b c_{\theta}\right)$ $\& S_{k \neq A}^{a}\left(N_{\theta}\right)>S_{k \neq A}^{a}\left(a b c_{\theta}\right) ; S_{A}^{j}\left(N_{\theta}\right)>S_{A}^{j}\left(a b c_{\theta}\right) \& S_{k=j}^{j}\left(N_{\theta}\right)<S_{k=j}^{j}\left(a b c_{\theta}\right)$, where $j \in[b, c]$.

$$
S_{k}^{\text {world }}\left(N_{\theta}\right)<S_{k}^{\text {world }}\left(a b c_{\theta}\right) \text { where } k \in[A, B, C]
$$

The increased production of the dirty good $A$ naturally leads to an increased level of negative externality associated with this production process, the level of pollution. We can see that a free trade world agreement with no environmental clause attached to it would cause an increase in the environmental damages for both local and global levels of pollution.

\subsubsection{Deep Trade Agreements}

In this subsection, we examine the effect on the environmental damages of various deep trade agreements: a deep FTA between two clean countries, a deep FTA between one clean and one dirty country, two different integrated hub-and-spoke trade regimes, an integrated CU between two 
clean countries, an integrated CU between one clean and one dirty country, and an integrated free trade.

The formation of a deep FTA between two clean countries causes an increase in the level of environmental damages in both members, and creates no distortion from the no agreement level in the outsider of this agreement, the dirty country $a$, if pollution is local. As a result, we observe the increase in the world level of pollution. However, with the global pollution externality, all three countries decrease the level of damages, and consequently, the world damages decline below the no agreement level as well. An integrated FTA between one clean and one dirty country leads to an increase in the level of damages in the member with a comparative advantage in the production of the dirty $\operatorname{good} A$ and a clean outsider of this agreement relative to the no agreement level, if pollution is local. The clean member of this deep FTA exhibits a decline in the environmental damages for both levels of pollution. Both a clean outsider and a dirty member of $\left(a b_{g}^{i}\right)$ display the reduction in the level of environmental damages with a global pollution externality. The formation of an integrated customs union between one clean and one dirty country induces no change in the level of environmental damages in all three countries, and consequently, in the world, for both local and global levels of pollution, relative to the $\left(a b_{\theta}^{i}\right)$ level of damages. The only deep trade agreement which causes a decrease in the world damages below the no agreement level, if pollution is local, is a deep customs union between two clean countries. Both hub-and-spoke trade regimes lead to the integrated free trade level of the world damages for both local and global levels of pollution, and now, we can state the following:

Proposition 3.15: If pollution is global, then a fully integrated world is the least polluted. One of the results, we presented in the previous subsection states that a free trade world with no environmental agreement causes an increase in the environmental damages for all levels of externality. However, if our asymmetric countries have to agree not only on the removal of the tariffs but also on the environmental tax they levy on their producers of the dirty good $A$, then the environmental tax shows no distortion from its socially optimal no agreement level, if pollution is local. In this case, countries enjoy deep specialization on goods they have comparative advantage in, and 
bear no cost of spillovers. If pollution is global, then all three players get to be equally effected by an increased production of the dirty good $A$, and as a result their environmental agreement induces the tax to the level of $3 \gamma$. No surprisingly, clean part of the world would love to live in a fully integrated world, and the only dirty player would prefer any other agreement to this one.

\subsection{Endogenous Preferential Environmental and/or Trade Agreements}

\subsubsection{Announcements and Strategy Sets}

In this part of the paper, we describe announcements and strategy sets for all three stage games of environmental agreements and/or trade liberalization: an Environmental Agreement game (E game), a Customs Union game (CU Game), a Free Trade Agreement game (FTA Game), an Integrated Customs Union game (IU Game), and an Integrated Free Trade Agreement game (I Game). In an Environmental Agreement game, players announce the names of the countries they would like to form pure environmental agreements with. This announcements are free of any trade policies. The difference between the CU and FTA games lies in the nature of two types of preferential trade agreements. In the CU game, a member of a trade union cannot unilaterally sign another agreement with a non-member country. In order to do so, a member would need to get a consent of a current PTA partner, as members of a trade union impose a jointly optimal tariff on the imports from the outsider. On the contrary, in the FTA game, members levy an individually optimal tariffs on the non-member, and due to that, they are free to form another agreement without any consent of a current PTA member. In the IU and I games, each player announces the names of the countries with whom they want to sign an integrated agreement. Integrated agreements always include an environmental component, namely, members have to agree on the level of tax they levy on their producers of the dirty good $A$. Regardless of the nature of these trade and environmental agreements, the stages of the games are as follows: in the first stage, each player simultaneously announces the names of the countries with whom it wants to form an agreement; in the second stage, given the trade and/or environmental policy regime, countries choose their optimal tariffs 
and/or environmental taxes they impose on the production of a dirty good $A$; in the final stage of each game, consumption, production and international trade take place.

In the first stage of each game, each player simultaneously announces the names of the countries with whom it wishes to sign an environmental and/or trade agreement. Country $j$ 's announcement is denoted by $\sigma_{j}$, and its strategy set $S_{j}$ includes all possible announcements:

$$
\begin{aligned}
& S_{a}=\{\{\varnothing, \varnothing\},\{b, \varnothing\},\{\varnothing, c\},\{b, c\}\} \\
& S_{b}=\{\{\varnothing, \varnothing\},\{a, \varnothing\},\{\varnothing, c\},\{a, c\}\} \\
& S_{c}=\{\{\varnothing, \varnothing\},\{a, \varnothing\},\{\varnothing, b\},\{a, b\}\}
\end{aligned}
$$

To describe strategy sets, we use country $b$ as an example. Country $b$ 's announcement in favour of no agreement with any of the countries is denoted by $\{\varnothing, \varnothing\}$. If country $b$ would like to form an agreement with only one of the countries, the announcement would look as follow: $\{a, \varnothing\}$ or $\{\varnothing, c\}$. The announcement $\{a, c\}$ indicates country b's desire to be a part of an agreement with both trading partners.

\subsubsection{Coalition-Proof Nash Equilibria}

In this paper, we distinguish coalition-proof Nash equilibria from the set of multiple Nash equilibria. Bernheim etal.(1987) argue that "it is natural to assume that players can freely discuss their strategies, but cannot make binding commitments". We also follow Missios etal.(2016) and acknowledge that in the present world, countries have the capacity to communicate without having to make binding commitments. Based on that, in our model, we allow countries to discuss possible environmental and/or trade agreements prior to their announcement. We follow the concept of coalition-proof Nash Equilibrium introduced in Bernheim etal.(1987): “..,the concept of Coalition-Proof Nash equilibrium, that is designed to capture the notion of an efficient selfenforcing agreement for environments with unlimited, but nonbinding, pre-play communication. An agreement is coalition-proof if and only if it is Pareto efficient within a class of self-enforcing 
agreements...an agreement is self-enforcing if and only if no proper subset (coalition) of players, taking the action of its complement as fixed, can agree to deviate in a way that makes all of its members better off." Coalition-proof Nash equilibria have to survive all possible self-enforcing coalitional deviations. When we consider whether a particular coalition-proof Nash equilibria holds, we keep the announcement of non-deviating countries unchanged.

\subsection{Endogenous Environmental Agreements}

\subsubsection{Pure Environmental Agreements}

In this part of the paper, we describe different environmental agreements which can arise in this game game. When countries form an environmental agreement, they agree on the tax they levy on their producers of the dirty good $A$, but they are still free to impose individually optimal tariffs on the imports from each other. In the first stage of this game, players announce countries they would like to form an environmental agreement with. Each player's strategy set $\left(S_{j}^{e}\right)$ consists of four possible announcements denoted as $\sigma_{j}^{e}$ :

$$
\begin{aligned}
& S_{a}^{e}=\left\{\{\varnothing, \varnothing\},\left\{b^{e}, \varnothing\right\},\left\{\varnothing, c^{e}\right\},\left\{b^{e}, c^{e}\right\}\right\} \\
& S_{b}^{e}=\left\{\{\varnothing, \varnothing\},\left\{a^{e}, \varnothing\right\},\left\{\varnothing, c^{e}\right\},\left\{a^{e}, c^{e}\right\}\right\} \\
& S_{c}^{e}=\left\{\{\varnothing, \varnothing\},\left\{a^{e}, \varnothing\right\},\left\{\varnothing, b^{e}\right\},\left\{a^{e}, b^{e}\right\}\right\}
\end{aligned}
$$

where announcement $\sigma_{j}^{e}=\{\varnothing, \varnothing\}$ indicates player's desire to stay away from any environmental agreement; if $\sigma_{j}^{e}$ includes only one of the two countries then it denotes the player's wish to form

an environmental agreement only with that country; if $\sigma_{j}^{e}$ has two other countries then it indicates player's desire to be a part of a world environmental agreement.

Countries are free to choose their announcements, and the environmental agreements can be formed only if partners announce each other. In the environmental agreement game, the countries strategy sets map into the following environmental agreements: 
(i) The announcement profile $\left\langle\Phi^{e}\right\rangle$, no agreement, arises when either all three countries announce in the favour of no environmental agreement or countries' announcements do not match. In this case, countries apply individually optimal environmental taxes on their producers of the dirty $\operatorname{good} A$.

(ii) If countries $a$ and $b$ call each other and exclude country $c$, it results in the environmental agreement between one clean and one dirty country, denoted $\langle a b e\rangle$. In this case, an outsider's announcement would not influence the outcome unless at least one of the members would include an outsider's name in its announcement. This agreement implies, that members have to agree on the environmental tax they impose, but they still apply individually optimal tariffs on the imports from each other.

(iii) Similar to (ii), announcement profile $\langle b c e\rangle$ indicate two countries' desire to exclude the third member of the world. In this case, two clean countries exclude the dirty country $a$ and form an environmental agreement which includes only clean members.

(iv) The announcement profile $\langle E\rangle$ signals all three countries' desire to live in an environmentally integrated world. This profile implies, that all three countries agree on the environmental tax they levy on their domestic producers of the dirty good $A$.

\subsubsection{Welfare Effects of Various Environmental Agreements in the E Game}

LEMMA 3.1: The welfare impact of various types of environmental agreements on members and non-members is as follows:

$\left(i^{e}\right) W^{a}\left(a b_{\theta}^{e}\right)<W^{a}\left(N_{\theta}\right) ; W^{a}\left(b c_{\theta}^{e}\right) \geqslant W^{a}\left(N_{\theta}\right) ; W^{a}\left(a b c_{\theta}^{e}\right)<W^{a}\left(a b_{\theta}^{e}\right)$

$\left(i i^{e}\right) W^{b}\left(a b c_{\theta}^{e}\right)>W^{b}\left(a b_{\theta}^{e}\right)>W^{b}\left(N_{\theta}\right) ; W^{c}\left(a b c_{\theta}^{e}\right)>W^{c}\left(a b_{\theta}^{e}\right)>W^{c}\left(N_{\theta}\right)$

$\left(i i i^{e}\right) W^{j}\left(b c_{l}^{e}\right)<W^{j}\left(N_{l}\right)$ and $W^{j}\left(b c_{g}^{e}\right)>W^{j}\left(N_{g}\right)$ where $j \neq a$

Lemma3.1 $\left(-i^{e}\right)$ illustrates a self-exclusion incentive since the dirty country $a$ prefers to stay away from any environmental agreement. The lowest welfare this country can achieve in this game is under a global environmental agreement. Being an outsider of an environmental agreement between two clean countries brings the highest level of welfare to country $a$ if pollution is global, 
while the welfare level of no agreement is highest if pollution exhibits local characteristics. Based on the results in Lemma3.1 $\left(-i i^{e}\right)$, we can conclude that a clean country prefers a dirty player to be a part of any environmental agreement, even if this clean country is an outsider of the agreement. The highest welfare clean countries can achieve is under global environmental agreement. Lemma3.1 $\left(-i i^{e}\right)$ states that a clean country would prefer to be in an environmental agreement with nobody versus being in the agreement with another clean country if the pollution is local, and clean countries would benefit from getting into an environmental agreement, even if a dirty country is not a part of it, if pollution is global.

\subsubsection{Announcement Profiles, Associated Environmental Agreements and Nash Equilibria in the $\mathbf{E}$ Game}

Proposition 3.16: In the E game, the Nash equilibria announcement profiles and the associated environmental agreements are shown in Table 3.1.

\begin{tabular}{|l|c|c|c|}
\hline \multirow{2}{*}{ Announcement Profiles } & Environmental & \multicolumn{2}{|c|}{ Nash Equilibria } \\
\cline { 3 - 4 } & Agreements & local & global \\
\hline \hline$\Omega^{\Phi^{e}} \equiv\left\{\sigma_{a}^{e}=\{\varnothing, \varnothing\}, \sigma_{b}^{e}=\{\varnothing, \varnothing\}, \sigma_{c}^{e}=\{\varnothing, \varnothing\}\right\}$ & $\left\langle\Phi^{e}\right\rangle$ & Yes & Yes \\
\hline$\Omega^{a b e} \equiv\left\{\sigma_{a}^{e}=\{b, \varnothing\}, \sigma_{b}^{e}=\{a, \varnothing\}, \sigma_{c}^{e}=\{\varnothing, \varnothing\}\right\}$ & $\langle a b e\rangle$ & No & No \\
\hline$\Omega^{b c e} \equiv\left\{\sigma_{a}^{e}=\{\varnothing, \varnothing\}, \sigma_{b}^{e}=\{\varnothing, c\}, \sigma_{c}^{e}=\{\varnothing, b\}\right\}$ & $\langle b c e\rangle$ & No & Yes \\
\hline$\Omega^{E} \equiv\left\{\sigma_{a}^{e}=\{b, c\}, \sigma_{b}^{e}=\{a, c\}, \sigma_{c}^{e}=\{a, b\}\right\}$ & $\langle E\rangle$ & No & No \\
\hline
\end{tabular}

Table 3.1: The Nash equilibria announcement profiles and the associated environmental agreements in the E game

An announcement profile $\Omega^{\Phi^{e}}$, which results in no environmental agreement, is a Nash equilibria for both local and global levels of pollution. Countries cannot increase their welfare by unilaterally 
altering their announcement. To prove that $\Omega^{a b e}$ is not a Nash equilibria for both levels of pollution, we use the results of Lemma3.1 $\left(-i^{e}\right)$. These results show that the dirty country $a$ can improve its welfare by unilateral changing the announcement to $\{\varnothing, \varnothing\}$; this change in the announcement would lead to no environmental agreement scenario and country $a$ 's increased welfare gain. The results of Lemma3.1 $\left(-i i i^{e}\right)$ illustrate that the announcement profile $\Omega^{b c e}$ does not constitute a Nash equilibria if pollution exhibits local characteristics. If pollution is local, then either member of the clean countries environmental union can improve its welfare by unilaterally changing the announcement to $\{\varnothing, \varnothing\}$, which would result in no agreement announcement profile and bring a higher welfare gains to both clean countries. For the global level of pollution, Lemma3.1(-iii $\left.{ }^{e}\right)$ shows that neither $b$ no $c$ has an incentive to unilaterally change their announcements from $\{\varnothing, c\}$ and $\{\varnothing, b\}$ respectively. Any change in the announcement would either lead to no change in welfare or would lead to no agreement scenario (change to $\{\varnothing, \varnothing\}$ or $\{a, \varnothing\}$ ) and a decrease in the level of welfare gains for both clean countries. We use the results of Lemma3.1 $\left(-i^{e}\right)$ to prove that the announcement profile $\Omega^{E}$ is not a Nash equilibria for both local and global levels of pollution. The dirty country $a$ prefers being an outsider of an environmental agreement between two clean countries to being a part of a global environmental agreement. To improve its welfare, country a would unilaterally change its announcement into $\{\varnothing, \varnothing\} .{ }^{12}$

\subsubsection{Coalition-Proof Nash Equilibria in the E Game}

Coalition-proof Nash equilibria is a refinement of a set of Nash equilibria. CPNE announcement profiles need to be immune not only to all individual deviations, but also to all meaningful selfenforcing coalitions. Although, an announcement profile $\Omega^{\Phi^{e}}$ is a Nash equilibria for both local and global levels of pollution, it is not a CPNE if pollution is global. To prove that, we consider a coalition formed by two clean players. Lemma3.1 $\left(-i i^{e}\right)$ shows that a formation of an environmental agreement between two clean countries would increase both of their welfares. They would

\footnotetext{
${ }^{12}$ For the proofs, please Appendix A.3.6
} 
also benefit from including country $a$ into an environmental agreement, but country $a$ prefers to be an outsider. Based on the above, we can conclude that clean countries can form a self-enforcing deviation, and consequently, $\Omega^{\Phi^{e}}$ is not a CPNE if pollution is global.

Proposition 3.17: If pollution is local then the only coalition-proof Nash equilibria of the E game is the announcement profile $\Omega^{\Phi^{e}}$ which constitutes a world with no environmental agreements in it; and if pollution is global then the only CPNE of the E game is the announcement profile $\Omega^{\text {bce }}$ which constitutes an environmental agreement between two clean countries.

We show that the announcement profile $\Omega^{\Phi^{e}}$ is immune to all meaningful coalitional deviations if pollution is local in the following steps: first, we examine the deviation of one clean and one dirty country, second, the deviation of two clean countries, and third, deviation by the grand coalition. First, we consider the coalitional deviation of countries $a$ and $b$. In this case, the changes in the announcements would result in an environmental agreement $\langle a b e\rangle$. The results in Lemma3.1 $\left(-i^{e}\right)$ tell us that a dirty country is not interested in this initial deviation. Now, we study the coalition of $b$ and $c$ that would result in $\langle b c e\rangle$. According to Lemma3.1 $\left(-i i i^{e}\right)$, none of clean countries has an incentive to alter the original announcement. Finally, we consider the grand coalition. The results in Lemma3.1 $\left(-i^{e}\right)$ show that country $a$ would prefer to face an environmental agreement between two clean countries than to be a part of a global environmental agreement. Based on the above, we can conclude that $\Omega^{\Phi^{e}}$ is a CPNE for the local level of pollution.

If pollution is global, then though clean countries would enjoy the increased welfare gains if a dirty player joins any of the environmental agreements, the dirty country $a$ prefers to be an outsider for both levels of pollution, Lemma3.1 $\left(-i^{e}\right)$. If pollution is global, then an environmental agreement between two clean countries induces them to increase their individually optimal tariffs on the imports from the outsider, the dirty country $a$, as well as to increase their jointly optimal environmental tax on the domestic producers of the dirty good $A$ above socially optimal level, $\gamma$. Those two actions lead to an increased welfare in the members above no agreement level. Based on the above, we can conclude that $\Omega^{b c e}$ is a CPNE for the global level of pollution. ${ }^{13}$

\footnotetext{
${ }^{13}$ For the proofs, please Appendix A.3.6
} 


\subsection{Endogenous Shallow Trade Agreements}

\subsubsection{The Customs Union Game}

\subsubsection{Preferential Trade Agreements in the CU Game}

In this part of the paper, we describe different preferential trade agreements which can arise under the customs union game. In the first stage of this game, players announce countries they would like to form a customs union with. Each player's strategy set $\left(S_{j}^{u}\right)$ consists of four possible announcements denoted as $\sigma_{j}^{u}$ :

$$
\begin{aligned}
& S_{a}^{u}=\left\{\{\varnothing, \varnothing\},\left\{b^{u}, \varnothing\right\},\left\{\varnothing, c^{u}\right\},\left\{b^{u}, c^{u}\right\}\right\} \\
& S_{b}^{u}=\left\{\{\varnothing, \varnothing\},\left\{a^{u}, \varnothing\right\},\left\{\varnothing, c^{u}\right\},\left\{a^{u}, c^{u}\right\}\right\} \\
& S_{c}^{u}=\left\{\{\varnothing, \varnothing\},\left\{a^{u}, \varnothing\right\},\left\{\varnothing, b^{u}\right\},\left\{a^{u}, b^{u}\right\}\right\}
\end{aligned}
$$

where announcement $\sigma_{j}^{u}=\{\varnothing, \varnothing\}$ indicates country's desire to stay away from any customs union; if $\sigma_{j}^{u}$ includes only one of the two countries then it denotes the player's wish to form a bilateral preferential trade agreement in the form of a customs union with that country only and exclude the third player; if $\sigma_{j}^{u}$ has two other countries then it indicates player's desire to be a part of a free trade world.

Countries are free to choose their announcements, and the agreements can be formed only if partners announce each other. In the customs union game, the countries strategy sets map into the following trade agreements:

(i) Announcement profile $\left\langle\Phi^{u}\right\rangle$ implies that either all three countries announce in the favour of no agreement or countries' announcements do not match. In this case, countries apply individually optimal tariffs and environmental taxes.

(ii) Announcement profile $\langle a b u\rangle$ arises when counties $a$ and $b$ call each other. In this case, members apply zero tariffs on imports from each other and jointly optimal tariff on the import from the outsider, country $c$. However, in the $\mathrm{CU}$ game, we allow only trade agreements, so both 
members and the outsider can still apply an individually optimal environmental tax on the domestic producers of the dirty good $A$.

(iii) Similar to (ii), announcement profile $\langle b c u\rangle$ indicate two countries' desire to exclude the third member of the world. In this case, two clean countries exclude the dirty country $a$ and form a trade union which includes only clean members.

(iv) The announcement profile $\left\langle F^{u}\right\rangle$ signals all three countries' desire to live in a free trade world. Under this profile countries apply zero tariffs on the imports from each other, but they still impose individually optimal environmental taxes.

\subsubsection{Welfare Effects of Various Trade Agreements in the CU Game}

LEMMA 3.2: The welfare impact of various types of trade agreements on members and nonmembers is as follows:

$$
\begin{gathered}
\left(\mathrm{i}^{u}\right) W^{a}\left(a b_{\theta}^{u}\right)>W^{a}\left(N_{\theta}\right) ; W^{b}\left(a b_{\theta}^{u}\right)>W^{b}\left(N_{\theta}\right) ; W^{c}\left(a b_{\theta}^{u}\right)<W^{c}\left(N_{\theta}\right) \\
W^{a}\left(b c_{\theta}^{u}\right)<W^{a}\left(N_{\theta}\right) ; W^{b}\left(b c_{\theta}^{u}\right)>W^{b}\left(N_{\theta}\right) ; W^{c}\left(b c_{\theta}^{u}\right)>W^{c}\left(N_{\theta}\right) \\
\left(\mathrm{ii}^{u}\right) W^{a}\left(a b_{\theta}^{u}\right)>W^{a}\left(a b c_{\theta}\right) ; W^{b}\left(a b_{\theta}^{u}\right)>W^{b}\left(a b c_{\theta}\right) ; W^{c}\left(a b_{\theta}^{u}\right)<W^{c}\left(a b c_{\theta}\right) \\
W^{a}\left(b c_{\theta}^{u}\right)<W^{a}\left(a b c_{\theta}\right) ; W^{b}\left(b c_{\theta}^{u}\right)>W^{b}\left(a b c_{\theta}\right) ; W^{c}\left(b c_{\theta}^{u}\right)>W^{c}\left(a b c_{\theta}\right) \\
\left(\mathrm{iii}^{u}\right) W^{b}\left(a b_{l}^{u}\right)>W^{b}\left(b c_{l}^{u}\right) \text { and } W^{b}\left(a b_{g}^{u}\right)<W^{b}\left(b c_{g}^{u}\right)
\end{gathered}
$$

Based on Lemma3.2 $\left(-i^{u}\right)$, we can conclude that any two countries are better off in a trade union than in no agreement scenario for both local and global levels of pollution. Also, non-members are worse off. The results in Lemma3.2( $\left(-i i^{u}\right)$ illustrate an exclusion incentive; any two countries prefer a trade union to a free trade. Also, a non-member would prefer to be a part of a world trade agreement to being an outsider of a trade union. Lemma3.2(-iii $\left.{ }^{u}\right)$ states that a clean country would prefer to get into a trade union with a dirty country if pollution is local, and a clean country would rather partner with another clean country if pollution exhibits global characteristics. 


\subsubsection{Announcements Profiles, Associated Trade Agreements and Nash Equilibria in the CU Game}

Proposition 3.18: In the CU game, the Nash equilibria announcement profiles and the associated trade agreements are shown in Table 3.2.

\begin{tabular}{|l|c|c|c|}
\hline \multirow{2}{*}{ Announcement Profiles } & \multirow{2}{*}{ Trade } & \multicolumn{2}{|c|}{ Nash Equilibria } \\
\cline { 3 - 4 } & Agreements & local & global \\
\hline \hline$\Omega^{\Phi^{u}} \equiv\left\{\sigma_{a}^{u}=\{\varnothing, \varnothing\}, \sigma_{b}^{u}=\{\varnothing, \varnothing\}, \sigma_{c}^{u}=\{\varnothing, \varnothing\}\right\}$ & $\left\langle\Phi^{u}\right\rangle$ & Yes & Yes \\
\hline$\Omega^{a b u} \equiv\left\{\sigma_{a}^{u}=\{b, \varnothing\}, \sigma_{b}^{u}=\{a, \varnothing\}, \sigma_{c}^{u}=\{\varnothing, \varnothing\}\right\}$ & $\langle a b u\rangle$ & Yes & Yes \\
\hline$\Omega^{b c u} \equiv\left\{\sigma_{a}^{u}=\{\varnothing, \varnothing\}, \sigma_{b}^{u}=\{\varnothing, c\}, \sigma_{c}^{u}=\{\varnothing, b\}\right\}$ & $\langle b c u\rangle$ & Yes & Yes \\
\hline$\Omega^{F^{u}} \equiv\left\{\sigma_{a}^{u}=\{b, c\}, \sigma_{b}^{u}=\{a, c\}, \sigma_{c}^{u}=\{a, b\}\right\}$ & $\left\langle F^{u}\right\rangle$ & No & No \\
\hline
\end{tabular}

Table 3.2: The Nash equilibria announcement profiles and the associated trade agreements in the CU game

Countries cannot be forced into an agreement. Countries enter a bilateral/multilateral trade agreement only if they announce each other; consequently, countries have no incentive to announce any other country unless they are going to be announced back. Based on that, we can say that $\Omega^{\Phi^{u}}$ is a Nash equilibria. $\Omega^{a b u}$ and $\Omega^{b c u}$ are Nash equilibria as well, based on the results in Lemma3.2 $\left(-i^{u}\right)$, which states that none of the countries has an incentive to change its announcements unilaterally. If members of either trade union would decide to change their announcement, it would lead to $\Omega^{\Phi^{u}}$, and their welfares would decrease relative to the trade union outcome. The change of the outsider's announcement would simply have no influence on the outcome, unless members announce that name as well. $\Omega^{F^{u}}$ is not a Nash equilibria. If pollution exhibits local characteristics, then the dirty country would improve its welfare by calling only one of the clean countries, as country $a$ is indifferent between forming a trade union with either clean country. In 
this case, the "lucky" one (either $b$ or $c$ ) would improve its welfare by getting into a union with a dirty partner and excluding another clean member of the world. The "unlucky" one would have no choice but except being an outsider, and consequently, would face lower welfare. In the case of global pollution, clean countries would exclude the dirty member of the world by announcing only each other. This change of announcement would lead an improved welfare in the clean part of the world, and the dirty country $a$ would be left as an outsider with the lower welfare gains. ${ }^{14}$

\subsubsection{Coalition-Proof Nash Equilibria of the CU Game}

Though the announcement profile $\Omega^{\Phi^{u}}$ constitutes a Nash equilibria, it is not a CPNE for both local and global levels of pollution. To prove that, we first assume that the pollution is pure local and countries $a$ and $b$ coalitionally deviate to a trade union. In this case, the announcement profile would be changed into $\Omega^{a b u}$ and both parties would achieve the highest levels of welfare in this game. Based on that, we can conclude that one clean and one dirty country can form a selfenforcing coalition. Second, if we assume that the pollution exhibits global characteristics, the two clean countries form a bilateral trade agreement in the form of a customs union. These changes in the announcements would alter the profile into $\Omega^{b c u}$, and both countries would achieve the highest welfare gains in this game. Based on than, we conclude that a self-enforcing coalition between two clean countries is possible if pollution is global. It is easy to see that the announcement profile $\Omega^{a b u}$ is not a CPNE if pollution is global. In this case, two clean countries have a strong incentive to exclude the dirty player, form a trade union, and gain the highest welfare in this game. In a similar way we can show that the announcement profile $\Omega^{b c u}$ is not a CPNE if pollution exhibit local characteristics; one clean and one dirty country can benefit from excluding an "unlucky" clean country by forming a trade union. Members would enjoy the highest welfare level in this game. As we have shown in the previous section, the announcement profile $\Omega^{F^{u}}$ is not a Nash equilibria for both levels of pollution, and consequently, it cannot be a CPNE.

\footnotetext{
${ }^{14}$ For the proofs, please Appendix A.3.7.1
} 
Proposition 3.19: If pollution is local then the only coalition-proof Nash equilibria of the $C U$ game is the announcement profile $\Omega^{a b u}$ which constitutes a trade union between one clean and one dirty country; and if pollution is global then the only CPNE of the CU game is the announcement profile $\Omega^{b c u}$ which constitutes a trade union between two clean countries.

If pollution is local, then members of $\left(a b_{l}^{u}\right)$ cannot improve their welfares by altering their original announcements:

$$
W^{a}\left(a b_{l}^{u}\right)>W^{a}\left(N_{l}\right)>W^{a}\left(a b c_{l}\right)>W^{a}\left(b c_{l}^{u}\right) \text { and } W^{b}\left(a b_{l}^{u}\right)>W^{b}\left(b c_{l}^{u}\right)>W^{b}\left(a b c_{l}\right)>W^{b}\left(N_{l}\right)
$$

Based on the above, we conclude that $\Omega^{a b u}$ is a self-enforcing commitment between one clean and one dirty country if pollution exhibits local characteristics.

If pollution is global, then we can see that neither $b$ or $c$ can do better by deviating from their original announcement which results in $\left(b c_{g}^{u}\right)$ :

$$
W^{b}\left(b c_{g}^{u}\right)>W^{b}\left(a b_{g}^{u}\right)>W^{b}\left(N_{g}\right)>W^{b}\left(a b c_{g}\right) \text { and } W^{c}\left(b c_{g}^{u}\right)>W^{c}\left(a b c_{g}\right)>W^{c}\left(N_{g}\right)>W^{c}\left(a b_{g}^{u}\right)
$$

We conclude that, $\Omega^{b c u}$ is a self-enforcing commitment between two clean countries if pollution exhibits global characteristics. ${ }^{15}$

\subsubsection{The Free Trade Agreement Game}

\subsubsection{Preferential Trade Agreements in the FTA Game}

In the first stage of the FTA game, players also announce countries they would like to form a PTA with, but in this game preferential trade agreements take the form of free trade agreements. Each player's strategy set $\left(S_{j}\right)$ consists of four possible announcements denoted as $\sigma_{j}$ :

$$
\begin{aligned}
& S_{a}=\{\{\varnothing, \varnothing\},\{b, \varnothing\},\{\varnothing, c\},\{b, c\}\} \\
& S_{b}=\{\{\varnothing, \varnothing\},\{a, \varnothing\},\{\varnothing, c\},\{a, c\}\} \\
& S_{c}=\{\{\varnothing, \varnothing\},\{a, \varnothing\},\{\varnothing, b\},\{a, b\}\}
\end{aligned}
$$

\footnotetext{
${ }^{15}$ For the proofs, please Appendix A.3.7.1
} 
where announcement $\sigma_{j}=\{\varnothing, \varnothing\}$ indicates player's desire to stay away from any free trade agreement with either partner; if $\sigma_{j}$ includes only one of the two countries then it denotes the player's wish to form a bilateral free trade agreement with that country only and exclude the third player; if $\sigma_{j}$ has two other countries then it indicates player's desire to be a trade partner of both countries. Countries are free to choose their announcements, and free trade agreements can be formed only if partners announce each other. In the FTA game, the countries strategy sets map into the following free trade agreements:

(i) If all three players announce $\{\varnothing, \varnothing\}$ or the announcement profiles do not match, it results in the profile $\langle\Phi\rangle$ - no agreement, and each player applies individually optimal tariffs.

(ii) Country $a$ 's announcement $\{b, \varnothing\}$ and country $b$ 's announcement $\{a, \varnothing\}$ lead to a profile $\langle a b\rangle$. The changes in country c's announcement would not alter the profile because neither $a$ no $b$ is calling $c$. This profile implies that members apply zero tariffs on imports from each other and individually optimal tariffs of the import from the outsider, country $c$.

(iii) Similar to (ii), announcement profile $\langle b c\rangle$ indicate two countries' desire to exclude a third member of the world. In this case, two clean countries exclude the dirty country $a$ and form a free trade agreement which includes only clean members.

(iv) If both clean countries announce only in the favour of a free trade agreement with a dirty country, and the dirty country announces in the favour of a free trade world, then these announcements result in a hub-and-spoke trade regime. In this case, the dirty country $a$ is a hub, and two clean countries are the spokes, $\langle a h\rangle$. Under this profile, country $a$ imposes zero tariffs on the imports from the clean part of the world as well as both clean countries impose zero tariffs on the imports of the dirty good $A$. However, two clean countries still impose positive tariffs on the imports from each other.

(v) Similar to (iv), if one clean and one dirty country announce in the favour of a third country, and that country announces in the favour of a free trade world, then that third country would turn into a hub and other two would be the spokes. The profile matching those announcements is $\langle b h\rangle$, where $b$ is a hub, and countries $a$ and $c$ are the spokes. 
(iv) As in the CU game, the announcement profile $\langle F\rangle$ signals all three countries' desire to live in a free trade world. Under this profile countries apply zero tariffs on the imports from each other, but they still impose individually optimal environmental taxes.

\subsubsection{Welfare Effects of Various Trade Agreements in the FTA Game}

LEMMA 3.3: The welfare impact of various types of trade agreements on members and nonmembers is as follows:

(i) $W^{a}\left(a b_{\theta}\right)>W^{a}\left(N_{\theta}\right) ; W^{b}\left(a b_{\theta}\right)>W^{b}\left(N_{\theta}\right) ; W^{c}\left(a b_{\theta}\right)<W^{c}\left(N_{\theta}\right)$

$$
W^{a}\left(b c_{\theta}\right)<W^{a}\left(N_{\theta}\right) ; W^{b}\left(b c_{\theta}\right)>W^{b}\left(N_{\theta}\right) ; W^{c}\left(b c_{\theta}\right)>W^{c}\left(N_{\theta}\right)
$$

(ii) $W^{a}\left(a b_{\theta}\right)>W^{a}\left(a b c_{\theta}\right) ; W^{b}\left(a b_{\theta}\right)>W^{b}\left(a b c_{\theta}\right) ; W^{c}\left(a b_{\theta}\right)<W^{c}\left(a b c_{\theta}\right)$

$$
W^{a}\left(b c_{\theta}\right)<W\left(a b c_{\theta}\right) ; W^{j \neq a}\left(b c_{l}\right)<W^{j \neq a}\left(a b c_{l}\right) \text { and } W^{j \neq a}\left(b c_{g}\right)>W^{j \neq a}\left(a b c_{g}\right)
$$

(iii) $W^{b}\left(a b_{l}\right)>W^{b}\left(a b c_{l}\right)>W^{b}\left(b c_{l}\right)$ and $W^{b}\left(b c_{g}\right)>W^{b}\left(a b_{g}\right)>W^{b}\left(a b c_{g}\right)$

(iv) $W^{a}\left(a_{\theta}^{h}\right)>W^{a}\left(a b_{\theta}\right) ; W^{b}\left(a_{\theta}^{h}\right)<W^{b}\left(a b_{\theta}\right) ; W^{c}\left(a_{\theta}^{h}\right)>W^{c}\left(a b_{\theta}\right)$

$$
W^{a}\left(b_{\theta}^{h}\right)<W\left(a b_{\theta}\right) ; W^{b}\left(b_{l}^{h}\right)>W^{b}\left(a b_{l}\right) ; W^{c}\left(b_{\theta}^{h}\right)>W^{c}\left(a b_{\theta}\right)
$$

(v) $W^{a}\left(a_{\theta}^{h}\right)>W^{a}\left(a b c_{\theta}\right) ; W^{b}\left(a_{\theta}^{h}\right)<W^{b}\left(a b c_{\theta}\right) ; W^{c}\left(a_{\theta}^{h}\right)<W^{c}\left(a b c_{\theta}\right)$

$$
W^{a}\left(b_{\theta}^{h}\right)<W\left(a b c_{\theta}\right) ; W^{b}\left(b_{l}^{h}\right)>W^{b}\left(a b c_{l}\right) ; W^{c}\left(b_{\theta}^{h}\right)<W^{c}\left(a b c_{\theta}\right)
$$

Similar to Lemma3.2( $\left(-i^{u}\right)$, Lemma3.3(-i) states that any two countries are better off in a bilateral FTA than in the no agreement scenario for both local and global levels of pollution, and a non-member is always worse off. The results in Lemma3.3(-ii) show an exclusion incentive when pollution is global for all countries, and in this case a non-member would prefer to be a part of a free trade agreement to being an outsider of a bilateral trade agreement. However, if pollution is local, then clean countries would be better off in a free trade agreement than in the bilateral trade agreement between clean countries only. Lemma3.3(-iii) exhibits similar results to Lemma3.3 $\left(-i i^{u}\right)$ and states that a clean country would prefer to get into a bilateral trade agreement with the dirty country if pollution is local, and a clean country would rather be a partner 
with another clean country if pollution exhibits global characteristics. Lemma3.3(-iv) illustrates the following: first, it is better to be a spoke than a non-member of a bilateral FTA; second, it is better to be a member of a bilateral FTA than to be a spoke; and third, naturally, being a hub is very beneficial. Finally, Lemma3.3(-v) states that countries would rather be a part of an FTA than being spokes, and not surprisingly, it is better to be a hub than a part of a free trade world.

3.7.2.3 Nash Equilibria Announcement Profiles and Associated Trade Agreements in the FTA Game

Proposition 3.20: In the FTA game, the Nash equilibria announcement profiles and the associated trade agreements are shown in Table 3.3.

\begin{tabular}{|l|c|c|c|}
\hline & Trade & \multicolumn{2}{|c|}{ Nash Equilibria } \\
\cline { 3 - 4 } Announcement Profiles & Agreements & local & global \\
\hline \hline$\Omega^{\Phi} \equiv\left\{\sigma_{a}=\{\varnothing, \varnothing\}, \sigma_{b}=\{\varnothing, \varnothing\}, \sigma_{c}=\{\varnothing, \varnothing\}\right\}$ & $\langle\Phi\rangle$ & Yes & Yes \\
\hline$\Omega^{a b} \equiv\left\{\sigma_{a}=\{b, \varnothing\}, \sigma_{b}=\{a, \varnothing\}, \sigma_{c}=\{\varnothing, \varnothing\}\right\}$ & $\langle a b\rangle$ & Yes & Yes \\
\hline$\Omega^{b c} \equiv\left\{\sigma_{a}=\{\varnothing, \varnothing\}, \sigma_{b}=\{\varnothing, c\}, \sigma_{c}=\{\varnothing, b\}\right\}$ & $\langle b c\rangle$ & Yes & Yes \\
\hline$\Omega^{a h} \equiv\left\{\sigma_{a}=\{b, c\}, \sigma_{b}=\{a, \varnothing\}, \sigma_{c}=\{a, \varnothing\}\right\}$ & $\langle a h\rangle$ & Yes & Yes \\
\hline$\Omega^{b h} \equiv\left\{\sigma_{a}=\{b, \varnothing\}, \sigma_{b}=\{a, c\}, \sigma_{c}=\{\varnothing, b\}\right\}$ & $\langle b h\rangle$ & Yes & Yes \\
\hline$\Omega^{F} \equiv\left\{\sigma_{a}=\{b, c\}, \sigma_{b}=\{a, c\}, \sigma_{c}=\{a, b\}\right\}$ & $\langle F\rangle$ & Yes & Yes \\
\hline
\end{tabular}

Table 3.3: The Nash equilibria announcement profiles and the associated trade agreements in the FTA game

Based on the results in Lemma3.3(-i), we can state that the announcement profile $\Omega^{\Phi}$ is a Nash equilibria; no player would be better off by unilaterally changing its announcement. Profiles $\Omega^{a b}$ 
and $\Omega^{b c}$ are Nash equilibria as well. If any member of either bilateral free trade agreement alters its announcement, the profile would be changed into $\Omega^{\Phi}$ with lower levels of welfare gains relative to the original announcement profile (Lemma3.3 $(-i)$ ). The changes in the announcement of the outsider of either of these agreements would have no effect on the outcome. Now, we evaluate the announcement profiles of two hub-and-spoke regimes, $\Omega^{a h}$ and $\Omega^{b h}$. First, a hub country achieves the highest welfare level in this game, so it has zero incentive to change its announcement. Second, if any of the spokes changes its announcement, it would turn into an outsider of a bilateral free trade agreement with a loss in welfare (Lemma3.3( $-v)$ ). Finally, we show that in this game the announcement profile $\Omega^{F}$ is immune to unilateral deviations. The difference between the $\mathrm{CU}$ game and the FTA game is in the presence of hub-and-spoke trade regimes in the latter of these two games. If either of the three players decide to unilaterally change its announcement, this change would either lead to one of the other countries becoming a hub or two other countries would end up in a bilateral trade agreement. Neither of those alterations is beneficial for any player. For both local and global pollution, all three countries would prefer to take their part in a free trade world versus being a spoke or an outsider of a bilateral trade agreement (Lemma3.3( $-v)$ and Lemma3.3(-ii)). ${ }^{16}$

\subsubsection{Coalition-Proof Nash Equilibria of the FTA Game}

Again, coalition-proof Nash equilibria is a refinement of a set of Nash equilibria which needs to survive all possible meaningful self-enforcing coalitions. In the FTA game, the only Nash equilibria resistant to all such coalitions is an announcement profile $\Omega^{F}$ which constitutes a free trade world. In this part of the paper, we first show, that all announcement profiles but $\Omega^{F}$ do not survive coalitional deviations, and then we prove that $\Omega^{F}$ is the only CPNE for both local and global levels of pollution in the FTA game. The results of in Lemma3.3( $-i)$ show that $\Omega^{\Phi}$ is not a CPNE for both local and global levels of pollution; any two countries can achieve higher welfare gains

\footnotetext{
${ }^{16}$ For the proofs, please Appendix A.3.7.2
} 
by altering their announcement profiles into either $\Omega^{a b}$ or $\Omega^{b c}$. To prove that the announcement profile $\Omega^{a b}$ is not a CPNE for both local and global levels of pollution, we consider a coalition between the dirty part of this agreement, country $a$, and an outsider, country $c$. This coalition would be beneficial for both countries (in Lemma3.3(-iv)), and the announcement profile would be changed into $\{\{b, c\},\{a, \varnothing\},\{a, \varnothing\}\}$. We can see, that country $c$ would prefer to be a spoke versus being an outsider of the trade agreement between two other countries. We hold country $b$ 's announcement constant and observe that neither $a$ or $c$ has an incentive to deviate. We can conclude that $\Omega^{a b}$ is not a CPNE for both local and global levels of pollution. To show that $\Omega^{b c}$ is not a CPNE, we analyze whether countries $a$ and $b$ can form a self-enforcing coalition. In this case, the announcement profile would take a form of $\Omega^{b h}$, and as we can see from in Lemma 3.3(-iv), it is beneficial for both players. It is clear that the dirty country $a$ would prefer to be a spoke than face an agreement between two clean countries. We hold country $c$ 's announcement constant and observe that neither partner of the proposed coalition has an incentive to deviate any further by unilaterally changing its announcement. We can conclude that $\Omega^{b c}$ is not a CPNE for both local and global levels of pollution. Though both announcement profiles $\Omega^{a h}$ and $\Omega^{b h}$, which constitute two different hub-and-spoke trade regimes, are Nash equilibria, they do not survive a coalition-proof Nash equilibria refinement. To prove that, we use the results of in Lemma3.3( $-v)$ which states that countries would rather be a part of a free trade world than being a spoke. We hold the hub country's announcement constant and conclude that any two spokes can form a self-enforcing trade agreement with no further individual deviation and, as a result, turn any hub-and-spoke regime into a free trade world.

Proposition 3.21: The only coalition proof Nash equilibria of the FTA game, for both local and global levels of pollution, is the announcement profile $\Omega^{\digamma}$ which constitutes a free trade world. This key result is very similar to Missios etal.(2016), as we also conclude that though any two countries can benefit from excluding the third one from the agreement, none of the countries would exercise it in equilibrium. To prove that, let us first assume, that countries $a$ and $b$ decided to form a bilateral trade agreement by altering these profiles into the following announcement: 
$\Omega^{a b} \equiv\left\{\sigma_{a}=\{b, \varnothing\}, \sigma_{b}=\{a, \varnothing\}, \sigma_{c}=\{a, b\}\right\}$. We can see that these joint changes in the announcements are beneficial for both countries: $W^{a}\left(a b_{\theta}\right)>W^{a}\left(a b c_{\theta}\right)$ and $W^{b}\left(a b_{\theta}\right)>W^{b}\left(a b c_{\theta}\right)$ (Lemma3.3(-ii)). (However, the results of Lemma3.3(-iv) illustrate both countries incentive to deviate and become a hub. Based on the above, we can conclude that this deviation is not self-enforcing and countries would go back to their original announcement profile $\Omega^{\digamma}$. Now, we assume that countries $b$ and $c$ decided to form a bilateral trade agreement by altering this profiles into the following announcement: $\Omega^{b c} \equiv\left\{\sigma_{a}=\{\varnothing, \varnothing\}, \sigma_{b}=\{\varnothing, c\}, \sigma_{c}=\{\varnothing, b\}\right\}$. Again, we can see that these joint changes in the announcements are beneficial to both countries: $W^{b}\left(b c_{\theta}\right)>$ $W^{b}\left(a b c_{\theta}\right)$ and $W^{c}\left(b c_{\theta}\right)>W^{c}\left(a b c_{\theta}\right)$ (in Lemma3.3(-ii))However, both countries have an incentive to deviate from this agreement, because $W^{b}\left(b_{\theta}^{h}\right)>W^{b}\left(b c_{\theta}\right)$ and $W^{c}\left(c_{\theta}^{h}\right)>W^{b}\left(b c_{\theta}\right)$ (in Lemma 3.3 $(-i v)$ ). Based on the above, we can conclude that the original announcement profile $\Omega^{\digamma}$ is immune to all meaningful self-enforcing coalitions. ${ }^{17}$

\subsection{Endogenous Deep Trade Agreements}

\subsubsection{The Integrated Customs Union Game}

\subsubsection{Integrated Customs Unions in the IU Game}

In this part of the paper, we describe different deep preferential trade agreements which can arise under the integrated customs union game. The difference between integrated customs union game and customs union game, described in the previous section, lies in the nature of deep and shallow trade agreements. In this game, countries' announcements are not limited to trade agreements only, but they also include an environmental clause. In the first stage of this game, players announce countries they would like to form an integrated union with. Each player's strategy set $\left(S_{j}^{i u}\right)$ consists of four possible announcements denoted as $\sigma_{j}^{i u}$ :

\footnotetext{
${ }^{17}$ For the proofs, please Appendix A.3.7.2
} 


$$
\begin{aligned}
& S_{a}^{i u}=\left\{\{\varnothing, \varnothing\},\left\{b^{i u}, \varnothing\right\},\left\{\varnothing, c^{i u}\right\},\left\{b^{i u}, c^{i u}\right\}\right\} \\
& S_{b}^{i u}=\left\{\{\varnothing, \varnothing\},\left\{a^{i u}, \varnothing\right\},\left\{\varnothing, c^{i u}\right\},\left\{a^{i u}, c^{i u}\right\}\right\} \\
& S_{c}^{i u}=\left\{\{\varnothing, \varnothing\},\left\{a^{i u}, \varnothing\right\},\left\{\varnothing, b^{i u}\right\},\left\{a^{i u}, b^{i u}\right\}\right\}
\end{aligned}
$$

where announcement $\sigma_{j}^{i u}=\{\varnothing, \varnothing\}$ indicates player's desire to stay away from any integrated union; if $\sigma_{j}^{i u}$ includes only one of the two countries then it denotes the player's wish to form an integrated union with that country only and exclude the third player; if $\sigma_{j}^{i u}$ has two other countries then it indicates player's desire to be a partner of both countries.

In the integrated customs union game, the countries strategy sets map into the following deep trade agreements:

(i) If all players announce in the favour of no agreement, or the announcements do not match, it results in the announcement profile $\left\langle\Phi^{i u}\right\rangle$. This profile implies that each player applies individually optimal tariffs and environmental taxes.

(ii) If one clean and one dirty country announce each other, and none of these countries call the second clean player, then the announcement profile $\langle a b i u\rangle$ arises. In this case, members agree on the environmental tax they levy on their producers of a dirty good $A$, apply zero tariffs on imports from each other and jointly optimal tariff on the import from the outsider, country $c$. An outsider is free to choose individually optimal tariffs and taxes.

(iii) Similar to (ii), announcement profile $\langle b c i u\rangle$ indicate two countries' desire to exclude the third member. In this case, two clean countries exclude a dirty country a and form an integrated customs union which includes only clean players.

(iv) The announcement profile $\left\langle F^{i u}\right\rangle$ signals all three countries' desire to live in an entirely integrated world. Under this profile countries agree on the environmental tax level and apply zero tariffs on the imports from each other. 


\subsubsection{Welfare Effects of Various Trade Agreements in the IU Game}

LEMMA 3.4: The welfare impact of various types of deep trade agreements on countries-members and non-members is as follows:

$$
\begin{aligned}
& \left(\mathrm{i}^{i u}\right) W^{a}\left(a b_{\theta}^{i u}\right)>W^{a}\left(N_{\theta}\right)^{18} ; W^{b}\left(a b_{\theta}^{i u}\right)>W^{b}\left(N_{\theta}\right) ; W^{j \neq a}\left(b c_{\theta}^{i u}\right)>W^{j \neq a}\left(N_{\theta}\right) \\
& W^{a}\left(b c_{\theta}^{i u}\right)<W^{a}\left(N_{\theta}\right) ; W^{c}\left(a b_{\theta}^{i u}\right)<W^{c}\left(N_{\theta}\right)^{19} \\
& \left(\mathrm{ii}^{i u}\right) W^{j}\left(a b c_{\theta}^{i}\right)>W^{j}\left(b c_{\theta}^{i u}\right)>W^{j}\left(N_{\theta}\right) \text { where } j \neq a \\
& \left(\mathrm{iii}^{i u}\right) W^{b}\left(a b_{l}^{i u}\right)>W^{b}\left(a b c_{l}^{i}\right) \text { and } W^{b}\left(a b c_{g}^{i}\right)>W^{b}\left(a b_{g}^{i u}\right)>W^{b}\left(b c_{g}^{i u}\right) \\
& \left(\mathrm{iv}^{i u}\right) W^{a}\left(a b c_{l}^{i}\right)>W^{a}\left(b c_{l}^{i u}\right) \text { and } W^{a}\left(a b c_{g}^{i}\right)<W^{a}\left(b c_{g}^{i u}\right)
\end{aligned}
$$

The results in Lemma3.4 $\left(-i^{i u}\right)$ indicate, first, that two symmetric clean countries are better off in an integrated union than in no agreement scenario for both local and global levels of pollution; second, that a dirty country prefers to be involved in no integrated agreement if productivity gap is sufficiently large, and third, an outsider of a bilateral integrated agreement between one clean and one dirty country would benefit relative to no agreement level if pollution is global and productivity gap is narrow. Lemma3.4 $\left(-i i^{i u}\right)$ states, that clean countries would prefer to include a dirty player into an agreement and live in an entirely integrated world versus being in an integrated agreement which includes only clean members. According to the results in Lemma 3.4(-ii $\left.i^{i u}\right)$ and Lemma3.4 $\left(-i i i^{i u}\right)$, a clean country would gain the highest level of welfare in this game if it is in the integrated union with a dirty country and the pollution is local. On the other hand, if pollution exhibits global characteristics, then a clean country would prefer to be a part of a fully integrated world. Results in Lemma3.4 $\left(-i v^{i u}\right)$ illustrate that a dirty country prefers to face an integrated agreement between two clean partners to being a part of a fully integrated world.

\footnotetext{
${ }^{18}$ holds for $\theta=g$ only if $\lambda \geq \lambda$ iu

${ }^{19}$ holds for $\theta=g$ only if $\lambda<\lambda$ iu
} 


\subsubsection{Announcement Profiles, Associated Trade Agreements and Nash Equilibria in the IU Game}

Proposition 3.22: In the IU game, the Nash equilibria announcement profile and associated deep trade agreements are shown in Table 3.4.

\begin{tabular}{|l|c|c|c|}
\hline \multirow{2}{*}{ Announcement Profiles } & Deep & \multicolumn{2}{|c|}{ Nash Equilibria } \\
\cline { 3 - 4 } & Agreements & local & global \\
\hline \hline$\Omega^{\Phi^{i u}} \equiv\left\{\sigma_{a}^{i u}=\{\varnothing, \varnothing\}, \sigma_{b}^{i u}=\{\varnothing, \varnothing\}, \sigma_{c}^{i u}=\{\varnothing, \varnothing\}\right\}$ & $\left\langle\Phi^{i u}\right\rangle$ & Yes & Yes \\
\hline$\Omega^{a b i u} \equiv\left\{\sigma_{a}^{i u}=\{b, \varnothing\}, \sigma_{b}^{i u}=\{a, \varnothing\}, \sigma_{c}^{i u}=\{\varnothing, \varnothing\}\right\}$ & $\langle a b i u\rangle$ & Yes & Yes if $\lambda \geq \lambda^{i u}$, \\
& & & No if $\lambda<\lambda^{i u}$ \\
\hline$\Omega^{b c i u} \equiv\left\{\sigma_{a}^{i u}=\{\varnothing, \varnothing\}, \sigma_{b}^{i u}=\{\varnothing, c\}, \sigma_{c}^{i u}=\{\varnothing, b\}\right\}$ & $\langle b c i u\rangle$ & Yes & Yes \\
\hline$\Omega^{F^{i u}} \equiv\left\{\sigma_{a}^{i u}=\{b, c\}, \sigma_{b}^{i u}=\{a, c\}, \sigma_{c}^{i u}=\{a, b\}\right\}$ & $\left\langle F^{i u}\right\rangle$ & No & No \\
\hline
\end{tabular}

Table 3.4: The Nash equilibria announcement profiles and the associated trade agreements in the IU game

The announcement profile $\Omega^{\Phi^{i u}}$ is a Nash equilibria for both local and global levels of pollution; a unilateral change in any player's announcement would not affect their welfare levels. The results in Lemma3.4 $\left(-i^{i u}\right)$ show that the announcement profile $\Omega^{a b i u}$, which results in a deep trade agreement between one clean and one dirty country, is a Nash equilibria for the local level of pollution and for the global level of pollution if productivity gap is relatively small. In this cases, by unilaterally changing their announcements neither country $a$ no country $b$ can increase their welfare gains; any unilateral change would simply lead to the no agreement level and decrease in the level of welfares achieved. An outsider of this agreements, country $c$, has no incentive to alter its announcement as well because any change in the outsider's announcement would not affect the outcome. We use the results in Lemma3.4 $\left(-i^{i u}\right)$ to prove that the announcement profile $\Omega^{a b i u}$ does not constitute 
a Nash equilibria if the pollution exhibits global characteristics and $\lambda<\lambda^{i u}$. The dirty country $a$ can improve its welfare by unilaterally changing the announcement from $\{b, \varnothing\}$ to $\{\varnothing, \varnothing\}$, and this change would result in $\Omega^{\Phi^{i u}}$ and a higher welfare gain for country $a$. The announcement profile $\Omega^{b c i u}$, which leads to an integrated union between two clean countries, is a Nash equilibria for both local and global level of pollution. The results in Lemma3.4 $\left(-i^{i u}\right)$ and 3.4 $\left(-i i^{i u}\right)$ illustrate that clean countries would not benefit from changing their announcement from the ones they make under $\Omega^{\text {bciu }}$, because those changes lead to no agreement announcement profile and lower welfare gains for both players. We use the results presented in Lemma3.4 $\left(-i^{i u}\right)$ through 3.4( $\left.-i i i^{i u}\right)$ show that the announcements profile $\Omega^{F^{i u}}$, which results in a fully integrated world, is not a Nash equilibria if pollution is local. In this case, country a can improve its welfare by announcing only one out of two clean countries. The lucky clean country would prefer to form a union with country $a$ versus the union with another clean country. Based on that, we conclude, that $\Omega^{\digamma^{i u}}$ is not a Nash Equilibria for the local level of pollution. Now, we use the results in Lemma3.4(-iv $\left.{ }^{i u}\right)$ to prove that $\Omega^{\digamma^{i u}}$ is not a Nash Equilibria if pollution is global as well. The dirty country $a$ would prefer to be an outsider of an integrated agreement between two clean countries than participate in a fully integrated world. Based on that we conclude, that $\Omega^{\digamma^{i u}}$ is not a Nash Equilibria for the global level of pollution. ${ }^{20}$

\subsubsection{Coalition-Proof Nash Equilibria of the IU Game}

Though the announcement profile $\Omega^{\Phi^{i u}}$ is a Nash equilibria for both local and global levels of pollution, it does not survive a coalition-proof Nash equilibria refinement. We prove it in three steps. First, we assume that pollution is local and consider a coalition between countries $a$ and $b$. In this case, the announcement profile would be altered into $\Omega^{a b i u}$, and the results in Lemma 3.4 $\left(-i^{i u}\right)$ illustrate welfare increases for both partners of this coalition. There is no further deviation, because the level of welfares countries $a$ and $b$ acquire in this integrated union are the highest they can

\footnotetext{
${ }^{20}$ For the proofs, please Appendix A.3.8.1
} 
achieve in the entire IU Game in the case of local pollution. Based on the above, we can conclude that $\Omega^{\Phi^{i u}}$ is not a CPNE if pollution is local. Second, we consider the case of global pollution and relatively narrow productivity gap. We let countries $a$ and $b$ form a trade and environmental union, and as a result, we observe that the levels of the welfares these two countries achieve are the highest in the IU Game if pollution is global and the productivity gap is relatively narrow. Finally, we consider the case of global pollution and a relatively large productivity gap. We assume that clean countries form a coalition by altering their announcements into $\Omega^{\text {bciu }}$ profile. Based on the results in Lemma3.4 $\left(-i i^{i u}\right)$, we can conclude, that clean countries can form a coalition. We can also rule out all further deviations based on the results in Lemma3.4 $\left(-i v^{i u}\right)$ which show that though clean countries would prefer to include a dirty player into their union, the dirty country $a$ would rather be an outsider than participate in a fully integrated world. Based on the above, we can conclude that $\Omega^{\Phi^{i u}}$ is not a CPNE if pollution is global. Now, we show that $\Omega^{\text {bciu }}$ is not a CPNE for the local level of pollution and for the global level of pollution if productivity gap is narrow. First, we consider a coalition of $a$ and $b$ in the case of local pollution, then $W^{a}\left(a b_{l}^{i u}\right)>W^{a}\left(b c_{l}^{i u}\right)$ and $W^{b}\left(a b_{l}^{i u}\right)>W^{b}\left(b c_{l}^{i u}\right)$. Also, the level of welfare countries $a$ and $b$ achieve from forming a trade and environmental union is the highest in this game, so none of the members would deviate any further. Second, we consider the case of global pollution and relatively narrow productivity gap, then $W^{a}\left(a b_{g}^{i u}\right)>W^{a}\left(b c_{g}^{i u}\right)$ and $W^{b}\left(a b_{g}^{i u}\right)>W^{b}\left(b c_{g}^{i u}\right)$. Also, the level of welfare country $a$ gets in this union is the highest in the entire game, and country $b$ can be better off only in the integrated world, but the dirty country $a$ is not interested in being a part of the integrated world. Based, on the above, we feel confident to conclude that $\Omega^{\text {bciu }}$ is not a CPNE for the local level of pollution and for the global level of pollution if productivity gap is relatively low.

Proposition 3.23: The announcement profile $\Omega^{a b i u}$, which constitutes an integrated union between one clean and one dirty country, is the only CPNE in this game for the local level of pollution and for the global level of pollution if productivity gap is sufficiently narrow; and the announcement profile $\Omega^{\text {bciu }}$, which constitutes an integrated union between two clean countries, is the only CPNE in this game for the global level of pollution if productivity gap is sufficiently 
large.

We prove it three steps. We start with considering the local level of pollution. Both countries, $a$ and $b$, have no incentive to form any other coalition, because the level of welfare each of them achieves is the highest in the entire IU Game. Now, we consider the global level of pollution and relatively narrow productivity gap. In this case, the dirty country $a$ has no incentive to form any other coalition, including a global one, because $a$ 's welfare is the highest in the trade and environmental union with only one clean country. Country $b$ would prefer to get into a global coalition, but country $a$ would not agree to that. Based on the above, we conclude that there is no coalition which can benefit by deviating in a self-enforcing manner, and the announcement profile $\Omega^{a b i u}$ is a CPNE for the local level of pollution and for the global level of pollution if productivity gap is relatively narrow. To prove that the announcement profile $\Omega^{\text {bciu }}$ is the only CPNE if pollution is global and productivity gap is relatively large, we start by considering a coalition between two asymmetric countries, $a$ and $b$, formed under the announcement profile $\Omega^{a b i u}$. This coalition would increase the level of welfares achieved by both members, $W^{a}\left(a b_{g}^{i u}\right)>W^{a}\left(b c_{g}^{i u}\right)$ if productivity gap is relatively large and $W^{b}\left(a b_{g}^{i u}\right)>W^{b}\left(b c_{g}^{i u}\right)$. However, this deviation is not self-enforcing, because country $a$ has an incentive to deviate further to the no agreement situation by changing its announcement into $\{\varnothing, \varnothing\}: W^{a}\left(a b_{g}^{i u}\right)<W^{a}\left(N_{g}\right)$ if productivity gap is relatively large. Based on the above, we can conclude that $\Omega^{b c i u}$ is a CPNE if pollution is global and productivity gap is relatively large. ${ }^{21}$

\subsubsection{The Integrated Free Trade Agreements Game}

\subsubsection{Integrated FTAs}

In the first stage of this game, players also announce countries they would like to form a deep trade agreement with, but in this game integrated agreements take the form of deep free trade agreements with an environmental clause. Each player's strategy set $\left(S_{j}^{i}\right)$ consists of four possible

\footnotetext{
${ }^{21}$ For the proofs, please Appendix A.3.8.1
} 
announcements denoted as $\sigma_{j}^{i}$ :

$$
\begin{aligned}
& S_{a}^{i}=\left\{\{\varnothing, \varnothing\},\left\{b^{i}, \varnothing\right\},\left\{\varnothing, c^{i}\right\},\left\{b^{i}, c^{i}\right\}\right\} \\
& S_{b}^{i}=\left\{\{\varnothing, \varnothing\},\left\{a^{i}, \varnothing\right\},\left\{\varnothing, c^{i}\right\},\left\{a^{i}, c^{i}\right\}\right\} \\
& S_{c}^{i}=\left\{\{\varnothing, \varnothing\},\left\{a^{i}, \varnothing\right\},\left\{\varnothing, b^{i}\right\},\left\{a^{i}, b^{i}\right\}\right\}
\end{aligned}
$$

where announcement $\sigma_{j}^{i}=\{\varnothing, \varnothing\}$ indicates player's desire to stay away from any deep trade agreement with either partner; if $\sigma_{j}^{i}$ includes only one of the two countries then it denotes the player's wish to form an integrated agreement with that country only and exclude the third player; if $\sigma_{j}^{i}$ has two other countries then it indicates player's desire to be a partner of both countries.

In the I game, the countries strategy sets map into the following deep trade agreements:

(i) If all three players announce in the favour of no agreement or the announcement profiles do not match, it results in the profile $\left\langle\Phi^{i}\right\rangle$. Under this profile each country applies individually optimal tariffs and environmental tax on its producers of the dirty $\operatorname{good} A$.

(ii) If country $a$ 's announcement is $\left\{b^{i}, \varnothing\right\}$ and country $b$ 's announcement is $\left\{a^{i}, \varnothing\right\}$, the profile $\langle a b i\rangle$ arises. The outsider's announcement would not alter this profile because neither member of this integrated agreement is calling $c$. This profile implies that members agree on the environmental tax they levy on their producers of the dirty good $A$, apply zero tariffs on imports from each other and individually optimal tariff on the import from the outsider, country $c$.

(iii) Similar to (ii), announcement profile $\langle b c i\rangle$ indicates two countries' desire to exclude a third member of the world. In this case, two clean countries exclude the dirty country $a$ and form a deep trade agreement which includes only clean members.

(iv) If both clean countries announce only in the favour of a deep trade agreement with the dirty country, and the dirty country announces in the favour of a fully integrated world, then these announcements result in a hub-and-spoke trade regime with a jointly optimal tax level. In this case, the dirty country $a$ is a hub, and two clean countries are the spokes, $\langle a h i\rangle$. Under this profile, country $a$ imposes zero tariffs on the imports from the clean part of the world as well as both clean 
countries impose zero tariffs on the imports of the dirty good $A$. However, two clean countries still impose positive tariffs on the imports from each other.

(v) Similar to (iv), if one clean and one dirty country announce in the favour of a third country, and that country announces in the favour of a fully integrated trade world, then that third country would turn into a hub and other two would be the spokes. The profile matching those announcements is $\langle b h i\rangle$, where $b$ is a hub, and countries $a$ and $c$ are the spokes.

(iv) As in the IU game, the announcement profile $\left\langle F^{i}\right\rangle$ signals all three countries' desire to live in an entirely integrated world. Under this profile countries apply jointly optimal environmental tax and zero tariffs on the imports from each other.

\subsubsection{Welfare Effects of Various Deep Trade Agreements in the I Game}

LEMMA 3.5: The welfare impact of various types of deep trade agreements in the I game on countries-members and non-members is as follows:

$\left(\mathrm{i}^{i}\right) W^{a}\left(a b_{\theta}^{i}\right)>W^{a}\left(N_{\theta}\right)$ holds for $\theta=g$ only if $\lambda \geq \lambda^{i} ; W^{a}\left(b c_{\theta}^{i}\right)<W^{a}\left(N_{\theta}\right)$;

$W^{a}\left(a b_{l}^{i}\right)>W^{a}\left(a_{l}^{h i}\right) \& W^{a}\left(a_{l}^{h i}\right)>W^{a}\left(a b c_{l}^{i}\right)>W^{a}\left(b c_{l}^{i}\right) ; W^{a}\left(b c_{g}^{i}\right)>W^{a}\left(a_{g}^{h i}\right)>W^{a}\left(a b c_{g}^{i}\right) ;$

(ii $i^{i} W^{b}\left(a b_{\theta}^{i}\right)>W^{b}\left(N_{\theta}\right) ; W^{j \neq a}\left(b c_{\theta}^{i}\right)>W^{j \neq a}\left(N_{\theta}\right) ; W^{b}\left(a b_{\theta}^{i}\right)>W^{b}\left(b c_{\theta}^{i}\right)$;

$W^{c}\left(N_{l}\right)>W^{c}\left(a b_{l}^{i}\right) \& W^{c}\left(a b_{g}^{i}\right)>W^{c}\left(b c_{g}^{i}\right)>W^{c}\left(N_{g}\right)$

$\left(\mathrm{iii}^{i}\right) W^{j}\left(j_{\theta}^{h i}\right)>W^{j}\left(a b c_{\theta}^{i}\right)>W^{j}\left(b c_{\theta}^{i}\right) ; W^{j}\left(a j_{l}^{i}\right)>W^{j}\left(a_{l}^{h i}\right) \& W^{j}\left(a j_{g}^{i}\right)<W^{j}\left(a_{g}^{h i}\right)$ where $j \neq a$ $W^{c}\left(a_{\theta}^{h i}\right)>W^{c}\left(b_{\theta}^{h i}\right) ; W^{a}\left(b c_{\theta}^{i}\right)>W^{a}\left(b_{\theta}^{h i}\right)$.

The results in Lemma 3.5 $\left(-i^{i}\right)$ indicate, first, that the dirty country prefers to be in a bilateral integrated agreement versus no agreement scenario only if pollution is local or if pollution is global and the productivity gap is relatively narrow; second, this lemma shows that the dirty country is better of in the no agreement scenario than as an outsider facing a bilateral integrated agreement between two clean countries, and third, it illustrates a self-exclusion incentive of country $a$ if pollution is global. Lemma3.5 $\left(-i i^{i}\right)$ states, first, that clean players are better off in a bilateral integrated 
agreement than in a fully disintegrated world; second, it shows that a clean country prefers to sign a bilateral integrated agreement with the dirty country versus acquiring a clean partner; and third, this lemma declares that if pollution is local then a clean country can gain a higher level of welfare in a world with no agreement versus facing a bilateral integrated agreement including two other players, however, if pollution exhibits global characteristics then a clean country is better off being an outsider of a bilateral integrated agreement than being a part of a world with no trade and environmental agreements in it. The results in Lemma3.5 $\left(-i i^{i}\right)$ say, first, that a clean country prefers to be a hub than to live in a fully integrated world; second, a clean country is better off in a bilateral integrated agreement with the dirty partner versus being a spoke with that dirty country acting as a hub if pollution is local, however, the results are reverse if the pollution exhibits global characteristics; third, a clean country would choose to be a spoke in a hub and spoke regime if a dirty country is a hub versus a clean country being a hub; and finally, this lemma states that being an outsider of a bilateral integrated agreement between two clean partners brings a higher welfare gains to the dirty player than being a spoke in a hub-and-spokes regime for both levels of pollution.

\subsubsection{Announcements Profiles, Associated Trade Agreements and Nash Equilibria in the} I Game

Proposition 3.24: In the I game, the Nash equilibria announcement profiles and the associated integrated agreements are shown in Table 3.5. 


\begin{tabular}{|l|c|c|c|}
\hline \multirow{2}{*}{ Announcement Profiles } & Deep & \multicolumn{2}{|c|}{ Nash Equilibria } \\
\cline { 3 - 4 } & Agreements & local & global \\
\hline \hline$\Omega^{\Phi^{i}} \equiv\left\{\sigma_{a}^{i}=\{\varnothing, \varnothing\}, \sigma_{b}^{i}=\{\varnothing, \varnothing\}, \sigma_{c}^{i}=\{\varnothing, \varnothing\}\right\}$ & $\left\langle\Phi^{i}\right\rangle$ & Yes & Yes \\
\hline$\Omega^{a b i} \equiv\left\{\sigma_{a}^{i}=\{b, \varnothing\}, \sigma_{b}^{i}=\{a, \varnothing\}, \sigma_{c}^{i}=\{\varnothing, \varnothing\}\right\}$ & $\langle a b i\rangle$ & Yes & Yes if $\lambda \geq \lambda^{i}$, \\
\hline$\Omega^{b c i} \equiv\left\{\sigma_{a}^{i}=\{\varnothing, \varnothing\}, \sigma_{b}^{i}=\{\varnothing, c\}, \sigma_{c}^{i}=\{\varnothing, b\}\right\}$ & $\langle b c i u\rangle$ & Yes if $\lambda<\lambda^{i}$ \\
\hline$\Omega^{a h i} \equiv\left\{\sigma_{a}^{i}=\{b, c\}, \sigma_{b}^{i}=\{a, \varnothing\}, \sigma_{c}^{i}=\{a, \varnothing\}\right\}$ & $\langle a h i\rangle$ & No & Yes \\
\hline$\Omega^{b h i} \equiv\left\{\sigma_{a}^{i}=\{b, \varnothing\}, \sigma_{b}^{i}=\{a, c\}, \sigma_{c}^{i}=\{\varnothing, b\}\right\}$ & $\langle b h i\rangle$ & No & No \\
\hline$\Omega^{F^{i}} \equiv\left\{\sigma_{a}^{i}=\{b, c\}, \sigma_{b}^{i}=\{a, c\}, \sigma_{c}^{i}=\{a, b\}\right\}$ & $\left\langle F^{i}\right\rangle$ & Yes & No \\
\hline
\end{tabular}

Table 3.5: The Nash equilibria announcement profiles and the associated trade agreements in the I game

For both local and global levels of pollution, the announcement profile $\Omega^{\Phi^{i}}$, which results in each country applying individually optimal tariffs and environmental taxes, is a Nash equilibria; unilateral change in any player's announcement would not affect their welfare levels. The announcement profile $\Omega^{a b i}$, which constitutes a bilateral integrated agreement between one clean and one dirty country, is a Nash equilibria for any value a productivity parameter can take if pollution is local, and it is a Nash equilibria if productivity gap is relatively narrow and pollution is global. To prove that, we use the results in Lemma3.5 $\left(-i^{i}\right)$ and Lemma3.5 $\left(-i i^{i}\right)$, which illustrate that neither members has an incentive to unilaterally change its announcement. Also, any changes in the announcement profile of the outsider of this bilateral integrated agreement (country $c$ ), have no effect on the resulting equilibrium announcement profile. The results illustrated in Lemma $3.5\left(-i^{i}\right)$ prove that the announcement profile $\Omega^{a b i}$ does not constitutes a Nash equilibria if productivity gap is relatively large and pollution is global; in this case, the dirty country $a$ can improve its welfare by unilaterally changing the announcement into $\{\varnothing, \varnothing\}$, which would lead to the world with no trade and environmental agreements in it. Based on the results in Lemma3.5 $\left(-i i^{i}\right)$, we conclude that 
the announcement profile $\Omega^{b c i}$, which leads to a bilateral integrated agreement between two clean countries constitutes a Nash equilibria for both local and global levels of pollution; neither of the members of this bilateral integrated agreement can gain a higher welfare by unilaterally changing the announcement. Now, we move to evaluating the announcement profiles of two hub-and-spokes regimes $\left(\Omega^{a h i}\right.$ and $\Omega^{b h i}$ ). Neither of these regimes constitutes a Nash equilibria, and we prove it in the following four steps. First, we consider the case of local pollution. The dirty country $a$ can unilaterally change its announcement by excluding one of the clean countries and improve its welfare: $W^{a}\left(a_{l}^{h i}\right)<W^{a}\left(a b_{l}^{i}\right)=W^{a}\left(a c_{l}^{i}\right)$. Next, we consider the case of global pollution and relatively small productivity gap. Similar to the previous step, we observe that the dirty country can improve its welfare by restricting its announcement to one clean country only: $W^{a}\left(a_{g}^{h i}\right)<W^{a}\left(a b_{g}^{i}\right)=W^{a}\left(a c_{g}^{i}\right)$ if productivity gap is relatively small. Third, we consider the case of global pollution and relatively large productivity gap. Country a can achieve the highest welfare in this game by announcing no agreement with both clean countries. Finally, we look into a hub-and-spokes regime with a clean country acting as a hub. The results in Lemma 3.5 $\left(-i i i^{i}\right)$ state, that country $a$ will deviate and gain a higher level of welfare by announcing no agreement with either clean country; the dirty country would prefer to be an outsider versus being a spoke. Based on the steps above, we can conclude that both hub-and-spoke regimes in this game, $\Omega^{a h i}$ and $\Omega^{b h i}$, do not constitute a Nash Equilibria for both local and global levels of pollution. The announcement profile $\Omega^{F^{i}}$, which leads to a fully integrated world, is a Nash equilibria if pollution is local. First, we analyze whether country $a$ has an incentive to change its announcement. If the dirty country alters its announcement from $\{b, c\}$ into $\{b, \varnothing\}$ or $\{\varnothing, c\}$, it would turn either of the clean players into a hub and lead to a lower welfare gains for the dirty player. If country $a$ decides to call no player, then this alteration in the announcement would lead to an announcement profile $\Omega^{b c i}$ and welfare loss for the dirty country $a$. We can conclude that country $a$ has no incentive to change its announcement. If either of the clean players attempts to alter its announcement, then it would either create a hub-and-spoke regime with the country that initiates that change acting as a spoke or create a bilateral integrated agreement between one clean and one dirty country with the country-initiator as an outsider. We 
can conclude that neither of the clean players has an incentive to alter its announcement due a lower welfare gains they would face. Based on the above, we conclude $\Omega^{\digamma^{i}}$ is a Nash Equilibria for the local level of pollution. Based on the results in Lemma3.5 $\left(-i^{i}\right)$, we can see that if pollution is global, then the dirty country $a$ acquires a higher welfare gains as an outsider of a bilateral integrated agreement between two clean countries than as a part of a fully integrated world. We can conclude that $\Omega \digamma^{i}$ is not a Nash Equilibria if pollution is global. ${ }^{22}$

\subsubsection{Coalition-Proof Nash Equilibria of the I Game}

In this game, the announcement profile $\Omega^{\Phi^{i}}$ is a Nash equilibria, but it does not survive the coalition-proof Nash equilibria refinement, and we prove it in the next three steps. First, we assume that pollution is local and consider the coalition of one clean and one dirty country. The results in Lemma3.5 $\left(-i^{i}\right)$ and Lemma3.5 $\left(-i i^{i}\right)$ show that deviating countries are better off in a coalition than in no agreement scenario, and we can conclude that $\Omega^{\Phi^{i}}$ is not a CPNE if pollution is local. Second, we consider the case of global pollution and relatively small productivity gap. We let countries $a$ and $b$ form an integrated agreement. We observe that country $a$ 's welfare is the highest in this game, and as a result, country $a$ would not include country $c$ in its announcement. No further deviation is sustainable. Now, we consider the case of global pollution, and we let two clean countries, $b$ and $c$, form an integrated agreement, then the announcement would be as follows: $\left\{\sigma_{a}^{i}=\{\varnothing, \varnothing\}, \sigma_{b}^{i}=\{\varnothing, c\}, \sigma_{c}^{i}=\{\varnothing, b\}\right\}$. In this case, $W^{b}\left(b c_{g}^{i}\right)>W^{b}\left(N_{g}\right)$ and $W^{c}\left(b c_{g}^{i}\right)>W^{c}\left(N_{g}\right)$. We can conclude, that clean countries can form a coalition. Based on the above, we can conclude that $\Omega^{\Phi^{i}}$ is not a CPNE if pollution is global as well. The announcement profile $\Omega^{a b i}$ does not survive the CPNE refinement for both local and global levels of pollution. To prove that we consider the coalition of two clean countries. This coalition would alter the announcement profile into $\Omega^{b h i}$, and the results illustrated in Lemma3.5(-iii $\left.{ }^{i}\right)$ show the welfare improvement for both clean players. We can conclude, that countries $b$ and $c$ can deviate, and con-

\footnotetext{
${ }^{22}$ For the proofs, please Appendix A.3.8.2
} 
sequently, that the announcement profile $\Omega^{a b i}$ is not a coalition-proof Nash equilibria. If pollution is purely local, then the announcement profile $\Omega^{b c i}$ is not a CPNE. We prove it by considering the grand coalition and analyzing all possible meaningful deviations from this announcement profile. First, we consider all possible deviations of the dirty country $a$. This country will not leave the integrated world because if it does so, then $W^{a}\left(b_{l}^{h i}\right)=W^{a}\left(c_{l}^{h i}\right)<W^{a}\left(b c_{l}^{i}\right)<W^{a}\left(a b c_{l}^{i}\right)$. Second, we analyze whether either of the clean countries would have an incentive to change the announcement, and we observe the following: $W^{b}\left(a b c_{l}^{i}\right)=W^{c}\left(a b c_{l}^{i}\right)>W^{b}\left(a b_{l}^{i}\right)=W^{c}\left(a c_{l}^{i}\right)>W^{b}\left(b c_{l}^{i}\right)=$ $W^{c}\left(b c_{l}^{i}\right)>W^{b}\left(a_{l}^{h i}\right)=W^{c}\left(a_{l}^{h i}\right)>W^{b}\left(c_{l}^{h i}\right)=W^{c}\left(b_{l}^{h i}\right)$. We can see that the grand coalition provides clean countries with the highest level of welfare relative to all possible deviations, and we can conclude that neither of the clean players would deviate from the grand coalition. Based on the above. we can conclude that $\Omega^{b c i}$ is not a CPNE for the local level of pollution.

Proposition 3.25: If pollution is local, then the only coalition-proof Nash equilibria of the I game is the announcement profile $\Omega^{F^{i}}$ which constitutes a fully integrated world; and if pollution is global, then the only coalition-proof Nash equilibria is the announcement profile $\Omega^{b c i}$ which constitutes an integrated agreement between two clean countries.

First, we assume that pollution is local, and in the next two steps, we prove the first part of the above proposition. In the first step, we analyze whether the coalition of one clean and one dirty country is possible and meaningful, and in the second step, we consider the coalition of two clean countries. If one clean and one dirty country form a coalition to exclude the second clean player, then the announcement profile would be altered into $\Omega^{a j i}$, where $j \neq a$. As a result of either of these bilateral integrated agreements, the following levels of welfares would arise: $W^{a}\left(a b_{l}^{i}\right)=W^{a}\left(a c_{l}^{i}\right)>W^{a}\left(a_{l}^{h i}\right)>W^{a}\left(a b c_{l}^{i}\right)$ and $W^{b}\left(a b_{l}^{i}\right)=W^{c}\left(a c_{l}^{i}\right)<W^{b}\left(a b c_{l}^{i}\right)=W^{c}\left(a b c_{l}^{i}\right)$. We can conclude, that though country $a$ would like to form the coalition, none of the clean payers is interested in the coalition with the dirty country. The results in Lemma3.5(-iii $\left.{ }^{i}\right)$ illustrate that the only incentive a clean player has to form an integrated agreement with the dirty player is to deviate further and become a hub. We can conclude that there would be no coalition between the dirty country $a$ and either of the clean payers. Now, we analyze the coalition of two clean coun- 
tries. This deviation would result in the announcement profile $\Omega^{b c i}$ and lower welfare gains for both parties of the coalition (Lemma 3.5 $\left(-i i i^{i}\right)$ ). Based on the above, we conclude that there is no coalition that can benefit by deviating in a self-enforcing manner if pollution exhibits pure local characteristics, and the announcement profile $\Omega^{F^{i}}$ is a coalition-proof Nash equilibria.

Now, we assume that pollution is global, and we prove the second part of the above proposition by considering whether the initial deviations are both possible and sustainable. First, we assume that countries $a$ and $b$ form a coalition, then the announcement would be changed to the following: $\left\{\sigma_{a}^{i}=\{b, \varnothing\}, \sigma_{b}^{i}=\{a, \varnothing\}, \sigma_{c}^{i}=\{\varnothing, b\}\right\}$. As a result, we observe $W^{a}\left(a b_{g}^{i}\right)>W^{a}\left(b c_{g}^{i}\right)$ and $W^{b}\left(a b_{g}^{i}\right)>W^{b}\left(b c_{g}^{i}\right)$. However, country $b$ has an incentive to alter this announcement by adding country $c$ and turning into a hub: $W^{b}\left(b_{g}^{h i}\right)>W^{b}\left(a b_{g}^{i}\right)$ and $W^{a}\left(b_{g}^{h i}\right)<W^{a}\left(b c_{g}^{i}\right)$. We can conclude, that initial deviation is not sustainable. Next, we assume that countries $a$ and $c$ form a coalition, then the announcement would be changed to the following: $\left\{\sigma_{a}^{i}=\{\varnothing, c\}, \sigma_{b}^{i}=\{\varnothing, c\}, \sigma_{c}^{i}=\{a, \varnothing\}\right\}$. As a result, we observe $W^{a}\left(a c_{g}^{i}\right)>W^{a}\left(b c_{g}^{i}\right)$ and $W^{c}\left(a c_{g}^{i}\right)>W^{c}\left(b c_{g}^{i}\right)$. However, country $c$, similar to country $b$ in the previous step, has an incentive to alter this announcement by adding a second clean country and enjoying the benefits of being a hub: $W^{c}\left(c_{g}^{h i}\right)>W^{c}\left(a c_{g}^{i}\right)$ and $W^{a}\left(c_{g}^{h i}\right)<$ $W^{a}\left(b c_{g}^{i}\right)$. We can conclude, this initial deviation is not sustainable. Finally, if all three countries form a grand coalition, we observe $W^{a}\left(a b c_{g}^{i}\right)<W^{a}\left(b c_{g}^{i}\right)$ and conclude that the grand coalition is not sustainable as well. Based on the above, we conclude that $\Omega^{b c i}$ is a CPNE for the global level of pollution. ${ }^{23}$

\subsection{Further Discussion on Shallow versus Deep Integration}

\subsubsection{Article XXIV Restriction on External Tariffs}

In this subsection, we analyze the consequences of restricting members of various deep and shallow trade agreements from raising their external tariff above the no agreement level. According to Article XXIV of GATT/WTO, members are not allowed to bring their joint tariff on non-members

\footnotetext{
${ }^{23}$ For the proofs, please Appendix A.3.8.2
} 
above the pre-existing level. In our model, the pre-existing level of the external tariff is the optimal Nash tariff under no trade and/or environmental agreement.

\subsubsection{Article XXIV Restriction on External Tariffs of Shallow Trade Agreements}

In our model, in the absence of Article XXIV restrictions, only members of customs unions raise their external tariffs above the no agreement level due to the pooling of their market power whereas FTA members do not. Precisely, $t_{C}\left(a b_{\theta}^{u}\right)>t_{C}^{a}\left(N_{\theta}\right)=t_{C}^{b}\left(N_{\theta}\right)$ and $t_{A}\left(b c_{\theta}^{u}\right)>t_{A}^{b}\left(N_{\theta}\right)=t_{A}^{c}\left(N_{\theta}\right)$. We apply the restrictions of Article XXIV by holding the external tariff of the $\left(a b^{u}\right)$ and $\left(b c^{u}\right)$ members constant at the pre-existing level; namely, $t_{C}\left(a b_{\theta}^{u r}\right)=t_{C}^{a}\left(N_{\theta}\right)=t_{C}^{b}\left(N_{\theta}\right)$ and $t_{A}\left(b c_{\theta}^{u r}\right)=$ $t_{A}^{b}\left(N_{\theta}\right)=t_{A}^{c}\left(N_{\theta}\right)$. It turns out, that even when members of customs unions are prohibited from raising their tariffs on the non-member, the coalition-proof Nash equilibrium outcome does not change. Similar to the results shown in Missios et al. (2016) paper, though the restrictions of Article XXIV prevent members of customs unions from raising their external tariffs on the non-member above the pre-existence level, it does not result in a free trade world. The announcement profile $\Omega^{b c u r}$, which results in a trade union including only clean members, is a coalition-proof Nash equilibria if pollution is global, and the announcement profile $\Omega^{a b u r}$, which results in a trade union including one clean and one dirty member, is a coalition-proof Nash equilibria if pollution is local.

\subsubsection{Article XXIV Restriction on External Tariffs of Deep Trade Agreements}

In shallow trade agreements games, only members of the union between one clean and one dirty country would otherwise raise their tariff above the no agreement level; however, in the integrated customs union game, both unions apply a jointly optimal tariff which exceeds the no agreement level. Furthermore, in deep trade agreements games, we observe an increase above the no agreement level in the tariffs applied by the members of an integrated bilateral trade agreement between two clean countries if pollution is global, as well as an increase in tariff applied by one spoke 
on the imports from another spoke in hub-and-spoke trade regime with a clean country as a hub. First, we apply the restrictions of Article XXIV in the integrated customs union game. We apply those restrictions by holding the external tariff of the $\left(a b^{i u}\right)$ and $\left(b c^{i u}\right)$ members constant at the pre-existing level; namely, $t_{C}\left(a b_{\theta}^{i u r}\right)=t_{C}^{a}\left(N_{\theta}\right)=t_{C}^{b}\left(N_{\theta}\right)$ and $t_{A}\left(b c_{\theta}^{i u r}\right)=t_{A}^{b}\left(N_{\theta}\right)=t_{A}^{c}\left(N_{\theta}\right)$.

If pollution is local, then the only announcement profile, which survives all possible meaningful deviations, is $\Omega^{\text {abiur }}$. This profile results in the integrated union between one clean and one dirty country. We can conclude that even after applying the restrictions of Article XXIV, we do not observe any change relative to the coalition-proof Nash equilibrium outcome of the IU game in case of local pollution. However, if pollution exhibits global characteristics, then the coalitionproof Nash equilibrium outcome changes for the certain levels of productivity parameter.

Proposition 3.26: In the integrated customs union game, if we apply the restrictions on external tariffs of Article XXIV, then the announcement profile $\Omega^{\text {abiur }}$, which constitutes an integrated union between one clean and one dirty country, is the only CPNE for the global level of pollution if the productivity gap is relatively narrow, and the announcement profile $\Omega^{\text {bciur }}$, which constitutes an integrated union between one clean and one dirty country, is the only CPNE for the global level of pollution if productivity gap is relatively large.

We prove the first part of the above proposition in two steps. First, we acknowledge that the dirty country achieves the highest welfare level in this game by announcing one of the clean countries and excluding the other. We can conclude, that country $a$ would not participate in any coalitional deviations. Second, we suppose countries $b$ and $c$ form a coalition and exclude the dirty players, then $W^{b}\left(b c_{g}^{i u r}\right)<W\left(a b_{g}^{i u r}\right)$ and $W^{c}\left(b c_{g}^{i u r}\right)<W^{c}\left(a b_{g}^{i u r}\right)$. We can conclude that clean countries would not form a coalition and exclude the dirty country $a$. Based on the above, we conclude that $\Omega^{\text {abiur }}$ is a CPNE for the global level of pollution and $\lambda \geq \lambda^{i}$.

To prove the second part of the above proposition, we consider the only possible deviation, the coalition between one clean and one dirty country. The result of this deviation would be the increase in both countries welfares: $W^{a}\left(a b_{g}^{i u r}\right)>W^{a}\left(b c_{g}^{i u r}\right)$ and $W^{b}\left(a b_{g}^{i u r}\right)>W^{b}\left(b c_{g}^{i u r}\right)$. However, the dirty payer has a strong incentive to deviate further: $W^{a}\left(N_{g}\right)>W^{a}\left(a b_{g}^{i u r}\right)$. Based on the above, 
we conclude that the initial deviation is not sustainable and the announcement profile $\Omega^{\text {bciur }}$ survives all possible deviations and constitutes a coalition-proof Nash equilibria if pollution is global and $\lambda<\lambda^{i}$.

As before, we have to acknowledge, that though the restrictions of Article XXIV prevent members of integrated customs unions from raising their external tariffs on the non-member above the pre-existence level, it still does not lead to a fully integrated world. If pollution is local, then as in the integrated union game without any restrictions on the external tariff, the only CPNE is the announcement profile that results in a integrated union between one clean and one dirty country. If pollution is global and productivity gap is relatively narrow, then the only CPNE is the announcement profile $\Omega^{\text {abiur }}$. The announcement profile $\Omega^{\text {bciur }}$, which results in an integrated union including only clean members, is the only coalition-proof Nash equilibria if pollution is global and productivity productivity gap is relatively large.

We now apply the restrictions of Article XXIV to the integrated FTA game. We hold the external tariffs of the $\left(b c_{g}^{i}\right)$ members constant at the pre-existing level if pollution is global, and if pollution is local, then we restrict the tariff applied by one of the spokes (country $c$ ) in the hub-and-spoke regime with a clean country $b$ as a hub. Based on these results, we can conclude that even when the members of preferential integrated trade agreements are prevented from bringing their individual tariffs above the pre-existing no agreement level, a fully integrated world still fails to survive a coalition-proof Nash equilibria refinement if pollution exhibits global characteristics. We still observe an integrated customs union of two clean countries as a coalition-proof Nash equilibria if pollution is global. If pollution is local, then a coalition-proof Nash equilibria is a fully integrated world.

\subsubsection{Choice of Deep and Shallow Agreements}

In the previous sections of this paper, we restricted countries' sets of announcements to a particular game. So far, we have described five games: the environmental agreements game, two shallow 
trade agreements games, the CU game and the FTA game; and two deep trade agreements games, the integrated customs union game and the integrated FTA game. In this section, we consider four extended games: the shallow trade agreements game, where countries can choose between shallow CU and FTA agreements; the deep trade agreements game, where players can choose between integrated customs unions and integrated FTAs; and the extended game with the choice between pure trade customs unions and integrated customs unions; and the extended game with the choice between deep and shallow FTA.

\subsubsection{Shallow Trade Agreements Game}

In this extended game, both types of shallow preferential trade agreements are permitted. Each player simultaneously announces the name(s) of the country(ies) and identifies whether they are willing to form a customs union or a free trade agreement. Both signals should match in order to form a PTA. Each player's strategy set $\left(S_{j}^{C U / F T A}\right)$ consists of seven possible announcements denoted as $\sigma_{j}^{C U / F T A}$ :

$$
\begin{aligned}
S_{a}^{C U / F T A} & =\left\{\{\varnothing, \varnothing\},\{b, \varnothing\},\{\varnothing, c\},\{b, c\}\left\{b^{u}, \varnothing\right\},\left\{\varnothing, c^{u}\right\},\left\{b^{u}, c^{u}\right\}\right\} \\
S_{b}^{C U / F T A} & =\left\{\{\varnothing, \varnothing\},\{a, \varnothing\},\{\varnothing, c\},\{a, c\},\left\{a^{u}, \varnothing\right\},\left\{\varnothing, c^{u}\right\},\left\{a^{u}, c^{u}\right\}\right\} \\
S_{c}^{C U / F T A} & =\left\{\{\varnothing, \varnothing\},\{a, \varnothing\},\{\varnothing, b\},\{a, b\},\left\{a^{u}, \varnothing\right\},\left\{\varnothing, b^{u}\right\},\left\{a^{u}, b^{u}\right\}\right\}
\end{aligned}
$$

where announcement $\sigma_{j}^{C U / F T A}=\{\varnothing, \varnothing\}$ indicates player's desire to stay away from any shallow trade agreement; if $\sigma_{j}^{C U / F T A}$ includes only one of the two countries with no superscript then it denotes the player's wish to form an FTA with that country only, and if $\sigma_{j}^{C U / F T A}$ includes only one of the two countries with the superscript " $U$ " then it denotes this player's wish to form a bilateral preferential trade agreement in the form of a customs union with that country only and exclude the third player; if $\sigma_{j}^{C U / F T A}$ has two other countries either with or without a superscript "u" then it indicates player's desire to be a trade partner of both countries. Though both announcement 
profiles, $\{b, c\}$ and $\left\{b^{u}, c^{u}\right\}$ indicate country $a$ 's desire to live in a free trade world, only the first one would allow a possibility of hub-and-spoke regimes to arise, and due to that those announcement profiles are different.

For trade agreements to arise in this shallow trade agreements game, countries profiles should match at two levels, the partner's name and the type of a shallow preferential trade agreement. As a result, the following trade agreements can emerge: (i) $\langle\Phi\rangle$ - no agreement announcement profile implies that either all three countries announce in the favour of no shallow trade agreement, or countries' announcements do not match on both or either levels; (ii) announcement profiles $\langle a b u\rangle$ and $\langle a b\rangle$ arise when one clean and one dirty country announce each other, the former one, trade union, implies that countries $a$ and $b$ call in favour of customs union, and the latter one, when these countries declare their desire to form an FTA; (iii) similar to (ii), announcement profiles $\langle b c u\rangle$ and $\langle b c\rangle$ indicate two countries' desire to exclude the third member of the world in the form of either CU or FTA; (iv) hub-and-spoke trade regimes, $\langle a h\rangle$ and $\langle b h\rangle$, can arise only if countries declare in favour of FTA, the nature of customs unions prevents these announcement profiles; (v) both announcement profiles, $\left\langle F^{u}\right\rangle$ and $\langle F\rangle$, signal all three countries' desire to live in a free trade world. The results in Lemma3.2 $\left(-i^{u}\right)$ and Lemma3.3 $(-i)$ show that though the announcement profile $\langle\Phi\rangle$ is a Nash equilibrium, it does not survive the coalition-proof Nash equilibrium refinement; players have an incentive to form a coalition and deviate to either a CU or an FTA, and these coalitional deviations are self-enforcing. To prove that announcement profiles resulting in either $\langle a b\rangle$ or $\langle b c\rangle$ do not survive the CPNE refinement, we use the results in Lemma3.3(-iv). These results show that outsiders of those agreements would prefer to be spokes, and as a desirable consequence, enjoy the increased size of the market, than face a bilateral trade agreement between two other countries. We use the results in Lemma3.3(-v) to prove that both hub-and-spoke trade regimes are not CPNEs in this extended game. By holding the hub's announcement constant, we can see that any two spokes can form a self-enforcing trade agreement and turn hub-and-spoke regime into a free trade world. However, neither $\left\langle F^{u}\right\rangle$ not $\langle F\rangle$ survive the coalition-proof Nash equilibria refinement in this shallow trade agreements game following the results in Lemma3.2( $\left.-i i^{u}\right)$. If 
pollution is local, then the only coalition-proof Nash equilibria profile is $\langle a b u\rangle$, and if pollution is global then the only profile which survives this refinement is $\langle b c u\rangle$. In this case, the finding result is very similar to Missios etal.(2016): when players are given a freedom to choose between two types of PTAs, the CPNE yields a customs union. We also conclude that in general customs unions are more coalitionally stable agreements, and long as the option of CU is on the table, countries do not end up in a free trade world.

\subsubsection{Deep Trade Agreements Game}

In this extended game, both types of deep preferential trade agreements are permitted. Each player simultaneously announces the name(s) of the country(ies) and identifies whether they are willing to form an integrated customs union or an integrated free trade agreement. Both signals should match in order to form a deep trade agreement. Each player's strategy set $\left(S_{j}^{I / I U}\right)$ consists of seven possible announcements denoted as $\sigma_{j}^{I / I U}$ :

$$
\begin{aligned}
& S_{a}^{I / I U}=\left\{\{\varnothing, \varnothing\},\left\{b^{i}, \varnothing\right\},\left\{\varnothing, c^{i}\right\},\left\{b^{i}, c^{i}\right\}\left\{b^{i u}, \varnothing\right\},\left\{\varnothing, c^{i u}\right\},\left\{b^{i u}, c^{i u}\right\}\right\} \\
& S_{b}^{I / I U}=\left\{\{\varnothing, \varnothing\},\left\{a^{i}, \varnothing\right\},\left\{\varnothing, c^{i}\right\},\left\{a^{i}, c^{i}\right\},\left\{a^{i u}, \varnothing\right\},\left\{\varnothing, c^{i u}\right\},\left\{a^{i u}, c^{i u}\right\}\right\} \\
& S_{c}^{I / I U}=\left\{\{\varnothing, \varnothing\},\left\{a^{i}, \varnothing\right\},\left\{\varnothing, b^{i}\right\},\left\{a^{i}, b^{i}\right\},\left\{a^{i u}, \varnothing\right\},\left\{\varnothing, b^{i u}\right\},\left\{a^{i u}, b^{i u}\right\}\right\}
\end{aligned}
$$

where announcement $\sigma_{j}^{I / I U}=\{\varnothing, \varnothing\}$ indicates player's desire to stay away from any deep trade agreement; if $\sigma_{j}^{I / I U}$ includes only one of the two countries with the superscript "I" then it denotes the player's wish to form a deep bilateral trade agreement with that country only, and if $\sigma_{j}^{I / I U}$ includes only one of the two countries with the superscript "IU" then it denotes this player's wish to form an integrated customs union with that country only and exclude the third player from both trade and environmental agreements; if $\sigma_{j}^{I / I U}$ has two other countries with either superscript, it indicates player's desire to be a partner of both countries. Though both announcement profiles, $\left\{b^{i}, c^{i}\right\}$ and $\left\{b^{i u}, c^{i u}\right\}$ indicate country $a$ 's desire to be a part of a world trade and environmental 
agreement, only the first one would allow a possibility of a hub-and-spoke regime to arise, and due to that, those announcement profiles are different.

In this deep trade agreements game, countries profiles should match at two levels, the partner's name and the type of deep preferential trade agreement. As a result the following deep trade agreements can arise: (i) $\left\langle\Phi^{i}\right\rangle$ - no agreement announcement profile implies that either all three countries announce in the favour of no deep trade agreement, or countries' announcements do not match on both or either levels; (ii) announcement profiles $\langle a b i u\rangle$ and $\langle a b i\rangle$ emerge when one clean and one dirty country announce each other; the former one, integrated union, implies that countries $a$ and $b$ call in favour of customs union with an environmental clause, and the latter one, when these countries declare their desire to form a deep FTA; (iii) similar to (ii), announcement profiles $\langle b c i u\rangle$ and $\langle b c i\rangle$ indicate two countries' desire to exclude the third member of the world in the form of either IU or integrated FTA; (iv) hub-and-spoke trade regimes, $\langle a h i\rangle$ and $\langle b h i\rangle$, can arise only if countries declare in favour of an integrated FTA, the nature of customs unions prevents these announcement profiles; (v) both announcement profiles, $\left\langle F^{i u}\right\rangle$ and $\left\langle F^{i}\right\rangle$, signal all three countries' desire to live in a fully integrated world.

Similar to our findings in the shallow trade agreements game, both announcement profiles, $\left\langle F^{i u}\right\rangle$ and $\left\langle F^{i}\right\rangle$, resulting in a fully integrated world, do not survive a coalition-proof Nash equilibria refinement. The presence of an environmental clause does not lead to a world united under the same trade and environmental agreement. If pollution is global, then the only dirty player prefers to face either integrated PTA between two clean countries than to be a part of a fully integrated world. Furthermore, even when pollution is local, the announcement profile $\left\langle F^{i u}\right\rangle$ does not survive the Nash equilibria refinement. The dirty country $a$ can unilaterally change its announcement and improve its welfare by calling only one of two clean countries. In this case, either clean country would gladly accept the offer and exclude the second clean country. Though the announcement profile $\left\langle F^{i}\right\rangle$ is a Nash equilibria if pollution is local, it is not a coalition-proof Nash equilibria. When a choice of integrated customs union is an option, the dirty player can form a coalition with either clean country, and this deviation is self-enforcing. 
The results presented in Lemma3.4 $\left(-i^{i u}\right)$ and Lemma3.5 $\left(-i i^{i}\right)$ state that $\left\langle\Phi^{i}\right\rangle$ does not survive the coalition-proof Nash equilibria refinement. If pollution is global, the announcement profile $\langle a b i\rangle$ is not a Nash equilibria if productivity gap is relatively narrow, and though $\langle b c i\rangle$ does meet Nash equilibria requirements for all levels of lambda and pollution, both profiles do not survive the coalition-proof Nash equilibria refinement, and the results in Lemma 3.5 $\left(-i^{i}\right)$ and Lemma 3.5 $\left(-i i^{i}\right)$ show that. The announcement profiles resulting in two different hub-and-spokes regimes, $\langle a h i\rangle$ and $\langle b h i\rangle$, do not not satisfy the Nash equilibria refinements. The dirty player is better off in the world with no trade and environmental agreement than it is in the role of a hub; and as a hub, country $a$ can bring our small world into the no agreement scenario by unilaterally changing its announcement. The results in Lemma3.5 $\left(-i i i^{i}\right)$ state that for any level of pollution the dirty country $a$ would prefer to face an integrated FTA of two clean players versus assuming the role of a spoke, and consequently, country $a$ would exclude itself from this integrated agreement as well. In this extended game, the only announcement profile that survives the coalition-proof Nash equilibria refinement in the case of local pollution is $\langle a b i u\rangle$. The dirty player acquires the highest level of welfare in this game, and though a clean country would prefer to become a hub, this deviation is not possible due to the nature of customs unions. If pollution is global and productivity gap is relatively narrow, then the announcement profile $\langle a b i u\rangle$ survives the coalition-proof Nash equilibria refinement as well. In this case, a dirty player has no incentive to become a part of any other coalition including a grand one, and though a clean partner of this agreement would prefer to live in a fully integrated world, the dirty player would not sign that agreement. However, if pollution is global and productivity gap is relatively large, then the integrated union between two clean players survives the coalition-proof Nash equilibria refinement. The results in Lemma 3.4(-iii $\left.{ }^{i u}\right)$ show that though either member of this integrated customs union is tempted to deviate into an agreement with country $a$, this deviation is not self-enforcing, and the dirty player would deviate further and bring our small world into the no agreement scenario. 


\subsubsection{The Choice between Deep and Shallow Customs Unions}

In the previous parts of this paper, we have always restricted our players to either choose between different types of shallow FTAs and/or shallow customs unions or deep FTAs and/or integrated customs unions. However, in this extended game, we permit both types of customs unions; our players can either decide to form a shallow $\mathrm{CU}$ or add an environmental clause to it and sign an integrated customs union. Each player simultaneously announces the name(s) of the country(ies) and identifies whether they are willing to form a shallow or an integrated customs union. Both signals should match in order to form an agreement. Each player's strategy set $\left(S_{j}^{C U / I U}\right)$ consists of seven possible announcements denoted as $\sigma_{j}^{C U / I U}$ :

$$
\begin{aligned}
& S_{a}^{C U / I U}=\left\{\{\varnothing, \varnothing\},\left\{b^{u}, \varnothing\right\},\left\{\varnothing, c^{u}\right\},\left\{b^{u}, c^{u}\right\}\left\{b^{i u}, \varnothing\right\},\left\{\varnothing, c^{i u}\right\},\left\{b^{i u}, c^{i u}\right\}\right\} \\
& S_{b}^{C U / I U}=\left\{\{\varnothing, \varnothing\},\left\{a^{u}, \varnothing\right\},\left\{\varnothing, c^{u}\right\},\left\{a^{u}, c^{u}\right\},\left\{a^{i u}, \varnothing\right\},\left\{\varnothing, c^{i u}\right\},\left\{a^{i u}, c^{i u}\right\}\right\} \\
& S_{c}^{C U / I U}=\left\{\{\varnothing, \varnothing\},\left\{a^{u}, \varnothing\right\},\left\{\varnothing, b^{u}\right\},\left\{a^{u}, b^{u}\right\},\left\{a^{i u}, \varnothing\right\},\left\{\varnothing, b^{i u}\right\},\left\{a^{i u}, b^{i u}\right\}\right\}
\end{aligned}
$$

where announcement $\sigma_{j}^{C U / I U}=\{\varnothing, \varnothing\}$ indicates player's desire to stay away from any agreement; if $\sigma_{j}^{C U / I U}$ includes only one of the two countries then it denotes that payers' desire to form a customs union with that country only, where superscript " $U$ " indicates player's wish to form a shallow CU, and the superscript "IU" denotes this player's wish to form an integrated customs union with that country only and exclude the third player from this trade and environmental agreement; if $\sigma_{j}^{C U / I U}$ has two other countries, it could either indicate the player's desire to be a part of a free trade world with no environmental agreement in it or to live in a fully integrated world. For an agreement to arise, countries announcements should match at two levels, the partner's name and the type of customs union. As a result, the following trade or integrated agreements can emerge: (i) $\left\langle\Phi^{u}\right\rangle$ - no agreement announcement profile implies that either all three countries announce in the favour of no customs union, or countries' announcements do not match on both or either levels; (ii) announcement profiles $\langle a b i u\rangle$ and $\langle a b u\rangle$ emerge when one clean and one dirty country announce 
each other; the former one, integrated union, implies that countries $a$ and $b$ call in favour of customs union with an environmental clause, and the latter one, when these countries declare their desire to form a shallow CU; (iii) similar to (ii), announcement profiles $\langle b c i u\rangle$ and $\langle b c u\rangle$ indicate two countries' enthusiasm to exclude the third member of the world in the form of either IU or CU; (iv) announcement profile $\left\langle F^{u}\right\rangle$ signals all three countries' will to live in a free trade; and (v) $\left\langle F^{i u}\right\rangle$ arises when all three players declare their desire to form a fully integrated world.

In this extended game, both announcement profiles, $\left\langle F^{u}\right\rangle$ and $\left\langle F^{i u}\right\rangle$, do not constitute Nash equilibria. If pollution is local, then the dirty country can simply improve its welfare by limiting the announcement to one of the clean countries. Either clean player would be happy to trade a free trade or a fully integrated world to a shallow or deep customs union with the dirty partner. If pollution is global, then in the case of shallow free trade, clean countries can improve their welfare gains by eliminating the dirty player and announcing in favour of the shallow CU between clean countries only; and in the case of a fully integrated world, country $a$ can increase its welfare by simply self-excluding from the world agreement. Though the announcement profile $\left\langle\Phi^{u}\right\rangle$ is a Nash equilibria, it does not constitute a CPNE, following the results presented in Lemma 3.2 $\left(-i^{u}\right)$ and Lemma 3.4 $\left(-i^{i u}\right)$. If pollution is local, then two announcement profiles survive the coalition-proof Nash equilibria refinement, $\langle a b i u\rangle$ and $\langle a b u\rangle$. The dirty player $a$ gains the highest welfare in the shallow trade union with one of the clean countries, and a clean partner of this agreement would rather add an environmental clause to it and sign an integrated customs union agreement with the dirty country. Welfare of the members is higher under the integrated customs union agreement, and based on that we can conclude that a clean country can convince a dirty partner to add an environmental clause to their agreement but only with some transfer. If productivity gap is relatively narrow and pollution exhibits global characteristics, then the only announcement profile which survives the CPNE refinement is $\langle a b i u\rangle$. In this case, though the dirty player can benefit from removing an environmental clause from the agreement, a clean player would not go for it, and though a clean player would rather be a part of a fully integrated world, the dirty player is not interested in an environmental agreement. However, if pollution is global and productivity gap 
is relatively large, the announcement profile $\langle b c i u\rangle$ survives the CPNE refinement. Though either member of this integrated customs union would be better off in an integrated union with the only dirty player, this deviation is not self-enforcing, because the dirty player can improve its welfare by deviating further and building a world with no trade and environmental agreements in it.

\subsubsection{The Choice between Deep and Shallow FTAs}

In this extended game, our players can choose between various deep and shallow trade agreements. Players simultaneously announce the name(s) of the country(ies) and identifies what agreement they are willing to commit to. Both signals should match in order for the agreement to arise. Each player's strategy set $\left(S_{j}^{F T A / I}\right)$ consists of seven possible announcements denoted as $\sigma_{j}^{F T A / I}$ :

$$
\begin{gathered}
S_{a}^{F T A / I}=\left\{\{\varnothing, \varnothing\},\{b, \varnothing\},\{\varnothing, c\},\{b, c\}\left\{b^{i}, \varnothing\right\},\left\{\varnothing, c^{i}\right\},\left\{b^{i}, c^{i}\right\}\right\} \\
S_{b}^{F T A / I}=\left\{\{\varnothing, \varnothing\},\{a, \varnothing\},\{\varnothing, c\},\{a, c\},\left\{a^{i}, \varnothing\right\},\left\{\varnothing, c^{i}\right\},\left\{a^{i}, c^{i}\right\}\right\} \\
S_{c}^{F T A / I}=\left\{\{\varnothing, \varnothing\},\{a, \varnothing\},\{\varnothing, b\},\{a, b\},\left\{a^{i}, \varnothing\right\},\left\{\varnothing, b^{i}\right\},\left\{a^{i}, b^{i}\right\}\right\}
\end{gathered}
$$

where announcement $\sigma_{j}^{F T A / I}=\{\varnothing, \varnothing\}$ indicates player's desire to stay away from any agreement; if $\sigma_{j}^{F T A / I}$ includes only one of the two countries with no superscript then it denotes the player's wish to form a shallow FTA with that country only, and the subscript "i”" denotes this player's wish to form a deep FTA; if $\sigma_{j}^{F T A / I}$ contains the names of two other countries, it could either indicate the player's desire to be a part of a free trade world with no environmental agreement in it, and in this case countries would have no superscripts, or to live in a fully integrated world, and in this case countries' names would have a superscript "I". Only if countries announcements match at both levels, the partner's name and the type of FTA, either deep or shallow free trade agreement can arise. As a result, the following trade or integrated agreements can emerge: (i) $\langle\Phi\rangle$ - no agreement announcement profile implies that either all three countries announce in the favour of no FTA, or countries' announcements do not match on both or either levels; (ii) announcement 
profiles $\langle a b\rangle$ and $\langle a b i\rangle$ emerge when one clean and one dirty country announce each other; the former one, shallow FTA, implies that countries $a$ and $b$ call in favour of a pure trade agreement with no environmental clause attached to it, and the latter one, when these countries declare their desire to form a deep FTA; (iii) similar to (ii), announcement profiles $\langle b c\rangle$ and $\langle b c i\rangle$ indicate two countries' desire to exclude the third member of the world in the form of either shallow or deep FTA; (iv) hub-and-spoke trade regimes, $\langle a h\rangle /\langle b h\rangle$ or $\langle a h i\rangle /\langle b h i\rangle$, can arise if the hub declares in the favour of either shallow or deep world agreement, and the spokes declare their desire to exclude each other; (v) the announcement profile $\langle F\rangle$ signal all payers wish to form a shallow free trade, and $\left\langle F^{i}\right\rangle$ indicates all three countries' will to live in a fully integrated world.

Given the choice between shallow and deep FTAs, the only announcement profile that survives the coalition-proof Nash equilibria refinements, if pollution is local, is $\left\langle F^{i}\right\rangle$ which constitutes a fully integrated world. Though the dirty country $a$ would prefer to deviate with one of the clean countries in the form of either deep or shallow bilateral trade agreement, clean countries would rather live in the world united under the same trade and environmental agreement. The clean part of the world is not interested in removing an environmental clause or in excluding the only dirty player in either form of bilateral free trade agreement between clean countries exclusively. In the case of local pollution, the dirty player has no incentive to exclude itself from the world agreement; country $a$ would rather be a part of a fully integrated world than face either shallow or deep bilateral trade agreement of clean countries. On the other hand, if pollution is global, than the only dirty player is better off as an outsider. The only announcement profile which survives the coalitionproof Nash equilibria refinement, if pollution exhibits global characteristics, is a deep bilateral trade agreement between two clean countries, $\langle b c i\rangle$. Though the dirty country would like to offer a deviation to either of the members in the form of deep bilateral trade agreement, this deviation is not self-enforcing, because a clean member has an intensive to deviate further and become a hub. Also, clean members are not interested in eliminating an environmental clause in the form of both grand coalition and shallow FTA.

No agreement announcement profile does not survive the coalition-proof Nash equilibria refine- 
ment simply because any two countries can improve their welfares by announcing each other in this extended game. Both announcement profiles which constitute shallow bilateral trade agreements, $\langle a b\rangle$ and $\langle b c\rangle$, satisfy the Nash equilibria requirement for any level of productivity parameter and pollution, but neither of them constitutes a CPNE. In both cases, clean countries have an incentive to become a hub. A deep bilateral trade agreement between one clean and one dirty country does not survive the Nash equilibria refinement if productivity gap is relatively large and pollution is global; in this case, country $a$ has an incentive to deviate into the no agreement profile by unilaterally altering its announcement. Though a deep bilateral trade agreement between two clean countries is a Nash equilibria for all levels of productivity gap and pollution, neither deep FTA survives the coalition-proof Nash equilibria refinement if pollution is local; one of the clean countries can get into a coalition and become a hub. Both shallow hub-and-spoke trade regimes are Nash equilibria, but neither of them survives the coalition-proof Nash equilibria refinement. All three countries would rather live in a free trade world than being spokes. Neither deep huband-spoke trade regime survives the Nash equilibria refinement. The dirty country $a$ prefers no agreement world to a role of a hub as long as environmental agreement is a part of a deal, and the dirty player would rather be an outsider of a deep bilateral trade agreement between two clean countries than a spoke. Announcement profile $\left\langle F^{i}\right\rangle$, which constitutes a free trade world, is a Nash equilibria for all levels of productivity gap and pollution, but it does not survive the coalition-proof

Nash equilibria refinement. Any of the clean players would prefer to make a deal with the dirty country and deviate into a deep bilateral trade agreement. This deviation is self-enforcing, since we hold the second clean player's announcement constant.

\subsection{Conclusion}

Trade agreements have been increasingly included non-trade elements. As the effects of this trend on the stability of trade regimes and counties' welfare gains are unknown, our objective in this paper has been to investigate how equilibrium agreements differ based on being deep or shallow. 
To our knowledge, there is no equilibrium theory on what agreement we should see and how these agreements impact welfares and environments. In this paper, we attempt to narrow this gap by answering three different and equally important questions: (i) how do equilibrium agreements differ when countries choose deep rather than shallow agreements?; (ii) given the choice between deep and shallow trade agreements, would countries prefer to incorporate an environmental clause into their equilibrium trade deal?; and (iii) what are the implications of including non-trade elements in PTAs for the pursuit of global free trade?

It is well-known in the literature, that pure environmental agreements tend to be small and primarily include countries which are very similar. In our model with both trade and externality concerns, we show similar results, with no agreement prevailing in equilibrium if pollution is local, and a bilateral environmental agreement arising between clean countries if pollution is global.

Our results confirm, that in general, customs unions are more coalitionally stable than free trade agreements, and countries are not willing to form either deep or shallow free trade agreements as long as they have the option of excluding the third member in the form of a deep or shallow CU. In our model, we have asymmetric countries, and as a result, the self-exclusion incentive arises as well. For example, though the global pollution surfaces clean countries desire to form either shallow or deep free trade agreement, the dirty player would never agree to that. The dirty country would rather face a deep or shallow customs union of two symmetric clean countries than be a part of world agreement. Furthermore, even when we comply with the Article XXIV restriction and prevent customs unions from increasing their jointly optimal tariffs on the imports from the outsider, we still do not observe either deep or shallow global free trade. However, shallow global free trade survives all coalitional deviations when countries consider FTAs. In this case, though any two countries can benefit from excluding the third one from the agreement, none of them would excise it in equilibrium; the exclusion incentive is still high but the incentive to become a hub is stronger.

Our analysis of the environmental damages caused by different endogenously formed shallow and deep trade agreements shows that equilibrium shallow free trade induces the highest level of pollu- 
tion. Free trade naturally leads to a deeper specialization, and consequently, higher levels of world production, trade and consumption of all goods. In turn, the increased production of the dirty good creates an increased level of negative externality associated with this production process, the level of pollution. We observe that a free trade world agreement with no environmental clause attached to it would cause an increase in the environmental damages for both local and global levels of pollution. However, if pollution is global, then a fully integrated world is the least polluted. If countries have to agree not only on the removal of the tariffs but also on the environmental tax they levy on their producers of the dirty good, then the environmental tax shows no distortion from its socially optimal no agreement level, if pollution is local. In this case, countries enjoy deep specialization on goods they have comparative advantage in, and bear no cost of spillovers. If pollution is global, then all three countries are equally effected by an increased production of the dirty good, and as a result their environmental agreement includes a proportionally higher tax. Not surprisingly, clean part of the world would love to live in a fully integrated world, and the only dirty player would prefer any other agreement to this one.

The results we acquire in our extended games confirm that customs unions are more coalitionally stable agreements even given the asymmetry of the players. Given the choice between deep and shallow customs unions, both deep and free trade agreements do not constitute Nash equilibria. However, the choice between deep and shallow free trade agreements leads to a deep free trade if pollution is local, and to a deep bilateral trade agreement between to symmetric clean countries, if pollution is global. Though, if pollution is local, the dirty country exhibits the exclusion incentive and would prefer to deviate with one of the clean countries in the form of either deep or shallow bilateral FTA, clean countries would rather be a part of a deep free trade agreement. In the case of local pollution, the dirty player has no incentive to exclude itself from the world agreement; the dirty country would rather be a part of a fully integrated world than face either shallow or deep bilateral trade agreement of two clean countries. However, if pollution is global, then the only dirty player is better off as an outsider. The dirty country would like to offer a deviation to either of the two other members in the form of a deep bilateral trade agreement, but this deviation is not 
self-enforcing, because a clean member has an intensive to deviate further and become a hub. Also, clean members are not interested in eliminating an environmental clause in the form of both grand coalition and shallow FTA. Given the choice between deep and shallow endogenously formed trade agreements, only deep ones survive coalition-proof Nash equilibria refinement; countries actually prefer to add an environmental clause versus signing a pure trade deal. 


\section{Chapter 4}

\subsection{Introduction}

Over the past few decades, the growing number of preferential trade agreements has been accompanied by a widespread inclusion of non-trade elements, such as domestic policy over the environment, labour, intellectual property, health and investment. One area that has received a great deal of attention is the environment. As of June 11, 2019, the number of cumulative notifications of PTAs both in force and inactive has reached 681 ; the cumulative number of notifications in force has increased to 467 (goods, services and accessions are counted separately); and cumulative number of physical regional trade agreements is 291 (goods, services and accessions are counted together). ${ }^{24}$ According to Limão 2016, 46\% of all current preferential trade agreements contain some environmental laws, and provisions on environmental laws are enforceable in 35\%. Another data set on the Trade \& Environment/TREND (Morin etal.2018), also shows the increasing number of trade agreements as well as the increasing share of trade agreements that included environmental provisions over the past few decades, precisely, between 1947 and 2016. In this paper, we investigate shallow (trade-only) and deep (trade and other factors) trade agreements which endogenously arise in the model of three large asymmetric countries. We develop a three-country, three-good competing exporters model with cross-border negative spillovers and perfect competition in product markets, where each country produces all three goods but has a comparative advantage in the production of only two out of three goods. To examine the stability of endogenous deep and shallow trade agreements we set up various three stage games and use coalition-proof Nash equilibria refinement to circumvent the multiplicity of Nash equilibria. Our objective is to investigate how equilibrium agreements differ based on being deep or shallow.

In a recent paper, Missios etal.(2016) examine the stability of endogenous trade agreements between three countries, and similarly, we also use an adapted version of the perfectly competitive two-country comparative advantage model of Horn et al.(2010). However, while we are interested

\footnotetext{
${ }^{24}$ https://www.wto.org/index.htm
} 
in similar issues, there are important differences between the models. First, in this chapter we consider a competing exporters model, where each country has a symmetric comparative advantage in the production of two goods, and consequently, exports both goods. Second, we have two active policy instruments, non-prohibitive import tariffs and non-prohibitive environmental taxes on the domestic producers of the polluting good (the "dirty" good). This enables us to illustrate the optimal policies under each possible trade agreement, as well as in the absence of any agreement. As a result, in addition to the standard tariff complementary on the same good export market, we also investigate the relationship of taxes and tariffs on the production and international trade of the dirty good. To make the model tractable, and in general, to simplify the analysis, only one of the three non-numeraire goods generates negative per unit production externality, pollution. As in Horn etal.(2010), we also assume a constant externality per unit of production, potentially with symmetric cross border spillovers. Though all countries produce all three non-numeraire goods, only two countries have a comparative advantage in the production of the dirty good, and consequently, only one of the countries is a natural importer of this good.

As in the previous chapter, deep and shallow trade agreements arise endogenously. The difference between this analysis and that of the previous chapter is that multiple countries have a comparative advantage in the dirty good. In this way, we examine similar questions as the last chapter but in a case with different incentives. As a result, in this paper, we have five games and four extended games. Regardless of the nature of trade and/or environmental agreements, the stages of the games are the same: in the first stage, players simultaneously announce the name(s) of the countries with whom they want to form an agreement; in the second stage, given the trade and/or environmental policy regime, countries choose their optimal tariffs and/or environmental taxes they impose on the production of the dirty good; and in the final stage of each game, consumption, production and international trade take place. In the first five games, we restrict countries' sets of announcements to either shallow or deep trade agreements and derive Nash equilibria of five different games of environmental and/or trade liberalization: an environmental agreement game (E game), a customs union game (CU Game), a free trade agreement game (FTA Game), an integrated customs union 
game (IU Game), and an integrated free trade agreement game (I Game). In the E game, members agree on domestic policy exclusively, and they are free in the choice of border policies, so players announce the names of the countries they would like to form pure environmental agreements with. The nature of the shallow CU and shallow FTA, described above, explained the difference between a shallow CU and a shallow FTA game; a member of a shallow CU would need to get a consent of a current PTA partner in order to make a deal with an outsider, and FTA members are free to make those deals. Contrary to shallow trade agreement games, in deep trade agreement games countries' announcements include an environmental component. In both IU and I game, members have to agree on both border policy and domestic policy. Furthermore, we examine the differences between shallow and deep trade agreements in four extended games: a shallow trade agreements game, where countries can choose between shallow CU and FTA agreements; a deep trade agreements game, where countries can choose between integrated customs unions and integrated FTAs; an extended game with the choice between deep and shallow customs unions; and an extended game with the choice between deep and shallow FTAs. Here, regardless of the game played, countries profiles should match at two levels, the partner's name and the type of a preferential trade agreement in order for shallow or deep trade agreements to arise.

As a result, in each of the nine games (five games and four extended games), we have multiple endogenous deep and/or shallow trade agreement. Some of those agreements do not survive unilateral deviations, and consequently, do not constitute Nash equilibria. Furthermore, to circumvent the multiplicity of Nash equilibria, we use the equilibrium refinement concept of coalitionproof Nash equilibrium. To do so, we follow Bernheim etal.(1987) and Missios etal.(2016). Bernheim etal.(1987) argue that "it is natural to assume that players can freely discuss their strategies, but cannot make binding commitments". Based on that, coalition-proof Nash equilibria have to survive all possible self-enforcing coalitional deviations.

In this chapter, using a "competing exporters" framework, we attempt to answer three different and equally important questions: (i) how do equilibrium agreements differ when countries choose deep rather than shallow agreements?; (ii) given the choice between deep and shallow trade agreements, 
would countries prefer to incorporate an environmental clause into their equilibrium trade deal?; (iii) what are the implications of including non-trade elements in PTAs for the pursuit of global free trade?

The rest of the chapter has the following structure: section 4.2 sets up the basic model and analyses optimal Nash tariffs and taxes; section 4.3 explores environmental and trade agreements and their effects on tariffs and taxes; section 4.4 investigates environmental and trade agreements and their effects on the environmental damages; section 4.5 revels announcements and strategy sets and provides the notion of coalition-proof Nash equilibrium; section 4.6 analyses endogenous environmental agreements; section 4.7 analyses endogenous shallow trade agreements; section 4.8 analyses endogenous deep trade agreements; section 4.9 provides further discussion on shallow versus deep integration, Article XXIV restriction and four extended games; section 4.10 concludes the chapter.

\subsection{The Model: Overview and Optimal Nash Tariffs and Taxes}

We consider three large countries which live in a perfectly competitive world, $j \in[a, b, c]$, and produce four goods, three non-numeraire goods, $k \in[A, B, C]$, and one numeraire good, $v_{0}$. Only production of good $A$ generates pollution which may have a transboundary effect on both neighbours. The production of other goods, $\operatorname{good} B, \operatorname{good} C$, and the numeraire good, do not generate any negative externality and considered to be clean. All three countries do not levy any taxes on the production of clean goods, and they impose a non-prohibitive environmental tax $\left(e_{A}^{j}\right)$ on the domestic producers of the dirty good $A$. The numeraire good is freely traded, and all other goods are subject to non-prohibitive import tariffs $\left(t_{k}^{j}\right)$. On the demand side, the representative consumer's utility function is quadratic and additively separable in the three non-numeraire goods, and it is linear in the numeraire good:

$$
U\left(v, v_{0}\right)=u(v)+v_{0}
$$

where $v_{0}$ stands for the consumption of the numeraire good, and $v=\left[v_{A}, v_{B}, v_{C}\right]$ is the consumption vector for the three non-numeraire goods. The demand for good $k$ in country $j$ is given by: 


$$
d\left(p_{k}^{j}\right)=\alpha-\beta p_{k}^{j}
$$

Again, for simplicity, we assume $\alpha=\beta=1$. On the supply side, labour $(l)$ is the only factor of production, and as as in Horn etal.(2010), we assume that the supply of labour is large enough to always produce numeraire good in all three countries, and this good is produced according to constant-returns-to-scale technology. In the production of each non-numeraire good labour is employed according to decreasing-returns-to-scale technology; $x_{k}^{j}=\sqrt{2 \lambda_{k}^{j} l}$, where $\lambda_{k}^{j}$ is a productivity parameter. If $\lambda_{k}^{j}=1$, then we say that country $j$ has a comparative advantage in the production of good $k$, and consequently, that country $j$ is a natural exporter of that good $k$, and if $\lambda_{k}^{j}<1$, then we say that country $j$ is a natural importer of good $k$. As a result, the supply of non-numeraire good $k$ in country $j$ is as follows:

$$
s_{k}^{j}=\lambda_{k}^{j}\left(q_{k}^{j}-e_{k}^{j}\right), \text { where } k=A \quad \text { and } \quad s_{k}^{j}=\lambda_{k}^{j} q_{k}^{j} \text {, where } k \in[B, C]
$$

where $q_{k}^{j}$ is the producer's price of good $k$ in country $j$, and $e_{k}^{j}$ is the non-prohibitive environmental tax imposed on the producers of the dirty $\operatorname{good} A$ in country $j$. We assume a symmetric comparative advantage structure across all three countries, specifically, $\lambda_{A}^{a}=\lambda_{B}^{b}=\lambda_{C}^{c}=\lambda<1$ and $\lambda_{B}^{a}=\lambda_{C}^{a}=$ $\lambda_{A}^{b}=\lambda_{C}^{b}=\lambda_{A}^{c}=\lambda_{B}^{c}=1$. Under this assumption each country has a comparative disadvantage in the good that coincides with the identity of the country that imports this good from the other two countries, and each country has an advantage in the production of the other two goods and exports different goods to each of the two countries. In this way, we assume that countries are competing exporters; each country imports one non-numeraire good and exports two non-numeraire goods. We assume free trade within each country, and due to that we have $\mathrm{q}_{k}^{j}=p_{k}^{j}$, if $k \in[B, C]$, and $\mathrm{q}_{k}^{j}=p_{k}^{j}-e_{k}^{j}$, if $k=A$. However, all three countries can impose specific tariffs on the imported non-numeraire good; $t_{k}^{j}$ is the tariff imposed on country j's exports of good k. We obtain the following no-arbitrage conditions and eliminate prohibitive tariffs:

$$
p_{A}^{a}=p_{A}^{b}+t_{A}^{b}=p_{A}^{c}+t_{A}^{c} \& p_{B}^{b}=p_{B}^{a}+t_{B}^{a}=p_{B}^{c}+t_{B}^{c} \& p_{C}^{c}=p_{C}^{a}+t_{C}^{a}=p_{C}^{b}+t_{C}^{b}
$$

where, for example, $t_{A}^{b}$ is a specific tariff faced by country $b$ while exporting good $A$ to country a. To simplify the notation, we ignore the importer's subscript; each country imports the good it 
has a comparative disadvantage in, and that good is indexed by the same uppercase letter as the identity of the country. In our model, each country produces all four goods, but only production of good $A$ generates pollution. As in Horn etal. (2010), we assume a constant externality per unit of production, $\gamma$, with symmetric cross border spillovers. Specifically, we assume the following environmental damage function in country $j$ :

$$
\Psi^{a}=\gamma\left(s_{A}^{a}+z \sum_{j \neq a} s_{A}^{j}\right), \quad \Psi^{b}=\gamma\left(s_{A}^{b}+z \sum_{j \neq b} s_{A}^{j}\right), \quad \Psi^{c}=\gamma\left(s_{A}^{c}+z \sum_{j \neq c} s_{A}^{j}\right)
$$

where $z$ is the degree of transboundary spillovers, $z \in[0,1]$. As $z$ approaches 1 , the pollution generated from the production of $\operatorname{good} A$ in country $j$ affects the two other countries in the same way as it affects the country $j$ itself. If $z=0$, then the pollution is purely local, and the production of $A$ affects only the country the good $A$ is actually produced in.

Let $m_{k}$ denote the total import demand for $\operatorname{good} k$, then $m_{k}\left(p_{k}^{j}\right)=d\left(p_{k}^{j}\right)-s_{k}^{j}\left(p_{k}^{j}\right)$ where, $j=k$ and

$$
m_{A}\left(p_{A}^{a}\right)=\sum m_{j \neq a}^{a} \quad \text { and } \quad m_{B}\left(p_{B}^{b}\right)=\sum m_{j \neq b}^{b} \quad \text { and } \quad m_{C}\left(p_{C}^{c}\right)=\sum m_{j \neq c}^{c}
$$

where $m_{b}^{a}$ and $m_{c}^{a}$ are respectively import demand of good $A$ by country $a$ from country $b$ and import demand of good $A$ by country $a$ from country $c ; m_{a}^{b}$ and $m_{c}^{b}$ are respectively import demand of good $B$ by country $b$ from country $a$ and import demand of good $B$ by country $b$ from country $c ; m_{a}^{c}$ and $m_{b}^{c}$ are respectively import demand of good $C$ by country $c$ from country $a$ and import demand of good $C$ by country $c$ from country $b$. Please, see Figure 4.1 "The Pattern of Trade". To simplify the notation, we omit products' subscripts; each country has a comparative disadvantage in the production of only one product, and that product is indexed by the same uppercase letter as the identity of the country. For the convenience, we use good $A$ as an example, and let $x_{A}^{b} \& x_{A}^{c}$ denote the exports of good $A$ to country $a$ by countries $b$ and $c$ :

$$
x=x_{A}^{b}+x_{A}^{c}=s_{A}^{b}\left(p_{A}^{b}\right)-d_{A}^{b}\left(p_{A}^{b}\right)+s_{A}^{c}\left(p_{A}^{c}\right)-d_{A}^{c}\left(p_{A}^{c}\right)
$$

The market clearing condition for good $\mathrm{k}$ is as follows:

$$
x_{k}=m_{k}\left(p_{k}^{j}\right) \quad \text { where } k=j
$$




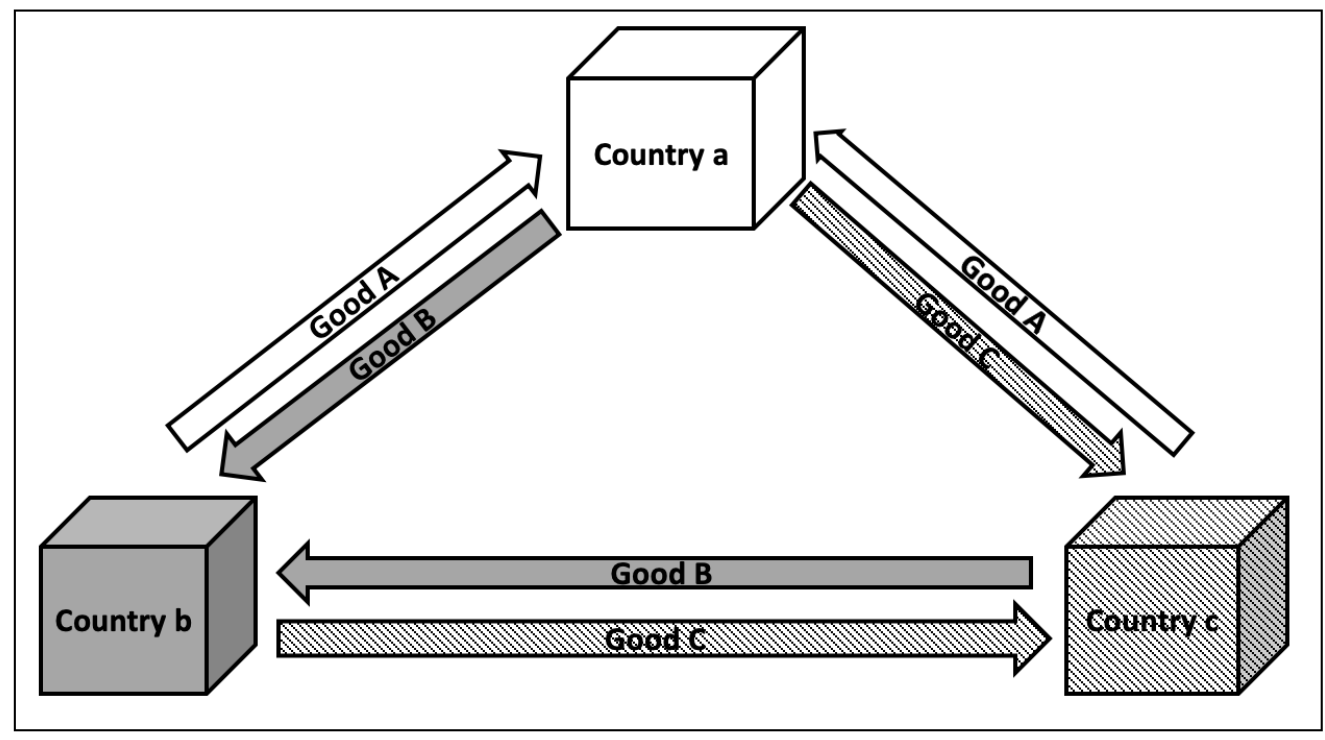

Figure 4.1: The Pattern of Trade

The equilibrium price of the dirty good $A$ in country $a$ and in country $b$ respectfully are:

$$
p_{A}^{a}=\frac{3+\lambda e_{A}^{a}+\sum_{j \neq a} e_{A}^{j}+2 \sum_{j \neq a} a_{A}^{j}}{5+\lambda} \quad \text { and } \quad p_{A}^{b}=\frac{3+\lambda e_{A}^{a}+\sum_{j \neq a} e_{A}^{j}-(3+\lambda) t_{A}^{b}+2 t_{A}^{c}}{5+\lambda}
$$

the equilibrium prices of the clean good $B$ in countries $b$ and $a$ respectfully are:

$$
p_{B}^{b}=\frac{3+\sum_{j+b} t_{B}^{j}}{5+\lambda} \quad \text { and } \quad p_{B}^{a}=\frac{3+2 t_{B}^{c}-(3+\lambda) t_{B}^{a}}{5+\lambda}
$$

Equation (4.9) illustrates the price of the dirty good $A$, in both export and domestic markets. The prices are increasing in the environmental taxes imposed on the production of this good in all three countries. However, the environmental tax imposed by country $a$ has a smaller effect on the price of that good than the environmental taxes imposed by both dirty countries, the ones with the comparative advantage in the production of the dirty good $A$. Equation (4.10) shows export and domestic price of the clean $\operatorname{good} B$. We can see that the price of the good in the country with no comparative advantage in the production of that good is increasing in the tariffs faced by both exporters of the good. The price of the good in the country with comparative advantage in the production of that good is increasing in the tariff faced by the competitor and decreasing in the 
tariff faced by that country, and the former effect is stronger than the latter. We can see that the domestic price of comparative advantage good does not increase one-to-one with the tariff faced by the competitor and does not decrease one-to-one with the tariff faced by that country.

Given the prices in equation (4.9), and the market clearing condition for the import and export levels of the dirty $\operatorname{good} A$, country $a$ 's import of the $\operatorname{good} A$ and the export levels of the trading partners, country $b$ and country $c$, respectively are:

$$
\begin{gathered}
m_{A}=m_{b}^{a}+m_{c}^{a}=\frac{2(1-\lambda)+4 \lambda e_{A}^{a}-(1+\lambda)\left(\sum_{A}^{j \neq a} e_{A}^{j}+2 \sum_{A}^{j \neq a} t_{A}^{j}\right)}{\lambda+5} \\
x_{A}^{b}=\frac{1+4 t_{A}^{c}+2\left(\lambda e_{A}^{a}+e_{A}^{c}\right)-(3+\lambda)\left(e_{A}^{b}+2 t_{A}^{b}\right)}{\lambda+5} \text { and } x_{A}^{c}=\frac{1+4 t_{A}^{b}+2\left(\lambda e_{A}^{a}+e_{A}^{b}\right)-(3+\lambda)\left(e_{A}^{c}+2 t_{A}^{c}\right)}{\lambda+5}
\end{gathered}
$$

Country $a$ 's total imports decrease with the environmental tax imposed by the exporters of the dirty good $A$, country $b$ and country $c$, and with the tariffs imposed by country $a$ on the imports from these countries. The total import of the good $A$ by country $a$ increases with the environmental tax imposed on the local producers of the dirty $\operatorname{good} A$, and the effect is stronger than the one caused by the foreign tax. The total exports of the $\operatorname{dirty} \operatorname{good} A$ for each exporter, either country $b$ or country $c$, is increasing with the tariff faced by the competitor and with the tax implied by the competitor and/or importer. The export of $A$ by countries $b$ and $c$ is decreasing in their local environmental taxes and the tariffs they face, and the tariffs have a stronger effect on the level of exports than the taxes do.

We use $\operatorname{good} B$ as an example of a clean good, then given the prices in Equation (4.10), and the market clearing condition for the import and export levels of the good $B$, country $b$ 's import of the good $B$ and the export levels of the trading partners, country $a$ and country $c$, respectively are:

$$
m_{B}=m_{a}^{b}+m_{c}^{b}=\frac{2(1+\lambda)\left(1-\sum_{B}^{j \neq b} t_{B}^{j}\right)}{\lambda+5} ; x_{B}^{a}=\frac{1-\lambda-2(3+\lambda) t_{B}^{a}+4 t_{B}^{c}}{\lambda+5} \text { and } x_{B}^{c}=\frac{1-\lambda-2(3+\lambda) t_{B}^{c}+4 t_{B}^{a}}{\lambda+5}
$$

As expected, country $b$ 's total imports decrease with the tariffs on good $B$, and total exports of that good for each exporter, country $a$ and/or country $c$, decrease with its tariff on good $B$ and increases with its rival's tariff. 
Country $j$ 's welfare is defined as the sum of consumer surplus and producer surplus over all goods, tariff revenue over one imported non-numeraire good, tax revenue on the production of a dirty $\operatorname{good} A$, minus environmental damages caused by the production of that $\operatorname{dirty} \operatorname{good} A$ :

$$
W^{j}=\sum_{k} C S_{k}^{j}\left(p_{k}^{j}\right)+\sum_{k} P S_{k}^{j}\left(p_{k}^{j}\right)+\sum_{j \neq k} t_{k}^{j} m_{k}^{j}\left(p_{k}^{j}\right)+e_{A}^{j} s_{A}^{j}-\Psi^{j}
$$

where $\sum_{j \neq k} t_{k}^{j} m_{k}^{j}\left(p_{k}^{j}\right)$ is tariff revenue of country $j$, and $e_{A}^{j} s_{A}^{j}$ is tax revenue of country $j$ over the production of the dirty good $A$. In the absence of any environmental and/or trade agreement, each country simultaneously chooses its tariffs and tax to maximize it's individual welfare. The optimal Nash specific tariffs and environmental taxes are calculated by:

$$
\frac{\partial W^{j}}{\partial t_{k}^{j \neq k}}=0 \text { and } \frac{\partial W^{j}}{\partial e_{A}^{j}}=0, \text { where } j \in[a, b, c] \text {, and } k \in[A, B, C]
$$

then we have the following relationships between the reaction functions:

$$
\begin{gathered}
\frac{\partial t_{A}^{b}}{\partial t_{A}^{c}}=\frac{\partial t_{A}^{c}}{\partial t_{A}^{b}}=\frac{\partial t_{B}^{a}}{\partial t_{B}^{c}}=\frac{\partial t_{B}^{c}}{\partial t_{B}^{a}}=\frac{\partial t_{C}^{a}}{\partial t_{C}^{b}}=\frac{\partial t_{C}^{b}}{\partial t_{C}^{a}}=\frac{3 \lambda+11}{\lambda^{2}+3 \lambda+14}>0 \& \frac{\partial t_{B}^{a}}{\partial t_{A}^{b}}=\frac{\partial t_{C}^{a}}{\partial t_{A}^{c}}=\frac{\partial t_{A}^{b}}{\partial t_{B}^{a}}=\frac{\partial t_{C}^{b}}{\partial t_{B}^{c}}=\frac{\partial t_{A}^{c}}{\partial t_{C}^{a}}=\frac{\partial t_{B}^{c}}{\partial t_{C}^{b}}=0 \\
\frac{\partial e_{A}^{b}}{\partial e_{A}^{a}}=\frac{\partial e_{A}^{c}}{\partial e_{A}^{a}}=\frac{2 \lambda}{\lambda^{2}+10 \lambda+23}>0 ; \frac{\partial e_{A}^{b}}{\partial e_{A}^{c}}=\frac{\partial e_{A}^{c}}{\partial e_{A}^{b}}=\frac{2}{\lambda^{2}+10 \lambda+23}>0 ; \frac{\partial e_{A}^{a}}{\partial e_{A}^{b}}=\frac{\partial e_{A}^{a}}{\partial e_{A}^{c}}=\frac{\lambda+1}{2 \lambda+25}>0 \\
\frac{\partial t_{A}^{b}}{\partial e_{A}^{b}}=\frac{\partial t_{A}^{c}}{\partial e_{A}^{c}}=-\frac{1}{4} \frac{\lambda^{2}+6 \lambda+13}{\lambda^{2}+7 \lambda+14}<0 ; \frac{\partial e_{A}^{b}}{\partial t_{A}^{b}}=\frac{\partial e_{A}^{c}}{\partial t_{A}^{c}}=-\frac{2(\lambda+3)}{\lambda^{2}+10 \lambda+23}<0 ; \frac{\partial e_{A}^{b}}{\partial t_{A}^{c}}=\frac{\partial e_{A}^{c}}{\partial t_{A}^{b}}=\frac{4}{\lambda^{2}+10 \lambda+23}>0 ; \\
\frac{\partial e_{A}^{a}}{\partial t_{A}^{b}}=\frac{\partial e_{A}^{a}}{\partial t_{A}^{c}}=\frac{4(\lambda+3)}{9 \lambda+25}>0
\end{gathered}
$$

We observe exporter's tariffs increase with their rival's tariffs, so we have tariff complementarity and positively sloped reaction functions on the same good export market. In the absence of any agreement, an importer would find it reasonable to either increase or decrease import tariffs on both trading partners instead of increasing tariff on only one of them and decreasing on the other. Tariffs on different goods are independent. Though we observe complementarity of environmental taxes on the production of the dirty good $A$ levied in all three countries, the change in the tax level imposed by one competitor in export of good $A$ has a stronger effect on the other competitor's tax than the same tax change levied by the importer of the dirty good $A$, country $a$. If either exporter 
of the dirty good $A$, country $b$ and/or country $c$, faces an increase in the tariff on the dirty good $A$ set by the only importer of this good, country $a$, this exporter would have to reduce the level of environmental tax on the local producers of the dirty good $A$ to simply stay competitive on the export market. This provides the intuition for why environmental taxes levied in dirty rivals and and tariffs faced by those countries are negatively related in our model. In the same time, environmental tax levied in either dirty country and tariffs faced by its rival are strategic complements; the higher the tariff faced by the competitor - the higher the upper bound of the local tax which still allows a dirty country to compete for country $a$ 's market.

The equilibrium no agreement tariffs on clean goods, $B$ and $C$, and on the dirty good $A$, and the equilibrium no agreement taxes applied by all three countries on the domestic producers of the dirty $\operatorname{good} A$ respectfully are:

$$
\begin{gathered}
t_{B}^{a}\left(N_{\theta}\right)=t_{C}^{a}\left(N_{\theta}\right)=t_{C}^{b}\left(N_{\theta}\right)=t_{B}^{c}\left(N_{\theta}\right)=\frac{1}{4} \frac{1-\lambda}{3+\lambda} \text { and } \\
t_{A}^{b}\left(N_{\theta}\right)=t_{A}^{c}\left(N_{\theta}\right)=\frac{1}{2} \frac{4+\gamma \lambda^{2}(1+2 z)+3 \gamma \lambda(1+4 z)-4 \gamma(1+5.5 z)-\lambda(3+\lambda)}{(\lambda+5)(2 \lambda+5)} \\
e_{A}^{a}\left(N_{\theta}\right)=\gamma \text { and } e_{A}^{b}\left(N_{\theta}\right)=e_{A}^{c}\left(N_{\theta}\right)=\frac{1}{4} \frac{(1-\lambda)+2 \gamma \lambda^{2}(1-z)-\gamma z(7+9 \lambda)+8 \gamma(3+2 \lambda)}{(\lambda+5)(2 \lambda+5)}
\end{gathered}
$$

where $\gamma$ is the constant externality per unit of production of the dirty $\operatorname{good} A$, and $(\mathrm{N})$ indicates no agreement scenario. In this chapter, we examine two levels of externality: purely local, $\theta=l$, and purely global pollution, $\theta=g$. As we can see from Equation (4.16), only country with no comparative advantage in the production of the dirty good $A$ shows no distortion in the environmental tax from the optimal level, $\gamma$; and two symmetric dirty countries, $b$ and $c$, distort the tax level from the socially optimal level, $\gamma^{25}$

\footnotetext{
${ }^{25}$ If pollution is local, $z=0$, then $e_{A}^{j}>e_{A}^{a}$, where $j \neq a$, and if pollution is global, $z=1$, then $e_{A}^{j}<e_{A}^{a}$, where $j \neq a$.
} 


\subsection{Environmental and Trade Agreements and their Effects on Tariffs and}

\section{Taxes}

In this section, we first consider various pure environmental agreements: agreements between two dirty countries, environmental agreement between one clean and one dirty country, and world environmental agreement. Then, we move to shallow trade agreements: customs unions of two symmetric and two asymmetric countries, bilateral preferential trade agreement between symmetric and asymmetric countries, two different hub-and-spoke agreements, and a free trade world. Finally, we analyze deep trade agreements of the same types. The difference between shallow and deep trade agreements arises from the nature of the agreement-negotiation process. Shallow trade agreements let countries negotiate only pure trade deals. In this case, members do not discuss the level of non-prohibitive environmental tax they levy on their producers of the dirty good $A$. Consequently, the level of an environmental tax can vary among members of any shallow trade agreement. Both members and outsiders of any shallow trade deal maximize their individual welfares and set the level of tax accordingly. On the contrary, deep trade agreements let their members negotiate both tariffs and taxes. Members of such kind of agreements have to agree on the level of non-prohibitive environmental tax they set on the domestic producers of the dirty good $A$. However, outsiders of those deep trade agreements are free to choose any level of tax they find optimal.

\subsubsection{Pure Environmental Agreements}

In this subsection, we, first, analyze an environmental agreement between two dirty countries, then we describe an environmental agreement between one clean and one dirty country, and finally, we examine a world environmental agreement which includes all three countries.

A pure environmental agreement between two dirty countries, denoted by $\left(b c_{\theta}^{e}\right)$, implies that members agree only on the tax they levy on the domestic producers of the dirty good $A$, and they still impose their individually optimal external tariffs on each other as well as on the non-member country by solving: 


$$
\frac{\partial\left(W^{b}\left(b c_{\theta}^{e}\right)+W^{c}\left(b c_{\theta}^{e}\right)\right)}{\partial e_{A}\left(b c_{\theta}^{e}\right)}=0 ; \frac{\partial W^{b}\left(b c_{\theta}^{e}\right)}{\partial t_{B}^{j \neq b}\left(b c_{\theta}^{e}\right)}=0 \text { and } \frac{\partial W^{c}\left(b c_{\theta}^{e}\right)}{\partial t_{C}^{j \neq c}\left(b c_{\theta}^{e}\right)}=0
$$

Both members of this environmental agreement, country $b$ and country $c$, and the outsider of this agreement, country $a$, impose no taxes on the producers of the two clean non-numeraire goods, good $B$ and good $C$, and the only good which is subject to non-prohibitive environmental tax is the dirty $\operatorname{good} A$. Consequently, any environmental agreement would not cause any distortion of the tariffs on clean goods from their no agreement levels. Also, an environmental agreement between two dirty countries would not alter the level of the environmental tax levied by the outsider of this agreements, the clean country $a$. However, both jointly optimal environmental tax levied by the members of $\left(b c_{\theta}^{e}\right)$ and tariffs they face while exporting the dirty good $A$ to the outsider of this agreement, the clean country $a$, are subject to change.

$$
t_{A}^{j}\left(b c_{\theta}^{e}\right)<t_{A}^{j}\left(N_{\theta}\right) \text { and } e_{A}\left(b c_{\theta}^{e}\right)>e_{A}^{j}\left(N_{\theta}\right) \text { where } j \in[b, c]
$$

Proposition 4.1: An environmental agreement between two dirty countries would lead to an increase in the jointly optimal tax level relative to the individually optimal no agreement levels levied by each member, and to a decrease in the tariff imposed by the outsider of this agreement, the clean country a, on its imports of the dirty good A from the members of $\left(b c_{\theta}^{e}\right)$.

The explanation for the above proposition lies in the findings presented in the Equation (4.15). Environmental tax levied in the rival countries with the competitive advantage in the production of the dirty good $A$ and the tariff set by the only importer of this good, the clean country $a$, are inversely related. When dirty competitors form an environmental agreement, they naturally agree on the higher level of local environmental tax, and the clean importer has no choice but lower its tariffs if they want to continue importing at a reasonable price.

A pure environmental agreement between one clean and one dirty country, denoted by $\left(a b_{\theta}^{e}\right)$, similar to the previous case, implies that these countries agree only on the tax they levy on their domestic producers of the dirty good $A$, and they still impose their individually optimal external tariffs on each other as well as on the non-member country. However, in the case of this environmental agreement, we need to oblige with the most favored nation (MFN) clause in Article I of 
the General Agreements on Tariffs and Trade. Under that clause the WTO members are required to set the same tariffs on the same products from all other members. In this case, we set tariffs as follows: $t_{A}^{c}\left(a b_{\theta}^{e}\right)=t_{A}^{b}\left(a b_{\theta}^{e}\right){ }^{26}$

Now, we examine a world environmental agreement, denoted by $\left(a b c_{\theta}^{e}\right)$. In this case, all countries apply the same environmental tax on their local producers of the $\operatorname{dirty} \operatorname{good} A$, but they still impose their individually optimal external tariffs on each other by solving:

$$
\frac{\partial \sum^{j} W^{j}\left(a b c_{\theta}^{e}\right)}{\partial e_{A}\left(a b c_{\theta}^{e}\right)}=0 \text { and } \frac{\partial W^{j}\left(a b c_{\theta}^{e}\right)}{\partial t_{k}^{j}\left(a b c_{\theta}^{e}\right)}=0 \text { where } j \in[a, b, c] \text { and } k \in[A, B, C] \text { and } k \neq j
$$

As expected, an environmental agreement between all three countries would not affect the world tariffs on the clean goods, good $B$ and good $C$, and now we can state the following:

Proposition 4.2: If pollution is local, then the clean importer of the dirty good A would increase the level of tariffs on both rivals above the no agreement level, and if pollution is global, the tariff is decreased below the no agreement level.

The explanation lies in the distortion of the environmental tax from the no agreement level in all three countries: $e_{A}\left(a b c_{l}^{e}\right)<e_{A}^{j}\left(N_{l}\right) \& e_{A}\left(a b c_{g}^{e}\right)>e_{A}^{j}\left(N_{g}\right)$ where $j \in[a, b, c]$. The results presented in Equation (4.15) illustrate the negative relationship between taxes levied in the countries with the comparative advantage in the production of the dirty good $A$ and tariffs those rivals face while exporting to the clean country $a$. Furthermore, under this world environmental agreement the tax is the highest for all three countries, if pollution is global, relative to all environmental agreements. As a result, we observe the lowest level of production and trade in this dirty good $A$, and consequently, the lowest level of environmental damages.

\subsubsection{Shallow Trade Agreements}

In this part of the chapter, we analyze different pure trade agreements. This type of agreements does not contain any environmental clause. Members simply agree to eliminate tariffs on each

\footnotetext{
${ }^{26}$ Ignoring this clause, would create the following distortions in the tariffs on $\operatorname{good} A: t_{A}^{c}\left(a b_{l}^{e}\right)<t_{A}^{b}\left(a b_{l}^{e}\right)$ and $t_{A}^{c}\left(a b_{g}^{e}\right)>t_{A}^{b}\left(a b_{g}^{e}\right)$
} 
other, but they set individually optimal environmental taxes. We start with shallow bilateral free trade agreements and hub-and-spoke trade regimes, then we consider customs unions, and finally, we examine a global free trade.

\subsubsection{Free Trade Agreements}

In this subsection, we consider four types of shallow free trade agreements: an FTA between two dirty countries, an FTA between one clean and one dirty country, a hub-and-spoke trade regime with a clean country as a hub, and a hub-and-spoke trade regime with a dirty country as a hub. In any of these free trade agreements, members agree to eliminate tariffs on each other, but they set individually optimal tariffs on the imports from the outsider, as well as, individually optimal environmental taxes on their producers of the dirty good $A$. First, we consider an FTA between the two dirty countries, denoted by $\left(b c_{\theta}\right)$. Members independently set their external tariffs and environmental taxes on the $\operatorname{dirty} \operatorname{good} A$ by maximizing their utility functions:

$$
\left.\frac{\partial W^{j=k}\left(b c_{\theta}\right)}{\partial t_{k}^{a}\left(b c_{\theta}\right)}\right|_{t_{k}^{j \neq k}\left(b c_{\theta}\right)=0}=0 \text { and } \frac{\partial W^{j}\left(b c_{\theta}\right)}{\partial e_{A}^{j}\left(b c_{\theta}\right)}=0 \text { where } j \in[b, c] \text { and } k \in[B, C]
$$

An outsider chooses its tariffs and environmental tax to maximize its welfare independently from the two members of this FTA; country a's maximization problem is the same as under no agreement. If one clean and one dirty country form a free trade agreement, denoted by $\left(a b_{\theta}\right)$, then similar to the previous case, members eliminate tariffs on the imports from each other and impose individually optimal tariffs on the imports from the outsider. All three countries are free to impose individually optimal environmental taxes. In the case of $\left(a b_{\theta}\right)$, country $c$ is an outsider, and it is free to impose individually optimal tariffs on the imports from the members, country $a$ and country $b$. Bilateral trade agreement between two symmetric dirty countries, country $b$ and country $c$, causes no distortion of the level of the environmental tax in all three countries relative to the no 
agreement level: $e_{A}^{a}\left(b c_{\theta}\right)=e_{A}^{a}\left(N_{\theta}\right)$ and $e_{A}^{j}\left(b c_{l}\right)=e_{A}^{j}\left(N_{l}\right) \& e_{A}^{j}\left(b c_{l}\right)=e_{A}^{j}\left(N_{l}\right)$ where $j \in[b, c]$. However, a shallow bilateral trade agreement between one clean and one dirty country induces the clean member to lower its environmental tax below the no agreement level, and on the contrary, induces the dirty member to increase the tax above the no agreement level for both local and global levels of pollution. This can be explained with complementarity of local taxes and import tariffs on the dirty good $A$ in the clean country $a$, and with the negative relationship between local taxes and tariffs on the export of the dirty good $A$ faced by the dirty country $b$, Equation (4.15). Now, we state the following:

Proposition 4.3: Both types of bilateral FTAs, between two dirty countries and between one clean and one dirty country, induce the members to lower their tariffs on the imports from the non-member while these agreements do not distort tariffs imposed by the outsider relative to the no agreement level.

The explanation for the above proposition lies in the complementarity of tariffs imposed by different countries on the imports of the same good and in the independence of the tariffs imposed on different goods. The elimination of the tariffs between two dirty countries on imports from each other, $t_{C}^{b}\left(b c_{\theta}\right)=t_{B}^{c}\left(b c_{\theta}\right)=0$, leads to a decrease in the level of tariffs imposed on the imports from the outsider of this agreement, the clean country $c, t_{k}^{a}\left(b c_{\theta}\right)<t_{k}^{a}\left(N_{\theta}\right)$ where $k \in[B, C]$. Similar to this, when the members of $\left(a b_{\theta}\right)$ agree to eliminate tariffs on each other, $t_{B}^{a}\left(a b_{\theta}\right)=t_{A}^{b}\left(a b_{\theta}\right)=0$, it causes the reduction in the tariffs faced by the outsider of this bilateral trade agreement, country $c$, $t_{A}^{c}\left(a b_{l}\right)<t_{A}^{c}\left(N_{l}\right) \& t_{A}^{c}\left(a b_{g}\right)<t_{A}^{c}\left(N_{g}\right) \& t_{B}^{c}\left(a b_{\theta}\right)<t_{B}^{c}\left(N_{\theta}\right)$.

The nature of bilateral free trade agreements allow hub-and-spoke trade regimes to arise. Members of such FTAs are free to impose their individually optimal external tariffs, so each member is free to make a "side deal" with another country. As a result of these "side deals", hub-and-spoke trade regimes can arise. We have two different hub-and-spoke trade regimes: first, the clean country assumes a role of a hub, and second, a dirty country acts as a hub. Hub trades freely with both spokes, and spokes still impose individually optimal tariffs on the imports from each other. 
Proposition 4.4: Both types of hub-and-spoke trade regimes, with a clean country acting as a hub, $\left(a_{\theta}^{h}\right)$, or with a dirty player being a hub, $\left(b_{\theta}^{h}\right)$, induce spokes to reduce their individual tariffs below the no agreement level.

We can consider each spoke being an outsider of a bilateral shallow trade agreement between the hub and the other spoke. Following this logic, we explain the above proposition using tariff complementarity. If the clean country $a$ is a hub, then both spokes, country $b$ and country $c$, face no tariffs while exporting to $a$, and country $a$ itself faces no tariffs on its exports to both spokes, so $t_{k}^{a}\left(a_{\theta}^{h}\right)=t_{A}^{j}\left(a_{\theta}^{h}\right)=0$ where $k \in[B, C]$ and $j \in[b, c]$. This in turn lead to a decrease in tariffs applied by both spokes on the imports from each other, $t_{k}^{j}\left(a_{\theta}^{h}\right)<t_{k}^{j}\left(N_{\theta}\right)$ where $k \in[B, C]$ and $j \in[b, c]$ and $j \neq k$. If the dirty country $b$ becomes a hub, then $t_{k}^{b}\left(b_{\theta}^{h}\right)=t_{B}^{j}\left(b_{\theta}^{h}\right)=0$ where $k \in[A, C]$ and $j \in[a, c]$, and consequently, it will cause the reduction in the tariffs faced by the spokes while exporting to each other's markets, $t_{C}^{a}\left(b_{\theta}^{h}\right)<t_{C}^{a}\left(N_{\theta}\right)$ and $t_{A}^{c}\left(b_{l}^{h}\right)<t_{A}^{c}\left(N_{l}\right) \& t_{A}^{c}\left(b_{g}^{h}\right)<t_{A}^{c}\left(N_{g}\right)$.

\subsubsection{Customs Unions}

In this subsection, we analyze shallow customs unions. Customs unions are a different type of preferential trade agreements. Similar to shallow FTA members, members of customs unions eliminate the tariffs on the imports from each other, but unlike the FTA members, they also impose a jointly optimal tariff on the imports from the outsider. Two types of customs unions can arise in our model: two symmetric dirty countries can form a customs union and exclude the clean country, denoted by $\left(b c_{\theta}^{u}\right)$, or one clean and one dirty country can get into a union and exclude the second dirty player, denoted by $\left(a b_{\theta}^{u}\right)$. First, we analyze $\left(b c_{\theta}^{u}\right)$, and then we move to customs union of two asymmetric countries, $\left(a b_{\theta}^{u}\right)$. Members of a customs union between two symmetric dirty countries then solve the following:

$$
\left.\frac{\partial \Sigma^{j} W^{j}\left(b c_{\theta}^{u}\right)}{\partial t^{a}\left(b c_{\theta}^{u}\right)}\right|_{t_{k}^{j}\left(b c_{\theta}^{u}\right)=0}=0 \text { and } \frac{\partial W^{j}\left(b c_{\theta}^{u}\right)}{\partial e_{A}^{j}\left(b c_{\theta}^{u}\right)}=0 \text { where } j \in[b, c] \text { and } k \in[B, C] \text { and } j \neq k
$$


Shallow union of two dirty countries leads to a reduction in tariffs applied to the imports from the clean outsider of this union, country $a, t^{a}\left(b c_{\theta}^{u}\right)<t_{k}^{a}\left(N_{\theta}\right)$ where where $k \in[B, C]$. The reason for this jointly optimal tariff to be lower than individual tariffs applied by the members in the no agreement scenario lies in the tariff complementarity. When each member sets the tariff on the imports from another member to zero, $t_{C}^{b}\left(b c_{\theta}^{u}\right)=t_{B}^{c}\left(b c_{\theta}^{u}\right)=0$, it reducers the tariffs on the same goods import from the outsider as well, $t^{a}\left(b c_{\theta}^{u}\right)<t_{B}^{a}\left(N_{\theta}\right)=t_{C}^{a}\left(N_{\theta}\right)$. In the same time, the shallow union of two dirty countries does not create any distortion in the tariffs applies by the outsider of this union, country $a$, on its imports from the members, $t_{A}^{j}\left(b c_{l}^{u}\right)=t_{A}^{j}\left(N_{l}\right)$ and $t_{A}^{j}\left(b c_{g}^{u}\right)=t_{A}^{j}\left(N_{g}\right)$ where $j \in[b, c]$. This can be explained with the independence of the tariffs levied on two different goods, equation (15). This in turn can be used to explain no distortion in the level of environmental tax applied by all three countries from the no agreement levels: $e_{A}^{a}\left(b c_{\theta}^{u}\right)=e_{A}^{a}\left(N_{\theta}\right)=\gamma, e_{A}^{j}\left(b c_{l}^{u}\right)=$ $e_{A}^{j}\left(N_{l}\right)$ and $e_{A}^{j}\left(b c_{g}^{u}\right)=e_{A}^{j}\left(N_{g}\right)$ where $j \in[b, c]$.

Article XXIV of GATT requires all members of preferential trade agreements keep their external tariffs on non-member countries at least at the pre-existing level. Members are free to lower their tariffs, like in the case of the customs union between two symmetric countries we discussed above, but they cannot raise their external tariffs on the non-member countries. We ignore this tariff restriction for now, and simply assume that members of a customs union between one clean and one dirty country, $\left(a b_{\theta}^{u}\right)$, are free to increase the level of tariff if and when they find it jointly optimal. We examine the effect of the restrictions of Article XXIV in the later sections of this paper.

Proposition 4.5: If pollution is global, then the jointly optimal tariff the outsider faces while exporting to $\left(a b_{\theta}^{u}\right)$ exceeds the no agreement level of tariff on the clean good $B$ and loses to the no agreement level of tariff on the dirty good A; and if pollution is local, then the jointly optimal tariff is below the no agreement level on the imports of the clean good B for any level of $\lambda$ and on the import of the dirty good A if the productivity gap is narrow, and above the no agreement level if the productivity gap is relatively wide.

The explanation for the above proposition lies in the difference of the no agreement levels of tariffs 
applied on the imports of two different goods, the clean good $B$ and the dirty good $A$. If pollution is local, then the tariff country $c$ faces on its export of the clean good $B$ to country $b$ is higher than the tariff applied by county $a$ on its imports of the dirty good $A, t_{B}^{c}\left(N_{l}\right)>t_{A}^{c}\left(N_{l}\right)$. Consequently, when the union of those two importers, country $a$ and country $b$, agrees on the same level of tariff on their imports from the outsider, country $c$, this level is lower than the no agreement level of good $B$ and higher than the no agreement level of good $A$ for a relatively wide productivity gap. Also, the no agreement level of tariff faced by country $c$ on its export to country $b$ is lower than the tariff country $a$ applies on its imports of the dirty $\operatorname{good} A$ from country $c$ if pollution is global, $t_{B}^{c}\left(N_{g}\right)<t_{A}^{c}\left(N_{g}\right)$. And again the jointly optimal level of tariff on the imports from the outsider is greater than the no agreement level on the clean $\operatorname{good} B$ and lower than the no agreement level of the dirty $\operatorname{good} A, t_{B}^{c}\left(N_{g}\right)<t^{c}\left(a b_{g}^{u}\right)<t_{A}^{c}\left(N_{g}\right)$.

Proposition 4.6: A shallow customs union between two asymmetric countries, $\left(a b_{\theta}^{u}\right)$, induces distortions in the level of environmental taxes levied in all three countries relative to the no agreement levels for both local and global levels of pollution, though the formation of a customs union of two symmetric dirty countries, $\left(b c_{\theta}^{u}\right)$, does not create such distortions.

The intuition behind the above proposition stems from the independence of tariffs applied on two different goods. When two dirty countries, country $b$ and country $c$, form a shallow union, they set the tariffs on imports from each other to zero, and that in turn leads to a decrease in the level jointly optimal tariff they apply on the imports from the outside, country $a$. However, the outsider's tariffs on its imports of the dirty good $A$ from the union shows no distortion from the no agreement level, and consequently, the environmental tax on the local producers of the dirty good $A$ stays at its no agreement level in all three countries. Contrary to that, the union of two asymmetric countries, country $a$ and country $b$, creates distortions in the level of tariffs applied by the clean member of this union on its imports of the $\operatorname{dirty} \operatorname{good} A$ from the other member as well as from the outsider of this union, the dirty country $c$. As a result, we observe the distortions from the no agreement level of environmental taxes levied on the dirty producers by both members of this union as well as by the outsider of this shallow trade union. 


\subsubsection{Free Trade}

Under shallow free trade agreement, all members of the world set the tariffs on their imports from each other to zero, and they still levy individually optimal environmental taxes on their local producers of the good $A$.

Proposition 4.7: Shallow free trade induces the clean country a to lower its level of environmental tax for both local and global levels of pollution and induces the dirty countries $b$ and $c$ to bring their taxes above the no agreement level.

To explain the logic behind this proposition, we use the results presented in the Equation (4.15). Complementarity of the local tax and the import tariffs on the dirty good $A$ set by the clean country $a$ induces a decrease in the tax level when $t_{A}^{b}\left(a b c_{\theta}\right)=t_{A}^{c}\left(a b c_{\theta}\right)=0$ under a shallow free trade. In the same time, tariffs dirty countries face of their exports of the dirty good $A$ and the environmental taxes they levy on their producers of this good are substitutes, and as a result, we observe an increase in the level of tax in country $b$ and country $c$ for both local and global levels of pollution.

\subsubsection{Deep Trade Agreements}

In this part of the chapter, we examine deep trade agreements. Similar to members of shallow trade agreement, members of deep trade agreement also eliminate tariffs on imports from each other, but in addition to that, they have to agree on the level of environmental tax they levy on their producers of the dirty good $A$. First, we analyze deep bilateral free trade agreements and integrated hub-and-spoke trade regimes, then we consider integrated customs unions, and finally, we examine an integrated free trade. 


\subsubsection{Deep Tree Trade Agreements}

In this subsection, we analyze four different types of deep free trade agreements: a deep FTA between two symmetric dirty countries, $\left(b c_{\theta}^{i}\right)$, a deep FTA between one clean and one dirty country, $\left(a b_{\theta}^{i}\right)$, an integrated hub-and-spoke trade regime with a clean county as a hub, $\left(a_{\theta}^{h i}\right)$, and an integrated hub-and-spoke trade regime with a dirty country as a hub, $\left(b_{\theta}^{h i}\right)$. Shallow trade agreements imply that though members set the tariffs on the imports from each other to zero, they are free to impose an individually optimal environmental tax on their producers of the good $A$. However, when countries negotiate deep FTAs, they have to add an environmental clause to it. A deep bilateral free trade agreement of two symmetric dirty countries, country $b$ and country $c$, entails tariffs elimination on the trade between those countries and setting of environmental tax on the jointly optimal level, but members are free to impose individually optimal tariffs on imports from the outsider of this agreement, country $a$. As a result, members solve the following problems under $\left(b c_{\theta}^{i}\right):$

$$
\left.\frac{\partial W^{j=k}\left(b c_{\theta}^{i}\right)}{\partial t_{k}^{a}\left(b c_{\theta}^{i}\right)}\right|_{t_{k}^{j \neq k}\left(b c_{\theta}^{i}\right)=0}=0 \text { and } \frac{\partial \sum^{j} W^{j}\left(b c_{\theta}^{i}\right)}{\partial e_{A}\left(b c_{\theta}^{i}\right)}=0 \text { where } j \in[b, c] \text { and } k \in[B, C]
$$

An outsider's choice of import tariffs and environmental tax are independent from the members' decision, and as a result, country a's maximization problem does not change relative to the no agreement one. The maximization problem faced by the members of $\left(a b_{\theta}^{i}\right)$ is very similar to the above equations. Both clean and dirty members of this deep bilateral FTA agree to eliminate tariffs on the imports from each other, as well as they agree on the level of tax to levy on their local producers of the dirty good $A$; and similar to the above, the outsider's problem does not change relative to the no agreement scenario. Both deep bilateral FTAs, $\left(b c_{\theta}^{i}\right)$ and $\left(a b_{\theta}^{i}\right)$, induce their members to lower their tariffs on the imports from the outsiders of those agreements: $t_{k}^{a}\left(b c_{\theta}^{i}\right)<$ $t_{k}^{a}\left(N_{\theta}\right)$ where $k \in[B, C]$, as well as $t_{B}^{c}\left(a b_{\theta}^{i}\right)<t_{B}^{c}\left(N_{\theta}\right)$ and $t_{A}^{c}\left(a b_{l}^{i}\right)<t_{A}^{c}\left(N_{l}\right) \& t_{A}^{c}\left(a b_{g}^{i}\right)<t_{A}^{c}\left(N_{g}\right)$. To explain this, we use the results presented in Equation (4.15) which illustrate tariff complementarity. When members of either deep bilateral FTA set the tariffs on imports from each other equal to zero, 
$t_{k}^{j}\left(b c_{\theta}^{i}\right)=0$ where $j \in[b, c] \& k \in[B, C] \& j \neq k$, or $t_{k}^{j}\left(a b_{\theta}^{i}\right)=0$ where $j \in[a, b] \& k \in[A, B] \&$ $j \neq k$, it induces a decrease in tariffs on the outsider's export to the member countries. Now, we can state the following:

Proposition 4.8: While a shallow bilateral FTA between two symmetric dirty countries does not cause any distortions in the level of tariffs applied by the outsider of this agreement on the imports from the members, a deep bilateral FTA between those countries induces the non-member to lower its tariffs on members for both local and global levels of pollution.

The explanation for that lies in the distortion from the no agreement tax level in the member countries of this deep bilateral trade agreement. The formation of a shallow bilateral trade agreement does not lead to any distortion of the environmental tax level in all three countries relative to the no agreement level, and consequently, there are no distortions in the tariffs applied by the outsider of this agreement on its imports of the dirty good $A$ from both members. Contrary to that, a deep bilateral FTA of two symmetric dirty countries, country $b$ and country $c$, creates a distortion in the level of the environmental tax the members levy on their producers of the dirty $\operatorname{good} A$, $e_{A}\left(b c_{\theta}^{i}\right)>e_{A}^{j}\left(N_{\theta}\right)$ where $j \in[b, c]$, and in turn, it leads to a decrease in the tariffs applied by the outsider on its import from the members, $t_{A}^{j}\left(b c_{\theta}^{i}\right)<t_{A}^{j}\left(N_{\theta}\right)$.

The nature of bilateral FTAs, both shallow and deep, allows countries to make "side deals" with the outsiders of their bilateral FTAs agreements, and as a result, we observe the birth of hub-and-spoke trade regimes. In our model, we have two different deep hub-and-spoke trade regimes: $\left(a_{\theta}^{h i}\right)$ has the clean country $a$ serving as a hub, and $\left(b_{\theta}^{h i}\right)$ which has one of the dirty members of the world, country $b$, assuming the role of the hub country. Deep hub-and-spoke trade regimes are different from the shallow hub-and-spoke trade regimes in the inclusion of the environmental tax in this "side deal". We assume that, when a member of a deep FTA makes a "side deal" with an outsider, they have to agree on the environmental tax as well.

Both hub-and-spoke trade regimes, $\left(a_{\theta}^{h i}\right)$ and $\left(b_{\theta}^{h i}\right)$, induce spokes to reduce their tariffs on import from each other for both levels of pollution, and those results are very similar to our finding presented in the previous section on shallow hub-and-spoke trade regimes. The nature of hub-and- 
spoke trade regimes imply that both spokes trade with the hub freely, and the hub trades freely with both spokes, but spokes still apply individually optimal tariffs on imports from each other. As a result, when $t_{A}^{j}\left(a_{\theta}^{h i}\right)$ and $t_{k}^{a}\left(a_{\theta}^{h i}\right)$ are set to zero than tariff complementarity gives us $t_{k}^{j}\left(a_{\theta}^{h i}\right)<t_{k}^{j}\left(N_{\theta}\right)$ where $j \varepsilon[b, c] \& k \in[B, C] \& j \neq k$. Similar to that, when $t_{B}^{j}\left(b_{\theta}^{h i}\right)$ and $t_{k}^{b}\left(b_{\theta}^{h i}\right)$ are set to zero than tariff complementarity gives us $t_{k}^{j}\left(a_{\theta}^{h i}\right)<t_{k}^{j}\left(N_{\theta}\right)$ where $j \in[a, c] \& k \varepsilon[A, C] \& j \neq k$.

Now, we can state the following proposition:

PROPOSITION 4.9: The formation of a deep hub-and-spoke trade regime with a dirty country acting as a hub leads to a lower level of the environmental tax than the formation of a deep huband-spoke trade regime with the clean country being a hub.

Environmental taxes levied in each dirty country and the tariffs on the dirty good $A$ faced by each competitor are complements, and also the level of tax set by the clean importer of this dirty good $A$ country $a$ are complements as well, Equation (4.15). As a result, the elimination of both tariffs

applied by country $a, t_{A}^{b}\left(a_{\theta}^{h i}\right)$ and $t_{A}^{c}\left(a_{\theta}^{h i}\right)$, has a stronger effect on the level of jointly optimal tax levied by all three countries than the elimination of the tariffs on only one competitor in the export of the dirty good $A$, country $b$, under the deep hub-and-spoke trade regime with the dirty country $b$ acting as a hub.

\subsubsection{Integrated Customs Unions}

In this subsection, we examine a different type of deep preferential trade agreements, integrated customs unions. Two different deep customs unions can arise in our model: an integrated customs union of two symmetric dirty countries, denoted by $\left(b c_{\theta}^{i u}\right)$, and an integrated customs union between one clean and one dirty country, denoted by $\left(a b_{\theta}^{i u}\right)$. Similar to members of deep FTAs, members of deep customs unions have to agree on the jointly optimal tax they apply to their producers of the dirty good $A$ as well as on eliminating the tariffs on imports from each other. However, unlike members of deep FTAs, members of deep customs unions also impose a jointly 
optimal tariff on the imports from the outsider. Members of $\left(b c_{\theta}^{i u}\right)$ set $t_{C}^{b}\left(b c_{\theta}^{i u}\right)=t_{B}^{c}\left(b c_{\theta}^{i u}\right)=0$, $e_{A}^{b}\left(b c_{\theta}^{i u}\right)=e_{A}^{c}\left(b c_{\theta}^{i u}\right)=e_{A}\left(b c_{\theta}^{i u}\right)$, and $t_{B}^{a}\left(b c_{\theta}^{i u}\right)=t_{C}^{a}\left(b c_{\theta}^{i u}\right)=t^{a}\left(b c_{\theta}^{i u}\right)$; and members of $\left(a b_{\theta}^{i u}\right)$ set $t_{B}^{a}\left(a b_{\theta}^{i u}\right)=t_{A}^{b}\left(a b_{\theta}^{i u}\right)=0, e_{A}^{a}\left(a b_{\theta}^{i u}\right)=e_{A}^{b}\left(a b_{\theta}^{i u}\right)=e_{A}\left(a b_{\theta}^{i u}\right)$, and $t_{A}^{c}\left(a b_{\theta}^{i u}\right)=t_{B}^{c}\left(a b_{\theta}^{i u}\right)=t^{c}\left(a b_{\theta}^{i u}\right)$. Similar to the subsection on shallow customs unions, here we also ignore the tariff restrictions required according to Article XXIV of the GATT/WTO, and simply assume that members of $\left(a b_{\theta}^{i u}\right)$ are free to increase the level of tariff if and when they find it jointly optimal, and we examine the effect of these restrictions on the formation of integrated customs unions in later sections of this paper. Members of the integrated customs union between two dirty countries solve the following:

$\left.\frac{\partial \Sigma^{j} W^{j}\left(b c_{\theta}^{i u}\right)}{\partial t^{a}\left(b c_{\theta}^{i u}\right)}\right|_{t_{k}^{j}\left(b c_{\theta}^{i u}\right)=0}=0$ and $\frac{\partial \Sigma^{j} W^{j}\left(b c_{\theta}^{i u}\right)}{\partial e_{A}\left(b c_{\theta}^{i l}\right)}=0$ where $j \in[b, c]$ and $k \in[B, C]$ and $j \neq k$

Similar to shallow customs union of two symmetric dirty countries, country $b$ and country $c$, a deep customs union of these two countries causes a decrease in the tariff applied on the imports from the outsider, the clean country $a: t^{a}\left(b c_{\theta}^{i u}\right)<t_{k}^{a}\left(N_{\theta}\right)$ where $k \in[B, C]$. And similar to the previous section, this can be explained by tariff complementarity. Now, we can state the following:

Proposition 4.10: Members of the integrated customs union of two dirty countries face a lower tariff on their exports to the outsider relative to no agreement, and members of shallow customs union of these countries face the no agreement level of tariffs on their exports of the dirty good A. The logic behind the above proposition stems from the distortion of the jointly optimal environmental tax level applied by the members of this deep customs union, and consequently, the absence of such distortions when these countries do not include the environmental clause into their customs union trade agreement. When two dirty countries form an integrated customs union, they find it optimal to increase the tax they levy on their producers of the dirty good $A$ above the no agreement level, $e_{A}\left(b c_{\theta}^{i u}\right)>e_{A}^{j}\left(N_{\theta}\right)$ where $j \in[b, c]$, and consequently, the only importer of this dirty good $A$ country $a$ has no choice but decrease the level of tariffs below the no agreement level, $t_{A}^{j}\left(b c_{\theta}^{i u}\right)<t_{A}^{j}\left(N_{\theta}\right)$ where $j \in[b, c]$. Equation (4.15) illustrates the negative relationship between the tariffs levied by country $a$ and the taxes applied in the two countries with the comparative advantage in the production of this dirty good $A$. 
Members of a deep customs union between one clean and one dirty country, similar to the members of a shallow customs union of these two countries, set their jointly optimal tariff on the imports from the outsider, country $c$, above the no agreement level of the tariff on the clean good $B$ and below the no agreement level of the tariff on the dirty $\operatorname{good} A$ if pollution is global. If pollution is local then the jointly optimal tariff is below the no agreement level of tariff on both goods exported by the outsider, country $c$. Our explanation is very similar to the one we used in the previous section of this paper, and it lies in the difference of the no agreement levels of tariffs applied by the members of $\left(a b_{\theta}^{i u}\right)$, country $a$ on its imports of the dirty good $A$ and country $b$ on its imports of the clean good $B$. If pollution is global, then the no agreement level of tariff faced by country $c$ on its exports of good $B$ is lower than the tariff country $c$ faces on its imports of the $\operatorname{dirty} \operatorname{good} A$. Consequently, the jointly optimal level of tariff on the imports from the outsider is greater than the no agreement level on the clean good $B$ and lower than the no agreement level of tariff on the dirty $\operatorname{good} A$.

\subsubsection{Integrated Free Trade}

Under integrated free trade agreement, all three countries eliminate their tariffs on the imports from each other and impose jointly optimal environmental tax on their domestic producers of the dirty $\operatorname{good} A$.

Proposition 4.11: The formation of an integrated free trade agreement induces the members to choose an environmental tax equal to marginal damages, with both local and global externalities. The production of the dirty good $A$ generates a negative externality, pollution, which may have a transboundary effect on both neighbours. If pollution is pure local, then the transboundary effect is zero, and integrated free trade agreements induces all members to set an environmental tax at its socially optimal level. With a global externality and symmetric cross border spillovers, the production of the dirty good $A$ affects all three countries equally regardless of the location of the 
dirty good A producer. In this case, an integrated free trade agreement induces the members to set the tax at the level of $3 \gamma$, which is equal to world marginal damages.

\subsection{Environmental and Trade Agreements and their Effects on Environ- mental Damages}

In this section, we examine the effect of various deep and shallow trade agreements on environmental damages. The only good that creates negative production externality, pollution, in our model is $\operatorname{good} A$. We start our analysis with the effect of pure environmental agreements on the environmental damages, then we move to shallow trade agreement, and finally, we consider deep trade agreements.

\subsubsection{Pure Environmental Agreements}

In this subsection, we analyze how different environmental agreements affect the level of environmental damages in each country and in the world. The environmental agreements are: an environmental agreement between two symmetric dirty countries, $\left(b c_{\theta}^{e}\right)$, an environmental agreement between one clean and one dirty country, $\left(a b_{\theta}^{e}\right)$, and a global environmental agreement, $\left(a b c_{\theta}^{e}\right)$.

The formation of an environmental agreement between two asymmetric countries, $\left(a b_{l}^{e}\right)$, induces an increase in the level of world environmental damages, if pollution is local, relative to the no agreement level. The explanation lies in the increased production of the $\operatorname{dirty} \operatorname{good} A$ in the world which entirely caused by the increased production in the members of $\left(a b_{l}^{e}\right)$ and export of the dirty member of this environmental agreement. Contrary to that, an outsider of this agreement, country $c$, has the lowest level of exports of $\operatorname{good} A$ among all environmental agreements. If pollution is local, then the formation of an environmental agreement between two symmetric dirty countries, $\left(b c_{l}^{e}\right)$ induces the lowest level of environmental damages in the world. In this case, we observe the reduction in the exports of the dirty good $A$, the lowest world production of that 
good, and consequently, both dirty countries exhibit the lowest level of damages. If pollution is global, then the level of world damages is higher under $\left(a b_{g}^{e}\right)$ than under $\left(b c_{g}^{e}\right)$, but both types of agreements induce a reduction in the level of world damages below the no agreement level. The world production of the dirty good $A$ falls under the no agreement level for both types of environmental agreements, however, contrary to the local pollution case, an outsider of $\left(a b_{g}^{e}\right)$, country $c$, increases its exports of good $A$ above the no agreement level, but export of country $b$ falls below the no agreement level. The explanation lies in the transboundary effect of the production of the dirty $\operatorname{good} A$. If pollution is local, then the spillovers are zero, so an environmental agreement between two asymmetric countries, country $a$ and country $b$, leads to an increase in the production and export of good $A$ by the member with the comparative advantage in the production of this good, country $b$, and consequently, induces a reduction in the export from the outsider, country c. Therefore, if pollution is global, then the transboundary effect is one and, consequently, an environmental agreement between country $a$ and country $b$ leads to a decrease in the production and export of the dirty good $A$ by country $b$, and the outsider gets to increase its production and export due to no obligations to the clean importer of this good, country $a$. Now, we can state the following:

PROPOSITION 4.12: If pollution is local, then the formation of a global environmental agreement induces the highest level of world damages, and if pollution is global, then the lowest level of environmental damages is observed under a global environmental agreement.

The explanation, again, lies in the understanding of the transboundary effect of negative externality in our model, pollution. If pollution is local, then the transboundary effect of the production of the dirty good $A$ on both neighbours is zero; as a result, we observe the highest level of production of this dirty good $A$ in the world, as well as the highest level of exports and consumption. If pollution is global, then the production of the dirty good affects all countries equally regardless of the producer's location, and as a result, we observe the lowest level of production of the dirty good $A$ under a global environmental agreement. Furthermore, global pollution induces a decrease in the import demand for the dirty good $A$ in the only clean country, country $a$, from both competing 
exporters of this good. As a result, we observe the lowest level of world environmental damages, if pollution is global.

\subsubsection{Shallow Trade Agreements}

In this subsection, we examine the effect of various shallow trade agreements on the level of environmental damages. Precisely, we analyze the following shallow trade agreements: a bilateral FTA between two symmetric dirty countries, $\left(b c_{\theta}\right)$, a bilateral FTA between one clean and one dirty country, $\left(a b_{\theta}\right)$, two different hub-and-spoke trade regimes, $\left(a_{\theta}^{h}\right)$ and $\left(b_{\theta}^{h}\right)$, a CU between two dirty countries, $\left(b c_{\theta}^{u}\right)$, a CU between one clean and one dirty country, $\left(a b_{\theta}^{u}\right)$, and a global shallow free trade, $\left(a b c_{\theta}\right)$.

Both types of bilateral PTAs, an FTA and a CU, between two symmetric dirty countries, country $b$ and country $c$, induce no distortion in the level of environmental damages in all three countries, and consequently, in the world, for both local and global levels of pollution. In both cases, the world production and export of the $\operatorname{dirty} \operatorname{good} A$ remains at the no agreement level. However, contrary to the formation of $\left(b c_{\theta}\right)$ or $\left(b c_{\theta}^{u}\right)$, the formation of either shallow PTA between one clean and one dirty country, $\left(a b_{\theta}\right)$ or $\left(a b_{\theta}^{u}\right)$, induces an increase in the level of environmental damages in all three countries for both local and global levels of negative production externality. The removal of trade tariffs by the members of $\left(a b_{\theta}\right)$ or $\left(a b_{\theta}^{u}\right)$ leads to an increased export of the dirty good $A$ by the dirty member of either PTA, country $b$, to the clean member, country $a$. Furthermore, the formation of $\left(a b_{\theta}^{u}\right)$ leads the highest level of export from country $b$ to country $a$ among all shallow trade agreements for both local and global levels of pollution, and again, for both levels of pollution, the clean member of $\left(a b_{\theta}\right)$ or $\left(a b_{\theta}^{u}\right)$ increases the local production of the dirty good $A$ above the no agreement level. The formation of a bilateral FTA between one clean and one dirty country induces an increased demand for the dirty good $A$ by the clean country $a$ from the outsider of this agreement, country $c$, as well as from the dirty member of $\left(a b_{\theta}\right)$, for both levels of pollution, but the formation of $\left(a b_{\theta}^{u}\right)$ leads to the lowest import demand from the outsider, country 
$c$, for both local and global levels of pollution. Hub-and-spoke trade regime with a dirty country as a hub, $\left(b_{\theta}^{h}\right)$, induces the same level of damages, production, and export of the $\operatorname{dirty} \operatorname{good} A$ as a shallow FTA between one clean and one dirty country, $\left(a b_{\theta}\right)$. However, a hub-and-spoke trade regime with the clean country as a hub, $\left(a_{\theta}^{h}\right)$, induces the highest level of environmental damages as well as a free trade world, and now we can state the following:

Proposition 4.13: Both trade regimes, shallow free trade world and shallow hub-and-spoke trade regime with the clean country acting as a hub, induce the highest level of pollution.

Both trade regimes, shallow free trade and shallow hub-and-spoke trade regime with the clean country acting as a hub, imply zero tariffs on the dirty good $A$, and consequently, the removal of those tariffs lead to a deeper specialization and increased production and trade of this good. As a result, we observe the highest level of production and world export of the dirty good $A$, and the increased production of the dirty good $A$ naturally leads to an increased level of negative externality associated with this production process, the level of pollution. We can see that a world with no tariffs on the dirty good, given that there is no environmental agreement, would cause an increase in the environmental damages for both local and global levels of pollution.

\subsubsection{Deep Trade Agreements}

In this subsection, we examine the effect of various deep trade agreements on the environmental damages: a deep bilateral FTA between two symmetric dirty clean countries, $\left(b c_{\theta}^{i}\right)$, a deep FTA of two asymmetric members, $\left(a b_{\theta}^{i}\right)$, two different integrated hub-and-spoke trade regimes, $\left(a_{\theta}^{h i}\right)$ and $\left(b_{\theta}^{h i}\right)$, a deep customs union of two symmetric countries, $\left(b c_{\theta}^{i u}\right)$, a deep CU of two asymmetric members, $\left(a b_{\theta}^{i u}\right)$, and a deep free trade, $\left(\digamma^{i}\right)$.

The formation of $\left(b c_{\theta}^{i}\right)$, a deep FTA of two symmetric dirty countries, induces no distortion in the level of the environmental damages in all three countries from the no agreement level, and consequently, in the world. Contrary to that, the formation of $\left(b c_{\theta}^{i u}\right)$, a deep customs union of country $b$ and country $c$, reduces the world level of pollution. The explanation lies in the lower 
levels of import demand of the dirty good $A$ by the outsider of this agreement, the clean country $a$, for both local and global levels of pollution. If pollution is global, then the formation of a deep FTA of two asymmetric countries, $\left(a b_{\theta}^{i}\right)$, leads to the highest level of environmental damages in the world. In this case, the natural importer of $\operatorname{good} A$, country $a$, exhibits an increase in demand from both the dirty member of $\left(a b_{l}^{i}\right)$ and the outsider of this agreement, country $c$. If pollution is global, then the formation of $\left(a b_{g}^{i}\right)$ leads to the highest level of world trade in the dirty good $A$, but in this case, the consumption of the locally produced dirty good falls bellow the no agreement level, and consequently, the world environmental damages fall bellow the no agreement level as well. The formation of hub-and-spoke trade regimes induces the same level of damages as a deep tree trade agreement for both local and global levels of pollution, and now we are ready to state the following:

Proposition 4.14: If pollution is global, then a fully integrated world is the least polluted.

The explanation for the above lies in the decreased level of production in all three countries; each of them exhibits the lowest level of production of the dirty good $A$ under a deep free trade agreement. Though, the only natural importer of the dirty $\operatorname{good} A$, country $a$, still demands the import level of $\operatorname{good} A$ which is higher than under both types of deep PTAs between two symmetric dirty countries, $\left(b c_{g}^{i}\right)$ and $\left(b c_{g}^{i u}\right)$, the local production is at the lowest level in all three members of this deep free trade agreement. In the previous section of this paper, we stated that a shallow free trade agreement induces the highest level of world environmental damages. In this section, we conclude, that adding an environmental clause to a free trade deal leads to a cleaner world. However, if pollution is local, then members of this deep free trade agreement bear no cost of spillovers and simply enjoy a deeper specialization in their comparative advantage goods. As a result, if pollution is local, then we observe the lowest level of production of the dirty good $A$, and consequently, environmental damages, in the only country with no comparative advantage in the production of this good, the clean country $a$, and the level of environmental damages exceeds the no agreement level in both competing exporters of this $\operatorname{dirty} \operatorname{good} A$, country $b$ and country $c$. 


\subsection{Endogenous Preferential Environmental and/or Trade Agreements}

\subsubsection{Announcements and Strategy Sets}

In this subsection, we describe announcements and strategy sets for all three stage games of environmental agreements and/or trade liberalization: an Environmental Agreement game (E game), a Customs Union game (CU Game), a Free Trade Agreement game (FTA Game), an Integrated Customs Union game (IU Game), and an Integrated Free Trade Agreement game (I Game). In an Environmental Agreement game, players announce the names of the countries they would like to form pure environmental agreements with. This announcements are free of any trade policies. The difference between the CU and FTA games lies in the nature of two types of preferential trade agreements. In the $\mathrm{CU}$ game, a member of a trade union cannot unilaterally sign another agreement with a non-member country. In order to do so, a member would need to get a consent of a current PTA partner, as members of a trade union impose a jointly optimal tariff on the imports from the outsider. On the contrary, in the FTA game, members levy an individually optimal tariffs on the non-member, and due to that, they are free to form another agreement without any consent of a current PTA member. In the IU and I games, each player announces the names of the countries with whom they want to sign an integrated agreement. Integrated agreements always include an environmental component, namely, members have to agree on the level of tax they levy on their producers of the dirty good $A$. Regardless of the nature of these trade and environmental agreements, the stages of the games are as follows: in the first stage, each player simultaneously announces the names of the countries with whom it wants to form an agreement; in the second stage, given the trade and/or environmental policy regime, countries choose their optimal tariffs and/or environmental taxes they impose on the production of a dirty good $A$; in the final stage of each game, consumption, production and international trade take place.

In the first stage of each game, each player simultaneously announces the names of the countries with whom it wishes to sign an environmental and/or trade agreement. Country $j$ 's announcement is denoted by $\sigma_{j}$, and its strategy set $S_{j}$ includes all possible announcements: 


$$
\begin{aligned}
& S_{a}=\{\{\varnothing, \varnothing\},\{b, \varnothing\},\{\varnothing, c\},\{b, c\}\} \\
& S_{b}=\{\{\varnothing, \varnothing\},\{a, \varnothing\},\{\varnothing, c\},\{a, c\}\} \\
& S_{c}=\{\{\varnothing, \varnothing\},\{a, \varnothing\},\{\varnothing, b\},\{a, b\}\}
\end{aligned}
$$

To describe strategy sets, we use country $b$ as an example. Country $b$ 's announcement in favour of no agreement with any of the countries is denoted by $\{\varnothing, \varnothing\}$. If country $b$ would like to form an agreement with only one of the countries, the announcement would look as follow: $\{a, \varnothing\}$ or $\{\varnothing, c\}$. The announcement $\{a, c\}$ indicates country $b$ 's desire to be a part of an agreement with both trading partners.

\subsubsection{Coalition-Proof Nash Equilibria}

As in chapter 3, we distinguish coalition-proof Nash equilibria from the set of multiple Nash equilibria. Again, we follow the concept of coalition-proof Nash Equilibrium introduced in Bernheim etal.(1987). Coalition-proof Nash equilibria have to survive all possible self-enforcing coalitional deviations. When we consider whether a particular coalition-proof Nash equilibria holds, we keep the announcement of non-deviating countries unchanged.

\subsection{Endogenous Environmental Agreements}

\subsubsection{Pure Environmental Agreements}

Next, we describe different environmental agreements which can arise in this game. Under a pure environmental agreement, members have to agree on the tax they levy on the producers of the dirty good $A$, but they apply individually optimal tariffs on the import from each other as well as on the imports from the outsider. In the first stage of this game, players announce countries they would like to form an environmental agreement with. Each player's strategy set $\left(S_{j}^{e}\right)$ consists of four possible announcements denoted as $\sigma_{j}^{e}$ : 


$$
\begin{aligned}
& S_{a}^{e}=\left\{\{\varnothing, \varnothing\},\left\{b^{e}, \varnothing\right\},\left\{\varnothing, c^{e}\right\},\left\{b^{e}, c^{e}\right\}\right\} \\
& S_{b}^{e}=\left\{\{\varnothing, \varnothing\},\left\{a^{e}, \varnothing\right\},\left\{\varnothing, c^{e}\right\},\left\{a^{e}, c^{e}\right\}\right\} \\
& S_{c}^{e}=\left\{\{\varnothing, \varnothing\},\left\{a^{e}, \varnothing\right\},\left\{\varnothing, b^{e}\right\},\left\{a^{e}, b^{e}\right\}\right\}
\end{aligned}
$$

where announcement $\sigma_{j}^{e}=\{\varnothing, \varnothing\}$ indicates player's desire to stay away from any environmental agreement; if $\sigma_{j}^{e}$ includes only one of the two countries then it denotes the player's wish to form an environmental agreement only with that country; if $\sigma_{j}^{e}$ has two other countries then it indicates player's desire to be a part of a world environmental agreement.

Countries are free to choose their announcements, and the environmental agreements can be formed only if partners announce each other. In the environmental agreement game, the countries strategy sets map into the following environmental agreements:

(i) The announcement profile $\left\langle\Phi^{e}\right\rangle$, no agreement, arises when either all three countries announce in the favour of no environmental agreement or countries' announcements do not match. In this case, countries apply individually optimal environmental taxes on their producers of the dirty $\operatorname{good} A$.

(ii) If countries $a$ and $b$ call each other and exclude country $c$, it results in the environmental agreement between one clean and one dirty country, denoted $\langle a b e\rangle$. In this case, an outsider's announcement would not influence the outcome. This agreement implies, that members have to agree on the environmental tax they impose, but they still apply individually optimal tariffs on the imports from each other as well as from the outsider.

(iii) Similar to (ii), announcement profile $\langle b c e\rangle$ indicate two countries' desire to exclude the third member of the world. In this case, two dirty countries exclude the clean country $a$ and form an environmental agreement which includes only dirty members.

(iv) The announcement profile $\langle E\rangle$ signals all three countries' desire to sign a world environmental agreement. This profile implies, that all three countries agree on the environmental tax they levy on their domestic producers of the dirty $\operatorname{good} A$. 


\subsubsection{Welfare Effects of Various Environmental Agreements in the E Game}

LEMMA 4.1: The welfare impact of various types of environmental agreements on members and non-members is as follows:

$\left(i^{e}\right) W^{j}\left(N_{l}\right)>W^{j}\left(b c_{l}^{e}\right)>W^{j}\left(a b_{l}^{e}\right)>W^{j}\left(a b c_{l}^{e}\right)$ where $j \neq a ; W^{a}\left(a b c_{l}^{e}\right)>W^{a}\left(a b_{l}^{e}\right)>W^{a}\left(N_{l}\right)>$ $W^{a}\left(b c_{l}^{e}\right)$

$\left(i i^{e}\right) W^{a}\left(a b c_{g}^{e}\right)>W^{a}\left(b c_{g}^{e}\right)>W^{a}\left(a b_{g}^{e}\right)>W^{a}\left(N_{g}\right)$

$\left(i i i^{e}\right) W^{b}\left(b c_{g}^{e}\right)>W^{b}\left(a b c_{g}^{e}\right)>W^{b}\left(N_{g}\right)>W^{b}\left(a b_{g}^{e}\right) ; W^{c}\left(b c_{g}^{e}\right)>W^{c}\left(a b c_{g}^{e}\right)>W^{c}\left(a b_{g}^{e}\right)>W^{c}\left(N_{g}\right)$

$\left(i v^{e}\right) W^{b}\left(N_{\theta}\right)>W^{j}\left(a b_{\theta}^{e}\right)$ where $j \neq a$

Part $\left(i^{e}\right)$ of Lemma4.1 illustrates a self-exclusion incentive for the dirty players since both of them, country $b$ and country c, gain the highest level of welfare in the no agreement scenario if pollution is local, and the lowest welfare these countries can achieve in this game is under a global environmental agreement. Contrary to that, the only clean country would prefer to live in the world united by the same environmental agreement. Based on the results in Lemma4.1(- $\left.i i^{e}\right)$, we can conclude that, if pollution is global, then the clean country would like to see either or both dirty players in any environmental agreement, even if the clean country itself is an outsider of the agreement. The highest welfare the clean country can achieve is under global environmental agreement. Lemma4.1 $\left(-i i^{e}\right)$ illustrates an exclusion incentive. If pollution is global, then dirty countries would prefer to form a bilateral environmental agreement and exclude the only clean country. An environmental agreement between two dirty countries brings its members the highest level of welfare in the entire game. Lemma $4.1\left(-i v^{e}\right)$ states that for any level of pollution either of the dirty countries, country $b$ or country c, would prefer to self-exclude itself from an environmental agreement with the clean country. 


\subsubsection{Announcements profiles, Associated Environmental Agreements and Nash Equilibria in the $\mathbf{E}$ Game}

Proposition 4.15: In the E game, the Nash equilibria announcement profiles and the associated environmental agreements are shown in Table 4.1.

\begin{tabular}{|l|c|c|c|}
\hline \multirow{2}{*}{ Announcement Profiles } & Environmental & \multicolumn{2}{|c|}{ Nash Equilibria } \\
\cline { 3 - 5 } & Agreements & local & global \\
\hline \hline$\Omega^{\Phi^{e}} \equiv\left\{\sigma_{a}^{e}=\{\varnothing, \varnothing\}, \sigma_{b}^{e}=\{\varnothing, \varnothing\}, \sigma_{c}^{e}=\{\varnothing, \varnothing\}\right\}$ & $\left\langle\Phi^{e}\right\rangle$ & Yes & Yes \\
\hline$\Omega^{a b e} \equiv\left\{\sigma_{a}^{e}=\{b, \varnothing\}, \sigma_{b}^{e}=\{a, \varnothing\}, \sigma_{c}^{e}=\{\varnothing, \varnothing\}\right\}$ & $\langle a b e\rangle$ & No & No \\
\hline$\Omega^{b c e} \equiv\left\{\sigma_{a}^{e}=\{\varnothing, \varnothing\}, \sigma_{b}^{e}=\{\varnothing, c\}, \sigma_{c}^{e}=\{\varnothing, b\}\right\}$ & $\langle b c e\rangle$ & No & Yes \\
\hline$\Omega^{E} \equiv\left\{\sigma_{a}^{e}=\{b, c\}, \sigma_{b}^{e}=\{a, c\}, \sigma_{c}^{e}=\{a, b\}\right\}$ & $\langle E\rangle$ & No & No \\
\hline
\end{tabular}

Table 4.1: The Nash equilibria announcement profiles and the associated environmental agreements in the E game

No environmental agreement announcement profile, $\Omega^{\Phi^{e}}$, is a Nash equilibria for both local and global levels of pollution. Countries cannot increase their welfares by unilaterally altering their announcements. To prove that $\Omega^{a b e}$ is not a Nash equilibria for both levels of pollution, we use the results of Lemma4.1 $\left(-i v^{e}\right)$. These results show that the dirty country $b$ can improve its welfare by unilaterally changing the announcement to $\{\varnothing, \varnothing\}$; this change in the announcement would lead to the no environmental agreement scenario and country $b$ 's increased welfare gain. The results of Lemma4.1 $\left(-i^{e}\right)$ illustrate that the announcement profile $\Omega^{b c e}$ does not constitute a Nash equilibria if pollution exhibits local characteristics. If pollution is local, then either member of this environmental agreement between two dirty countries can improve its welfare by unilaterally changing the announcement to $\{\varnothing, \varnothing\}$, which would result in the no agreement announcement profile and bring the highest welfare gains to both dirty countries in this entire game. For the global level of pollution, Lemma4.1 $\left(-i i i^{e}\right)$ shows that neither $b$ no $c$ has an incentive to change 
their announcements from $\{\varnothing, c\}$ and $\{\varnothing, b\}$ respectively. Any change in the announcement would either lead to no change in welfare or would lead to the no agreement scenario (change to $\{\varnothing, \varnothing\}$ or $\{a, \varnothing\})$ and a decrease in the level of welfare gains for both dirty countries. We prove that the announcement profile, $\Omega^{E}$, is not a Nash equilibria in two steps: first, we prove it for the case of local pollution, and then, we prove the above if pollution is global. Based on the results of Lemma4.1 $\left(-i^{e}\right)$, we can conclude that either of the dirty countries, country $b$ and/or country $c$, can self-exclude itself by changing the announcement to $\{\varnothing, \varnothing\}$ and improve its welfare level. To prove that the announcement profile $\Omega^{E}$ is not a Nash equilibria if pollution is global, we use the results of Lemma4.1 $\left(-i i i^{e}\right)$ which illustrate that either of the dirty countries can unilaterally improve its welfare by limiting its announcement to another dirty country only. If pollution is global, the dirty countries would prefer to exclude the only clean country. Based on the above, we conclude that the announcement profile $\Omega^{E}$ does not survive Nash equilibria refinement. ${ }^{27}$

\subsubsection{Coalition-Proof Nash Equilibria of the $E$ game}

Coalition-proof Nash equilibria announcement profiles need to be immune not only to all individual deviations, like Nash equilibria announcement profiles, but also to all meaningful self-enforcing coalitions. Although, an announcement profile $\Omega^{\Phi^{e}}$ is a Nash equilibria for both local and global levels of pollution, it does not survive a CPNE refinement if pollution is global. To prove that, we examine a coalition formed by two symmetric dirty countries. Lemma4.1(-iii $\left.{ }^{e}\right)$ states that an environmental agreement between two dirty countries would let its members to achieve the highest level of welfare in this entire game, and as a result, no further deviations can be meaningful. Based on the above, we can conclude that dirty countries can form a self-enforcing deviation, and consequently, $\Omega^{\Phi^{e}}$ is not a CPNE if pollution is global.

Proposition 4.16: If pollution is local then the only coalition-proof Nash equilibria of the E game is the announcement profile $\Omega^{\Phi^{e}}$ which constitutes a world with no environmental agree-

\footnotetext{
${ }^{27}$ For the proofs, please Appendix A.4.6
} 
ments in it.

To prove the above we show that the announcement profile $\Omega^{\Phi^{e}}$ is immune to all meaningful coalitional deviations if pollution is local. First, we analyze the coalitional deviation of two asymmetric countries, the clean country $a$ and the dirty country $b$. In this case, the changes in the announcements would result in an environmental agreement $\langle a b e\rangle$. The results in Lemma $4.1\left(-i^{e}\right)$ tell us that though the clean country would benefit from the coalition with the dirty country, the dirty country is not going to join this environmental union. We can conclude, that this initial deviation is not meaningful. Second, we assume that two dirty countries form a coalition, that would result in $\langle b c e\rangle$, and again, based on Lemma4.1 $\left(-i^{e}\right)$, we can conclude that this deviation is not meaningful. Now, we examine the grand environmental coalition, then the announcement profile would be $\Omega^{E}$, and the results of Lemma4.1 $\left(-i^{e}\right)$ illustrate that this deviation is not meaningful as well. Based on the above, we can conclude that $\Omega^{\Phi^{e}}$ is a CPNE if pollution is local. ${ }^{28}$

Proposition 4.17: If pollution is global then the only coalition-proof Nash equilibria of the E game is the announcement profile $\Omega^{\text {bce }}$ which constitutes an environmental agreement between two clean countries.

We prove the above by examining all possible meaningful deviations. First, we examine the coalitional deviation of two asymmetric countries, the clean country $a$ and the dirty country $b$, then it will result in the environmental agreement $\langle a b e\rangle$, and lower welfare gain for the dirty partner of this agreement, Lemma4.1 $\left(-i i^{e}\right)$. We can see that this deviation is not meaningful. Next, we examine the grand environmental coalition, which again, will result in a lower welfare gains for the dirty country, and we conclude that this deviation is not meaningful as well. Based on the above, we can conclude that $\Omega^{b c e}$ is a CPNE if pollution is global. ${ }^{29}$

\footnotetext{
${ }^{28}$ For the proofs, please Appendix A.4.6

${ }^{29}$ For the proofs, please Appendix A.4.6
} 


\subsection{Endogenous Shallow Trade Agreements}

\subsubsection{The Customs Union Game}

\subsubsection{Preferential Trade Agreements in the CU Game}

In this part of the paper, we describe different preferential trade agreements which can arise under the shallow customs union game. In the first stage of this game, players announce countries they would like to form a customs union with. Each player's strategy set $\left(S_{j}^{u}\right)$ consists of four possible announcements denoted as $\sigma_{j}^{u}$ :

$$
\begin{aligned}
& S_{a}^{u}=\left\{\{\varnothing, \varnothing\},\left\{b^{u}, \varnothing\right\},\left\{\varnothing, c^{u}\right\},\left\{b^{u}, c^{u}\right\}\right\} \\
& S_{b}^{u}=\left\{\{\varnothing, \varnothing\},\left\{a^{u}, \varnothing\right\},\left\{\varnothing, c^{u}\right\},\left\{a^{u}, c^{u}\right\}\right\} \\
& S_{c}^{u}=\left\{\{\varnothing, \varnothing\},\left\{a^{u}, \varnothing\right\},\left\{\varnothing, b^{u}\right\},\left\{a^{u}, b^{u}\right\}\right\}
\end{aligned}
$$

where announcement $\sigma_{j}^{u}=\{\varnothing, \varnothing\}$ indicates country's desire to stay away from any customs union; if $\sigma_{j}^{u}$ includes only one of the two countries then it denotes the player's wish to form a bilateral preferential trade agreement in the form of a customs union with that country only and exclude the third player; if $\sigma_{j}^{u}$ has two other countries then it indicates player's desire to be a part of a free trade world.

Countries are free to choose their announcements, and the agreements can be formed only if partners announce each other. In the customs union game, the countries strategy sets map into the following trade agreements:

(i) Announcement profile $\left\langle\Phi^{u}\right\rangle$ implies that either all three countries announce in the favour of no agreement or countries' announcements do not match. In this case, countries apply individually optimal tariffs and environmental taxes.

(ii) Announcement profile $\langle a b u\rangle$ arises when counties $a$ and $b$ call each other. In this case, members apply zero tariffs on imports from each other and jointly optimal tariff on the import from the outsider, country $c$. However, in the CU game, we allow only trade agreements, so both 
members and the outsider can still apply an individually optimal environmental tax on the domestic producers of the dirty good $A$.

(iii) Similar to (ii), announcement profile $\langle b c u\rangle$ indicate two countries' desire to exclude the third member of the world. In this case, two dirty countries exclude the clean country $a$ and form a trade union which includes only dirty members.

(iv) The announcement profile $\left\langle F^{u}\right\rangle$ signals all three countries' desire to live in a free trade world. Under this profile countries apply zero tariffs on the imports from each other, but they still impose individually optimal environmental taxes.

\subsubsection{Welfare Effects of Various Trade Agreements in the CU Game}

LEMMA 4.2: The welfare impact of various types of trade agreements on members and nonmembers is as follows:

$$
\begin{aligned}
& \left(i^{u}\right) W^{j}\left(b c_{\theta}^{u}\right)>W^{j}\left(N_{\theta}\right) \& W^{j}\left(a j_{\theta}^{u}\right)>W^{j}\left(N_{\theta}\right) \text { where } j \in[b, c] \\
& W^{c}\left(a b_{\theta}^{u}\right)<W^{c}\left(N_{\theta}\right) \text { and } W^{a}\left(b c_{\theta}^{u}\right)<W^{a}\left(N_{\theta}\right) \\
& \left(i i^{u}\right) W^{a}\left(a b_{l}^{u}\right)>W^{a}\left(N_{l}\right) \& W^{a}\left(a b_{g}^{u}\right)<W^{a}\left(N_{g}\right) \\
& \left(i i i^{u}\right) W^{j}\left(b c_{\theta}^{u}\right)>W^{j}\left(a b c_{\theta}\right) \text { where } j \in[b, c] \text { and } W^{a}\left(a b_{\theta}^{u}\right)>W^{a}\left(a b c_{\theta}\right) \\
& W^{a}\left(b c_{\theta}^{u}\right)<W^{a}\left(a b c_{\theta}\right) \text { and } W^{c}\left(a b_{\theta}^{u}\right)<W^{c}\left(a b c_{\theta}\right) \\
& \left(i v^{u}\right) W^{j}\left(a j_{l}^{u}\right)<W^{j}\left(a b c_{l}\right) \& W^{j}\left(a j_{g}^{u}\right)>W^{j}\left(a b c_{g}\right) \text { where } j \in[b, c] \\
& \left(v^{u}\right) W^{j}\left(a j_{\theta}^{u}\right)<W^{j}\left(b c_{\theta}^{u}\right) \text { where } j \in[b, c]
\end{aligned}
$$

The results presented in Lemma4.2( $\left(-i^{u}\right)$ show that both dirty countries are better off in a shallow trade union, either with another dirty country or with the only clean country, than in the no agreement scenario for both local and global levels of pollution. Also, both clean and dirty non-members of the respective unions are worse off. The results in Lemma4.2(-ii $\left.i^{u}\right)$ illustrate a self-exclusion incentive of the clean country $a$; this country is better off in the world with no trade agreements

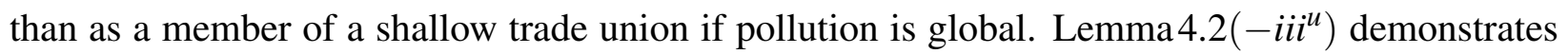


an exclusion incentive; two dirty countries prefer a dirty trade union to a free trade, and the clean country $a$ is better off as a part of a shallow trade union than as a member of a free trade world. Also, a non-member would prefer to be a part of a world trade agreement to being an outsider of a trade union. Lemma4.2(-iv $\left.v^{u}\right)$ states that a dirty country is better off under a world trade agreement than in a shallow trade union with the only clean member of this world if pollution is local. The results in Lemma4.2(- $\left.v^{u}\right)$ show that given the choice between trade union of two symmetric dirty countries and a trade union of two asymmetric, one clean and one dirty, countries, either dirty player would go with former option for both local and global levels of pollution.

\subsubsection{Announcement Profiles, Associated Trade Agreements and Nash Equilibria in the CU Game}

Proposition 4.18: In the CU game, the Nash equilibria announcement profiles and the associated trade agreements are shown in Table 4.2.

\begin{tabular}{|l|c|c|c|}
\hline & Shallow & \multicolumn{2}{|c|}{ Nash Equilibria } \\
\cline { 3 - 5 } Announcement Profiles & Agreements & local & global \\
\hline \hline$\Omega^{\Phi^{u}} \equiv\left\{\sigma_{a}^{u}=\{\varnothing, \varnothing\}, \sigma_{b}^{u}=\{\varnothing, \varnothing\}, \sigma_{c}^{u}=\{\varnothing, \varnothing\}\right\}$ & $\left\langle\Phi^{u}\right\rangle$ & Yes & Yes \\
\hline$\Omega^{a b u} \equiv\left\{\sigma_{a}^{u}=\{b, \varnothing\}, \sigma_{b}^{u}=\{a, \varnothing\}, \sigma_{c}^{u}=\{\varnothing, \varnothing\}\right\}$ & $\langle a b u\rangle$ & Yes & No \\
\hline$\Omega^{b c u} \equiv\left\{\sigma_{a}^{u}=\{\varnothing, \varnothing\}, \sigma_{b}^{u}=\{\varnothing, c\}, \sigma_{c}^{u}=\{\varnothing, b\}\right\}$ & $\langle b c u\rangle$ & Yes & Yes \\
\hline$\Omega^{F^{u}} \equiv\left\{\sigma_{a}^{u}=\{b, c\}, \sigma_{b}^{u}=\{a, c\}, \sigma_{c}^{u}=\{a, b\}\right\}$ & $\left\langle F^{u}\right\rangle$ & No & No \\
\hline
\end{tabular}

Table 4.2: The Nash equilibria announcement profiles and the associated trade agreements in the CU game

To constitute a Nash equilibria, an announcement profile should survive all unilateral deviations, and based on that, the announcement profile $\Omega^{\Phi^{u}}$ is a Nash equilibria. Countries have no incentive 
to announce other countries unless they are going to be announced back, and bilateral/multilateral trade agreements can be formed only if members announce each other. Countries cannot be forced into any agreements. The announcement profile $\Omega^{a b u}$, which constitutes a shallow trade union of one clean and one dirty country, survives the Nash equilibria refinement if pollution is local. To prove that, we use the results presented in Lemma4.2( $\left.-i^{u}\right)$ and Lemma4.2( $\left(-i i^{u}\right)$; neither member can improve its welfare by performing a unilateral deviation into the no agreement scenario. Using the same logic, and the results in Lemma4.2(-ii $\left.{ }^{u}\right)$, we show that the announcement profile $\Omega^{a b u}$ does not survive the Nash equilibria refinement, if pollution is global. In this case, the clean country $a$ would unilaterally deviate by altering its announcements from $\left\{b^{u}, \varnothing\right\}$ into $\{\varnothing, \varnothing\}$ and gain a higher level of welfare by simply excluding itself from this shallow union. The announcement profile $\Omega^{b c u}$, which constitutes a shallow trade union of two symmetric dirty countries, survives Nash equilibria refinement for both local and global levels of pollution. We derive that conclusion based on the results in Lemma4.2(-i $\left.i^{u}\right)$, which states that none of the members has an incentive to change its announcement; the change would lead to the world with no agreements in it and lower level of welfare gains for both dirty countries. The announcement profile $\Omega^{F^{u}}$, which constitutes a free trade world, is not a Nash equilibria for both local and global levels of pollution. The results in Lemma 4.2(-iii $\left.{ }^{u}\right)$ show that either of the dirty countries can improve its welfare by calling another dirty country exclusively. Dirty countries would prefer to exclude the clean partner for both local and global levels of pollution, and based on the above, we are confident to conclude that $\Omega^{\digamma^{u}}$ is not a Nash Equilibria for both local and global levels of pollution. ${ }^{30}$

\subsubsection{Coalition-Proof Nash Equilibria in the CU Game}

To survive the coalition-proof Nash equilibria refinement, an announcement profile should be immune not only to all unilateral deviations, but also to all meaningful coalitional deviations. Based on that, though the announcement profile $\Omega^{\Phi^{u}}$ survives all unilateral deviations, and con-

\footnotetext{
${ }^{30}$ For the proofs, please Appendix A.4.7.1
} 
sequently, constitutes a Nash equilibria, it is not a CPNE for both local and global levels of pollution. To prove that, we analyze a coalitional deviation of two symmetric dirty countries, country $b$ and country $c$. This coalition would alter the announcement profile into the following: $\Omega \equiv\left\{\sigma_{a}^{u}=\{\varnothing, \varnothing\}, \sigma_{b}^{u}=\left\{\varnothing, c^{u}\right\}, \sigma_{c}^{u}=\left\{\varnothing, b^{u}\right\}\right\}$. As a result, we observe an increase in members' welfare levels, $W^{j}\left(b c_{\theta}^{u}\right)>W^{j}\left(N_{\theta}\right)$ where $j \in[b, c]$. This trade union brings its members the highest level of welfare in this entire game, so we can conclude that country $b$ and country $c$ can form a self-enforcing trade agreement for both levels of pollution, and no further deviations would occur. The results in Lemma4.2(-v $\left.v^{u}\right)$ show that the announcement profile $\Omega^{a b u}$ is not a CPNE; the dirty member of this union would deviate to form a shallow trade union with another dirty country and by doing so achieve the highest level of welfare possible in this game. As we have shown in the previous section, the announcement profile $\Omega^{F^{u}}$ is not a Nash equilibria for both levels of pollution, and consequently, it cannot be a CPNE. Now, we are ready to state the following:

Proposition 4.19: The only coalition-proof Nash equilibria of the CU game is the announcement profile $\Omega^{b c u}$ which constitutes a shallow trade union between two symmetric dirty countries. Neither member of this union can improve its welfare by deviating from the original announcement: $\sigma_{b}^{u}=\{\varnothing, c\}$ and $\sigma_{c}^{u}=\{\varnothing, b\}$. Any possible deviation, unilateral or coalitional, would result in a lower welfare gains for the deviating member as well as for the second member of this union. The level of welfare members achieve under a shallow trade union of two symmetric dirty countries is the highest in the entire game. We conclude that, $\Omega^{b c u}$ is a self-enforcing commitment between two dirty countries for both local and global levels of pollution. ${ }^{31}$

\footnotetext{
${ }^{31}$ For the proofs, please Appendix A.4.7.1
} 


\subsubsection{The Free Trade Agreement Game}

\subsubsection{Preferential Trade Agreements in the FTA Game}

In the first stage of the FTA game, players also announce countries they would like to form a PTA with, but in this game preferential trade agreements take the form of free trade agreements. Each player's strategy set $\left(S_{j}\right)$ consists of four possible announcements denoted as $\sigma_{j}$ :

$$
\begin{aligned}
& S_{a}=\{\{\varnothing, \varnothing\},\{b, \varnothing\},\{\varnothing, c\},\{b, c\}\} \\
& S_{b}=\{\{\varnothing, \varnothing\},\{a, \varnothing\},\{\varnothing, c\},\{a, c\}\} \\
& S_{c}=\{\{\varnothing, \varnothing\},\{a, \varnothing\},\{\varnothing, b\},\{a, b\}\}
\end{aligned}
$$

where announcement $\sigma_{j}=\{\varnothing, \varnothing\}$ indicates player's desire to stay away from any free trade agreement with either partner; if $\sigma_{j}$ includes only one of the two countries then it denotes the player's wish to form a bilateral free trade agreement with that country only and exclude the third player; if $\sigma_{j}$ has two other countries then it indicates player's desire to be a trade partner of both countries. Countries are free to choose their announcements, and free trade agreements can be formed only if partners announce each other. In the FTA game, the countries strategy sets map into the following free trade agreements:

(i) If all three players announce $\{\varnothing, \varnothing\}$ or the announcement profiles do not match, it results in the profile $\langle\Phi\rangle$ - no agreement, and each player applies individually optimal tariffs.

(ii) Country $a$ 's announcement $\{b, \varnothing\}$ and country $b$ 's announcement $\{a, \varnothing\}$ lead to a profile $\langle a b\rangle$. The changes in country c's announcement would not alter the profile because neither $a$ no $b$ is calling $c$. This profile implies that members apply zero tariffs on imports from each other and individually optimal tariffs of the import from the outsider, country $c$.

(iii) Similar to (ii), announcement profile $\langle b c\rangle$ indicate two countries' desire to exclude a third member of the world. In this case, two dirty countries exclude the clean country $a$ and form a free trade agreement which includes only dirty members. 
(iv) If both dirty countries announce only in favour of a free trade agreement with the clean country, and the clean country announces in the favour of a free trade world, then these announcements result in a hub-and-spoke trade regime. In this case, the clean country $a$ is the hub, and two dirty countries are the spokes, $\langle a h\rangle$. Under this profile, country $a$ imposes zero tariffs on the imports from the dirty part of the world as well as both dirty countries impose zero tariffs on the imports from the clean country $a$. However, these dirty spokes still impose positive tariffs on the imports from each other.

(v) Similar to (iv), if one clean and one dirty country announce in the favour of a third country, and that country announces in the favour of a free trade world, then that third country would turn into a hub and other two would be the spokes. The profile matching those announcements is $\langle b h\rangle$, where $b$ is the hub, and countries $a$ and $c$ are the spokes.

(iv) As in the CU game, the announcement profile $\langle F\rangle$ signals all three countries' desire to live in a free trade world. Under this profile countries apply zero tariffs on the imports from each other, but they still impose individually optimal environmental taxes.

\subsubsection{Welfare Effects of Various Trade Agreements in the FTA Game}

LEMMA 4.3: The welfare impact of various types of trade agreements on members and nonmembers is as follows:

(i) $W^{a}\left(b c_{\theta}\right)>W^{a}\left(N_{\theta}\right) ; W^{a}\left(a b c_{l}\right)>W^{a}\left(a b_{l}\right)>W^{a}\left(b c_{l}\right) \& W^{a}\left(b c_{g}\right)>W^{a}\left(N_{g}\right)>W^{a}\left(a b c_{g}\right)$

$$
W^{c}\left(a b_{l}\right) \stackrel{\lambda>\bar{\lambda}}{>} W^{c}\left(a b c_{l}\right)>W^{c}\left(N_{l}\right) ; W^{c}\left(a b c_{l}\right) \stackrel{\lambda \leq \bar{\lambda}}{>} W^{c}\left(a b_{l}\right)
$$

(ii) $W^{a}\left(a b_{g}\right)<W^{a}\left(N_{g}\right) ; W^{b}\left(a b_{l}\right) \stackrel{\lambda \leq \lambda}{<} W^{b}\left(N_{l}\right) ; W^{b}\left(a b_{g}\right) \stackrel{\lambda>\bar{\lambda}}{<} W^{b}\left(N_{g}\right)$

$$
W^{a}\left(a b_{l}\right)>W^{a}\left(N_{l}\right) ; W^{b}\left(a b_{l}\right) \stackrel{\lambda>\lambda}{>} W^{b}\left(N_{l}\right) ; W^{b}\left(a b_{g}\right) \stackrel{\lambda \leq \lambda}{>} W^{b}\left(N_{g}\right)
$$

(iii) $W^{j}\left(b c_{\theta}\right)>W^{j}\left(N_{\theta}\right) ; W^{j}\left(b c_{l}\right)<W^{j}\left(a b c_{l}\right) \& W^{j}\left(b c_{g}\right)>W^{j}\left(a b c_{g}\right) ; W^{j}\left(b c_{\theta}\right)>W^{j}\left(a j_{\theta}\right), j \in$ $[b, c]$

(iv) $W^{a}\left(a_{l}^{h}\right)>W^{a}\left(a b_{l}\right) ; W^{b}\left(b_{\theta}^{h}\right)>W^{b}\left(b c_{\theta}\right) ; W^{c}\left(a b_{l}\right)>W^{c}\left(b_{l}^{h}\right)>W^{c}\left(a_{l}^{h}\right)$ 


$$
W^{a}\left(a_{g}^{h}\right)<W\left(N_{g}\right) ; W^{a}\left(b c_{l}\right) \stackrel{\lambda \leq \lambda}{>} W^{a}\left(b_{l}^{h}\right) ; W^{a}\left(b c_{l}\right) \stackrel{\lambda>\lambda}{<}=\stackrel{\lambda}{=} W^{a}\left(b_{l}^{h}\right) ; W^{c}\left(b_{g}^{h}\right)<W^{c}\left(a b_{g}\right) ;
$$

The results of Lemma4.3(-i) illustrate that each of the three countries can benefit from excluding itself from a free trade world for some levels of productivity parameter and negative externality. The only clean country, country $a$, prefers to be an outsider of a bilateral trade agreement between two dirty countries for any levels lambda and pollution, and if pollution is global then that clean country $a$ would be happy to exclude itself from a world trade agreement to achieve the highest level of welfare in this entire game. Either dirty country would do exactly the same by excluding themselves from the world trade agreement if pollution is local and the productivity gap is relatively narrow. The results in Lemma4.3(-ii) state that both, clean and dirty, members of a shallow FTA prefer to self-exclude themselves from this agreement for some levels of productivity parameter and negative externality. Precisely, the clean country $a$ is better off in the world with no trade agreements than in a shallow bilateral FTA with one of the dirty countries if pollution is global, and the dirty country $b$ would prefer to exit this bilateral trade agreement for both levels of pollution if the productivity gap is relatively narrow. Lemma4.3(-iii) shows that dirty countries are always better off in a shallow FTA than in the no agreement scenario. Also, if pollution is global then dirty players have an incentive to exclude the only clean member of the world, and if pollution is local, then those dirty country countries would prefer the clean country to join them in a shallow trade agreement. Lemma4.3(-iv) illustrates the following: if pollution is local then one of the dirty spokes would always prefer to exclude itself from both hub-and-spoke trade regimes and become an outsider of a bilateral FTA between one clean and one dirty country, and if pollution is global then the only clean country would self-exclude itself. Self-Exclusion of country $a$ would either give us the world with no trade agreements in it (the self-exclusion of a hub) or the world with a bilateral FTA of two symmetric dirty countries (self-exclusion of a spoke), and in either cases, the clean country $a$ would benefit from being an outsider and enjoy the higher levels of welfare gains. 


\subsubsection{Announcement Profiles, Associated Trade Agreements and Nash Equilibria in the}

FTA Game

Proposition 4.20: In the FTA game, the Nash equilibria announcement profiles and the associated trade agreements are shown in Table 4.3.

\begin{tabular}{|l|c|c|c|}
\hline & Shallow & \multicolumn{2}{|c|}{ Nash Equilibria } \\
\cline { 3 - 4 } Announcement Profiles & Agreements & local & global \\
\hline \hline$\Omega^{\Phi} \equiv\left\{\sigma_{a}=\{\varnothing, \varnothing\}, \sigma_{b}=\{\varnothing, \varnothing\}, \sigma_{c}=\{\varnothing, \varnothing\}\right\}$ & $\langle\Phi\rangle$ & Yes & Yes \\
\hline$\Omega^{a b} \equiv\left\{\sigma_{a}=\{b, \varnothing\}, \sigma_{b}=\{a, \varnothing\}, \sigma_{c}=\{\varnothing, \varnothing\}\right\}$ & $\langle a b\rangle$ & Yes if $\lambda \leq \underline{\lambda}$, & No \\
\hline$\Omega^{b c} \equiv\left\{\sigma_{a}=\{\varnothing, \varnothing\}, \sigma_{b}=\{\varnothing, c\}, \sigma_{c}=\{\varnothing, b\}\right\}$ & $\langle b c\rangle$ & No if $\lambda>\underline{\lambda}$ & \\
\hline$\Omega^{a h} \equiv\left\{\sigma_{a}=\{b, c\}, \sigma_{b}=\{a, \varnothing\}, \sigma_{c}=\{a, \varnothing\}\right\}$ & $\langle a h\rangle$ & Yes & Yes \\
\hline$\Omega^{b h} \equiv\left\{\sigma_{a}=\{b, \varnothing\}, \sigma_{b}=\{a, c\}, \sigma_{c}=\{\varnothing, b\}\right\}$ & $\langle b h\rangle$ & No & No \\
\hline$\Omega^{F} \equiv\left\{\sigma_{a}=\{b, c\}, \sigma_{b}=\{a, c\}, \sigma_{c}=\{a, b\}\right\}$ & $\langle F\rangle$ & Yes if $\lambda \leq \bar{\lambda}$, & No \\
\end{tabular}

Table 4.3: The Nash equilibria announcement profiles and the associated trade agreements in the FTA game

To prove that the announcement profile $\Omega^{\Phi}$, which constitutes the world with no trade agreements in it, is a Nash equilibria, we use the logic similar to the one we used in the CU game. Simply, no player would be better off by unilaterally changing its announcement, and therefore, $\Omega^{\Phi}$ is a Nash equilibria. We use the results presented in Lemma4.3(-ii) to prove that the announcement profile $\Omega^{a b}$, which constitutes a shallow bilateral trade agreement between one clean and one dirty country, is a Nash equilibria if pollution is local and the productivity gap is relatively wide. In this case, none of the members, neither country $a$ no country $b$, can improve their welfares by deviating 
into the no agreement scenario, and this deviation is the only one possible. The same lemma shows that the announcement profile $\Omega^{a b}$ does not survive Nash equilibria refinement if pollution is local and the productivity gap is relatively small; the dirty country $b$ can improve its welfare by unilaterally changing the announcement to deviate into the no agreement scenario. Also, the results in Lemma4.3(-ii) show that if pollution is global, then the clean country $a$ would prefer to selfexclude itself from the shallow FTA with one of the dirty countries and enjoy the increased welfare under the no agreement scenario. The announcement profile $\Omega^{b c}$, which constitutes a shallow FTA between two symmetric dirty countries, is a Nash equilibria for both levels of pollution, and we prove it by using the results in Lemma4.3(-iii). These results show that neither member can improve its welfare by performing a unilateral deviation; the dirty countries are better off together than in the no agreement scenario.

In our model, two different shallow hub-and-spoke trade regimes can arise, $\left(a_{\theta}^{h}\right)$ and $\left(b_{\theta}^{h}\right)$. The announcement profile $\Omega^{a h}$ results in $\left(a_{\theta}^{h}\right)$, and the announcement profile $\Omega^{b h}$ in $\left(b_{\theta}^{h}\right)$. The results in Lemma 4.3 $(-i v)$ clearly show that none of these profiles constitutes a Nash equilibria: if pollution is local then country $c$, the spoke in both $\left(a_{\theta}^{h}\right)$ and $\left(b_{\theta}^{h}\right)$, would prefer to self-exclude itself and face the bilateral FTA as an outsider versus being a spoke in either hub-and-spoke trade regime; and if pollution is global than the clean country $a$ would self-exclude itself from either hub-andspoke trade regimes. As a hub in $\left(a_{\theta}^{h}\right)$ trade regime, country $a$ has enough power to bring world to the no agreement scenario, and as one of the spokes in $\left(b_{\theta}^{h}\right)$ trade regime, the clean country $a$ can enjoy the highest level of welfare in the entire game by simply self-excluding itself to become an outsider of a bilateral FTA between two dirty countries. The announcement profile $\Omega^{F}$ is immune to all unilateral deviations if pollution is local and the productivity gap is relatively large, and to prove it we use the results in Lemma4.3(-i) and Lemma4.3(-iii). The results in those lemmas show that neither member of this world free trade agreement has an incentive to perform a unilateral deviation and become either a spoke or an outsider of a bilateral trade agreement of other two members of the world. To prove that the announcement profile $\Omega^{F}$ does not survive the Nash equilibria refinement if pollution is local and the productivity gap is relatively narrow we use 
the results in Lemma4.3(-i), which state that either dirty member of the world can benefit from separating itself from a world shallow free trade agreement and becoming an outsider of a bilateral FTA of one clean and one dirty country. Also, the results in Lemma4.3(-i) show that if pollution is global, then the only clean member of the world would undertake a unilateral deviation and exclude itself from the world free trade agreement to become and outsider of a bilateral FTA of two dirty players and gain the highest level of welfare possible in this entire game. Based on that, we conclude that $\Omega^{F}$ is not a Nash equilibria if pollution is local and productivity gap is relatively narrow and if pollution is global. ${ }^{32}$

\subsubsection{Coalition-Proof Nash Equilibria of the FTA Game}

Coalition-proof Nash equilibria is a refinement of a set of Nash equilibria which needs to survive all possible meaningful self-enforcing coalitions, and again, though the no agreement announcement profile, $\Omega^{\Phi}$, constitutes a Nash equilibria, this profile does not survive coalition-proof Nash equilibria refinement. We prove it by considering the coalitional deviation of two symmetric dirty countries in the form of a shallow bilateral trade agreement, and the results in Lemma 4.3(-iii) show that dirty countries are always better off in a shallow FTA than in the no agreement scenario. Based of that, we conclude that $\Omega^{\Phi}$ is not a CPNE for both local and global levels of pollution. Also, thought the announcement profile $\Omega^{a b}$ survives all Nash equilibria refinements if pollution is local and the productivity gap is relatively large, it does not constitute a CPNE. To prove it, we analyze the grand coalition and observe the following: all three countries can improve their welfares by deviating to form a free trade world: $W^{a}\left(a b c_{l}\right)>W^{a}\left(a b_{l}\right)$ and $W^{b}\left(a b c_{l}\right)>W^{b}\left(a b_{l}\right)$, and $W^{c}\left(a b c_{l}\right)>W^{c}\left(a b_{l}\right)$ if productivity gap is relatively large, Lemma4.3(-i) and Lemma4.3(-iii). The announcement profile $\Omega^{b c}$, which constitutes a shallow bilateral trade agreement between two symmetric dirty countries, survives Nash equilibria refinement for all levels of pollution and productivity parameter, but it does not survive a coalition-proof Nash equilibria refinement if pollution

\footnotetext{
${ }^{32}$ For the proofs, please Appendix A.4.7.2
} 
is local. We prove the above in two steps. First, we examine the grand coalition, and again we observe that all three countries can improve their welfares by deviating to form a free trade world: $W^{a}\left(a b c_{l}\right)>W^{a}\left(b c_{l}\right)$ and $W^{b}\left(a b c_{l}\right)>W^{b}\left(b c_{l}\right) ; W^{c}\left(a b c_{l}\right)>W^{c}\left(b c_{l}\right)$ and $W^{c}\left(a b c_{l}\right)>W^{c}\left(a b_{l}\right)$ if productivity gap is relatively large, Lemma4.3(-i) and Lemma4.3(-iii). This deviation is selfenforcing, because any change in either member's announcement would turn one of the two other countries into a hub or make the country, which changes the announcement, into an outsider of a bilateral trade agreement, and either move would lead to lower welfare gains for a deviating country. Based on that, we conclude, that this deviation is both meaningful and self-enforcing, and consequently, $\Omega^{b c}$ is not a CPNE if pollution is local and productivity gap is relatively large. The case of local pollution and narrow productivity gap is examined later in this section. We can conclude, that $\Omega^{a b}$ is not a CPNE. Now, we can state the following:

Proposition 4.21: The only coalition-proof Nash equilibria of the FTA game, if pollution is global, is the announcement profile $\Omega^{b c}$ which constitutes a bilateral free trade agreement between two symmetric dirty countries.

To prove the above proposition, we examine all possible meaningful deviations. First, we consider the coalition of two asymmetries countries, clean country $a$ and dirty country $b$, and we observe that this deviation is not meaningful due to negative changes in the welfare gains of both members, Lemma4.3(-i) and Lemma4.3(-iii). Now, we examine the grand coalition, and again we observe that the only clean country, country $a$, prefers to stay an outsider of this shallow trade agreement between two symmetric dirty countries, because the role of an outsider brings country $a$ the highest level of welfare in this entire game. Again, we can see that this deviation is not meaningful. Based on the above, we conclude, $\Omega^{b c}$ is a CPNE if pollution is global.

Proposition 4.22: The only coalition proof Nash equilibria of the FTA game, if pollution is local and the productivity gap is relatively large, is the announcement profile $\Omega^{F}$ which constitutes a free trade world; and if pollution is local and the productivity gap is relatively narrow, then there is no coalition-proof Nash equilibria in this game.

To prove the above, we examine all possible meaningful deviations. First, we consider the coalition 
of two asymmetries countries, country $a$ and country $b$, and we observe that this coalitional deviation would result is a lower welfare gains for both members, Lemma4.3(-i) and Lemma4.3(-iii), and based on that, we conclude that this deviation is not meaningful. Now, we consider the coalition of two symmetries dirty countries, country $b$ and country $c$, and again we observe, that this coalitional deviation would lead to a reduced welfare gains for both deviating countries, Lemma4.3(-iii), and consequently, we conclude that this deviation is not meaning, too. Based on the above, we conclude, $\Omega^{F}$ is a CPNE if pollution is local and the productivity gap is relatively large.

Though, if pollution is local and productivity gap is relatively narrow, there are two announcement profiles which survive Nash equilibria refinement, $\Omega^{\Phi}$ and $\Omega^{b c}$, none of them constitutes a CPNE. As we stated above, two symmetric dirty countries are always better off in an agreement with each other than in the world with no agreements in it, the results in Lemma4.3(-iii). Consequently, this coalitional deviation is both meaningful and self-enforcing, and as a result of it, the announcement profile $\Omega^{\Phi}$ cannot be a CPNE. Now, we examine the announcement profile $\Omega^{b c}$, if pollution is local and the productivity gap is relatively narrow, and we observe that the coalitional deviation of one clean and one dirty country in the case of local pollution and relatively narrow productivity gap is possible. Either member of $\left(b c_{l}\right)$ is interested in making a side deal with the only clean member of the world, country $a$. Country a would except this offer from either dirty country. The clean player is better of as a spoke than as an outsider of a shallow FTA of two dirty countries, Lemma 4.3(-iv). Based on the above, we conclude, $\Omega^{b c}$ is not a CPNE if pollution is local and productivity gap is relatively narrow. ${ }^{33}$

\footnotetext{
${ }^{33}$ For the proofs, please Appendix A.4.7.2
} 


\subsection{Endogenous Deep Trade Agreements}

\subsubsection{The Integrated Customs Union Game}

\subsubsection{Integrated Customs Unions In the IU Game}

In this part of the paper, we describe different deep preferential trade agreements which can arise under the integrated customs union game. The difference between integrated customs union game and customs union game, described in the previous section, lies in the nature of deep and shallow trade agreements. In this game, countries' announcements are not limited to trade agreements only, but they also include an environmental clause. In the first stage of this game, players announce countries they would like to form an integrated union with. Each player's strategy set $\left(S_{j}^{i u}\right)$ consists of four possible announcements denoted as $\sigma_{j}^{i u}$ :

$$
\begin{aligned}
& S_{a}^{i u}=\left\{\{\varnothing, \varnothing\},\left\{b^{i u}, \varnothing\right\},\left\{\varnothing, c^{i u}\right\},\left\{b^{i u}, c^{i u}\right\}\right\} \\
& S_{b}^{i u}=\left\{\{\varnothing, \varnothing\},\left\{a^{i u}, \varnothing\right\},\left\{\varnothing, c^{i u}\right\},\left\{a^{i u}, c^{i u}\right\}\right\} \\
& S_{c}^{i u}=\left\{\{\varnothing, \varnothing\},\left\{a^{i u}, \varnothing\right\},\left\{\varnothing, b^{i u}\right\},\left\{a^{i u}, b^{i u}\right\}\right\}
\end{aligned}
$$

where announcement $\sigma_{j}^{i u}=\{\varnothing, \varnothing\}$ indicates player's desire to stay away from any integrated union; if $\sigma_{j}^{i u}$ includes only one of the two countries then it denotes the player's wish to form an integrated union with that country only and exclude the third player; if $\sigma_{j}^{i u}$ has two other countries then it indicates player's desire to be a partner of both countries.

In the integrated customs union game, the countries strategy sets map into the following deep trade agreements:

(i) If all players announce in the favour of no agreement, or the announcements do not match, it results in the announcement profile $\left\langle\Phi^{i u}\right\rangle$. This profile implies that each player applies individually optimal tariffs and environmental taxes.

(ii) If one clean and one dirty country announce each other, and none of these countries call the second dirty player, then the announcement profile $\langle a b i u\rangle$ arises. In this case, members agree 
on the environmental tax they levy on their producers of the dirty good $A$, apply zero tariffs on imports from each other and jointly optimal tariff on the import from the outsider, country $c$. An outsider is free to choose individually optimal tariffs and taxes.

(iii) Similar to (ii), announcement profile $\langle b c i u\rangle$ indicate two countries' desire to exclude the third member. In this case, two clean countries exclude a dirty country a and form an integrated customs union which includes only clean players.

(iv) The announcement profile $\left\langle F^{i u}\right\rangle$ signals all three countries' desire to live in an entirely integrated world. Under this profile countries agree on the environmental tax level and apply zero tariffs on the imports from each other.

\subsubsection{Welfare Effects of Various Deep Trade Agreements in the IU Game}

LEMMA 4.4: The welfare impact of various types of deep trade agreements on countries-members and non-members is as follows:

$$
\begin{aligned}
& \left(i^{i u}\right) W^{a}\left(a b_{\theta}^{i u}\right)>W^{a}\left(N_{\theta}\right) ; W^{b}\left(a b_{l}^{i u}\right)>W^{b}\left(N_{l}\right) \& W^{b}\left(a b_{g}^{i u}\right)<W^{b}\left(N_{g}\right) \\
& W^{j}\left(b c_{\theta}^{i u}\right)>W^{j}\left(N_{\theta}\right) \text { where } j \in[b, c] \\
& \left(i i^{i u}\right) W^{a}\left(a b c_{\theta}^{i}\right)>W^{a}\left(a b_{\theta}^{i u}\right)>W^{a}\left(N_{\theta}\right) \\
& W^{j}\left(b c_{\theta}^{i u}\right)>W^{j}\left(a b c_{\theta}^{i}\right)>W^{j}\left(N_{\theta}\right) \& W^{j}\left(b c_{\theta}^{i u}\right)<W^{j}\left(a j_{\theta}^{i u}\right) \text { where } j \in[b, c]
\end{aligned}
$$

The results in Lemma4.4 $\left(-i^{i u}\right)$ show that the only clean country, country $a$, is always better off in a deep union with one of the dirty countries, but a dirty country would get into a deep trade agreement with the clean partner only if pollution is purely local. If pollution is global, then a dirty partner of a deep trade union between two asymmetric countries would separate itself and achieve higher welfare gains in the the world with no integrated agreements. Also, Lemma $4.4\left(-i^{i u}\right)$ states that dirty countries would prefer to form a deep trade union versus being a part of no agreement at all for any level of pollution and productivity parameter. The results in Lemma4.4(-ii $\left.{ }^{i u}\right)$ illustrate that the clean member of the world has no exclusion incentive and would prefer to be a part of a 
fully integrated world versus being a member of a bilateral deep trade agreement. On the other hand, the same lemma shows that dirty countries have an incentive to exclude the clean member in the form of a deep trade union of dirty members exclusively, because this union brings its members the highest level of welfare in this entire game.

\subsubsection{Announcement Profiles, Associated Trade Agreements and Nash Equilibria in the IU Game}

Proposition 4.23: In the IU game, the Nash equilibria announcement profile and associated deep trade agreements are shown in Table 4.4.

\begin{tabular}{|l|c|c|c|}
\hline & \multirow{2}{*}{ Deep } & \multicolumn{2}{|c|}{ Nash Equilibria } \\
\cline { 3 - 4 } Announcement Profiles & Agreements & local & global \\
\hline \hline$\Omega^{\Phi^{i u}} \equiv\left\{\sigma_{a}^{i u}=\{\varnothing, \varnothing\}, \sigma_{b}^{i u}=\{\varnothing, \varnothing\}, \sigma_{c}^{i u}=\{\varnothing, \varnothing\}\right\}$ & $\left\langle\Phi^{i u}\right\rangle$ & Yes & Yes \\
\hline$\Omega^{a b i u} \equiv\left\{\sigma_{a}^{i u}=\{b, \varnothing\}, \sigma_{b}^{i u}=\{a, \varnothing\}, \sigma_{c}^{i u}=\{\varnothing, \varnothing\}\right\}$ & $\langle a b i u\rangle$ & Yes & No \\
\hline$\Omega^{b c i u} \equiv\left\{\sigma_{a}^{i u}=\{\varnothing, \varnothing\}, \sigma_{b}^{i u}=\{\varnothing, c\}, \sigma_{c}^{i u}=\{\varnothing, b\}\right\}$ & $\langle b c i u\rangle$ & Yes & Yes \\
\hline$\Omega^{\digamma^{i u}} \equiv\left\{\sigma_{a}^{i u}=\{b, c\}, \sigma_{b}^{i u}=\{a, c\}, \sigma_{c}^{i u}=\{a, b\}\right\}$ & $\left\langle F^{i u}\right\rangle$ & No & No \\
\hline
\end{tabular}

Table 4.4: The Nash equilibria announcement profiles and the associated trade agreements in the IU game

The announcement profile $\Omega^{\Phi^{i u}}$, which constitutes a world with no agreements in it, is a Nash equilibria for both local and global levels of pollution; a unilateral change in any player's announcement does not affect their welfare levels. We use the results in Lemma 4.4 $\left(-i^{i u}\right)$ to prove that the announcement profile $\Omega^{a b i u}$, which results in a deep trade agreement between one clean and one dirty country, is a Nash equilibria if pollution is local, and this announcement profile does 
survive Nash equilibria refinement if pollution exhibits global characteristics. If pollution is local, then neither member of a deep trade union between two asymmetric countries can improve its welfare by unilaterally deviating; both members accrue higher levels of welfare in the deep union with each other than in the no agreement scenario. However, if pollution is global, then the clean partner of this deep trade agreement can improve its welfare gains by deviating into the no agreement scenario. Based on the above, we conclude that the announcement profile $\Omega^{\text {abiu }}$ constitutes Nash equilibria if pollution is local, and if pollution is global, then this profile does not survive Nash equilibria refinement. The announcement profile $\Omega^{\text {bciu }}$, which leads to an integrated union between two dirty countries, is a Nash equilibria for both local and global levels of pollution. To prove that, we use the results in Lemma $4.4\left(-i^{i u}\right)$; dirty countries are better off in a deep trade union with each other than in the no agreement scenario. As a result, there is no unilateral deviation to undertake for either of the members in order to improve their welfares. We prove that the announcement profile $\Omega^{\digamma^{i u}}$, which constitutes a world united under the same environmental agreement with no trade barriers, does not survive Nash equilibria refinement by using the results presented in Lemma 4.4 $\left(-i i^{i u}\right)$. These results show that two dirty players would prefer to exclude the clean country for both local and global levels of pollution; either dirty country can improve its welfare by calling another dirty country exclusively. Dirty countries would always prefer a deep trade of union of dirty members not only to an integrated world but also to a deep trade union with the clean country $a$. Based on that, we conclude, that $\Omega^{\digamma^{i u}}$ is not a Nash equilibria for both local and global levels of pollution. ${ }^{34}$

\subsubsection{Coalition-Proof Nash Equilibria in the IU Game}

The announcement profile $\Omega^{\Phi^{i u}}$ is a Nash equilibria for both local and global levels of pollution, but it does not survive coalition-proof Nash equilibria refinements, and we prove it by considering a deep trade union of two symmetric dirty countries, $b$ and $c$. This trade union brings its members

\footnotetext{
${ }^{34}$ For the proofs, please Appendix A.4.8.1
} 
the highest level of welfares in this game, so we can conclude that these two dirty counties can form a self-enforcing deep trade agreement for both levels of pollution, and no further deviations can occur. Based on the above, we conclude that $\Omega^{\Phi^{i u}}$ is not a CPNE for both levels of pollution. We use similar logic to show that the announcement profile $\Omega^{\text {abiu }}$ does not survive coalitionproof Nash equilibria refinement as well. Again, we consider a deviation of two symmetric dirty countries, country $b$ and country $c$, in the form of a trade and environmental union; the level of welfare these countries achieve from forming an integrated union is the highest in this game, so none of the members would deviate any further. Based on that, we conclude that $\Omega^{a b i u}$ is not a CPNE. Now, we can state the following:

Proposition 4.24: The announcement profile $\Omega^{\text {bciu }}$, which constitutes an integrated union between two symmetric dirty countries, is the only CPNE in this game for both local and global levels of pollution.

Neither member can do better by deviating from their original announcement for both levels of pollution. The level of welfare countries achieve in this deep trade agreement is the highest in this entire game, and based on that we conclude that, $\Omega^{\text {bciu }}$ is a self-enforcing commitment between two dirty countries for both local and global levels of pollution. ${ }^{35}$

\subsubsection{The Integrated Free Trade Agreement Game}

\subsubsection{Integrated FTAs}

In the first stage of this game, players also announce countries they would like to form a deep trade agreement with, but in this game integrated agreements take the form of deep free trade agreements with an environmental clause. Each player's strategy set $\left(S_{j}^{i}\right)$ consists of four possible announcements denoted as $\sigma_{j}^{i}$ :

$$
S_{a}^{i}=\left\{\{\varnothing, \varnothing\},\left\{b^{i}, \varnothing\right\},\left\{\varnothing, c^{i}\right\},\left\{b^{i}, c^{i}\right\}\right\}
$$

\footnotetext{
${ }^{35}$ For the proofs, please Appendix A.4.8.1
} 


$$
\begin{aligned}
& S_{b}^{i}=\left\{\{\varnothing, \varnothing\},\left\{a^{i}, \varnothing\right\},\left\{\varnothing, c^{i}\right\},\left\{a^{i}, c^{i}\right\}\right\} \\
& S_{c}^{i}=\left\{\{\varnothing, \varnothing\},\left\{a^{i}, \varnothing\right\},\left\{\varnothing, b^{i}\right\},\left\{a^{i}, b^{i}\right\}\right\}
\end{aligned}
$$

where announcement $\sigma_{j}^{i}=\{\varnothing, \varnothing\}$ indicates player's desire to stay away from any deep trade agreement with either partner; if $\sigma_{j}^{i}$ includes only one of the two countries then it denotes the player's wish to form an integrated agreement with that country only and exclude the third player; if $\sigma_{j}^{i}$ has two other countries then it indicates player's desire to be a partner of both countries. In the I game, the countries strategy sets map into the following deep trade agreements:

(i) If all three players announce in the favour of no agreement or the announcement profiles do not match, it results in the profile $\left\langle\Phi^{i}\right\rangle$. Under this profile each country applies individually optimal tariffs and environmental tax on its producers of the dirty $\operatorname{good} A$.

(ii) If country $a$ 's announcement is $\left\{b^{i}, \varnothing\right\}$ and country $b$ 's announcement is $\left\{a^{i}, \varnothing\right\}$, the profile $\langle a b i\rangle$ arises. The outsider's announcement would not alter this profile because neither member of this integrated agreement is calling $c$. This profile implies that members agree on the environmental tax they levy on their producers of the dirty good $A$, apply zero tariffs on imports from each other and individually optimal tariff on the import from the outsider, country $c$.

(iii) Similar to (ii), announcement profile $\langle b c i\rangle$ indicates two countries' desire to exclude a third member of the world. In this case, two dirty countries exclude the clean country $a$ and form a deep trade agreement which includes only dirty members.

(iv) If both dirty countries announce only in the favour of a deep trade agreement with the clean country, and the clean country announces in the favour of a fully integrated world, then these announcements result in a hub-and-spoke trade regime with a jointly optimal tax level. In this case, the clean country $a$ is a hub, and two dirty countries are the spokes, $\langle a h i\rangle$. Under this profile, country $a$ imposes zero tariffs on the imports from the dirty part of the world as well as both dirty countries impose zero tariffs on the imports from country $a$. However, two dirty countries still impose positive tariffs on the imports from each other.

(v) Similar to (iv), if one clean and one dirty country announce in the favour of a third country, and that country announces in the favour of a fully integrated trade world, then that third country 
would turn into a hub and other two would be the spokes. The profile matching those announcements is $\langle b h i\rangle$, where $b$ is a hub, and countries $a$ and $c$ are the spokes.

(iv) As in the IU game, the announcement profile $\left\langle F^{i}\right\rangle$ signals all three countries' desire to live in an entirely integrated world. Under this profile countries apply jointly optimal environmental tax and zero tariffs on the imports from each other.

\subsubsection{Welfare Effects of Various Deep Trade Agreements in the I Game}

LEMMA 4.5: The welfare impact of various types of deep trade agreements in the I game on countries-members and non-members is as follows:

$\left(i^{i}\right) W^{a}\left(a b_{\theta}^{i}\right)>W^{a}\left(N_{\theta}\right) ; W^{b}\left(a b_{l}^{i}\right)<W^{b}\left(N_{l}\right) \& W^{b}\left(a b_{g}^{i}\right)>W^{b}\left(N_{g}\right) ; W^{c}\left(a b_{\theta}^{i}\right)>W^{c}\left(N_{\theta}\right) ;$

$\left(i i^{i}\right) W^{j}\left(b c_{\theta}^{i}\right)>W^{j}\left(N_{\theta}\right)$, where $j \neq a ; W^{a}\left(b c_{l}^{i}\right)<W^{a}\left(N_{l}\right) \& W^{a}\left(b c_{g}^{i}\right)>W^{a}\left(N_{g}\right)$;

$\left(i i i^{i}\right) W^{c}\left(a_{l}^{h i}\right)<W^{c}\left(a b_{l}^{i}\right) \& W^{j}\left(a_{g}^{h i}\right)>W^{j}\left(a b_{g}^{i}\right)$ where $j \neq a ; W^{c}\left(b_{\theta}^{h i}\right)<W^{c}\left(a b_{\theta}^{i}\right)$;

$\left(i v^{i}\right) W^{c}\left(a b c_{l}^{i}\right)<W^{c}\left(a b_{l}^{i}\right) \& W^{c}\left(a b c_{g}^{i}\right)>W^{c}\left(a b_{g}^{i}\right)$

$W^{a}\left(a b c_{\theta}^{i}\right)>W^{a}\left(b_{\theta}^{h i}\right)>W^{a}\left(b c_{\theta}^{i}\right) ; W^{c}\left(a b c_{g}^{i}\right)>W^{c}\left(a_{g}^{h i}\right)>W^{c}\left(a b_{g}^{i}\right)>W^{c}\left(b_{g}^{h i}\right) ;$

$\left(v^{i}\right) W^{j}\left(b c_{l}^{i}\right)>W^{j}\left(j_{l}^{h i}\right)$ if $\lambda \leq \underline{\lambda^{i}} \& W^{j}\left(b c_{l}^{i}\right)<W^{j}\left(j_{l}^{h i}\right)$ if $\lambda>\underline{\lambda^{i}} \& W^{j}\left(b c_{g}^{i}\right)<W^{j}\left(j_{g}^{h i}\right), j \neq a$

$\left(v i^{i}\right) W^{a}\left(a b c_{\theta}^{i}\right)>W^{a}\left(a j_{\theta}^{i}\right)$ where $j \neq a$;

$W^{j}\left(j_{g}^{h i}\right)>W^{j}\left(b c_{g}^{i}\right)>W^{j}\left(a b c_{g}^{i}\right)$ if $\lambda \leq \overline{\lambda^{i}} \& W^{j}\left(j_{g}^{h i}\right)>W^{j}\left(a b c_{g}^{i}\right)>W^{j}\left(b c_{g}^{i}\right)$ if $\lambda>\overline{\lambda^{i}}, j \neq a$;

The results in Lemma4.5 $\left(-i^{i}\right)$ state that the clean country would prefer to be a part of a deep trade agreement with either dirty member of the world, for both local and global levels of pollution, but a dirty country is interested in forming this deep bilateral FTA only if pollution is global. Furthermore, "a silent winner" of this agreement is an outsider, country $c$, for both local and global levels of pollution. Lemma4.5 $\left(-i i^{i}\right)$ shows that dirty countries acquire higher welfare gains in a deep trade agreement with each other than in the no agreement scenario, for both levels of pollution, and the clean outsider, country $a$, would actually prefer this agreement to the world with no agreements, but only if pollution is global. The results in Lemma4.5 $\left(-i i^{i}\right)$ reveal, that if 
pollution is local and the clean country is a hub, then each spoke is better of as an outsider of a bilateral deep trade agreement between the hub and the other spoke than as a spoke in this huband-spoke trade regime. However, if pollution is global, then being a spoke is better than being an outsider or even a member of a deep bilateral FTA with the clean country. Also, the same lemma states, that if one of the dirty countries assumes the role of the hub, then the other dirty country would deviate in order to be an outsider of a deep FTA between the hub and the clean spoke, and this deviation would create an increase in the welfare gains of the deviating dirty spoke. The results in Lemma 4.5 $\left(-i v^{i}\right)$ illustrate, first, that either dirty country would rather face a deep bilateral FTA as an outsider than be a part of a fully integrated world if pollution is local, second, if pollution is global, then a self-exclusion of any player would lead to a reduction in this deviating player's welfare, and third, the clean country is better of as a spoke than as an outsider of a deep FTA of two dirty players for any level of pollution and productivity parameter. Lemma4.5 $\left(-v^{i}\right)$ shows that, for any dirty country, it is better to be a hub than a member of a deep bilateral trade agreement with another dirty country if pollution is global and if pollution is local and the productivity gap is relatively narrow. However, if pollution is local and the productivity gap is relatively wide, then those two dirty countries achieve the highest level of welfare in the deep FTA with each other. The results in Lemma 4.5 $\left(-v i^{i}\right)$ state that the clean country $a$ would always prefer to be a part of a fully integrated world to being a member of a deep bilateral FTA, and the dirty countries prefer the same if pollution is global and the productivity gap is relatively narrow. 


\subsubsection{Announcement Profiles, Associated Trade Agreements and Nash Equilibria in the I}

Game

Proposition 4.25: In the I game, the Nash equilibria announcement profiles and the associated integrated agreements are shown in Table 4.5.

\begin{tabular}{|l|c|c|c|}
\hline & Deep & \multicolumn{2}{|c|}{ Nash Equilibria } \\
\cline { 3 - 4 } Announcement Profiles & Agreements & local & global \\
\hline \hline$\Omega^{\Phi^{i}} \equiv\left\{\sigma_{a}^{i}=\{\varnothing, \varnothing\}, \sigma_{b}^{i}=\{\varnothing, \varnothing\}, \sigma_{c}^{i}=\{\varnothing, \varnothing\}\right\}$ & $\left\langle\Phi^{i}\right\rangle$ & Yes & Yes \\
\hline$\Omega^{a b i} \equiv\left\{\sigma_{a}^{i}=\{b, \varnothing\}, \sigma_{b}^{i}=\{a, \varnothing\}, \sigma_{c}^{i}=\{\varnothing, \varnothing\}\right\}$ & $\langle a b i\rangle$ & No & Yes \\
\hline$\Omega^{b c i} \equiv\left\{\sigma_{a}^{i}=\{\varnothing, \varnothing\}, \sigma_{b}^{i}=\{\varnothing, c\}, \sigma_{c}^{i}=\{\varnothing, b\}\right\}$ & $\langle b c i u\rangle$ & Yes & Yes \\
\hline$\Omega^{a h i} \equiv\left\{\sigma_{a}^{i}=\{b, c\}, \sigma_{b}^{i}=\{a, \varnothing\}, \sigma_{c}^{i}=\{a, \varnothing\}\right\}$ & $\langle a h i\rangle$ & No & Yes \\
\hline$\Omega^{b h i} \equiv\left\{\sigma_{a}^{i}=\{b, \varnothing\}, \sigma_{b}^{i}=\{a, c\}, \sigma_{c}^{i}=\{\varnothing, b\}\right\}$ & $\langle b h i\rangle$ & No & No \\
\hline$\Omega^{F^{i}} \equiv\left\{\sigma_{a}^{i}=\{b, c\}, \sigma_{b}^{i}=\{a, c\}, \sigma_{c}^{i}=\{a, b\}\right\}$ & $\left\langle F^{i}\right\rangle$ & No & Yes \\
\hline
\end{tabular}

Table 4.5: The Nash equilibria announcement profiles and the associated trade agreements in the I game

The announcement profile $\Omega^{\Phi^{i}}$, which results in each country applying individually optimal trade tariffs and environmental taxes, again, constitutes a non-cooperative Nash equilibria for both local and global levels of pollution; any unilateral change any player can perform would not results in the change in their welfare levels. The announcement profile $\Omega^{a b i}$, which constitutes a deep trade agreement between one clean and one dirty country, is not a Nash equilibria if pollution is local. The results in Lemma4.5 $\left(-i^{i}\right)$ state that though the clean member of the world has no incentive to deviate from its announcement, the dirty partner of this agreement is better off in the world with no agreements in it than in an agreement with the clean country if pollution is local. Based on that, we conclude that $\Omega^{a b i}$ does not survive unilateral deviations, and consequently, cannot be a 
Nash equilibria if pollution is local. The same lemma shows that if pollution is global, then neither member can improve its welfare by deviating unilaterally, so $\Omega^{a b i}$ is a Nash equilibria if pollution is global. Based on the results in Lemma4.5 $\left(-i i^{i}\right)$, we conclude that the announcement profile $\Omega^{b c i}$, which constitutes a deep FTA between two symmetric dirty countries, is a Nash equilibria for both local and global levels of pollution. Neither member of this agreement can improve its welfare by unilaterally changing their announcements. The announcement profile $\Omega^{a h i}$, which constitutes a deep hub-and-spoke trade regime with the clean country assuming the role of the hub, does not survive Nash equilibria refinement if pollution is local. To prove that, we use the results presented in Lemma4.5 $\left(-i i^{i}\right)$; either dirty spoke has an incentive to perform a unilateral deviation in order to face a bilateral FTA between the clean hub and the second dirty spoke. This change in the announcement would improve the deviating country's welfare, and based on that, we conclude that the announcement profile $\Omega^{a h i}$ is not a Nash equilibria if pollution is local. However, the global level of pollution creates an incentive for the dirty spokes to stay in this deep hub-and-spoke trade regime, Lemma 4.5 $\left(-i i i^{i}\right)$, and we conclude that $\Omega^{a h i}$ survives all Nash equilibria refinements if pollution is global. Also, based on the results in the same lemma, Lemma4.5(-iii $\left.{ }^{i}\right)$, we conclude that the announcement profile $\Omega^{b h i}$, which constitutes a deep hub-and-spoke trade regime with one of the dirty countries assuming the role of the hub, is not a Nash equilibria for both local and global levels of pollution. In this case, the dirty spoke is better off deviating into the outsider of a deep FTA between the hub and the clean spoke. This unilateral deviation would lead to an increase in the welfare level of the dirty spoke, and based on the above, we conclude that $\Omega^{b h i}$ is not a Nash equilibria for both local and global levels of pollution. The announcement profile $\Omega^{\digamma^{i}}$, which constitutes a fully integrated world, does not survive Nash equilibria refinement if pollution is local, and to prove that, we use the results in Lemma4.5 $\left(-i v^{i}\right)$. These results show that if pollution is local, then either dirty country has an incentive to self-exclude from this deep free trade agreement to improve its welfare gains; for a dirty country, being an outsider of a deep bilateral FTA between the clean country and the second dirty player brings higher welfare gains than being a part of a fully integrated world if pollution is local. Based on the above, we conclude that the announcement 
profile $\Omega^{\digamma^{i}}$ is not a Nash equilibria if pollution is local. Also, the results in Lemma 4.5 $\left(-i v^{i}\right)$ show that if pollution is global than none of the members has an incentive to deviate from the deep free trade agreement. In this case, there are two possible unilateral deviations: first, any country can completely separate itself from this agreement, by changing its announcement into $\{\varnothing, \varnothing\}$, and this would lead to this deviating country facing a deep FTA of two other members of the world, and lower welfare gains; and second, a deviating country can just limit its announcement and include only one of two other countries, and this change would lead to a creation of one of the two hub-and-spoke deep trade regimes, and consequently, result in a lower level of welfare gains for the deviating country. Based on the above, we conclude that there is no meaningful unilateral deviations, and the announcement profile $\Omega^{\digamma^{i}}$ is a Nash equilibria if pollution is global. ${ }^{36}$

\subsubsection{Coalition-Proof Nash Equilibria of the I Game}

Again, though the announcement profile $\Omega^{\Phi^{i}}$ constitutes a Nash equilibria for both local and global levels of pollution, it does not survive the coalition-proof Nash equilibria refinement. To prove it, we examine the coalitional deviation of two symmetric dirty countries, country $b$ and country $c$, and based on the results in Lemma4.5 $\left(-i i^{i}\right)$, we conclude that this deviation in meaningful and self-enforcing, and consequently, $\Omega^{\Phi^{i}}$ is not a CPNE for both levels of pollution. The announcement profile $\Omega^{b c i}$, as well as $\Omega^{\Phi^{i}}$, survives all possible unilateral deviations, and consequently constitutes Nash equilibria for all levels of pollution and productivity parameter, but it does not survive the coalition-proof Nash equilibria refinement if pollution is global and if pollution is local and the productivity gap is relatively narrow. We discuss the case of local pollution later in this section, and now we examine the case of global pollution. The results in Lemma $4.5\left(-i v^{i}\right)$ show that the clean country $a$ is better off as a spoke than as an outsider of $\langle b c i\rangle$ if pollution is global, and Lemma4.5 $\left(-v^{i}\right)$ states that any dirty country is better off as a hub than as a member of a deep FTA with another dirty country. Based on this, we conclude that either member of $\langle b c i\rangle$ would offer

\footnotetext{
${ }^{36}$ For the proofs, please Appendix A.4.8.2
} 
a deal to the outsider, country $a$, and turn into a hub, and consequently, the announcement profile $\Omega^{b c i}$ does not survive coalition-proof Nash equilibria refinement if pollution is global. Now, we can state the following proposition:

Proposition 4.26: If pollution is local and the productivity gap is relatively large, then the only coalition-proof Nash equilibria of the I game is the announcement profile $\Omega^{b c i}$, which constitutes a deep bilateral trade agreement between two symmetric dirty countries, and if productivity gap is relatively narrow, then there is no coalition-proof Nash equilibria is this game.

If pollution is local and the productivity gap is relatively wide, the level of welfares the members of $\langle b c i\rangle$ acquire is the highest in this entire game, Lemma4.5 $\left(-v^{i}\right)$, and based on that, we conclude that there are no meaningful coalitional deviations, and the announcement profile $\Omega^{b c i}$ constitutes a CPNE. If pollution is local and the productivity gap is relatively narrow, then there is no coalitionproof Nash equilibria in this game. There are only two announcement profiles, $\Omega^{\Phi^{i}}$ and $\Omega^{b c i}$, which survive all unilateral deviations, and consequently constitute Nash equilibria in this game, if pollution is local and the productivity gap is relatively narrow. We have already ruled out the no agreement announcement profile earlier in this section, and now, we are going to present our reasons to rule out the second candidate, $\Omega^{b c i}$. To do so, we examining the coalitional deviation of one clean and one dirty country. Either member of $\langle b c i\rangle$ is interested in making a side deal with the only clean member of the world, country $a$, Lemma $4.5\left(-v^{i}\right)$, and country $a$ would except this offer from either dirty country, Lemma $4.5\left(-i v^{i}\right)$. Either dirty country is better off as a hub than as a member of a deep bilateral FTA with another dirty country, and the clean player is better of as a spoke than as an outsider of this deep FTA. Based on the above, we conclude that there is no announcement profile that satisfies coalition-proof Nash equilibria requirements in the I game, if pollution is local and the productivity gap is relatively narrow.

Proposition 4.27: If pollution is global, then the only coalition-proof Nash equilibria of the I game is the announcement profile $\Omega^{\digamma^{i}}$, which constitutes a fully integrated world.

We prove the above by examining all possible deviations. The first deviation we examine is the coalition of the clean country $a$ and one of the dirty players, then according to Lemma $4.5\left(-v i^{i}\right)$, 
the clean country $a$ is worse off, and we conclude that this deviation is not meaningful. Second, we consider the coalitional deviation of two symmetric dirty countries, if pollution is global and productivity gap is relatively large. In this case, the results in Lemma4.5 $\left(-i v^{i}\right)$ illustrate that this initial deviation is meaningful, but in the same time, both dirty countries have an incentive to deviate further and become a hub, Lemma4.5 $\left(-v i^{i}\right)$, and based on that, we conclude that though this deviation is meaningful, it is not self-enforcing. In this step, we consider the coalitional deviation of two symmetric dirty countries when productivity gap is relatively narrow, and we observe that this initial deviation is not meaningful, and the only reason dirty countries would form this agreement is a further deviation to become a hub, Lemma4.5(-vi $i^{i}$. Based on the above, we conclude that the announcement profile $\Omega^{\digamma^{i}}$ survives all possible meaningful and self-enforcing deviations, and consequently, constitutes a CPNE if pollution is global. ${ }^{37}$

\subsection{Further Discussion on Shallow versus Deep Integration}

\subsubsection{Article XXIV Restriction on External Tariffs}

The Article XXIV of GATT/WTO prevents the members from rising their jointly optimal tariff on the non-member above the pre-existing level. In our model, the pre-existing level of the external tariff is the optimal Nash tariffs under no agreement. In the previous sections of this paper, we have ignored this restriction and let countries set their tariffs at the levels they find optimal. However, in this subsection, we factor the Article XXIV in and analyze the consequences of restricting members of various deep and shallow trade agreements from raising their external tariff above the no agreement level.

The pooled market power of customs unions' members allows them to bring their jointly optimal tariff above the no agreement level, and due to that, in our model, we observe the increase in the tariffs on the imports from the outsider under the formation of both deep and shallow CUs of two asymmetric countries, country $a$ and country $b$. In our competing exporters model, countries are

\footnotetext{
${ }^{37}$ For the proofs, please Appendix A.4.8.2
} 
natural importers of only one good, the good they do not have a comparative advantage in. As a result of this set up, the outsider of either deep or shallow union of country $a$ and country $b$, country $c$, faces a single tariff on its export of two different goods, the dirty good $A$ to the clean good $B$. Precisely, $t^{c}\left(a b_{l}^{u}\right)>t_{A}^{c}\left(N_{l}\right)$ and $t^{c}\left(a b_{g}^{u}\right)>t_{B}^{c}\left(N_{g}\right)$ and $t^{c}\left(a b_{g}^{i u}\right)>t_{B}^{c}\left(N_{g}\right)$. The explanation for the above inequalities lies in the nature of those two goods, one is clean and one is dirty, and this consequently explains the difference in the no agreement levels of tariffs on those two goods: $t_{B}^{c}\left(N_{l}\right)>t_{A}^{c}\left(N_{l}\right)$ and $t_{B}^{c}\left(N_{g}\right)<t_{A}^{c}\left(N_{g}\right)$. In order to comply with the Article XXIV restrictions, we

set the levels of these jointly optimal tariffs as follows: $t^{c}\left(a b_{l}^{u}\right)=t_{A}^{c}\left(N_{l}\right)$ and $t^{c}\left(a b_{g}^{u}\right)=t_{B}^{c}\left(N_{g}\right)$ and $t^{c}\left(a b_{g}^{i u}\right)=t_{B}^{c}\left(N_{g}\right)$. Those changes do not alter our main results; even the implication of the Article XXIV still leads to either shallow or deep customs union of two symmetric countries surviving the coalition-proof Nash equilibria refinement in respectively shallow and deep CU game.

\subsubsection{Choice of Deep and Shallow Agreements}

So far in this chapter, we have described five games: the environmental agreements game, the E game, two shallow trade agreements games, the CU game and the FTA game, and two deep trade agreements games, the IU game and the I game. In each of those games, the countries' announcement sets are limited to a particular type of trade agreements. In this section, we take a step further and consider four extended games: the shallow trade agreements game, where countries can choose between shallow CU and FTA agreements; the deep trade agreements game, where players can choose between integrated customs unions and integrated FTAs; and the extended game with the choice between pure trade customs unions and integrated customs unions; and the extended game with the choice between deep and shallow FTA. 


\subsubsection{Shallow Trade Agreements Game}

In this extended game, both types of shallow preferential trade agreements are permitted. Each player simultaneously announces the name(s) of the country(ies) and identifies whether they are willing to form a customs union or a free trade agreement. The PTS are formed only if both signals match. Each player's strategy set $\left(S_{j}^{C U / F T A}\right)$ consists of seven possible announcements denoted as $\sigma_{j}^{C U / F T A}:$

$$
\begin{gathered}
S_{a}^{C U / F T A}=\left\{\{\varnothing, \varnothing\},\{b, \varnothing\},\{\varnothing, c\},\{b, c\}\left\{b^{u}, \varnothing\right\},\left\{\varnothing, c^{u}\right\},\left\{b^{u}, c^{u}\right\}\right\} \\
S_{b}^{C U / F T A}=\left\{\{\varnothing, \varnothing\},\{a, \varnothing\},\{\varnothing, c\},\{a, c\},\left\{a^{u}, \varnothing\right\},\left\{\varnothing, c^{u}\right\},\left\{a^{u}, c^{u}\right\}\right\} \\
S_{c}^{C U / F T A}=\left\{\{\varnothing, \varnothing\},\{a, \varnothing\},\{\varnothing, b\},\{a, b\},\left\{a^{u}, \varnothing\right\},\left\{\varnothing, b^{u}\right\},\left\{a^{u}, b^{u}\right\}\right\}
\end{gathered}
$$

where announcement $\sigma_{j}^{C U / F T A}=\{\varnothing, \varnothing\}$ indicates player's desire to stay away from any shallow trade agreement; if $\sigma_{j}^{C U / F T A}$ includes only one of the two countries with no superscript then it denotes the player's wish to form an FTA with that country only, and if $\sigma_{j}^{C U / F T A}$ includes only one of the two countries with the superscript " $U$ " then it denotes this player's wish to form a bilateral preferential trade agreement in the form of a customs union with that country only and exclude the third player; if $\sigma_{j}^{C U / F T A}$ has two other countries either with or without a superscript "u" then it indicates player's desire to be a trade partner of both countries. Though both announcement profiles, $\{b, c\}$ and $\left\{b^{u}, c^{u}\right\}$ indicate country $a$ 's desire to live in a free trade world, only the first one would allow the possibility of hub-and-spoke regimes to arise, and due to that, those announcement profiles are different.

For trade agreements to arise in this shallow trade agreements game, countries profiles should match at two levels, the partner's name and the type of a shallow preferential trade agreement. As a result, the following trade agreements can emerge: $(i)\langle\Phi\rangle$ - no agreement announcement profile implies that either all three countries announce in the favour of no shallow trade agreement, or countries' announcements do not match on both or either levels; (ii) announcement profiles $\langle a b u\rangle$ 
and $\langle a b\rangle$ arise when one clean and one dirty country announce each other, the former one, trade union, implies that countries $a$ and $b$ call in favour of customs union, and the latter one, when these countries declare their desire to form an FTA; (iii) similar to (ii), announcement profiles $\langle b c u\rangle$ and $\langle b c\rangle$ indicate two countries' desire to exclude the third member of the world in the form of either CU or FTA; (iv) hub-and-spoke trade regimes, $\langle a h\rangle$ and $\langle b h\rangle$, can arise only if countries declare in favour of FTA, the nature of customs unions prevents these announcement profiles; (v) both announcement profiles, $\left\langle F^{u}\right\rangle$ and $\langle F\rangle$, signal all three countries' desire to live in a free trade world. The announcement profile $\langle\Phi\rangle$ survives all Nash equilibria refinement but, it does not constitute a coalition-proof Nash equilibria for both local and global levels of pollution. To prove that, we use the results in Lemma4.2( $\left(-i^{u}\right)$ and Lemma4.3( $\left.-i\right)$, which illustrate dirty players' incentive to form a coalition and deviate to either a CU or an FTA, and these coalitional deviations are selfenforcing. The announcement profile $\langle a b\rangle$ doest not constitute Nash equilibria if pollution is local and productivity gap is relatively narrow, and this announcement profile does not survive Nash equilibria refinement if pollution is global for any level of productivity parameter. In the former case, the dirty member of this agreement has an incentive to deviate into the no agreement scenario, and if pollution is global then the clean member exhibits the same incentive. Though the announcement profile $\langle a b\rangle$ constitutes Nash equilibria if pollution is local and productivity gap is relatively wide, it does not survive the coalition-proof Nash equilibria refinement. In this case, two symmetric dirty countries, country $b$ and country $c$, would deviate in the form of a customs union, and though they both would prefer to announce the clean country $a$ as well, and consequently, turn into a hub, the nature of customs unions prevents this deviation, and we conclude that original deviation is self-enforcing. The announcement profile $\langle a b u\rangle$ is not a Nash equilibria if pollution is global; the clean country $a$ is simply better off in the no agreement scenario, and consequently, it would perform a unilateral deviation and improve its welfare gains. If pollution is global, then the announcement profile $\langle a b u\rangle$ survives all unilateral deviation, and constitutes a Nash equilibria. However, it does not survive the coalition-proof Nash equilibria refinement; again, two symmetric dirty country have an incentive to deviate in the form of a CU, and again, though each member of 
this coalitional deviation would prefer to announce the clean country $a$ as well in order to assume the role of a hub, the nature of customs unions prevents this type of deviations. Though the announcement profile $\langle b c\rangle$ constitutes a Nash equilibria for both local and global levels of pollution, it does survive coalition-proof Nash equilibria refinement. Members of this shallow FTA would deviate together to form a customs union instead, and again no further deviation can occur, because the nature of customs union prevents hub-and-spoke trade regimes. Neither of the two hub-andspoke trade regimes, $\langle a h\rangle$ and $\langle b h\rangle$, constitutes a Nash equilibria. In case of local pollution, country $c$, a spoke in both regimes, has an incentive to become an outsider and face a shallow FTA of one clean and one dirty country, and if pollution is global, then the clean country $a$ would prefer to self-exclude from either of those trade regimes. The announcement profile $\langle F\rangle$, which constitutes a shallow free trade, does not survive Nash equilibria refinement if pollution is global and if pollution is local and the productivity gap is relatively narrow. In the former case, the clean country $a$ is better off as an outsider of a shallow FTA of two dirty countries, and in the latter case, either dirty country is better of as an outsider. Though the announcement profile $\langle F\rangle$ is a Nash equilibria if pollution is local and the productivity gap is relatively wide, it is not a CPNE. Two symmetric dirty countries would prefer to deviate in the form of a $\mathrm{CU}$, and again, though both members have an incentive to announce the clean country $a$, the nature of customs unions prevents this deviation. In this extended game, the only announcement profile which survives all meaningful self-enforcing deviations, and consequently, constitutes a coalition-proof Nash equilibria, is the announcement profile $\langle b c u\rangle$. We prove it by examining every possible deviation. First, we consider the coalitional deviation of two asymmetric countries, the clean country $a$ and the dirty country $b$, in the form of either PTA, FTA or CU, and we observe that neither of these deviations is meaningful. Second, we consider a coalitional deviation of two symmetric dirty countries, country $b$ and country $c$, into a different type of PTA, namely an FTA, and again, we find that this deviation is not meaningful. Next, we examine the grand coalition of all three countries, and this deviation is not meaningful as well for either dirty country. Finally, we acknowledge that though both members of this shallow trade union would benefit from including the clean country $a$ into their announcement, and 
consequently, become a hub, the nature of customs unions prevents hub-and-spoke trade regimes from arising. Based on the above, we conclude that the only announcement profile which survives a CPNE refinement in this extended game is $\langle b c u\rangle$, which constitutes a shallow customs union of two symmetric dirty countries. Our finding are in line with the leading literature on this topic, given a freedom to choose between two types of PTAs, the CPNE yields a customs union of two symmetric countries. ${ }^{38}$

\subsubsection{Deep Trade Agreements Game}

In this extended game, both types of deep preferential trade agreements are permitted. Each player simultaneously announces the name(s) of the country(ies) and identifies whether they are willing to form an integrated customs union or an integrated free trade agreement. Both signals should match in order to form a deep trade agreement. Each player's strategy set $\left(S_{j}^{I / I U}\right)$ consists of seven possible announcements denoted as $\sigma_{j}^{I / I U}$ :

$$
\begin{aligned}
& S_{a}^{I / I U}=\left\{\{\varnothing, \varnothing\},\left\{b^{i}, \varnothing\right\},\left\{\varnothing, c^{i}\right\},\left\{b^{i}, c^{i}\right\}\left\{b^{i u}, \varnothing\right\},\left\{\varnothing, c^{i u}\right\},\left\{b^{i u}, c^{i u}\right\}\right\} \\
& S_{b}^{I / I U}=\left\{\{\varnothing, \varnothing\},\left\{a^{i}, \varnothing\right\},\left\{\varnothing, c^{i}\right\},\left\{a^{i}, c^{i}\right\},\left\{a^{i u}, \varnothing\right\},\left\{\varnothing, c^{i u}\right\},\left\{a^{i u}, c^{i u}\right\}\right\} \\
& S_{c}^{I / I U}=\left\{\{\varnothing, \varnothing\},\left\{a^{i}, \varnothing\right\},\left\{\varnothing, b^{i}\right\},\left\{a^{i}, b^{i}\right\},\left\{a^{i u}, \varnothing\right\},\left\{\varnothing, b^{i u}\right\},\left\{a^{i u}, b^{i u}\right\}\right\}
\end{aligned}
$$

where announcement $\sigma_{j}^{I / I U}=\{\varnothing, \varnothing\}$ indicates player's desire to stay away from any deep trade agreement; if $\sigma_{j}^{I / I U}$ includes only one of the two countries with the superscript "I" then it denotes the player's wish to form a deep bilateral trade agreement with that country only, and if $\sigma_{j}^{I / I U}$ includes only one of the two countries with the superscript "IU" then it denotes this player's wish to form an integrated customs union with that country only and exclude the third player from both trade and environmental agreements; if $\sigma_{j}^{I / I U}$ has two other countries with either superscript, it indicates player's desire to be a partner of both countries. Though both announcement profiles,

\footnotetext{
${ }^{38}$ For the proofs, please Appendix A.4.9.1
} 
$\left\{b^{i}, c^{i}\right\}$ and $\left\{b^{i u}, c^{i u}\right\}$ indicate country $a$ 's desire to be a part of a world trade and environmental agreement, only the first one would allow a possibility of a hub-and-spoke regime to arise, and due to that, those announcement profiles are different.

In this deep trade agreements game, countries profiles should match at two levels, the partner's name and the type of deep preferential trade agreement. As a result the following deep trade agreements can arise: (i) $\left\langle\Phi^{i}\right\rangle$ - no agreement announcement profile implies that either all three countries announce in the favour of no deep trade agreement, or countries' announcements do not match on both or either levels; (ii) announcement profiles $\langle a b i u\rangle$ and $\langle a b i\rangle$ emerge when one clean and one dirty country announce each other; the former one, integrated union, implies that countries $a$ and $b$ call in favour of customs union with an environmental clause, and the latter one, when these countries declare their desire to form a deep FTA; (iii) similar to (ii), announcement profiles $\langle$ bciu $\rangle$ and $\langle b c i\rangle$ indicate two countries' desire to exclude the third member of the world in the form of either IU or an integrated FTA; (iv) hub-and-spoke trade regimes, $\langle a h i\rangle$ and $\langle b h i\rangle$, can arise only if countries declare in favour of an integrated FTA, the nature of customs unions prevents these announcement profiles; $(v)$ both announcement profiles, $\left\langle F^{i u}\right\rangle$ and $\left\langle F^{i}\right\rangle$, signal all three countries' desire to live in a fully integrated world.

The results we presented in the section above show that the announcement profile $\langle F\rangle$, which constitutes a shallow free trade, does not survive coalition-proof Nash equilibria refinement, and similar to that, neither $\left\langle F^{i u}\right\rangle$ nor $\left\langle F^{i}\right\rangle$ announcement profiles, which both result in a deep free trade agreement, survive coalition-proof Nash equilibria refinement. As long as the option of either deep or shallow $\mathrm{CU}$ is on the table, countries do not end up in a free trade agreement. If pollution is local, then the announcement profile $\left\langle F^{i}\right\rangle$ does not survive Nash equilibria refinement; either dirty country has an incentive to self-exclude and face a deep bilateral FTA of two other countries. Furthermore, the announcement profile $\left\langle F^{i u}\right\rangle$ does not constitute Nash equilibria for both local and global levels of pollution. In this case, dirty countries prefer to exclude the only clean player, and to do so, either of them can just limit its announcement to the other dirty country. Though the announcement profile $\left\langle F^{i}\right\rangle$ constitutes a Nash equilibria if pollution is global, it does 
not survive coalition-proof Nash equilibria refinement, and to prove it we examine the coalitional deviation of two symmetric dirty countries in the form of a deep customs union. In this case, if the productivity gap is relatively wide, then neither member of $\langle b c i u\rangle$ has an incentive to deviate simply because this level of welfare is the highest members can achieve in this extended game. However, if pollution is global and the productivity gap is relatively narrow then either member of this deep CU has an incentive to include the clean country a in its announcement, and consequently, turn into a hub, but this deviation is not attainable based on the nature of customs union. Based on the above, we conclude that deep tree trade does not constitutes a CPNE in this extended game for any level of pollution or productivity parameter.

The announcement profile $\left\langle\Phi^{i}\right\rangle$ does not survive the coalition-proof Nash equilibria refinement, and we conclude that based on the results presented in Lemma4.4 $\left(-i^{i u}\right)$, Lemma4.4 $\left(-i i^{i u}\right)$, Lemma4.5 $\left(-i^{i}\right)$ and Lemma4.5 $\left(-i i^{i}\right)$. If pollution is local, then the announcement profile $\langle a b i\rangle$, which constitutes a deep FTA between one clean and one dirty country, does not meet Nash equilibria requirement; the dirty member of this agreement has an incentive to self-exclude and gain a higher level of welfare in the world with no trade and environmental agreements. Though this announcement profile survives Nash equilibria refinement if pollution is global, it does not constitute a CPNE. In this case, two symmetric dirty countries have an incentive to deviate in the form of a deep CU and gain the highest level of welfare if the productivity gap is relatively wide. However, even if the productivity gap is relatively narrow, then this initial deviation is still meaningful and self-enforcing, because though both members of this coalition would prefer to announce country $a$ as well and turn into a hub, this deviation is not possible due to the nature of customs unions. The announcement profile $\langle a b i u\rangle$ is a Nash equilibria if pollution is local, and it does not constitute a Nash equilibria if pollution is global. In the latter case, the dirty member of this deep CU is better of in the no agreement scenario, and naturally, it will unilaterally deviate to improve its welfare level. However, even if pollution is local and an integrated customs union between one clean and one dirty country survives Nash equilibria refinement, it still does not constitute a CPNE. In this case, two symmetric dirty countries would form a coalition, $\langle b c i u\rangle$. The deep trade union of two 
symmetric dirty countries lets its members to acquire the highest level of welfares in this extended game, if pollution is local, and based on that we conclude that this coalitional deviation is both meaningful and self-enforcing. Though the announcement profile $\langle b c i\rangle$ constitutes a Nash equilibria for both levels of pollution, it does not survive coalition-proof Nash equilibria refinement. Members of this deep FTA are better of in a deep CU, so we can conclude that dirty countries would deviate to form a deep customs union instead. Both deep hub-and-spoke trade regimes, $\langle a h i\rangle$ and $\langle b h i\rangle$, do not constitute a Nash equilibria if pollution is local, and $\langle b h i\rangle$ is not a Nash equilibria if pollution is global as well. In all these cases, country $c$, a spoke in both trade regimes. is better off as an outsider of a bilateral FTA of two other countries. However, if pollution is global then $\langle a h i\rangle$ survives Nash equilibria refinement, but it does not constitute a CPNE. In this case, two symmetric dirty countries have an incentive to deviate in the form of a deep CU, and this deviation is both meaningful and self-enforcing. The only announcement profile which survives coalitionproof Nash equilibria refinement for both levels of pollution is a deep custom union between two symmetric dirty countries, $\langle b c i u\rangle$. To prove that this announcement profile indeed constitutes a CPNE, we consider all possible deviations. First, we consider a coalitional deviation of two asymmetric countries, the clean country $a$ and the dirty country $b$, in the form of either deep PTA, a deep FTA or a deep CU, and as a result, we observe that neither of these deviations is meaningful; the dirty country $b$ is better off in a deep CU with another dirty country. Second, we examine a coalitional deviation of two members of this deep PTA into a different PTA, namely a deep FTA, and again, we observe that this deviation is not meaningful. Next, we examine, the grand coalition, and we conclude that this deviation is not meaningful, too. Finally, if pollution is global and productivity gap is relatively wide, we acknowledge that though both members would benefit from signing a side deal with the clean country $a$ in oder to enjoy the benefits of being a hub, they cannot perform this deviation based on the nature of customs unions which prevents hub-and-spoke trade regimes from arising. 39

\footnotetext{
${ }^{39}$ For the proofs, please Appendix A.4.9.2
} 


\subsubsection{The Choice between Deep and Shallow Customs Unions}

So far, we have always restricted our players choice to either deep or shallow trade agreements, and in this extended game, we permit both types of customs unions. Countries can either decide to form a shallow CU or add an environmental clause to it and sign an integrated customs union instead. Each player simultaneously announces the name(s) of the country(ies) and identifies whether they are willing to form a shallow or an integrated customs union. Both signals should match in order to form an agreement. Each player's strategy set $\left(S_{j}^{C U / I U}\right)$ consists of seven possible announcements denoted as $\sigma_{j}^{C U / I U}$ :

$$
\begin{gathered}
S_{a}^{C U / I U}=\left\{\{\varnothing, \varnothing\},\left\{b^{u}, \varnothing\right\},\left\{\varnothing, c^{u}\right\},\left\{b^{u}, c^{u}\right\}\left\{b^{i u}, \varnothing\right\},\left\{\varnothing, c^{i u}\right\},\left\{b^{i u}, c^{i u}\right\}\right\} \\
S_{b}^{C U / I U}=\left\{\{\varnothing, \varnothing\},\left\{a^{u}, \varnothing\right\},\left\{\varnothing, c^{u}\right\},\left\{a^{u}, c^{u}\right\},\left\{a^{i u}, \varnothing\right\},\left\{\varnothing, c^{i u}\right\},\left\{a^{i u}, c^{i u}\right\}\right\} \\
S_{c}^{C U / I U}=\left\{\{\varnothing, \varnothing\},\left\{a^{u}, \varnothing\right\},\left\{\varnothing, b^{u}\right\},\left\{a^{u}, b^{u}\right\},\left\{a^{i u}, \varnothing\right\},\left\{\varnothing, b^{i u}\right\},\left\{a^{i u}, b^{i u}\right\}\right\}
\end{gathered}
$$

where announcement $\sigma_{j}^{C U / I U}=\{\varnothing, \varnothing\}$ indicates player's desire to stay away from any agreement; if $\sigma_{j}^{C U / I U}$ includes only one of the two countries then it denotes that payers' desire to form a customs union with that country only, where superscript "U" indicates player's wish to form a shallow $\mathrm{CU}$, and the superscript "IU" denotes this player's wish to form an integrated customs union with that country only and exclude the third player from this trade and environmental agreement; if $\sigma_{j}^{C U / I U}$ has two other countries, it could either indicate the player's desire to be a part of a free trade world with no environmental agreement in it or to live in a fully integrated world. For an agreement to arise, countries announcements should match at two levels, the partner's name and the type of customs union. As a result, the following trade or integrated agreements can emerge: (i) $\left\langle\Phi^{u}\right\rangle$ - no agreement announcement profile implies that either all three countries announce in the favour of no customs union, or countries' announcements do not match on both or either levels; (ii) announcement profiles $\langle a b i u\rangle$ and $\langle a b u\rangle$ emerge when one clean and one dirty country announce each other; the former one, an integrated union, implies that countries $a$ and $b$ call in favour of 
customs union with an environmental clause, and the latter one, when these countries declare their desire to form a shallow $\mathrm{CU}$; (iii) similar to (ii), announcement profiles $\langle b c i u\rangle$ and $\langle b c u\rangle$ indicate two countries' enthusiasm to exclude the third member of the world in the form of either IU or CU; (iv) announcement profile $\left\langle F^{u}\right\rangle$ signals all three countries' will to live in a free trade; and (v) $\left\langle F^{i u}\right\rangle$ arises when all three players declare their desire to form a fully integrated world.

Given the choice between deep and shallow CUs, countries do not end up in either shallow or deep free trade. Both announcement profiles, $\left\langle F^{u}\right\rangle$ and $\left\langle F^{i u}\right\rangle$, do not survive Nash equilibria refinement. Two symmetric dirty countries are better off in either shallow or deep customs union than in a shallow or deep free trade agreement, and consequently, each of those countries can improve its welfare by unilaterally changing the announcement in order to exclude the only clean country. And again, the announcement profile $\left\langle\Phi^{u}\right\rangle$ does not survive coalition-proof Nash equilibria refinement, though it is a Nash equilibria for both local and global levels of pollution, Lemma4.2( $\left(-i^{u}\right)$ and Lemma4.2( $\left.-i^{i u}\right)$. Both announcement profiles which constitute a custom union of two asymmetric countries, $\langle a b i u\rangle$ and $\langle a b u\rangle$, do not survive Nash equilibria refinement if pollution is global; the clean country $a$ is better off in the no agreement scenario than in the shallow trade union with one dirty country, and the dirty member of $\langle a b i u\rangle$ would unilaterally deviate into the no agreement scenario. Thought both customs unions, $\langle a b i u\rangle$ and $\langle a b u\rangle$, survive Nash equilibria refinement if pollution local, neither of them constitutes a CPNE. To prove the above, we examine the coalitional deviation of two symmetric dirty countries in a form of a deep CU, and we observe that the level of welfare the deviating countries achieve is the highest in this entire game, and based on that we conclude that the initial deviation is both meaningful and self-enforcing. Though the announcement profile $\langle b c u\rangle$ constitutes a Nash equilibria for both levels of pollution, it does nit survive a coalition-proof Nash equilibria refinement. In this case, members of $\langle b c u\rangle$ would prefer to add an environmental clause to their shallow trade agreement and form a deep CU instead. In this extended game, the only announcement profile which survives a coalition-proof Nash equilibria refinement is a deep custom union of two symmetric dirty countries, $\langle b c i u\rangle$. To prove the above, we examine every possible deviation. First, we consider a coalitional deviation of one clean 
and one dirty country in the form of either shallow or deep CU, and we observe that neither of this deviations is meaningful for a dirty country. Second, we examine whether the members of $\langle b c i u\rangle$ are interested in removing an environmental clause from their agreement, and we observe that this deviation would only decrease the members' welfares. Next, we examine the grand coalition to either shallow or deep free trade, and again, we observe, that neither of these deviations is meaningful for either member of $\langle b c i u\rangle$. Based on the above, we conclude that the announcement profile $\langle$ bciu $\rangle$ survives a CPNE refinement for both local and global levels of pollution. ${ }^{40}$

\subsubsection{The Choice between Deep and Shallow FTAs}

In this extended game, our players can choose between various deep and shallow free trade agreements. Players simultaneously announce the name(s) of the country(ies) and identifies what agreement they are willing to commit to. Both signals should match in order for the agreement to arise. Each player's strategy set $\left(S_{j}^{F T A / I}\right)$ consists of seven possible announcements denoted as $\sigma_{j}^{F T A / I}$ :

$$
\begin{gathered}
S_{a}^{F T A / I}=\left\{\{\varnothing, \varnothing\},\{b, \varnothing\},\{\varnothing, c\},\{b, c\}\left\{b^{i}, \varnothing\right\},\left\{\varnothing, c^{i}\right\},\left\{b^{i}, c^{i}\right\}\right\} \\
S_{b}^{F T A / I}=\left\{\{\varnothing, \varnothing\},\{a, \varnothing\},\{\varnothing, c\},\{a, c\},\left\{a^{i}, \varnothing\right\},\left\{\varnothing, c^{i}\right\},\left\{a^{i}, c^{i}\right\}\right\} \\
S_{c}^{F T A / I}=\left\{\{\varnothing, \varnothing\},\{a, \varnothing\},\{\varnothing, b\},\{a, b\},\left\{a^{i}, \varnothing\right\},\left\{\varnothing, b^{i}\right\},\left\{a^{i}, b^{i}\right\}\right\}
\end{gathered}
$$

where announcement $\sigma_{j}^{F T A / I}=\{\varnothing, \varnothing\}$ indicates player's desire to stay away from any agreement; if $\sigma_{j}^{F T A / I}$ includes only one of the two countries with no superscript then it denotes the player's wish to form a shallow FTA with that country only, and the subscript "i”" denotes this player's wish to form a deep FTA; if $\sigma_{j}^{F T A / I}$ contains the names of two other countries, it could either indicate the player's desire to be a part of a free trade world with no environmental agreement in it, and in this case countries would have no superscripts, or to live in a fully integrated world, and in this case countries' names would have a superscript "I". Only if countries announcements

\footnotetext{
${ }^{40}$ For the proofs, please Appendix A.4.9.3
} 
match at both levels, the partner's name and the type of FTA, either deep or shallow free trade agreement can arise. As a result, the following trade or integrated agreements can emerge: $(i)\langle\Phi\rangle$ - no agreement announcement profile implies that either all three countries announce in the favour of no FTA, or countries' announcements do not match on both or either levels; (ii) announcement profiles $\langle a b\rangle$ and $\langle a b i\rangle$ emerge when one clean and one dirty country announce each other; the former one, shallow FTA, implies that countries $a$ and $b$ call in favour of a pure trade agreement with no environmental clause attached to it, and the latter one, when these countries declare their desire to form a deep FTA; (iii) similar to (ii), announcement profiles $\langle b c\rangle$ and $\langle b c i\rangle$ indicate two countries' desire to exclude the third member of the world in the form of either shallow or deep FTA; (iv) hub-and-spoke trade regimes, $\langle a h\rangle /\langle b h\rangle$ or $\langle a h i\rangle /\langle b h i\rangle$, can arise if the hub declares in the favour of either shallow or deep world agreement, and the spokes declare their desire to exclude each other; $(v)$ the announcement profile - $\langle F\rangle$ signal all payers wish to live in a free trade world with no environmental agreements in it, and $\left\langle F^{i}\right\rangle$ indicates all three countries' will to live in a fully integrated world.

The no agreement announcement profile, $\langle\Phi\rangle$, again, does not survive coalition-proof Nash equilibria refinement; two symmetric dirty countries are better off in a deep FTA. If pollution is local and the productivity gap is relatively narrow, the announcement profile $\langle a b\rangle$ does not constitute a Nash equilibria; in this case, the dirty member would unilaterally deviate into the no agreement scenario. Also, this announcement profile does not survive Nash equilibria refinement if pollution is global, but in this case, the clean member would deviate into the no agreement scenario. Though a shallow FTA of two asymmetric countries constitutes a Nash equilibria if pollution is local and productivity gap is relatively large, it is not a CPNE. We prove it by examining the coalitional deviation of two symmetric dirty countries in the form of a deep bilateral trade agreement. As a result, we observe that deviating members achieve higher welfare gains, and though both of them would prefer to deviate further to become a hub in a shallow hub-and-spoke trade regime by calling country a as well, the nature of $\langle b c i\rangle$ prevents it, the announcement profiles should match at both levels, the partner's name and the type of FTA. The announcement profile $\langle a b i\rangle$ is not a Nash equilibria if 
pollution is local; the dirty member, has an incentive ti deviate into the no agreement scenario. A deep bilateral FTA of two asymmetric countries survives Nash equilibria refinement if pollution is global, but it does not constitute a CPNE, and we prove it by examining the grand coalition. This deviation is meaningful for all three countries, and though for some levels of productivity parameter, dirty countries would achieve higher welfare levels if they exclude the only clean country from the deep free trade agreement, they would not agree to that, because each of them has an incentive to deviate further and still announce the clean country $a$, and by doing so, turn into a hub. Based on that, we conclude that no further deviations can occur, and $\Omega^{a b i}$ is not a CPNE. The announcement profile $\langle b c\rangle$, which constitutes a shallow FTA between two symmetric dirty countries is a Nash equilibria for both local and global levels of pollution, but it does not survive coalition-proof Nash equilibria refinement; if pollution is local and productivity gap is relatively narrow, then the clean country $a$ is interested in forming a coalition with either dirty country to become a spoke; is pollution is local and the productivity gap is relatively large or if pollution is purely global, then members of $\langle b c\rangle$ can simply add an environmental clause to their shallow trade agreement and gain higher levels of welfares. Based on the above, we conclude that $\langle b c\rangle$ does not survive coalitionproof Nash equilibria refinement. Both shallow hub-and-spoke trade regimes, $\langle a h\rangle$ and $\langle b h\rangle$, do not constitute Nash equilibria for both levels of pollution. If pollution is local, then country $c$, a spoke in both regimes, has an incentive to become an outsider of a shallow FTA of two other countries; and if pollution is global, then the clean country $a$ has an incentive to self-exclude, for a hub, self-exclusion leads to the no agreement scenario, and for a spoke, to a shallow FTA between two symmetric dirty countries. A deep hub-and-spoke trade regime, $\langle b h i\rangle$, does not survive a Nash equilibria refinement for both levels of pollution; in this case, again the dirty spoke, country $c$, has an incentive to deviate. A deep hub-and-spoke trade regime with the clean country acting as a hub, $\langle a h i\rangle$, is a Nash equilibria if pollution is global, and it does not survive CPNE refinement, and to prove the above, we consider a coalitional deviation of two dirty countries, country $b$ and country $c$, in the form of a deep FTA. By forming this coalition these two players would "drive" the clean country into a deep free trade agreement, and improve their welfare levels. Dirty countries 
would prefer to live in a fully integrated world versus being the spokes. Though for some levels of lambda, clean countries would achieve higher welfare levels if they exclude the only clean country form the deep free trade agreement, neither of them would agree to that, because in this case both members would have an incentive to keep country $a$ in their announcement and turn into a hub themselves. Based on the above, we conclude that $\Omega^{a h i}$ is not a CPNE if pollution is global. Though the announcement profile $\langle b c i\rangle$, which constitutes a deep FTA between the two dirty countries, is a Nash equilibria for both levels of pollution and all levels of lambda, it is a CPNE only if pollution is local and the productivity gap is relatively large. In this case, the only meaningful deviation for either member of $\langle b c i\rangle$ is to turn into a hub in a shallow hub-and-spoke trade regime, and this deviation is not possible, because in order for trade agreements to arise, the announcement profiles should match at both levels, country name and the type of FTA. If pollution is local and the productivity gap is relatively narrow or if pollution is global, then the clean country $a$ is interested in becoming a spoke in a deep hub-and-spoke trade regime, and due to that, the announcement profile $\langle b c i\rangle$ does not survive coalition-proof Nash equilibria refinement. A shallow free trade agreement does not constitute a Nash equilibria if pollution is local and the productivity gap is relatively narrow and if the pollution is global. In the former case, the clean country $a$ has an incentive to become an outsider of a shallow FTA between two dirty countries, and in the latter case, each of the dirty countries exhibits exactly the case incentive to self-exclude. However, if pollution is local and the productivity gap is relatively large, the announcement profile $\langle F\rangle$ constitutes a Nash equilibria, but in this case, two dirty countries have an incentive to form a coalition to sign a deep FTA, and as a result of that, $\langle F\rangle$ cannot be a CPNE. The announcement profile $\left\langle F^{i}\right\rangle$, which constitutes a deep free trade agreement, is not a Nash equilibria if pollution is local; in this case, either dirty country has an incentive to self-exclude in oder to face a deep bilateral FTA of two other countries, and consequently, enjoy the higher level of welfare. However, if pollution is global, then the only announcement profile which survives coalition-proof Nash equilibria refinement is $\left\langle F^{i}\right\rangle$, and to prove it, we consider every possible deviation. First, we consider a coalitional deviation of one clean and one dirty country in the form of either deep or shallow FTA, and we 
observe that these deviations are not meaningful. Second, we consider a coalitional deviation of two symmetric dirty countries, country $b$ and country $c$, in the form of a shallow FTA, and again, we observe that this initial deviation is not meaningful. Now, we examine the coalitional deviation of country $b$ and country $c$ in the form of a deep FTA, and we observe, that if the productivity gap is relatively narrow, then the initial deviation is meaningful but not self-enforcing, because each member would prefer to be a hub, and if the productivity gap is relatively large, then the initial deviation is not meaningful. In this final step, we consider the grand coalition in the form of a shallow free trade, and we can see that the removal of an environmental clause is not meaningful, too. Based on the above, we can conclude, that if pollution is global, then the only announcement profile which survives coalition-proof Nash equilibria refinement in a deep free trade. ${ }^{41}$

\subsection{Conclusion}

The growing number of preferential trade agreements has been accompanied with a widespread inclusion of non-trade elements, such as domestic policy over the environment. As the effects of this trend on the stability of trade regimes and counties' welfare gains are unknown, our objective in this paper has been to investigate how equilibrium agreements differ based on being deep or shallow. To our knowledge, there is no equilibrium theory on what agreement we should see and how these agreements impact welfares and environments. In this paper, we attempt to narrow this gap by answering three different and equally important questions: (i) how do equilibrium agreements differ when countries choose deep rather than shallow agreements?; (ii) given the choice between deep and shallow trade agreements, would countries prefer to incorporate an environmental clause into their equilibrium trade deal?; and (iii) what are the implications of including non-trade elements in PTAs for the pursuit of global free trade? We now move to discussing those questions.

The first question we ask in this chapter is on whether and how equilibrium agreements differ when

\footnotetext{
${ }^{41}$ For the proofs, please Appendix A.4.9.4
} 
countries choose deep rather than shallow agreements. In this paper, we have two customs union games: a shallow customs union game (CU game) and a deep customs union game (IU game). In both games, neither shallow free trade nor deep free trade emerges as a Nash equilibria outcome, and this enables us to conclude that regardless of being deep or shallow, customs unions are more coalitionally stable agreements. A customs union of two symmetric dirty countries survives coalition-proof Nash equilibria refinements in the CU game for both local and global levels of pollution, and an integrated customs union between these two countries constitutes a CPNE in the IU game for both levels of pollution as well. In both games, customs unions of two dirty countries are self-enforcing commitments; neither member can improve its welfare by undertaking any unilateral and/or coalitional deviation. An announcement profile which constitutes a shallow free trade does not constitute a Nash equilibria in a shallow free trade agreement game (FTA game) if pollution is global, but a shallow free trade survives a coalition-proof Nash equilibria requirement if pollution is local and the productivity gap is sufficiently narrow. If pollution is global, then the only clean country is better as an outsider of a bilateral FTA of two dirty countries, and as a result of this strong self-exclusion incentive, a shallow FTA of two dirty countries arises aa coalitionproof Nash equilibria outcome. When pollution is global, and countries have to agree on their domestic policy as well as on border policies (I game), a deep free trade survives all coalitional self-enforcing deviations, and consequently, constitutes a CPNE. However, with the zero degree of transboundary spillovers (local pollution), a deep FTA of two symmetric dirty countries survives coalition-proof Nash equilibria requirements and only if the productivity gap is sufficiently wide, otherwise we do not observe any announcement profile surviving a CPNE requirements.

The second question we answer in this chapter is whether given the choice between deep and shallow trade agreements countries would actually prefer to incorporate an environmental clause into their equilibrium trade deal. The answer to this question is one of the main findings in our paper. In both extended game, where we provide our players with the choice between deep and shallow PTAs (the choice between deep and shallow CUs and the choice between deep and shallow FTAs), we observe that deep agreements are the ones which survive all meaningful coalitional self- 
enforcing deviations, and consequently, they constitute respective CPNEs. In the choice between deep and shallow CUs, an integrated customs union of two symmetric dirty countries survives coalition-proof Nash equilibria refinements. Given the choice, the dirty countries actually prefer to coordinate their domestic policies as well as agree on the border policies. If pollution local, then the choice between deep and shallow FTAs leads to a deep free trade, but only if pollution is global. The global pollution implies that all countries are equally affected by the production of the dirty good regardless the location of the producer of that good, and under this assumption, we observe that asymmetric countries prefer to add an environmental clause to their agreement and coordinate both border policies and domestic policies in order to achieve higher welfare gains.

Next, we investigate the implications of including non-trade elements in PTAs for the pursuit of global free trade. Our results show, that including non-trade elements (environmental tax) is crucial in order for a global free trade agreement of three large asymmetric countries to arise if pollution is global. If pollution is global, then deep free trade agreement survives all coalition-proof Nash equilibria requirement not only in the deep FTA game, but also in the extended game with the choice between deep and shallow FTAs. On the other hand, a shallow free trade constitutes a CPNE only in a shallow FTA game, and only if pollution is local and the productivity gap is sufficiently wide. 


\section{Conclusion}

In practice, we observe a widespread inclusion of non-trade elements in modern PTAs, such as domestic policies over the environment, labour, intellectual property, health and investment. Countries ability to use both border policies and domestic policies in order to improve their terms-oftrade and increase their gains from trade has received a great deal of attention in both literature and in practice. In this dissertation, we have developed three models of asymmetric countries, that include both trade (import tariffs) and environmental externalities (environmental taxes) and study the incentives to form international trade agreements between those asymmetric countries.

In chapter 2, we develop a two-country, two-good model with cross-border negative spillovers and perfect competition in product markets. We analyze a pure environmental agreement (environment only), a shallow trade agreement (trade only), and a deep trade agreement (trade and environment), and we show that shallow and deep trade agreements have different outcomes in terms of world and individual countries welfares, trade specialization and environmental damages. Therefore, in chapter 2, we have answered three questions: (i) how do deep and shallow trade agreements affect countries' choices of domestic policies and their trade specialization given different degrees of transboundary spillovers?; (ii) given the degree of transboundary spillovers, how do deep and shallow trade agreements affect world and individual countries' welfare levels?; and (iii) what are the implications of inclusion of the non-trade elements in a shallow trade deal on the world and individual countries' environmental damages?

Our findings on question (i) show that under no agreement (with the complete flexibility over both border policies and domestic instruments), only the dirty country would use both border policies and domestic policies together to alter the terms of trade, and the clean country will alter its border policies exclusively and set the environmental tax at the socially optimal level (equal to marginal damages). However, once countries lose control over their border policies (form a shallow trade deal), they both turn to their domestic policies in order to manipulate the terms-of-trade. Loosing control over the domestic policies as well as over the border policies (deep trade agreement) leads to a socially optimal level of the environmental tax regardless the level of pollution. Our results 
also show that though a deep trade agreement encourages a deeper specialization, still both deep and shallow trade deals increase members specialization relative to the no agreement scenario. The second question we have analyzed in chapter 2 has illustrated that in the case of local pollution a shallow free trade leads to an increase in the world welfare level relative to the no agreement scenario; however, while the clean country is better off for any level of negative externality and/or productivity parameter, the dirty country would agree to be a part of a free trade world only if the production externality is sufficiently low and the productivity gap is sufficiently wide. Also, our findings show that if pollution is global, then a shallow trade agreement would lead to an increased level of world welfare only if the productivity gap is sufficiently wide and the negative per unit production externality is sufficiently low. Furthermore, though under a deep free trade agreement we observe an increase in the level of world welfare relative to both the no agreement and a shallow free trade, countries do not benefit equally from this agreement as well. With the local production externality, the dirty country would prefer to keep control over its domestic policies if productivity gap is sufficiently large, and the clean country would prefer to coordinate both border policies and domestic policies for any level of per unit production externality and the productivity gap. Contrary to that, the global pollution, low level of production externally and a wide productivity gap would encourage both countries to keep control over their domestic policies. The last question we investigated in chapter 2, question (iii), shows that if pollution is purely local, then both deep and shallow free trade agreements lead to an increase in the level of world environmental damages. However, only a shallow free trade encourages an increase in the level of production of the polluting good in both countries, and consequently, in the level of world environmental damages, and full coordination over both border policies and domestic policies leads to an increase in the environmental damages only in the dirty country. If pollution is global, then inclusion of non-trade elements in a shallow trade deal would lead to a decrease in the world level of damages relative to both the no agreement and a shallow free trade if per unit production externality is sufficiently high, and otherwise we observe an increase.

In chapter 3 and chapter 4, we have developed two three-country, three-goods models, a "com- 
peting importers model" (chapter 3) and a "competing exporters model"(chapter 4). Respectively, in those two different models of multiple asymmetric countries, we have asked and answered the following questions: (i) how do equilibrium agreements differ when countries choose deep rather than shallow agreements?; (ii) given the choice between deep and shallow trade agreements, would countries prefer to incorporate an environmental clause into their equilibrium trade deal?; and (iii) what are the implications of including non-trade elements in PTAs for the pursuit of global free trade? And now, we move to discussing similarities and differences in the answers we got in those two different models.

Our results of the first game we played in both chapter, the Environmental agreement game, are in line with the main body of literature on the environmental agreements. It is well-established, that pure environmental agreements arise between homogeneous countries, and in general, tend to be small. Both "competing importers model" and "competing exporters model" show that no agreement outcome survives all coalition-proof Nash equilibria refinement if pollution is purely local, and if pollution is global, then coalitionally stable agreements are the ones between two similar countries (two clean countries in competing importers model, and two dirty countries in competing exporters model). Table 5.1 and Table 5.2 illustrate those results. The question (i) we ask is on whether and how equilibrium agreements differ when countries choose deep rather than shallow agreements. Based on our results in both chapter 3 and chapter 4 , we conclude, that in general, customs unions are more coalitionally stable agreements. Regardless of being deep or shallow, customs unions emerge as coalition-proof Nash equilibria outcomes in both model (Table 5.1 and Table 5.2). Again, these results are in line with the main body of literature on shallow trade agreements (the stability of CUs versus FTAs). However, our results also show that in competing exporters framework, both shallow and deep CUs between two dirty countries survive all coalition-proof Nash equilibria refinement for both local and global level of pollution, and in the competing importers framework a clean country actually prefers to form a union with the dirty importer over the clean one, and that allows the trade union (either deep or shallow) survive all CPNE refinements if pollution is local. Furthermore, if pollution is global and the productivity 
gap is sufficiently wide, then the deep customs union between one clean and one dirty country is a coalitionally stable agreement. The presence of hub-and-spoke trade regimes allow shallow free trade to survive all coalition-proof Nash equilibria refinements for both local and global levels of pollution in the FTA game in the competing importers framework (though the exclusion incentive is still high, the incentive to become a hub is stronger). Contrary to that, in the competing exporters framework, a shallow free trade survives a coalition-proof Nash equilibria requirement only if pollution is local and the productivity gap is sufficiently narrow, and furthermore, an announcement profile which constitutes a shallow free trade does not constitute a Nash equilibria if pollution is global. However, the results of the integrated FTA games in both "competing importers model" and "competing exporters model" show, that a deep free trade is a coalitionally stable agreement between asymmetric countries with the global degree of transboundary spillovers. If pollution is local, then we observe that FTAs between two similar countries survive all CPNE refinements in either model (a deep bilateral FTA between two clean countries in the competing importers model and a deep FTA between two dirty countries in the competing exporters model if the productivity gap is sufficiently narrow), see Table 5.1 and Table 5.2.

The next question we have answered is whether given the choice between deep and shallow trade agreements countries would actually prefer to incorporate an environmental clause into their equilibrium trade deal. The answer to this question is one of the main findings in this dissertation. In both "competing importers model" and "competing exporters model" we provide countries with the choice between deep and shallow PTAs (the choice between deep and shallow CUs and the choice between deep and shallow FTAs), and in both models we observe that deep trade agreements survive all coalition-proof Nash equilibria refinements, see Table 5.1 and Table 5.2. Though in "competing importers model" there are two announcement profiles (both shallow a deep CUs between one clean and one dirty country) which constitute coalition-proof Nash equilibria, a deep $\mathrm{CU}$ provides a greater welfare gain for the members. In the competing exporters model, given the choice between deep and shallow CUs, two dirty countries find it more beneficial to coordinate both border policies and domestic policies for both local and global levels of pollution, namely, 
they sign a deep trade agreement. Furthermore, given the choice between deep and shallow FTAs, a deep free trade survives all coalition-proof Nash equilibria refinements if pollution is local in the competing importers framework and constitutes a CPNE in the competing exporters framework if pollution is global. And it is the third question, we have investigated, and we conclude that the inclusion of non-trade elements is crucial in order for a global free trade agreement to arise between large asymmetric countries. Furthermore, based on our results, we conclude that, given the choice, asymmetric countries would actually choose to coordinate both border policies and domestic policies in order to achieve higher welfare gains.

\begin{tabular}{|l|c|c|}
\hline \multirow{2}{*}{ Games } & \multicolumn{2}{c|}{ CPNE: Local Pollution } \\
\cline { 2 - 3 } & CI & CE \\
\hline Environmental Agreement Game & $\Omega^{\Phi^{e}}$ & $\Omega^{\Phi^{e}}$ \\
\hline Customs Union Game & $\Omega^{a b u}$ & $\Omega^{b c u}$ \\
\hline Free Trade Agreement Game & $\Omega^{F}$ & $\Omega^{F}$ if $\lambda \leq \lambda_{c e}$ \\
\hline Integrated Customs Union Game & $\Omega^{a b i u}$ & $\Omega^{b c i u}$ \\
\hline Integrated FTA Game & $\Omega^{F^{i}}$ & $\Omega^{b c i}$ if $\lambda \leq \lambda_{c e}^{i}$ \\
\hline Shallow Trade Agreement Game & $\Omega^{a b u}$ & $\Omega^{b c u}$ \\
\hline Deep Trade Agreement Game & $\Omega^{a b i u}$ & $\Omega^{b c i u}$ \\
\hline The Choice between Deep and Shallow CUs & $\Omega^{a b u} / \Omega^{a b i u}$ & $\Omega^{b c i u}$ \\
\hline The Choice between Deep and Shallow FTAs & $\Omega^{F^{i}}$ & $\Omega^{b c i}$ if $\lambda \leq \lambda_{c e}^{i}$ \\
\hline
\end{tabular}

Table 5.1: Coalition-Proof Nash Equilibria Outcomes in the Case of Local Pollution 


\begin{tabular}{|c|c|c|}
\hline \multirow{2}{*}{ Games } & \multicolumn{2}{|c|}{ CPNE: Global Pollution } \\
\hline & CI & $\mathrm{CE}$ \\
\hline Environmental Agreement Game & $\Omega^{b c e}$ & $\Omega^{\text {bce }}$ \\
\hline Customs Union Game & $\Omega^{b c u}$ & $\Omega^{b c u}$ \\
\hline Free Trade Agreement Game & $\Omega^{F}$ & $\Omega^{b c}$ \\
\hline Integrated Customs Union Game & $\begin{array}{l}\Omega^{b c i u} \text { if } \lambda \leq \lambda_{c i}, \\
\Omega^{a b i u} \text { if } \lambda>\lambda_{c i}\end{array}$ & $\Omega^{b c i u}$ \\
\hline Integrated FTA Game & $\Omega^{b c i}$ & $\Omega^{F^{i}}$ \\
\hline Shallow Trade Agreement Game & $\Omega^{b c u}$ & $\Omega^{b c u}$ \\
\hline Deep Trade Agreement Game & $\begin{array}{l}\Omega^{b c i u} \text { if } \lambda \leq \lambda_{c i}, \\
\Omega^{a b i u} \text { if } \lambda>\lambda_{c i}\end{array}$ & $\Omega^{b c i u}$ \\
\hline The Choice between Deep and Shallow CUs & $\begin{array}{l}\Omega^{b c i u} \text { if } \lambda \leq \lambda_{c i}, \\
\Omega^{a b i u} \text { if } \lambda>\lambda_{c i}\end{array}$ & $\Omega^{b c i u}$ \\
\hline The Choice between Deep and Shallow FTAs & $\Omega^{b c i}$ & $\Omega^{F^{i}}$ \\
\hline
\end{tabular}

Table 5.2: Coalition-Proof Nash Equilibria Outcomes in the Case of Global Pollution 


\section{Appendices}




\section{Appendix of Chapter 3}

\section{A. 3.6 The Environmental Agreement Game}

Welfare effects of various type of environmental agreements:

$W^{a}\left(b c_{l}^{e}\right)=W^{a}\left(N_{l}\right)>W^{a}\left(a b_{l}^{e}\right)>W^{a}\left(a b c_{l}^{e}\right)$ Country a, local pollution

$W^{a}\left(b c_{g}^{e}\right)>W^{a}\left(N_{g}\right)>W^{a}\left(a b_{g}^{e}\right)>W^{a}\left(a b c_{g}^{e}\right)$ Country a, global pollution

$W^{b}\left(a b c_{l}^{e}\right)>W^{b}\left(a b_{l}^{e}\right)>W^{b}\left(N_{l}\right)>W^{b}\left(b c_{l}^{e}\right)$ Country b, local pollution

$W^{b}\left(a b c_{g}^{e}\right)>W^{b}\left(a b_{g}^{e}\right)>W^{b}\left(b c_{g}^{e}\right)>W^{b}\left(N_{g}\right)$ Country b, global pollution

$W^{c}\left(a b c_{l}^{e}\right)>W^{c}\left(a b_{l}^{e}\right)>W^{c}\left(N_{l}\right)>W^{c}\left(b c_{l}^{e}\right)$ Country c, local pollution

$W^{c}\left(a b c_{g}^{e}\right)>W^{c}\left(a b_{g}^{e}\right)>W^{c}\left(b c_{g}^{e}\right)>W^{c}\left(N_{g}\right)$ Country c, global pollution

\begin{tabular}{|c|c|}
\hline Announcement Profiles & Environmental Agreements \\
\hline \hline$\Omega^{\Phi^{e}} \equiv\left\{\sigma_{a}^{e}=\{\varnothing, \varnothing\}, \sigma_{b}^{e}=\{\varnothing, \varnothing\}, \sigma_{c}^{e}=\{\varnothing, \varnothing\}\right\}$ & $\left\langle\Phi^{e}\right\rangle$ \\
\hline$\Omega^{a b e} \equiv\left\{\sigma_{a}^{e}=\{b, \varnothing\}, \sigma_{b}^{e}=\{a, \varnothing\}, \sigma_{c}^{e}=\{\varnothing, \varnothing\}\right\}$ & $\langle a b e\rangle$ \\
\hline$\Omega^{b c e} \equiv\left\{\sigma_{a}^{e}=\{\varnothing, \varnothing\}, \sigma_{b}^{e}=\{\varnothing, c\}, \sigma_{c}^{e}=\{\varnothing, b\}\right\}$ & $\langle b c e\rangle$ \\
\hline$\Omega^{E} \equiv\left\{\sigma_{a}^{e}=\{b, c\}, \sigma_{b}^{e}=\{a, c\}, \sigma_{c}^{e}=\{a, b\}\right\}$ & $\langle E\rangle$ \\
\hline
\end{tabular}

$$
\Omega^{\Phi^{e}} \equiv\left\{\sigma_{a}^{e}=\{\varnothing, \varnothing\}, \sigma_{b}^{e}=\{\varnothing, \varnothing\}, \sigma_{c}^{e}=\{\varnothing, \varnothing\}\right\}
$$

$\Omega^{\Phi^{e}}$ is a Nash Equilibria for both local and global levels of pollution.

\section{PROOF:}

Countries cannot change their welfares by unilaterally changing the announcements.

$\Omega^{\Phi^{e}}$ is a CPNE for the local level of pollution.

\section{PROOF:}

First, we assume that countries a and b form a coalition, then the announcement will be as follows: $\sigma_{a}^{e}=\{b, \varnothing\}$ and $\sigma_{b}^{e}=\{a, \varnothing\}$, and as a result, $W^{a}\left(a b_{l}^{e}\right)<W^{a}\left(N_{l}\right)$ and $W^{b}\left(a b_{l}^{e}\right)>W^{b}\left(N_{l}\right)$

We can conclude, that though a clean country would benefit from the coalition with the dirty country, the dirty country is not going to be interested in that environmental union. As a results, there will be no initial deviation. 
Second, we assume that two clean countries form a coalition, then the announcement will be as follows: $\sigma_{b}^{e}=\{\varnothing, c\}$ and $\sigma_{c}^{e}=\{\varnothing, b\}$, and it will result in $W^{b}\left(b c_{l}^{e}\right)<W^{b}\left(N_{l}\right)$ and $W^{c}\left(b c_{l}^{e}\right)<$ $W^{c}\left(N_{l}\right)$

We can see that two clean countries are not interested in the forming the environmental coalition. Now, we let countries form a grand coalition, then the announcement will be as follows:

$\Omega \equiv\left\{\sigma_{a}^{e}=\{b, c\}, \sigma_{b}^{e}=\{a, c\}, \sigma_{c}^{e}=\{a, b\}\right\}$

$W^{a}\left(b c_{l}^{e}\right)=W^{a}\left(N_{l}\right)>W^{a}\left(a b c_{l}^{e}\right)$.

We can see that a dirty country a would prefer to be an outsider than a part of the world environmental agreement.

Based on the above, we can conclude that $\Omega^{\Phi^{e}}$ is a CPNE for the local level of pollution. $\Omega^{\Phi^{e}}$ is not a CPNE for the global level of pollution.

\section{PROOF:}

We let two clean countries form an environmental coalition, then their announcements will be altered as follows: $\sigma_{b}^{e}=\{\varnothing, c\}$ and $\sigma_{c}^{e}=\{\varnothing, b\}$, and as a result, we observe that $W^{b}\left(b c_{g}^{e}\right)>$ $W^{b}\left(N_{g}\right)$ and $W^{c}\left(b c_{g}^{e}\right)>W^{c}\left(N_{g}\right)$. Two clean countries would also benefit from including country a into an environmental agreement; however, country a prefers to be an outsider.

Based on the above, we feel confident to conclude that $\Omega^{\Phi^{e}}$ is not a CPNE if the pollution is global.

$$
\Omega^{a b e} \equiv\left\{\sigma_{a}^{e}=\{b, \varnothing\}, \sigma_{b}^{e}=\{a, \varnothing\}, \sigma_{c}^{e}=\{\varnothing, \varnothing\}\right\}
$$

$\Omega^{\text {abe }}$ is not a Nash Equilibria for both local and global levels of pollution.

\section{PROOF:}

country $\mathrm{a}=\{b, \varnothing\} \stackrel{\text { change }}{\longrightarrow}\{b, c\} \stackrel{\text { result }}{\longrightarrow}$ no change in a's welfare

country a $=\{b, \varnothing\} \stackrel{\text { change }}{\longrightarrow}\{\varnothing, c\} /\{\varnothing, \varnothing\} \stackrel{\text { result }}{\longrightarrow} W^{a}\left(a b_{\theta}^{e}\right)<W^{a}\left(N_{\theta}\right)$

We can conclude, that country a can deviate and improve its welfare.

$$
\Omega^{b c e} \equiv\left\{\sigma_{a}^{e}=\{\varnothing, \varnothing\}, \sigma_{b}^{e}=\{\varnothing, c\}, \sigma_{c}^{e}=\{\varnothing, b\}\right\}
$$

$\Omega^{\text {bce }}$ is not a Nash Equilibria for the local level of pollution.

PROOF: 
country $\mathrm{b}=\{\varnothing, c\} \stackrel{\text { change }}{\longrightarrow}\{b, c\} \stackrel{\text { result }}{\longrightarrow}$ no change in b's welfare

country $\mathrm{b}=\{\varnothing, c\} \stackrel{\text { change }}{\longrightarrow}\{a, \varnothing\} /\{\varnothing, \varnothing\} \stackrel{\text { result }}{\longrightarrow} W^{b}\left(b c_{\theta}^{e}\right)<W^{b}\left(N_{\theta}\right)$

We can conclude, that country b can deviate and improve its welfare.

$\Omega^{\text {bce }}$ is a Nash Equilibria for the global level of pollution.

\section{PROOF:}

country a $=\{\varnothing, \varnothing\} \stackrel{\text { change }}{\longrightarrow}\{b, \varnothing\} /\{\varnothing, c\} /\{b, c\} \stackrel{\text { result }}{\longrightarrow}$ no change in a's welfare

We can conclude, that country a has no incentive to change its announcement.

country $\mathrm{b}=\{\varnothing, c\} \stackrel{\text { change }}{\longrightarrow}\{a, c\} \stackrel{\text { result }}{\longrightarrow}$ no change in b's welfare

country $\mathrm{b}=\{\varnothing, c\} \stackrel{\text { change }}{\longrightarrow}\{a, \varnothing\} /\{\varnothing, \varnothing\} \stackrel{\text { result }}{\longrightarrow} W^{b}\left(b c_{g}^{e}\right)>W^{b}\left(N_{g}\right)$

We can conclude, that country b has no incentive to change its announcement.

country $\mathrm{c}=\{\varnothing, b\} \stackrel{\text { change }}{\longrightarrow}\{a, b\} \stackrel{\text { result }}{\longrightarrow}$ no change in c's welfare

country c $=\{\varnothing, b\} \stackrel{\text { change }}{\longrightarrow}\{a, \varnothing\} /\{\varnothing, \varnothing\} \stackrel{\text { result }}{\longrightarrow} W^{c}\left(b c_{g}^{e}\right)>W^{c}\left(N_{g}\right)$

We can conclude, that country c has no incentive to change its announcement.

Based on the above, we conclude that $\Omega^{b c e}$ is a Nash Equilibria for the global level of pollution.

$\Omega^{\text {bce }}$ is a CPNE for the global level of pollution.

\section{PROOF:}

First, we let a and b form a coalition, then $W^{a}\left(a b_{g}^{e}\right)<W^{a}\left(N_{g}\right)$. We can see that country a is not interested in this coalition.

Next, we let all three countries form a grand environmental coalition, then $W^{a}\left(a b c_{g}^{e}\right)<W^{a}\left(b c_{g}^{e}\right)$.

We can see that country a would still prefer to stay an outsider.

Based on the above, we can conclude that $\Omega^{b c e}$ is a CPNE for the global level of pollution.

$$
\Omega^{E} \equiv\left\{\sigma_{a}^{e}=\{b, c\}, \sigma_{b}^{e}=\{a, c\}, \sigma_{c}^{e}=\{a, b\}\right\}
$$

$\Omega^{E}$ is not a Nash Equilibria for both local and global levels of pollution.

\section{PROOF:}

country a $=\{b, c\} \stackrel{\text { change }}{\longrightarrow}\{\varnothing, \varnothing\} \stackrel{\text { result }}{\longrightarrow} W^{a}\left(a b c_{\theta}^{e}\right)<W^{a}\left(b c_{\theta}^{e}\right)$

We can conclude, that country a can deviate and improve its welfare. 


\section{A. 3.7.1 The Customs Union Game}

Welfare effects of various type of trade agreements:

$W^{a}\left(a b_{l}^{u}\right)>W^{a}\left(N_{l}\right)>W^{a}\left(a b c_{l}\right)>W^{a}\left(b c_{l}^{u}\right)$ Country $a$, local pollution

$W^{a}\left(a b_{g}^{u}\right)>W^{a}\left(a b c_{g}\right)>W^{a}\left(N_{g}\right)>W^{a}\left(b c_{g}^{u}\right)$ Country $a$, global pollution

$W^{b}\left(a b_{l}^{u}\right)>W^{b}\left(b c_{l}^{u}\right)>W^{b}\left(a b c_{l}\right)>W^{b}\left(N_{l}\right)$ Country $b$, local pollution

$W^{b}\left(b c_{g}^{u}\right)>W^{b}\left(a b_{g}^{u}\right)>W^{b}\left(N_{g}\right)>W^{b}\left(a b c_{g}\right)$ Country $b$, global pollution

$W^{c}\left(b c_{l}^{u}\right)>W^{c}\left(a b c_{l}\right)>W^{c}\left(N_{l}\right)>W^{c}\left(a b_{l}^{u}\right)$ Country $c$, local pollution

$W^{c}\left(b c_{g}^{u}\right)>W^{c}\left(N_{g}\right)>W^{c}\left(a b c_{g}\right)>W^{c}\left(a b_{g}^{u}\right)$ Country $c$, global pollution

\begin{tabular}{|c|c|}
\hline Announcement Profiles & Trade Agreements \\
\hline \hline$\Omega^{\Phi^{u}} \equiv\left\{\sigma_{a}^{u}=\{\varnothing, \varnothing\}, \sigma_{b}^{u}=\{\varnothing, \varnothing\}, \sigma_{c}^{u}=\{\varnothing, \varnothing\}\right\}$ & $\left\langle\Phi^{u}\right\rangle$ \\
\hline$\Omega^{a b u} \equiv\left\{\sigma_{a}^{u}=\{b, \varnothing\}, \sigma_{b}^{u}=\{a, \varnothing\}, \sigma_{c}^{u}=\{\varnothing, \varnothing\}\right\}$ & $\langle a b u\rangle$ \\
\hline$\Omega^{b c u} \equiv\left\{\sigma_{a}^{u}=\{\varnothing, \varnothing\}, \sigma_{b}^{u}=\{\varnothing, c\}, \sigma_{c}^{u}=\{\varnothing, b\}\right\}$ & $\langle b c u\rangle$ \\
\hline$\Omega^{F^{u}} \equiv\left\{\sigma_{a}^{u}=\{b, c\}, \sigma_{b}^{u}=\{a, c\}, \sigma_{c}^{u}=\{a, b\}\right\}$ & $\left\langle F^{u}\right\rangle$ \\
\hline
\end{tabular}

$$
\Omega^{\Phi^{u}} \equiv\left\{\sigma_{a}^{u}=\{\varnothing, \varnothing\}, \sigma_{b}^{u}=\{\varnothing, \varnothing\}, \sigma_{c}^{u}=\{\varnothing, \varnothing\}\right\}
$$

$\Omega^{\Phi^{u}}$ is a Nash Equilibria for both local and global levels of pollution.

\section{PROOF:}

Countries cannot get better off by unilaterally changing the announcements; countries have no incentive to announce any other country unless they are going to be announced back.

$\Omega^{\Phi^{u}}$ is not a CPNE for both local and global levels of pollution.

\section{PROOF:}

First, we assume that pollution is local and countries $a$ and $b$ form a trade union, then their announcement profiles would look as follows: $\sigma_{a}^{u}=\{b, \varnothing\}$ and $\sigma_{b}^{u}=\{a, \varnothing\}$.

$W^{a}\left(a b_{l}^{u}\right)>W^{a}\left(N_{l}\right)>W^{a}\left(a b c_{l}\right)>W^{a}\left(b c_{l}^{u}\right)$ and $W^{b}\left(a b_{l}^{u}\right)>W^{b}\left(b c_{l}^{u}\right)>W^{b}\left(a b c_{l}\right)>W^{b}\left(N_{l}\right)$

We can conclude that countries $a$ and $b$ can form a self-enforcing trade agreement for the local level of pollution. 
Second, we assume that pollution is global and countries $b$ and $c$ get into a trade union, then their announcement profiles would be altered as follows: $\sigma_{b}^{u}=\{\varnothing, c\}$ and $\sigma_{c}^{u}=\{\varnothing, b\}$. $W^{b}\left(b c_{g}^{u}\right)>W^{b}\left(a b_{g}^{u}\right)>W^{b}\left(N_{g}\right)>W^{b}\left(a b c_{g}\right)$ and $W^{c}\left(b c_{g}^{u}\right)>W^{c}\left(N_{g}\right)>W^{c}\left(a b c_{g}\right)>W^{c}\left(a b_{g}^{u}\right)$

We can conclude that countries $b$ and $c$ can form a self-enforcing trade agreement if pollution is global.

We are confident to conclude that $\Omega^{\Phi^{u}}$ is not a CPNE for both local and global levels of pollution.

$$
\Omega^{a b u} \equiv\left\{\sigma_{a}^{u}=\{b, \varnothing\}, \sigma_{b}^{u}=\{a, \varnothing\}, \sigma_{c}^{u}=\{\varnothing, \varnothing\}\right\}
$$

$\Omega^{a b u}$ is a Nash Equilibria for both local and global levels of pollution.

PROOF:

country a $=\{b, \varnothing\} \stackrel{\text { change }}{\longrightarrow}\{b, c\} \stackrel{\text { result }}{\longrightarrow}$ no change in $a$ 's welfare

country a $=\{b, \varnothing\} \stackrel{\text { change }}{\longrightarrow}\{\varnothing, c\} /\{\varnothing, \varnothing\} \stackrel{\text { result }}{\longrightarrow} W^{a}\left(a b_{\theta}^{u}\right)>W^{a}\left(N_{\theta}\right)$

We can conclude, that country $a$ has no incentive to change its announcement.

country $\mathrm{b}=\{a, \varnothing\} \stackrel{\text { change }}{\longrightarrow}\{a, c\} \stackrel{\text { result }}{\longrightarrow}$ no change in $b$ 's welfare

country $\mathrm{b}=\{a, \varnothing\} \stackrel{\text { change }}{\longrightarrow}\{\varnothing, c\} /\{\varnothing, \varnothing\} \stackrel{\text { result }}{\longrightarrow} W^{b}\left(a b_{\theta}^{u}\right)>W^{b}\left(N_{\theta}\right)$

We can conclude, that country $b$ has no incentive to change its announcement.

country $\mathrm{c}=\{\varnothing, \varnothing\} \stackrel{\text { change }}{\longrightarrow}\{a, \varnothing\} /\{\varnothing, b\} /\{a, b\} \stackrel{\text { result }}{\longrightarrow}$ no change in $c$ 's welfare

We can conclude, that country $c$ has no incentive to change its announcement.

Based on the above, $\Omega^{a b u}$ is a Nash Equilibria for both local and global levels of pollution.

$\Omega^{a b u}$ is a CPNE if pollution is local.

PROOF:

Neither $a$ or $b$ cannot do better by deviating from their original announcement:

$W^{a}\left(a b_{l}^{u}\right)>W^{a}\left(N_{l}\right)>W^{a}\left(a b c_{l}\right)>W^{a}\left(b c_{l}^{u}\right)$ and $W^{b}\left(a b_{l}^{u}\right)>W^{b}\left(b c_{l}^{u}\right)>W^{b}\left(a b c_{l}\right)>W^{b}\left(N_{l}\right)$

We conclude that, $\Omega^{a b u}$ is a self-enforcing commitment between one clean and one dirty country if pollution exhibits local characteristics.

$\Omega^{a b u}$ is not a CPNE if pollution is global.

PROOF:

Suppose, $b$ and $c$ get into a trade union and exclude $a$, then 
$W^{b}\left(b c_{g}^{u}\right)>W^{b}\left(a b_{g}^{u}\right)>W^{b}\left(N_{g}\right)>W^{b}\left(a b c_{g}\right)$ and $W^{c}\left(b c_{g}^{u}\right)>W^{c}\left(N_{g}\right)>W^{c}\left(a b c_{g}\right)>W^{c}\left(a b_{g}^{u}\right)$

We can conclude that clean countries would form a trade union and exclude $a$ if pollution exhibits global characteristics.

$$
\Omega^{b c u} \equiv\left\{\sigma_{a}^{u}=\{\varnothing, \varnothing\}, \sigma_{b}^{u}=\{\varnothing, c\}, \sigma_{c}^{u}=\{\varnothing, b\}\right\}
$$

$\Omega^{b c u}$ is a Nash Equilibria for both local and global levels of pollution.

PROOF:

country a $=\{\varnothing, \varnothing\} \stackrel{\text { change }}{\longrightarrow}\{b, \varnothing\} /\{\varnothing, c\} /\{b, c\} \stackrel{\text { result }}{\longrightarrow}$ no change in a's welfare

We can conclude, that country $a$ has no incentive to change its announcement.

country $\mathrm{b}=\{\varnothing, c\} \stackrel{\text { change }}{\longrightarrow}\{a, c\} \stackrel{\text { result }}{\longrightarrow}$ no change in $b$ 's welfare

country $\mathrm{b}=\{\varnothing, c\} \stackrel{\text { change }}{\longrightarrow}\{a, \varnothing\} /\{\varnothing, \varnothing\} \stackrel{\text { result }}{\longrightarrow} W^{b}\left(b c_{\theta}^{u}\right)>W^{b}\left(N_{\theta}\right)$

We can conclude, that country $b$ has no incentive to change its announcement.

country $\mathrm{c}=\{\varnothing, b\} \stackrel{\text { change }}{\longrightarrow}\{a, b\} \stackrel{\text { result }}{\longrightarrow}$ no change in $c$ 's welfare

country $\mathrm{c}=\{\varnothing, b\} \stackrel{\text { change }}{\longrightarrow}\{a, \varnothing\} /\{\varnothing, \varnothing\} \stackrel{\text { result }}{\longrightarrow} W^{c}\left(b c_{\theta}^{u}\right)>W^{c}\left(N_{\theta}\right)$

We can conclude, that country $c$ has no incentive to change its announcement.

Based on the above, $\Omega^{b c u}$ is a Nash Equilibria for both local and global levels of pollution.

$\Omega^{b c u}$ is not a CPNE for the local level of pollution.

PROOF:

Suppose, that countries $a$ and $b$ get into a trade union and exclude $c$, then

$W^{a}\left(a b_{l}^{u}\right)>W^{a}\left(N_{l}\right)>W^{a}\left(a b c_{l}\right)>W^{a}\left(b c_{l}^{u}\right)$ and $W^{b}\left(a b_{l}^{u}\right)>W^{b}\left(b c_{l}^{u}\right)>W^{b}\left(a b c_{l}\right)>W^{b}\left(N_{l}\right)$

We can conclude that one clean and one dirty country would form a trade union and exclude $c$ if pollution is local.

$\Omega^{b c u}$ is a CPNE if pollution is global.

PROOF:

Neither $b$ or $c$ can do better by deviating from their original announcement;

$W^{b}\left(b c_{g}^{u}\right)>W^{b}\left(a b_{g}^{u}\right)>W^{b}\left(N_{g}\right)>W^{b}\left(a b c_{g}\right)$ and $W^{c}\left(b c_{g}^{u}\right)>W^{c}\left(N_{g}\right)>W^{c}\left(a b c_{g}\right)>W^{c}\left(a b_{g}^{u}\right)$

We conclude that, $\Omega^{b c u}$ is a self-enforcing commitment between two clean countries if pollution exhibits global characteristics. 


$$
\Omega^{F^{u}} \equiv\left\{\sigma_{a}^{u}=\{b, c\}, \sigma_{b}^{u}=\{a, c\}, \sigma_{c}^{u}=\{a, b\}\right\}
$$

$\Omega^{\digamma^{u}}$ is not a Nash Equilibria for both local and global levels of pollution.

\section{PROOF:}

First, we consider the case of local pollution. Country $a$ can unilaterally change its announcement and improve its welfare:

country a $=\{b, c\} \stackrel{\text { change }}{\longrightarrow}\{b, \varnothing\} /\{c, \varnothing\} \stackrel{\text { result }}{\longrightarrow} W^{a}\left(a b_{l}^{u}\right)=W^{a}\left(a c_{l}^{u}\right)>W^{a}\left(a b c_{l}\right)$

Country $a$ is indifferent between these announcements, and the lucky country, $b$ or $c$, would improve its welfare. The unlucky one would be simply excluded.

Now, we consider the case of global pollution. In this case, clean countries can improve their welfare by excluding the dirty country $a$ :

country $\mathrm{b}=\{a, c\} \stackrel{\text { change }}{\longrightarrow}\{\varnothing, c\} \stackrel{\text { result }}{\longrightarrow} W^{b}\left(b c_{g}^{u}\right)>W^{b}\left(a b c_{g}\right)$

country $\mathrm{c}=\{a, b\} \stackrel{\text { change }}{\longrightarrow}\{\varnothing, b\} \stackrel{\text { result }}{\longrightarrow} W^{c}\left(b c_{g}^{u}\right)>W^{c}\left(a b c_{g}\right)$

We can conclude, that either of the clean countries can improve its welfare by calling another clean country only. Clean countries would prefer to exclude the dirty partner if pollution is global. Based on the above, we are confident to conclude that $\Omega^{\digamma^{u}}$ is not a Nash Equilibria for both local and global levels of pollution.

\section{A. 3.7.2 The Free Trade Agreement Game}

Welfare effects of various type of trade agreements:

$W^{a}\left(a_{l}^{h}\right)>W^{a}\left(a b_{l}\right)>W^{a}\left(N_{l}\right)>W^{a}\left(a b c_{l}\right)>W^{a}\left(b_{l}^{h}\right)>W^{a}\left(b c_{l}\right)$ Country $a$, local pollution $W^{a}\left(a_{g}^{h}\right)>W^{a}\left(a b_{g}\right)>W^{a}\left(a b c_{g}\right)>W^{a}\left(N_{g}\right)>W^{a}\left(b_{g}^{h}\right)>W^{a}\left(b c_{g}\right)$ Country $a$, global pollution $W^{b}\left(b_{l}^{h}\right)>W^{b}\left(a b_{l}\right)>W^{b}\left(a b c_{l}\right)>W^{b}\left(b c_{l}\right)>W^{b}\left(a_{l}^{h}\right)>W^{b}\left(N_{l}\right)$ Country $b$, local pollution $W^{b}\left(b_{g}^{h}\right)>W^{b}\left(b c_{g}\right)>W^{b}\left(a b_{g}\right)>W^{b}\left(N_{g}\right)>W^{b}\left(a b c_{g}\right)>W^{b}\left(a_{g}^{h}\right)$ Country $b$, global pollution $W^{c}\left(a b c_{l}\right)>W^{c}\left(b c_{l}\right)>W^{c}\left(a_{l}^{h}\right)>W^{c}\left(N_{l}\right)>W^{c}\left(b_{l}^{h}\right)>W^{c}\left(a b_{l}\right)$ Country $c$, local pollution $W^{c}\left(b c_{g}\right)>W^{c}\left(N_{g}\right)>W^{c}\left(a b c_{g}\right)>W^{c}\left(b_{g}^{h}\right)>W^{c}\left(a_{g}^{h}\right)>W^{c}\left(a b_{g}\right)$ Country $c$, global pollution 


\begin{tabular}{|c|c|}
\hline Announcement Profiles & Trade Agreements \\
\hline \hline$\Omega^{\Phi} \equiv\left\{\sigma_{a}=\{\varnothing, \varnothing\}, \sigma_{b}=\{\varnothing, \varnothing\}, \sigma_{c}=\{\varnothing, \varnothing\}\right\}$ & $\langle\Phi\rangle$ \\
\hline$\Omega^{a b} \equiv\left\{\sigma_{a}=\{b, \varnothing\}, \sigma_{b}=\{a, \varnothing\}, \sigma_{c}=\{\varnothing, \varnothing\}\right\}$ & $\langle a b\rangle$ \\
\hline$\Omega^{b c} \equiv\left\{\sigma_{a}=\{\varnothing, \varnothing\}, \sigma_{b}=\{\varnothing, c\}, \sigma_{c}=\{\varnothing, b\}\right\}$ & $\langle b c\rangle$ \\
\hline$\Omega^{a h} \equiv\left\{\sigma_{a}=\{b, c\}, \sigma_{b}=\{a, \varnothing\}, \sigma_{c}=\{a, \varnothing\}\right\}$ & $\langle a h\rangle$ \\
\hline$\Omega^{b h} \equiv\left\{\sigma_{a}=\{b, \varnothing\}, \sigma_{b}=\{a, c\}, \sigma_{c}=\{\varnothing, b\}\right\}$ & $\langle b h\rangle$ \\
\hline$\Omega^{F} \equiv\left\{\sigma_{a}=\{b, c\}, \sigma_{b}=\{a, c\}, \sigma_{c}=\{a, b\}\right\}$ & $\langle F\rangle$ \\
\hline
\end{tabular}

$$
\Omega^{\Phi} \equiv\left\{\sigma_{a}=\{\varnothing, \varnothing\}, \sigma_{b}=\{\varnothing, \varnothing\}, \sigma_{c}=\{\varnothing, \varnothing\}\right\}
$$

$\Omega^{\Phi}$ is a Nash Equilibria for both local and global levels of pollution.

PROOF:

Countries cannot get better off by unilaterally changing the announcements; countries have no incentive to announce any other country unless they are going to be announced back.

$\Omega^{\Phi}$ is not a CPNE for both local and global levels of pollution.

PROOF:

Any two countries can be better off by announcing each other; for example, $W^{a}\left(a b_{\theta}\right)>W^{a}\left(N_{\theta}\right)$ and $W^{b}\left(a b_{\theta}\right)>W^{b}\left(N_{\theta}\right)$.

$$
\Omega^{a b} \equiv\left\{\sigma_{a}=\{b, \varnothing\}, \sigma_{b}=\{a, \varnothing\}, \sigma_{c}=\{\varnothing, \varnothing\}\right\}
$$

$\Omega^{a b}$ is a Nash Equilibria for both local and global levels of pollution.

\section{PROOF:}

country $\mathrm{a}=\{b, \varnothing\} \stackrel{\text { change }}{\longrightarrow}\{b, c\} \stackrel{\text { result }}{\longrightarrow}$ no change in a's welfare

country a $=\{b, \varnothing\} \stackrel{\text { change }}{\longrightarrow}\{\varnothing, c\} /\{\varnothing, \varnothing\} \stackrel{\text { result }}{\longrightarrow} W^{a}\left(a b_{\theta}\right)>W^{a}\left(N_{\theta}\right)$

We can conclude, that country $a$ has no incentive to change its announcement.

country $\mathrm{b}=\{a, \varnothing\} \stackrel{\text { change }}{\longrightarrow}\{a, c\} \stackrel{\text { result }}{\longrightarrow}$ no change in $b$ 's welfare

country $\mathrm{b}=\{a, \varnothing\} \stackrel{\text { change }}{\longrightarrow}\{\varnothing, c\} /\{\varnothing, \varnothing\} \stackrel{\text { result }}{\longrightarrow} W^{b}\left(a b_{\theta}\right)>W^{b}\left(N_{\theta}\right)$

We can conclude, that country $b$ has no incentive to change its announcement. 
country $\mathrm{c}=\{\varnothing, \varnothing\} \stackrel{\text { change }}{\longrightarrow}\{a, \varnothing\} /\{\varnothing, b\} /\{a, b\} \stackrel{\text { result }}{\longrightarrow}$ no change in c's welfare

We can conclude, that country $c$ has no incentive to change its announcement.

Based on the above, we conclude that $\Omega^{a b}$ is a Nash Equilibria for both local and global levels of pollution.

$\Omega^{a b}$ is not a CPNE for both local and global levels of pollution.

PROOF:

Let $a$ and $c$ form a coalition, then

$\Omega \equiv\left\{\sigma_{a}=\{b, c\}, \sigma_{b}=\{a, \varnothing\}, \sigma_{c}=\{a, \varnothing\}\right\}$, and $W^{a}\left(a_{\theta}^{h}\right)>W^{a}\left(a b_{\theta}\right)$ and $W^{c}\left(a_{\theta}^{h}\right)>W^{c}\left(a b_{\theta}\right)$. We can see, that country $c$ would prefer to be a spoke versus being an outsider of the trade agreement between two other countries. We can conclude that $\Omega^{a b}$ is not a CPNE for both local and global levels of pollution.

$$
\Omega^{b c} \equiv\left\{\sigma_{a}=\{\varnothing, \varnothing\}, \sigma_{b}=\{\varnothing, c\}, \sigma_{c}=\{\varnothing, b\}\right\}
$$

$\Omega^{b c}$ is a Nash Equilibria for both local and global levels of pollution.

PROOF:

country a $=\{\varnothing, \varnothing\} \stackrel{\text { change }}{\longrightarrow}\{b, \varnothing\} /\{\varnothing, c\} /\{b, c\} \stackrel{\text { result }}{\longrightarrow}$ no change in $a$ 's welfare

We can conclude, that country $a$ has no incentive to change its announcement.

country $\mathrm{b}=\{\varnothing, c\} \stackrel{\text { change }}{\longrightarrow}\{a, c\} \stackrel{\text { result }}{\longrightarrow}$ no change in $b$ 's welfare

country $\mathrm{b}=\{\varnothing, c\} \stackrel{\text { change }}{\longrightarrow}\{a, \varnothing\} /\{\varnothing, \varnothing\} \stackrel{\text { result }}{\longrightarrow} W^{b}\left(b c_{\theta}\right)>W^{b}\left(N_{\theta}\right)$

We can conclude, that country $b$ has no incentive to change its announcement.

country $\mathrm{c}=\{\varnothing, b\} \stackrel{\text { change }}{\longrightarrow}\{a, b\} \stackrel{\text { result }}{\longrightarrow}$ no change in $c$ 's welfare

country c $=\{\varnothing, b\} \stackrel{\text { change }}{\longrightarrow}\{a, \varnothing\} /\{\varnothing, \varnothing\} \stackrel{\text { result }}{\longrightarrow} W^{c}\left(b c_{\theta}\right)>W^{c}\left(N_{\theta}\right)$

We can conclude, that country $c$ has no incentive to change its announcement.

Based on the above, we conclude that $\Omega^{b c}$ is a Nash Equilibria for both local and global levels of pollution.

$\Omega^{b c}$ is not a CPNE for both local and global levels of pollution.

PROOF: 
Let $a$ and $b$ form a coalition, then

$\Omega \equiv\left\{\sigma_{a}=\{b, \varnothing\}, \sigma_{b}=\{a, c\}, \sigma_{c}=\{\varnothing, b\}\right\}$, and

$W^{a}\left(b_{\theta}^{h}\right)>W^{a}\left(b c_{\theta}\right)$ and $W^{b}\left(b_{\theta}^{h}\right)>W^{b}\left(b c_{\theta}\right)$. It is clear that the dirty country $a$ would prefer to be a spoke that face an agreement between two clean countries. We can conclude that $\Omega^{b c}$ is not a CPNE for both local and global levels of pollution.

$$
\Omega^{a h} \equiv\left\{\sigma_{a}=\{b, c\}, \sigma_{b}=\{a, \varnothing\}, \sigma_{c}=\{a, \varnothing\}\right\}
$$

$\Omega^{a h}$ is a Nash Equilibria for both local and global levels of pollution.

PROOF:

country a $=\{b, c\} \stackrel{\text { change }}{\longrightarrow}\{b, \varnothing\} /\{\varnothing, c\} \stackrel{\text { result }}{\longrightarrow} W^{a}\left(a_{\theta}^{h}\right)>W^{a}\left(a b_{\theta}\right)=W^{a}\left(a c_{\theta}\right)$

country a $=\{b, c\} \stackrel{\text { change }}{\longrightarrow}\{\varnothing, \varnothing\} \stackrel{\text { result }}{\longrightarrow} W^{a}\left(a_{\theta}^{h}\right)>W^{a}\left(N_{\theta}\right)$

We can conclude, that country $a$ has no incentive to change its announcement.

country $\mathrm{b}=\{a, \varnothing\} \stackrel{\text { change }}{\longrightarrow}\{a, c\} \stackrel{\text { result }}{\longrightarrow}$ no change in $b$ 's welfare

country $\mathrm{b}=\{a, \varnothing\} \stackrel{\text { change }}{\longrightarrow}\{\varnothing, c\} /\{\varnothing, \varnothing\} \stackrel{\text { result }}{\longrightarrow} W^{b}\left(a_{\theta}^{h}\right)>W^{b}\left(a c_{\theta}\right)$

We can conclude, that country $b$ has no incentive to change its announcement.

country $\mathrm{c}=\{a, \varnothing\} \stackrel{\text { change }}{\longrightarrow}\{a, b\} \stackrel{\text { result }}{\longrightarrow}$ no change in $c$ 's welfare

country $\mathrm{c}=\{a, \varnothing\} \stackrel{\text { change }}{\longrightarrow}\{\varnothing, b\} /\{\varnothing, \varnothing\} \stackrel{\text { result }}{\longrightarrow} W^{c}\left(a_{\theta}^{h}\right)>W^{c}\left(a b_{\theta}\right)$

We can conclude, that country $c$ has no incentive to change its announcement.

Based on the above, we can conclude that $\Omega^{a h}$ is a Nash Equilibria for both local and global levels of pollution.

$\Omega^{\text {ah }}$ is not a CPNE for both local and global levels of pollution.

\section{PROOF:}

Let $b$ and $c$ form a coalition, then

$\Omega \equiv\left\{\sigma_{a}=\{b, c\}, \sigma_{b}=\{a, c\}, \sigma_{c}=\{a, b\}\right\}$, and

$W^{b}\left(a b c_{\theta}\right)>W^{b}\left(a_{\theta}^{h}\right)$ and $W^{c}\left(a b c_{\theta}\right)>W^{c}\left(a_{\theta}^{h}\right)$. We can see that clean countries would rather be a part of a free trade world than being spokes. We can conclude that $\Omega^{a h}$ is not a CPNE for both local and global levels of pollution. 


$$
\Omega^{b h} \equiv\left\{\sigma_{a}=\{b, \varnothing\}, \sigma_{b}=\{a, c\}, \sigma_{c}=\{\varnothing, b\}\right\}
$$

$\Omega^{\text {bh }}$ is a Nash Equilibria for both local and global levels of pollution.

\section{PROOF:}

country a $=\{b, \varnothing\} \stackrel{\text { change }}{\longrightarrow}\{b, c\} \stackrel{\text { result }}{\longrightarrow}$ no change in $a$ 's welfare

country a $=\{b, \varnothing\} \stackrel{\text { change }}{\longrightarrow}\{\varnothing, c\} /\{\varnothing, \varnothing\} \stackrel{\text { result }}{\longrightarrow} W^{a}\left(b_{\theta}^{h}\right)>W^{a}\left(b c_{\theta}\right)$

We can conclude, that country $a$ has no incentive to change its announcement.

country $\mathrm{b}=\{a, c\} \stackrel{\text { change }}{\longrightarrow}\{a, \varnothing\} \stackrel{\text { result }}{\longrightarrow} W^{b}\left(b_{\theta}^{h}\right)>W^{b}\left(a b_{\theta}\right)$

country $\mathrm{b}=\{a, c\} \stackrel{\text { change }}{\longrightarrow}\{\varnothing, c\} \stackrel{\text { result }}{\longrightarrow} W^{b}\left(b_{\theta}^{h}\right)>W^{b}\left(b c_{\theta}\right)$

country $\mathrm{b}=\{a, c\} \stackrel{\text { change }}{\longrightarrow}\{\varnothing, \varnothing\} \stackrel{\text { result }}{\longrightarrow} W^{b}\left(b_{\theta}^{h}\right)>W^{b}\left(N_{\theta}\right)$

We can conclude, that country $b$ has no incentive to change its announcement.

country $\mathrm{c}=\{\varnothing, b\} \stackrel{\text { change }}{\longrightarrow}\{a, b\} \stackrel{\text { result }}{\longrightarrow}$ no change in $c$ 's welfare

country c $=\{\varnothing, b\} \stackrel{\text { change }}{\longrightarrow}\{a, \varnothing\} /\{\varnothing, \varnothing\} \stackrel{\text { result }}{\longrightarrow} W^{c}\left(b_{\theta}^{h}\right)>W^{c}\left(a b_{\theta}\right)$

We can conclude, that country $c$ has no incentive to change its announcement.

Based on the above, we conclude that $\Omega^{b h}$ is a Nash Equilibria for both local and global levels of pollution.

$\Omega^{\text {bh }}$ is not a CPNE for both local and global levels of pollution.

PROOF:

Let $a$ and $c$ form a coalition, then

$\Omega \equiv\left\{\sigma_{a}=\{b, c\}, \sigma_{b}=\{a, c\}, \sigma_{c}=\{a, b\}\right\}$, and

$W^{a}\left(a b c_{\theta}\right)>W^{a}\left(b_{\theta}^{h}\right)$ and $W^{c}\left(a b c_{\theta}\right)>W^{c}\left(b_{\theta}^{h}\right)$. We can see that both countries, the clean country $c$ and the dirty country $a$, would prefer to be a part of a free trade world versus being spokes. We can conclude that $\Omega^{b h}$ is not a CPNE for both local and global levels of pollution.

$$
\Omega^{F} \equiv\left\{\sigma_{a}=\{b, c\}, \sigma_{b}=\{a, c\}, \sigma_{c}=\{a, b\}\right\}
$$

$\Omega^{\digamma}$ is a Nash Equilibria for both local and global levels of pollution.

ProOF:

country $\mathrm{a}=\{b, c\} \stackrel{\text { change }}{\longrightarrow}\{b, \varnothing\} /\{\varnothing, c\} \stackrel{\text { result }}{\longrightarrow} W^{a}\left(a b c_{\theta}\right)>W^{a}\left(b_{\theta}^{h}\right)=W^{a}\left(c_{\theta}^{h}\right)$ 
country a $=\{b, c\} \stackrel{\text { change }}{\longrightarrow}\{\varnothing, \varnothing\} \stackrel{\text { result }}{\longrightarrow} W^{a}\left(a b c_{\theta}\right)>W^{a}\left(b c_{\theta}\right)$

We can conclude, that country $a$ has no incentive to change its announcement.

country $\mathrm{b}=\{a, c\} \stackrel{\text { change }}{\longrightarrow}\{a, \varnothing\} \stackrel{\text { result }}{\longrightarrow} W^{b}\left(a b c_{\theta}\right)>W^{b}\left(a_{\theta}^{h}\right)$

country $\mathrm{b}=\{a, c\} \stackrel{\text { change }}{\longrightarrow}\{\varnothing, c\} \stackrel{\text { result }}{\longrightarrow} W^{b}\left(a b c_{\theta}\right)>W^{b}\left(c_{\theta}^{h}\right)$

country $\mathrm{b}=\{a, c\} \stackrel{\text { change }}{\longrightarrow}\{\varnothing, \varnothing\} \stackrel{\text { result }}{\longrightarrow} W^{b}\left(a b c_{\theta}\right)>W^{b}\left(a c_{\theta}\right)$

We can conclude, that country $b$ has no incentive to change its announcement.

country $\mathrm{c}=\{a, b\} \stackrel{\text { change }}{\longrightarrow}\{\varnothing, b\} \stackrel{\text { result }}{\longrightarrow} W^{c}\left(a b c_{\theta}\right)>W^{c}\left(b_{\theta}^{h}\right)$

country c $=\{a, b\} \stackrel{\text { change }}{\longrightarrow}\{a, \varnothing\} \stackrel{\text { result }}{\longrightarrow} W^{c}\left(a b c_{\theta}\right)>W^{c}\left(a_{\theta}^{h}\right)$

country $\mathrm{c}=\{a, b\} \stackrel{\text { change }}{\longrightarrow}\{\varnothing, \varnothing\} \stackrel{\text { result }}{\longrightarrow} W^{c}\left(a b c_{\theta}\right)>W^{c}\left(a b_{\theta}\right)$

We can conclude, that country $c$ has no incentive to change its announcement.

Based on the above, we conclude that $\Omega^{\digamma}$ is a Nash Equilibria for both local and global levels of pollution.

$\Omega^{\digamma}$ is a CPNE for both local and global levels of pollution.

\section{PROOF:}

Though any two countries can benefit from excluding the third one from the agreement, none of the countries would excise it in equilibrium. To proof that, let us assume, first, that countries $a$ and $b$ decided to form a bilateral trade agreement by altering these profiles in to the following announcement:

$\Omega \equiv\left\{\sigma_{a}=\{b, \varnothing\}, \sigma_{b}=\{a, \varnothing\}, \sigma_{c}=\{a, b\}\right\}$

We can see that these joint changes in the announcements are beneficial to both countries: $W^{a}\left(a b_{\theta}\right)>$ $W^{a}\left(a b c_{\theta}\right)$ and $W^{b}\left(a b_{\theta}\right)>W^{b}\left(a b c_{\theta}\right)$. However, both countries have an incentive to deviate from this agreement and include country $c$ in their announcement, because $W^{a}\left(a_{\theta}^{h}\right)>W^{a}\left(a b_{\theta}\right)$ and $W^{b}\left(b_{\theta}^{h}\right)>W^{b}\left(a b_{\theta}\right)$. Based on the above, we can conclude that countries would go back to the original announcement profile $\Omega^{\digamma}$.

Now, we assume that countries $b$ and $c$ decided to form a bilateral trade agreement by altering this profiles in to the following announcement:

$\Omega \equiv\left\{\sigma_{a}=\{b, c\}, \sigma_{b}=\{\varnothing, c\}, \sigma_{c}=\{\varnothing, b\}\right\}$ 
Again, we can see that these joint changes in the announcements are beneficial to both countries: $W^{b}\left(b c_{\theta}\right)>W^{b}\left(a b c_{\theta}\right)$ and $W^{c}\left(b c_{\theta}\right)>W^{c}\left(a b c_{\theta}\right)$. However, both countries have an incentive to deviate from this agreement and include $a$ as well, because $W^{b}\left(b_{\theta}^{h}\right)>W^{b}\left(b c_{\theta}\right)$ and $W^{c}\left(c_{\theta}^{h}\right)>W^{b}\left(b c_{\theta}\right)$. Based on the above, we can conclude that countries would go back to the original announcement profile $\Omega^{\digamma}$.

\section{A. 3.8.1 The Integrated Customs Union Game}

Welfare effects of various type of trade and environmental agreements:

$W^{a}\left(a b_{l}^{i u}\right)>W^{a}\left(N_{l}\right)>W^{a}\left(a b c_{l}^{i}\right)>W^{a}\left(b c_{l}^{i u}\right)$ Country a, local pollution

$W^{a}\left(a b_{g}^{i u}\right) \stackrel{\lambda \in(0.008,0.1]}{>} W^{a}\left(N_{g}\right)>W^{a}\left(b c_{g}^{i u}\right)>W^{a}\left(a b c_{g}^{i}\right)$ Country a, global pollution $\& \lambda \in(0.008,0.1]$

$W^{a}\left(N_{g}\right) \stackrel{\lambda \in(0,0.008]}{>} W^{a}\left(a b_{g}^{i u}\right)>W^{a}\left(b c_{g}^{i u}\right)>W^{a}\left(a b c_{g}^{i}\right)$ Country a, global pollution $\& \lambda \in(0,0.008]$

$W^{b}\left(a b_{l}^{i u}\right)>W^{b}\left(a b c_{l}^{i}\right)>W^{b}\left(b c_{l}^{i u}\right)>W^{b}\left(N_{l}\right)$ Country b, local pollution

$W^{b}\left(a b c_{g}^{i}\right)>W^{b}\left(a b_{g}^{i u}\right)>W^{b}\left(b c_{g}^{i u}\right)>W^{b}\left(N_{g}\right)$ Country b, global pollution

$W^{c}\left(a b c_{l}^{i}\right)>W^{c}\left(b c_{l}^{i u}\right)>W^{c}\left(N_{l}\right)>W^{c}\left(a b_{l}^{i u}\right)$ Country c, local pollution

$W^{c}\left(a b c_{g}^{i}\right)>W^{c}\left(b c_{g}^{i u}\right)>W^{c}\left(N_{g}\right) \stackrel{\lambda \in(0,0.067]}{>} W^{c}\left(a b_{g}^{i u}\right)$ Country c, global pollution $\& \lambda \in(0,0.067]$

$W^{c}\left(a b c_{g}^{i}\right)>W^{c}\left(b c_{g}^{i u}\right)>W^{c}\left(a b_{g}^{i u}\right) \stackrel{\lambda \in(0.067,0.1]}{>} W^{c}\left(N_{g}\right)$ Country c, global pollution $\& \lambda \in(0.067,0.1]$

\begin{tabular}{|c|c|}
\hline Announcement Profiles & Integrated Agreements \\
\hline \hline$\Omega^{\Phi^{i u}} \equiv\left\{\sigma_{a}^{i u}=\{\varnothing, \varnothing\}, \sigma_{b}^{i u}=\{\varnothing, \varnothing\}, \sigma_{c}^{i u}=\{\varnothing, \varnothing\}\right\}$ & $\left\langle\Phi^{i u}\right\rangle$ \\
\hline$\Omega^{a b i u} \equiv\left\{\sigma_{a}^{i u}=\{b, \varnothing\}, \sigma_{b}^{i u}=\{a, \varnothing\}, \sigma_{c}^{i u}=\{\varnothing, \varnothing\}\right\}$ & $\langle a b i u\rangle$ \\
\hline$\Omega^{b c i u} \equiv\left\{\sigma_{a}^{i u}=\{\varnothing, \varnothing\}, \sigma_{b}^{i u}=\{\varnothing, c\}, \sigma_{c}^{i u}=\{\varnothing, b\}\right\}$ & $\langle b c i u\rangle$ \\
\hline$\Omega^{F^{i u}} \equiv\left\{\sigma_{a}^{i u}=\{b, c\}, \sigma_{b}^{i u}=\{a, c\}, \sigma_{c}^{i u}=\{a, b\}\right\}$ & $\left\langle F^{i u}\right\rangle$ \\
\hline
\end{tabular}

$$
\Omega^{\Phi^{i u}} \equiv\left\{\sigma_{a}^{i u}=\{\varnothing, \varnothing\}, \sigma_{b}^{i u}=\{\varnothing, \varnothing\}, \sigma_{c}^{i u}=\{\varnothing, \varnothing\}\right\}
$$

$\Omega^{\Phi^{i u}}$ is a Nash Equilibria for both local and global levels of pollution.

\section{PROOF:}

Countries cannot change their welfares by unilaterally changing the announcements. $\Omega^{\Phi^{i u}}$ is not a CPNE for both local and global levels of pollution. 


\section{PROOF:}

First, we let countries $a$ and $b$ form a trade and environmental union, then the announcement would be as follows:

$\Omega \equiv\left\{\sigma_{a}^{i u}=\{b, \varnothing\}, \sigma_{b}^{i u}=\{a, \varnothing\}, \sigma_{c}^{i u}=\{\varnothing, \varnothing\}\right\}$ and $W^{a}\left(a b_{l}^{i u}\right)>W^{a}\left(N_{l}\right)$ and $W^{b}\left(a b_{l}^{i u}\right)>W^{b}\left(N_{l}\right)$. We don't check for any further deviations, because the level of welfares members acquire in this union are the highest in the entire IU Game in the case of local pollution. Based on the above, we can conclude that $\Omega^{\Phi^{i u}}$ is not a CPNE if pollution is local.

Second, we consider the case of global pollution and $\lambda \in(0.008,0.1]$. We let countries $a$ and $b$ form a trade and environmental union, and as a result, we observe that the levels of welfares these two countries achieve are the highest in the IU Game if pollution is global and lambda is relatively high.

Now, we consider the case of global pollution, and we let countries $b$ and $c$ form a trade and environmental union, then the announcement would be as follows:

$\Omega^{b c i u} \equiv\left\{\sigma_{a}^{i u}=\{\varnothing, \varnothing\}, \sigma_{b}^{i u}=\{\varnothing, c\}, \sigma_{c}^{i u}=\{\varnothing, b\}\right\}$ and $W^{b}\left(b c_{g}^{i u}\right)>W^{b}\left(N_{g}\right)$ and $W^{c}\left(b c_{g}^{i u}\right)>W^{c}\left(N_{g}\right)$. We can conclude, that clean countries can form a coalition. We can also rule out all further deviations based on the results that though clean countries would prefer to include the dirty player into the union, the dirty country $a$ would rather be an outsider than participate in a fully integrated world. Based on the above, we can conclude that $\Omega^{i u}$ is not a CPNE if pollution is global.

$$
\Omega^{a b i u} \equiv\left\{\sigma_{a}^{i u}=\{b, \varnothing\}, \sigma_{b}^{i u}=\{a, \varnothing\}, \sigma_{c}^{i u}=\{\varnothing, \varnothing\}\right\}
$$

$\Omega^{a b i u}$ is a Nash Equilibria if pollution is local and if pollution is global and $\lambda \in(0.008,0.1]$.

PROOF:

country a $=\{b, \varnothing\} \stackrel{\text { change }}{\longrightarrow}\{b, c\} \stackrel{\text { result }}{\longrightarrow}$ no change in $a$ 's welfare

country a $=\{b, \varnothing\} \stackrel{\text { change }}{\longrightarrow}\{\varnothing, c\} /\{\varnothing, \varnothing\} \stackrel{\text { result }}{\longrightarrow} W^{a}\left(a b_{l}^{i u}\right)>W^{a}\left(N_{l}\right) \& W^{a}\left(a b_{g}^{i u}\right)>W^{a}\left(N_{g}\right)$ if $\lambda \in$ $(0.008,0.1]$ 
We can conclude, that country $a$ has no incentive to change its announcement if pollution is local. Also, country $a$ has no incentive to alter its announcement if pollution is global and $\lambda \in$ $(0.008,0.1]$.

country $\mathrm{b}=\{a, \varnothing\} \stackrel{\text { change }}{\longrightarrow}\{a, c\} \stackrel{\text { result }}{\longrightarrow}$ no change in $b$ 's welfare

country $\mathrm{b}=\{a, \varnothing\} \stackrel{\text { change }}{\longrightarrow}\{\varnothing, c\} /\{\varnothing, \varnothing\} \stackrel{\text { result }}{\longrightarrow} W^{b}\left(a b_{\theta}^{i u}\right)>W^{b}\left(N_{\theta}\right)$

We can conclude, that country $b$ has no incentive to change its announcement.

country $\mathrm{c}=\{\varnothing, \varnothing\} \stackrel{\text { change }}{\longrightarrow}\{a, \varnothing\} /\{\varnothing, b\} /\{a, b\} \stackrel{\text { result }}{\longrightarrow}$ no change in $c$ 's welfare

We can conclude, that country $c$ has no incentive to change its announcement.

Based on the above, we conclude that $\Omega^{a b i u}$ is a Nash Equilibria for local level of pollution and for global level of pollution if $\lambda \in(0.008,0.1]$.

$\Omega^{\text {abiu }}$ is not a Nash Equilibria if pollution is global and $\lambda \in(0,0.008]$.

PROOF:

country a $=\{b, \varnothing\} \stackrel{\text { change }}{\longrightarrow}\{\varnothing, \varnothing\} \stackrel{\text { result }}{\longrightarrow} W^{a}\left(a b_{g}^{i u}\right)<W^{a}\left(N_{g}\right)$ if $\lambda \in(0,0.008]$.

We can conclude, that country $a$ can unilaterally change its announcement and gain a higher level of welfare.

$\Omega^{\text {abiu }}$ is a CPNE if pollution is local and if pollution is global and $\lambda \in(0.008,0.1]$.

\section{PROOF:}

We start with considering the local level of pollution. Both countries, $a$ and $b$, have no incentive to form any other coalition, because their welfare is the highest in the entire IU Game. Now, we consider the global level of pollution and $\lambda \in(0.008,0.1]$. In this case, the dirty country $a$ has no incentive to form any other coalition, including a global one, because $a$ 's welfare is the highest in the trade and environmental union with only one dirty country. Country $b$ would prefer to get into a global coalition, but country $a$ would not agree to that.

$$
\Omega^{b c i u} \equiv\left\{\sigma_{a}^{i u}=\{\varnothing, \varnothing\}, \sigma_{b}^{i u}=\{\varnothing, c\}, \sigma_{c}^{i u}=\{\varnothing, b\}\right\}
$$

$\Omega^{\text {bciu }}$ is a Nash Equilibria for both local and global levels of pollution.

PROOF:

country a $=\{\varnothing, \varnothing\} \stackrel{\text { change }}{\longrightarrow}\{b, \varnothing\} /\{\varnothing, c\} /\{b, c\} \stackrel{\text { result }}{\longrightarrow}$ no change in $a$ 's welfare 
We can conclude, that country $a$ has no incentive to change its announcement.

country $\mathrm{b}=\{\varnothing, c\} \stackrel{\text { change }}{\longrightarrow}\{a, c\} \stackrel{\text { result }}{\longrightarrow}$ no change in b's welfare

country $\mathrm{b}=\{\varnothing, c\} \stackrel{\text { change }}{\longrightarrow}\{a, \varnothing\} /\{\varnothing, \varnothing\} \stackrel{\text { result }}{\longrightarrow} W^{b}\left(b c_{\theta}^{i u}\right)>W^{b}\left(N_{\theta}\right)$

We can conclude, that country $b$ has no incentive to change its announcement.

country $\mathrm{c}=\{\varnothing, b\} \stackrel{\text { change }}{\longrightarrow}\{a, b\} \stackrel{\text { result }}{\longrightarrow}$ no change in $c$ 's welfare

country $\mathrm{c}=\{\varnothing, b\} \stackrel{\text { change }}{\longrightarrow}\{a, \varnothing\} /\{\varnothing, \varnothing\} \stackrel{\text { result }}{\longrightarrow} W^{c}\left(b c_{\theta}^{i u}\right)>W^{c}\left(N_{\theta}\right)$

We can conclude, that country $c$ has no incentive to change its announcement.

Based on the above, we conclude that $\Omega^{b c i u}$ is a Nash Equilibria for both local and global levels of pollution.

$\Omega^{\text {bciu }}$ is not a CPNE if pollution is local and if pollution is global and $\lambda \in(0.008,0.1]$.

PROOF:

First, we consider countries $a$ and $b$ forming a trade and environmental union in the case of local pollution, then $W^{a}\left(a b_{l}^{i u}\right)>W^{a}\left(b c_{l}^{i u}\right)$ and $W^{b}\left(a b_{l}^{i u}\right)>W^{b}\left(b c_{l}^{i u}\right)$. Also, the level of welfare countries $a$ and $b$ achieve from forming a trade and environmental union is the highest in this game, so none of the members would deviate any further. Second, we consider the case of global pollution and $\lambda \in(0.008,0.1]$, then $W^{a}\left(a b_{g}^{i u}\right)>W^{a}\left(b c_{g}^{i u}\right)$ and $W^{b}\left(a b_{g}^{i u}\right)>W^{b}\left(b c_{g}^{i u}\right)$. Also, the level of welfare country $a$ gets in this union is the highest in the entire game, and country $b$ can be better off only in the integrated world, but the dirty country $a$ is not interested in being a part of the integrated world. Based, on the above, we are confident to conclude that $\Omega^{\text {bciu }}$ is not a CPNE for the local level of pollution and for the global level of pollution if $\lambda \in(0.008,0.1]$.

$\Omega^{\text {bciu }}$ is a CPNE if pollution is global and $\lambda \in(0,0.008]$.

PROOF:

We let countries $a$ and $b$ form a trade and environmental union, then the announcement would be as follows:

$\Omega \equiv\left\{\sigma_{a}^{i u}=\{b, \varnothing\}, \sigma_{b}^{i u}=\{a, \varnothing\}, \sigma_{c}^{i u}=\{\varnothing, b\}\right\}$ $W^{a}\left(a b_{g}^{i u}\right)>W^{a}\left(b c_{g}^{i u}\right)$ if $\lambda \in(0,0.008]$ and $W^{b}\left(a b_{g}^{i u}\right)>W^{b}\left(b c_{g}^{i u}\right)$. However, this deviation is not self-enforcing, because country $a$ has an incentive to deviate to the no agreement situation by 
changing its announcement into $\{\varnothing, \varnothing\}: W^{a}\left(a b_{g}^{i u}\right)<W^{a}\left(N_{g}\right)$ if $\lambda \in(0,0.008]$. Based on the above, we can conclude that $\Omega^{b c i u}$ is a CPNE if pollution is global and $\lambda \in(0,0.008]$.

$$
\Omega^{F^{i u}} \equiv\left\{\sigma_{a}^{i u}=\{b, c\}, \sigma_{b}^{i u}=\{a, c\}, \sigma_{c}^{i u}=\{a, b\}\right\}
$$

$\Omega^{\digamma^{i u}}$ is not a Nash Equilibria for both local and global levels of pollution.

PROOF:

First, we prove that it is not a Nash equilibria if pollution is local. Country $a$ can improve its welfare by announcing only one out of two clean countries. The lucky clean country would prefer to form a union with the dirty country $a$ versus the union with another clean country. We can conclude, that $\Omega^{\digamma^{i u}}$ is not a Nash Equilibria.

Now, we show that it is not a Nash equilibria for the global level of pollution we well. The dirty country $a$ would prefer to be an outsider of an integrated agreement between two clean countries than participate in a fully integrated world: $W^{a}\left(a b c_{g}^{i}\right)<W^{a}\left(b c_{g}^{i u}\right)$. Based on that we conclude, that $\Omega^{\digamma^{i u}}$ is not a Nash Equilibria if pollution is global.

\section{A. 3.8.2 The Integrated Free Trade Agreements Game}

Welfare effects of various type of trade and environmental agreements:

$W^{a}\left(a b_{l}^{i}\right)>W^{a}\left(N_{l}\right)>W^{a}\left(a_{l}^{h i}\right)>W^{a}\left(a b c_{l}^{i}\right)>W^{a}\left(b c_{l}^{i}\right)>W^{a}\left(b_{l}^{h i}\right)$ Country a, local pollution $W^{a}\left(N_{g}\right) \stackrel{\lambda \in(0,0.053]}{>} W^{a}\left(a b_{g}^{i}\right)>W^{a}\left(b c_{g}^{i}\right)>W^{a}\left(a_{g}^{h i}\right)>W^{a}\left(a b c_{g}^{i}\right)>W^{a}\left(b_{g}^{h i}\right)$ Country a, global pollution $\& \lambda \in(0,0.053]$

$W^{a}\left(a b_{g}^{i}\right) \stackrel{\lambda \in(0.053,0.1]}{>} W^{a}\left(N_{g}\right)>W^{a}\left(b c_{g}^{i}\right)>W^{a}\left(a_{g}^{h i}\right)>W^{a}\left(a b c_{g}^{i}\right)>W^{a}\left(b_{g}^{h i}\right)$ Country a, global pollution $\& \lambda \in(0.053,0.1]$ $W^{b}\left(b_{l}^{h i}\right)>W^{b}\left(a b c_{l}^{i}\right)>W^{b}\left(a b_{l}^{i}\right)>W^{b}\left(b c_{l}^{i}\right)>W^{b}\left(a_{l}^{h i}\right)>W^{b}\left(N_{l}\right)$ Country b, local pollution $W^{b}\left(b_{g}^{h i}\right)>W^{b}\left(a b c_{g}^{i}\right)>W^{b}\left(a_{g}^{h i}\right)>W^{b}\left(a b_{g}^{i}\right)>W^{b}\left(b c_{g}^{i}\right)>W^{b}\left(N_{g}\right)$ Country b, global pollution $W^{c}\left(a b c_{l}^{i}\right)>W^{c}\left(b c_{l}^{i}\right)>W^{c}\left(a_{l}^{h i}\right)>W^{c}\left(b_{l}^{h i}\right)>W^{c}\left(N_{l}\right)>W^{c}\left(a b_{l}^{i}\right)$ Country c, local pollution $W^{c}\left(a b c_{g}^{i}\right)>W^{c}\left(a_{g}^{h i}\right)>W^{c}\left(b_{g}^{h i}\right)>W^{c}\left(a b_{g}^{i}\right)>W^{c}\left(b c_{g}^{i}\right)>W^{c}\left(N_{g}\right)$ Country c, global pollution ${ }^{42}$

\footnotetext{
${ }^{42}$ In this game, to assure positive imports of good A by country c when we have country b as a hub, we had to restrict $\lambda$ further, $\lambda \in(0,0.01]$
} 


\begin{tabular}{|c|c|}
\hline Announcement Profiles & Integrated Agreements \\
\hline \hline$\Omega^{\Phi^{i}} \equiv\left\{\sigma_{a}^{i}=\{\varnothing, \varnothing\}, \sigma_{b}^{i}=\{\varnothing, \varnothing\}, \sigma_{c}^{i}=\{\varnothing, \varnothing\}\right\}$ & $\left\langle\Phi^{i}\right\rangle$ \\
\hline$\Omega^{a b i} \equiv\left\{\sigma_{a}^{i}=\{b, \varnothing\}, \sigma_{b}^{i}=\{a, \varnothing\}, \sigma_{c}^{i}=\{\varnothing, \varnothing\}\right\}$ & $\langle a b i\rangle$ \\
\hline$\Omega^{b c i} \equiv\left\{\sigma_{a}^{i}=\{\varnothing, \varnothing\}, \sigma_{b}^{i}=\{\varnothing, c\}, \sigma_{c}^{i}=\{\varnothing, b\}\right\}$ & $\langle b c i\rangle$ \\
\hline$\Omega^{a h i} \equiv\left\{\sigma_{a}^{i}=\{b, c\}, \sigma_{b}^{i}=\{a, \varnothing\}, \sigma_{c}^{i}=\{a, \varnothing\}\right\}$ & $\langle a h i\rangle$ \\
\hline$\Omega^{b h i} \equiv\left\{\sigma_{a}^{i}=\{b, \varnothing\}, \sigma_{b}^{i}=\{a, c\}, \sigma_{c}^{i}=\{\varnothing, b\}\right\}$ & $\langle b h i\rangle$ \\
\hline$\Omega^{F^{i}} \equiv\left\{\sigma_{a}^{i}=\{b, c\}, \sigma_{b}^{i}=\{a, c\}, \sigma_{c}^{i}=\{a, b\}\right\}$ & $\left\langle F^{i}\right\rangle$ \\
\hline
\end{tabular}

$$
\Omega^{\Phi^{i}} \equiv\left\{\sigma_{a}^{i}=\{\varnothing, \varnothing\}, \sigma_{b}^{i}=\{\varnothing, \varnothing\}, \sigma_{c}^{i}=\{\varnothing, \varnothing\}\right\}
$$

$\Omega^{\Phi^{i}}$ is a Nash Equilibria for both local and global levels of pollution.

PROOF:

Countries cannot get better off by unilaterally changing the announcement.

$\Omega^{\Phi^{i}}$ is not a CPNE for both local and global levels of pollution.

\section{PROOF:}

First, we let countries $a$ and $b$ form an integrated agreement, then the announcement would be as follows:

$\Omega \equiv\left\{\sigma_{a}^{i}=\{b, \varnothing\}, \sigma_{b}^{i}=\{a, \varnothing\}, \sigma_{c}^{i}=\{\varnothing, \varnothing\}\right\}$ and $W^{a}\left(a b_{l}^{i}\right)>W^{a}\left(N_{l}\right)$ and $W^{b}\left(a b_{l}^{i}\right)>W^{b}\left(N_{l}\right)$. We don't check for any further deviation, because the level of welfare is the highest for country $a$ in the entire I Game in the case of local pollution. Country $b$ would prefer to become a hub or be a part of a fully integrated world, but the dirty country $a$ would not announce country $c$. Based on the above, we can conclude that $\Omega^{\Phi^{i}}$ is not a CPNE if pollution is local.

Second, we consider the case of global pollution and $\lambda \in(0.053,0.1]$. We let countries $a$ and $b$ form an integrated agreement. We observe that country $a$ 's welfare is the highest in this game, and as a result, country $a$ would not include country $c$ in its announcement. No further deviation is sustainable. 
Now, we consider the case of global pollution, and we let countries $b$ and $c$ form an integrated agreement, then the announcement would be as follows:

$\Omega \equiv\left\{\sigma_{a}^{i}=\{\varnothing, \varnothing\}, \sigma_{b}^{i}=\{\varnothing, c\}, \sigma_{c}^{i}=\{\varnothing, b\}\right\}$ and $W^{b}\left(b c_{g}^{i}\right)>W^{b}\left(N_{g}\right)$ and $W^{c}\left(b c_{g}^{i}\right)>W^{c}\left(N_{g}\right)$. We can conclude, that clean countries can form a coalition. Based on the above, we can conclude that $\Omega^{i}$ is not a CPNE if pollution is global.

$$
\Omega^{a b i} \equiv\left\{\sigma_{a}^{i}=\{b, \varnothing\}, \sigma_{b}^{i}=\{a, \varnothing\}, \sigma_{c}^{i}=\{\varnothing, \varnothing\}\right\}
$$

$\Omega^{a b i}$ is a Nash Equilibria if pollution is local and if pollution is global and $\lambda \in(0.053,0.1]$.

PROOF:

country a $=\{b, \varnothing\} \stackrel{\text { change }}{\longrightarrow}\{b, c\} \stackrel{\text { result }}{\longrightarrow}$ no change in $a$ 's welfare

country a $=\{b, \varnothing\} \stackrel{\text { change }}{\longrightarrow}\{\varnothing, c\} /\{\varnothing, \varnothing\} \stackrel{\text { result }}{\longrightarrow} W^{a}\left(a b_{l}^{i}\right)>W^{a}\left(N_{l}\right) \& W^{a}\left(a b_{g}^{i}\right)>W^{a}\left(N_{g}\right)$ if $\lambda \in$ $(0.053,0.1]$.

We can conclude, that country $a$ has no incentive to change its announcement if pollution is local. Also, country $a$ has no incentive to alter its announcement if pollution is global and $\lambda \in$ $(0.053,0.1]$.

country $\mathrm{b}=\{a, \varnothing\} \stackrel{\text { change }}{\longrightarrow}\{a, c\} \stackrel{\text { result }}{\longrightarrow}$ no change in $b$ 's welfare

country $\mathrm{b}=\{a, \varnothing\} \stackrel{\text { change }}{\longrightarrow}\{\varnothing, c\} /\{\varnothing, \varnothing\} \stackrel{\text { result }}{\longrightarrow} W^{b}\left(a b_{\theta}^{i}\right)>W^{b}\left(N_{\theta}\right)$

We can conclude, that country $b$ has no incentive to change its announcement.

country $\mathrm{c}=\{\varnothing, \varnothing\} \stackrel{\text { change }}{\longrightarrow}\{a, \varnothing\} /\{\varnothing, b\} /\{a, b\} \stackrel{\text { result }}{\longrightarrow}$ no change in $c$ 's welfare

We can conclude, that country $c$ has no incentive to change its announcement.

Based on the above, we conclude $\Omega^{a b i}$ is a Nash Equilibria for the local level of pollution and for the global level of pollution if $\lambda \in(0.053,0.1]$.

$\Omega^{a b i}$ is not a Nash Equilibria if pollution is global and $\lambda \in(0,0.053]$.

PROOF:

country a $=\{b, \varnothing\} \stackrel{\text { change }}{\longrightarrow}\{\varnothing, \varnothing\} \stackrel{\text { result }}{\longrightarrow} W^{a}\left(a b_{g}^{i}\right)<W^{a}\left(N_{g}\right)$ if $\lambda \in(0,0.053]$.

We can conclude, that country $a$ can unilaterally change its announcement and gain a higher level of welfare.

$\Omega^{a b i}$ is not a CPNE for both local and global levels of pollution. 


\section{PROOF:}

We let two clean countries form an integrated agreement, then the announcement would be as follows:

$\Omega \equiv\left\{\sigma_{a}^{i}=\{b, \varnothing\}, \sigma_{b}^{i}=\{\varnothing, c\}, \sigma_{c}^{i}=\{\varnothing, b\}\right\}$ $W^{b}\left(b_{\theta}^{h i}\right)>W^{b}\left(a b_{\theta}^{i}\right)$ and $W^{c}\left(b_{\theta}^{h i}\right)>W^{c}\left(a b_{\theta}^{i}\right)$. We can conclude, that countries $b$ and $c$ can deviate.

$$
\Omega^{b c i} \equiv\left\{\sigma_{a}^{i}=\{\varnothing, \varnothing\}, \sigma_{b}^{i}=\{\varnothing, c\}, \sigma_{c}^{i}=\{\varnothing, b\}\right\}
$$

$\Omega^{b c i}$ is a Nash Equilibria for both local and global levels of pollution.

\section{PROOF:}

country a $=\{\varnothing, \varnothing\} \stackrel{\text { change }}{\longrightarrow}\{b, \varnothing\} /\{\varnothing, c\} /\{b, c\} \stackrel{\text { result }}{\longrightarrow}$ no change in $a$ 's welfare

We can conclude, that country $a$ has no incentive to change its announcement.

country $\mathrm{b}=\{\varnothing, c\} \stackrel{\text { change }}{\longrightarrow}\{a, c\} \stackrel{\text { result }}{\longrightarrow}$ no change in $b$ 's welfare

country $\mathrm{b}=\{\varnothing, c\} \stackrel{\text { change }}{\longrightarrow}\{a, \varnothing\} /\{\varnothing, \varnothing\} \stackrel{\text { result }}{\longrightarrow} W^{b}\left(b c_{\theta}^{i}\right)>W^{b}\left(N_{\theta}\right)$

We can conclude, that country $b$ has no incentive to change its announcement.

country $\mathrm{c}=\{\varnothing, b\} \stackrel{\text { change }}{\longrightarrow}\{a, b\} \stackrel{\text { result }}{\longrightarrow}$ no change in $c$ 's welfare

country c $=\{\varnothing, b\} \stackrel{\text { change }}{\longrightarrow}\{a, \varnothing\} /\{\varnothing, \varnothing\} \stackrel{\text { result }}{\longrightarrow} W^{c}\left(b c_{\theta}^{i}\right)>W^{c}\left(N_{\theta}\right)$

We can conclude, that country $c$ has no incentive to change its announcement.

Based on the above, we can conclude $\Omega^{b c i}$ is a Nash Equilibria for both local and global levels of pollution.

$\Omega^{\text {bci }}$ is not a CPNE if pollution is local.

\section{PROOF:}

To prove the above, we examine the grand coalition. First, we consider the possible deviation of the dirty country $a$. This country will not leave the integrated world because if it does so, then $W^{a}\left(b_{l}^{h i}\right)=W^{a}\left(c_{l}^{h i}\right)<W^{a}\left(b c_{l}^{i}\right)<W^{a}\left(a b c_{l}^{i}\right)$. Second, we consider whether either of the clean countries would have an incentive to change the announcement: $W^{b}\left(a b c_{l}^{i}\right)=W^{c}\left(a b c_{l}^{i}\right)>W^{b}\left(a b_{l}^{i}\right)=$ $W^{c}\left(a c_{l}^{i}\right)>W^{b}\left(b c_{l}^{i}\right)=W^{c}\left(b c_{l}^{i}\right)>W^{b}\left(a_{l}^{h i}\right)=W^{c}\left(a_{l}^{h i}\right)>W^{b}\left(c_{l}^{h i}\right)=W^{c}\left(b_{l}^{h i}\right)$. Based on the above. we can conclude that $\Omega^{b c i}$ is not a CPNE for the local level of pollution. $\Omega^{b c i}$ is a CPNE if pollution is global. 


\section{PROOF:}

First, we assume that countries $a$ and $b$ form a coalition, then the announcement would be changed to the following:

$\Omega \equiv\left\{\sigma_{a}^{i}=\{b, \varnothing\}, \sigma_{b}^{i}=\{a, \varnothing\}, \sigma_{c}^{i}=\{\varnothing, b\}\right\}$ and As a result, we observe $W^{a}\left(a b_{g}^{i}\right)>W^{a}\left(b c_{g}^{i}\right)$ and $W^{b}\left(a b_{g}^{i}\right)>W^{b}\left(b c_{g}^{i}\right)$. However, country $b$ has an incentive to alter this announcement by adding country $c$ and turning into a hub: $W^{b}\left(b_{g}^{h i}\right)>$ $W^{b}\left(a b_{g}^{i}\right)$ and $W^{a}\left(b_{g}^{h i}\right)<W^{a}\left(b c_{g}^{i}\right)$. We can conclude, that initial deviation is not sustainable.

Next, we assume that countries $a$ and $c$ form a coalition, then the announcement would be changed into the following:

$\Omega \equiv\left\{\sigma_{a}^{i}=\{\varnothing, c\}, \sigma_{b}^{i}=\{\varnothing, c\}, \sigma_{c}^{i}=\{a, \varnothing\}\right\}$

As a result, we observe $W^{a}\left(a c_{g}^{i}\right)>W^{a}\left(b c_{g}^{i}\right)$ and $W^{c}\left(a c_{g}^{i}\right)>W^{c}\left(b c_{g}^{i}\right)$. However, country $c$, similar to country $b$ in the previous step, has an incentive to alter this announcement by adding a second clean country and enjoy the benefits of being a hub: $W^{c}\left(c_{g}^{h i}\right)>W^{c}\left(a c_{g}^{i}\right)$ and $W^{a}\left(c_{g}^{h i}\right)<W^{a}\left(b c_{g}^{i}\right)$. We can conclude, this initial deviation is not sustainable.

Finally, we assume that all three countries form a coalition. In this scenario, we observe $W^{a}\left(a b c_{g}^{i}\right)<$ $W^{a}\left(b c_{g}^{i}\right)$ and conclude that grand coalition is not sustainable as well.

Based on the above, we are confident to conclude that $\Omega^{b c i}$ is a CPNE for the global level of pollution.

$$
\Omega^{a h i} \equiv\left\{\sigma_{a}^{i}=\{b, c\}, \sigma_{b}^{i}=\{a, \varnothing\}, \sigma_{c}^{i}=\{a, \varnothing\}\right\}
$$

$\Omega^{a h i}$ is not a Nash Equilibria for both local and global levels of pollution.

\section{PROOF:}

First, we consider the case of local pollution. Country $a$ can unilaterally change its announcement by excluding one of the clean countries and improve its welfare: $W^{a}\left(a_{l}^{h i}\right)<W^{a}\left(a b_{l}^{i}\right)=W^{a}\left(a c_{l}^{i}\right)$. Now, we consider the case of global pollution and $\lambda \in(0.053,0.1]$. Similar to the previous step, we observe that the dirty country $a$ can improve its welfare by restricting its announcement to only one clean country: $W^{a}\left(a_{g}^{h i}\right)<W^{a}\left(a b_{g}^{i}\right)=W^{a}\left(a c_{g}^{i}\right)$ and $\lambda \in(0.053,0.1]$. 
Finally, we consider the case of global pollution and $\lambda \in(0,0.053]$. Country $a$ can achieve the highest welfare in this game by announcing no agreement with both clean countries.

Based on the steps above, we can conclude that $\Omega^{a h i}$ is not a Nash Equilibria for both local and global levels of pollution.

$$
\Omega^{b h i} \equiv\left\{\sigma_{a}^{i}=\{b, \varnothing\}, \sigma_{b}^{i}=\{a, c\}, \sigma_{c}^{i}=\{\varnothing, b\}\right\}
$$

$\Omega^{\text {bhi }}$ is not a Nash Equilibria for both local and global levels of pollution.

ProOF:

country a $=\{b, \varnothing\} \stackrel{\text { change }}{\longrightarrow}\{\varnothing, \varnothing\} \stackrel{\text { result }}{\longrightarrow} W^{a}\left(b c_{\theta}^{i}\right)>W^{a}\left(b_{\theta}^{h i}\right)$

We can conclude, that country $a$ will deviate and gain a higher level of welfare by announcing no agreement with either clean country. The dirty country would prefer to be an outsider versus being a spoke.

$$
\Omega^{F^{i}} \equiv\left\{\sigma_{a}^{i}=\{b, c\}, \sigma_{b}^{i}=\{a, c\}, \sigma_{c}^{i}=\{a, b\}\right\}
$$

$\Omega^{\digamma^{i}}$ is a Nash Equilibria if pollution is local.

ProOF:

country a $=\{b, c\} \stackrel{\text { change }}{\longrightarrow}\{b, \varnothing\} \stackrel{\text { result }}{\longrightarrow} W^{a}\left(a b c_{l}^{i}\right)>W^{a}\left(b_{l}^{\text {hi }}\right)$

country a $=\{b, c\} \stackrel{\text { change }}{\longrightarrow}\{\varnothing, c\} /\{\varnothing, \varnothing\} \stackrel{\text { result }}{\longrightarrow} W^{a}\left(a b c_{l}^{i}\right)>W^{a}\left(c_{l}^{h i}\right)$

We can conclude, that country $a$ has no incentive to change its announcement.

country $\mathrm{b}=\{a, c\} \stackrel{\text { change }}{\longrightarrow}\{a, \varnothing\} \stackrel{\text { result }}{\longrightarrow} W^{b}\left(a b c_{l}^{i}\right)>W^{b}\left(a_{l}^{\text {hi }}\right)$

country $\mathrm{b}=\{a, c\} \stackrel{\text { change }}{\longrightarrow}\{\varnothing, c\} \stackrel{\text { result }}{\longrightarrow} W^{b}\left(a b c_{l}^{i}\right)>W^{b}\left(c_{l}^{h i}\right)$

country $\mathrm{b}=\{a, c\} \stackrel{\text { change }}{\longrightarrow}\{\varnothing, \varnothing\} \stackrel{\text { result }}{\longrightarrow} W^{b}\left(a b c_{l}^{i}\right)>W^{b}\left(a c_{l}^{l}\right)$

We can conclude, that country $b$ has no incentive to change its announcement.

country $\mathrm{c}=\{a, b\} \stackrel{\text { change }}{\longrightarrow}\{\varnothing, b\} \stackrel{\text { result }}{\longrightarrow} W^{c}\left(a b c_{l}^{i}\right)>W^{c}\left(b_{l}^{h i}\right)$

country $\mathrm{c}=\{a, b\} \stackrel{\text { change }}{\longrightarrow}\{a, \varnothing\} \stackrel{\text { result }}{\longrightarrow} W^{c}\left(a b c_{l}^{i}\right)>W^{c}\left(a_{l}^{h i}\right)$

country $\mathrm{c}=\{a, b\} \stackrel{\text { change }}{\longrightarrow}\{\varnothing, \varnothing\} \stackrel{\text { result }}{\longrightarrow} W^{c}\left(a b c_{l}^{i}\right)>W^{c}\left(a b_{l}^{i}\right)$

We can conclude, that country $c$ has no incentive to change its announcement.

Based on the above, we conclude $\Omega^{\digamma^{i}}$ is a Nash Equilibria for the local level of pollution. 
$\Omega^{\digamma^{i}}$ is not a Nash Equilibria if pollution is global.

PROOF:

country a $=\{b, c\} \stackrel{\text { change }}{\longrightarrow}\{\varnothing, \varnothing\} \stackrel{\text { result }}{\longrightarrow} W^{a}\left(a b c_{g}^{i}\right)<W^{a}\left(b c_{g}^{i}\right)$

We can see that the dirty country $a$ would deviate by announcing no agreement with either clean country and improve its welfare.

$\Omega^{\digamma^{i}}$ is a CPNE if pollution is local.

PROOF:

First, we assume that the dirty country $a$ forms a coalition with one of the clean countries, then the announcements could be as follows:

$\Omega \equiv\left\{\sigma_{a}^{i}=\{b, \varnothing\}, \sigma_{b}^{i}=\{a, \varnothing\}, \sigma_{c}^{i}=\{a, b\}\right\}$ or $\Omega^{a b i} \equiv\left\{\sigma_{a}^{i}=\{\varnothing, c\}, \sigma_{b}^{i}=\{a, c\}, \sigma_{c}^{i}=\{a, \varnothing\}\right\}$ As a result of either of these agreements, we have the following levels of welfares $W^{a}\left(a b_{l}^{i}\right)=$ $W^{a}\left(a c_{l}^{i}\right)>W^{a}\left(a_{l}^{h i}\right)>W^{a}\left(a b c_{l}^{i}\right)$ and $W^{b}\left(a b_{l}^{i}\right)=W^{c}\left(a c_{l}^{i}\right)<W^{b}\left(a b c_{l}^{i}\right)=W^{c}\left(a b c_{l}^{i}\right)$. We can conclude, that though country $a$ would like to form a coalition, none of the clean payers is interested in the coalition with the dirty country. The only reason for country $b$ or $c$ to get into an agreement with $a$ is a further deviation to become a hub, because $W^{b}\left(b_{l}^{h i}\right)=W^{c}\left(c_{l}^{h i}\right)>W^{b}\left(a b c_{l}^{i}\right)=W^{c}\left(a b c_{l}^{i}\right)$. We can conclude that there would be no coalition between the dirty country $a$ and either of the clean payers.

Now, we assume that two clean countries decide to form an integrated agreement and exclude the dirty country $a$, then the announcement would be as follows:

$\Omega \equiv\left\{\sigma_{a}^{i}=\{b, c\}, \sigma_{b}^{i}=\{\varnothing, c\}, \sigma_{c}^{i}=\{\varnothing, b\}\right\}$

We observe the following levels of welfares as a result of this agreement: $W^{b}\left(b c_{l}^{i}\right)=W^{c}\left(b c_{l}^{i}\right)<$ $W^{b}\left(a b c_{l}^{i}\right)=W^{c}\left(a b c_{l}^{i}\right)$. We see that this coalition is not sustainable as well.

We are confident to conclude that $\Omega^{\digamma^{i}}$ is a CPNE if pollution is local.

\section{A. 3.9.2.1 Shallow Trade Agreements Game}

Welfare effects of various type of shallow trade agreements:

$W^{a}\left(a b_{l}^{u}\right)>W^{a}\left(a_{l}^{h}\right)>W^{a}\left(a b_{l}\right)>W^{a}\left(N_{l}\right)>W^{a}\left(a b c_{l}\right)>W^{a}\left(b_{l}^{h}\right)>W^{a}\left(b c_{l}\right)>W^{a}\left(b c_{l}^{u}\right)$ Country 
$a$, local

$W^{a}\left(a_{g}^{h}\right)>W^{a}\left(a b_{g}^{u}\right)>W^{a}\left(a b_{g}\right)>W^{a}\left(a b c_{g}\right)>W^{a}\left(N_{g}\right)>W^{a}\left(b_{g}^{h}\right)>W^{a}\left(b c_{g}\right)>W^{a}\left(b c_{g}^{u}\right)$ Country

$a$, global

$W^{b}\left(b_{l}^{h}\right)>W^{b}\left(a b_{l}^{u}\right)>W^{b}\left(b c_{l}^{u}\right)>W^{b}\left(a b_{l}\right)>W^{b}\left(a b c_{l}\right)>W^{b}\left(b c_{l}\right)>W^{b}\left(a_{l}^{h}\right)>W^{b}\left(N_{l}\right)$ Country

$b$, local

$W^{b}\left(b c_{g}^{u}\right)>W^{b}\left(b_{g}^{h}\right)>W^{b}\left(b c_{g}\right) \stackrel{\lambda \in(0.073,0.1]}{>} W^{b}\left(a b_{g}^{u}\right)>W^{b}\left(a b_{g}\right)>W^{b}\left(N_{g}\right)>W^{b}\left(a b c_{g}\right)>W^{b}\left(a_{g}^{h}\right)$

Country $b$, global $\& \lambda \in(0.073,0.1]$

$W^{b}\left(b c_{g}^{u}\right)>W^{b}\left(b_{g}^{h}\right)>W^{b}\left(a b_{g}^{u}\right) \stackrel{\lambda \in(0,0.073]}{>} W^{b}\left(b c_{g}\right)>W^{b}\left(a b_{g}\right)>W^{b}\left(N_{g}\right)>W^{b}\left(a b c_{g}\right)>W^{b}\left(a_{g}^{h}\right)$

Country $b$, global $\& \lambda \in(0,0.073]$

$W^{c}\left(b c_{l}^{u}\right)>W^{c}\left(a b c_{l}\right)>W^{c}\left(b c_{l}\right)>W^{c}\left(a_{l}^{h}\right)>W^{c}\left(N_{l}\right)>W^{c}\left(b_{l}^{h}\right)>W^{c}\left(a b_{l}\right)>W^{c}\left(a b_{l}^{u}\right)$ Country $c$,

local

$W^{c}\left(b c_{g}^{u}\right)>W^{c}\left(b c_{g}\right)>W^{c}\left(N_{g}\right)>W^{c}\left(a b c_{g}\right)>W^{c}\left(b_{g}^{h}\right)>W^{c}\left(a_{g}^{h}\right)>W^{c}\left(a b_{g}\right)>W^{c}\left(a b_{g}^{u}\right)$ Country

$c$, global

\begin{tabular}{|c|c|}
\hline Announcement Profiles & Shallow Trade Agreements \\
\hline \hline$\Omega^{\Phi} \equiv\left\{\sigma_{a}=\{\varnothing, \varnothing\}, \sigma_{b}=\{\varnothing, \varnothing\}, \sigma_{c}=\{\varnothing, \varnothing\}\right\}$ & $\langle\Phi\rangle$ \\
\hline$\Omega^{a b} \equiv\left\{\sigma_{a}=\{b, \varnothing\}, \sigma_{b}=\{a, \varnothing\}, \sigma_{c}=\{\varnothing, \varnothing\}\right\}$ & $\langle a b\rangle$ \\
\hline$\Omega^{a b u} \equiv\left\{\sigma_{a}^{u}=\left\{b^{u}, \varnothing\right\}, \sigma_{b}^{u}=\left\{a^{u}, \varnothing\right\}, \sigma_{c}^{u}=\{\varnothing, \varnothing\}\right\}$ & $\langle a b u\rangle$ \\
\hline$\Omega^{b c} \equiv\left\{\sigma_{a}=\{\varnothing, \varnothing\}, \sigma_{b}=\{\varnothing, c\}, \sigma_{c}=\{\varnothing, b\}\right\}$ & $\langle b c\rangle$ \\
\hline$\Omega^{b c u} \equiv\left\{\sigma_{a}^{u}=\{\varnothing, \varnothing\}, \sigma_{b}^{u}=\left\{\varnothing, c^{u}\right\}, \sigma_{c}^{u}=\left\{\varnothing, b^{u}\right\}\right\}$ & $\langle a h\rangle$ \\
\hline$\Omega^{a h} \equiv\left\{\sigma_{a}=\{b, c\}, \sigma_{b}=\{a, \varnothing\}, \sigma_{c}=\{a, \varnothing\}\right\}$ & $\langle b h\rangle$ \\
\hline$\Omega^{b h} \equiv\left\{\sigma_{a}=\{b, \varnothing\}, \sigma_{b}=\{a, c\}, \sigma_{c}=\{\varnothing, b\}\right\}$ & $\langle F\rangle$ \\
\hline$\Omega^{F^{u}} \equiv\left\{\sigma_{a}^{u}=\left\{b^{u}, c^{u}\right\}, \sigma_{b}^{u}=\left\{a^{u}, c^{u}\right\}, \sigma_{c}^{u}=\left\{a^{u}, b^{u}\right\}\right\}$ & \\
\hline$\Omega^{F} \equiv\left\{\sigma_{a}=\{b, c\}, \sigma_{b}=\{a, c\}, \sigma_{c}=\{a, b\}\right\}$ & \\
\hline
\end{tabular}

$$
\Omega^{\Phi} \equiv\left\{\sigma_{a}=\{\varnothing, \varnothing\}, \sigma_{b}=\{\varnothing, \varnothing\}, \sigma_{c}=\{\varnothing, \varnothing\}\right\}
$$

$\Omega^{\Phi}$ is a Nash Equilibria for both local and global levels of pollution.

\section{PROOF:}

Countries cannot get better off by unilaterally changing the announcements; countries have no incentive to announce any other country unless they are going to be announced back. $\Omega^{\Phi}$ is not a CPNE for both local and global levels of pollution. 


\section{PROOF:}

Any two countries can be better off by announcing each other; for example, $W^{a}\left(a b_{\theta}\right)>W^{a}\left(N_{\theta}\right)$ and $W^{b}\left(a b_{\theta}\right)>W^{b}\left(N_{\theta}\right)$ or $W^{a}\left(a b_{\theta}^{u}\right)>W^{a}\left(N_{\theta}\right)$ and $W^{b}\left(a b_{\theta}^{u}\right)>W^{b}\left(N_{\theta}\right)$.

$$
\Omega^{a b} \equiv\left\{\sigma_{a}=\{b, \varnothing\}, \sigma_{b}=\{a, \varnothing\}, \sigma_{c}=\{\varnothing, \varnothing\}\right\}
$$

$\Omega^{a b}$ is a Nash Equilibria for both local and global levels of pollution.

\section{PROOF:}

country $\mathrm{a}=\{b, \varnothing\} \stackrel{\text { change }}{\longrightarrow}\{b, c\} \stackrel{\text { result }}{\longrightarrow}$ no change in $a$ 's welfare

country a $=\{b, \varnothing\} \stackrel{\text { change }}{\longrightarrow}\{\varnothing, c\} /\left\{\varnothing, c^{u}\right\} /\left\{b^{u}, \varnothing\right\} /\{\varnothing, \varnothing\} /\left\{b^{u}, c^{u}\right\} \stackrel{\text { result }}{\longrightarrow} W^{a}\left(a b_{\theta}\right)>W^{a}\left(N_{\theta}\right)$

We can conclude, that country $a$ has no incentive to change its announcement.

country $\mathrm{b}=\{a, \varnothing\} \stackrel{\text { change }}{\longrightarrow}\{a, c\} \stackrel{\text { result }}{\longrightarrow}$ no change in $b$ 's welfare

country $\mathrm{b}=\{a, \varnothing\} \stackrel{\text { change }}{\longrightarrow}\{\varnothing, c\} /\left\{\varnothing, c^{u}\right\} /\left\{a^{u}, \varnothing\right\} /\{\varnothing, \varnothing\} /\left\{a^{u}, c^{u}\right\} \stackrel{\text { result }}{\longrightarrow} W^{b}\left(a b_{\theta}\right)>W^{b}\left(N_{\theta}\right)$

We can conclude, that country $b$ has no incentive to change its announcement.

country $\mathrm{c}=\{\varnothing, \varnothing\} \stackrel{\text { change }}{\longrightarrow}\{a, \varnothing\} /\left\{a^{u}, \varnothing\right\} /\{\varnothing, b\} /\left\{\varnothing, b^{u}\right\} /\{a, b\} /\left\{a^{u}, b^{u}\right\} \stackrel{\text { result }}{\longrightarrow}$ no change in $c^{\prime} s$ welfare

We can conclude, that country $c$ has no incentive to change its announcement.

Based on the above, we conclude that $\Omega^{a b}$ is a Nash Equilibria for both local and global levels of pollution.

$\Omega^{a b}$ is not a CPNE for both local and global levels of pollution.

PROOF:

Countries $a$ and $b$ can form a coalition to sign a different PTA, then $\Omega \equiv\left\{\sigma_{a}^{u}=\{b, \varnothing\}, \sigma_{b}^{u}=\right.$ $\left.\{a, \varnothing\}, \sigma_{c}^{u}=\{\varnothing, \varnothing\}\right\}$, and $W^{a}\left(a b_{\theta}^{u}\right)>W^{a}\left(a b_{\theta}\right) \& W^{b}\left(a b_{\theta}^{u}\right)>W^{b}\left(a b_{\theta}\right)$.

We can conclude that $\Omega^{a b}$ is not a CPNE for both local and global levels of pollution.

$$
\Omega^{a b u} \equiv\left\{\sigma_{a}^{u}=\left\{b^{u}, \varnothing\right\}, \sigma_{b}^{u}=\left\{a^{u}, \varnothing\right\}, \sigma_{c}^{u}=\{\varnothing, \varnothing\}\right\}
$$

$\Omega^{a b u}$ is a Nash Equilibria for both local and global levels of pollution.

PROOF:

country a $=\left\{b^{u}, \varnothing\right\} \stackrel{\text { change }}{\longrightarrow}\left\{b^{u}, c^{u}\right\} \stackrel{\text { result }}{\longrightarrow}$ no change in $a$ 's welfare 
country a $=\left\{b^{u}, \varnothing\right\} \stackrel{\text { change }}{\longrightarrow}\{\varnothing, c\} /\left\{\varnothing, c^{u}\right\} /\{\varnothing, \varnothing\} /\{b, c\} /\{b, \varnothing\} \stackrel{\text { result }}{\longrightarrow} W^{a}\left(a b_{\theta}^{u}\right)>W^{a}\left(N_{\theta}\right)$

We can conclude, that country $a$ has no incentive to change its announcement.

country $\mathrm{b}=\left\{a^{u}, \varnothing\right\} \stackrel{\text { change }}{\longrightarrow}\left\{a^{u}, c^{u}\right\} \stackrel{\text { result }}{\longrightarrow}$ no change in $b$ 's welfare

country $\mathrm{b}=\left\{a^{u}, \varnothing\right\} \stackrel{\text { change }}{\longrightarrow}\{\varnothing, c\} /\left\{\varnothing, c^{u}\right\} /\{\varnothing, \varnothing\} /\{a, c\} /\{a, \varnothing\} \stackrel{\text { result }}{\longrightarrow} W^{b}\left(a b_{\theta}^{u}\right)>W^{b}\left(N_{\theta}\right)$

We can conclude, that country $b$ has no incentive to change its announcement.

country $\mathrm{c}=\{\varnothing, \varnothing\} \stackrel{\text { change }}{\longrightarrow}\{a, \varnothing\} /\left\{a^{u}, \varnothing\right\} /\{\varnothing, b\} /\left\{\varnothing, b^{u}\right\} /\{a, b\} /\left\{a^{u}, b^{u}\right\} \stackrel{\text { result }}{\longrightarrow}$ no change in $c^{\prime} s$ welfare

We can conclude, that country $c$ has no incentive to change its announcement.

Based on the above, $\Omega^{a b u}$ is a Nash Equilibria for both local and global levels of pollution. $\Omega^{a b u}$ is a CPNE if pollution is local.

\section{PROOF:}

To prove the above, in next four step, we consider every possible deviation:

First, we consider a possible coalition of two clean countries, then $W^{b}\left(b c_{l}^{u}\right)<W^{b}\left(a b_{l}^{u}\right)$ and $W^{b}\left(b c_{l}\right)<W^{b}\left(a b_{l}^{u}\right)$. We can see, that a clean country is not interested in excluding the dirty partner in the form of either PTA which includes only clean countries.

Second, we acknowledge that though a clean partner of this union would rather be a hub than a part of this bilateral trade agreement, this deviation is not possible due to the nature of customs unions. Third, we examine the deviation of the members of this union to another form of PTA between them, then $W^{a}\left(a b_{l}^{u}\right)>W^{a}\left(a b_{l}\right)$ and $W^{b}\left(a b_{l}^{u}\right)>W^{b}\left(a b_{l}\right)$. We can that see this deviation is not meaningful.

Finally, we consider the grand coalition. In this case, $W^{a}\left(a b_{l}^{u}\right)>W^{a}\left(a b c_{l}\right)$ and $W^{b}\left(a b_{l}^{u}\right)>$ $W^{b}\left(a b c_{l}\right)$. We can see that this coalitional deviation is not meaningful as well.

Based on the above, we conclude that $\Omega^{a b u}$ is a CPNE if pollution is local.

$\Omega^{a b u}$ is not a CPNE if pollution is global.

PROOF:

Suppose, $b$ and $c$ get into a trade union and exclude $a$, then $W^{b}\left(b c_{g}^{u}\right)>W^{b}\left(a b_{g}^{u}\right)$ and $W^{c}\left(b c_{g}^{u}\right)>$ $W^{c}\left(a b_{g}^{u}\right)$, and we can conclude that clean countries would form a trade union and exclude $a$ if 
the pollution exhibits global characteristics. We do not need to check for any further deviations, because the level of welfares members acquire in this union are the highest in the entire game.

$$
\Omega^{b c} \equiv\left\{\sigma_{a}=\{\varnothing, \varnothing\}, \sigma_{b}=\{\varnothing, c\}, \sigma_{c}=\{\varnothing, b\}\right\}
$$

$\Omega^{b c}$ is a Nash Equilibria for both local and global levels of pollution.

PROOF:

country a $=\{\varnothing, \varnothing\} \stackrel{\text { change }}{\longrightarrow}\{b, \varnothing\} /\left\{b^{u}, \varnothing\right\} /\{\varnothing, c\} /\left\{\varnothing, c^{u}\right\} /\{b, c\} /\left\{b^{u}, c^{u}\right\} \stackrel{\text { result }}{\longrightarrow}$ no change in $a$ 's welfare

We can conclude, that country $a$ has no incentive to change its announcement.

country $\mathrm{b}=\{\varnothing, c\} \stackrel{\text { change }}{\longrightarrow}\{a, c\} \stackrel{\text { result }}{\longrightarrow}$ no change in $b$ 's welfare

country $\mathrm{b}=\{\varnothing, c\} \stackrel{\text { change }}{\longrightarrow}\{a, \varnothing\} /\left\{a^{u}, \varnothing\right\} /\{\varnothing, \varnothing\} /\left\{\varnothing, c^{u}\right\} /\left\{a^{u}, c^{u}\right\} \stackrel{\text { result }}{\longrightarrow} W^{b}\left(b c_{\theta}\right)>W^{b}\left(N_{\theta}\right)$

We can conclude, that country $b$ has no incentive to change its announcement.

country $\mathrm{c}=\{\varnothing, b\} \stackrel{\text { change }}{\longrightarrow}\{a, b\} \stackrel{\text { result }}{\longrightarrow}$ no change in $c$ 's welfare

country $\mathrm{c}=\{\varnothing, b\} \stackrel{\text { change }}{\longrightarrow}\{a, \varnothing\} /\left\{a^{u}, \varnothing\right\} /\{\varnothing, \varnothing\} /\left\{\varnothing, b^{u}\right\} /\left\{a^{u}, b^{u}\right\} \stackrel{\text { result }}{\longrightarrow} W^{c}\left(b c_{\theta}\right)>W^{c}\left(N_{\theta}\right)$

We can conclude, that country $c$ has no incentive to change its announcement.

Based on the above, we conclude that $\Omega^{b c}$ is a Nash Equilibria for both local and global levels of pollution.

$\Omega^{b c}$ is not a CPNE for both local and global levels of pollution.

PROOF:

Countries $b$ and $c$ can form a coalition to sign a different PTA, then $\Omega \equiv\left\{\sigma_{a}^{u}=\{\varnothing, \varnothing\}, \sigma_{b}^{u}=\right.$ $\left.\{\varnothing, c\}, \sigma_{c}^{u}=\{\varnothing, b\}\right\}$, and $W^{b}\left(b c_{\theta}^{u}\right)=W^{c}\left(b c_{\theta}^{u}\right)>W^{b}\left(b c_{\theta}\right)=W^{c}\left(b c_{\theta}\right)$. We can conclude that $\Omega^{b c}$ is not a CPNE for both local and global levels of pollution.

$$
\Omega^{b c u} \equiv\left\{\sigma_{a}^{u}=\{\varnothing, \varnothing\}, \sigma_{b}^{u}=\left\{\varnothing, c^{u}\right\}, \sigma_{c}^{u}=\left\{\varnothing, b^{u}\right\}\right\}
$$

$\Omega^{b c u}$ is a Nash Equilibria for both local and global levels of pollution.

\section{PROOF:}

country a $=\{\varnothing, \varnothing\} \stackrel{\text { change }}{\longrightarrow}\{b, \varnothing\} /\left\{b^{u}, \varnothing\right\} /\{\varnothing, c\} /\left\{\varnothing, c^{u}\right\} /\{b, c\} /\left\{b^{u}, c^{u}\right\} \stackrel{\text { result }}{\longrightarrow}$ no change in $a$ 's welfare 
We can conclude, that country $a$ has no incentive to change its announcement.

country $\mathrm{b}=\left\{\varnothing, c^{u}\right\} \stackrel{\text { change }}{\longrightarrow}\left\{a^{u}, c^{u}\right\} \stackrel{\text { result }}{\longrightarrow}$ no change in $b$ 's welfare

country $\mathrm{b}=\left\{\varnothing, c^{u}\right\} \stackrel{\text { change }}{\longrightarrow}\{a, \varnothing\} /\left\{a^{u}, \varnothing\right\} /\{\varnothing, \varnothing\} /\{a, c\} /\{\varnothing, c\} \stackrel{\text { result }}{\longrightarrow} W^{b}\left(b c_{\theta}^{u}\right)>W^{b}\left(N_{\theta}\right)$

We can conclude, that country $b$ has no incentive to change its announcement.

country $\mathrm{c}=\left\{\varnothing, b^{u}\right\} \stackrel{\text { change }}{\longrightarrow}\left\{a^{u}, b^{u}\right\} \stackrel{\text { result }}{\longrightarrow}$ no change in $c^{\prime}$ 's welfare

country c $=\left\{\varnothing, b^{u}\right\} \stackrel{\text { change }}{\longrightarrow}\{a, \varnothing\} /\left\{a^{u}, \varnothing\right\} /\{\varnothing, \varnothing\} /\{a, b\} /\{\varnothing, b\} \stackrel{\text { result }}{\longrightarrow} W^{c}\left(b c_{\theta}^{u}\right)>W^{c}\left(N_{\theta}\right)$

We can conclude, that country $c$ has no incentive to change its announcement.

Based on the above, $\Omega^{b c u}$ is a Nash Equilibria for both local and global levels of pollution.

$\Omega^{b c u}$ is not a CPNE for the local level of pollution.

PROOF:

Suppose, that countries $a$ and $b$ get into a trade union and exclude $c$, then $W^{a}\left(a b_{l}^{u}\right)>W^{a}\left(b c_{l}^{u}\right)$ and $W^{b}\left(a b_{l}^{u}\right)>W^{b}\left(b c_{l}^{u}\right)$. We can conclude that one clean and one dirty country would form a trade union and exclude $c$ if pollution is local.

$\Omega^{b c u}$ is a CPNE if pollution is global.

PROOF:

Neither $b$ or $c$ can do better by deviating from their original announcements. The level of welfare clean countries acquire in this customs union is the highest they can achieve in this extended game. We conclude that, $\Omega^{b c u}$ is a self-enforcing commitment between two clean countries if pollution exhibits global characteristics.

$$
\Omega^{a h} \equiv\left\{\sigma_{a}=\{b, c\}, \sigma_{b}=\{a, \varnothing\}, \sigma_{c}=\{a, \varnothing\}\right\}
$$

$\Omega^{a h}$ is a Nash Equilibria for both local and global levels of pollution.

PROOF:

country a $=\{b, c\} \stackrel{\text { change }}{\longrightarrow}\{b, \varnothing\} /\{\varnothing, c\} \stackrel{\text { result }}{\longrightarrow} W^{a}\left(a_{\theta}^{h}\right)>W^{a}\left(a b_{\theta}\right)=W^{a}\left(a c_{\theta}\right)$

country a $=\{b, c\} \stackrel{\text { change }}{\longrightarrow}\{\varnothing, \varnothing\} /\left\{b^{u}, c^{u}\right\} /\left\{b^{u}, \varnothing\right\} /\left\{\varnothing, c^{u}\right\} \stackrel{\text { result }}{\longrightarrow} W^{a}\left(a_{\theta}^{h}\right)>W^{a}\left(N_{\theta}\right)$

We can conclude, that country $a$ has no incentive to change its announcement.

country $\mathrm{b}=\{a, \varnothing\} \stackrel{\text { change }}{\longrightarrow}\{a, c\} \stackrel{\text { result }}{\longrightarrow}$ no change in $b$ 's welfare

country $\mathrm{b}=\{a, \varnothing\} \stackrel{\text { change }}{\longrightarrow}\{\varnothing, \varnothing\} /\left\{a^{u}, c^{u}\right\} /\{\varnothing, c\} /\left\{\varnothing, c^{u}\right\} /\left\{a^{u}, \varnothing\right\} \stackrel{\text { result }}{\longrightarrow} W^{b}\left(a_{\theta}^{h}\right)>W^{b}\left(a c_{\theta}\right)$ 
We can conclude, that country $b$ has no incentive to change its announcement.

country $\mathrm{c}=\{a, \varnothing\} \stackrel{\text { change }}{\longrightarrow}\{a, b\} \stackrel{\text { result }}{\longrightarrow}$ no change in $c$ 's welfare

country c $=\{a, \varnothing\} \stackrel{\text { change }}{\longrightarrow}\{\varnothing, \varnothing\} /\left\{a^{u}, b^{u}\right\} /\{\varnothing, b\} /\left\{\varnothing, b^{u}\right\} /\left\{a^{u}, \varnothing\right\} \stackrel{\text { result }}{\longrightarrow} W^{c}\left(a_{\theta}^{h}\right)>W^{c}\left(a b_{\theta}\right)$

We can conclude, that country $c$ has no incentive to change its announcement.

Based on the above, we can conclude that $\Omega^{a h}$ is a Nash Equilibria for both local and global levels of pollution.

$\Omega^{a h}$ is not a CPNE for both local and global levels of pollution.

\section{PROOF:}

Let $\mathrm{b}$ and $\mathrm{c}$ form a coalition, then $\Omega \equiv\left\{\sigma_{a}=\{b, c\}, \sigma_{b}=\{a, c\}, \sigma_{c}=\{a, b\}\right\}$, then $W^{b}\left(a b c_{\theta}\right)>$ $W^{b}\left(a_{\theta}^{h}\right)$ and $W^{c}\left(a b c_{\theta}\right)>W^{c}\left(a_{\theta}^{h}\right)$. We can see that clean countries would rather be a part of a free trade world than being spokes. We can conclude that $\Omega^{a h}$ is not a CPNE for both local and global levels of pollution.

$$
\Omega^{b h} \equiv\left\{\sigma_{a}=\{b, \varnothing\}, \sigma_{b}=\{a, c\}, \sigma_{c}=\{\varnothing, b\}\right\}
$$

$\Omega^{\text {bh }}$ is a Nash Equilibria for both local and global levels of pollution.

\section{PROOF:}

country a $=\{b, \varnothing\} \stackrel{\text { change }}{\longrightarrow}\{b, c\} \stackrel{\text { result }}{\longrightarrow}$ no change in $a$ 's welfare

country a $=\{b, \varnothing\} \stackrel{\text { change }}{\longrightarrow}\{\varnothing, \varnothing\} /\left\{b^{u}, c^{u}\right\} /\{\varnothing, c\} /\left\{\varnothing, c^{u}\right\} /\left\{a^{u}, \varnothing\right\} \stackrel{\text { result }}{\longrightarrow} W^{a}\left(b_{\theta}^{h}\right)>W^{a}\left(b c_{\theta}\right)$

We can conclude, that country $a$ has no incentive to change its announcement.

country $\mathrm{b}=\{a, c\} \stackrel{\text { change }}{\longrightarrow}\{a, \varnothing\} /\{\varnothing, c\} \stackrel{\text { result }}{\longrightarrow} W^{b}\left(b_{\theta}^{h}\right)>W^{b}\left(a b_{\theta}\right) \& W^{b}\left(b_{\theta}^{h}\right)>W^{b}\left(b c_{\theta}\right)$

country $\mathrm{b}=\{a, c\} \stackrel{\text { change }}{\longrightarrow}\{\varnothing, \varnothing\} /\left\{a^{u}, c^{u}\right\} /\left\{a^{u}, \varnothing\right\} /\left\{\varnothing, c^{u}\right\} \stackrel{\text { result }}{\longrightarrow} W^{b}\left(b_{\theta}^{h}\right)>W^{b}\left(N_{\theta}\right)$

We can conclude, that country $b$ has no incentive to change its announcement.

country $\mathrm{c}=\{\varnothing, b\} \stackrel{\text { change }}{\longrightarrow}\{a, b\} \stackrel{\text { result }}{\longrightarrow}$ no change in $c$ 's welfare

country c $=\{\varnothing, b\} \stackrel{\text { change }}{\longrightarrow}\{\varnothing, \varnothing\} /\left\{a^{u}, b^{u}\right\} /\{a, \varnothing\} /\left\{a^{u}, \varnothing\right\} /\left\{\varnothing, b^{u}\right\} \stackrel{\text { result }}{\longrightarrow} W^{c}\left(b_{\theta}^{h}\right)>W^{c}\left(a b_{\theta}\right)$

We can conclude, that country $c$ has no incentive to change its announcement.

Based on the above, we conclude that $\Omega^{b h}$ is a Nash Equilibria for both local and global levels of pollution.

$\Omega^{\text {bh }}$ is not a CPNE for both local and global levels of pollution. 


\section{PROOF:}

Let $a$ and $c$ form a coalition, then $\Omega \equiv\left\{\sigma_{a}=\{b, c\}, \sigma_{b}=\{a, c\}, \sigma_{c}=\{a, b\}\right\}$, then $W^{a}\left(a b c_{\theta}\right)>$ $W^{a}\left(b_{\theta}^{h}\right)$ and $W^{c}\left(a b c_{\theta}\right)>W^{c}\left(b_{\theta}^{h}\right)$. We can see that both countries, a clean country $c$ and the dirty country $a$, would prefer to be a part of a free trade world versus being spokes. We can conclude that $\Omega^{b h}$ is not a CPNE for both local and global levels of pollution.

$$
\Omega^{F^{u}} \equiv\left\{\sigma_{a}^{u}=\left\{b^{u}, c^{u}\right\}, \sigma_{b}^{u}=\left\{a^{u}, c^{u}\right\}, \sigma_{c}^{u}=\left\{a^{u}, b^{u}\right\}\right\}
$$

$\Omega^{\digamma^{u}}$ is not a Nash Equilibria for both local and global levels of pollution.

\section{PROOF:}

First, we consider the case of local pollution. Country $a$ can unilaterally change its announcement and improve its welfare:

country a $=\left\{b^{u}, c^{u}\right\} \stackrel{\text { change }}{\longrightarrow}\left\{b^{u}, \varnothing\right\} /\left\{\varnothing, c^{u}\right\} \stackrel{\text { result }}{\longrightarrow} W^{a}\left(a b_{l}^{u}\right)=W^{a}\left(a c_{l}^{u}\right)>W^{a}\left(a b c_{l}\right) \& W^{b}\left(a b_{l}^{u}\right)=$ $W^{c}\left(a c_{l}^{u}\right)>W^{b}\left(a b c_{l}\right)=W^{c}\left(a b c_{l}\right)$.

Country $a$ is indifferent between these announcements, and the lucky country, $b$ or $c$, would improve its welfare. The unlucky one would be simply excluded.

Now, we consider the case of global pollution. In this case, clean countries can improve their welfare by excluding the dirty country $a$ :

country $\mathrm{b}=\{a, c\} \stackrel{\text { change }}{\longrightarrow}\{\varnothing, c\} \stackrel{\text { result }}{\longrightarrow} W^{b}\left(b c_{g}^{u}\right)>W^{b}\left(a b c_{g}\right)$

country c $=\{a, b\} \stackrel{\text { change }}{\longrightarrow}\{\varnothing, b\} \stackrel{\text { result }}{\longrightarrow} W^{c}\left(b c_{g}^{u}\right)>W^{c}\left(a b c_{g}\right)$

We can conclude, that either of the clean countries can improve its welfare by calling another clean country only. Clean countries would prefer to exclude the dirty player if pollution is global. Based on the above, we conclude that $\Omega^{\digamma^{u}}$ is not a Nash Equilibria for both local and global levels of pollution.

$$
\Omega^{F} \equiv\left\{\sigma_{a}=\{b, c\}, \sigma_{b}=\{a, c\}, \sigma_{c}=\{a, b\}\right\}
$$

$\Omega^{\digamma}$ is a Nash Equilibria for both local and global levels of pollution.

PROOF:

country a $=\{b, c\} \stackrel{\text { change }}{\longrightarrow}\{b, \varnothing\} \stackrel{\text { result }}{\longrightarrow} W^{a}\left(a b c_{\theta}\right)>W^{a}\left(b_{\theta}^{h}\right)$ 
country a $=\{b, c\} \stackrel{\text { change }}{\longrightarrow}\{\varnothing, c\} \stackrel{\text { result }}{\longrightarrow} W^{a}\left(a b c_{\theta}\right)>W^{a}\left(c_{\theta}^{h}\right)$

country $\mathrm{a}=\{b, c\} \stackrel{\text { change }}{\longrightarrow}\{\varnothing, \varnothing\} /\left\{b^{u}, c^{u}\right\} /\left\{b^{u}, \varnothing\right\} /\left\{\varnothing, c^{u}\right\} \stackrel{\text { result }}{\longrightarrow} W^{a}\left(a b c_{\theta}\right)>W^{a}\left(b c_{\theta}\right)$

We can conclude, that country $a$ has no incentive to change its announcement.

country $\mathrm{b}=\{a, c\} \stackrel{\text { change }}{\longrightarrow}\{a, \varnothing\} \stackrel{\text { result }}{\longrightarrow} W^{b}\left(a b c_{\theta}\right)>W^{b}\left(a_{\theta}^{h}\right)$

country $\mathrm{b}=\{a, c\} \stackrel{\text { change }}{\longrightarrow}\{\varnothing, c\} \stackrel{\text { result }}{\longrightarrow} W^{b}\left(a b c_{\theta}\right)>W^{b}\left(c_{\theta}^{h}\right)$

country $\mathrm{b}=\{a, c\} \stackrel{\text { change }}{\longrightarrow}\{\varnothing, \varnothing\} /\left\{a^{u}, c^{u}\right\} /\left\{a^{u}, \varnothing\right\} /\left\{\varnothing, c^{u}\right\} \stackrel{\text { result }}{\longrightarrow} W^{b}\left(a b c_{\theta}\right)>W^{b}\left(a c_{\theta}\right)$

We can conclude, that country $b$ has no incentive to change its announcement.

country $\mathrm{c}=\{a, b\} \stackrel{\text { change }}{\longrightarrow}\{a, \varnothing\} \stackrel{\text { result }}{\longrightarrow} W^{c}\left(a b c_{\theta}\right)>W^{c}\left(a_{\theta}^{h}\right)$

country c $=\{a, b\} \stackrel{\text { change }}{\longrightarrow}\{\varnothing, b\} \stackrel{\text { result }}{\longrightarrow} W^{c}\left(a b c_{\theta}\right)>W^{c}\left(b_{\theta}^{h}\right)$

country $\mathrm{c}=\{a, b\} \stackrel{\text { change }}{\longrightarrow}\{\varnothing, \varnothing\} /\left\{a^{u}, b^{u}\right\} /\left\{a^{u}, \varnothing\right\} /\left\{\varnothing, b^{u}\right\} \stackrel{\text { result }}{\longrightarrow} W^{c}\left(a b c_{\theta}\right)>W^{c}\left(a b_{\theta}\right)$

We can conclude, that country $c$ has no incentive to change its announcement.

Based on the above, we conclude that $\Omega^{\digamma}$ is a Nash Equilibria for both local and global levels of pollution.

$\Omega^{\digamma}$ is not a CPNE for both local and global levels of pollution.

PROOF:

If pollution is local, then the dirty country $a$ can form a CU with either clean partner, then $W^{a}\left(a b_{l}^{u}\right)=W^{a}\left(a c_{l}^{u}\right)>W^{a}\left(a b c_{l}\right)$ and $W^{b}\left(a b_{l}^{u}\right)=W^{c}\left(a c_{l}^{u}\right)>W^{b}\left(a b c_{l}\right)=W^{c}\left(a b c_{l}\right)$. If pollution is global, then two clean countries can form a coalition in the form of customs union and gain the highest level of welfare in this game. Based on the above, we can conclude that the announcement profile $\Omega^{\digamma}$ does not survive a coalition-proof Nash equilibria refinement.

\section{A. 3.9.2.2 Deep Trade Agreements Game}

Welfare effects of various type of shallow trade agreements:

$W^{a}\left(a b_{l}^{i u}\right)>W^{a}\left(a b_{l}^{i}\right)>W^{a}\left(N_{l}\right)>W^{a}\left(a_{l}^{h i}\right)>W^{a}\left(a b c_{l}^{i}\right)>W^{a}\left(b c_{l}^{i}\right)>W^{a}\left(b_{l}^{h i}\right)>W^{a}\left(b c_{l}^{i u}\right)$ Country

a, local

$W^{a}\left(N_{g}\right) \stackrel{\lambda \in(0,0.008]}{>} W^{a}\left(a b_{g}^{i u}\right)>W^{a}\left(a b_{g}^{i}\right)>W^{a}\left(b c_{g}^{i}\right)>W^{a}\left(b c_{g}^{i u}\right)>W^{a}\left(a_{g}^{h i}\right)>W^{a}\left(a b c_{g}^{i}\right)>W^{a}\left(b_{g}^{h i}\right)$

Country a, global \& $\lambda \in(0,0.008]$ 
$W^{a}\left(a b_{g}^{i u}\right) \stackrel{\lambda \in(0.008,0.1]}{>} W^{a}\left(N_{g}\right) \stackrel{\lambda \in(0,0.053]}{>} W^{a}\left(a b_{g}^{i}\right)>W^{a}\left(b c_{g}^{i}\right)>W^{a}\left(b c_{g}^{i u}\right)>W^{a}\left(a_{g}^{h i}\right)>W^{a}\left(a b c_{g}^{i}\right)>$ $W^{a}\left(b_{g}^{h i}\right)$ Country a, global $\& \lambda \in(0.008,0.053]$

$W^{a}\left(a b_{g}^{i u}\right)>W^{a}\left(a b_{g}^{i}\right) \stackrel{\lambda \in(0.053,0.1]}{>} W^{a}\left(N_{g}\right)>W^{a}\left(b c_{g}^{i}\right)>W^{a}\left(b c_{g}^{i u}\right)>W^{a}\left(a_{g}^{h i}\right)>W^{a}\left(a b c_{g}^{i}\right)>W^{a}\left(b_{g}^{h i}\right)$

Country a, global $\& \lambda \in(0.053,0.1]$

$W^{b}\left(b_{l}^{h i}\right)>W^{b}\left(a b_{l}^{i u}\right)>W^{b}\left(a b c_{l}^{i}\right)>W^{b}\left(a b_{l}^{i}\right)>W^{b}\left(b c_{l}^{i u}\right)>W^{b}\left(b c_{l}^{i}\right)>W^{b}\left(a_{l}^{h i}\right)>W^{b}\left(N_{l}\right)$ Country

b, local

$W^{b}\left(b_{g}^{h i}\right)>W^{b}\left(a b c_{g}^{i}\right)>W^{b}\left(a_{g}^{h i}\right)>W\left(a b_{g}^{i u}\right)>W^{b}\left(a b_{g}^{i}\right)>W^{b}\left(b c_{g}^{i u}\right)>W^{b}\left(b c_{g}^{i}\right)>W^{b}\left(N_{g}\right)$ Country

b, global

$W^{c}\left(a b c_{l}^{i}\right)>W^{c}\left(b c_{l}^{i u}\right)>W^{c}\left(b c_{l}^{i}\right)>W^{c}\left(a_{l}^{h i}\right)>W^{c}\left(b_{l}^{h i}\right)>W^{c}\left(N_{l}\right)>W^{c}\left(a b_{l}^{i}\right)>W^{c}\left(a b_{l}^{i u}\right)$ Country

c, local

$W^{c}\left(a b c_{g}^{i}\right)>W^{c}\left(a_{g}^{h i}\right)>W^{c}\left(b_{g}^{h i}\right)>W^{c}\left(b c_{g}^{i u}\right)>W^{c}\left(a b_{g}^{i}\right)>W^{c}\left(b c_{g}^{i}\right)>W^{c}\left(N_{g}\right)>W^{c}\left(a b_{g}^{i u}\right)$ Country

c, global $^{43}$

\begin{tabular}{|c|c|}
\hline Announcement Profiles & Shallow Trade Agreements \\
\hline \hline$\Omega^{\Phi^{i}} \equiv\left\{\sigma_{a}^{i}=\{\varnothing, \varnothing\}, \sigma_{b}^{i}=\{\varnothing, \varnothing\}, \sigma_{c}^{i}=\{\varnothing, \varnothing\}\right\}$ & $\left\langle\Phi^{i}\right\rangle$ \\
\hline$\Omega^{a b i} \equiv\left\{\sigma_{a}^{i}=\left\{b^{i}, \varnothing\right\}, \sigma_{b}^{i}=\left\{a^{i}, \varnothing\right\}, \sigma_{c}^{i}=\{\varnothing, \varnothing\}\right\}$ & $\langle a b i\rangle$ \\
\hline$\Omega^{a b i u} \equiv\left\{\sigma_{a}^{i u}=\left\{b^{i u}, \varnothing\right\}, \sigma_{b}^{i u}=\left\{a^{i u}, \varnothing\right\}, \sigma_{c}^{i u}=\{\varnothing, \varnothing\}\right\}$ & $\langle a b i u\rangle$ \\
\hline$\Omega^{b c i} \equiv\left\{\sigma_{a}^{i}=\{\varnothing, \varnothing\}, \sigma_{b}^{i}=\left\{\varnothing, c^{i}\right\}, \sigma_{c}^{i}=\left\{\varnothing, b^{i}\right\}\right\}$ & $\langle b c i\rangle$ \\
\hline$\Omega^{b c i u} \equiv\left\{\sigma_{a}^{i u}=\{\varnothing, \varnothing\}, \sigma_{b}^{i u}=\left\{\varnothing, c^{i u}\right\}, \sigma_{c}^{i u}=\left\{\varnothing, b^{i u}\right\}\right\}$ & $\langle b c i u\rangle$ \\
\hline$\Omega^{a h i} \equiv\left\{\sigma_{a}^{i}=\left\{b^{i}, c^{i}\right\}, \sigma_{b}^{i}=\left\{a^{i}, \varnothing\right\}, \sigma_{c}^{i}=\left\{a^{i}, \varnothing\right\}\right\}$ & $\langle$ ahi $\rangle$ \\
\hline$\Omega^{b h i} \equiv\left\{\sigma_{a}^{i}=\left\{b^{i}, \varnothing\right\}, \sigma_{b}^{i}=\left\{a^{i}, c^{i}\right\}, \sigma_{c}^{i}=\left\{\varnothing, b^{i}\right\}\right\}$ & $\left\langle F^{i u}\right\rangle$ \\
\hline$\Omega^{F^{i u}} \equiv\left\{\sigma_{a}^{i u}=\left\{b^{i u}, c^{i u}\right\}, \sigma_{b}^{i u}=\left\{a^{i u}, c^{i u}\right\}, \sigma_{c}^{i u}=\left\{a^{i u}, b^{i u}\right\}\right\}$ & $\left\langle F^{i}\right\rangle$ \\
\hline$\Omega^{F^{i}} \equiv\left\{\sigma_{a}^{i}=\left\{b^{i}, c^{i}\right\}, \sigma_{b}^{i}=\left\{a^{i}, c^{i}\right\}, \sigma_{c}^{i}=\left\{a^{i}, b^{i}\right\}\right\}$ & \\
\hline
\end{tabular}

$$
\Omega^{\Phi^{i}} \equiv\left\{\sigma_{a}^{i}=\{\varnothing, \varnothing\}, \sigma_{b}^{i}=\{\varnothing, \varnothing\}, \sigma_{c}^{i}=\{\varnothing, \varnothing\}\right\}
$$

$\Omega^{\Phi^{i}}$ is a Nash Equilibria for both local and global levels of pollution.

\section{PROOF:}

Countries cannot get better off by unilaterally changing the announcements; countries have no incentive to announce any other country unless they are going to be announced back.

\footnotetext{
${ }^{43}$ In this game, to assure positive imports of good A by country c when we have country b as a hub, we had to restrict $\lambda$ further, $\lambda \in(0,0.01]$ (similar to I game)
} 
$\Omega^{\Phi^{i}}$ is not a CPNE for both local and global levels of pollution.

PROOF:

Any two countries can be better off by announcing each other; for example, $W^{a}\left(a b_{\theta}^{i u}\right)>W^{a}\left(N_{\theta}\right)$ and $W^{b}\left(a b_{\theta}^{i u}\right)>W^{b}\left(N_{\theta}\right)$ or $W^{a}\left(a b_{\theta}^{i}\right)>W^{a}\left(N_{\theta}\right)$ and $W^{b}\left(a b_{\theta}^{i}\right)>W^{b}\left(N_{\theta}\right)$.

$$
\Omega^{a b i} \equiv\left\{\sigma_{a}^{i}=\left\{b^{i}, \varnothing\right\}, \sigma_{b}^{i}=\left\{a^{i}, \varnothing\right\}, \sigma_{c}^{i}=\{\varnothing, \varnothing\}\right\}
$$

$\Omega^{a b i}$ is a Nash Equilibria for the local level of pollution and for the global level of pollution if $\lambda \in(0.053,0.1]$.

PROOF:

country $\mathrm{a}=\left\{b^{i}, \varnothing\right\} \stackrel{\text { change }}{\longrightarrow}\left\{b^{i}, c^{i}\right\} \stackrel{\text { result }}{\longrightarrow}$ no change in $a^{\prime}$ s welfare

country a $=\left\{b^{i}, \varnothing\right\} \stackrel{\text { change }}{\longrightarrow}\left\{\varnothing, c^{i}\right\} /\left\{\varnothing, c^{i u}\right\} /\left\{b^{i u}, \varnothing\right\} /\{\varnothing, \varnothing\} /\left\{b^{i u}, c^{i u}\right\} \stackrel{\text { result }}{\longrightarrow} W^{a}\left(a b_{l}^{i}\right)>W^{a}\left(N_{l}\right)$ $\& W^{a}\left(a b_{g}^{i}\right)>W^{a}\left(N_{g}\right)$ if $\lambda \in(0.053,0.1]$.

We can conclude, that country $a$ has no incentive to change its announcement if pollution is local. Also, country $a$ has no incentive to alter its announcement if pollution is global and $\lambda \in$ $(0.053,0.1]$.

country $\mathrm{b}=\left\{a^{i}, \varnothing\right\} \stackrel{\text { change }}{\longrightarrow}\left\{a^{i}, c^{i}\right\} \stackrel{\text { result }}{\longrightarrow}$ no change in $b$ 's welfare

country $\mathrm{b}=\left\{a^{i}, \varnothing\right\} \stackrel{\text { change }}{\longrightarrow}\left\{\varnothing, c^{i}\right\} /\left\{\varnothing, c^{i u}\right\} /\left\{a^{i u}, \varnothing\right\} /\{\varnothing, \varnothing\} /\left\{a^{i u}, c^{i u}\right\} \stackrel{\text { result }}{\longrightarrow} W^{b}\left(a b_{\theta}^{i}\right)>W^{b}\left(N_{\theta}\right)$

We can conclude, that country $b$ has no incentive to change its announcement.

country $\mathrm{c}=\{\varnothing, \varnothing\} \stackrel{\text { change }}{\longrightarrow}\left\{a^{i}, \varnothing\right\} /\left\{a^{i u}, \varnothing\right\} /\left\{\varnothing, b^{i}\right\} /\left\{\varnothing, b^{i u}\right\} /\left\{a^{i}, b^{i}\right\} /\left\{a^{i u}, b^{i u}\right\} \stackrel{\text { result }}{\longrightarrow}$ no change in $c$ 's welfare

We can conclude, that country $c$ has no incentive to change its announcement.

Based on the above, we conclude $\Omega^{a b i}$ is a Nash Equilibria if pollution is local and if pollution is global and $\lambda \in(0.053,0.1]$.

$\Omega^{a b i}$ is not a Nash Equilibria if the pollution is global and $\lambda \in(0,0.053]$.

PROOF:

country $\mathrm{a}=\left\{b^{i}, \varnothing\right\} \stackrel{\text { change }}{\longrightarrow}\left\{\varnothing, c^{i}\right\} /\left\{\varnothing, c^{i u}\right\} /\left\{b^{i u}, \varnothing\right\} /\{\varnothing, \varnothing\} /\left\{b^{i u}, c^{i u}\right\} \stackrel{\text { result }}{\longrightarrow} W^{a}\left(a b_{g}^{i}\right)<W^{a}\left(N_{g}\right)$ if $\lambda \in(0,0.053]$. 
We can conclude, that country $a$ can unilaterally change its announcement and gain a higher level of welfare.

$\Omega^{a b i}$ is not a CPNE for both local and global levels of pollution.

PROOF:

Countries $a$ and $b$ can form a coalition to sign a different PTA, then $\Omega \equiv\left\{\sigma_{a}^{i u}=\left\{b^{i u}, \varnothing\right\}, \sigma_{b}^{i u}=\right.$ $\left.\left\{a^{i u}, \varnothing\right\}, \sigma_{c}^{i}=\{\varnothing, \varnothing\}\right\}$, and $W^{a}\left(a b_{\theta}^{i u}\right)>W^{a}\left(a b_{\theta}^{i}\right) \& W^{b}\left(a b_{\theta}^{i u}\right)>W^{b}\left(a b_{\theta}^{i}\right)$. We can conclude that $\Omega^{a b i}$ is not a CPNE for both local and global levels of pollution.

$$
\Omega^{a b i u} \equiv\left\{\sigma_{a}^{i u}=\left\{b^{i u}, \varnothing\right\}, \sigma_{b}^{i u}=\left\{a^{i u}, \varnothing\right\}, \sigma_{c}^{i u}=\{\varnothing, \varnothing\}\right\}
$$

$\Omega^{a b i u}$ is a Nash Equilibria if pollution is local and if pollution is global and $\lambda \in(0.008,0.1]$.

ProOF:

country $\mathrm{a}=\left\{b^{i u}, \varnothing\right\} \stackrel{\text { change }}{\longrightarrow}\left\{b^{i u}, c^{i u}\right\} \stackrel{\text { result }}{\longrightarrow}$ no change in $a$ 's welfare

country a $=\left\{b^{i u}, \varnothing\right\} \stackrel{\text { change }}{\longrightarrow}\left\{\varnothing, c^{i}\right\} /\left\{\varnothing, c^{i u}\right\} /\{\varnothing, \varnothing\} /\left\{b^{i}, c^{i}\right\} /\left\{b^{i}, \varnothing\right\} \stackrel{\text { result }}{\longrightarrow} W^{a}\left(a b_{l}^{i u}\right)>W^{a}\left(N_{l}\right) \&$ $W^{a}\left(a b_{g}^{i u}\right)>W^{a}\left(N_{g}\right)$ if $\lambda \in(0.008,0.1]$.

We can conclude, that country $a$ has no incentive to change its announcement if pollution is local. Also, country $a$ has no incentive to alter its announcement if pollution is global and $\lambda \in$ $(0.008,0.1]$.

country $\mathrm{b}=\left\{a^{i u}, \varnothing\right\} \stackrel{\text { change }}{\longrightarrow}\left\{a^{i u}, c^{i u}\right\} \stackrel{\text { result }}{\longrightarrow}$ no change in $b$ 's welfare country $\mathrm{b}=\left\{a^{i u}, \varnothing\right\} \stackrel{\text { change }}{\longrightarrow}\left\{\varnothing, c^{i}\right\} /\left\{\varnothing, c^{i u}\right\} /\{\varnothing, \varnothing\} /\left\{a^{i}, c^{i}\right\} /\left\{a^{i}, \varnothing\right\} \stackrel{\text { result }}{\longrightarrow} W^{b}\left(a b_{\theta}^{i u}\right)>W^{b}\left(N_{\theta}\right)$

We can conclude, that country $b$ has no incentive to change its announcement.

country $\mathrm{c}=\{\varnothing, \varnothing\} \stackrel{\text { change }}{\longrightarrow}\left\{a^{i}, \varnothing\right\} /\left\{a^{i u}, \varnothing\right\} /\left\{\varnothing, b^{i}\right\} /\left\{\varnothing, b^{i u}\right\} /\left\{a^{i}, b^{i}\right\} /\left\{a^{i u}, b^{i u}\right\} \stackrel{\text { result }}{\longrightarrow}$ no change in $c$ 's welfare

We can conclude, that country $c$ has no incentive to change its announcement.

Based on the above, we conclude that $\Omega^{a b i u}$ is a Nash Equilibria if pollution is local and if pollution is global and $\lambda \in(0.008,0.1]$.

$\Omega^{\text {abiu }}$ is not a Nash Equilibria if pollution is global and $\lambda \in(0,0.008]$.

PROOF: 
country a $=\left\{b^{i u}, \varnothing\right\} \stackrel{\text { change }}{\longrightarrow}\left\{\varnothing, c^{i}\right\} /\left\{\varnothing, c^{i u}\right\} /\{\varnothing, \varnothing\} /\left\{b^{i}, c^{i}\right\} /\left\{b^{i}, \varnothing\right\} \stackrel{\text { result }}{\longrightarrow} W^{a}\left(a b_{g}^{i u}\right)<W^{a}\left(N_{g}\right)$ if $\lambda \in(0,0.008]$.

We can conclude, that country $a$ can unilaterally change its announcement and gain a higher level of welfare.

$\Omega^{\text {abiu }}$ is a CPNE for the local level of pollution and for the global level of pollution if $\lambda \in$ $(0.008,0.1]$.

PROOF:

To prove the above, in the next four steps, we consider every possible deviation:

First, we consider a possible coalition of two clean countries, then $W^{b}\left(b c_{\theta}^{i u}\right)<W^{b}\left(a b_{\theta}^{i u}\right)$ and $W^{b}\left(b c_{\theta}^{i}\right)<W^{b}\left(a b_{\theta}^{i u}\right)$. We can see, that country $b$ is not interested in excluding the dirty partner in the form of either integrated PTA which includes only clean countries, and we conclude that this deviation is not meaningful.

Second, we acknowledge that though a clean partner of this union would rather be a hub than a part of this integrated customs union, this deviation is not possible due to the nature of customs unions. Third, we examine the deviation of members of this union to another form of integrated PTA, then $W^{a}\left(a b_{\theta}^{i u}\right)>W^{a}\left(a b_{\theta}^{i}\right)$ and $W^{b}\left(a b_{\theta}^{i u}\right)>W^{b}\left(a b_{\theta}^{i}\right)$. We can that see this deviation is not meaningful. Finally, we consider the grand coalition. In this case, if pollution is local, then $W^{a}\left(a b_{l}^{i u}\right)>$ $W^{a}\left(a b c_{l}^{i}\right)$ and $W^{b}\left(a b_{l}^{i u}\right)>W^{b}\left(a b c_{l}^{i}\right)$, and we can see that this coalitional deviation is not meaningful as well. If pollution is global, then the dirty country $a$ would not agree to be a part of a fully integrated world; it would rather be an outsider of either integrated PTA of clean countries than join them.

Based on the above, we conclude that $\Omega^{a b i u}$ is a CPNE if pollution is local, and it is a CPNE if pollution is global and $\lambda \in(0.008,0.1]$.

$$
\Omega^{b c i} \equiv\left\{\sigma_{a}^{i}=\{\varnothing, \varnothing\}, \sigma_{b}^{i}=\left\{\varnothing, c^{i}\right\}, \sigma_{c}^{i}=\left\{\varnothing, b^{i}\right\}\right\}
$$

$\Omega^{b c i}$ is a Nash Equilibria for both local and global levels of pollution.

PROOF: 
country a $=\{\varnothing, \varnothing\} \stackrel{\text { change }}{\longrightarrow}\left\{b^{i}, \varnothing\right\} /\left\{b^{i u}, \varnothing\right\} /\left\{\varnothing, c^{i}\right\} /\left\{\varnothing, c^{i u}\right\} /\left\{b^{i}, c^{i}\right\} /\left\{b^{i u}, c^{i u}\right\} \stackrel{\text { result }}{\longrightarrow}$ no change in $a$ 's welfare

We can conclude, that country $a$ has no incentive to change its announcement.

country $\mathrm{b}=\left\{\varnothing, c^{i}\right\} \stackrel{\text { change }}{\longrightarrow}\left\{a^{i}, c^{i}\right\} \stackrel{\text { result }}{\longrightarrow}$ no change in $b$ 's welfare

country $\mathrm{b}=\left\{\varnothing, c^{i}\right\} \stackrel{\text { change }}{\longrightarrow}\left\{a^{i}, \varnothing\right\} /\left\{a^{i u}, \varnothing\right\} /\{\varnothing, \varnothing\} /\left\{\varnothing, c^{i u}\right\} /\left\{a^{i u}, c^{i u}\right\} \stackrel{\text { result }}{\longrightarrow} W^{b}\left(b c_{\theta}^{i}\right)>W^{b}\left(N_{\theta}\right)$

We can conclude, that country $b$ has no incentive to change its announcement.

country $\mathrm{c}=\left\{\varnothing, b^{i}\right\} \stackrel{\text { change }}{\longrightarrow}\left\{a^{i}, b^{i}\right\} \stackrel{\text { result }}{\longrightarrow}$ no change in $c^{\prime}$ 's welfare

country $\mathrm{c}=\left\{\varnothing, b^{i}\right\} \stackrel{\text { change }}{\longrightarrow}\left\{a^{i}, \varnothing\right\} /\left\{a^{i u}, \varnothing\right\} /\{\varnothing, \varnothing\} /\left\{\varnothing, b^{i u}\right\} /\left\{a^{i u}, b^{i u}\right\} \stackrel{\text { result }}{\longrightarrow} W^{c}\left(b c_{\theta}^{i}\right)>W^{c}\left(N_{\theta}\right)$

We can conclude, that country $c$ has no incentive to change its announcement.

Based on the above, we conclude that $\Omega^{b c i}$ is a Nash Equilibria for both local and global levels of pollution.

$\Omega^{b c i}$ is not a CPNE for both local and global levels of pollution.

PROOF:

Members can form a coalition to sign a different deep trade agreement, then $\Omega \equiv\left\{\sigma_{a}^{i}=\{\varnothing, \varnothing\}, \sigma_{b}^{i u}=\right.$ $\left.\left\{\varnothing, c^{i u}\right\}, \sigma_{c}^{i u}=\left\{\varnothing, b^{i u}\right\}\right\}$, and $W^{b}\left(b c_{\theta}^{i u}\right)=W^{c}\left(b c_{\theta}^{i u}\right)>W^{b}\left(b c_{\theta}^{i}\right)=W^{c}\left(b c_{\theta}^{i}\right)$. We can conclude that $\Omega^{b c i}$ is not a CPNE for both local and global levels of pollution.

$$
\Omega^{b c i u} \equiv\left\{\sigma_{a}^{i u}=\{\varnothing, \varnothing\}, \sigma_{b}^{i u}=\left\{\varnothing, c^{i u}\right\}, \sigma_{c}^{i u}=\left\{\varnothing, b^{i u}\right\}\right\}
$$

$\Omega^{\text {bciu }}$ is a Nash Equilibria for both local and global levels of pollution.

PROOF:

country a $=\{\varnothing, \varnothing\} \stackrel{\text { change }}{\longrightarrow}\left\{b^{i}, \varnothing\right\} /\left\{b^{i u}, \varnothing\right\} /\left\{\varnothing, c^{i}\right\} /\left\{\varnothing, c^{i u}\right\} /\left\{b^{i}, c^{i}\right\} /\left\{b^{i u}, c^{i u}\right\} \stackrel{\text { result }}{\longrightarrow}$ no change in $a$ 's welfare

We can conclude, that country $a$ has no incentive to change its announcement.

country $\mathrm{b}=\left\{\varnothing, c^{i u}\right\} \stackrel{\text { change }}{\longrightarrow}\left\{a^{i u}, c^{i u}\right\} \stackrel{\text { result }}{\longrightarrow}$ no change in $b$ 's welfare

country $\mathrm{b}=\left\{\varnothing, c^{i u}\right\} \stackrel{\text { change }}{\longrightarrow}\left\{a^{i}, \varnothing\right\} /\left\{a^{i u}, \varnothing\right\} /\{\varnothing, \varnothing\} /\left\{a^{i}, c^{i}\right\} /\left\{\varnothing, c^{i}\right\} \stackrel{\text { result }}{\longrightarrow} W^{b}\left(b c_{\theta}^{i u}\right)>W^{b}\left(N_{\theta}\right)$

We can conclude, that country $b$ has no incentive to change its announcement.

country $\mathrm{c}=\left\{\varnothing, b^{i u}\right\} \stackrel{\text { change }}{\longrightarrow}\left\{a^{i u}, b^{i u}\right\} \stackrel{\text { result }}{\longrightarrow}$ no change in $c$ 's welfare 
country $\mathrm{c}=\left\{\varnothing, b^{i u}\right\} \stackrel{\text { change }}{\longrightarrow}\left\{a^{i}, \varnothing\right\} /\left\{a^{i u}, \varnothing\right\} /\{\varnothing, \varnothing\} /\left\{a^{i}, b^{i}\right\} /\left\{\varnothing, b^{i}\right\} \stackrel{\text { result }}{\longrightarrow} W^{c}\left(b c_{\theta}^{i u}\right)>W^{c}\left(N_{\theta}\right)$

We can conclude, that country $c$ has no incentive to change its announcement.

Based on the above, $\Omega^{b c i u}$ is a Nash Equilibria for both local and global levels of pollution.

$\Omega^{\text {bciu }}$ is not a CPNE if pollution is local and if pollution is global and $\lambda \in(0.008,0.1]$.

\section{PROOF:}

Any member can form an integrated customs union with the dirty player, exclude the other clean country, and improve its welfare as follows: $W^{b}\left(a b_{\theta}^{i u}\right)=W^{c}\left(a c_{\theta}^{i u}\right)>W^{b}\left(b c_{\theta}^{i u}\right)=W^{c}\left(b c_{\theta}^{i u}\right)$. The dirty country $a$ would happily agree to that for any levels of lambda if pollution is local and for relatively high lambda if pollution is global. Based, on the above, we are confident to conclude that $\Omega^{\text {bciu }}$ is not a CPNE for the local level of pollution and for the global level of pollution if $\lambda \in(0.008,0.1]$

$\Omega^{\text {bciu }}$ is a CPNE if pollution is global and $\lambda \in(0,0.008]$.

PROOF:

To prove the above, in the next three steps we consider every possible deviation:

First, though either clean member of the world would prefer to deviate with the dirty player in the form of an integrated union to gain a higher welfare $W^{b}\left(a b_{g}^{i u}\right)=W^{c}\left(a c_{g}^{i u}\right)>W^{b}\left(b c_{g}^{i u}\right)=W^{c}\left(b c_{g}^{i u}\right)$, this deviation is not self-enforcing for relatively low levels of lambda. Country $a$ has an incentive to deviate further into no agreement scenario and improve its welfare.

Second, we acknowledge that though either clean partner of this integrated union would rather be a hub, but this deviation is not possible due to the nature of integrated customs unions.

Third, we consider the grand coalition. In this case, $W^{b}\left(b c_{g}^{i u}\right)=W^{c}\left(b c_{g}^{i u}\right)<W^{b}\left(a b c_{g}^{i}\right)=W^{c}\left(a b c_{g}^{i}\right)$, but country $a$ would not agree to be a part of a fully integrated world. The dirty country a would rather be an outsider of an integrated customs union of clean countries than join them.

Based on the above, we can conclude that $\Omega^{b c i u}$ is a CPNE if pollution is global and $\lambda \in(0,0.008]$.

$$
\Omega^{a h i} \equiv\left\{\sigma_{a}^{i}=\left\{b^{i}, c^{i}\right\}, \sigma_{b}^{i}=\left\{a^{i}, \varnothing\right\}, \sigma_{c}^{i}=\left\{a^{i}, \varnothing\right\}\right\}
$$

$\Omega^{\text {ahi }}$ is not a Nash Equilibria for both local and global levels of pollution. 
PROOF:

country a $=\left\{b^{i}, c^{i}\right\} \stackrel{\text { change }}{\longrightarrow}\{\varnothing, \varnothing\} /\left\{b^{i u}, c^{i u}\right\} /\left\{b^{i u}, \varnothing\right\} /\left\{\varnothing, c^{i u}\right\} \stackrel{\text { result }}{\longrightarrow} W^{a}\left(a_{\theta}^{\text {hi }}\right)<W^{a}\left(N_{\theta}\right)$

We can conclude, that country $a$ would deviate, and based on that $\Omega^{a h i}$ is not a Nash Equilibria for both local and global levels of pollution.

$$
\Omega^{b h i} \equiv\left\{\sigma_{a}^{i}=\left\{b^{i}, \varnothing\right\}, \sigma_{b}^{i}=\left\{a^{i}, c^{i}\right\}, \sigma_{c}^{i}=\left\{\varnothing, b^{i}\right\}\right\}
$$

$\Omega^{\text {bhi }}$ is not a Nash Equilibria for both local and global levels of pollution.

PROOF:

country a $=\left\{b^{i}, \varnothing\right\} \stackrel{\text { change }}{\longrightarrow}\{\varnothing, \varnothing\} /\left\{b^{i u}, c^{i u}\right\} /\left\{b^{i u}, \varnothing\right\} /\left\{\varnothing, c^{i}\right\} \stackrel{\text { result }}{\longrightarrow} W^{a}\left(b c_{\theta}^{i}\right)>W^{a}\left(b_{\theta}^{h i}\right)$

We can conclude, that country a would deviate, and based on that $\Omega^{b h i}$ is not a Nash Equilibria for both local and global levels of pollution.

$$
\Omega^{F^{i u}} \equiv\left\{\sigma_{a}^{i u}=\left\{b^{i u}, c^{i u}\right\}, \sigma_{b}^{i u}=\left\{a^{i u}, c^{i u}\right\}, \sigma_{c}^{i u}=\left\{a^{i u}, b^{i u}\right\}\right\}
$$

$\Omega^{\digamma^{i u}}$ is not a Nash Equilibria for both local and global levels of pollution.

PROOF:

First, we prove that it is not a Nash equilibria if pollution is local. Country a can improve its welfare by announcing only one out of two clean countries. The lucky clean country would prefer to form an integrated union with country $a$ versus the union with another clean country. We can conclude, that $\Omega^{\digamma^{i u}}$ is not a Nash Equilibria if pollution is local.

Now, we show that it is not a Nash equilibria for the global level of pollution we well. The dirty country $a$ would prefer to be an outsider of an integrated agreement between two clean countries than participate in a fully integrated world, $W^{a}\left(a b c_{g}^{i}\right)<W^{a}\left(b c_{g}^{i u}\right)$. Based on that we conclude, that $\Omega^{\digamma^{i u}}$ is not a Nash Equilibria if pollution is global as well.

$$
\Omega^{F^{i}} \equiv\left\{\sigma_{a}^{i}=\left\{b^{i}, c^{i}\right\}, \sigma_{b}^{i}=\left\{a^{i}, c^{i}\right\}, \sigma_{c}^{i}=\left\{a^{i}, b^{i}\right\}\right\}
$$

$\Omega^{\digamma^{i}}$ is a Nash Equilibria if pollution is local.

PROOF:

country a $=\left\{b^{i}, c^{i}\right\} \stackrel{\text { change }}{\longrightarrow}\left\{b^{i}, \varnothing\right\} /\left\{\varnothing, c^{i}\right\} \stackrel{\text { result }}{\longrightarrow} W^{a}\left(a b c_{l}^{i}\right)>W^{a}\left(b_{l}^{h i}\right)=W^{a}\left(c_{l}^{h i}\right)$ 
country a $=\left\{b^{i}, c^{i}\right\} \stackrel{\text { change }}{\longrightarrow}\{\varnothing, \varnothing\} /\left\{b^{i u}, c^{i u}\right\} /\left\{b^{i u}, \varnothing\right\} /\left\{\varnothing, c^{i u}\right\} \stackrel{\text { result }}{\longrightarrow} W^{a}\left(a b c_{l}^{i}\right)>W^{a}\left(b c_{l}^{i}\right)$

We can conclude, that country $a$ has no incentive to change its announcement.

country $\mathrm{b}=\left\{a^{i}, c^{i}\right\} \stackrel{\text { change }}{\longrightarrow}\left\{a^{i}, \varnothing\right\} \stackrel{\text { result }}{\longrightarrow} W^{b}\left(a b c_{l}^{i}\right)>W^{b}\left(a_{l}^{h i}\right)$

country $\mathrm{b}=\left\{a^{i}, c^{i}\right\} \stackrel{\text { change }}{\longrightarrow}\left\{\varnothing, c^{i}\right\} \stackrel{\text { result }}{\longrightarrow} W^{b}\left(a b c_{l}^{i}\right)>W^{b}\left(c_{l}^{h i}\right)$

country $\mathrm{b}=\left\{a^{i}, c^{i}\right\} \stackrel{\text { change }}{\longrightarrow}\{\varnothing, \varnothing\} /\left\{a^{i u}, c^{i u}\right\} /\left\{a^{i u}, \varnothing\right\} /\left\{\varnothing, c^{i u}\right\} \stackrel{\text { result }}{\longrightarrow} W^{b}\left(a b c_{l}^{i}\right)>W^{b}\left(a c_{l}^{i}\right)$

We can conclude, that country $b$ has no incentive to change its announcement.

country $\mathrm{c}=\left\{a^{i}, b^{i}\right\} \stackrel{\text { change }}{\longrightarrow}\left\{a^{i}, \varnothing\right\} \stackrel{\text { result }}{\longrightarrow} W^{c}\left(a b c_{l}^{i}\right)>W^{c}\left(a_{l}^{h i}\right)$

country $\mathrm{c}=\left\{a^{i}, b^{i}\right\} \stackrel{\text { change }}{\longrightarrow}\left\{\varnothing, b^{i}\right\} \stackrel{\text { result }}{\longrightarrow} W^{c}\left(a b c_{l}^{i}\right)>W^{c}\left(b_{l}^{h i}\right)$

country $\mathrm{c}=\left\{a^{i}, b^{i}\right\} \stackrel{\text { change }}{\longrightarrow}\{\varnothing, \varnothing\} /\left\{a^{i u}, b^{i u}\right\} /\left\{a^{i u}, \varnothing\right\} /\left\{\varnothing, b^{i u}\right\} \stackrel{\text { result }}{\longrightarrow} W^{c}\left(a b c_{l}^{i}\right)>W^{c}\left(a b_{l}^{i}\right)$

We can conclude, that country $c$ has no incentive to change its announcement.

Based on the above, we conclude that $\Omega^{\digamma^{i}}$ is a Nash Equilibria if pollution is local.

$\Omega \digamma^{\digamma^{i}}$ is not a Nash Equilibria if pollution is global.

PROOF:

country $\mathrm{a}=\left\{b^{i}, c^{i}\right\} \stackrel{\text { change }}{\longrightarrow}\{\varnothing, \varnothing\} /\left\{b^{i u}, c^{i u}\right\} /\left\{b^{i u}, \varnothing\right\} /\left\{\varnothing, c^{i u}\right\} \stackrel{\text { result }}{\longrightarrow} W^{a}\left(a b c_{g}^{i}\right)>W^{a}\left(b c_{g}^{i}\right)$

We can conclude, that country $a$ will deviate, and $\Omega^{\digamma^{i}}$ is not a Nash Equilibria if pollution is global.

$\Omega^{\digamma^{i}}$ is not a CPNE if pollution is local.

PROOF:

If pollution is local, then the dirty country $a$ can form an integrated union with either clean partner and exclude the other clean country, then $W^{a}\left(a b_{l}^{i u}\right)=W^{a}\left(a c_{l}^{i u}\right)>W^{a}\left(a b c_{l}^{i}\right)$ and $W^{b}\left(a b_{l}^{i u}\right)=$ $W^{c}\left(a c_{l}^{i u}\right)>W^{b}\left(a b c_{l}^{i}\right)=W^{c}\left(a b c_{l}^{i}\right)$. Based on that, we can conclude that the announcement profile $\Omega \digamma^{i}$ does not survive a coalition-proof Nash equilibria refinement.

\section{A. 3.9.2.3 The Choice between Deep and Shallow Customs Unions}

Welfare effects of various type of deep and shallow trade agreements:

$W^{a}\left(a b_{l}^{u}\right)>W^{a}\left(a b_{l}^{i u}\right)>W^{a}\left(N_{l}\right)>W^{a}\left(a b c_{l}\right)>W^{a}\left(a b c_{l}^{i}\right)>W^{a}\left(b c_{l}^{i u}\right)=W^{a}\left(b c_{l}^{u}\right)$ Country a, local 
$W^{a}\left(a b_{g}^{u}\right)>W^{a}\left(a b c_{g}\right)>W^{a}\left(N_{g}\right) \stackrel{\lambda \in(0,0.008]}{>} W^{a}\left(a b_{g}^{i u}\right)>W^{a}\left(b c_{g}^{i u}\right)>W^{a}\left(b c_{g}^{u}\right)>W^{a}\left(a b c_{g}^{i}\right)$ Country

a, global \& $\lambda \in(0,0.008]$

$W^{a}\left(a b_{g}^{u}\right)>W^{a}\left(a b c_{g}\right) \stackrel{\lambda \in(0,0.076]}{>} W^{a}\left(a b_{g}^{i u}\right) \stackrel{\lambda \in(0.008,0.1]}{>} W^{a}\left(N_{g}\right)>W^{a}\left(b c_{g}^{i u}\right)>W^{a}\left(b c_{g}^{u}\right)>W^{a}\left(a b c_{g}^{i}\right)$

Country a, global $\& \lambda \in(0.008,0.076]$

$W^{a}\left(a b_{g}^{u}\right)>W^{a}\left(a b_{g}^{i u}\right) \stackrel{\lambda \in(0.076,0.1]}{>} W^{a}\left(a b c_{g}\right)>W^{a}\left(N_{g}\right)>W^{a}\left(b c_{g}^{i u}\right)>W^{a}\left(b c_{g}^{u}\right)>W^{a}\left(a b c_{g}^{i}\right)$ Coun-

try a, global \& $\lambda \in(0.076,0.1]$

$W^{b}\left(a b_{l}^{i u}\right)>W^{b}\left(a b c_{l}^{i}\right)>W^{b}\left(a b_{l}^{u}\right)>W^{b}\left(b c_{l}^{i u}\right)>W^{b}\left(b c_{l}^{i}\right)>W^{b}\left(a b c_{l}\right)>W^{b}\left(N_{l}\right)$ Country b, local $W^{b}\left(a b c_{g}^{i}\right)>W^{b}\left(a b_{g}^{i u}\right)>W^{b}\left(b c_{g}^{i u}\right)>W^{b}\left(b c_{g}^{u}\right)>W^{b}\left(a b_{g}^{u}\right)>W^{b}\left(N_{g}\right)>W^{b}\left(a b c_{g}\right)$ Country b, global $W^{c}\left(a b c_{l}^{i}\right)>W^{c}\left(b c_{l}^{i u}\right)>W^{c}\left(b c_{l}^{u}\right)>W^{c}\left(a b c_{l}\right)>W^{c}\left(N_{l}\right)>W^{c}\left(a b_{l}^{i u}\right)>W^{c}\left(a b_{l}^{u}\right)$ Country c, local $W^{c}\left(a b c_{g}^{i}\right)>W^{c}\left(b c_{g}^{i u}\right)>W^{c}\left(b c_{g}^{u}\right)>W^{c}\left(N_{g}\right)>W^{c}\left(a b c_{g}\right) \stackrel{\lambda \in(0,0.024]}{>} W^{c}\left(a b_{g}^{i u}\right)>W^{c}\left(a b_{g}^{u}\right)$ Country c, global \& $\lambda \in(0,0.024]$

$W^{c}\left(a b c_{g}^{i}\right)>W^{c}\left(b c_{g}^{i u}\right)>W^{c}\left(b c_{g}^{u}\right)>W^{c}\left(N_{g}\right) \stackrel{\lambda \in(0,0.067]}{>} W^{c}\left(a b_{g}^{i u}\right) \stackrel{\lambda \in(0.024,0.1]}{>} W^{c}\left(a b c_{g}\right)>W^{c}\left(a b_{g}^{u}\right)$

Country c, global $\lambda \in(0.024,0.067]$

$W^{c}\left(a b c_{g}^{i}\right)>W^{c}\left(b c_{g}^{i u}\right)>W^{c}\left(b c_{g}^{u}\right)>W^{c}\left(a b_{g}^{i u}\right) \stackrel{\lambda \in(0.067,0.1]}{>} W^{c}\left(N_{g}\right)>W^{c}\left(a b c_{g}\right)>W^{c}\left(a b_{g}^{u}\right)$ Country c, global $\lambda \in(0.067,0.1]$

\begin{tabular}{|c|c|}
\hline Announcement Profiles & Trade Agreements: CU vs. IU \\
\hline \hline$\Omega^{\Phi^{u}} \equiv\left\{\sigma_{a}^{u}=\{\varnothing, \varnothing\}, \sigma_{b}^{u}=\{\varnothing, \varnothing\}, \sigma_{c}^{u}=\{\varnothing, \varnothing\}\right\}$ & $\left\langle\Phi^{u}\right\rangle$ \\
\hline$\Omega^{a b u} \equiv\left\{\sigma_{a}^{u}=\left\{b^{u}, \varnothing\right\}, \sigma_{b}^{u}=\left\{a^{u}, \varnothing\right\}, \sigma_{c}^{u}=\{\varnothing, \varnothing\}\right\}$ & $\langle a b u\rangle$ \\
\hline$\Omega^{a b i u} \equiv\left\{\sigma_{a}^{i u}=\left\{b^{i u}, \varnothing\right\}, \sigma_{b}^{i u}=\left\{a^{i u}, \varnothing\right\}, \sigma_{c}^{i u}=\{\varnothing, \varnothing\}\right\}$ & $\langle a b i u\rangle$ \\
\hline$\Omega^{b c u} \equiv\left\{\sigma_{a}^{u}=\{\varnothing, \varnothing\}, \sigma_{b}^{u}=\left\{\varnothing, c^{u}\right\}, \sigma_{c}^{u}=\left\{\varnothing, b^{u}\right\}\right\}$ & $\langle b c u\rangle$ \\
\hline$\Omega^{b c i u} \equiv\left\{\sigma_{a}^{i u}=\{\varnothing, \varnothing\}, \sigma_{b}^{i u}=\left\{\varnothing, c^{i u}\right\}, \sigma_{c}^{i u}=\left\{\varnothing, b^{i u}\right\}\right\}$ & $\langle b c i u\rangle$ \\
\hline$\Omega^{F^{u}} \equiv\left\{\sigma_{a}^{u}=\left\{b^{u}, c^{u}\right\}, \sigma_{b}^{u}=\left\{a^{u}, c^{u}\right\}, \sigma_{c}^{u}=\left\{a^{u}, b^{u}\right\}\right\}$ & $\left\langle F^{u}\right\rangle$ \\
\hline$\Omega^{F^{i u}} \equiv\left\{\sigma_{a}^{i u}=\left\{b^{i u}, c^{i u}\right\}, \sigma_{b}^{i u}=\left\{a^{i u}, c^{i u}\right\}, \sigma_{c}^{i u}=\left\{a^{i u}, b^{i u}\right\}\right\}$ & $\left\langle F^{i u}\right\rangle$ \\
\hline
\end{tabular}

$$
\Omega^{\Phi^{u}} \equiv\left\{\sigma_{a}^{u}=\{\varnothing, \varnothing\}, \sigma_{b}^{u}=\{\varnothing, \varnothing\}, \sigma_{c}^{u}=\{\varnothing, \varnothing\}\right\}
$$

$\Omega^{\Phi^{u}}$ is a Nash Equilibria for both local and global levels of pollution.

\section{PROOF:}

Countries cannot get better off by unilaterally changing the announcements; countries have no incentive to announce any other country unless they are going to be announced back. 
$\Omega^{\Phi^{u}}$ is not a CPNE for both local and global levels of pollution.

\section{PROOF:}

Any two countries can be better off by announcing each other.

$$
\Omega^{a b u} \equiv\left\{\sigma_{a}^{u}=\left\{b^{u}, \varnothing\right\}, \sigma_{b}^{u}=\left\{a^{u}, \varnothing\right\}, \sigma_{c}^{u}=\{\varnothing, \varnothing\}\right\}
$$

$\Omega^{a b u}$ is a Nash Equilibria for both local and global levels of pollution.

PROOF:

country a $=\left\{b^{u}, \varnothing\right\} \stackrel{\text { change }}{\longrightarrow}\left\{b^{u}, c^{u}\right\} \stackrel{\text { result }}{\longrightarrow}$ no change in $a$ 's welfare

country a $=\left\{b^{u}, \varnothing\right\} \stackrel{\text { change }}{\longrightarrow}\left\{\varnothing, c^{u}\right\} /\left\{\varnothing, c^{i u}\right\} /\{\varnothing, \varnothing\} /\left\{b^{i u}, \varnothing\right\} /\left\{b^{i u}, c^{i u}\right\} \stackrel{\text { result }}{\longrightarrow} W^{a}\left(a b_{\theta}^{u}\right)>W^{a}\left(N_{\theta}\right)$

We can conclude, that country $a$ has no incentive to change its announcement.

country $\mathrm{b}=\left\{a^{u}, \varnothing\right\} \stackrel{\text { change }}{\longrightarrow}\left\{a^{u}, c^{u}\right\} \stackrel{\text { result }}{\longrightarrow}$ no change in $b$ 's welfare

country $\mathrm{b}=\left\{a^{u}, \varnothing\right\} \stackrel{\text { change }}{\longrightarrow}\left\{\varnothing, c^{u}\right\} /\left\{\varnothing, c^{i u}\right\} /\{\varnothing, \varnothing\} /\left\{a^{i u}, c^{i u}\right\} /\left\{a^{i u}, \varnothing\right\} \stackrel{\text { result }}{\longrightarrow} W^{b}\left(a b_{\theta}^{u}\right)>W^{b}\left(N_{\theta}\right)$

We can conclude, that country $b$ has no incentive to change its announcement.

country $\mathrm{c}=\{\varnothing, \varnothing\} \stackrel{\text { change }}{\longrightarrow}\left\{a^{u}, \varnothing\right\} /\left\{a^{i u}, \varnothing\right\} /\left\{\varnothing, b^{u}\right\} /\left\{\varnothing, b^{i u}\right\} /\left\{a^{u}, b^{u}\right\} /\left\{a^{i u}, b^{i u}\right\} \stackrel{\text { result }}{\longrightarrow}$ no change in $c$ 's welfare

We can conclude, that country $c$ has no incentive to change its announcement.

Based on the above, $\Omega^{a b u}$ is a Nash Equilibria for both local and global levels of pollution.

$\Omega^{a b u}$ is a CPNE if pollution is local.

\section{PROOF:}

To prove the above, in next three steps, we consider every possible deviation:

First, we consider a coalition of two clean countries, then $W^{b}\left(b c_{l}^{u}\right)<W^{b}\left(a b_{l}^{u}\right)$ and $W^{b}\left(b c_{l}^{i u}\right)<$ $W^{b}\left(a b_{l}^{u}\right)$. We can see, that a clean country is not interested in excluding the dirty partner in the form of either customs union which includes only clean countries, and we conclude that this deviation is not meaningful.

Second, we examine whether members would prefer to add an environmental clause to their original agreement: $W^{b}\left(a b_{l}^{i u}\right)>W^{b}\left(a b_{l}^{u}\right)$, but $W^{a}\left(a b_{l}^{i u}\right)<W^{a}\left(a b_{l}^{u}\right)$. We can that see that country $a$ would not be interested, and we conclude that this deviation is not meaningful as well. 
Finally, we consider the grand coalition. In this case, $W^{a}\left(a b_{l}^{u}\right)>W^{a}\left(a b c_{l}\right)>W^{a}\left(a b c_{l}^{i}\right)$. We can see that the dirty player does not prefer a tree trade or a fully integrated world to a shallow union, and again we find that this deviation is not meaningful.

Based on the above, we conclude that $\Omega^{a b u}$ is a CPNE if pollution is local.

$\Omega^{a b u}$ is not a CPNE if pollution is global.

PROOF:

Suppose, $b$ and $c$ form an integrated union and exclude $a$, then $W^{b}\left(b c_{g}^{i u}\right)>W^{b}\left(a b_{g}^{i u}\right)$ and $W^{c}\left(b c_{g}^{i u}\right)>$ $W^{c}\left(a b_{g}^{u}\right)$. We can conclude that clean countries would form an integrated union and exclude $a$ if pollution exhibits global characteristics. Though clean players would prefer to live in a fully integrated world, the dirty country $a$ would rather be an outsider of either union of two clean countries, deep or shallow, than join a fully integrated world.

$$
\Omega^{a b i u} \equiv\left\{\sigma_{a}^{i u}=\left\{b^{i u}, \varnothing\right\}, \sigma_{b}^{i u}=\left\{a^{i u}, \varnothing\right\}, \sigma_{c}^{i u}=\{\varnothing, \varnothing\}\right\}
$$

$\Omega^{a b i u}$ is a Nash Equilibria if pollution is local and if pollution is global and $\lambda \in(0.008,0.1]$.

ProOF:

country a $=\left\{b^{i u}, \varnothing\right\} \stackrel{\text { change }}{\longrightarrow}\left\{b^{i u}, c^{i u}\right\} \stackrel{\text { result }}{\longrightarrow}$ no change in $a$ 's welfare

country $\mathrm{a}=\left\{b^{i u}, \varnothing\right\} \stackrel{\text { change }}{\longrightarrow}\left\{\varnothing, c^{u}\right\} /\left\{\varnothing, c^{i u}\right\} /\{\varnothing, \varnothing\} /\left\{b^{u}, c^{u}\right\} /\left\{b^{u}, \varnothing\right\} \stackrel{\text { result }}{\longrightarrow} W^{a}\left(a b_{l}^{i u}\right)>W^{a}\left(N_{l}\right) \&$ $W^{a}\left(a b_{g}^{i u}\right)>W^{a}\left(N_{g}\right)$ if $\lambda \in(0.008,0.1]$.

We can conclude, that country $a$ has no incentive to change its announcement if pollution is local. Also, country $a$ has no incentive to alter its announcement if pollution is global and $\lambda \in$ $(0.008,0.1]$.

country $\mathrm{b}=\left\{a^{i u}, \varnothing\right\} \stackrel{\text { change }}{\longrightarrow}\left\{a^{i u}, c^{i u}\right\} \stackrel{\text { result }}{\longrightarrow}$ no change in $b$ 's welfare

country $\mathrm{b}=\left\{a^{i u}, \varnothing\right\} \stackrel{\text { change }}{\longrightarrow}\left\{\varnothing, c^{u}\right\} /\left\{\varnothing, c^{i u}\right\} /\{\varnothing, \varnothing\} /\left\{a^{u}, c^{u}\right\} /\left\{a^{u}, \varnothing\right\} \stackrel{\text { result }}{\longrightarrow} W^{b}\left(a b_{\theta}^{i u}\right)>W^{b}\left(N_{\theta}\right)$

We can conclude, that country $b$ has no incentive to change its announcement.

country $\mathrm{c}=\{\varnothing, \varnothing\} \stackrel{\text { change }}{\longrightarrow}\left\{a^{u}, \varnothing\right\} /\left\{a^{i u}, \varnothing\right\} /\left\{\varnothing, b^{u}\right\} /\left\{\varnothing, b^{i u}\right\} /\left\{a^{u}, b^{u}\right\} /\left\{a^{i u}, b^{i u}\right\} \stackrel{\text { result }}{\longrightarrow}$ no change in $c$ 's welfare

We can conclude, that country $c$ has no incentive to change its announcement. 
Based on the above, we conclude that $\Omega^{a b i u}$ is a Nash Equilibria if pollution is local and if pollution is global and $\lambda \in(0.008,0.1]$.

$\Omega^{\text {abiu }}$ is not a Nash Equilibria if pollution is global and $\lambda \in(0,0.008]$.

PROOF:

country a $=\left\{b^{i u}, \varnothing\right\} \stackrel{\text { change }}{\longrightarrow}\left\{\varnothing, c^{u}\right\} /\left\{\varnothing, c^{i u}\right\} /\{\varnothing, \varnothing\} /\left\{b^{u}, c^{u}\right\} /\left\{b^{u}, \varnothing\right\} \stackrel{\text { result }}{\longrightarrow} W^{a}\left(a b_{g}^{i u}\right)<W^{a}\left(N_{g}\right)$ if $\lambda \in(0,0.008]$.

We can conclude, that country $a$ can unilaterally change its announcement and gain a higher level of welfare.

$\Omega^{a b i u}$ is a CPNE if pollution is local and if pollution is global and $\lambda \in(0.008,0.1]$.

PROOF:

To prove the above, we consider every possible deviation in the next three steps:

First, we consider a possible coalition of two clean countries, then $W^{b}\left(b c_{\theta}^{i u}\right)<W^{b}\left(a b_{\theta}^{i u}\right)$ and $W^{b}\left(b c_{\theta}^{u}\right)<W^{b}\left(a b_{\theta}^{i u}\right)$. We can see, that country $b$ is not interested in excluding the dirty partner in the form of either PTA, deep or shallow, which would include only clean countries.

Second, we examine whether the members of this integrated customs union would prefer to remove an environmental clause from their agreement. In this case, we have the following welfare gains $W^{a}\left(a b_{\theta}^{u}\right)>W^{a}\left(a b_{\theta}^{i u}\right)$ and $W^{b}\left(a b_{\theta}^{i u}\right)>W^{b}\left(a b_{\theta}^{u}\right)$. We can that see a clean member of this union would not agree to the change.

Finally, we consider the grand coalition. In this case, if pollution is local, then $W^{a}\left(a b_{l}^{i u}\right)>$ $W^{a}\left(a b c_{l}^{i}\right)$ and $W^{b}\left(a b_{l}^{i u}\right)>W^{b}\left(a b c_{l}^{i}\right)$, and we can see that this coalitional deviation is not meaningful. If pollution is global, then country the dirty country $a$ would not agree to be a part of a fully integrated world, and it would rather be an outsider of either deep or shallow customs union of clean countries than join them.

Based on the above, we conclude that $\Omega^{a b i u}$ is a CPNE if pollution is local, and it is a CPNE if pollution is global and $\lambda \in(0.008,0.1]$.

$$
\Omega^{b c u} \equiv\left\{\sigma_{a}^{u}=\{\varnothing, \varnothing\}, \sigma_{b}^{u}=\left\{\varnothing, c^{u}\right\}, \sigma_{c}^{u}=\left\{\varnothing, b^{u}\right\}\right\}
$$

$\Omega^{b c u}$ is a Nash Equilibria for both local and global levels of pollution. 


\section{PROOF:}

country a $=\{\varnothing, \varnothing\} \stackrel{\text { change }}{\longrightarrow}\left\{b^{u}, \varnothing\right\} /\left\{b^{i u}, \varnothing\right\} /\left\{\varnothing, c^{u}\right\} /\left\{\varnothing, c^{i u}\right\} /\left\{b^{u}, c^{u}\right\} /\left\{b^{i u}, c^{i u}\right\} \stackrel{\text { result }}{\longrightarrow}$ no change in $a$ 's welfare

We can conclude, that country $a$ has no incentive to change its announcement.

country $\mathrm{b}=\left\{\varnothing, c^{u}\right\} \stackrel{\text { change }}{\longrightarrow}\left\{a^{u}, c^{u}\right\} \stackrel{\text { result }}{\longrightarrow}$ no change in $b$ 's welfare

country $\mathrm{b}=\left\{\varnothing, c^{u}\right\} \stackrel{\text { change }}{\longrightarrow}\left\{a^{u}, \varnothing\right\} /\left\{a^{i u}, \varnothing\right\} /\{\varnothing, \varnothing\} /\left\{a^{i u}, c^{i u}\right\} /\left\{\varnothing, c^{i u}\right\} \stackrel{\text { result }}{\longrightarrow} W^{b}\left(b c_{\theta}^{u}\right)>W^{b}\left(N_{\theta}\right)$

We can conclude, that country $b$ has no incentive to change its announcement.

country $\mathrm{c}=\left\{\varnothing, b^{u}\right\} \stackrel{\text { change }}{\longrightarrow}\left\{a^{u}, b^{u}\right\} \stackrel{\text { result }}{\longrightarrow}$ no change in $c$ 's welfare

country $\mathrm{c}=\left\{\varnothing, b^{u}\right\} \stackrel{\text { change }}{\longrightarrow}\left\{a^{u}, \varnothing\right\} /\left\{a^{i u}, \varnothing\right\} /\{\varnothing, \varnothing\} /\left\{a^{i u}, b^{i u}\right\} /\left\{\varnothing, b^{i u}\right\} \stackrel{\text { result }}{\longrightarrow} W^{c}\left(b c_{\theta}^{u}\right)>W^{c}\left(N_{\theta}\right)$

We can conclude, that country $c$ has no incentive to change its announcement.

Based on the above, $\Omega^{b c u}$ is a Nash Equilibria for both local and global levels of pollution.

$\Omega^{b c u}$ is not a CPNE for both local and global levels of pollution.

\section{PROOF:}

Suppose, that members add an environmental clause to their agreement, then $W^{b}\left(b c_{\theta}^{i u}\right)=W^{c}\left(b c_{\theta}^{i u}\right)>$ $W^{b}\left(b c_{\theta}^{u}\right)=W^{c}\left(b c_{\theta}^{u}\right)$, and we can conclude that $\Omega^{b c u}$ is not a CPNE for both local and global levels of pollution.

$$
\Omega^{b c i u} \equiv\left\{\sigma_{a}^{i u}=\{\varnothing, \varnothing\}, \sigma_{b}^{i u}=\left\{\varnothing, c^{i u}\right\}, \sigma_{c}^{i u}=\left\{\varnothing, b^{i u}\right\}\right\}
$$

$\Omega^{\text {bciu }}$ is a Nash Equilibria for both local and global levels of pollution.

\section{PROOF:}

country a $=\{\varnothing, \varnothing\} \stackrel{\text { change }}{\longrightarrow}\left\{b^{u}, \varnothing\right\} /\left\{b^{i u}, \varnothing\right\} /\left\{\varnothing, c^{u}\right\} /\left\{\varnothing, c^{i u}\right\} /\left\{b^{u}, c^{u}\right\} /\left\{b^{i u}, c^{i u}\right\} \stackrel{\text { result }}{\longrightarrow}$ no change in $a$ 's welfare

We can conclude, that country $a$ has no incentive to change its announcement.

country $\mathrm{b}=\left\{\varnothing, c^{i u}\right\} \stackrel{\text { change }}{\longrightarrow}\left\{a^{i u}, c^{i u}\right\} \stackrel{\text { result }}{\longrightarrow}$ no change in $b$ 's welfare

country $\mathrm{b}=\left\{\varnothing, c^{i u}\right\} \stackrel{\text { change }}{\longrightarrow}\left\{a^{u}, \varnothing\right\} /\left\{a^{i u}, \varnothing\right\} /\{\varnothing, \varnothing\} /\left\{a^{u}, c^{u}\right\} /\left\{\varnothing, c^{u}\right\} \stackrel{\text { result }}{\longrightarrow} W^{b}\left(b c_{\theta}^{i u}\right)>W^{b}\left(N_{\theta}\right)$

We can conclude, that country $b$ has no incentive to change its announcement.

country $\mathrm{c}=\left\{\varnothing, b^{i u}\right\} \stackrel{\text { change }}{\longrightarrow}\left\{a^{i u}, b^{i u}\right\} \stackrel{\text { result }}{\longrightarrow}$ no change in $c^{\prime}$ 's welfare

country c $=\left\{\varnothing, b^{i u}\right\} \stackrel{\text { change }}{\longrightarrow}\left\{a^{u}, \varnothing\right\} /\left\{a^{i u}, \varnothing\right\} /\{\varnothing, \varnothing\} /\left\{a^{u}, b^{u}\right\} /\left\{\varnothing, b^{u}\right\} \stackrel{\text { result }}{\longrightarrow} W^{c}\left(b c_{\theta}^{i u}\right)>W^{c}\left(N_{\theta}\right)$ 
We can conclude, that country $c$ has no incentive to change its announcement.

Based on the above, $\Omega^{b c i u}$ is a Nash Equilibria for both local and global levels of pollution.

$\Omega^{\text {bciu }}$ is not a CPNE if pollution is local and if pollution is global and $\lambda \in(0.008,0.1]$.

PROOF:

Either member can form either shallow or deep union with the only dirty player, exclude the other clean country, and improve its welfare as follows:

$W^{b}\left(a b_{\theta}^{i u}\right)=W^{c}\left(a c_{\theta}^{i u}\right)>W^{b}\left(b c_{\theta}^{i u}\right)=W^{c}\left(b c_{\theta}^{i u}\right)$ or $W^{b}\left(a b_{\theta}^{u}\right)=W^{c}\left(a c_{\theta}^{u}\right)>W^{b}\left(b c_{\theta}^{i u}\right)=W^{c}\left(b c_{\theta}^{i u}\right)$.

The dirty country $a$ would happily agree to that for any level of lambda if pollution is local and for relatively high lambda if pollution is global. Based, on the above, we are confident to conclude that $\Omega^{b c i u}$ is not a CPNE if pollution is local and if pollution is global and $\lambda \in(0.008,0.1]$.

$\Omega^{\text {bciu }}$ is a CPNE if pollution is global and $\lambda \in(0,0.008]$.

PROOF:

To prove the above, in the next two steps we consider every possible deviation:

First, though either clean member of the world would prefer to deviate with the dirty player in the form of either deep or shallow trade union to gain a higher welfare, this deviation is not selfenforcing for relatively low levels of lambda. The dirty country $a$ has an incentive to deviate further into the no agreement scenario and improve its welfare.

Second, we consider the grand coalition, and we observe that the dirty country $a$ would not agree to be a part of a fully integrated world, and it would rather be an outsider of an integrated customs union of clean countries than join them. The dirty country $a$ would not mind to be a part of a shallow free trade agreement, but the clean countries are better off in a deep CU, so this deviation is not meaningful.

Based on the above, we can conclude that $\Omega^{b c i u}$ is a CPNE if pollution is global and $\lambda \in(0,0.008]$.

$$
\Omega^{F^{u}} \equiv\left\{\sigma_{a}^{u}=\left\{b^{u}, c^{u}\right\}, \sigma_{b}^{u}=\left\{a^{u}, c^{u}\right\}, \sigma_{c}^{u}=\left\{a^{u}, b^{u}\right\}\right\}
$$

$\Omega^{\digamma^{u}}$ is not a Nash Equilibria for both local and global levels of pollution.

PROOF: 
First, we consider the case of local pollution, and we observe that the dirty country $a$ can unilaterally change its announcement and improve its welfare:

country a $=\left\{b^{u}, c^{u}\right\} \stackrel{\text { change }}{\longrightarrow}\left\{b^{u}, \varnothing\right\} /\left\{\varnothing, c^{u}\right\} \stackrel{\text { result }}{\longrightarrow} W^{a}\left(a b_{l}^{u}\right)=W^{a}\left(a c_{l}^{u}\right)>W^{a}\left(a b c_{l}\right) \& W^{b}\left(a b_{l}^{u}\right)=$ $W^{c}\left(a c_{l}^{u}\right)>W^{b}\left(a b c_{l}\right)=W^{c}\left(a b c_{l}\right)$.

Country $a$ is indifferent between these announcements, and the lucky country, $b$ or $c$, would improve its welfare. The unlucky one would be simply excluded.

Now, we consider the case of global pollution. In this case, either clean country can improve its welfare by excluding the dirty country $a$ :

country $\mathrm{b}=\left\{a^{u}, c^{u}\right\} \stackrel{\text { change }}{\longrightarrow}\left\{\varnothing, c^{u}\right\} \stackrel{\text { result }}{\longrightarrow} W^{b}\left(b c_{g}^{u}\right)>W^{b}\left(a b c_{g}\right)$

country $\mathrm{c}=\left\{a^{u}, b^{u}\right\} \stackrel{\text { change }}{\longrightarrow}\left\{\varnothing, b^{u}\right\} \stackrel{\text { result }}{\longrightarrow} W^{c}\left(b c_{g}^{u}\right)>W^{c}\left(a b c_{g}\right)$

We can conclude, that either of the clean countries can improve its welfare by calling another clean country only. Clean countries would prefer to exclude the dirty partner if pollution is global. Based on the above, we are confident to conclude that $\Omega^{\digamma^{u}}$ is not a Nash Equilibria for both local and global levels of pollution.

$$
\Omega^{F^{i u}} \equiv\left\{\sigma_{a}^{i u}=\left\{b^{i u}, c^{i u}\right\}, \sigma_{b}^{i u}=\left\{a^{i u}, c^{i u}\right\}, \sigma_{c}^{i u}=\left\{a^{i u}, b^{i u}\right\}\right\}
$$

$\Omega^{\digamma^{i u}}$ is not a Nash Equilibria for both local and global levels of pollution.

\section{PROOF:}

First, we prove that it is not a Nash equilibria if pollution is local. The dirty country $a$ can improve its welfare by announcing only one out of two clean countries. The lucky clean country would prefer to form an integrated union with country $a$ versus the union with another clean country. We can conclude, that $\Omega^{\digamma^{i u}}$ is not a Nash Equilibria if pollution is local.

Now, we show that it is not a Nash equilibria if pollution is global as well. The dirty country $a$ would prefer to be an outsider of an integrated agreement between two clean countries than participate in a fully integrated world, $W^{a}\left(a b c_{g}^{i}\right)<W^{a}\left(b c_{g}^{i u}\right)$. Based on that we conclude, that $\Omega^{\digamma^{i u}}$ is not a Nash Equilibria if pollution is global. 


\section{A. 3.9.2.4 The Choice between Deep and Shallow FTAs}

Welfare effects of various type of deep and shallow trade agreements:

$W^{a}\left(a_{l}^{h}\right)>W^{a}\left(a b_{l}\right)>W^{a}\left(a b_{l}^{i}\right)>W^{a}\left(N_{l}\right)>W^{a}\left(a_{l}^{h i}\right)>W^{a}\left(a b c_{l}\right)>W^{a}\left(b_{l}^{h}\right)>W^{a}\left(a b c_{l}^{i}\right)>W^{a}\left(b c_{l}^{i}\right)>$ $W^{a}\left(b c_{l}\right)>W^{a}\left(b_{l}^{h i}\right)$ Country a, local

$W^{a}\left(a_{g}^{h}\right)>W^{a}\left(a b_{g}\right)>W^{a}\left(a b c_{g}\right)>W^{a}\left(N_{g}\right) \stackrel{\lambda \in(0,0.053]}{>} W^{a}\left(a b_{g}^{i}\right)>W^{a}\left(b_{g}^{h}\right) \stackrel{\lambda \in(0,0.084]}{>} W^{a}\left(b c_{g}^{i}\right)>$ $W^{a}\left(b c_{g}\right)>W^{a}\left(a_{g}^{h i}\right)>W^{a}\left(a b c_{g}^{i}\right)>W^{a}\left(b_{g}^{h i}\right)$ Country a, global $\& \lambda \in(0,0.053]$

$W^{a}\left(a_{g}^{h}\right)>W^{a}\left(a b_{g}\right)>W^{a}\left(a b c_{g}\right)>W^{a}\left(a b_{g}^{i}\right) \stackrel{\lambda \in(0.053,0.1]}{>} W^{a}\left(N_{g}\right)>W^{a}\left(b_{g}^{h}\right) \stackrel{\lambda \in(0,0.084]}{>} W^{a}\left(b c_{g}^{i}\right)>$ $W^{a}\left(b c_{g}\right)>W^{a}\left(a_{g}^{h i}\right)>W^{a}\left(a b c_{g}^{i}\right)>W^{a}\left(b_{g}^{h i}\right)$ Country a, global \& $\lambda \in(0.053,0.084]$

$W^{a}\left(a_{g}^{h}\right)>W^{a}\left(a b_{g}\right)>W^{a}\left(a b c_{g}\right)>W^{a}\left(a b_{g}^{i}\right) \stackrel{\lambda \in(0.053,0.1]}{>} W^{a}\left(N_{g}\right)>W^{a}\left(b c_{g}^{i}\right) \stackrel{\lambda \in(0.084,0.1]}{>} W^{a}\left(b_{g}^{h}\right)>$ $W^{a}\left(b c_{g}\right)>W^{a}\left(a_{g}^{h i}\right)>W^{a}\left(a b c_{g}^{i}\right)>W^{a}\left(b_{g}^{h i}\right)$ Country a, global $\& \lambda \in(0.084,0.1]$ $W^{b}\left(b_{l}^{h i}\right)>W^{b}\left(b_{l}^{h}\right)>W^{b}\left(a b c_{l}^{i}\right)>W^{b}\left(a b_{l}^{i}\right)>W^{b}\left(a b_{l}\right)>W^{b}\left(a b c_{l}\right)>W^{b}\left(b c_{l}\right)>W^{b}\left(b c_{l}^{i}\right)>W^{b}\left(a_{l}^{h i}\right)>$ $W^{b}\left(a_{l}^{h}\right)>W^{b}\left(N_{l}\right)$ Country b, local $W^{b}\left(b_{g}^{h i}\right)>W^{b}\left(a b c_{g}^{i}\right)>W^{b}\left(a_{g}^{h i}\right)>W^{b}\left(a b_{g}^{i}\right)>W^{b}\left(b_{g}^{h}\right) \stackrel{\lambda \in(0,0.065]}{>} W^{b}\left(b c_{g}^{i}\right)>W^{b}\left(b c_{g}\right)>W^{b}\left(a b_{g}\right)>$ $W^{b}\left(N_{g}\right)>W^{b}\left(a b c_{g}\right)>W^{b}\left(a_{g}^{h}\right)$ Country b, global $\& \lambda \in(0,0.065]$ $W^{b}\left(b_{g}^{h i}\right)>W^{b}\left(a b c_{g}^{i}\right)>W^{b}\left(a_{g}^{h i}\right)>W^{b}\left(a b_{g}^{i}\right)>W^{b}\left(b c_{g}^{i}\right) \stackrel{\lambda \in(0.065,0.1]}{>} W^{b}\left(b_{g}^{h}\right)>W^{b}\left(b c_{g}\right)>W^{b}\left(a b_{g}\right)>$ $W^{b}\left(N_{g}\right)>W^{b}\left(a b c_{g}\right)>W^{b}\left(a_{g}^{h}\right)$ Country b, global \& $\lambda \in(0.065,0.1]$ $W^{c}\left(a b c_{l}^{i}\right)>W^{c}\left(a b c_{l}\right)>W^{c}\left(b c_{l}\right)>W^{c}\left(b c_{l}^{i}\right)>W^{c}\left(a_{l}^{h i}\right)>W^{c}\left(b_{l}^{h i}\right)>W^{c}\left(a_{l}^{h}\right)>W^{c}\left(N_{l}\right)>W^{c}\left(b_{l}^{h}\right)>$ $W^{c}\left(a b_{l}^{i}\right)>W^{c}\left(a b_{l}\right)$ Country c, local $W^{c}\left(a b c_{g}^{i}\right)>W^{c}\left(a_{g}^{h i}\right)>W^{c}\left(b_{g}^{h i}\right)>W^{c}\left(a b_{g}^{i}\right)>W^{c}\left(b c_{g}^{i}\right)>W^{c}\left(b c_{g}\right)>W^{c}\left(N_{g}\right)>W^{c}\left(a b c_{g}\right)>W^{c}\left(b_{g}^{h}\right)>$ $W^{c}\left(a_{g}^{h}\right)>W^{c}\left(a b_{g}\right)$ Country c, global ${ }^{44}$

\footnotetext{
${ }^{44}$ In this game, to assure positive imports of good A by country c when we have country b as a hub, we had to restrict $\lambda$ further, $\lambda \in(0,0.01]$ (similar to I game)
} 


\begin{tabular}{|c|c|}
\hline Announcement Profiles & Shallow \& Deep Trade Agreements \\
\hline \hline$\Omega^{\Phi} \equiv\left\{\sigma_{a}=\{\varnothing, \varnothing\}, \sigma_{b}=\{\varnothing, \varnothing\}, \sigma_{c}=\{\varnothing, \varnothing\}\right\}$ & $\langle\Phi\rangle$ \\
\hline$\Omega^{a b} \equiv\left\{\sigma_{a}=\{b, \varnothing\}, \sigma_{b}=\{a, \varnothing\}, \sigma_{c}=\{\varnothing, \varnothing\}\right\}$ & $\langle a b\rangle$ \\
\hline$\Omega^{a b i} \equiv\left\{\sigma_{a}^{i}=\left\{b^{i}, \varnothing\right\}, \sigma_{b}^{i}=\left\{a^{i}, \varnothing\right\}, \sigma_{c}^{i}=\{\varnothing, \varnothing\}\right\}$ & $\langle a b i\rangle$ \\
\hline$\Omega^{b c} \equiv\left\{\sigma_{a}=\{\varnothing, \varnothing\}, \sigma_{b}=\{\varnothing, c\}, \sigma_{c}=\{\varnothing, b\}\right\}$ & $\langle b c\rangle$ \\
\hline$\Omega^{b c i} \equiv\left\{\sigma_{a}^{i}=\{\varnothing, \varnothing\}, \sigma_{b}^{i}=\left\{\varnothing, c^{i}\right\}, \sigma_{c}^{i}=\left\{\varnothing, b^{i}\right\}\right\}$ & $\langle b c i\rangle$ \\
\hline$\Omega^{a h} \equiv\left\{\sigma_{a}=\{b, c\}, \sigma_{b}=\{a, \varnothing\}, \sigma_{c}=\{a, \varnothing\}\right\}$ & $\langle a h\rangle$ \\
\hline$\Omega^{a h i} \equiv\left\{\sigma_{a}^{i}=\left\{b^{i}, c^{i}\right\}, \sigma_{b}^{i}=\left\{a^{i}, \varnothing\right\}, \sigma_{c}^{i}=\left\{a^{i}, \varnothing\right\}\right\}$ & $\langle b h\rangle$ \\
\hline$\Omega^{b h} \equiv\left\{\sigma_{a}=\{b, \varnothing\}, \sigma_{b}=\{a, c\}, \sigma_{c}=\{\varnothing, b\}\right\}$ & $\langle b h i\rangle$ \\
\hline$\Omega^{b h i} \equiv\left\{\sigma_{a}^{i}=\left\{b^{i}, \varnothing\right\}, \sigma_{b}^{i}=\left\{a^{i}, c^{i}\right\}, \sigma_{c}^{i}=\left\{\varnothing, b^{i}\right\}\right\}$ & $\langle F\rangle$ \\
\hline$\Omega^{F} \equiv\left\{\sigma_{a}=\{b, c\}, \sigma_{b}=\{a, c\}, \sigma_{c}=\{a, b\}\right\}$ & $\left\langle F^{i}\right\rangle$ \\
\hline$\Omega^{F^{i}} \equiv\left\{\sigma_{a}^{i}=\left\{b^{i}, c^{i}\right\}, \sigma_{b}^{i}=\left\{a^{i}, c^{i}\right\}, \sigma_{c}^{i}=\left\{a^{i}, b^{i}\right\}\right\}$ & \\
\hline
\end{tabular}

$$
\Omega^{\Phi} \equiv\left\{\sigma_{a}=\{\varnothing, \varnothing\}, \sigma_{b}=\{\varnothing, \varnothing\}, \sigma_{c}=\{\varnothing, \varnothing\}\right\}
$$

$\Omega^{\Phi}$ is a Nash Equilibria for both local and global levels of pollution.

PROOF:

Countries cannot get better off by unilaterally changing the announcements; countries have no incentive to announce any other country unless they are going to be announced back.

$\Omega^{\Phi}$ is not a CPNE for both local and global levels of pollution.

PROOF:

Any two countries can be better off by announcing each other.

$$
\Omega^{a b} \equiv\left\{\sigma_{a}=\{b, \varnothing\}, \sigma_{b}=\{a, \varnothing\}, \sigma_{c}=\{\varnothing, \varnothing\}\right\}
$$

$\Omega^{a b}$ is a Nash Equilibria for both local and global levels of pollution.

PROOF:

country a $=\{b, \varnothing\} \stackrel{\text { change }}{\longrightarrow}\{b, c\} \stackrel{\text { result }}{\longrightarrow}$ no change in $a$ 's welfare

country a $=\{b, \varnothing\} \stackrel{\text { change }}{\longrightarrow}\{\varnothing, c\} /\left\{\varnothing, c^{i}\right\} /\left\{b^{i}, \varnothing\right\} /\{\varnothing, \varnothing\} /\left\{b^{i}, c^{i}\right\} \stackrel{\text { result }}{\longrightarrow} W^{a}\left(a b_{\theta}\right)>W^{a}\left(N_{\theta}\right)$

We can conclude, that country $a$ has no incentive to change its announcement.

country $\mathrm{b}=\{a, \varnothing\} \stackrel{\text { change }}{\longrightarrow}\{a, c\} \stackrel{\text { result }}{\longrightarrow}$ no change in $b$ 's welfare

country $\mathrm{b}=\{a, \varnothing\} \stackrel{\text { change }}{\longrightarrow}\{\varnothing, c\} /\left\{\varnothing, c^{i}\right\} /\left\{a^{i}, \varnothing\right\} /\{\varnothing, \varnothing\} /\left\{a^{i}, c^{i}\right\} \stackrel{\text { result }}{\longrightarrow} W^{b}\left(a b_{\theta}\right)>W^{b}\left(N_{\theta}\right)$ 
We can conclude, that country $b$ has no incentive to change its announcement.

country $\mathrm{c}=\{\varnothing, \varnothing\} \stackrel{\text { change }}{\longrightarrow}\{a, \varnothing\} /\left\{a^{i}, \varnothing\right\} /\{\varnothing, b\} /\left\{\varnothing, b^{i}\right\} /\{a, b\} /\left\{a^{i}, b^{i}\right\} \stackrel{\text { result }}{\longrightarrow}$ no change in $c^{\prime} s$ welfare

We can conclude, that country $c$ has no incentive to change its announcement.

Based on the above, we conclude that $\Omega^{a b}$ is a Nash Equilibria for both local and global levels of pollution.

$\Omega^{a b}$ is not a CPNE for both local and global levels of pollution.

\section{PROOF:}

To prove the above, we consider the coalitional deviation of two symmetric clean countries, country $b$ and country $c$, then $\Omega \equiv\left\{\sigma_{a}=\{b, \varnothing\}, \sigma_{b}=\{a, c\}, \sigma_{c}=\{\varnothing, b\}\right\}$, and $W^{b}\left(b_{\theta}^{h}\right)>W^{b}\left(a b_{\theta}\right)$ and $W^{c}\left(b_{\theta}^{h}\right)>W^{c}\left(a b_{\theta}\right)$. We can see, that country $c$ would prefer to be a spoke versus being an outsider of the shallow trade agreement between two other countries. We can conclude that $\Omega^{a b}$ is not a CPNE for both local and global levels of pollution.

$$
\Omega^{a b i} \equiv\left\{\sigma_{a}^{i}=\left\{b^{i}, \varnothing\right\}, \sigma_{b}^{i}=\left\{a^{i}, \varnothing\right\}, \sigma_{c}^{i}=\{\varnothing, \varnothing\}\right\}
$$

$\Omega^{a b i}$ is a Nash Equilibria if pollution is local and if pollution is global and $\lambda \in(0.053,0.1]$.

\section{PROOF:}

country a $=\left\{b^{i}, \varnothing\right\} \stackrel{\text { change }}{\longrightarrow}\left\{b^{i}, c^{i}\right\} \stackrel{\text { result }}{\longrightarrow}$ no change in $a$ 's welfare

country $\mathrm{a}=\left\{b^{i}, \varnothing\right\} \stackrel{\text { change }}{\longrightarrow}\{\varnothing, c\} /\left\{\varnothing, c^{i}\right\} /\{b, \varnothing\} /\{\varnothing, \varnothing\} /\{b, c\} \stackrel{\text { result }}{\longrightarrow} W^{a}\left(a b_{l}^{i}\right)>W^{a}\left(N_{l}\right) \& W^{a}\left(a b_{g}^{i}\right)>$ $W^{a}\left(N_{g}\right)$ if $\lambda \in(0.053,0.1]$.

We can conclude, that country $a$ has no incentive to change its announcement if pollution is local. Also, country $a$ has no incentive to alter its announcement if pollution is global and $\lambda \in$ $(0.053,0.1]$.

country $\mathrm{b}=\left\{a^{i}, \varnothing\right\} \stackrel{\text { change }}{\longrightarrow}\left\{a^{i}, c^{i}\right\} \stackrel{\text { result }}{\longrightarrow}$ no change in $b$ 's welfare

country $\mathrm{b}=\left\{a^{i}, \varnothing\right\} \stackrel{\text { change }}{\longrightarrow}\{\varnothing, c\} /\left\{\varnothing, c^{i}\right\} /\{a, \varnothing\} /\{\varnothing, \varnothing\} /\{a, c\} \stackrel{\text { result }}{\longrightarrow} W^{b}\left(a b_{\theta}^{i}\right)>W^{b}\left(N_{\theta}\right)$

We can conclude, that country $b$ has no incentive to change its announcement.

country $\mathrm{c}=\{\varnothing, \varnothing\} \stackrel{\text { change }}{\longrightarrow}\{a, \varnothing\} /\left\{a^{i}, \varnothing\right\} /\{\varnothing, b\} /\left\{\varnothing, b^{i}\right\} /\{a, b\} /\left\{a^{i}, b^{i}\right\} \stackrel{\text { result }}{\longrightarrow}$ no change in $c^{\prime} s$ welfare 
We can conclude, that country $c$ has no incentive to change its announcement.

Based on the above, we conclude $\Omega^{a b i}$ is a Nash Equilibria if pollution is local and if pollution is global and $\lambda \in(0.053,0.1]$.

$\Omega^{a b i}$ is not a Nash Equilibria if the pollution is global and $\lambda \in(0,0.053]$.

PROOF:

country a $=\left\{b^{i}, \varnothing\right\} \stackrel{\text { change }}{\longrightarrow}\{\varnothing, c\} /\left\{\varnothing, c^{i}\right\} /\{b, \varnothing\} /\{\varnothing, \varnothing\} /\{b, c\} \stackrel{\text { result }}{\longrightarrow} W^{a}\left(a b_{g}^{i}\right)<W^{a}\left(N_{g}\right)$ if $\lambda \in$ $(0,0.053]$.

We can conclude, that country $a$ can unilaterally change its announcement and gain a higher level of welfare.

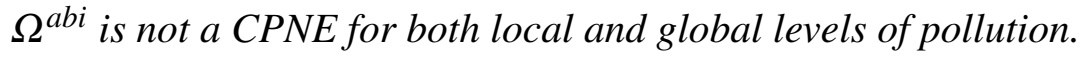

PROOF:

To prove the above, we examine the coalitional deviation of two symmetric clean countries, then $\Omega \equiv\left\{\sigma_{a}^{i}=\left\{b^{i}, \varnothing\right\}, \sigma_{b}^{i}=\left\{a^{i}, c^{i}\right\}, \sigma_{c}^{i}=\left\{\varnothing, b^{i}\right\}\right\}$, and $W^{b}\left(b_{\theta}^{h i}\right)>W^{b}\left(a b_{\theta}^{i}\right)$ and $W^{c}\left(b_{\theta}^{h i}\right)>W^{c}\left(a b_{\theta}^{i}\right)$. We can see, that country $c$ would prefer to be a spoke versus being an outsider. We can conclude that $\Omega^{a b i}$ is not a CPNE for both local and global levels of pollution.

$$
\Omega^{b c} \equiv\left\{\sigma_{a}=\{\varnothing, \varnothing\}, \sigma_{b}=\{\varnothing, c\}, \sigma_{c}=\{\varnothing, b\}\right\}
$$

$\Omega^{b c}$ is a Nash Equilibria for both local and global levels of pollution.

PROOF:

country a $=\{\varnothing, \varnothing\} \stackrel{\text { change }}{\longrightarrow}\{b, \varnothing\} /\left\{b^{i}, \varnothing\right\} /\{\varnothing, c\} /\left\{\varnothing, c^{i}\right\} /\{b, c\} /\left\{b^{i}, c^{i}\right\} \stackrel{\text { result }}{\longrightarrow}$ no change in $a$ 's welfare

We can conclude, that country $a$ has no incentive to change its announcement.

country $\mathrm{b}=\{\varnothing, c\} \stackrel{\text { change }}{\longrightarrow}\{a, c\} \stackrel{\text { result }}{\longrightarrow}$ no change in $b$ 's welfare

country $\mathrm{b}=\{\varnothing, c\} \stackrel{\text { change }}{\longrightarrow}\{a, \varnothing\} /\left\{a^{i}, \varnothing\right\} /\{\varnothing, \varnothing\} /\left\{\varnothing, c^{i}\right\} /\left\{a^{i}, c^{i}\right\} \stackrel{\text { result }}{\longrightarrow} W^{b}\left(b c_{\theta}\right)>W^{b}\left(N_{\theta}\right)$

We can conclude, that country $b$ has no incentive to change its announcement.

country $\mathrm{c}=\{\varnothing, b\} \stackrel{\text { change }}{\longrightarrow}\{a, b\} \stackrel{\text { result }}{\longrightarrow}$ no change in $c$ 's welfare

country $\mathrm{c}=\{\varnothing, b\} \stackrel{\text { change }}{\longrightarrow}\{a, \varnothing\} /\left\{a^{i}, \varnothing\right\} /\{\varnothing, \varnothing\} /\left\{\varnothing, b^{i}\right\} /\left\{a^{i}, b^{i}\right\} \stackrel{\text { result }}{\longrightarrow} W^{c}\left(b c_{\theta}\right)>W^{c}\left(N_{\theta}\right)$

We can conclude, that country $c$ has no incentive to change its announcement. 
Based on the above, we conclude that $\Omega^{b c}$ is a Nash Equilibria for both local and global levels of pollution.

$\Omega^{b c}$ is not a CPNE for both local and global levels of pollution.

PROOF:

Country $a$ can form a coalition with either clean country, and in this case welfare levels would be as follows: $W^{b}\left(b_{\theta}^{h}\right)=W^{c}\left(c_{\theta}^{h}\right)>W^{b}\left(b c_{\theta}\right)=W^{c}\left(b c_{\theta}\right)$ and $W^{a}\left(b_{\theta}^{h}\right)=W^{a}\left(c_{\theta}^{h}\right)>W^{a}\left(b c_{\theta}\right)$. We can conclude that $\Omega^{b c}$ is not a CPNE for both local and global levels of pollution.

$$
\Omega^{b c i} \equiv\left\{\sigma_{a}^{i}=\{\varnothing, \varnothing\}, \sigma_{b}^{i}=\left\{\varnothing, c^{i}\right\}, \sigma_{c}^{i}=\left\{\varnothing, b^{i}\right\}\right\}
$$

$\Omega^{b c i}$ is a Nash Equilibria for both local and global levels of pollution.

\section{PROOF:}

country a $=\{\varnothing, \varnothing\} \stackrel{\text { change }}{\longrightarrow}\{b, \varnothing\} /\left\{b^{i}, \varnothing\right\} /\{\varnothing, c\} /\left\{\varnothing, c^{i}\right\} /\{b, c\} /\left\{b^{i u}, c^{i u}\right\} \stackrel{\text { result }}{\longrightarrow}$ no change in $a^{\prime} s$ welfare

We can conclude, that country $a$ has no incentive to change its announcement.

country $\mathrm{b}=\left\{\varnothing, c^{i}\right\} \stackrel{\text { change }}{\longrightarrow}\left\{a^{i}, c^{i}\right\} \stackrel{\text { result }}{\longrightarrow}$ no change in $b$ 's welfare

country $\mathrm{b}=\left\{\varnothing, c^{i}\right\} \stackrel{\text { change }}{\longrightarrow}\{a, \varnothing\} /\left\{a^{i}, \varnothing\right\} /\{\varnothing, \varnothing\} /\{\varnothing, c\} /\{a, c\} \stackrel{\text { result }}{\longrightarrow} W^{b}\left(b c_{\theta}^{i}\right)>W^{b}\left(N_{\theta}\right)$

We can conclude, that country $b$ has no incentive to change its announcement.

country $\mathrm{c}=\left\{\varnothing, b^{i}\right\} \stackrel{\text { change }}{\longrightarrow}\left\{a^{i}, b^{i}\right\} \stackrel{\text { result }}{\longrightarrow}$ no change in $c$ 's welfare

country $\mathrm{c}=\left\{\varnothing, b^{i}\right\} \stackrel{\text { change }}{\longrightarrow}\{a, \varnothing\} /\left\{a^{i}, \varnothing\right\} /\{\varnothing, \varnothing\} /\{\varnothing, b\} /\{a, b\} \stackrel{\text { result }}{\longrightarrow} W^{c}\left(b c_{\theta}^{i}\right)>W^{c}\left(N_{\theta}\right)$

We can conclude, that country $c$ has no incentive to change its announcement.

Based on the above, we conclude that $\Omega^{b c i}$ is a Nash Equilibria for both local and global levels of pollution.

$\Omega^{b c i}$ is not a CPNE if pollution is local.

PROOF:

Members can improve their welfare levels by removing an environmental clause from their agreement, then $\Omega \equiv\left\{\sigma_{a}=\{\varnothing, \varnothing\}, \sigma_{b}=\{\varnothing, c\}, \sigma_{c}=\{\varnothing, b\}\right\}$, and $W^{b}\left(b c_{l}\right)=W^{c}\left(b c_{l}\right)>W^{b}\left(b c_{l}^{i}\right)=$ $W^{c}\left(b c_{l}^{i}\right)$. We can conclude that $\Omega^{b c i}$ is not a CPNE if pollution is local.

$\Omega^{\text {bci }}$ is a CPNE if pollution is global. 


\section{PROOF:}

To prove the above, we consider every possible deviation in the following five steps:

First, we assume that one clean and one dirty country deviate in the firm of a deep bilateral trade agreement, then $\Omega \equiv\left\{\sigma_{a}^{i}=\left\{b^{i}, \varnothing\right\}, \sigma_{b}^{i}=\left\{a^{i}, \varnothing\right\}, \sigma_{c}^{i}=\left\{\varnothing, b^{i}\right\}\right\}$, and $W^{b}\left(a b_{g}^{i}\right)>W^{b}\left(b c_{g}^{i}\right) \&$ $\mathrm{W}^{a}\left(a b_{g}^{i}\right)>W^{a}\left(b c_{g}^{i}\right)$. However, this deviation is not self-enforcing. Country $b$ can unilaterally change its announcement and become a hub, then $\Omega \equiv\left\{\sigma_{a}^{i}=\left\{b^{i}, \varnothing\right\}, \sigma_{b}^{i}=\left\{a^{i}, c^{i}\right\}, \sigma_{c}^{i}=\left\{\varnothing, b^{i}\right\}\right\}$, and $W^{b}\left(a b_{g}^{i}\right)<W^{b}\left(b_{g}^{h i}\right) \& W^{a}\left(b c_{g}^{i}\right)>W^{a}\left(b_{g}^{h i}\right)$. We can see that the initial deviation is not selfenforcing, and the dirty country $a$ would not agree to form an integrated bilateral trade agreement with any clean partner.

Second, we consider a shallow trade agreement between one clean and one dirty country, then $W^{b}\left(a b_{g}\right)=W^{c}\left(a c_{g}\right)<W^{b}\left(b c_{g}^{i}\right)=W^{c}\left(b c_{g}^{i}\right)$. We can see that clean countries are not interested.

Third, we examine whether members of this deep trade agreement are interested in removing an environmental clause, then $W^{b}\left(b c_{g}\right)=W^{c}\left(b c_{g}\right)<W^{b}\left(b c_{g}^{i}\right)=W^{c}\left(b c_{g}^{i}\right)$. We can see that clean countries prefer to sign a deep trade agreement if pollution exhibits global characteristics.

Fourth, we consider the grand coalition in the form of fully integrated world, and we observe that the dirty player would actually prefer to face either deep or shallow trade agreement between clean countries than join them.

Finally, we consider the grand coalition in the form of free trade world, and we observe that clean countries exhibit higher welfare levels in the bilateral deep trade agreement versus free trade world. Based on the above, we can conclude that $\Omega^{b c i}$ is a CPNE if pollution is global.

$$
\Omega^{a h} \equiv\left\{\sigma_{a}=\{b, c\}, \sigma_{b}=\{a, \varnothing\}, \sigma_{c}=\{a, \varnothing\}\right\}
$$

$\Omega^{\text {ah }}$ is a Nash Equilibria for both local and global levels of pollution.

\section{PROOF:}

country a $=\{b, c\} \stackrel{\text { change }}{\longrightarrow}\{b, \varnothing\} /\{\varnothing, c\} \stackrel{\text { result }}{\longrightarrow} W^{a}\left(a_{\theta}^{h}\right)>W^{a}\left(a b_{\theta}\right)=W^{a}\left(a c_{\theta}\right)$

country a $=\{b, c\} \stackrel{\text { change }}{\longrightarrow}\{\varnothing, \varnothing\} /\left\{b^{i}, c^{i}\right\} /\left\{b^{i}, \varnothing\right\} /\left\{\varnothing, c^{i}\right\} \stackrel{\text { result }}{\longrightarrow} W^{a}\left(a_{\theta}^{h}\right)>W^{a}\left(N_{\theta}\right)$

We can conclude, that country $a$ has no incentive to change its announcement.

country $\mathrm{b}=\{a, \varnothing\} \stackrel{\text { change }}{\longrightarrow}\{a, c\} \stackrel{\text { result }}{\longrightarrow}$ no change in $b$ 's welfare 
country $\mathrm{b}=\{a, \varnothing\} \stackrel{\text { change }}{\longrightarrow}\{\varnothing, \varnothing\} /\left\{a^{i}, c^{i}\right\} /\{\varnothing, c\} /\left\{\varnothing, c^{i}\right\} /\left\{a^{i}, \varnothing\right\} \stackrel{\text { result }}{\longrightarrow} W^{b}\left(a_{\theta}^{h}\right)>W^{b}\left(a c_{\theta}\right)$

We can conclude, that country $b$ has no incentive to change its announcement.

country $\mathrm{c}=\{a, \varnothing\} \stackrel{\text { change }}{\longrightarrow}\{a, b\} \stackrel{\text { result }}{\longrightarrow}$ no change in $c$ 's welfare

country c $=\{a, \varnothing\} \stackrel{\text { change }}{\longrightarrow}\{\varnothing, \varnothing\} /\left\{a^{i}, b^{i}\right\} /\{\varnothing, b\} /\left\{\varnothing, b^{i}\right\} /\left\{a^{i}, \varnothing\right\} \stackrel{\text { result }}{\longrightarrow} W^{c}\left(a_{\theta}^{h}\right)>W^{c}\left(a b_{\theta}\right)$

We can conclude, that country $c$ has no incentive to change its announcement.

Based on the above, we can conclude that $\Omega^{a h}$ is a Nash Equilibria for both local and global levels of pollution.

$\Omega^{\text {ah }}$ is not a CPNE for both local and global levels of pollution.

PROOF:

To prove the above, we examine the coalition of two clean countries, country $b$ and country $c$, to form a free trade world, then $\Omega \equiv\left\{\sigma_{a}=\{b, c\}, \sigma_{b}=\{a, c\}, \sigma_{c}=\{a, b\}\right\}$, and $W^{b}\left(a b c_{\theta}\right)>W^{b}\left(a_{\theta}^{h}\right)$ and $W^{c}\left(a b c_{\theta}\right)>W^{c}\left(a_{\theta}^{h}\right)$. We can see that clean countries would rather be a part of a free trade world than being spokes. We can conclude that $\Omega^{a h}$ is not a CPNE for both local and global levels of pollution.

$$
\Omega^{a h i} \equiv\left\{\sigma_{a}^{i}=\left\{b^{i}, c^{i}\right\}, \sigma_{b}^{i}=\left\{a^{i}, \varnothing\right\}, \sigma_{c}^{i}=\left\{a^{i}, \varnothing\right\}\right\}
$$

$\Omega^{\text {ahi }}$ is not a Nash Equilibria for both local and global levels of pollution.

PROOF:

country a $=\left\{b^{i}, c^{i}\right\} \stackrel{\text { change }}{\longrightarrow}\{\varnothing, \varnothing\} /\{b, c\} /\{b, \varnothing\} /\{\varnothing, c\} \stackrel{\text { result }}{\longrightarrow} W^{a}\left(a_{\theta}^{h i}\right)<W^{a}\left(N_{\theta}\right)$

We can conclude, that country $a$ would deviate, and based on that $\Omega^{a h i}$ is not a Nash Equilibria for both local and global levels of pollution.

$$
\Omega^{b h} \equiv\left\{\sigma_{a}=\{b, \varnothing\}, \sigma_{b}=\{a, c\}, \sigma_{c}=\{\varnothing, b\}\right\}
$$

$\Omega^{\text {bh }}$ is a Nash Equilibria for both local and global levels of pollution.

PROOF:

country $\mathrm{a}=\{b, \varnothing\} \stackrel{\text { change }}{\longrightarrow}\{b, c\} \stackrel{\text { result }}{\longrightarrow}$ no change in $a$ 's welfare

country a $=\{b, \varnothing\} \stackrel{\text { change }}{\longrightarrow}\{\varnothing, \varnothing\} /\left\{b^{i}, c^{i}\right\} /\{\varnothing, c\} /\left\{\varnothing, c^{i}\right\} /\left\{a^{i}, \varnothing\right\} \stackrel{\text { result }}{\longrightarrow} W^{a}\left(b_{\theta}^{h}\right)>W^{a}\left(b c_{\theta}\right)$

We can conclude, that country $a$ has no incentive to change its announcement. 
country $\mathrm{b}=\{a, c\} \stackrel{\text { change }}{\longrightarrow}\{a, \varnothing\} /\{\varnothing, c\} \stackrel{\text { result }}{\longrightarrow} W^{b}\left(b_{\theta}^{h}\right)>W^{b}\left(a b_{\theta}\right) \& W^{b}\left(b_{\theta}^{h}\right)>W^{b}\left(b c_{\theta}\right)$

country $\mathrm{b}=\{a, c\} \stackrel{\text { change }}{\longrightarrow}\{\varnothing, \varnothing\} /\left\{a^{i}, c^{i}\right\} /\left\{a^{i}, \varnothing\right\} /\left\{\varnothing, c^{i}\right\} \stackrel{\text { result }}{\longrightarrow} W^{b}\left(b_{\theta}^{h}\right)>W^{b}\left(N_{\theta}\right)$

We can conclude, that country $b$ has no incentive to change its announcement.

country $\mathrm{c}=\{\varnothing, b\} \stackrel{\text { change }}{\longrightarrow}\{a, b\} \stackrel{\text { result }}{\longrightarrow}$ no change in $c$ 's welfare

country $\mathrm{c}=\{\varnothing, b\} \stackrel{\text { change }}{\longrightarrow}\{\varnothing, \varnothing\} /\left\{a^{i}, b^{i}\right\} /\{a, \varnothing\} /\left\{a^{i}, \varnothing\right\} /\left\{\varnothing, b^{i}\right\} \stackrel{\text { result }}{\longrightarrow} W^{c}\left(b_{\theta}^{h}\right)>W^{c}\left(a b_{\theta}\right)$

We can conclude, that country $c$ has no incentive to change its announcement.

Based on the above, we conclude that $\Omega^{b h}$ is a Nash Equilibria for both local and global levels of pollution.

$\Omega^{\text {bh }}$ is not a CPNE for both local and global levels of pollution.

PROOF:

We prove the above by examining a coalitional deviation of countries $a$ and $c$, then $\Omega \equiv\left\{\sigma_{a}=\right.$ $\left.\{b, c\}, \sigma_{b}=\{a, c\}, \sigma_{c}=\{a, b\}\right\}$, then $W^{a}\left(a b c_{\theta}\right)>W^{a}\left(b_{\theta}^{h}\right)$ and $W^{c}\left(a b c_{\theta}\right)>W^{c}\left(b_{\theta}^{h}\right)$. We can see that both countries, the clean country $c$ and the dirty country $a$, would prefer to be a part of a free trade world versus being spokes. We can conclude that $\Omega^{b h}$ is a Nash Equilibria for both local and global levels of pollution.

$$
\Omega^{b h i} \equiv\left\{\sigma_{a}^{i}=\left\{b^{i}, \varnothing\right\}, \sigma_{b}^{i}=\left\{a^{i}, c^{i}\right\}, \sigma_{c}^{i}=\left\{\varnothing, b^{i}\right\}\right\}
$$

$\Omega^{\text {bhi }}$ is not a Nash Equilibria for both local and global levels of pollution.

PROOF:

country a $=\left\{b^{i}, \varnothing\right\} \stackrel{\text { change }}{\longrightarrow}\{\varnothing, \varnothing\} /\{b, c\} /\{b, \varnothing\} /\left\{\varnothing, c^{i}\right\} \stackrel{\text { result }}{\longrightarrow} W^{a}\left(b c_{\theta}^{i}\right)>W^{a}\left(b_{\theta}^{h i}\right)$

We can conclude, that country $a$ would deviate, and based on that $\Omega^{b h i}$ is not a Nash Equilibria for both local and global levels of pollution.

$$
\Omega^{F} \equiv\left\{\sigma_{a}=\{b, c\}, \sigma_{b}=\{a, c\}, \sigma_{c}=\{a, b\}\right\}
$$

$\Omega^{\digamma}$ is a Nash Equilibria for both local and global levels of pollution.

PROOF:

country a $=\{b, c\} \stackrel{\text { change }}{\longrightarrow}\{b, \varnothing\} /\{\varnothing, c\} \stackrel{\text { result }}{\longrightarrow} W^{a}\left(a b c_{\theta}\right)>W^{a}\left(b_{\theta}^{h}\right)=W^{a}\left(c_{\theta}^{h}\right)$

country a $=\{b, c\} \stackrel{\text { change }}{\longrightarrow}\{\varnothing, \varnothing\} /\left\{b^{i}, c^{i}\right\} /\left\{b^{i}, \varnothing\right\} /\left\{\varnothing, c^{i}\right\} \stackrel{\text { result }}{\longrightarrow} W^{a}\left(a b c_{\theta}\right)>W^{a}\left(b c_{\theta}\right)$ 
We can conclude, that country $a$ has no incentive to change its announcement.

country $\mathrm{b}=\{a, c\} \stackrel{\text { change }}{\longrightarrow}\{a, \varnothing\} \stackrel{\text { result }}{\longrightarrow} W^{b}\left(a b c_{\theta}\right)>W^{b}\left(a_{\theta}^{h}\right)$

country $\mathrm{b}=\{a, c\} \stackrel{\text { change }}{\longrightarrow}\{\varnothing, c\} \stackrel{\text { result }}{\longrightarrow} W^{b}\left(a b c_{\theta}\right)>W^{b}\left(c_{\theta}^{h}\right)$

country $\mathrm{b}=\{a, c\} \stackrel{\text { change }}{\longrightarrow}\{\varnothing, \varnothing\} /\left\{a^{i}, c^{i}\right\} /\left\{a^{i}, \varnothing\right\} /\left\{\varnothing, c^{i}\right\} \stackrel{\text { result }}{\longrightarrow} W^{b}\left(a b c_{\theta}\right)>W^{b}\left(a c_{\theta}\right)$

We can conclude, that country $b$ has no incentive to change its announcement.

country $\mathrm{c}=\{a, b\} \stackrel{\text { change }}{\longrightarrow}\{a, \varnothing\} \stackrel{\text { result }}{\longrightarrow} W^{c}\left(a b c_{\theta}\right)>W^{c}\left(a_{\theta}^{h}\right)$

country c $=\{a, b\} \stackrel{\text { change }}{\longrightarrow}\{\varnothing, b\} \stackrel{\text { result }}{\longrightarrow} W^{c}\left(a b c_{\theta}\right)>W^{c}\left(b_{\theta}^{h}\right)$

country $\mathrm{c}=\{a, b\} \stackrel{\text { change }}{\longrightarrow}\{\varnothing, \varnothing\} /\left\{a^{i}, b^{i}\right\} /\left\{a^{i}, \varnothing\right\} /\left\{\varnothing, b^{i}\right\} \stackrel{\text { result }}{\longrightarrow} W^{c}\left(a b c_{\theta}\right)>W^{c}\left(a b_{\theta}\right)$

We can conclude, that country $c$ has no incentive to change its announcement.

Based on the above, we conclude that $\Omega^{\digamma}$ is a Nash Equilibria for both local and global levels of pollution.

$\Omega^{\digamma}$ is not a CPNE for both local and global levels of pollution.

PROOF:

First, we consider the case of local pollution. The dirty country $a$ can form a deep bilateral trade agreement with one of the clean countries, then $W^{a}\left(a b_{l}^{i}\right)=W^{a}\left(a c_{l}^{i}\right)>W^{a}\left(a b c_{l}\right)$ and $W^{b}\left(a b_{l}^{i}\right)=$ $W^{c}\left(a c_{l}^{i}\right)>W^{b}\left(a b c_{l}\right)=W^{c}\left(a b c_{l}\right)$. Now, we consider the case of global pollution. Clean countries can form a deep trade agreement, then $W^{b}\left(b c_{g}^{i}\right)=W^{c}\left(b c_{g}^{i}\right)>W^{b}\left(a b c_{g}\right)=W^{c}\left(a b c_{g}\right)$. There cannot be any further deviations, because an outsider of this agreement does not announce an environmental clause. Based on the above, we can conclude that the announcement profile $\Omega^{\digamma}$ does not survive a coalition-proof Nash equilibria refinement.

$$
\Omega^{F^{i}} \equiv\left\{\sigma_{a}^{i}=\left\{b^{i}, c^{i}\right\}, \sigma_{b}^{i}=\left\{a^{i}, c^{i}\right\}, \sigma_{c}^{i}=\left\{a^{i}, b^{i}\right\}\right\}
$$

$\Omega^{\digamma^{i}}$ is a Nash Equilibria if pollution is local.

PROOF:

country a $=\left\{b^{i}, c^{i}\right\} \stackrel{\text { change }}{\longrightarrow}\left\{b^{i}, \varnothing\right\} /\left\{\varnothing, c^{i}\right\} \stackrel{\text { result }}{\longrightarrow} W^{a}\left(a b c_{l}^{i}\right)>W^{a}\left(b_{l}^{h i}\right)=W^{a}\left(c_{l}^{h i}\right)$

country a $=\left\{b^{i}, c^{i}\right\} \stackrel{\text { change }}{\longrightarrow}\{\varnothing, \varnothing\} /\{b, c\} /\{b, \varnothing\} /\{\varnothing, c\} \stackrel{\text { result }}{\longrightarrow} W^{a}\left(a b c_{l}^{i}\right)>W^{a}\left(b c_{l}^{i}\right)$

We can conclude, that country $a$ has no incentive to change its announcement.

country $\mathrm{b}=\left\{a^{i}, c^{i}\right\} \stackrel{\text { change }}{\longrightarrow}\left\{a^{i}, \varnothing\right\} \stackrel{\text { result }}{\longrightarrow} W^{b}\left(a b c_{l}^{i}\right)>W^{b}\left(a_{l}^{h i}\right)$ 
country $\mathrm{b}=\left\{a^{i}, c^{i}\right\} \stackrel{\text { change }}{\longrightarrow}\left\{\varnothing, c^{i}\right\} \stackrel{\text { result }}{\longrightarrow} W^{b}\left(a b c_{l}^{i}\right)>W^{b}\left(c_{l}^{\text {hi }}\right)$

country $\mathrm{b}=\left\{a^{i}, c^{i}\right\} \stackrel{\text { change }}{\longrightarrow}\{\varnothing, \varnothing\} /\{a, c\} /\{a, \varnothing\} /\{\varnothing, c\} \stackrel{\text { result }}{\longrightarrow} W^{b}\left(a b c_{l}^{i}\right)>W^{b}\left(a c_{l}^{i}\right)$

We can conclude, that country $b$ has no incentive to change its announcement.

country $\mathrm{c}=\left\{a^{i}, b^{i}\right\} \stackrel{\text { change }}{\longrightarrow}\left\{a^{i}, \varnothing\right\} \stackrel{\text { result }}{\longrightarrow} W^{c}\left(a b c_{l}^{i}\right)>W^{c}\left(a_{l}^{h i}\right)$

country $\mathrm{c}=\left\{a^{i}, b^{i}\right\} \stackrel{\text { change }}{\longrightarrow}\left\{\varnothing, b^{i}\right\} \stackrel{\text { result }}{\longrightarrow} W^{c}\left(a b c_{l}^{i}\right)>W^{c}\left(b_{l}^{h i}\right)$

country c $=\left\{a^{i}, b^{i}\right\} \stackrel{\text { change }}{\longrightarrow}\{\varnothing, \varnothing\} /\{a, b\} /\{a, \varnothing\} /\{\varnothing, b\} \stackrel{\text { result }}{\longrightarrow} W^{c}\left(a b c_{l}^{i}\right)>W^{c}\left(a b_{l}^{i}\right)$

We can conclude, that country $c$ has no incentive to change its announcement.

Based on the above, we conclude that $\Omega^{\digamma^{i}}$ is a Nash Equilibria if pollution is local.

$\Omega^{\digamma^{i}}$ is not a Nash Equilibria if pollution is global.

PROOF:

country a $=\left\{b^{i}, c^{i}\right\} \stackrel{\text { change }}{\longrightarrow}\{\varnothing, \varnothing\} /\{b, c\} /\{b, \varnothing\} /\{\varnothing, c\} \stackrel{\text { result }}{\longrightarrow} W^{a}\left(a b c_{g}^{i}\right)>W^{a}\left(b c_{g}^{i}\right)$

We can conclude, that country $a$ will deviate, and $\Omega^{\digamma^{i}}$ is not a Nash Equilibria if pollution is global.

$\Omega^{\digamma^{i}}$ is a CPNE if pollution is local.

\section{PROOF:}

To prove the above, we consider every possible deviation in the following five steps:

First, we assume that one clean and one dirty country deviate in the firm of a shallow bilateral trade agreement, then $W^{b}\left(a b_{l}\right)=W^{c}\left(a c_{l}\right)<W^{b}\left(a b c_{l}^{i}\right)=W^{c}\left(a b c_{l}^{i}\right)$. We can see that clean countries prefer to leave in a fully integrated world.

Second, we assume that one clean and one dirty country deviate in the firm of a deep bilateral trade agreement, then $W^{b}\left(a b_{l}^{i}\right)=W^{c}\left(a c_{l}^{i}\right)<W^{b}\left(a b c_{l}^{i}\right)=W^{c}\left(a b c_{l}^{i}\right)$. Again, we observe that clean countries prefer to leave in a fully integrated world.

Now, we consider clean countries' deviation in the form of shallow trade agreement, then $W^{b}\left(b c_{l}\right)=$ $W^{c}\left(b c_{l}\right)<W^{b}\left(a b c_{l}^{i}\right)=W^{c}\left(a b c_{l}^{i}\right)$. Similar to the above, we observe that clean countries prefer to leave in a fully integrated world.

In this step, we consider clean countries' deviation in the form of deep trade agreement, then $W^{b}\left(b c_{l}^{i}\right)=W^{c}\left(b c_{l}^{i}\right)<W^{b}\left(a b c_{l}^{i}\right)=W^{c}\left(a b c_{l}^{i}\right)$. Again, we observe that clean countries prefer to 
leave in a fully integrated world.

Finally, we consider a grand coalition in the form of free trade world, and we observe that clean countries exhibit higher welfare levels in the presence of world environmental agreement. Based on the above, we can conclude that $\Omega^{\digamma^{i}}$ is a CPNE if pollution is local. 


\section{Appendix of Chapter 4}

\section{A. 4.3 Environmental and Trade Agreements and their Effects on Tariffs and}

\section{Taxes}

\section{A. 4.3.1 Pure Environmental Agreements}

Tariffs imposed by country a:

$t_{A}^{j}\left(a b c_{l}^{e}\right)>t_{A}^{j}\left(a b_{l}^{e}\right) \stackrel{\lambda \in(0,0.098]}{>} t_{A}^{j}\left(N_{l}\right)>t_{A}^{j}\left(b c_{l}^{e}\right)$ where $j \in[b, c] \& \lambda \in(0,0.098]$

$t_{A}^{j}\left(a b c_{l}^{e}\right)>t_{A}^{j}\left(N_{l}\right) \stackrel{\lambda \in(0.098,0.1]}{>} t_{A}^{j}\left(a b_{l}^{e}\right)>t_{A}^{j}\left(b c_{l}^{e}\right)$ where $j \in[b, c] \& \lambda \in(0.098,0.1]$

$t_{A}^{j}\left(N_{g}\right) \stackrel{\lambda \in(0,0.090]}{>} t_{A}^{j}\left(a b_{g}^{e}\right)>t_{A}^{j}\left(b c_{g}^{e}\right) \stackrel{\lambda \in(0,0.037]}{>} t_{A}^{b}\left(a b c_{g}^{e}\right)$ where $j \in[b, c] \& \lambda \in(0,0.037]$

$t_{A}^{j}\left(N_{g}\right) \stackrel{\lambda \in(0,0.090]}{>} t_{A}^{j}\left(a b_{g}^{e}\right)>t_{A}^{j}\left(a b c_{g}^{e}\right) \stackrel{\lambda \in(0.037,0.1]}{>} t_{A}^{b}\left(b c_{g}^{e}\right)$ where $j \in[b, c] \& \lambda \in(0.037,0.090]$

$t_{A}^{j}\left(a b_{g}^{e}\right) \stackrel{\lambda \in(0.090,0.1]}{>} t_{A}^{j}\left(N_{g}\right)>t_{A}^{j}\left(a b c_{g}^{e}\right) \stackrel{\lambda \in(0.037,0.1]}{>} t_{A}^{b}\left(b c_{g}^{e}\right)$ where $j \in[b, c] \& \lambda \in(0.090,0.1]$

Tariffs imposed by country b:

$t_{B}^{j}\left(N_{\theta}\right)=t_{B}^{j}\left(b c_{\theta}^{e}\right)=t_{B}^{j}\left(a b_{\theta}^{e}\right)=t_{\theta}^{j}\left(a b c_{\theta}^{e}\right)$ where $j \in[a, c]$

Tariffs imposed by country c:

$t_{C}^{j}\left(N_{\theta}\right)=t_{C}^{j}\left(b c_{\theta}^{e}\right)=t_{C}^{j}\left(a b_{\theta}^{e}\right)=t_{C}^{j}\left(a b c_{\theta}^{e}\right)$ where $j \in[a, b]$

Taxes imposed by country a:

$e_{A}^{a}\left(N_{l}\right)=e_{A}^{a}\left(b c_{l}^{e}\right)>e_{A}\left(a b c_{l}^{e}\right)>e_{A}\left(a b_{l}^{e}\right) \& e_{A}\left(a b c_{g}^{e}\right)>e_{A}\left(a b_{g}^{e}\right)>e_{A}^{a}\left(N_{g}\right)=e_{A}^{a}\left(b c_{g}^{e}\right)$

Taxes imposed by country b:

$e_{A}\left(b c_{l}^{e}\right)>e_{A}^{b}\left(N_{l}\right)>e_{A}\left(a b c_{l}^{e}\right)>e_{A}\left(a b_{l}^{e}\right) \& e_{A}\left(a b c_{g}^{e}\right)>e_{A}\left(b c_{g}^{e}\right)>e_{A}\left(a b_{g}^{e}\right)=e_{A}^{b}\left(N_{g}\right)$

Taxes imposed by country c:

$e_{A}\left(b c_{l}^{e}\right)>e_{A}^{c}\left(N_{l}\right)>e_{A}^{c}\left(a b_{l}^{e}\right)>e_{A}\left(a b c_{l}^{e}\right) \& e_{A}\left(a b c_{g}^{e}\right)>e_{A}\left(b c_{g}^{e}\right)>e_{A}^{c}\left(a b_{g}^{e}\right)=e_{A}^{c}\left(N_{g}\right)$

Taxes and Tariffs under an Environmental Agreement between two symmetric dirty countries,

$\left(b c_{\theta}^{e}\right):$

$t_{B}^{a}\left(b c_{\theta}^{e}\right)=t_{C}^{a}\left(b c_{\theta}^{e}\right)=t_{C}^{b}\left(b c_{\theta}^{e}\right)=t_{B}^{c}\left(b c_{\theta}^{e}\right)=\frac{1}{4} \frac{1-\lambda}{\lambda+3}$

$t_{A}^{b}\left(b c_{\theta}^{e}\right)=t_{A}^{c}\left(b c_{\theta}^{e}\right)=\frac{1}{16} \frac{9+\lambda^{2}(2 z-3)+2 \lambda(4 z-2)+14 z}{(\lambda+5)(\lambda+2)}$, then

$t_{A}^{b}\left(b c_{l}^{e}\right)=t_{A}^{c}\left(b c_{l}^{e}\right)=\frac{3}{16} \frac{3-\lambda(\lambda+2)}{(\lambda+5)(\lambda+2)} \& t_{A}^{b}\left(b c_{g}^{e}\right)=t_{A}^{c}\left(b c_{g}^{e}\right)=\frac{1}{16} \frac{23-\lambda(\lambda-2)}{(\lambda+5)(\lambda+2)}$ 
$e_{A}^{a}\left(b c_{\theta}^{e}\right)=\frac{1}{4} \& e_{A}\left(b c_{\theta}^{e}\right)=\frac{1}{4} \frac{13+\lambda^{2}(1-z)+\lambda(4-z)+8 z}{(\lambda+5)(\lambda+2)}$, then $e_{A}\left(b c_{l}^{e}\right)=\frac{1}{4} \frac{13+\lambda(4-z)}{(\lambda+5)(\lambda+2)} \& e_{A}\left(b c_{g}^{e}\right)=\frac{3}{4} \frac{7+\lambda}{(\lambda+5)(\lambda+2)}$

Taxes and Tariffs under an Environmental Agreement between two asymmetric countries, $\left(a b_{\theta}^{e}\right)$ :

$t_{B}^{a}\left(a b_{\theta}^{e}\right)=t_{C}^{a}\left(a b_{\theta}^{e}\right)=t_{C}^{b}\left(a b_{\theta}^{e}\right)=t_{B}^{c}\left(a b_{\theta}^{e}\right)=\frac{1}{4} \frac{1-\lambda}{\lambda+3}$

$t_{A}^{b}\left(a b_{\theta}^{e}\right)=t_{A}^{c}\left(a b_{\theta}^{e}\right)=\frac{1}{4} \frac{(\lambda+1)\left(25 z \lambda^{2}+92 z \lambda-15 \lambda^{2}+39 z-9 \lambda+24\right)}{(\lambda+5)\left(13 \lambda^{2}+46 \lambda+19\right)}$, then

$t_{A}^{b}\left(a b_{l}^{e}\right)=t_{A}^{c}\left(a b_{l}^{e}\right)=\frac{1}{4} \frac{(\lambda+1)\left(24-15 \lambda^{2}-9 \lambda\right)}{(\lambda+5)\left(13 \lambda^{2}+46 \lambda+19\right)} \& t_{A}^{b}\left(a b_{g}^{e}\right)=t_{A}^{c}\left(a b_{g}^{e}\right)=\frac{1}{4} \frac{(\lambda+1)\left(63+10 \lambda^{2}+83 \lambda\right)}{(\lambda+5)\left(13 \lambda^{2}+46 \lambda+19\right)}$

$e_{A}\left(a b_{\theta}^{e}\right)=\frac{1}{4} \frac{80+\lambda^{3}(23 z+7)+\lambda^{2}(109 z+126)+\lambda(121 z+255)+35 z}{(\lambda+5)\left(13 \lambda^{2}+46 \lambda+19\right)}$, then

$e_{A}\left(a b_{l}^{e}\right)=\frac{1}{4} \frac{80+7 \lambda^{3}+126 \lambda^{2}+255 \lambda}{(\lambda+5)\left(13 \lambda^{2}+46 \lambda+19\right)} \& e_{A}\left(a b_{g}^{e}\right)=\frac{1}{4} \frac{115+30 \lambda^{3}+235 \lambda^{2}+376 \lambda}{(\lambda+5)\left(13 \lambda^{2}+46 \lambda+19\right)}$

$e_{A}^{c}\left(a b_{\theta}^{e}\right)=\frac{1}{4} \frac{104+13 \lambda^{3}(1-z)+\lambda^{2}(90-63 z)+\lambda(261-71 z)-21 z}{(\lambda+5)\left(13 \lambda^{2}+46 \lambda+19\right)}$, then

$e_{A}^{c}\left(a b_{l}^{e}\right)=\frac{1}{4} \frac{104+13 \lambda^{3}+90 \lambda^{2}+261 \lambda}{(\lambda+5)\left(13 \lambda^{2}+46 \lambda+19\right)} \& e_{A}^{c}\left(a b_{g}^{e}\right)=\frac{1}{4} \frac{83+27 \lambda^{2}+190 \lambda}{(\lambda+5)\left(13 \lambda^{2}+46 \lambda+19\right)}$

Taxes and Tariffs under World Environmental Agreement, $\left(a b c_{\theta}^{e}\right)$ :

$t_{B}^{a}\left(a b c_{\theta}^{e}\right)=t_{C}^{a}\left(a b c_{\theta}^{e}\right)=t_{C}^{b}\left(a b c_{\theta}^{e}\right)=t_{B}^{c}\left(a b c_{\theta}^{e}\right)=\frac{1}{4} \frac{1-\lambda}{\lambda+3}$

$t_{A}^{b}\left(a b c_{\theta}^{e}\right)=t_{A}^{c}\left(a b c_{\theta}^{e}\right)=\frac{3}{8} \frac{(\lambda+2)\left(7 z \lambda^{2}+26 z \lambda-3 \lambda^{2}+3 z+3\right)}{(\lambda+5)\left(3 \lambda^{2}+14 \lambda+7\right)}$, then

$t_{A}^{b}\left(a b c_{l}^{e}\right)=t_{A}^{c}\left(a b c_{l}^{e}\right)=\frac{3}{8} \frac{(\lambda+2)\left(3-3 \lambda^{2}\right)}{(\lambda+5)\left(3 \lambda^{2}+14 \lambda+7\right)} \& t_{A}^{b}\left(a b c_{g}^{e}\right)=t_{A}^{c}\left(a b c_{g}^{e}\right)=\frac{3}{8} \frac{(\lambda+2)\left(4 \lambda^{2}+26 \lambda+6\right)}{(\lambda+5)\left(3 \lambda^{2}+14 \lambda+7\right)}$

$e_{A}\left(a b c_{\theta}^{e}\right)=\frac{1}{4} \frac{32+13 z \lambda^{3}+77 z \lambda^{2}+131 z \lambda+32 \lambda^{2}+67 z+80 \lambda}{(\lambda+5)\left(3 \lambda^{2}+14 \lambda+7\right)}$, then

$e_{A}\left(a b c_{l}^{e}\right)=\frac{1}{4} \frac{32+32 \lambda^{2}+80 \lambda}{(\lambda+5)\left(3 \lambda^{2}+14 \lambda+7\right)} \& e_{A}\left(a b c_{g}^{e}\right)=\frac{1}{4} \frac{99+13 z \lambda^{3}+109 z \lambda^{2}+211 \lambda}{(\lambda+5)\left(3 \lambda^{2}+14 \lambda+7\right)}$

\section{A. 4.3.2 Shallow Trade Agreements}

Tariffs imposed by country a:

$t_{A}^{b}\left(N_{l}\right)=t_{A}^{b}\left(b c_{l}\right)=t_{A}^{b}\left(b c_{l}^{u}\right)>t_{A}^{b}\left(a b c_{l}\right)=t_{A}^{b}\left(a b_{l}\right)=t_{A}^{b}\left(a b_{l}^{u}\right)=t_{A}^{b}\left(a_{l}^{h}\right)=t_{A}^{b}\left(b_{l}^{h}\right)=0$

$t_{A}^{b}\left(N_{g}\right)=t_{A}^{b}\left(b c_{g}\right)=t_{A}^{b}\left(b c_{g}^{u}\right)>t_{A}^{b}\left(a b c_{g}\right)=t_{A}^{b}\left(a b_{g}\right)=t_{A}^{b}\left(a b_{g}^{u}\right)=t_{A}^{b}\left(a_{g}^{h}\right)=t_{A}^{b}\left(b_{g}^{h}\right)=0$

$t_{A}^{c}\left(a b_{l}^{u}\right) \stackrel{\lambda \in(0,0.067]}{>} t_{A}^{c}\left(N_{l}\right)=t_{A}^{c}\left(b c_{l}^{u}\right)=t_{A}^{c}\left(b c_{l}\right)>t_{A}^{c}\left(a b_{l}\right)=t_{A}^{c}\left(b_{l}^{h}\right)>t_{A}^{c}\left(a b c_{l}\right)=t_{A}^{c}\left(a_{l}^{h}\right)=0$ if $\lambda \in$

$(0,0.067]$

$t_{A}^{c}\left(N_{l}\right)=t_{A}^{c}\left(b c_{l}^{u}\right)=t_{A}^{c}\left(b c_{l}\right) \stackrel{\lambda \in(0.067,0.1]}{>} t_{A}^{c}\left(a b_{l}^{u}\right)>t_{A}^{c}\left(a b_{l}\right)=t_{A}^{c}\left(b_{l}^{h}\right)>t_{A}^{c}\left(a b c_{l}\right)=t_{A}^{c}\left(a_{l}^{h}\right)=0$ if $\lambda \in$ $(0.067,0.1]$

$t_{A}^{c}\left(N_{g}\right)=t_{A}^{c}\left(b c_{g}^{u}\right)=t_{A}^{c}\left(b c_{g}\right)>t_{A}^{c}\left(a b_{g}^{u}\right)>t_{A}^{c}\left(a b_{g}\right)=t_{A}^{c}\left(b_{g}^{h}\right)>t_{A}^{c}\left(a b c_{g}\right)=t_{A}^{c}\left(a_{g}^{h}\right)=0$

Tariffs imposed by country b:

$t_{B}^{a}\left(N_{l}\right)>t^{a}\left(b c_{l}^{u}\right)>t_{B}^{a}\left(b c_{l}\right)>t_{B}^{a}\left(a b c_{l}\right)=t_{B}^{a}\left(a b_{l}\right)=t_{B}^{a}\left(a b_{l}^{u}\right)=t_{B}^{a}\left(a_{l}^{h}\right)=t_{B}^{a}\left(b_{l}^{h}\right)=0$ 
$t_{B}^{a}\left(N_{g}\right)>t^{a}\left(b c_{g}^{u}\right)>t_{B}^{a}\left(b c_{g}\right)>t_{B}^{a}\left(a b c_{g}\right)=t_{B}^{a}\left(a b_{g}\right)=t_{B}^{a}\left(a b_{g}^{u}\right)=t_{B}^{a}\left(a_{g}^{h}\right)=t_{B}^{a}\left(b_{g}^{h}\right)=0$

$t_{B}^{c}\left(N_{l}\right)>t^{c}\left(a b_{l}^{u}\right)>t_{B}^{c}\left(a b_{l}\right)=t_{B}^{c}\left(a_{l}^{h}\right)>t_{B}^{c}\left(a b c_{l}\right)=t_{B}^{c}\left(b c_{l}^{u}\right)=t_{B}^{c}\left(b c_{l}\right)=t_{B}^{c}\left(b_{l}^{h}\right)=0$

$t^{c}\left(a b_{g}^{u}\right)>t^{c}\left(N_{g}\right)>t_{B}^{c}\left(a b_{g}\right)=t_{B}^{c}\left(a_{g}^{h}\right)>t_{B}^{c}\left(a b c_{g}\right)=t_{B}^{c}\left(b c_{g}^{u}\right)=t_{B}^{c}\left(b c_{g}\right)=t_{B}^{c}\left(b_{g}^{h}\right)=0$

Tariffs imposed by country c:

$t_{C}^{a}\left(N_{l}\right)=t_{C}^{a}\left(a b_{l}^{u}\right)=t_{C}^{a}\left(a b_{l}\right)>t^{a}\left(b c_{l}^{u}\right)>t_{C}^{a}\left(b c_{l}\right)=t_{C}^{a}\left(b_{l}^{h}\right)>t_{C}^{a}\left(a b c_{l}\right)=t_{C}^{a}\left(a_{l}^{h}\right)=0$

$t_{C}^{a}\left(N_{g}\right)=t_{C}^{a}\left(a b_{g}^{u}\right)=t_{C}^{a}\left(a b_{g}\right)>t^{a}\left(b c_{g}^{u}\right)>t_{C}^{a}\left(b c_{g}\right)=t_{C}^{a}\left(b_{g}^{h}\right)>t_{C}^{a}\left(a b c_{g}\right)=t_{C}^{a}\left(a_{g}^{h}\right)=0$

$t_{C}^{b}\left(a b_{l}^{u}\right)=t_{C}^{b}\left(a b_{l}\right)=t_{C}^{b}\left(N_{l}\right)>t_{C}^{b}\left(a_{l}^{h}\right)>t_{C}^{b}\left(b c_{l}^{u}\right)=t_{C}^{b}\left(b c_{l}\right)=t_{C}^{b}\left(a b c_{l}\right)=t_{C}^{b}\left(b_{l}^{h}\right)=0$

$t_{C}^{b}\left(a b_{g}^{u}\right)=t_{C}^{b}\left(a b_{g}\right)=t_{C}^{b}\left(N_{g}\right)>t_{C}^{b}\left(a_{g}^{h}\right)>t_{C}^{b}\left(b c_{g}^{u}\right)=t_{C}^{b}\left(b c_{g}\right)=t_{C}^{b}\left(a b c_{g}\right)=t_{C}^{b}\left(b_{g}^{h}\right)=0$

Taxes imposed by country a:

$e_{A}^{a}\left(N_{l}\right)=e_{A}^{a}\left(b c_{l}^{u}\right)=e_{A}^{a}\left(b c_{l}\right)>e_{A}^{a}\left(a b_{l}^{u}\right)>e_{A}^{a}\left(a b_{l}\right)=e_{A}^{a}\left(b_{l}^{h}\right)>e_{A}^{a}\left(a_{l}^{h}\right)=e_{A}^{a}\left(a b c_{l}\right)$

$e_{A}^{a}\left(N_{g}\right)=e_{A}^{a}\left(b c_{g}^{u}\right)=e_{A}^{a}\left(b c_{g}\right)>e_{A}^{a}\left(a b_{g}^{u}\right)>e_{A}^{a}\left(a b_{g}\right)=e_{A}^{a}\left(b_{g}^{h}\right)>e_{A}^{a}\left(a_{g}^{h}\right)=e_{A}^{a}\left(a b c_{g}\right)$

Taxes imposed by country b:

$e_{A}^{b}\left(a b_{l}^{u}\right)>e_{A}^{b}\left(a b_{l}\right)=e_{A}^{b}\left(b_{l}^{h}\right)>e_{A}^{b}\left(a_{l}^{h}\right)=e_{A}^{b}\left(a b c_{l}\right)>e_{A}^{b}\left(N_{l}\right)=e_{A}^{b}\left(b c_{l}^{u}\right)=e_{A}^{b}\left(b c_{l}\right)$

$e_{A}^{b}\left(a b_{g}^{u}\right)>e_{A}^{b}\left(a b_{g}\right)=e_{A}^{b}\left(b_{g}^{h}\right)>e_{A}^{b}\left(a_{g}^{h}\right)=e_{A}^{b}\left(a b c_{g}\right)>e_{A}^{b}\left(N_{g}\right)=e_{A}^{b}\left(b c_{g}^{u}\right)=e_{A}^{b}\left(b c_{g}\right)$

Taxes imposed by country c:

$e_{A}^{c}\left(a_{l}^{h}\right)=e_{A}^{c}\left(a b c_{l}\right)>e_{A}^{c}\left(b_{l}^{h}\right)=e_{A}^{c}\left(a b_{l}\right)>e_{A}^{c}\left(N_{l}\right)=e_{A}^{c}\left(b c_{l}^{u}\right)=e_{A}^{c}\left(b c_{l}\right)>e_{A}^{c}\left(a b_{l}^{u}\right)$

$e_{A}^{c}\left(a_{g}^{h}\right)=e_{A}^{c}\left(a b c_{g}\right)>e_{A}^{c}\left(b_{g}^{h}\right)=e_{A}^{c}\left(a b_{g}\right)>e_{A}^{c}\left(N_{g}\right)=e_{A}^{c}\left(b c_{g}^{u}\right)=e_{A}^{c}\left(b c_{g}\right)>e_{A}^{c}\left(a b_{g}^{u}\right)$

Taxes and Tariffs under Shallow FTA between two dirty countries, $\left(b c_{\theta}\right)$ :

$t_{C}^{b}\left(b c_{\theta}\right)=t_{B}^{c}\left(b c_{\theta}\right)=0$

$t_{B}^{a}\left(b c_{\theta}\right)=t_{C}^{a}\left(b c_{\theta}\right)=\frac{1}{4} \frac{1-\lambda^{2}}{\lambda^{2}+7 \lambda+14}$

$t_{A}^{b}\left(b c_{\theta}\right)=t_{A}^{c}\left(b c_{\theta}\right)=\frac{1}{8} \frac{12+2 z \lambda(\lambda+6)-3 \lambda(\lambda+3)+22 z}{(\lambda+5)(2 \lambda+5)}$, then

$t_{A}^{b}\left(b c_{l}\right)=t_{A}^{c}\left(b c_{l}\right)=\frac{3}{8} \frac{4-\lambda(\lambda+3)}{(\lambda+5)(2 \lambda+5)} \& t_{A}^{b}\left(b c_{g}\right)=t_{A}^{c}\left(b c_{g}\right)=\frac{1}{8} \frac{34-\lambda(\lambda-3)}{(\lambda+5)(2 \lambda+5)}$

$e_{A}^{a}\left(b c_{\theta}\right)=\frac{1}{4}$

$e_{A}^{b}\left(b c_{\theta}\right)=e_{A}^{c}\left(b c_{\theta}\right)=\frac{1}{4} \frac{7(4-z)+2 \lambda^{2}(1-z)+3 \lambda(4-3 z)}{(\lambda+5)(2 \lambda+5)}$, then

$e_{A}^{b}\left(b c_{l}\right)=e_{A}^{c}\left(b c_{l}\right)=\frac{1}{2} \frac{14+\lambda(\lambda+6)}{(\lambda+5)(2 \lambda+5)} \& e_{A}^{b}\left(b c_{g}\right)=e_{A}^{c}\left(b c_{g}\right)=\frac{3}{4} \frac{7+\lambda}{(\lambda+5)(2 \lambda+5)}$

Taxes and Tariffs under Shallow FTA between one clean and one dirty country, $\left(a b_{\theta}\right)$ :

$t_{B}^{a}\left(a b_{\theta}\right)=t_{A}^{b}\left(a b_{\theta}\right)=0$ 


$$
\begin{aligned}
& t_{C}^{a}\left(a b_{\theta}\right)=t_{C}^{b}\left(a b_{\theta}\right)=\frac{1}{4} \frac{1-\lambda}{\lambda+3} \\
& t_{B}^{c}\left(a b_{\theta}\right)=\frac{1}{4} \frac{1-\lambda^{2}}{\lambda^{2}+7 \lambda+14} \\
& t_{A}^{c}\left(a b_{\theta}\right)=\frac{1}{8} \frac{12+2 z \lambda(\lambda+6)-3 \lambda(\lambda+3)+22 z}{10 \lambda^{2}+67 \lambda+107}, \text { then } t_{A}^{c}\left(a b_{l}\right)=\frac{3}{8} \frac{4-\lambda(\lambda+3)}{10 \lambda^{2}+67 \lambda+107} \& t_{A}^{c}\left(a b_{g}\right)=\frac{1}{8} \frac{34-\lambda^{2}+3 \lambda}{10 \lambda^{2}+67 \lambda+107} \\
& e_{A}^{a}\left(a b_{\theta}\right)=\frac{1}{4} \frac{427+4 \lambda^{3}(4-z)+4 \lambda(41 \lambda-38 z)-6 z\left(7 \lambda^{2}+33\right)+509 \lambda}{(\lambda+5)\left(10 \lambda^{2}+69 \lambda+107\right)}, \text { then } \\
& e_{A}^{a}\left(a b_{l}\right)=\frac{1}{4} \frac{427+4 \lambda^{2}(4 \lambda+41)+509 \lambda}{(\lambda+5)\left(10 \lambda^{2}+69 \lambda+107\right)} \& e_{A}^{a}\left(a b_{g}\right)=\frac{1}{4} \frac{299+2 \lambda^{2}(6 \lambda+61)+357 \lambda}{(\lambda+5)\left(10 \lambda^{2}+69 \lambda+107\right)} \\
& e_{A}^{b}\left(a b_{\theta}\right)=\frac{1}{4} \frac{616+10 \lambda^{3}(1-z)+\lambda^{2}(101-87 z)+\lambda(389-216 z)-119 z}{(\lambda+5)\left(10 \lambda^{2}+69 \lambda+107\right)}, \text { then } \\
& e_{A}^{b}\left(a b_{l}\right)=\frac{1}{4} \frac{616+\lambda\left(10 \lambda^{2}+101 \lambda+89\right)}{(\lambda+5)\left(10 \lambda^{2}+69 \lambda+107\right)} \& e_{A}^{b}\left(a b_{g}\right)=\frac{1}{4} \frac{497+14 \lambda^{2}+173 \lambda}{(\lambda+5)\left(10 \lambda^{2}+69 \lambda+107\right)} \\
& e_{A}^{c}\left(a b_{\theta}\right)=\frac{1}{4} \frac{604+10 \lambda^{3}(1-z)+4 \lambda(26 \lambda-57 z)+\lambda(398-89 z \lambda)-141 z}{(\lambda+5)\left(10 \lambda^{2}+69 \lambda+107\right)}, \text { then } \\
& e_{A}^{c}\left(a b_{l}\right)=\frac{1}{4} \frac{604+10 \lambda^{3}+104 \lambda^{2}+389 \lambda}{(\lambda+5)\left(10 \lambda^{2}+69 \lambda+107\right)} \& e_{A}^{c}\left(a b_{g}\right)=\frac{1}{4} \frac{463+15 \lambda^{2}+170 \lambda}{(\lambda+5)\left(10 \lambda^{2}+69 \lambda+107\right)}
\end{aligned}
$$

Taxes and Tariffs under Shallow Hub-and-Spoke, Country a is the Hub, $\left(a_{\theta}^{h}\right)$ :

$$
\begin{aligned}
& t_{A}^{b}\left(a_{\theta}^{h}\right)=t_{A}^{c}\left(a_{\theta}^{h}\right)=t_{B}^{a}\left(a_{\theta}^{h}\right)=t_{C}^{a}\left(a_{\theta}^{h}\right)=0 \\
& t_{C}^{b}\left(a_{\theta}^{h}\right)=t_{B}^{c}\left(a_{\theta}^{h}\right)=\frac{1}{4} \frac{1-\lambda^{2}}{\lambda^{2}+7 \lambda+14} \\
& e_{A}^{a}\left(a_{\theta}^{h}\right)=\frac{1}{12} \frac{81-4 z \lambda(\lambda+6)+3 \lambda(5 \lambda+28)-44 z}{(\lambda+5)(3 \lambda+7)}, \text { then } e_{A}^{a}\left(a_{l}^{h}\right)=\frac{1}{12} \frac{81+3 \lambda(5 \lambda+28)}{(\lambda+5)(3 \lambda+7)} \& e_{A}^{a}\left(a_{g}^{h}\right)=\frac{1}{12} \frac{37+11 \lambda^{2}+60 \lambda}{(\lambda+5)(3 \lambda+7)} \\
& e_{A}^{b}\left(a_{\theta}^{h}\right)=\frac{1}{12} \frac{120+9 \lambda^{2}(1-z)-5 z(5+7.6 \lambda)+51 \lambda}{(\lambda+5)(3 \lambda+7)}=e_{A}^{c}\left(a_{\theta}^{h}\right), \text { then } \\
& e_{A}^{b}\left(a_{l}^{h}\right)=\frac{1}{12} \frac{120+9 \lambda^{2}+51 \lambda}{(\lambda+5)(3 \lambda+7)}=e_{A}^{c}\left(a_{l}^{h}\right) \& e_{A}^{b}\left(a_{g}^{h}\right)=\frac{1}{12} \frac{95+13 \lambda}{(\lambda+5)(3 \lambda+7)}=e_{A}^{c}\left(a_{g}^{h}\right)
\end{aligned}
$$

Taxes and Tariffs under Shallow Hub-and-Spoke, Country b is the Hub, $\left(b_{\theta}^{h}\right)$ :

$$
\begin{aligned}
& t_{B}^{a}\left(b_{\theta}^{h}\right)=t_{A}^{b}\left(b_{\theta}^{h}\right)=t_{C}^{b}\left(b_{\theta}^{h}\right)=t_{B}^{c}\left(b_{\theta}^{h}\right)=0 \\
& t_{C}^{a}\left(b_{\theta}^{h}\right)=\frac{1}{4} \frac{1-\lambda^{2}}{\lambda^{2}+7 \lambda+14} \\
& t_{A}^{c}\left(b_{\theta}^{h}\right)=\frac{1}{8} \frac{12+2 z \lambda(\lambda+6)-3 \lambda(\lambda+3)+22 z}{10 \lambda^{2}+67 \lambda+107}, \text { then } t_{A}^{c}\left(b_{l}^{h}\right)=\frac{3}{8} \frac{4-\lambda(\lambda+3)}{10 \lambda^{2}+67 \lambda+107} \& t_{A}^{c}\left(b_{g}^{h}\right)=\frac{1}{8} \frac{34-\lambda^{2}+3 \lambda}{10 \lambda^{2}+67 \lambda+107} \\
& e_{A}^{a}\left(b_{\theta}^{h}\right)=\frac{1}{4} \frac{427+4 \lambda^{3}(4-z)+4 \lambda(41 \lambda-38 z)-6 z\left(7 \lambda^{2}+33\right)+509 \lambda}{(\lambda+5)\left(10 \lambda^{2}+69 \lambda+107\right)}, \text { then } \\
& e_{A}^{a}\left(b_{l}^{h}\right)=\frac{1}{4} \frac{427+4 \lambda^{2}(4 \lambda+41)+509 \lambda}{(\lambda+5)\left(10 \lambda^{2}+69 \lambda+107\right)} \& e_{A}^{a}\left(b_{g}^{h}\right)=\frac{1}{4} \frac{299+2 \lambda^{2}(6 \lambda+61)+357 \lambda}{(\lambda+5)\left(10 \lambda^{2}+69 \lambda+107\right)} \\
& e_{A}^{b}\left(b_{\theta}^{h}\right)=\frac{1}{4} \frac{616+10 \lambda^{3}(1-z)+\lambda^{2}(101-87 z)+\lambda(389-216 z)-119 z}{(\lambda+5)\left(10 \lambda^{2}+69 \lambda+107\right)}, \text { then } \\
& e_{A}^{b}\left(b_{l}^{h}\right)=\frac{1}{4} \frac{616+\lambda\left(10 \lambda^{2}+101 \lambda+89\right)}{(\lambda+5)\left(10 \lambda^{2}+69 \lambda+107\right)} \& e_{A}^{b}\left(b_{g}^{h}\right)=\frac{1}{4} \frac{497+14 \lambda^{2}+173 \lambda}{(\lambda+5)\left(10 \lambda^{2}+69 \lambda+107\right)} \\
& e_{A}^{c}\left(b_{\theta}^{h}\right)=\frac{1}{4} \frac{604+10 \lambda^{3}(1-z)+4 \lambda(26 \lambda-57 z)+\lambda(398-89 z \lambda)-141 z}{(\lambda+5)\left(10 \lambda^{2}+69 \lambda+107\right)}, \text { then } \\
& e_{A}^{c}\left(b_{l}^{h}\right)=\frac{1}{4} \frac{604+10 \lambda^{3}+104 \lambda^{2}+389 \lambda}{(\lambda+5)\left(10 \lambda^{2}+69 \lambda+107\right)} \& e_{A}^{c}\left(b_{g}^{h}\right)=\frac{1}{4} \frac{463+15 \lambda^{2}+170 \lambda}{(\lambda+5)\left(10 \lambda^{2}+69 \lambda+107\right)}
\end{aligned}
$$

Taxes and Tariffs under Shallow Tree Trade, $\left(a b c_{\theta}\right)$ :

$t_{B}^{a}\left(a b c_{\theta}\right)=t_{C}^{a}\left(a b c_{\theta}\right)=t_{A}^{b}\left(a b c_{\theta}\right)=t_{C}^{b}\left(a b c_{\theta}\right)=t_{A}^{c}\left(a b c_{\theta}\right)=t_{B}^{c}\left(a b c_{\theta}\right)=0$ 
$e_{A}^{a}\left(a b c_{\theta}\right)=\frac{1}{12} \frac{81-4 z \lambda(\lambda+6)+3 \lambda(5 \lambda+28)-44 z}{(\lambda+5)(3 \lambda+7)}$, then $e_{A}^{a}\left(a b c_{l}\right)=\frac{1}{12} \frac{81+3 \lambda(5 \lambda+28)}{(\lambda+5)(3 \lambda+7)} \& e_{A}^{a}\left(a b c_{g}\right)=\frac{1}{12} \frac{37+11 \lambda^{2}+60 \lambda}{(\lambda+5)(3 \lambda+7)}$

$e_{A}^{b}\left(a b c_{\theta}\right)=\frac{1}{12} \frac{120+9 \lambda^{2}(1-z)-5 z(5+7.6 \lambda)+51 \lambda}{(\lambda+5)(3 \lambda+7)}=e_{A}^{c}\left(a b c_{\theta}\right)$, then

$e_{A}^{b}\left(a b c_{l}\right)=\frac{1}{12} \frac{120+9 \lambda^{2}+51 \lambda}{(\lambda+5)(3 \lambda+7)}=e_{A}^{c}\left(a b c_{l}\right) \& e_{A}^{b}\left(a b c_{g}\right)=\frac{1}{12} \frac{95+13 \lambda}{(\lambda+5)(3 \lambda+7)}=e_{A}^{c}\left(a b c_{g}\right)$

Taxes and Tariffs under Shallow Union of Two Dirty Countries, $\left(b c_{\theta}^{u}\right)$ :

$t_{C}^{b}\left(b c_{\theta}^{u}\right)=t_{B}^{c}\left(b c_{\theta}^{u}\right)=0$

$t_{C}^{a}\left(b c_{\theta}^{u}\right)=t_{B}^{a}\left(b c_{\theta}^{u}\right)=t^{a}\left(b c_{\theta}^{u}\right)$

$t_{A}^{b}\left(b c_{\theta}^{u}\right)=t_{A}^{c}\left(b c_{\theta}^{u}\right)=\frac{1}{8} \frac{12+2 z \lambda(\lambda+6)-3 \lambda(\lambda+3)+22 z}{(\lambda+5)(2 \lambda+5)}$, then

$t_{A}^{b}\left(b c_{l}^{u}\right)=t_{A}^{c}\left(b c_{l}^{u}\right)=\frac{3}{8} \frac{4-\lambda(\lambda+3)}{(\lambda+5)(2 \lambda+5)} \& t_{A}^{b}\left(b c_{g}^{u}\right)=t_{A}^{c}\left(b c_{g}^{u}\right)=\frac{1}{8} \frac{34-\lambda(\lambda-3)}{(\lambda+5)(2 \lambda+5)}$

$t^{a}\left(b c_{\theta}^{u}\right)=\frac{1}{4} \frac{1-\lambda}{\lambda+4}$

$e_{A}^{a}\left(b c_{\theta}^{u}\right)=\frac{1}{4}$

$e_{A}^{b}\left(b c_{\theta}^{u}\right)=e_{A}^{c}\left(b c_{\theta}^{u}\right)=\frac{1}{4} \frac{7(4-z)+2 \lambda^{2}(1-z)+3 \lambda(4-3 z)}{(\lambda+5)(2 \lambda+5)}$, then

$e_{A}^{b}\left(b c_{l}^{u}\right)=e_{A}^{c}\left(b c_{l}^{u}\right)=\frac{1}{2} \frac{14+\lambda(\lambda+6)}{(\lambda+5)(2 \lambda+5)} \& e_{A}^{b}\left(b c_{g}^{u}\right)=e_{A}^{c}\left(b c_{g}^{u}\right)=\frac{3}{4} \frac{7+\lambda}{(\lambda+5)(2 \lambda+5)}$

Taxes and Tariffs under Shallow Union of One Dirty and One Clean Country, $\left(a b_{\theta}^{u}\right)$ :

$t_{B}^{a}\left(a b_{\theta}^{u}\right)=t_{A}^{b}\left(a b_{\theta}^{u}\right)=0$

$t_{A}^{c}\left(a b_{\theta}^{u}\right)=t_{B}^{c}\left(a b_{\theta}^{u}\right)=t^{c}\left(a b_{\theta}^{u}\right)$

$t_{C}^{a}\left(a b_{\theta}^{u}\right)=t_{C}^{b}\left(a b_{\theta}^{u}\right)=\frac{1}{4} \frac{1-\lambda}{3+\lambda}$

$t^{c}\left(a b_{\theta}^{u}\right)=\frac{1}{8} \frac{462-7 \lambda^{2}(z \lambda+30)-3 \lambda^{2}(11 z+13 \lambda)+3 \lambda(29 \lambda-71)+385 z}{3 \lambda(93 \lambda+302)+14\left(2 \lambda^{3}+68.5\right)}$, then

$t^{c}\left(a b_{l}^{u}\right)=\frac{1}{8} \frac{462-3 \lambda^{2}(13 \lambda+70)-213 \lambda}{3 \lambda(93 \lambda+302)+14\left(2 \lambda^{3}+68.5\right)} \& t^{c}\left(a b_{g}^{u}\right)=\frac{1}{8} \frac{847-9 \lambda(27 \lambda+14)-46 \lambda^{3}}{3 \lambda(93 \lambda+302)+14\left(2 \lambda^{3}+68.5\right)}$

$e_{A}^{a}\left(a b_{\theta}^{u}\right)=\frac{1}{4} \frac{4249+2 \lambda^{4}(19-7 z)-5 z \lambda^{2}(37 \lambda+181.4)+\lambda^{2}(526 \lambda+2633)-z(1951 \lambda+1551)+5586 \lambda}{(\lambda+5)\left(28 \lambda^{3}+279 \lambda^{2}+906 \lambda+959\right)}$, then

$e_{A}^{a}\left(a b_{l}^{u}\right)=\frac{1}{4} \frac{4249+2 \lambda^{3}(19 \lambda+263)+\lambda(2633 \lambda+5586)}{(\lambda+5)\left(28 \lambda^{3}+279 \lambda^{2}+906 \lambda+959\right)} \& e_{A}^{a}\left(a b_{g}^{u}\right)=\frac{1}{4} \frac{2698+24 \lambda^{4}+341 \lambda^{3}+1726 \lambda^{2}+3635 \lambda}{(\lambda+5)\left(28 \lambda^{3}+279 \lambda^{2}+906 \lambda+959\right)}$

$e_{A}^{b}\left(a b_{\theta}^{u}\right)=\frac{1}{4} \frac{5656+28 \lambda^{4}(1-z)+355 \lambda^{3}(1-z)+\lambda^{2}(1401 z+1904)+\lambda(5089-2281 z)-995 z}{(\lambda+5)\left(28 \lambda^{3}+279 \lambda^{2}+906 \lambda+959\right)}$, then

$e_{A}^{b}\left(a b_{\theta}^{u}\right)=\frac{1}{4} \frac{5656+28 \lambda^{4}+355 \lambda^{3}+1904 \lambda^{2}+5089 \lambda}{(\lambda+5)\left(28 \lambda^{3}+279 \lambda^{2}+906 \lambda+959\right)} \& e_{A}^{b}\left(a b_{g}^{u}\right)=\frac{1}{4} \frac{4661+20 \lambda^{3}+503 \lambda^{2}+2808 \lambda}{(\lambda+5)\left(28 \lambda^{3}+279 \lambda^{2}+906 \lambda+959\right)}$

$e_{A}^{c}\left(a b_{\theta}^{u}\right)=\frac{1}{2} \frac{2597+14 \lambda^{4}(1-z)+\lambda^{3}(197-164 z)+\lambda^{2}(1057-684 z)+\lambda(2651-1184 z)-690 z}{(\lambda+5)\left(28 \lambda^{3}+279 \lambda^{2}+906 \lambda+959\right)}$, then

$e_{A}^{c}\left(a b_{l}^{u}\right)=\frac{1}{2} \frac{2597+14 \lambda^{4}+197 \lambda^{3}+1057 \lambda^{2}+2651 \lambda}{(\lambda+5)\left(28 \lambda^{3}+279 \lambda^{2}+906 \lambda+959\right)} \& e_{A}^{c}\left(a b_{g}^{u}\right)=\frac{1}{2} \frac{1907+33 \lambda^{3}+373 \lambda^{2}+1467 \lambda}{(\lambda+5)\left(28 \lambda^{3}+279 \lambda^{2}+906 \lambda+959\right)}$

\section{A. 4.3.3 Deep Trade Agreements}

Tariffs imposed by country a: 


$$
\begin{aligned}
& t_{A}^{b}\left(N_{l}\right)>t_{A}^{b}\left(b c_{l}^{i}\right)=t_{A}^{b}\left(b c_{l}^{i u}\right)>t_{A}^{b}\left(a b c_{l}^{i}\right)=t_{A}^{b}\left(a b_{l}^{i}\right)=t_{A}^{b}\left(a b_{l}^{i u}\right)=t_{A}^{b}\left(a_{l}^{h i}\right)=t_{A}^{b}\left(b_{l}^{h i}\right)=0 \\
& t_{A}^{b}\left(N_{g}\right)>t_{A}^{b}\left(b c_{g}^{i}\right)=t_{A}^{b}\left(b c_{g}^{i u}\right)>t_{A}^{b}\left(a b c_{g}^{i}\right)=t_{A}^{b}\left(a b_{g}^{i}\right)=t_{A}^{b}\left(a b_{g}^{i u}\right)=t_{A}^{b}\left(a_{g}^{h i}\right)=t_{A}^{b}\left(b_{g}^{h i}\right)=0 \\
& t_{A}^{c}\left(N_{l}\right)>t_{A}^{c}\left(b c_{l}^{i}\right)=t_{A}^{c}\left(b c_{l}^{i u}\right)>t^{c}\left(a b_{l}^{i u}\right)>t_{A}^{c}\left(b_{l}^{h i}\right)>t_{A}^{c}\left(a b_{l}^{i}\right)>t_{A}^{c}\left(a b c_{l}^{i}\right)=t_{A}^{c}\left(a_{l}^{h i}\right)=0 \\
& t_{A}^{c}\left(N_{g}\right)>t_{A}^{c}\left(b c_{g}^{i}\right)=t_{A}^{c}\left(b c_{g}^{i u}\right)>t^{c}\left(a b_{g}^{i u}\right)>t_{A}^{c}\left(a b_{g}^{i}\right)>t_{A}^{c}\left(b_{g}^{h i}\right)>t_{A}^{c}\left(a b c_{g}^{i}\right)=t_{A}^{c}\left(a_{g}^{h i}\right)=0
\end{aligned}
$$

Tariffs imposed by country b:

$t_{B}^{a}\left(N_{l}\right)>t^{a}\left(b c_{l}^{i u}\right)>t_{B}^{a}\left(b c_{l}^{i}\right)>t_{B}^{a}\left(a b c_{l}^{i}\right)=t_{B}^{a}\left(a b_{l}^{i}\right)=t_{B}^{a}\left(a b_{l}^{i u}\right)=t_{B}^{a}\left(a_{l}^{h i}\right)=t_{B}^{a}\left(b_{l}^{h i}\right)=0$

$t_{B}^{a}\left(N_{g}\right)>t^{a}\left(b c_{g}^{i u}\right)>t_{B}^{a}\left(b c_{g}^{i}\right)>t_{B}^{a}\left(a b c_{g}^{i}\right)=t_{B}^{a}\left(a b_{g}^{i}\right)=t_{B}^{a}\left(a b_{g}^{i u}\right)=t_{B}^{a}\left(a_{g}^{h i}\right)=t_{B}^{a}\left(b_{g}^{h i}\right)=0$

$t_{B}^{c}\left(N_{l}\right)>t^{c}\left(a b_{l}^{i u}\right)>t_{B}^{c}\left(a b_{l}^{i}\right)=t_{B}^{c}\left(a_{l}^{h i}\right)>t_{B}^{c}\left(a b c_{l}^{i}\right)=t_{B}^{c}\left(b c_{l}^{i u}\right)=t_{B}^{c}\left(b c_{l}^{i}\right)=t_{B}^{c}\left(b_{l}^{h i}\right)=0$

$t^{c}\left(a b_{g}^{i u}\right)>t^{c}\left(N_{g}\right)>t_{B}^{c}\left(a b_{g}^{i}\right)=t_{B}^{c}\left(a_{g}^{h i}\right)>t_{B}^{c}\left(a b c_{g}^{i}\right)=t_{B}^{c}\left(b c_{g}^{i u}\right)=t_{B}^{c}\left(b c_{g}^{i}\right)=t_{B}^{c}\left(b_{g}^{h i}\right)=0$

Tariffs imposed by country c:

$t_{C}^{a}\left(N_{l}\right)=t_{C}^{a}\left(a b_{l}^{i u}\right)=t_{C}^{a}\left(a b_{l}^{i}\right)>t^{a}\left(b c_{l}^{i u}\right)>t_{C}^{a}\left(b c_{l}^{i}\right)=t_{C}^{a}\left(b_{l}^{h i}\right)>t_{C}^{a}\left(a b c_{l}^{i}\right)=t_{C}^{a}\left(a_{l}^{h i}\right)=0$

$t_{C}^{a}\left(N_{g}\right)=t_{C}^{a}\left(a b_{g}^{i u}\right)=t_{C}^{a}\left(a b_{g}^{i}\right)>t^{a}\left(b c_{g}^{i u}\right)>t_{C}^{a}\left(b c_{g}^{i}\right)=t_{C}^{a}\left(b_{g}^{h i}\right)>t_{C}^{a}\left(a b c_{g}^{i}\right)=t_{C}^{a}\left(a_{g}^{h i}\right)=0$

$t_{C}^{b}\left(N_{l}\right)=t_{C}^{b}\left(a b_{l}^{i u}\right)=t_{C}^{b}\left(a b_{l}^{i}\right)>t_{C}^{b}\left(a_{l}^{h i}\right)>t_{C}^{b}\left(a b c_{l}^{i}\right)=t_{C}^{b}\left(b c_{l}^{i u}\right)=t_{C}^{b}\left(b c_{l}^{i}\right)=t_{C}^{b}\left(b_{l}^{h i}\right)=0$

$t_{C}^{b}\left(N_{g}\right)=t_{C}^{b}\left(a b_{g}^{i u}\right)=t_{C}^{b}\left(a b_{g}^{i}\right)>t_{C}^{b}\left(a_{g}^{h i}\right)>t_{C}^{b}\left(a b c_{g}^{i}\right)=t_{C}^{b}\left(b c_{g}^{i u}\right)=t_{C}^{b}\left(b c_{g}^{i}\right)=t_{C}^{b}\left(b_{g}^{h i}\right)=0$

Taxes imposed by country a:

$e_{A}\left(a b_{l}^{i u}\right)>e_{A}^{a}\left(N_{l}\right)=e_{A}^{a}\left(b c_{l}^{i u}\right)=e_{A}^{a}\left(b c_{l}^{i}\right)=e_{A}\left(a_{l}^{h i}\right)=e_{A}\left(a b c_{l}^{i}\right)>e_{A}\left(b_{l}^{h i}\right)>e_{A}\left(a b_{l}^{i}\right)$

$e_{A}\left(a b c_{g}^{i}\right)=e_{A}\left(a_{g}^{h i}\right)>e_{A}\left(b_{g}^{h i}\right)>e_{A}\left(a b_{g}^{i u}\right)>e_{A}\left(a b_{g}^{i}\right)>e_{A}^{a}\left(N_{g}\right)=e_{A}^{a}\left(b c_{g}^{i u}\right)=e_{A}^{a}\left(b c_{g}^{i}\right)$

Taxes imposed by country b:

$e_{A}\left(b c_{l}^{i u}\right)=e_{A}\left(b c_{l}^{i}\right)>e_{A}^{b}\left(N_{l}\right)>e_{A}\left(a b_{l}^{i u}\right)>e_{A}\left(a_{l}^{h i}\right)=e_{A}\left(a b c_{l}^{i}\right)>e_{A}\left(b_{l}^{h i}\right)>e_{A}\left(a b_{l}^{i}\right)$

$e_{A}\left(a b c_{g}^{i}\right)=e_{A}\left(a_{g}^{h i}\right)>e_{A}\left(b_{g}^{h i}\right)>e_{A}\left(b c_{g}^{i u}\right)=e_{A}\left(b c_{g}^{i}\right)>e_{A}\left(a b_{g}^{i u}\right)>e_{A}\left(a b_{g}^{i}\right)>e_{A}^{b}\left(N_{g}\right)$

Taxes imposed by country c:

$e_{A}\left(b c_{l}^{i u}\right)=e_{A}\left(b c_{l}^{i}\right)>e_{A}^{c}\left(a b_{l}^{i}\right)>e_{A}^{c}\left(N_{l}\right)>e_{A}^{c}\left(a b_{l}^{i u}\right)>e_{A}\left(a_{l}^{h i}\right)=e_{A}\left(a b c_{l}^{i}\right)>e_{A}\left(b_{l}^{h i}\right)$

$e_{A}\left(a b c_{g}^{i}\right)=e_{A}\left(a_{g}^{h i}\right)>e_{A}\left(b_{g}^{h i}\right)>e_{A}\left(b c_{g}^{i u}\right)=e_{A}\left(b c_{g}^{i}\right)>e_{A}^{c}\left(N_{g}\right) \stackrel{\lambda \in(0,0.090]}{>} e_{A}^{c}\left(a b_{g}^{i u}\right)=e_{A}^{c}\left(a b_{g}^{i}\right)$ if $\lambda \in$ $(0,0.090]$

$e_{A}\left(a b c_{g}^{i}\right)=e_{A}\left(a_{g}^{h i}\right)>e_{A}\left(b_{g}^{h i}\right)>e_{A}\left(b c_{g}^{i u}\right)=e_{A}\left(b c_{g}^{i}\right)>e_{A}^{c}\left(a b_{g}^{i u}\right)=e_{A}^{c}\left(a b_{g}^{i}\right) \stackrel{\lambda \in(0.090,0.1]}{>} e_{A}^{c}\left(N_{g}\right)$ if $\lambda \in(0,0.090]$

Taxes and Tariffs under Deep FTA between Two Dirty Countries, $\left(b c_{\theta}^{i}\right)$ : 


$$
\begin{aligned}
& t_{C}^{b}\left(b c_{\theta}^{i}\right)=t_{B}^{c}\left(b c_{\theta}^{i}\right)=0 \\
& t_{B}^{a}\left(b c_{\theta}^{i}\right)=t_{C}^{a}\left(b c_{\theta}^{i}\right)=\frac{1}{4} \frac{1-\lambda^{2}}{\lambda^{2}+7 \lambda+14} \\
& t_{A}^{b}\left(b c_{\theta}^{i}\right)=t_{A}^{c}\left(b c_{\theta}^{i}\right)=\frac{1}{16} \frac{9+2 z \lambda(\lambda+4)-3 \lambda(\lambda+4)+14 z}{(\lambda+5)(\lambda+2)}, \text { then } \\
& t_{A}^{b}\left(b c_{l}^{i}\right)=t_{A}^{c}\left(b c_{l}^{i}\right)=\frac{3}{16} \frac{3-\lambda(\lambda+2)}{(\lambda+5)(\lambda+2)} \& t_{A}^{b}\left(b c_{g}^{i}\right)=t_{A}^{c}\left(b c_{g}^{i}\right)=\frac{1}{16} \frac{23-\lambda(\lambda-2)}{(\lambda+5)(\lambda+2)} \\
& e_{A}^{a}\left(b c_{\theta}\right)=\frac{1}{4} \& e_{A}\left(b c_{\theta}^{i}\right)=\frac{1}{4} \frac{13+\lambda^{2}(1-z)+z(8-\lambda)+4 \lambda}{(\lambda+5)(\lambda+2)}, \text { then } e_{A}\left(b c_{l}^{i}\right)=\frac{1}{4} \frac{13+\lambda(\lambda+4)}{(\lambda+5)(\lambda+2)} \& e_{A}\left(b c_{g}^{i}\right)=\frac{3}{4} \frac{7+\lambda}{(\lambda+5)(\lambda+2)}
\end{aligned}
$$

Taxes and Tariffs under Deep FTA between one Clean and One Dirty Country, $\left(a b_{\theta}^{i}\right)$ :

$$
\begin{aligned}
& t_{B}^{a}\left(a b_{\theta}^{i}\right)=t_{A}^{b}\left(a b_{\theta}^{i}\right)=0 \\
& t_{C}^{a}\left(a b_{\theta}^{i}\right)=t_{C}^{b}\left(a b_{\theta}^{i}\right)=\frac{1}{4} \frac{1-\lambda}{\lambda+3} \\
& t_{B}^{c}\left(a b_{\theta}^{i}\right)=\frac{1}{4} \frac{1-\lambda^{2}}{\lambda^{2}+7 \lambda+14} \\
& t_{A}^{c}\left(a b_{\theta}^{i}\right)=\frac{1}{8} \frac{\lambda^{2}(8 z-3)+3 \lambda(11 z+1)+25 z}{(2 \lambda+15)(\lambda+3)}, \text { then } t_{A}^{c}\left(a b_{l}^{i}\right)=\frac{3}{8} \frac{\lambda(1-\lambda)}{(2 \lambda+15)(\lambda+3)} \& t_{A}^{c}\left(a b_{g}^{i}\right)=\frac{1}{8} \frac{5\left(5+\lambda^{2}\right)+36 \lambda}{(2 \lambda+15)(\lambda+3)} \\
& e_{A}\left(a b_{\theta}^{i}\right)=\frac{1}{8} \frac{396+\lambda^{2} z(6 \lambda+65)+4 \lambda\left(\lambda^{2}+59 z\right)+2 \lambda(37 \lambda+171)+281 z}{(\lambda+3)(2 \lambda+15)(\lambda+5)}, \text { then } \\
& e_{A}\left(a b_{l}^{i}\right)=\frac{1}{8} \frac{396+2 \lambda^{2}(2 \lambda+37)+342 \lambda}{(\lambda+3)(2 \lambda+15)(\lambda+5)} \& e_{A}\left(a b_{g}^{i}\right)=\frac{1}{8} \frac{677+\lambda^{2}(10 \lambda+139)+578 \lambda}{(\lambda+3)(2 \lambda+15)(\lambda+5)} \\
& e_{A}^{c}\left(a b_{\theta}^{i}\right)=\frac{1}{4} \frac{252+2 \lambda^{3}(1-z)+\lambda^{2}(28-25 z)+\lambda(126-76 z)-53 z}{(\lambda+3)(2 \lambda+15)(\lambda+5)}, \text { then } \\
& e_{A}^{c}\left(a b_{l}^{i}\right)=\frac{1}{4} \frac{126(2+\lambda)+2 \lambda^{2}(\lambda+14)}{(\lambda+3)(2 \lambda+15)(\lambda+5)} \& e_{A}^{c}\left(a b_{g}^{i}\right)=\frac{1}{4} \frac{199+3 \lambda^{2}+50 \lambda}{(\lambda+3)(2 \lambda+15)(\lambda+5)}
\end{aligned}
$$

Taxes and Tariffs under Deep Hub-and-Spoke, Country a is the Hub, $\left(a_{\theta}^{h i}\right)$ :

$t_{A}^{b}\left(a_{\theta}^{h i}\right)=t_{A}^{c}\left(a_{\theta}^{h i}\right)=t_{B}^{a}\left(a_{\theta}^{h i}\right)=t_{C}^{a}\left(a_{\theta}^{h i}\right)=0$

$t_{C}^{b}\left(a_{\theta}^{h i}\right)=t_{B}^{c}\left(a_{\theta}^{h i}\right)=\frac{1}{4} \frac{1-\lambda^{2}}{\lambda^{2}+7 \lambda+14}$

$e_{A}\left(a_{\theta}^{h i}\right)=\frac{2 z+1}{4}$, then $e_{A}\left(a_{l}^{h i}\right)=\frac{1}{4} \& e_{A}\left(a_{g}^{h i}\right)=\frac{3}{4}$

Taxes and Tariffs under Deep Hub-and-Spoke, Country b is the Hub, $\left(b_{\theta}^{h i}\right)$ :

$t_{B}^{a}\left(b_{\theta}^{h i}\right)=t_{A}^{b}\left(b_{\theta}^{h i}\right)=t_{C}^{b}\left(b_{\theta}^{h i}\right)=t_{B}^{c}\left(b_{\theta}^{h i}\right)=0$

$t_{C}^{a}\left(b_{\theta}^{h i}\right)=\frac{1}{4} \frac{1-\lambda^{2}}{\lambda^{2}+7 \lambda+14}$

$t_{A}^{c}\left(b_{\theta}^{h i}\right)=\frac{3}{4} \frac{(\lambda+2)\left(7 z \lambda^{2}+26 z \lambda-3 \lambda^{2}+3 z+3\right)}{(\lambda+5)\left(9 \lambda^{2}+56 \lambda+67\right)}$, then $t_{A}^{c}\left(b_{l}^{h i}\right)=\frac{9}{4} \frac{(\lambda+2)\left(1-\lambda^{2}\right)}{(\lambda+5)\left(9 \lambda^{2}+56 \lambda+67\right)} \& t_{A}^{c}\left(b_{g}^{h i}\right)=\frac{6}{4} \frac{(\lambda+2)\left(2 \lambda^{2}+13 \lambda+3\right)}{(\lambda+5)\left(9 \lambda^{2}+56 \lambda+67\right)}$

$e_{A}\left(b_{\theta}^{h i}\right)=\frac{1}{4} \frac{332+25 \lambda\left(z \lambda^{2}+14\right)+2 \lambda^{2}(3 \lambda+52)+z \lambda(221 \lambda+671)+667 z}{(\lambda+5)\left(9 \lambda^{2}+56 \lambda+67\right)}$, then

$e_{A}\left(b_{l}^{h i}\right)=\frac{1}{4} \frac{332+6 \lambda^{3}+104 \lambda^{2}+350 \lambda}{(\lambda+5)\left(9 \lambda^{2}+56 \lambda+67\right)} \& e_{A}\left(b_{\theta}^{h i}\right)=\frac{1}{4} \frac{999+31 \lambda^{3}+325 \lambda^{2}+1021 \lambda}{(\lambda+5)\left(9 \lambda^{2}+56 \lambda+67\right)}$

Taxes and Tariffs under Deep Tree Trade, $\left(a b c_{\theta}^{i}\right)$ :

$t_{B}^{a}\left(a b c_{\theta}^{i}\right)=t_{C}^{a}\left(a b c_{\theta}^{i}\right)=t_{A}^{b}\left(a b c_{\theta}^{i}\right)=t_{C}^{b}\left(a b c_{\theta}^{i}\right)=t_{A}^{c}\left(a b c_{\theta}^{i}\right)=t_{B}^{c}\left(a b c_{\theta}^{i}\right)=0$

$e_{A}\left(a b c_{\theta}^{i}\right)=\frac{2 z+1}{4}$, then $e_{A}\left(a b c_{l}^{i}\right)=\frac{1}{4} \& e_{A}\left(a b c_{g}^{i}\right)=\frac{3}{4}$ 
Taxes and Tariffs under Deep Union of Two Dirty Countries, $\left(b c_{\theta}^{i u}\right)$ :

$t_{C}^{b}\left(b c_{\theta}^{i u}\right)=t_{B}^{c}\left(b c_{\theta}^{i u}\right)=0$

$t_{C}^{a}\left(b c_{\theta}^{i u}\right)=t_{B}^{a}\left(b c_{\theta}^{i u}\right)=t^{a}\left(b c_{\theta}^{i u}\right)$

$t_{A}^{b}\left(b c_{\theta}^{i u}\right)=t_{A}^{c}\left(b c_{\theta}^{i u}\right)=\frac{1}{16} \frac{9+\lambda^{2}(2 z-3)+2 z(4 \lambda+7)-6 \lambda}{(\lambda+5)(\lambda+2)}$, then

$t_{A}^{b}\left(b c_{l}^{i u}\right)=t_{A}^{c}\left(b c_{l}^{i u}\right)=\frac{3}{16} \frac{9-\lambda(\lambda+2)}{(\lambda+5)(\lambda+2)} \& t_{A}^{b}\left(b c_{g}^{i u}\right)=t_{A}^{c}\left(b c_{g}^{i u}\right)=\frac{1}{16} \frac{23+\lambda(2-\lambda)}{(\lambda+5)(\lambda+2)}$

$t^{a}\left(b c_{\theta}^{i u}\right)=\frac{1}{4} \frac{1-\lambda}{\lambda+4}$

$e_{A}^{a}\left(b c_{\theta}^{i u}\right)=\frac{1}{4} \& e_{A}\left(b c_{\theta}^{i u}\right)=\frac{1}{4} \frac{13+\lambda^{2}(1-z)+\lambda(4-z)+8 z}{(\lambda+5)(\lambda+2)}$, then $e_{A}\left(b c_{l}^{i u}\right)=\frac{1}{4} \frac{13+\lambda(\lambda+4)}{(\lambda+5)(\lambda+2)} \& e_{A}\left(b c_{g}^{i u}\right)=$ $\frac{3}{4} \frac{7+\lambda}{(\lambda+5)(\lambda+2)}$

Taxes and Tariffs under Deep Union of One Dirty and One Clean Country, $\left(a b_{\theta}^{i u}\right)$ :

$t_{B}^{a}\left(a b_{\theta}^{i u}\right)=t_{A}^{b}\left(a b_{\theta}^{i u}\right)=0$

$t_{A}^{c}\left(a b_{\theta}^{i u}\right)=t_{B}^{c}\left(a b_{\theta}^{i u}\right)=t^{c}\left(a b_{\theta}^{i u}\right)$

$t_{C}^{a}\left(a b_{\theta}^{i u}\right)=t_{C}^{b}\left(a b_{\theta}^{i u}\right)=\frac{1}{4} \frac{1-\lambda}{3+\lambda}$

$t^{c}\left(a b_{\theta}^{i u}\right)=\frac{1}{8} \frac{180+5 \lambda^{3}(z-3)+\lambda^{2}(59 z-88)+\lambda(227 z-77)+285 z}{8 \lambda^{3}+89 \lambda^{2}+332 \lambda+415}$, then

$t^{c}\left(a b_{l}^{i u}\right)=\frac{1}{8} \frac{180-15 \lambda^{3}-88 \lambda^{2}-77 \lambda}{8 \lambda^{3}+89 \lambda^{2}+332 \lambda+415} \& t^{c}\left(a b_{g}^{i u}\right)=\frac{1}{8} \frac{465-10 \lambda^{3}-29 \lambda^{2}+150 \lambda}{8 \lambda^{3}+89 \lambda^{2}+332 \lambda+415}$

$e_{A}\left(a b_{\theta}^{i u}\right)=\frac{1}{4} \frac{2141+\lambda^{4}(3 z+7)+\lambda^{3}(60 z+117)+\lambda^{2}(422 z+738)+\lambda(1268 z+2061)+1391 z}{(\lambda+5)\left(8 \lambda^{3}+89 \lambda^{2}+332 \lambda+415\right)}$, then

$e_{A}\left(a b_{l}^{i u}\right)=\frac{1}{4} \frac{2141+7 \lambda^{4}+117 \lambda^{3}+738 \lambda^{2}+2061 \lambda}{(\lambda+5)\left(8 \lambda^{3}+89 \lambda^{2}+332 \lambda+415\right)} \& e_{A}\left(a b_{g}^{i u}\right)=\frac{1}{4} \frac{3532+10 \lambda^{4}+117 \lambda^{3}+1160 \lambda^{2}+3329 \lambda}{(\lambda+5)\left(8 \lambda^{3}+89 \lambda^{2}+332 \lambda+415\right)}$

$e_{A}^{c}\left(a b_{\theta}^{i u}\right)=\frac{1}{2} \frac{1117+4 \lambda^{4}(1-z)-6 \lambda^{2} z(8+35)+\lambda^{2}(59 \lambda+353)+\lambda(999-322 z)-258 z}{(\lambda+5)\left(8 \lambda^{3}+89 \lambda^{2}+332 \lambda+415\right)}$, then

$e_{A}^{c}\left(a b_{l}^{i u}\right)=\frac{1}{2} \frac{1117+4 \lambda^{4}+59 \lambda^{3}+353 \lambda^{2}+999 \lambda}{(\lambda+5)\left(8 \lambda^{3}+89 \lambda^{2}+332 \lambda+415\right)} \& e_{A}^{c}\left(a b_{g}^{u}\right)=\frac{1}{2} \frac{859+11 \lambda^{3}+143 \lambda^{2}+607 \lambda}{(\lambda+5)\left(28 \lambda^{3}+279 \lambda^{2}+906 \lambda+959\right)}$

\section{A. 4.4 Environmental and Trade Agreements and their Effects on the Envi- ronmental Damages}

\section{A. 4.4.1 Pure Environmental Agreements}

World Damages:

$d^{w}\left(a b c_{l}^{e}\right)>d^{w}\left(a b_{l}^{e}\right)>d^{w}\left(N_{l}\right)>d^{w}\left(b c_{l}^{e}\right)$

$d^{w}\left(N_{g}\right)>d^{w}\left(a b_{g}^{e}\right)>d^{w}\left(b c_{g}^{e}\right)>d^{w}\left(a b c_{g}^{e}\right)$

Environmental damages in Country a: 
$d^{a}\left(a b_{l}^{e}\right)>d^{a}\left(b c_{l}^{e}\right)>d^{a}\left(a b c_{l}^{e}\right)>d^{a}\left(N_{l}\right)$

$d^{a}\left(N_{g}\right)>d^{a}\left(a b_{g}^{e}\right)>d^{a}\left(b c_{g}^{e}\right)>d^{a}\left(a b c_{g}^{e}\right)$

Environmental damages in Country b:

$d^{b}\left(a b_{l}^{e}\right)>d^{b}\left(a b c_{l}^{e}\right)>d^{b}\left(N_{l}\right)>d^{b}\left(b c_{l}^{e}\right)$

$d^{b}\left(N_{g}\right)>d^{b}\left(a b_{g}^{e}\right)>d^{b}\left(b c_{g}^{e}\right)>d^{b}\left(a b c_{g}^{e}\right)$

Environmental damages in Country c:

$d^{c}\left(a b c_{l}^{e}\right)>d^{c}\left(N_{l}\right)>d^{c}\left(a b_{l}^{e}\right)>d^{c}\left(b c_{l}^{e}\right)$

$d^{c}\left(N_{g}\right)>d^{c}\left(a b_{g}^{e}\right)>d^{c}\left(b c_{g}^{e}\right)>d^{c}\left(a b c_{g}^{e}\right)$

World Exports and Production of the Dirty Good A:

$x_{A}\left(a b c_{l}^{e}\right)>x_{A}\left(a b_{l}^{e}\right)>x_{A}\left(N_{l}\right)>x_{A}\left(b c_{l}^{e}\right)$

$x_{A}\left(N_{g}\right)>x_{A}\left(a b_{g}^{e}\right)>x_{A}\left(b c_{g}^{e}\right)>x_{A}\left(a b c_{g}^{e}\right)$

$s_{A}\left(a b c_{l}^{e}\right)>s_{A}\left(a b_{l}^{e}\right)>s_{A}\left(N_{l}\right)>s_{A}\left(b c_{l}^{e}\right)$

$s_{A}\left(N_{g}\right)>s_{A}\left(a b_{g}^{e}\right)>s_{A}\left(b c_{g}^{e}\right)>s_{A}\left(a b c_{g}^{e}\right)$

Export of Good A by Country b:

$x_{A}^{b}\left(a b_{l}^{e}\right)>x_{A}^{b}\left(a b c_{l}^{e}\right)>x_{A}^{b}\left(N_{l}\right)>x_{A}^{b}\left(b c_{l}^{e}\right)$

$x_{A}^{b}\left(N_{g}\right)>x_{A}^{b}\left(a b_{g}^{e}\right) \stackrel{\lambda \in(0,0.012]}{>} x_{A}^{b}\left(b c_{g}^{e}\right)>x_{A}^{b}\left(a b c_{l}^{e}\right)$ if $\lambda \in(0,0.012]$

$x_{A}^{b}\left(N_{g}\right)>x_{A}^{b}\left(b c_{g}^{e}\right) \stackrel{\lambda \in(0.012,0.1]}{>} x_{A}^{b}\left(a b_{g}^{e}\right)>x_{A}^{b}\left(a b c_{l}^{e}\right)$ if $\lambda \in(0,0.012]$

Export of Good A by Country c:

$x_{A}^{c}\left(a b c_{l}^{e}\right)>x_{A}^{c}\left(N_{l}\right)>x_{A}^{c}\left(b c_{l}^{e}\right)>x_{A}^{c}\left(a b_{l}^{e}\right)$

$x_{A}^{c}\left(a b_{g}^{e}\right)>x_{A}^{c}\left(N_{g}\right)>x_{A}^{c}\left(b c_{g}^{e}\right)>x_{A}^{c}\left(a b c_{g}^{e}\right)$

Export of Good A by Country b:

$x_{A}^{b}\left(a b_{l}\right)=x_{A}^{b}\left(b_{l}^{h}\right)>x_{A}^{b}\left(a b c_{l}\right)=x_{A}^{b}\left(a_{l}^{h}\right)>x_{A}^{b}\left(b c_{l}\right)=x_{A}^{b}\left(N_{l}\right)$

$x_{A}^{b}\left(a b_{g}\right)=x_{A}^{b}\left(b_{g}^{h}\right)>x_{A}^{b}\left(a b c_{g}\right)=x_{A}^{b}\left(a_{g}^{h}\right)>x_{A}^{b}\left(b c_{g}\right)=x_{A}^{b}\left(N_{g}\right)$

Export of Good A by Country c:

$x_{A}^{c}\left(a b c_{l}\right)=x_{A}^{c}\left(a_{l}^{h}\right)>x_{A}^{c}\left(a b_{l}\right)=x_{A}^{c}\left(b_{l}^{h}\right)>x_{A}^{c}\left(b c_{l}\right)=x_{A}^{c}\left(N_{l}\right)$

$x_{A}^{c}\left(a b c_{g}\right)=x_{A}^{c}\left(a_{g}^{h}\right)>x_{A}^{c}\left(a b_{g}\right)=x_{A}^{c}\left(b_{g}^{h}\right)>x_{A}^{c}\left(b c_{g}\right)=x_{A}^{c}\left(N_{g}\right)$ 


\section{A. 4.4.2 Shallow Trade Agreements}

World Damages:

$d^{w}\left(a b c_{l}\right)=d^{w}\left(a_{l}^{h}\right)>d^{w}\left(b_{l}^{h}\right)=d^{w}\left(a b_{l}\right)>d^{w}\left(a b_{l}^{u}\right)>d^{w}\left(b c_{l}\right)=d^{w}\left(b c_{l}^{u}\right)=d^{w}\left(N_{l}\right)$

$d^{w}\left(a b c_{g}\right)=d^{w}\left(a_{g}^{h}\right)>d^{w}\left(b_{g}^{h}\right)=d^{w}\left(a b_{g}\right)>d^{w}\left(a b_{g}^{u}\right)>d^{w}\left(b c_{g}\right)=d^{w}\left(b c_{g}^{u}\right)=d^{w}\left(N_{g}\right)$

Environmental damages in Country a:

$d^{a}\left(a b c_{l}\right)=d^{a}\left(a_{l}^{h}\right)>d^{a}\left(b_{l}^{h}\right)=d^{a}\left(a b_{l}\right)>d^{a}\left(a b_{l}^{u}\right)>d^{a}\left(b c_{l}\right)=d^{a}\left(b c_{l}^{u}\right)=d^{a}\left(N_{l}\right)$

$d^{a}\left(a b c_{g}\right)=d^{a}\left(a_{g}^{h}\right)>d^{a}\left(b_{g}^{h}\right)=d^{a}\left(a b_{g}\right)>d^{a}\left(a b_{g}^{u}\right)>d^{a}\left(b c_{g}\right)=d^{a}\left(b c_{g}^{u}\right)=d^{a}\left(N_{g}\right)$

Environmental damages in Country b:

$d^{b}\left(a b_{l}^{u}\right)>d^{b}\left(a b_{l}\right)=d^{b}\left(b_{l}^{h}\right)>d^{b}\left(a b c_{l}\right)=d^{b}\left(a_{l}^{h}\right)>d^{b}\left(b c_{l}\right)=d^{b}\left(b c_{l}^{u}\right)=d^{b}\left(N_{l}\right)$

$d^{b}\left(a b c_{g}\right)=d^{b}\left(a_{g}^{h}\right)>d^{b}\left(a b_{g}\right)=d^{b}\left(b_{g}^{h}\right)>d^{b}\left(a b_{g}^{u}\right)>d^{b}\left(b c_{g}\right)=d^{b}\left(b c_{g}^{u}\right)=d^{b}\left(N_{g}\right)$

Environmental damages in Country c:

$d^{c}\left(a b c_{l}\right)=d^{c}\left(a_{l}^{h}\right)>d^{c}\left(a b_{l}\right)=d^{c}\left(b_{l}^{h}\right)>d^{c}\left(b c_{l}\right)=d^{c}\left(b c_{l}^{u}\right)=d^{c}\left(N_{l}\right)>d^{c}\left(a b_{l}^{u}\right)$

$d^{c}\left(a b c_{g}\right)=d^{c}\left(a_{g}^{h}\right)>d^{c}\left(a b_{g}\right)=d^{c}\left(b_{g}^{h}\right)>d^{c}\left(a b_{g}^{u}\right)>d^{c}\left(b c_{g}\right)=d^{c}\left(b c_{g}^{u}\right)=d^{c}\left(N_{g}\right)$

World Exports of the Dirty Good A:

$x_{A}\left(a b c_{l}\right)=x_{A}\left(a_{l}^{h}\right)>x_{A}\left(b_{l}^{h}\right)=x_{A}\left(a b_{l}\right)>x_{A}\left(a b_{l}^{u}\right)>x_{A}\left(b c_{l}\right)=x_{A}\left(b c_{l}^{u}\right)=x_{A}\left(N_{l}\right)$

$x_{A}\left(a b c_{g}\right)=x_{A}\left(a_{g}^{h}\right)>x_{A}\left(b_{g}^{h}\right)=x_{A}\left(a b_{g}\right)>x_{A}\left(a b_{g}^{u}\right)>x_{A}\left(b c_{g}\right)=x_{A}\left(b c_{g}^{u}\right)=x_{A}\left(N_{g}\right)$

Export of Good A by Country b:

$x_{A}^{b}\left(a b_{l}^{u}\right)>x_{l}^{b}\left(a b_{l}\right)=x_{A}^{b}\left(b_{l}^{h}\right)>x_{A}^{b}\left(a b c_{l}\right)=x_{A}^{b}\left(a_{l}^{h}\right)>x_{A}^{b}\left(b c_{l}\right)=x_{A}^{b}\left(b c_{l}^{u}\right)=x_{A}^{b}\left(N_{l}\right)$

$x_{A}^{b}\left(a b_{g}^{u}\right)>x_{l}^{b}\left(a b_{g}\right)=x_{A}^{b}\left(b_{g}^{h}\right)>x_{A}^{b}\left(a b c_{g}\right)=x_{A}^{b}\left(a_{g}^{h}\right)>x_{A}^{b}\left(b c_{g}\right)=x_{A}^{b}\left(b c_{g}^{u}\right)=x_{A}^{b}\left(N_{g}\right)$

Export of Good A by Country c:

$x_{A}^{c}\left(a b c_{l}\right)=x_{A}^{c}\left(a_{l}^{h}\right)>x_{A}^{c}\left(a b_{l}\right)=x_{A}^{c}\left(b_{l}^{h}\right)>x_{A}^{c}\left(b c_{l}\right)=x_{A}^{c}\left(b c_{l}^{u}\right)=x_{A}^{c}\left(N_{l}\right)>x_{A}^{c}\left(a b_{l}^{u}\right)$

$x_{A}^{c}\left(a b c_{g}\right)=x_{A}^{c}\left(a_{g}^{h}\right)>x_{A}^{c}\left(a b_{g}\right)=x_{A}^{c}\left(b_{g}^{h}\right)>x_{A}^{c}\left(b c_{g}\right)=x_{A}^{c}\left(b c_{g}^{u}\right)=x_{A}^{c}\left(N_{g}\right)>x_{A}^{c}\left(a b_{g}^{u}\right)$

\section{A. 4.4.3 Deep Trade Agreements}

World Damages:

$d^{w}\left(a b_{l}^{i}\right)>d^{w}\left(a b c_{l}^{i}\right)=d^{w}\left(a_{l}^{h i}\right)>d^{w}\left(a b_{l}^{i u}\right)>d^{w}\left(b c_{l}^{i}\right)=d^{w}\left(N_{l}\right)>d^{w}\left(b c_{l}^{i u}\right)$ 
$d^{w}\left(N_{g}\right)=d^{w}\left(b c_{g}^{i}\right)>d^{w}\left(a b_{g}^{i}\right)>d^{w}\left(a b_{g}^{i u}\right)>d^{w}\left(b c_{g}^{i u}\right)>d^{w}\left(a b c_{g}^{i}\right)=d^{w}\left(a_{g}^{h i}\right)$

Environmental damages in Country a:

$d^{a}\left(b c_{l}^{i u}\right)>d^{a}\left(N_{l}\right)=d^{a}\left(b c_{l}^{i}\right)>d^{a}\left(a b_{l}^{i}\right)>d^{a}\left(a b_{l}^{i u}\right)>d^{a}\left(a b c_{l}^{i}\right)=d^{a}\left(a_{l}^{h i}\right)$

$d^{a}\left(N_{g}\right)=d^{a}\left(b c_{g}^{i}\right)>d^{a}\left(a b_{g}^{i}\right)>d^{a}\left(a b_{g}^{i u}\right)>d^{a}\left(b c_{g}^{i u}\right)>d^{a}\left(a b c_{g}^{i}\right)=d^{a}\left(a_{g}^{h i}\right)$

Environmental damages in Country b:

$d^{b}\left(a b_{l}^{i}\right)>d^{b}\left(a b c_{l}^{i}\right)=d^{b}\left(a_{l}^{h i}\right)>d^{b}\left(a b_{l}^{i u}\right)>d^{b}\left(b c_{l}^{i}\right)=d^{b}\left(N_{l}\right)>d^{b}\left(b c_{l}^{i u}\right)$

$d^{b}\left(N_{g}\right)=d^{b}\left(b c_{g}^{i}\right)>d^{b}\left(a b_{g}^{i}\right)>d^{b}\left(a b_{g}^{i u}\right)>d^{b}\left(b c_{g}^{i u}\right)>d^{b}\left(a b c_{g}^{i}\right)=d^{b}\left(a_{g}^{h i}\right)$

Environmental damages in Country c:

$d^{c}\left(a b c_{l}^{i}\right)=d^{c}\left(a_{l}^{h i}\right)>d^{c}\left(a b_{l}^{i}\right)>d^{c}\left(b c_{l}^{i}\right)=d^{c}\left(N_{l}\right)>d^{c}\left(a b_{l}^{i u}\right)>d^{c}\left(b c_{l}^{i u}\right)$

$d^{c}\left(N_{g}\right)=d^{c}\left(b c_{g}^{i}\right)>d^{c}\left(a b_{g}^{i}\right)>d^{c}\left(a b_{g}^{i u}\right)>d^{c}\left(b c_{g}^{i u}\right)>d^{c}\left(a b c_{g}^{i}\right)=d^{c}\left(a_{g}^{h i}\right)$

World Exports of the Dirty Good A:

$x_{A}\left(a b c_{l}^{i}\right)=x_{A}\left(a_{l}^{h i}\right)>x_{A}\left(a b_{l}^{i}\right)>x_{A}\left(a b_{l}^{i u}\right)>x_{A}\left(N_{l}\right)>x_{A}\left(b c_{l}^{i}\right)=x_{A}\left(b c_{l}^{i u}\right)$

$x_{A}\left(a b_{g}^{i}\right)>x_{A}\left(a b_{g}^{i u}\right)>x_{A}\left(N_{g}\right)>x_{A}\left(a b c_{g}^{i}\right)=x_{A}\left(a_{g}^{h i}\right)>x_{A}\left(b c_{g}^{i}\right)=x_{A}\left(b c_{g}^{i u}\right)$

Export of Good A by Country b:

$x_{A}^{b}\left(a b_{l}^{i u}\right)>x_{A}^{b}\left(a b_{l}^{i}\right)>x_{A}^{b}\left(a b c_{l}^{i}\right)=x_{A}^{b}\left(a_{l}^{h i}\right)>x_{A}^{b}\left(N_{l}\right)>x_{A}^{b}\left(b c_{l}^{i}\right)=x_{A}^{b}\left(b c_{l}^{i u}\right)$

$x_{A}^{b}\left(a b_{g}^{i u}\right)>x_{A}^{b}\left(a b_{g}^{i}\right)>x_{A}^{b}\left(N_{g}\right)>x_{A}^{b}\left(a b c_{g}^{i}\right)=x_{A}^{b}\left(a_{g}^{h i}\right)>x_{A}^{b}\left(b c_{g}^{i}\right)=x_{A}^{b}\left(b c_{g}^{i u}\right)$

Export of Good A by Country c:

$$
\begin{aligned}
& x_{A}^{c}\left(a b c_{l}^{i}\right)=x_{A}^{c}\left(a_{l}^{h i}\right)>x_{A}^{c}\left(a b_{l}^{i}\right)>x_{A}^{c}\left(N_{l}\right)>x_{A}^{c}\left(b c_{l}^{i}\right)=x_{A}^{c}\left(b c_{l}^{i u}\right)>x_{A}^{c}\left(a b_{l}^{i u}\right) \\
& x_{A}^{c}\left(a b_{g}^{i}\right)>x_{A}^{c}\left(N_{g}\right) \stackrel{\lambda \in(0,0.090]}{>} x_{A}^{c}\left(a b_{g}^{i u}\right)>x_{A}^{c}\left(a b c_{g}^{i}\right)=x_{A}^{c}\left(a_{g}^{h i}\right)>x_{A}^{c}\left(b c_{g}^{i}\right)=x_{A}^{c}\left(b c_{g}^{i u}\right) \\
& x_{A}^{c}\left(a b_{g}^{i}\right)>x_{A}^{c}\left(a b_{g}^{i u}\right) \stackrel{\lambda \in(0.090,0.1]}{>} x_{A}^{c}\left(N_{g}\right)>x_{A}^{c}\left(a b c_{g}^{i}\right)=x_{A}^{c}\left(a_{g}^{h i}\right)>x_{A}^{c}\left(b c_{g}^{i}\right)=x_{A}^{c}\left(b c_{g}^{i u}\right)
\end{aligned}
$$

\section{A. 4.6 The Environmental Agreement Game}

Welfare effects of various type of environmental agreements:

$W^{a}\left(a b c_{l}^{e}\right)>W^{a}\left(a b_{l}^{e}\right)>W^{a}\left(N_{l}\right)>W^{a}\left(b c_{l}^{e}\right)$ Country $a$, local pollution

$W^{a}\left(a b c_{g}^{e}\right)>W^{a}\left(b c_{g}^{e}\right)>W^{a}\left(a b_{g}^{e}\right)>W^{a}\left(N_{g}\right)$ Country $a$, global pollution

$W^{b}\left(N_{l}\right)>W^{b}\left(b c_{l}^{e}\right)>W^{b}\left(a b_{l}^{e}\right)>W^{b}\left(a b c_{l}^{e}\right)$ Country $b$, local pollution

$W^{b}\left(b c_{g}^{e}\right)>W^{b}\left(a b c_{g}^{e}\right)>W^{b}\left(N_{g}\right)>W^{b}\left(a b_{g}^{e}\right)$ Country $b$, global pollution 
$W^{c}\left(N_{l}\right)>W^{c}\left(b c_{l}^{e}\right)>W^{c}\left(a b_{l}^{e}\right)>W^{c}\left(a b c_{l}^{e}\right)$ Country $c$, local pollution

$W^{c}\left(b c_{g}^{e}\right)>W^{c}\left(a b c_{g}^{e}\right)>W^{c}\left(a b_{g}^{e}\right)>W^{c}\left(N_{g}\right)$ Country $c$, global pollution

\begin{tabular}{|c|c|}
\hline Announcement Profiles & Environmental Agreements \\
\hline \hline$\Omega^{\Phi^{e}} \equiv\left\{\sigma_{a}^{e}=\{\varnothing, \varnothing\}, \sigma_{b}^{e}=\{\varnothing, \varnothing\}, \sigma_{c}^{e}=\{\varnothing, \varnothing\}\right\}$ & $\left\langle\Phi^{e}\right\rangle$ \\
\hline$\Omega^{a b e} \equiv\left\{\sigma_{a}^{e}=\left\{b^{e}, \varnothing\right\}, \sigma_{b}^{e}=\left\{a^{e}, \varnothing\right\}, \sigma_{c}^{e}=\{\varnothing, \varnothing\}\right\}$ & $\langle a b e\rangle$ \\
\hline$\Omega^{b c e} \equiv\left\{\sigma_{a}^{e}=\{\varnothing, \varnothing\}, \sigma_{b}^{e}=\left\{\varnothing, c^{e}\right\}, \sigma_{c}^{e}=\left\{\varnothing, b^{e}\right\}\right\}$ & $\langle b c e\rangle$ \\
\hline$\Omega^{E} \equiv\left\{\sigma_{a}^{e}=\left\{b^{e}, c^{e}\right\}, \sigma_{b}^{e}=\left\{a^{e}, c^{e}\right\}, \sigma_{c}^{e}=\left\{a^{e}, b^{e}\right\}\right\}$ & $\langle E\rangle$ \\
\hline
\end{tabular}

$$
\Omega^{\Phi^{e}} \equiv\left\{\sigma_{a}^{e}=\{\varnothing, \varnothing\}, \sigma_{b}^{e}=\{\varnothing, \varnothing\}, \sigma_{c}^{e}=\{\varnothing, \varnothing\}\right\}
$$

$\Omega^{\Phi^{e}}$ is a Nash Equilibria for both local and global levels of pollution.

\section{PROOF:}

Countries cannot change their welfares by unilaterally changing the announcements.

$\Omega^{\Phi^{e}}$ is a CPNE if pollution is local.

\section{PROOF:}

We prove the above by examining all possible deviations. First, we analyze the coalitional deviation of two asymmetric countries, the clean country $a$ and the dirty country $b$, then their announcements would be as follows: $\sigma_{a}^{e}=\left\{b^{e}, \varnothing\right\}$ and $\sigma_{b}^{e}=\left\{a^{e}, \varnothing\right\}$, and as a result, $W^{b}\left(a b_{l}^{e}\right)<W^{b}\left(N_{l}\right)$ and $W^{a}\left(a b_{l}^{e}\right)>W^{a}\left(N_{l}\right)$. We can conclude, that though the clean country would benefit from the coalition with the dirty country, the dirty country is not going to be interested in that environmental union. We can conclude, that this initial deviation is not meaningful. Second, we assume that two dirty countries form a coalition, then the announcements would be as follows: $\sigma_{b}^{e}=\left\{\varnothing, c^{e}\right\}$ and $\sigma_{c}^{e}=\left\{\varnothing, b^{e}\right\}$, and it will result in $W^{j}\left(b c_{l}^{e}\right)<W^{j}\left(N_{l}\right)$ where $j \neq a$. Again, we can conclude that this deviation is not meaningful. Now, we examine the grand environmental coalition, then the announcement profile would be as follows: $\Omega^{E} \equiv\left\{\sigma_{a}^{e}=\left\{b^{e}, c^{e}\right\}, \sigma_{b}^{e}=\left\{a^{e}, c^{e}\right\}, \sigma_{c}^{e}=\left\{a^{e}, b^{e}\right\}\right\}$ and $W^{j}\left(N_{l}\right)>W^{j}\left(a b c_{l}^{e}\right)$ where $j \neq a$. We observe that this deviation is not meaningful as well. Based on the above, we can conclude that $\Omega^{\Phi^{e}}$ is a CPNE for the local level of pollution. $\Omega^{\Phi^{e}}$ is not a CPNE if pollution is global. 


\section{PROOF:}

To prove the above, we examine the coalitional deviation of two symmetric dirty countries, country $b$ and country $c$. Their announcements would be altered as follows: $\sigma_{b}^{e}=\left\{\varnothing, c^{e}\right\}$ and $\sigma_{c}^{e}=$ $\left\{\varnothing, b^{e}\right\}$, and as a result, we observe that $W^{j}\left(b c_{g}^{e}\right)>W^{j}\left(N_{g}\right)$ where $j \neq a$. Further deviations are not meaningful, because the level of welfares both members achieve under this environmental agreement is the highest in the entire game. Based on the above, we are confident to conclude that $\Omega^{\Phi^{e}}$ is not a CPNE if pollution is global.

$$
\Omega^{a b e} \equiv\left\{\sigma_{a}^{e}=\left\{b^{e}, \varnothing\right\}, \sigma_{b}^{e}=\left\{a^{e}, \varnothing\right\}, \sigma_{c}^{e}=\{\varnothing, \varnothing\}\right\}
$$

$\Omega^{\text {abe }}$ is not a Nash Equilibria for both local and global levels of pollution.

\section{PROOF:}

country $\mathrm{b}=\left\{a^{e}, \varnothing\right\} \stackrel{\text { change }}{\longrightarrow}\left\{\varnothing, c^{e}\right\} /\{\varnothing, \varnothing\} \stackrel{\text { result }}{\longrightarrow} W^{b}\left(a b_{\theta}^{e}\right)<W^{b}\left(N_{\theta}\right)$

We can conclude, that country the dirty country $b$ would deviate to improve its welfare. Based on that, $\Omega^{a b e}$ is not a Nash Equilibria for both local and global levels of pollution.

$$
\Omega^{b c e} \equiv\left\{\sigma_{a}^{e}=\{\varnothing, \varnothing\}, \sigma_{b}^{e}=\left\{\varnothing, c^{e}\right\}, \sigma_{c}^{e}=\left\{\varnothing, b^{e}\right\}\right\}
$$

$\Omega^{\text {bce }}$ is not a Nash Equilibria if pollution is local.

\section{PROOF:}

country $\mathrm{b}=\left\{\varnothing, c^{e}\right\} \stackrel{\text { change }}{\longrightarrow}\left\{a^{e}, \varnothing\right\} /\{\varnothing, \varnothing\} \stackrel{\text { result }}{\longrightarrow} W^{b}\left(b c_{\theta}^{e}\right)<W^{b}\left(N_{\theta}\right)$

country $\mathrm{c}=\left\{\varnothing, b^{e}\right\} \stackrel{\text { change }}{\longrightarrow}\left\{a^{e}, \varnothing\right\} /\{\varnothing, \varnothing\} \stackrel{\text { result }}{\longrightarrow} W^{c}\left(b c_{\theta}^{e}\right)<W^{c}\left(N_{\theta}\right)$

We can conclude, that either of the dirty countries, country $b$ and/or country $c$, can deviate and improve its welfare. Based on that, $\Omega^{b c e}$ is not a Nash Equilibria if pollution is local.

$\Omega^{\text {bce }}$ is a Nash Equilibria if pollution is global.

\section{PROOF:}

country a $=\{\varnothing, \varnothing\} \stackrel{\text { change }}{\longrightarrow}\left\{b^{e}, \varnothing\right\} /\left\{\varnothing, c^{e}\right\} /\left\{b^{e}, c^{e}\right\} \stackrel{\text { result }}{\longrightarrow}$ no change in $a$ 's welfare

We can conclude, that country $a$ has no incentive to change its announcement.

country $\mathrm{b}=\left\{\varnothing, c^{e}\right\} \stackrel{\text { change }}{\longrightarrow}\left\{a^{e}, c^{e}\right\} \stackrel{\text { result }}{\longrightarrow}$ no change in $b$ 's welfare

country $\mathrm{b}=\left\{\varnothing, c^{e}\right\} \stackrel{\text { change }}{\longrightarrow}\left\{a^{e}, \varnothing\right\} /\{\varnothing, \varnothing\} \stackrel{\text { result }}{\longrightarrow} W^{b}\left(b c_{g}^{e}\right)>W^{b}\left(N_{g}\right)$ 
We can conclude, that country $b$ has no incentive to change its announcement.

country $\mathrm{c}=\left\{\varnothing, b^{e}\right\} \stackrel{\text { change }}{\longrightarrow}\left\{a^{e}, b^{e}\right\} \stackrel{\text { result }}{\longrightarrow}$ no change in $c$ 's welfare

country $\mathrm{c}=\left\{\varnothing, b^{e}\right\} \stackrel{\text { change }}{\longrightarrow}\left\{a^{e}, \varnothing\right\} /\{\varnothing, \varnothing\} \stackrel{\text { result }}{\longrightarrow} W^{c}\left(b c_{g}^{e}\right)>W^{c}\left(N_{g}\right)$

We can conclude, that country $c$ has no incentive to change its announcement.

Based on the above, we conclude that $\Omega^{b c e}$ is a Nash Equilibria if pollution is global.

$\Omega^{\text {bce }}$ is a CPNE if pollution is global.

ProOF:

We prove the above by examining all possible deviations. First, we examine the coalitional deviation of two asymmetric countries, the clean country $a$ and the dirty country $b$, then $W^{b}\left(a b_{g}^{e}\right)<$ $W^{b}\left(b c_{g}^{e}\right)$. We can see that this deviation is not meaningful. Next, we examine the grand environmental coalition, then $W^{j}\left(a b c_{g}^{e}\right)<W^{j}\left(b c_{g}^{e}\right)$ where $j \neq a$. Again, we can see that this initial deviation is not meaningful for dirty countries. Based on the above, we can conclude that $\Omega^{b c e}$ is a CPNE if pollution is global.

$$
\Omega^{E} \equiv\left\{\sigma_{a}^{e}=\left\{b^{e}, c^{e}\right\}, \sigma_{b}^{e}=\left\{a^{e}, c^{e}\right\}, \sigma_{c}^{e}=\left\{a^{e}, b^{e}\right\}\right\}
$$

$\Omega^{E}$ is not a Nash Equilibria for both local and global levels of pollution.

PROOF:

We prove the above in two steps: first, we consider the case of local pollution, and then we examine the case of global pollution.

country $\mathrm{b}=\left\{a^{e}, c^{e}\right\} \stackrel{\text { change }}{\longrightarrow}\{\varnothing, \varnothing\} \stackrel{\text { result }}{\longrightarrow} W^{b}\left(a b c_{\theta}^{e}\right)<W^{b}\left(a c_{\theta}^{e}\right)$

country $\mathrm{c}=\left\{a^{e}, b^{e}\right\} \stackrel{\text { change }}{\longrightarrow}\{\varnothing, \varnothing\} \stackrel{\text { result }}{\longrightarrow} W^{c}\left(a b c_{\theta}^{e}\right)<W^{c}\left(a b_{\theta}^{e}\right)$

We can conclude, that either of the dirty countries, country $b$ and/or country $c$, can deviate and improve its welfare. Based on that, $\Omega^{E}$ is not a Nash Equilibria if pollution is local.

country $\mathrm{b}=\left\{a^{e}, c^{e}\right\} \stackrel{\text { change }}{\longrightarrow}\left\{\varnothing, c^{e}\right\} \stackrel{\text { result }}{\longrightarrow} W^{b}\left(b c_{g}^{u}\right)>W^{b}\left(a b c_{g}\right)$

country c $=\left\{a^{e}, b^{e}\right\} \stackrel{\text { change }}{\longrightarrow}\left\{\varnothing, b^{e}\right\} \stackrel{\text { result }}{\longrightarrow} W^{c}\left(b c_{g}^{u}\right)>W^{c}\left(a b c_{g}\right)$

We can conclude, that either of the dirty countries can improve its welfare by calling another dirty country only. Dirty countries would prefer to exclude the clean partner for both local and global 
levels of pollution. Based on the above, we are confident to conclude that $\Omega^{E}$ is not a Nash Equilibria for both local and global levels of pollution.

\section{A. 4.7.1 The Customs Union Game}

Welfare effects of various types of trade agreements

$$
\begin{aligned}
& W^{a}\left(a b_{l}^{u}\right)>W^{a}\left(a b c_{l}\right)>W^{a}\left(N_{l}\right)>W^{a}\left(b c_{l}^{u}\right) \text { Country } a, \theta=l \\
& W^{a}\left(N_{g}\right)>W^{a}\left(a b_{g}^{u}\right)>W^{a}\left(a b c_{g}\right) \stackrel{\lambda \in(0,0.089]}{>} W^{a}\left(b c_{g}^{u}\right) \text { Country } a, \theta=g \& \lambda \in(0,0.089] \\
& W^{a}\left(N_{g}\right)>W^{a}\left(a b_{g}^{u}\right)>W^{a}\left(b c_{g}^{u}\right) \stackrel{\lambda \in(0.089,0.1]}{>} W^{a}\left(a b c_{g}\right) \text { Country } a, \theta=g \& \lambda \in(0.089,0.1] \\
& W^{b}\left(b c_{l}^{u}\right)>W^{b}\left(a b c_{l}\right)>W^{b}\left(a b_{l}^{u}\right)>W^{b}\left(N_{l}\right) \text { Country } b, \theta=l \\
& W^{b}\left(b c_{g}^{u}\right)>W^{b}\left(a b_{g}^{u}\right)>W^{b}\left(N_{g}\right)>W^{b}\left(a b c_{g}\right) \text { Country } b, \theta=g \\
& W^{c}\left(b c_{l}^{u}\right)>W^{c}\left(a b c_{l}\right)>W^{c}\left(N_{l}\right)>W^{c}\left(a b_{l}^{u}\right) \text { Country } c, \theta=l \\
& W^{c}\left(b c_{g}^{u}\right)>W^{c}\left(N_{g}\right)>W^{c}\left(a b c_{g}\right)>W^{c}\left(a b_{g}^{u}\right) \text { Country } c, \theta=g
\end{aligned}
$$

\begin{tabular}{|c|c|}
\hline Announcement Profiles & Trade Agreements \\
\hline \hline$\Omega^{\Phi^{u}} \equiv\left\{\sigma_{a}^{u}=\{\varnothing, \varnothing\}, \sigma_{b}^{u}=\{\varnothing, \varnothing\}, \sigma_{c}^{u}=\{\varnothing, \varnothing\}\right\}$ & $\left\langle\Phi^{u}\right\rangle$ \\
\hline$\Omega^{a b u} \equiv\left\{\sigma_{a}^{u}=\left\{b^{u}, \varnothing\right\}, \sigma_{b}^{u}=\left\{a^{u}, \varnothing\right\}, \sigma_{c}^{u}=\{\varnothing, \varnothing\}\right\}$ & $\langle a b u\rangle$ \\
\hline$\Omega^{b c u} \equiv\left\{\sigma_{a}^{u}=\{\varnothing, \varnothing\}, \sigma_{b}^{u}=\left\{\varnothing, c^{u}\right\}, \sigma_{c}^{u}=\left\{\varnothing, b^{u}\right\}\right\}$ & $\langle b c u\rangle$ \\
\hline$\Omega^{F^{u}} \equiv\left\{\sigma_{a}^{u}=\left\{b^{u}, c^{u}\right\}, \sigma_{b}^{u}=\left\{a^{u}, c^{u}\right\}, \sigma_{c}^{u}=\left\{a^{u}, b^{u}\right\}\right\}$ & $\left\langle F^{u}\right\rangle$ \\
\hline
\end{tabular}

$$
\Omega^{\Phi^{u}} \equiv\left\{\sigma_{a}^{u}=\{\varnothing, \varnothing\}, \sigma_{b}^{u}=\{\varnothing, \varnothing\}, \sigma_{c}^{u}=\{\varnothing, \varnothing\}\right\}
$$

$\Omega^{\Phi^{u}}$ is a Nash Equilibria for both local and global levels of pollution.

\section{PROOF:}

Countries cannot get better off by unilaterally changing the announcements; countries have no incentive to announce any other country unless they are going to be announced back.

$\Omega^{\Phi^{u}}$ is not a CPNE for both local and global levels of pollution.

\section{PROOF:}

We assume that countries $b$ and $c$ get form a trade union, then the announcement profile would be altered as follows: $\Omega \equiv\left\{\sigma_{a}^{u}=\{\varnothing, \varnothing\}, \sigma_{b}^{u}=\left\{\varnothing, c^{u}\right\}, \sigma_{c}^{u}=\left\{\varnothing, b^{u}\right\}\right\}$. As a result, we observe an 
increase in members' welfare levels, $W^{b}\left(b c_{\theta}^{u}\right)>W^{b}\left(N_{\theta}\right)$ and $W^{c}\left(b c_{\theta}^{u}\right)>W^{c}\left(N_{\theta}\right)$. The trade union of two dirty countries brings them the highest level of welfare in this game, so we can conclude that those counties can form a self-enforcing trade agreement for both levels of pollution, and no further deviations can occur.

$$
\Omega^{a b u} \equiv\left\{\sigma_{a}^{u}=\left\{b^{u}, \varnothing\right\}, \sigma_{b}^{u}=\left\{a^{u}, \varnothing\right\}, \sigma_{c}^{u}=\{\varnothing, \varnothing\}\right\}
$$

$\Omega^{a b u}$ is a Nash Equilibria if pollution is local.

\section{PROOF:}

country a $=\left\{b^{u}, \varnothing\right\} \stackrel{\text { change }}{\longrightarrow}\left\{b^{u}, c^{u}\right\} \stackrel{\text { result }}{\longrightarrow}$ no change in $a$ 's welfare

country a $=\left\{b^{u}, \varnothing\right\} \stackrel{\text { change }}{\longrightarrow}\left\{\varnothing, c^{u}\right\} /\{\varnothing, \varnothing\} \stackrel{\text { result }}{\longrightarrow} W^{a}\left(a b_{l}^{u}\right)>W^{a}\left(N_{l}\right)$

We can conclude, that country $a$ has no incentive to change its announcement.

country $\mathrm{b}=\left\{a^{u}, \varnothing\right\} \stackrel{\text { change }}{\longrightarrow}\left\{a^{u}, c^{u}\right\} \stackrel{\text { result }}{\longrightarrow}$ no change in $b$ 's welfare

country $\mathrm{b}=\left\{a^{u}, \varnothing\right\} \stackrel{\text { change }}{\longrightarrow}\left\{\varnothing, c^{u}\right\} /\{\varnothing, \varnothing\} \stackrel{\text { result }}{\longrightarrow} W^{b}\left(a b_{l}^{u}\right)>W^{b}\left(N_{l}\right)$

We can conclude, that country $b$ has no incentive to change its announcement.

country $\mathrm{c}=\{\varnothing, \varnothing\} \stackrel{\text { change }}{\longrightarrow}\left\{a^{u}, \varnothing\right\} /\left\{\varnothing, b^{u}\right\} /\left\{a^{u}, b^{u}\right\} \stackrel{\text { result }}{\longrightarrow}$ no change in $c$ 's welfare

We can conclude, that country $c$ has no incentive to change its announcement.

Based on the above, $\Omega^{a b u}$ is a Nash Equilibria if pollution is local.

$\Omega^{a b u}$ is not a Nash Equilibria if pollution is global.

PROOF:

country a $=\left\{b^{u}, \varnothing\right\} \stackrel{\text { change }}{\longrightarrow}\{\varnothing, \varnothing\} \stackrel{\text { result }}{\longrightarrow} W^{a}\left(a b_{g}^{u}\right)<W^{a}\left(N_{g}\right)$

We can conclude, that country the clean country $a$ would deviate to improve its welfare. Based on that, $\Omega^{a b u}$ is not a Nash Equilibria if pollution is global.

$\Omega^{a b u}$ is not a CPNE if pollution is local.

PROOF:

Suppose, two dirty countries, $b$ and $c$, form a trade union and exclude $a$, then $W^{b}\left(b c_{\theta}^{u}\right)>W^{b}\left(a b_{\theta}^{u}\right)$ and $W^{c}\left(b c_{\theta}^{u}\right)>W^{c}\left(a b_{\theta}^{u}\right)$

The trade union between two dirty countries, $b$ and $c$, brings members the highest level of welfare in this game. We can conclude that those counties can form a self-enforcing trade agreement and 
exclude the clean country $a$. Also, no further deviations can occur.

$$
\Omega^{b c u} \equiv\left\{\sigma_{a}^{u}=\{\varnothing, \varnothing\}, \sigma_{b}^{u}=\left\{\varnothing, c^{u}\right\}, \sigma_{c}^{u}=\left\{\varnothing, b^{u}\right\}\right\}
$$

$\Omega^{b c u}$ is a Nash Equilibria for both local and global levels of pollution.

PROOF:

country a $=\{\varnothing, \varnothing\} \stackrel{\text { change }}{\longrightarrow}\left\{b^{u}, \varnothing\right\} /\left\{\varnothing, c^{u}\right\} /\left\{b^{u}, c^{u}\right\} \stackrel{\text { result }}{\longrightarrow}$ no change in $a$ 's welfare

We can conclude, that country $a$ has no incentive to change its announcement.

country $\mathrm{b}=\left\{\varnothing, c^{u}\right\} \stackrel{\text { change }}{\longrightarrow}\left\{a^{u}, c^{u}\right\} \stackrel{\text { result }}{\longrightarrow}$ no change in $b$ 's welfare

country $\mathrm{b}=\left\{\varnothing, c^{u}\right\} \stackrel{\text { change }}{\longrightarrow}\{\varnothing, \varnothing\} /\left\{a^{u}, \varnothing\right\} \stackrel{\text { result }}{\longrightarrow} W^{b}\left(b c_{\theta}^{u}\right)>W^{b}\left(N_{\theta}\right)$

We can conclude, that country $b$ has no incentive to change its announcement.

country $\mathrm{c}=\left\{\varnothing, b^{u}\right\} \stackrel{\text { change }}{\longrightarrow}\left\{a^{u}, b^{u}\right\} \stackrel{\text { result }}{\longrightarrow}$ no change in $c^{\prime}$ 's welfare

country $\mathrm{c}=\left\{\varnothing, b^{u}\right\} \stackrel{\text { change }}{\longrightarrow}\left\{a^{u}, \varnothing\right\} /\{\varnothing, \varnothing\} \stackrel{\text { result }}{\longrightarrow} W^{c}\left(b c_{\theta}^{u}\right)>W^{c}\left(N_{\theta}\right)$

We can conclude, that country $c$ has no incentive to change its announcement.

Based on the above, $\Omega^{b c u}$ is a Nash Equilibria for both local and global levels of pollution.

$\Omega^{b c u}$ is a CPNE for both local and global levels of pollution.

PROOF:

Neither member can do better by deviating from their original announcement for both levels of pollution:

local pollution: $W^{b}\left(b c_{l}^{u}\right)>W^{b}\left(a b c_{l}\right)>W^{b}\left(a b_{l}^{u}\right)>W^{b}\left(N_{l}\right) \& W^{c}\left(b c_{l}^{u}\right)>W^{c}\left(a b c_{l}\right)>W^{c}\left(N_{l}\right)>$ $W^{c}\left(a b_{l}^{u}\right)$

global pollution: $W^{b}\left(b c_{g}^{u}\right)>W^{b}\left(a b_{g}^{u}\right)>W^{b}\left(N_{g}\right)>W^{b}\left(a b c_{g}\right) \& W^{c}\left(b c_{g}^{u}\right)>W^{c c}\left(N_{g}\right)>W^{c}\left(a b c_{g}\right)>$ $W^{c}\left(a b_{g}^{u}\right)$.

We conclude that, $\Omega^{b c u}$ is a self-enforcing commitment between two dirty countries for both local and global levels of pollution.

$$
\Omega^{F^{u}} \equiv\left\{\sigma_{a}^{u}=\left\{b^{u}, c^{u}\right\}, \sigma_{b}^{u}=\left\{a^{u}, c^{u}\right\}, \sigma_{c}^{u}=\left\{a^{u}, b^{u}\right\}\right\}
$$

$\Omega^{\digamma^{u}}$ is not a Nash Equilibria for both local and global levels of pollution.

PROOF: 
Either dirty country can improve their welfare by excluding the clean country $a$ :

country $\mathrm{b}=\left\{a^{u}, c^{u}\right\} \stackrel{\text { change }}{\longrightarrow}\left\{\varnothing, c^{u}\right\} \stackrel{\text { result }}{\longrightarrow} W^{b}\left(b c_{\theta}^{u}\right)>W^{b}\left(a b c_{\theta}\right)$

country $\mathrm{c}=\left\{a^{u}, b^{u}\right\} \stackrel{\text { change }}{\longrightarrow}\left\{\varnothing, b^{u}\right\} \stackrel{\text { result }}{\longrightarrow} W^{c}\left(b c_{\theta}^{u}\right)>W^{c}\left(a b c_{\theta}\right)$

We can conclude, that either of the dirty countries can improve its welfare by calling another dirty country only. Dirty countries would prefer to exclude the clean partner for both local and global levels of pollution. Based on the above, we are confident to conclude that $\Omega^{\digamma^{u}}$ is not a Nash Equilibria for both local and global levels of pollution.

\section{A. 4.7.2 The Free Trade Agreement Game}

Welfare effects of various type of trade agreements:

Country a, local pollution

$W^{a}\left(a_{l}^{h}\right)>W^{a}\left(a b c_{l}\right)>W^{a}\left(a b_{l}\right)>W^{a}\left(b c_{l}\right) \stackrel{\lambda \in(0,0.023]}{>} W^{a}\left(b_{l}^{h}\right)>W^{a}\left(N_{l}\right) \lambda \in(0,0.023]$

$W^{a}\left(a_{l}^{h}\right)>W^{a}\left(a b c_{l}\right)>W^{a}\left(a b_{l}\right)>W^{a}\left(b_{l}^{h}\right) \stackrel{\lambda \in(0.023,0.1]}{>} W^{a}\left(b c_{l}\right)>W^{a}\left(N_{l}\right) \lambda \in(0.023,0.1]$

Country a, global pollution

$W^{a}\left(b c_{g}\right)>W^{a}\left(N_{g}\right)>W^{a}\left(a_{g}^{h}\right)>W^{a}\left(a b c_{g}\right)>W^{a}\left(a b_{g}\right)>W^{a}\left(b_{g}^{h}\right)$

Country b, local pollution

$W^{b}\left(b_{l}^{h}\right)>W^{b}\left(a b c_{l}\right)>W^{b}\left(b c_{l}\right)>W^{b}\left(a_{l}^{h}\right)>W^{b}\left(a b_{l}\right) \stackrel{\lambda \in(0,0.027]}{>} W^{b}\left(N_{l}\right) \lambda \in(0,0.027]$

$W^{b}\left(b_{l}^{h}\right)>W^{b}\left(a b c_{l}\right)>W^{b}\left(b c_{l}\right)>W^{b}\left(a_{l}^{h}\right) \stackrel{\lambda \in(0,0.082]}{>} W^{b}\left(N_{l}\right) \stackrel{\lambda \in(0.027,0.1]}{>} W^{b}\left(a b_{l}\right) \lambda \in(0.027,0.082]$

$W^{b}\left(b_{l}^{h}\right)>W^{b}\left(a b c_{l}\right)>W^{b}\left(b c_{l}\right)>W^{b}\left(N_{l}\right) \stackrel{\lambda \in(0.082,0.1]}{>} W^{b}\left(a_{l}^{h}\right)>W^{b}\left(a b_{l}\right) \lambda \in(0.082,0.1]$

Country b, global pollution

$W^{b}\left(b_{g}^{h}\right)>W^{b}\left(b c_{g}\right)>W^{b}\left(a b_{g}\right) \stackrel{\lambda \in(0,0.065]}{>} W^{b}\left(N_{g}\right)>W^{b}\left(a b c_{g}\right)>W^{b}\left(a_{g}^{h}\right) \lambda \in(0,0.065]$

$W^{b}\left(b_{g}^{h}\right)>W^{b}\left(b c_{g}\right)>W^{b}\left(N_{g}\right) \stackrel{\lambda \in(0.065,0.1]}{>} W^{b}\left(a b_{g}\right)>W^{b}\left(a b c_{g}\right)>W^{b}\left(a_{g}^{h}\right) \lambda \in(0.065,0.1]$

Country c, local pollution

$W^{c}\left(a b c_{l}\right) \stackrel{\lambda \in(0,0.043]}{>} W^{c}\left(a b_{l}\right)>W^{c}\left(b c_{l}\right)>W^{c}\left(b_{l}^{h}\right)>W^{c}\left(a_{l}^{h}\right) \stackrel{\lambda \in(0,0.082]}{>} W^{c}\left(N_{l}\right) \lambda \in(0,0.043]$

$W^{c}\left(a b_{l}\right) \stackrel{\lambda \in(0.043,0.1]}{>} W^{c}\left(a b c_{l}\right)>W^{c}\left(b c_{l}\right)>W^{c}\left(b_{l}^{h}\right)>W^{c}\left(a_{l}^{h}\right) \stackrel{\lambda \in(0,0.082]}{>} W^{c}\left(N_{l}\right) \lambda \in(0.043,0.082]$

$W^{c}\left(a b_{l}\right) \stackrel{\lambda \in(0.043,0.1]}{>} W^{c}\left(a b c_{l}\right)>W^{c}\left(b c_{l}\right)>W^{c}\left(b_{l}^{h}\right)>W^{c}\left(N_{l}\right) \stackrel{\lambda \in(0.082,0.1]}{>} W^{c}\left(a_{l}^{h}\right) \lambda \in(0.082,0.1]$

Country c, global pollution 
$W^{c}\left(b c_{g}\right)>W^{c}\left(N_{g}\right)>W^{c}\left(a b c_{g}\right)>W^{c}\left(a_{g}^{h}\right)>W^{c}\left(a b_{g}\right)>W^{c}\left(b_{g}^{h}\right)$

\begin{tabular}{|c|c|}
\hline Announcement Profiles & Trade Agreements \\
\hline \hline$\Omega^{\Phi} \equiv\left\{\sigma_{a}=\{\varnothing, \varnothing\}, \sigma_{b}=\{\varnothing, \varnothing\}, \sigma_{c}=\{\varnothing, \varnothing\}\right\}$ & $\langle\Phi\rangle$ \\
\hline$\Omega^{a b} \equiv\left\{\sigma_{a}=\{b, \varnothing\}, \sigma_{b}=\{a, \varnothing\}, \sigma_{c}=\{\varnothing, \varnothing\}\right\}$ & $\langle a b\rangle$ \\
\hline$\Omega^{b c} \equiv\left\{\sigma_{a}=\{\varnothing, \varnothing\}, \sigma_{b}=\{\varnothing, c\}, \sigma_{c}=\{\varnothing, b\}\right\}$ & $\langle b c\rangle$ \\
\hline$\Omega^{a h} \equiv\left\{\sigma_{a}=\{b, c\}, \sigma_{b}=\{a, \varnothing\}, \sigma_{c}=\{a, \varnothing\}\right\}$ & $\langle a h\rangle$ \\
\hline$\Omega^{b h} \equiv\left\{\sigma_{a}=\{b, \varnothing\}, \sigma_{b}=\{a, c\}, \sigma_{c}=\{\varnothing, b\}\right\}$ & $\langle b h\rangle$ \\
\hline$\Omega^{F} \equiv\left\{\sigma_{a}=\{b, c\}, \sigma_{b}=\{a, c\}, \sigma_{c}=\{a, b\}\right\}$ & $\langle F\rangle$ \\
\hline
\end{tabular}

$$
\Omega^{\Phi} \equiv\left\{\sigma_{a}=\{\varnothing, \varnothing\}, \sigma_{b}=\{\varnothing, \varnothing\}, \sigma_{c}=\{\varnothing, \varnothing\}\right\}
$$

$\Omega^{\Phi}$ is a Nash Equilibria for both local and global levels of pollution.

ProOF:

Countries cannot get better off by unilaterally changing the announcements; countries have no incentive to announce any other country unless they are going to be announced back. $\Omega^{\Phi}$ is not a CPNE for both local and global levels of pollution.

\section{PROOF:}

To prove the above, we assume that two symmetric dirty countries, $b$ and $c$, form a bilateral free trade agreement, then their announcement profiles would be altered as follows: $\sigma_{b}=\{\varnothing, c\}$ and $\sigma_{c}=\{\varnothing, b\}$. As a result, we observe the increase in the members' welfares: $W^{j}\left(b c_{\theta}\right)>W^{j}\left(N_{\theta}\right)$, where $j \neq a$. We are confident to conclude that $\Omega^{\Phi}$ is not a CPNE for both local and global levels of pollution.

$$
\Omega^{a b} \equiv\left\{\sigma_{a}=\{b, \varnothing\}, \sigma_{b}=\{a, \varnothing\}, \sigma_{c}=\{\varnothing, \varnothing\}\right\}
$$

$\Omega^{a b}$ is a Nash Equilibria if pollution is local and $\lambda \varepsilon(0,0.027]$.

PROOF:

country a $=\{b, \varnothing\} \stackrel{\text { change }}{\longrightarrow}\{b, c\} \stackrel{\text { result }}{\longrightarrow}$ no change in $a$ 's welfare

country a $=\{b, \varnothing\} \stackrel{\text { change }}{\longrightarrow}\{\varnothing, c\} /\{\varnothing, \varnothing\} \stackrel{\text { result }}{\longrightarrow} W^{a}\left(a b_{l}\right)>W^{a}\left(N_{l}\right)$ 
We can conclude, that country $a$ has no incentive to change its announcement.

country $\mathrm{b}=\{a, \varnothing\} \stackrel{\text { change }}{\longrightarrow}\{a, c\} \stackrel{\text { result }}{\longrightarrow}$ no change in $b$ 's welfare

country $\mathrm{b}=\{a, \varnothing\} \stackrel{\text { change }}{\longrightarrow}\{\varnothing, c\} /\{\varnothing, \varnothing\} \stackrel{\text { result }}{\longrightarrow} W^{b}\left(a b_{l}\right)>W^{b}\left(N_{l}\right) \& \lambda \varepsilon(0,0.027]$

We can conclude, that country $b$ has no incentive to change its announcement.

country $\mathrm{c}=\{\varnothing, \varnothing\} \stackrel{\text { change }}{\longrightarrow}\{a, \varnothing\} /\{\varnothing, b\} /\{a, b\} \stackrel{\text { result }}{\longrightarrow}$ no change in c's welfare

We can conclude, that country $c$ has no incentive to change its announcement.

Based on the above, we conclude that $\Omega^{a b}$ is a Nash Equilibria if pollution is local and $\lambda \varepsilon(0,0.027]$. $\Omega^{a b}$ is not a Nash Equilibria if pollution is local and $\lambda \varepsilon(0.027,0.1]$.

PROOF:

country $\mathrm{b}=\{a, \varnothing\} \stackrel{\text { change }}{\longrightarrow}\{\varnothing, c\} /\{\varnothing, \varnothing\} \stackrel{\text { result }}{\longrightarrow} W^{b}\left(a b_{l}\right)<W^{b}\left(N_{l}\right) \& \lambda \varepsilon(0.027,0.1]$

We can conclude, that country $b$ can improve its welfare by unilaterally changing its announcement and deviating into no agreement scenario, and based on that, we conclude that $\Omega^{a b}$ is not a Nash Equilibria if pollution is local and $\lambda \varepsilon(0.027,0.1]$.

$\Omega^{a b}$ is not a Nash Equilibria if pollution is global.

PROOF:

country a $=\{b, \varnothing\} \stackrel{\text { change }}{\longrightarrow}\{\varnothing, c\} /\{\varnothing, \varnothing\} \stackrel{\text { result }}{\longrightarrow} W^{a}\left(a b_{g}\right)<W^{a}\left(N_{g}\right)$

We can conclude, that country $a$ can improve its welfare by unilaterally changing its announcement and deviating into no agreement scenario, and based on that, we conclude that $\Omega^{a b}$ is not a Nash Equilibria if pollution is global.

$\Omega^{a b}$ is not a CPNE if pollution is local and $\lambda \varepsilon(0,0.027]$.

PROOF:

We prove the above by considering the grand coalition. We observe that all three countries can improve their welfares by deviating to form a free trade world: $W^{a}\left(a b c_{l}\right)>W^{a}\left(a b_{l}\right) ; W^{b}\left(a b c_{l}\right)>$ $W^{b}\left(a b_{l}\right) ; W^{c}\left(a b c_{l}\right)>W^{c}\left(a b_{l}\right)$ if $\lambda \varepsilon(0,0.043]$. We can conclude, that $\Omega^{a b}$ is not a CPNE if pollution is local and $\lambda \varepsilon(0,0.027]$.

$$
\Omega^{b c} \equiv\left\{\sigma_{a}=\{\varnothing, \varnothing\}, \sigma_{b}=\{\varnothing, c\}, \sigma_{c}=\{\varnothing, b\}\right\}
$$

$\Omega^{b c}$ is a Nash Equilibria for both local and global levels of pollution. 


\section{PROOF:}

country a $=\{\varnothing, \varnothing\} \stackrel{\text { change }}{\longrightarrow}\{b, \varnothing\} /\{\varnothing, c\} /\{b, c\} \stackrel{\text { result }}{\longrightarrow}$ no change in a's welfare

We can conclude, that country $a$ has no incentive to change its announcement.

country $\mathrm{b}=\{\varnothing, c\} \stackrel{\text { change }}{\longrightarrow}\{a, c\} \stackrel{\text { result }}{\longrightarrow}$ no change in $b$ 's welfare

country $\mathrm{b}=\{\varnothing, c\} \stackrel{\text { change }}{\longrightarrow}\{a, \varnothing\} /\{\varnothing, \varnothing\} \stackrel{\text { result }}{\longrightarrow} W^{b}\left(b c_{\theta}\right)>W^{b}\left(N_{\theta}\right)$

We can conclude, that country $b$ has no incentive to change its announcement.

country $\mathrm{c}=\{\varnothing, b\} \stackrel{\text { change }}{\longrightarrow}\{a, b\} \stackrel{\text { result }}{\longrightarrow}$ no change in $c$ 's welfare

country c $=\{\varnothing, b\} \stackrel{\text { change }}{\longrightarrow}\{a, \varnothing\} /\{\varnothing, \varnothing\} \stackrel{\text { result }}{\longrightarrow} W^{c}\left(b c_{\theta}\right)>W^{c}\left(N_{\theta}\right)$

We can conclude, that country $c$ has no incentive to change its announcement.

Based on the above, we conclude that $\Omega^{b c}$ is a Nash Equilibria for both local and global levels of pollution.

$\Omega^{b c}$ is not a CPNE if pollution is local.

PROOF:

We prove the above in two steps. First, we examine the grand coalition. We observe that all three countries can improve their welfares by deviating to form a free trade world: $W^{a}\left(a b c_{l}\right)>$ $W^{a}\left(b c_{l}\right) ; W^{b}\left(a b c_{l}\right)>W^{b}\left(b c_{l}\right) ; W^{c}\left(a b c_{l}\right)>W^{c}\left(b c_{l}\right)$ and $W^{c}\left(a b c_{l}\right)>W^{c}\left(a b_{l}\right)$ if $\lambda \varepsilon(0,0.043]$. This deviation is self-enforcing, because any change in either member's announcement would turn one of the two other countries into a hub or make the country, which changes the announcement, into an outsider of a bilateral trade agreement, and either move would lead to lower welfare gains. We can conclude, that this deviation is both meaningful and self-enforcing, and consequently, $\Omega^{b c}$ is not a CPNE if pollution is local and $\lambda \varepsilon(0,0.043]$. Now, we examine the coalitional deviation of one clean and one dirty country in the case of local pollution and $\lambda \varepsilon(0.043,0.1]$. Either member of $\left(b c_{l}\right)$ is interested in making a side deal with the only clean member of the world, country a. Country a would except this offer from either dirty country. The clean player is better of as a spoke than as an outsider of a shallow FTA of two dirty countries if pollution is local and $\lambda \varepsilon(0.023,0.1]$. Based on the above, we conclude, $\Omega^{b c}$ is not a CPNE if pollution is local.

$\Omega^{b c}$ is a CPNE if pollution is global. 


\section{PROOF:}

To prove the above, we examine all possible meaningful deviations. First, we consider the coalition of two asymmetries countries, country $a$ and country $b$, and we observe the following changes in the members' welfares: $W^{a}\left(a b_{g}\right)<W^{a}\left(b c_{g}\right)$ and $W^{b}\left(a b_{g}\right)<W^{b}\left(b c_{g}\right)$. We can conclude that this deviation is not meaningful. Now, we consider the grand coalition, and we observe the following changes in the welfares: $W^{a}\left(a b c_{g}\right)<W^{a}\left(b c_{g}\right)$ and $W^{j}\left(a b c_{g}\right)<W^{j}\left(b c_{g}\right)$ where $j \varepsilon[b, c]$. Again, we can see that this deviation is not meaningful. Based on the above, we conclude, $\Omega^{b c}$ is a CPNE if pollution is global.

$$
\Omega^{a h} \equiv\left\{\sigma_{a}=\{b, c\}, \sigma_{b}=\{a, \varnothing\}, \sigma_{c}=\{a, \varnothing\}\right\}
$$

$\Omega^{\text {ah }}$ is not a Nash Equilibria if pollution is local.

PROOF:

country c $=\{a, \varnothing\} \stackrel{\text { change }}{\longrightarrow}\{\varnothing, b\} /\{\varnothing, \varnothing\} \stackrel{\text { result }}{\longrightarrow} W^{c}\left(a_{l}^{h}\right)<W^{c}\left(a b_{l}\right)$

We can conclude, that country $c$ has an incentive to self-exclude itself.

Based on the above, we can conclude that $\Omega^{a h}$ is not a Nash Equilibria if pollution is local. $\Omega^{a h}$ is not a Nash Equilibria if pollution is global.

ProOF:

country a $=\{b, c\} \stackrel{\text { change }}{\longrightarrow}\{\varnothing, \varnothing\} \stackrel{\text { result }}{\longrightarrow} W^{a}\left(a_{g}^{h}\right)<W^{a}\left(N_{g}\right)$

We can conclude, that country $a$ has an incentive to self-exclude itself.

Based on the above, we can conclude that $\Omega^{a h}$ is not a Nash Equilibria if pollution is global.

$$
\Omega^{b h} \equiv\left\{\sigma_{a}=\{b, \varnothing\}, \sigma_{b}=\{a, c\}, \sigma_{c}=\{\varnothing, b\}\right\}
$$

$\Omega^{\text {bh }}$ is not a Nash Equilibria if pollution is local.

PROOF:

country $\mathrm{c}=\{\varnothing, b\} \stackrel{\text { change }}{\longrightarrow}\{a, \varnothing\} /\{\varnothing, \varnothing\} \stackrel{\text { result }}{\longrightarrow} W^{c}\left(b_{l}^{h}\right)<W^{c}\left(a b_{l}\right)$

We can conclude, that country $c$ has an incentive to self-exclude itself.

Based on the above, we conclude that $\Omega^{b h}$ is not a Nash Equilibria if pollution is local. $\Omega^{\text {bh }}$ is not a Nash Equilibria if pollution is global. 
PROOF:

country a $=\{b, \varnothing\} \stackrel{\text { change }}{\longrightarrow}\{\varnothing, \varnothing\} \stackrel{\text { result }}{\longrightarrow} W^{a}\left(b_{g}^{h}\right)<W^{a}\left(b c_{g}\right)$

We can conclude, that country $a$ has an incentive to self-exclude itself.

Based on the above, we can conclude that $\Omega^{b h}$ is not a Nash Equilibria if pollution is global.

$$
\Omega^{F} \equiv\left\{\sigma_{a}=\{b, c\}, \sigma_{b}=\{a, c\}, \sigma_{c}=\{a, b\}\right\}
$$

$\Omega^{\digamma}$ is a Nash Equilibria if pollution is local and $\lambda \varepsilon(0,0.043]$.

PROOF:

country a $=\{b, c\} \stackrel{\text { change }}{\longrightarrow}\{b, \varnothing\} /\{\varnothing, c\} \stackrel{\text { result }}{\longrightarrow} W^{a}\left(a b c_{l}\right)>W^{a}\left(b_{l}^{h}\right)=W^{a}\left(c_{l}^{h}\right)$

country a $=\{b, c\} \stackrel{\text { change }}{\longrightarrow}\{\varnothing, \varnothing\} \stackrel{\text { result }}{\longrightarrow} W^{a}\left(a b c_{l}\right)>W^{a}\left(b c_{l}\right)$

We can conclude, that country $a$ has no incentive to change its announcement.

country $\mathrm{b}=\{a, c\} \stackrel{\text { change }}{\longrightarrow}\{a, \varnothing\} \stackrel{\text { result }}{\longrightarrow} W^{b}\left(a b c_{l}\right)>W^{b}\left(a_{l}^{h}\right)$

country $\mathrm{b}=\{a, c\} \stackrel{\text { change }}{\longrightarrow}\{\varnothing, c\} \stackrel{\text { result }}{\longrightarrow} W^{b}\left(a b c_{l}\right)>W^{b}\left(c_{l}^{h}\right)$

country $\mathrm{b}=\{a, c\} \stackrel{\text { change }}{\longrightarrow}\{\varnothing, \varnothing\} \stackrel{\text { result }}{\longrightarrow} W^{b}\left(a b c_{l}\right)>W^{b}\left(a c_{l}\right) \& \lambda \varepsilon(0,0.043]$.

We can conclude, that country $b$ has no incentive to change its announcement.

country $\mathrm{c}=\{a, b\} \stackrel{\text { change }}{\longrightarrow}\{\varnothing, b\} \stackrel{\text { result }}{\longrightarrow} W^{c}\left(a b c_{l}\right)>W^{c}\left(b_{l}^{h}\right)$

country $\mathrm{c}=\{a, b\} \stackrel{\text { change }}{\longrightarrow}\{a, \varnothing\} \stackrel{\text { result }}{\longrightarrow} W^{c}\left(a b c_{l}\right)>W^{c}\left(a_{l}^{h}\right)$

country $\mathrm{c}=\{a, b\} \stackrel{\text { change }}{\longrightarrow}\{\varnothing, \varnothing\} \stackrel{\text { result }}{\longrightarrow} W^{c}\left(a b c_{l}\right)>W^{c}\left(a b_{l}\right) \& \lambda \varepsilon(0,0.043]$

We can conclude, that country $c$ has no incentive to change its announcement.

Based on the above, we conclude that $\Omega^{\digamma}$ is a Nash Equilibria if pollution is local and $\& \lambda \varepsilon(0,0.043]$. $\Omega^{\digamma}$ is not a Nash Equilibria if pollution is local and $\lambda \varepsilon(0.043,0.1]$.

PROOF:

country $\mathrm{c}=\{a, b\} \stackrel{\text { change }}{\longrightarrow}\{\varnothing, \varnothing\} \stackrel{\text { result }}{\longrightarrow} W^{c}\left(a b c_{l}\right)<W^{c}\left(a b_{l}\right) \& \lambda \varepsilon(0.043,0.1]$

We can conclude, that country $c$ has an incentive to self-exclude itself.

Based on the above, we conclude that $\Omega^{\digamma}$ is not a Nash Equilibria if pollution is local and \& $\lambda \varepsilon(0.043,0.1]$.

$\Omega^{\digamma}$ is not a Nash Equilibria if pollution is global.

PROOF: 
country a $=\{b, c\} \stackrel{\text { change }}{\longrightarrow}\{\varnothing, \varnothing\} \stackrel{\text { result }}{\longrightarrow} W^{a}\left(a b c_{l}\right)<W^{a}\left(b c_{l}\right)$

We can conclude, that country $a$ has an incentive to self-exclude itself.

Based on the above, we conclude that $\Omega^{\digamma}$ is not a Nash Equilibria if pollution is global.

$\Omega^{\digamma}$ is a CPNE if pollution is local and $\lambda \varepsilon(0,0.043]$.

\section{PROOF:}

To prove the above, we examine all possible meaningful deviations. First, we consider the coalition of two asymmetries countries, country $a$ and country $b$, and we observe the following changes in the members' welfares: $W^{a}\left(a b_{l}\right)<W^{a}\left(a b c_{l}\right)$ and $W^{b}\left(a b_{l}\right)<W^{b}\left(a b c_{l}\right)$. We can conclude that this deviation is not meaningful. Now, we consider the coalition of two symmetries dirty countries, country $b$ and country $c$, and we observe the following changes in the members' welfares: $W^{j}\left(b c_{l}\right)<W^{j}\left(a b c_{l}\right)$, where $j \neq a$. Again, we can see that this deviation is not meaningful. Based on the above, we conclude, $\Omega^{F}$ is a CPNE if pollution is local $\& \lambda \varepsilon(00.043]$.

\section{A. 4.8.1 The Integrated Customs Union Game}

Welfare effects of various type of trade and environmental agreements:

$W^{a}\left(a b c_{l}^{i}\right)>W^{a}\left(a b_{l}^{i u}\right)>W^{a}\left(N_{l}\right)>W^{a}\left(b c_{l}^{i u}\right)$ Country a, local pollution

$W^{a}\left(a b c_{g}^{i}\right)>W^{a}\left(b c_{g}^{i u}\right)>W^{a}\left(a b_{g}^{i u}\right)>W^{a}\left(N_{g}\right)$ Country a, global pollution

$W^{b}\left(b c_{l}^{i u}\right)>W^{b}\left(a b_{l}^{i u}\right)>W^{b}\left(a b c_{l}^{i}\right)>W^{b}\left(N_{l}\right)$ Country b, local pollution

$W^{b}\left(b c_{g}^{i u}\right)>W^{b}\left(a b c_{g}^{i}\right)>W^{b}\left(N_{g}\right)>W^{b}\left(a b_{g}^{i u}\right)$ Country b, global pollution

$W^{c}\left(b c_{l}^{i u}\right)>W^{c}\left(a b c_{l}^{i}\right)>W^{c}\left(N_{l}\right)>W^{c}\left(a b_{l}^{i u}\right)$ Country c, local pollution

$W^{c}\left(b c_{g}^{i u}\right)>W^{c}\left(a b c_{g}^{i}\right)>W^{c}\left(a b_{g}^{i u}\right)>W^{c}\left(N_{g}\right)$ Country c, global pollution

\begin{tabular}{|c|c|}
\hline Announcement Profiles & Integrated Agreements \\
\hline \hline$\Omega^{\Phi^{i u}} \equiv\left\{\sigma_{a}^{i u}=\{\varnothing, \varnothing\}, \sigma_{b}^{i u}=\{\varnothing, \varnothing\}, \sigma_{c}^{i u}=\{\varnothing, \varnothing\}\right\}$ & $\left\langle\Phi^{i u}\right\rangle$ \\
\hline$\Omega^{a b i u} \equiv\left\{\sigma_{a}^{i u}=\left\{b^{i u}, \varnothing\right\}, \sigma_{b}^{i u}=\left\{a^{i u}, \varnothing\right\}, \sigma_{c}^{i u}=\{\varnothing, \varnothing\}\right\}$ & $\langle a b i u\rangle$ \\
\hline$\Omega^{b c i u} \equiv\left\{\sigma_{a}^{i u}=\{\varnothing, \varnothing\}, \sigma_{b}^{i u}=\left\{\varnothing, c^{i u}\right\}, \sigma_{c}^{i u}=\left\{\varnothing, b^{i u}\right\}\right\}$ & $\langle b c i u\rangle$ \\
\hline$\Omega^{F^{i u}} \equiv\left\{\sigma_{a}^{i u}=\left\{b^{i u}, c^{i u}\right\}, \sigma_{b}^{i u}=\left\{a^{i u}, c^{i u}\right\}, \sigma_{c}^{i u}=\left\{a^{i u}, b^{i u}\right\}\right\}$ & $\left\langle F^{i u}\right\rangle$ \\
\hline
\end{tabular}




$$
\Omega^{\Phi^{i u}} \equiv\left\{\sigma_{a}^{i u}=\{\varnothing, \varnothing\}, \sigma_{b}^{i u}=\{\varnothing, \varnothing\}, \sigma_{c}^{i u}=\{\varnothing, \varnothing\}\right\}
$$

$\Omega^{\Phi^{i u}}$ is a Nash Equilibria for both local and global levels of pollution.

\section{PROOF:}

Countries cannot change their welfares by unilaterally changing the announcements.

$\Omega^{\Phi^{i u}}$ is not a CPNE for both local and global levels of pollution.

\section{PROOF:}

We prove the above by considering a deep trade union of two symmetric dirty countries, $b$ and $c$. The trade union of two dirty countries brings its members the highest level of welfare in this game, so we can conclude that those counties can form a self-enforcing deep trade agreement for both levels of pollution, and no further deviations can occur. Based on the above, we can conclude that $\Omega^{\Phi^{i u}}$ is not a CPNE for both levels of pollution.

$$
\Omega^{a b i u} \equiv\left\{\sigma_{a}^{i u}=\left\{b^{i u}, \varnothing\right\}, \sigma_{b}^{i u}=\left\{a^{i u}, \varnothing\right\}, \sigma_{c}^{i u}=\{\varnothing, \varnothing\}\right\}
$$

$\Omega^{\text {abiu }}$ is a Nash Equilibria if pollution is local.

\section{PROOF:}

country a $=\left\{b^{i u}, \varnothing\right\} \stackrel{\text { change }}{\longrightarrow}\left\{b^{i u}, c^{i u}\right\} \stackrel{\text { result }}{\longrightarrow}$ no change in $a$ 's welfare

country a $=\left\{b^{i u}, \varnothing\right\} \stackrel{\text { change }}{\longrightarrow}\left\{\varnothing, c^{i u}\right\} /\{\varnothing, \varnothing\} \stackrel{\text { result }}{\longrightarrow} W^{a}\left(a b_{l}^{i u}\right)>W^{a}\left(N_{l}\right)$

We can conclude, that country $a$ has no incentive to change its announcement.

country $\mathrm{b}=\left\{a^{i u}, \varnothing\right\} \stackrel{\text { change }}{\longrightarrow}\left\{a^{i u}, c^{i u}\right\} \stackrel{\text { result }}{\longrightarrow}$ no change in $b$ 's welfare

country $\mathrm{b}=\left\{a^{i u}, \varnothing\right\} \stackrel{\text { change }}{\longrightarrow}\left\{\varnothing, c^{i u}\right\} /\{\varnothing, \varnothing\} \stackrel{\text { result }}{\longrightarrow} W^{b}\left(a b_{l}^{i u}\right)>W^{b}\left(N_{l}\right)$

We can conclude, that country $b$ has no incentive to change its announcement.

country $\mathrm{c}=\{\varnothing, \varnothing\} \stackrel{\text { change }}{\longrightarrow}\left\{a^{i u}, \varnothing\right\} /\left\{\varnothing, b^{i u}\right\} /\left\{a^{i u}, b^{i u}\right\} \stackrel{\text { result }}{\longrightarrow}$ no change in $c$ 's welfare

We can conclude, that country $c$ has no incentive to change its announcement.

Based on the above, we conclude that $\Omega^{a b i u}$ is a Nash Equilibria if pollution is local. $\Omega^{\text {abiu }}$ is not a Nash Equilibria if pollution is global.

PROOF:

country $\mathrm{b}=\left\{a^{i u}, \varnothing\right\} \stackrel{\text { change }}{\longrightarrow}\left\{\varnothing, c^{i u}\right\} /\{\varnothing, \varnothing\} \stackrel{\text { result }}{\longrightarrow} W^{b}\left(a b_{g}^{i u}\right)<W^{b}\left(N_{g}\right)$ 
We can conclude, that country $b$ has an incentive to self-exclude itself.

Based on the above, we conclude that $\Omega^{a b i u}$ is not a Nash Equilibria if pollution is global.

$\Omega^{\text {abiu }}$ is not a CPNE if pollution is local.

PROOF:

To prove the above, we consider a trade and environmental union between two symmetric dirty countries, $\mathrm{b}$ and $\mathrm{c}$, then $W^{b}\left(b c_{l}^{i u}\right)>W^{b}\left(a b_{l}^{i u}\right)$ and $W^{c}\left(b c_{l}^{i u}\right)>W^{c}\left(a b_{l}^{i u}\right)$. Also, the level of welfare countries $b$ and $c$ achieve from forming an integrated union is the highest in this game, so none of the members would deviate any further.

$$
\Omega^{b c i u} \equiv\left\{\sigma_{a}^{i u}=\{\varnothing, \varnothing\}, \sigma_{b}^{i u}=\left\{\varnothing, c^{i u}\right\}, \sigma_{c}^{i u}=\left\{\varnothing, b^{i u}\right\}\right\}
$$

$\Omega^{\text {bciu }}$ is a Nash Equilibria for both local and global levels of pollution.

PROOF:

country a $=\{\varnothing, \varnothing\} \stackrel{\text { change }}{\longrightarrow}\left\{b^{i u}, \varnothing\right\} /\left\{\varnothing, c^{i u}\right\} /\left\{b^{i u}, c^{i u}\right\} \stackrel{\text { result }}{\longrightarrow}$ no change in a's welfare

We can conclude, that country $a$ has no incentive to change its announcement.

country $\mathrm{b}=\left\{\varnothing, c^{i u}\right\} \stackrel{\text { change }}{\longrightarrow}\left\{a^{i u}, c^{i u}\right\} \stackrel{\text { result }}{\longrightarrow}$ no change in $b$ 's welfare

country $\mathrm{b}=\left\{\varnothing, c^{i u}\right\} \stackrel{\text { change }}{\longrightarrow}\left\{a^{i u}, \varnothing\right\} /\{\varnothing, \varnothing\} \stackrel{\text { result }}{\longrightarrow} W^{b}\left(b c_{\theta}^{i u}\right)>W^{b}\left(N_{\theta}\right)$

We can conclude, that country $b$ has no incentive to change its announcement.

country $\mathrm{c}=\left\{\varnothing, b^{i u}\right\} \stackrel{\text { change }}{\longrightarrow}\left\{a^{i u}, b^{i u}\right\} \stackrel{\text { result }}{\longrightarrow}$ no change in $c$ 's welfare

country $\mathrm{c}=\left\{\varnothing, b^{i u}\right\} \stackrel{\text { change }}{\longrightarrow}\left\{a^{i u}, \varnothing\right\} /\{\varnothing, \varnothing\} \stackrel{\text { result }}{\longrightarrow} W^{c}\left(b c_{\theta}^{i u}\right)>W^{c}\left(N_{\theta}\right)$

We can conclude, that country $c$ has no incentive to change its announcement.

Based on the above, we conclude that $\Omega^{b c i u}$ is a Nash Equilibria for both local and global levels of pollution.

$\Omega^{\text {bciu }}$ is a CPNE for both local and global levels of pollution.

PROOF:

Neither member can do better by deviating from their original announcement for both levels of pollution. The level of welfare members achieve in this deep trade agreement is highest in this entire game, and based on that we conclude that, $\Omega^{b c i u}$ is a self-enforcing commitment between two dirty countries for both local and global levels of pollution. 


$$
\Omega^{F^{i u}} \equiv\left\{\sigma_{a}^{i u}=\left\{b^{i u}, c^{i u}\right\}, \sigma_{b}^{i u}=\left\{a^{i u}, c^{i u}\right\}, \sigma_{c}^{i u}=\left\{a^{i u}, b^{i u}\right\}\right\}
$$

$\Omega^{\digamma^{i u}}$ is not a Nash Equilibria for both local and global levels of pollution.

\section{PROOF:}

Either dirty country can improve their welfare by excluding the clean country $a$ :

country $\mathrm{b}=\left\{a^{i u}, c^{i u}\right\} \stackrel{\text { change }}{\longrightarrow}\left\{\varnothing, c^{i u}\right\} \stackrel{\text { result }}{\longrightarrow} W^{b}\left(b c_{\theta}^{i u}\right)>W^{b}\left(a b c_{\theta}^{i}\right)$

country $\mathrm{c}=\left\{a^{i u}, b^{i u}\right\} \stackrel{\text { change }}{\longrightarrow}\left\{\varnothing, b^{i u}\right\} \stackrel{\text { result }}{\longrightarrow} W^{c}\left(b c_{\theta}^{i u}\right)>W^{c}\left(a b c_{\theta}^{i}\right)$

We can conclude, that either of the dirty countries can improve its welfare by calling another dirty country only. Dirty countries would prefer to exclude the clean partner for both local and global levels of pollution. Based on the above, we are confident to conclude that $\Omega^{\digamma^{i u}}$ is not a Nash Equilibria for both local and global levels of pollution.

\section{A. 4.8.2 The Integrated Free Trade Agreements Game}

Welfare effects of various type of trade and environmental agreements:

Country a, local pollution

$W^{a}\left(a_{l}^{h i}\right)>W^{a}\left(a b c_{l}^{i}\right)>W^{a}\left(b_{l}^{h i}\right) \stackrel{\lambda \in(0,0.009]}{>} W^{a}\left(a b_{l}^{i}\right)>W^{a}\left(N_{l}\right)>W^{a}\left(b c_{l}^{i}\right) \lambda \in(0,0.009]$
$W^{a}\left(a_{l}^{h i}\right)>W^{a}\left(a b c_{l}^{i}\right)>W^{a}\left(a b_{l}^{i}\right) \stackrel{\lambda \in(0,009,0.1]}{>} W^{a}\left(b_{l}^{h i}\right)>W^{a}\left(N_{l}\right)>W^{a}\left(b c_{l}^{i}\right) \lambda \in(0.009,0.1]$

Country a, global pollution

$W^{a}\left(a_{g}^{h i}\right)>W^{a}\left(a b c_{g}^{i}\right)>W^{a}\left(b_{g}^{h i}\right)>W^{a}\left(b c_{g}^{i}\right)>W^{a}\left(a b_{g}^{i}\right)>W^{a}\left(N_{g}\right)$

Country $b$, local pollution

$W^{b}\left(b c_{l}^{i}\right) \stackrel{\lambda \in(0,0.008]}{>} W^{b}\left(b_{l}^{h i}\right)>W^{b}\left(a b c_{l}^{i}\right)>W^{b}\left(N_{l}\right)>W^{b}\left(a_{l}^{h i}\right)>W^{b}\left(a b_{l}^{i}\right) \lambda \in(0,0.008]$

$W^{b}\left(b_{l}^{h i}\right) \stackrel{\lambda \in(0.008,0.1]}{>} W^{b}\left(b c_{l}^{i}\right)>W^{b}\left(a b c_{l}^{i}\right)>W^{b}\left(N_{l}\right)>W^{b}\left(a_{l}^{h i}\right)>W^{b}\left(a b_{l}^{i}\right) \lambda \in(0.008,0.1]$

Country b, global pollution

$W^{b}\left(b_{g}^{h i}\right)>W^{b}\left(b c_{g}^{i}\right) \stackrel{\lambda \in(0,0.089]}{>} W^{b}\left(a b c_{g}^{i}\right)>W^{b}\left(a_{g}^{h i}\right)>W^{b}\left(a b_{g}^{i}\right)>W^{b}\left(N_{g}\right) \lambda \in(0,0.089]$

$W^{b}\left(b_{g}^{h i}\right)>W^{b}\left(a b c_{g}^{i}\right) \stackrel{\lambda \in(0.089,0.1]}{>} W^{b}\left(b c_{g}^{i}\right)>W^{b}\left(a_{g}^{h i}\right)>W^{b}\left(a b_{g}^{i}\right)>W^{b}\left(N_{g}\right) \lambda \in(0.089,0.1]$

Country c, local pollution

$W^{c}\left(b c_{l}^{i}\right)>W^{c}\left(a b_{l}^{i}\right)>W^{c}\left(a b c_{l}^{i}\right)>W^{c}\left(N_{l}\right)>W^{c}\left(b_{l}^{h i}\right)>W^{c}\left(a_{l}^{h i}\right)$

Country c, global pollution 


$$
\begin{aligned}
& W^{c}\left(b c_{g}^{i}\right) \stackrel{\lambda \in(0,0.089]}{>} W^{c}\left(a b c_{g}^{i}\right)>W^{c}\left(a_{g}^{h i}\right)>W^{c}\left(a b_{g}^{i}\right)>W^{c}\left(b_{g}^{h i}\right)>W^{c}\left(N_{g}\right) \lambda \in(0,0.089] \\
& W^{c}\left(a b c_{g}^{i}\right) \stackrel{\lambda \in(0.089,0.1]}{>} W^{c}\left(b c_{g}^{i}\right)>W^{c}\left(a_{g}^{h i}\right)>W^{c}\left(a b_{g}^{i}\right)>W^{c}\left(b_{g}^{h i}\right)>W^{c}\left(N_{g}\right) \lambda \in(0.089,0.1]
\end{aligned}
$$

\begin{tabular}{|c|c|}
\hline Announcement Profiles & Integrated Agreements \\
\hline \hline$\Omega^{\Phi^{i}} \equiv\left\{\sigma_{a}^{i}=\{\varnothing, \varnothing\}, \sigma_{b}^{i}=\{\varnothing, \varnothing\}, \sigma_{c}^{i}=\{\varnothing, \varnothing\}\right\}$ & $\left\langle\Phi^{i}\right\rangle$ \\
\hline$\Omega^{a b i} \equiv\left\{\sigma_{a}^{i}=\left\{b^{i}, \varnothing\right\}, \sigma_{b}^{i}=\left\{a^{i}, \varnothing\right\}, \sigma_{c}^{i}=\{\varnothing, \varnothing\}\right\}$ & $\langle a b i\rangle$ \\
\hline$\Omega^{b c i} \equiv\left\{\sigma_{a}^{i}=\{\varnothing, \varnothing\}, \sigma_{b}^{i}=\left\{\varnothing, c^{i}\right\}, \sigma_{c}^{i}=\left\{\varnothing, b^{i}\right\}\right\}$ & $\langle b c i\rangle$ \\
\hline$\Omega^{a h i} \equiv\left\{\sigma_{a}^{i}=\left\{b^{i}, c^{i}\right\}, \sigma_{b}^{i}=\left\{a^{i}, \varnothing\right\}, \sigma_{c}^{i}=\left\{a^{i}, \varnothing\right\}\right\}$ & $\langle a h i\rangle$ \\
\hline$\Omega^{b h i} \equiv\left\{\sigma_{a}^{i}=\left\{b^{i}, \varnothing\right\}, \sigma_{b}^{i}=\left\{a^{i}, c^{i}\right\}, \sigma_{c}^{i}=\left\{\varnothing, b^{i}\right\}\right\}$ & $\langle b h i\rangle$ \\
\hline$\Omega^{F^{i}} \equiv\left\{\sigma_{a}^{i}=\left\{b^{i}, c^{i}\right\}, \sigma_{b}^{i}=\left\{a^{i}, c^{i}\right\}, \sigma_{c}^{i}=\left\{a^{i}, b^{i}\right\}\right\}$ & $\left\langle F^{i}\right\rangle$ \\
\hline
\end{tabular}

$$
\Omega^{\Phi^{i}} \equiv\left\{\sigma_{a}^{i}=\{\varnothing, \varnothing\}, \sigma_{b}^{i}=\{\varnothing, \varnothing\}, \sigma_{c}^{i}=\{\varnothing, \varnothing\}\right\}
$$

$\Omega^{\Phi^{i}}$ is a Nash Equilibria for both local and global levels of pollution.

PROOF:

Countries cannot get better off by unilaterally changing the announcement.

$\Omega^{\Phi^{i}}$ is not a CPNE for both local and global levels of pollution.

\section{PROOF:}

To prove the above, we assume that two symmetric dirty countries, $b$ and $c$, form a deep bilateral free trade agreement, then their announcement profiles would be altered as follows: $\sigma_{b}^{i}=\left\{\varnothing, c^{i}\right\}$ and $\sigma_{c}^{i}=\left\{\varnothing, b^{i}\right\}$. As a result, we observe the increase in the members' welfares: $W^{j}\left(b c_{\theta}^{i}\right)>$ $W^{j}\left(N_{\theta}\right)$, where $j \neq a$. We are confident to conclude that $\Omega^{\Phi^{i}}$ is not a CPNE for both local and global levels of pollution.

$$
\Omega^{a b i} \equiv\left\{\sigma_{a}^{i}=\left\{b^{i}, \varnothing\right\}, \sigma_{b}^{i}=\left\{a^{i}, \varnothing\right\}, \sigma_{c}^{i}=\{\varnothing, \varnothing\}\right\}
$$

$\Omega^{a b i}$ is not a Nash Equilibria if pollution is local.

PROOF:

country $\mathrm{b}=\left\{a^{i}, \varnothing\right\} \stackrel{\text { change }}{\longrightarrow}\left\{\varnothing, c^{i}\right\} /\{\varnothing, \varnothing\} \stackrel{\text { result }}{\longrightarrow} W^{b}\left(a b_{l}^{i}\right)<W^{b}\left(N_{l}\right)$

We can conclude, that country $b$ has an incentive to self-exclude itself. 
Based on the above, we conclude $\Omega^{a b i}$ is not a Nash Equilibria if pollution is local. $\Omega^{a b i}$ is a Nash Equilibria if pollution is global.

PROOF:

country $\mathrm{a}=\left\{b^{i}, \varnothing\right\} \stackrel{\text { change }}{\longrightarrow}\left\{b^{i}, c^{i}\right\} \stackrel{\text { result }}{\longrightarrow}$ no change in a's welfare

country a $=\left\{b^{i}, \varnothing\right\} \stackrel{\text { change }}{\longrightarrow}\left\{\varnothing, c^{i}\right\} /\{\varnothing, \varnothing\} \stackrel{\text { result }}{\longrightarrow} W^{a}\left(a b_{g}^{i}\right)>W^{a}\left(N_{g}\right)$

We can conclude, that country $a$ has no incentive to change its announcement.

country $\mathrm{b}=\left\{a^{i}, \varnothing\right\} \stackrel{\text { change }}{\longrightarrow}\left\{a^{i}, c^{i}\right\} \stackrel{\text { result }}{\longrightarrow}$ no change in $b$ 's welfare

country $\mathrm{b}=\left\{a^{i}, \varnothing\right\} \stackrel{\text { change }}{\longrightarrow}\left\{\varnothing, c^{i}\right\} /\{\varnothing, \varnothing\} \stackrel{\text { result }}{\longrightarrow} W^{b}\left(a b_{g}^{i}\right)>W^{b}\left(N_{g}\right)$

We can conclude, that country $b$ has no incentive to change its announcement.

country $\mathrm{c}=\{\varnothing, \varnothing\} \stackrel{\text { change }}{\longrightarrow}\left\{a^{i}, \varnothing\right\} /\left\{\varnothing, b^{i}\right\} /\left\{a^{i}, b^{i}\right\} \stackrel{\text { result }}{\longrightarrow}$ no change in $c^{\prime}$ s welfare

We can conclude, that country $c$ has no incentive to change its announcement.

Based on the above, we conclude $\Omega^{a b i}$ is a Nash Equilibria if pollution is global.

$\Omega^{a b i}$ is not a CPNE if pollution is global.

\section{PROOF:}

To prove the above, we examine the grand coalition. We observe that all three countries would benefit from this deviation relative to a deep bilateral trade agreement between one clean and one dirty country: $W^{a}\left(a b_{g}^{i}\right)<W^{a}\left(a b c_{g}^{i}\right), W^{b}\left(a b_{g}^{i}\right)<W^{b}\left(a b c_{g}^{i}\right)$, and $W^{c}\left(a b_{g}^{i}\right)<W^{c}\left(a b c_{g}^{i}\right)$. This deviation is self-enforcing, because though the dirty countries would benefit from forming a coalition if $\lambda \varepsilon(0,0.089]$, it will never be exercise in equilibrium. Country $b$ has a an incentive to deviate and include country $a$ in its announcement to turn into a hub. Country $c$ would prefer to be an outsider of a deep bilateral FTA than being a spoke. Based on the above, we conclude that $\Omega^{a b i}$ is not a CPNE if pollution is global.

$$
\Omega^{b c i} \equiv\left\{\sigma_{a}^{i}=\{\varnothing, \varnothing\}, \sigma_{b}^{i}=\left\{\varnothing, c^{i}\right\}, \sigma_{c}^{i}=\left\{\varnothing, b^{i}\right\}\right\}
$$

$\Omega^{b c i}$ is a Nash Equilibria for both local and global levels of pollution.

\section{PROOF:}

country a $=\{\varnothing, \varnothing\} \stackrel{\text { change }}{\longrightarrow}\left\{b^{i}, \varnothing\right\} /\left\{\varnothing, c^{i}\right\} /\left\{b^{i}, c^{i}\right\} \stackrel{\text { result }}{\longrightarrow}$ no change in $a$ 's welfare

We can conclude, that country $a$ has no incentive to change its announcement. 
country $\mathrm{b}=\left\{\varnothing, c^{i}\right\} \stackrel{\text { change }}{\longrightarrow}\left\{a^{i}, c^{i}\right\} \stackrel{\text { result }}{\longrightarrow}$ no change in $b$ 's welfare

country $\mathrm{b}=\left\{\varnothing, c^{i}\right\} \stackrel{\text { change }}{\longrightarrow}\left\{a^{i}, \varnothing\right\} /\{\varnothing, \varnothing\} \stackrel{\text { result }}{\longrightarrow} W^{b}\left(b c_{\theta}^{i}\right)>W^{b}\left(N_{\theta}\right)$

We can conclude, that country $b$ has no incentive to change its announcement.

country $\mathrm{c}=\left\{\varnothing, b^{i}\right\} \stackrel{\text { change }}{\longrightarrow}\left\{a^{i}, b^{i}\right\} \stackrel{\text { result }}{\longrightarrow}$ no change in $c^{\prime}$ 's welfare

country $\mathrm{c}=\left\{\varnothing, b^{i}\right\} \stackrel{\text { change }}{\longrightarrow}\left\{a^{i}, \varnothing\right\} /\{\varnothing, \varnothing\} \stackrel{\text { result }}{\longrightarrow} W^{c}\left(b c_{\theta}^{i}\right)>W^{c}\left(N_{\theta}\right)$

We can conclude, that country $c$ has no incentive to change its announcement.

Based on the above, we can conclude $\Omega^{b c i}$ is a Nash Equilibria for both local and global levels of pollution.

$\Omega^{\text {bci }}$ is a CPNE if pollution is local \& $\lambda \varepsilon(0,0.008]$.

\section{PROOF:}

The level of welfare members of this deep bilateral FTA achieve is the highest in the entire game. Based on that, we conclude that there no coalitional deviations which can be meaningful for either member. $\Omega^{b c i}$ is a CPNE if pollution is local and $\lambda \varepsilon(0,0.008]$.

$\Omega^{b c i}$ is not a CPNE if pollution is local \& $\lambda \varepsilon(0.008,0]$ or if pollution is global.

\section{PROOF:}

We prove the above by examining the coalitional deviation of one clean and one dirty country. Either member of this deep bilateral trade agreement is interested in making a side deal with the only clean member of the world, country $a$. Country $a$ would except this offer from either dirty country. The clean player is better of as a spoke than as an outsider of a deep FTA of two dirty countries.

$$
\Omega^{a h i} \equiv\left\{\sigma_{a}^{i}=\left\{b^{i}, c^{i}\right\}, \sigma_{b}^{i}=\left\{a^{i}, \varnothing\right\}, \sigma_{c}^{i}=\left\{a^{i}, \varnothing\right\}\right\}
$$

$\Omega^{\text {ahi }}$ is not a Nash Equilibria if pollution is local.

\section{PROOF:}

country $\mathrm{c}=\left\{a^{i}, \varnothing\right\} \stackrel{\text { change }}{\longrightarrow}\left\{\varnothing, b^{i}\right\} /\{\varnothing, \varnothing\} \stackrel{\text { result }}{\longrightarrow} W^{c}\left(a_{l}^{h i}\right)<W^{c}\left(a b_{l}^{i}\right)$

We can conclude, that country $c$ has an incentive to self-exclude itself.

Based on the above, we conclude that $\Omega^{a h i}$ is not a Nash Equilibria if pollution is local. 
$\Omega^{a h i}$ is a Nash Equilibria if pollution is global.

ProOF:

country a $=\left\{b^{i}, c^{i}\right\} \stackrel{\text { change }}{\longrightarrow}\left\{b^{i}, \varnothing\right\} /\left\{\varnothing, c^{i}\right\} \stackrel{\text { result }}{\longrightarrow} W^{a}\left(a_{g}^{h i}\right)>W^{a}\left(a b_{g}^{i}\right)=W^{a}\left(a c_{g}^{i}\right)$

country a $=\left\{b^{i}, c^{i}\right\} \stackrel{\text { change }}{\longrightarrow}\{\varnothing, \varnothing\} \stackrel{\text { result }}{\longrightarrow} W^{a}\left(a_{g}^{h i}\right)>W^{a}\left(N_{g}\right)$

We can conclude, that country $a$ has no incentive to change its announcement.

country $\mathrm{b}=\left\{a^{i}, \varnothing\right\} \stackrel{\text { change }}{\longrightarrow}\left\{a^{i}, c^{i}\right\} \stackrel{\text { result }}{\longrightarrow}$ no change in $b$ 's welfare

country $\mathrm{b}=\left\{a^{i}, \varnothing\right\} \stackrel{\text { change }}{\longrightarrow}\left\{\varnothing, c^{i}\right\} /\{\varnothing, \varnothing\} \stackrel{\text { result }}{\longrightarrow} W^{b}\left(a_{g}^{h i}\right)>W^{b}\left(a c_{g}^{i}\right)$

We can conclude, that country $b$ has no incentive to change its announcement.

country $\mathrm{c}=\left\{a^{i}, \varnothing\right\} \stackrel{\text { change }}{\longrightarrow}\left\{a^{i}, b^{i}\right\} \stackrel{\text { result }}{\longrightarrow}$ no change in $c$ 's welfare

country c $=\left\{a^{i}, \varnothing\right\} \stackrel{\text { change }}{\longrightarrow}\left\{\varnothing, b^{i}\right\} /\{\varnothing, \varnothing\} \stackrel{\text { result }}{\longrightarrow} W^{c}\left(a_{g}^{h i}\right)>W^{c}\left(a b_{g}^{i}\right)$

We can conclude, that country $c$ has no incentive to change its announcement.

Based on the above, we conclude that $\Omega^{a h i}$ is a Nash Equilibria if pollution is global.

$\Omega^{\text {ahi }}$ is not a CPNE if pollution is global.

PROOF:

To prove the above, we consider a coalitional deviation of two dirty countries, country $b$ and country $c$. By forming this coalition these two players would "drive" the clean country into a deep free trade agreement, and improve their welfare levels. Dirty countries would prefer to live in a fully integrated world versus being spokes. Based on the above, we conclude that $\Omega^{a h i}$ is not a CPNE if pollution is global.

$$
\Omega^{b h i} \equiv\left\{\sigma_{a}^{i}=\left\{b^{i}, \varnothing\right\}, \sigma_{b}^{i}=\left\{a^{i}, c^{i}\right\}, \sigma_{c}^{i}=\left\{\varnothing, b^{i}\right\}\right\}
$$

$\Omega^{\text {bhi }}$ is not a Nash Equilibria for both local and global levels of pollution.

PROOF:

country $\mathrm{c}=\left\{\varnothing, b^{i}\right\} \stackrel{\text { change }}{\longrightarrow}\left\{a^{i}, \varnothing\right\} /\{\varnothing, \varnothing\} \stackrel{\text { result }}{\longrightarrow} W^{c}\left(b_{\theta}^{h i}\right)<W^{c}\left(a b_{\theta}^{i}\right)$

We can conclude, that country $c$ has an incentive to self-exclude itself.

Based on the above, we conclude that $\Omega^{b h i}$ is not a Nash Equilibria for both local and global levels of pollution. 


$$
\Omega^{F^{i}} \equiv\left\{\sigma_{a}^{i}=\left\{b^{i}, c^{i}\right\}, \sigma_{b}^{i}=\left\{a^{i}, c^{i}\right\}, \sigma_{c}^{i}=\left\{a^{i}, b^{i}\right\}\right\}
$$

$\Omega \digamma^{i}$ is not a Nash Equilibria if pollution is local.

\section{PROOF:}

country $\mathrm{c}=\left\{a^{i}, b^{i}\right\} \stackrel{\text { change }}{\longrightarrow}\{\varnothing, \varnothing\} \stackrel{\text { result }}{\longrightarrow} W^{c}\left(a b_{l}^{i}\right)>W^{c}\left(a b c_{l}^{i}\right)$

We can conclude, that country $c$ has an incentive to self-exclude itself.

Based on the above, we conclude $\Omega^{F^{i}}$ is not a Nash Equilibria if pollution is local.

$\Omega^{\digamma^{i}}$ is a Nash Equilibria if pollution is global.

ProOF:

country a $=\left\{b^{i}, c^{i}\right\} \stackrel{\text { change }}{\longrightarrow}\left\{b^{i}, \varnothing\right\} /\left\{\varnothing, c^{i}\right\} \stackrel{\text { result }}{\longrightarrow} W^{a}\left(a b c_{g}^{i}\right)>W^{a}\left(b_{g}^{h i}\right)=W^{a}\left(c_{g}^{h i}\right)$

country a $=\left\{b^{i}, c^{i}\right\} \stackrel{\text { change }}{\longrightarrow}\{\varnothing, \varnothing\} \stackrel{\text { result }}{\longrightarrow} W^{a}\left(a b c_{g}^{i}\right)>W^{a}\left(b c_{g}^{i}\right)$

We can conclude, that country $a$ has no incentive to change its announcement.

country $\mathrm{b}=\left\{a^{i}, c^{i}\right\} \stackrel{\text { change }}{\longrightarrow}\left\{a^{i}, \varnothing\right\} \stackrel{\text { result }}{\longrightarrow} W^{b}\left(a b c_{g}^{i}\right)>W^{b}\left(a_{g}^{h i}\right)$

country $\mathrm{b}=\left\{a^{i}, c^{i}\right\} \stackrel{\text { change }}{\longrightarrow}\left\{\varnothing, c^{i}\right\} \stackrel{\text { result }}{\longrightarrow} W^{b}\left(a b c_{g}^{i}\right)>W^{b}\left(c_{g}^{h i}\right)$

country $\mathrm{b}=\left\{a^{i}, c^{i}\right\} \stackrel{\text { change }}{\longrightarrow}\{\varnothing, \varnothing\} \stackrel{\text { result }}{\longrightarrow} W^{b}\left(a b c_{g}^{i}\right)>W^{b}\left(a c_{g}^{i}\right)$

We can conclude, that country $b$ has no incentive to change its announcement.

country $\mathrm{c}=\left\{a^{i}, b^{i}\right\} \stackrel{\text { change }}{\longrightarrow}\left\{\varnothing, b^{i}\right\} \stackrel{\text { result }}{\longrightarrow} W^{c}\left(a b c_{g}^{i}\right)>W^{c}\left(b_{g}^{h i}\right)$

country $\mathrm{c}=\left\{a^{i}, b^{i}\right\} \stackrel{\text { change }}{\longrightarrow}\left\{a^{i}, \varnothing\right\} \stackrel{\text { result }}{\longrightarrow} W^{c}\left(a b c_{g}^{i}\right)>W^{c}\left(a_{g}^{h i}\right)$

country $\mathrm{c}=\left\{a^{i}, b^{i}\right\} \stackrel{\text { change }}{\longrightarrow}\{\varnothing, \varnothing\} \stackrel{\text { result }}{\longrightarrow} W^{c}\left(a b c_{g}^{i}\right)>W^{c}\left(a b_{g}^{i}\right)$

We can conclude, that country $c$ has no incentive to change its announcement.

Based on the above, we conclude that $\Omega^{\digamma^{i}}$ is a Nash Equilibria if pollution is global.

$\Omega^{\digamma^{i}}$ is a CPNE if pollution is global.

\section{PROOF:}

We prove the above by examining all possible deviations. First, we assume that the clean country $a$ forms a coalition with one of the dirty players, then $W^{a}\left(a b_{\theta}^{i}\right)=W^{a}\left(a c_{\theta}^{i}\right)<W^{a}\left(a b c_{\theta}^{i}\right)$, and we conclude that this deviation is not meaningful. Second, we consider the coalitional deviation of two symmetric dirty countries and $\lambda \varepsilon(0,0.089]$, and as a result of this agreement, we have the following levels of welfares $W^{j}\left(b c_{g}^{i}\right)>W^{j}\left(a b c_{g}^{i}\right)$ where $j \neq a$. However, both countries have an 
incentive to deviate further and become a hub: $W^{j}\left(j_{g}^{h i}\right)>W^{j}\left(b c_{g}^{i}\right)$. We conclude that this deviation is not self-enforcing. Now, we consider the coalitional deviation of two symmetric dirty countries and $\lambda \varepsilon(0.089,0.1]$, and we observe that the only reason dirty countries would form this agreement is a further deviation to become a hub: $W^{j}\left(j_{g}^{i}\right)>W^{j}\left(a b c_{j}^{i}\right)>W^{j}\left(b c_{g}^{i}\right)$ where $j \neq a$. We conclude that there are no possible meaningful deviations, and $\Omega^{\digamma^{i}}$ is a CPNE if pollution is global.

\section{A. 4.9.2.1 Shallow Trade Agreements Game}

Welfare effects of various type of shallow trade agreements:

Country a, local pollution

$W^{a}\left(a_{l}^{h}\right)>W^{a}\left(a b_{l}^{u}\right)>W^{a}\left(a b c_{l}\right)>W^{a}\left(a b_{l}\right)>W^{a}\left(b c_{l}\right) \stackrel{\lambda \in(0,0.023]}{>} W^{a}\left(b_{l}^{h}\right)>W^{a}\left(N_{l}\right)>W^{a}\left(b c_{l}^{u}\right)$

$\lambda \in(0,0.023]$

$W^{a}\left(a_{l}^{h}\right)>W^{a}\left(a b_{l}^{u}\right)>W^{a}\left(a b c_{l}\right)>W^{a}\left(a b_{l}\right)>W^{a}\left(b_{l}^{h}\right) \stackrel{\lambda \in(0.023,0.1]}{>} W^{a}\left(b c_{l}\right)>W^{a}\left(N_{l}\right)>W^{a}\left(b c_{l}^{u}\right)$

$\lambda \in(0.023,0.1]$

Country a, global pollution

$W^{a}\left(b c_{g}\right)>W^{a}\left(N_{g}\right)>W^{a}\left(a b_{g}^{u}\right)>W^{a}\left(a_{g}^{h}\right)>W^{a}\left(a b c_{g}\right)>W^{a}\left(a b_{g}\right)>W^{a}\left(b_{g}^{h}\right) \stackrel{\lambda \in(0,0.046]}{>} W^{a}\left(b c_{g}^{u}\right)$

$\lambda \in(0,0.046]$

$W^{a}\left(b c_{g}\right)>W^{a}\left(N_{g}\right)>W^{a}\left(a b_{g}^{u}\right)>W^{a}\left(a_{g}^{h}\right)>W^{a}\left(a b c_{g}\right)>W^{a}\left(a b_{g}\right) \stackrel{\lambda \in(0,0.083]}{>} W^{a}\left(b c_{g}^{u}\right) \stackrel{\lambda \in(0.046,0.1]}{>}$

$W^{a}\left(b_{g}^{h}\right) \lambda \in(0.046,0.083]$

$W^{a}\left(b c_{g}\right)>W^{a}\left(N_{g}\right)>W^{a}\left(a b_{g}^{u}\right)>W^{a}\left(a_{g}^{h}\right)>W^{a}\left(a b c_{g}\right) \stackrel{\lambda \in(0,0.089]}{>} W^{a}\left(b c_{g}^{u}\right) \stackrel{\lambda \in(0.083,0.1]}{>} W^{a}\left(a b_{g}\right)>$

$W^{a}\left(b_{g}^{h}\right) \lambda \in(0.083,0.089]$

$W^{a}\left(b c_{g}\right)>W^{a}\left(N_{g}\right)>W^{a}\left(a b_{g}^{u}\right)>W^{a}\left(a_{g}^{h}\right)>W^{a}\left(b c_{g}^{u}\right) \stackrel{\lambda \in(0.089,0.1]}{>} W^{a}\left(a b c_{g}\right)>W^{a}\left(a b_{g}\right)>W^{a}\left(b_{g}^{h}\right)$

$\lambda \in(0.089,0.1]$

Country b, local pollution

$W^{b}\left(b_{l}^{h}\right)>W^{b}\left(b c_{l}^{u}\right)>W^{b}\left(a b c_{l}\right)>W^{b}\left(b c_{l}\right)>W^{b}\left(a b_{l}^{u}\right)>W^{b}\left(a_{l}^{h}\right)>W^{b}\left(a b_{l}\right) \stackrel{\lambda \in(0,0.027]}{>} W^{b}\left(N_{l}\right)$

$\lambda \in(0,0.027]$

$W^{b}\left(b_{l}^{h}\right)>W^{b}\left(b c_{l}^{u}\right)>W^{b}\left(a b c_{l}\right)>W^{b}\left(b c_{l}\right)>W^{b}\left(a b_{l}^{u}\right)>W^{b}\left(a_{l}^{h}\right) \stackrel{\lambda \in(0,0.082]}{>} W^{b}\left(N_{l}\right) \stackrel{\lambda \in(0.027,0.1]}{>}$

$W^{b}\left(a b_{l}\right) \lambda \in(0.027,0.082]$ 
$W^{b}\left(b_{l}^{h}\right)>W^{b}\left(b c_{l}^{u}\right)>W^{b}\left(a b c_{l}\right)>W^{b}\left(b c_{l}\right)>W^{b}\left(a b_{l}^{u}\right)>W^{b}\left(N_{l}\right) \stackrel{\lambda \in(0.082,0.1]}{>} W^{b}\left(a_{l}^{h}\right)>W^{b}\left(a b_{l}\right)$

$\lambda \in(0.082,0.1]$

Country b, global pollution

$W^{b}\left(b_{g}^{h}\right)>W^{b}\left(b c_{g}^{u}\right)>W^{b}\left(a b_{g}^{u}\right)>W^{b}\left(b c_{g}\right)>W^{b}\left(a b_{g}\right) \stackrel{\lambda \in(0,0.065]}{>} W^{b}\left(N_{g}\right)>W^{b}\left(a b c_{g}\right)>W^{b}\left(a_{g}^{h}\right)$

$\lambda \in(0,0.065]$

$W^{b}\left(b_{g}^{h}\right)>W^{b}\left(b c_{g}^{u}\right)>W^{b}\left(a b_{g}^{u}\right)>W^{b}\left(b c_{g}\right)>W^{b}\left(N_{g}\right) \stackrel{\lambda \in(0.065,0.1]}{>} W^{b}\left(a b_{g}\right)>W^{b}\left(a b c_{g}\right)>W^{b}\left(a_{g}^{h}\right)$

$\lambda \in(0.065,0.1]$

Country c, local pollution

$W^{c}\left(b c_{l}^{u}\right)>W^{c}\left(a b c_{l}\right) \stackrel{\lambda \in(0,0.043]}{>} W^{c}\left(a b_{l}\right)>W^{c}\left(b c_{l}\right)>W^{c}\left(b_{l}^{h}\right)>W^{c}\left(a_{l}^{h}\right) \stackrel{\lambda \in(0,0.082]}{>} W^{c}\left(N_{l}\right)>W^{c}\left(a b_{l}^{u}\right)$

$\lambda \in(0,0.043]$

$W^{c}\left(b c_{l}^{u}\right)>W^{c}\left(a b_{l}\right) \stackrel{\lambda \in(0.043,0.1]}{>} W^{c}\left(a b c_{l}\right)>W^{c}\left(b c_{l}\right)>W^{c}\left(b_{l}^{h}\right)>W^{c}\left(a_{l}^{h}\right) \stackrel{\lambda \in(0,0.082]}{>} W^{c}\left(N_{l}\right)>$ $W^{c}\left(a b_{l}^{u}\right) \lambda \in(0.043,0.082]$

$W^{c}\left(b c_{l}^{u}\right)>W^{c}\left(a b_{l}\right) \stackrel{\lambda \in(0.043,0.1]}{>} W^{c}\left(a b c_{l}\right)>W^{c}\left(b c_{l}\right)>W^{c}\left(b_{l}^{h}\right)>W^{c}(N) \stackrel{\lambda \in(0.082,0.1]}{>} W^{c}\left(a_{l}^{h}\right)>$

$W^{c}\left(a b_{l}^{u}\right) \lambda \in(0.082,0.1]$

Country c, global pollution

$W^{c}\left(b c_{g}^{u}\right)>W^{c}\left(b c_{g}\right)>W^{c}\left(N_{g}\right)>W^{c}\left(a b c_{g}\right)>W^{c}\left(a_{g}^{h}\right)>W^{c}\left(a b_{g}\right)>W^{c}\left(b_{g}^{h}\right)>W^{c}\left(a b_{g}^{u}\right)$

\begin{tabular}{|c|c|}
\hline Announcement Profiles & Shallow Trade Agreements \\
\hline \hline$\Omega^{\Phi} \equiv\left\{\sigma_{a}=\{\varnothing, \varnothing\}, \sigma_{b}=\{\varnothing, \varnothing\}, \sigma_{c}=\{\varnothing, \varnothing\}\right\}$ & $\langle\Phi\rangle$ \\
\hline$\Omega^{a b} \equiv\left\{\sigma_{a}=\{b, \varnothing\}, \sigma_{b}=\{a, \varnothing\}, \sigma_{c}=\{\varnothing, \varnothing\}\right\}$ & $\langle a b\rangle$ \\
\hline$\Omega^{a b u} \equiv\left\{\sigma_{a}^{u}=\left\{b^{u}, \varnothing\right\}, \sigma_{b}^{u}=\left\{a^{u}, \varnothing\right\}, \sigma_{c}^{u}=\{\varnothing, \varnothing\}\right\}$ & $\langle a b u\rangle$ \\
\hline$\Omega^{b c} \equiv\left\{\sigma_{a}=\{\varnothing, \varnothing\}, \sigma_{b}=\{\varnothing, c\}, \sigma_{c}=\{\varnothing, b\}\right\}$ & $\langle b c\rangle$ \\
\hline$\Omega^{b c u} \equiv\left\{\sigma_{a}^{u}=\{\varnothing, \varnothing\}, \sigma_{b}^{u}=\left\{\varnothing, c^{u}\right\}, \sigma_{c}^{u}=\left\{\varnothing, b^{u}\right\}\right\}$ & $\langle a h\rangle$ \\
\hline$\Omega^{a h} \equiv\left\{\sigma_{a}=\{b, c\}, \sigma_{b}=\{a, \varnothing\}, \sigma_{c}=\{a, \varnothing\}\right\}$ & $\langle b h\rangle$ \\
\hline$\Omega^{b h} \equiv\left\{\sigma_{a}=\{b, \varnothing\}, \sigma_{b}=\{a, c\}, \sigma_{c}=\{\varnothing, b\}\right\}$ & $\langle F\rangle$ \\
\hline$\Omega^{F} \equiv\left\{\sigma_{a}=\{b, c\}, \sigma_{b}=\{a, c\}, \sigma_{c}=\{a, b\}\right\}$ & $\left\langle F^{u}\right\rangle$ \\
\hline$\Omega^{F^{u}} \equiv\left\{\sigma_{a}^{u}=\left\{b^{u}, c^{u}\right\}, \sigma_{b}^{u}=\left\{a^{u}, c^{u}\right\}, \sigma_{c}^{u}=\left\{a^{u}, b^{u}\right\}\right\}$ & \\
\hline
\end{tabular}

$$
\Omega^{\Phi} \equiv\left\{\sigma_{a}=\{\varnothing, \varnothing\}, \sigma_{b}=\{\varnothing, \varnothing\}, \sigma_{c}=\{\varnothing, \varnothing\}\right\}
$$

$\Omega^{\Phi}$ is a Nash Equilibria for both local and global levels of pollution. 


\section{PROOF:}

Countries cannot get better off by unilaterally changing the announcements; countries have no incentive to announce any other country unless they are going to be announced back.

$\Omega^{\Phi}$ is not a CPNE for both local and global levels of pollution.

\section{PROOF:}

We prove the above by examining the coalitional deviation of two dirty countries in the form of a customs union. In this case, the announcement profile would be altered as follows: $\Omega \equiv\left\{\sigma_{a}=\right.$ $\left.\{\varnothing, \varnothing\}, \sigma_{b}^{u}=\left\{\varnothing, c^{u}\right\}, \sigma_{c}^{u}=\left\{\varnothing, b^{u}\right\}\right\}$, and as a result, we observe the increase in members' welfare levels, $W^{b}\left(b c_{\theta}^{u}\right)>W^{b}\left(N_{\theta}\right)$ and $W^{c}\left(b c_{\theta}^{u}\right)>W^{c}\left(N_{\theta}\right)$. Though both members have an incentive to deviate and form a side deal with the clean country $a$, the nature of customs unions prevent this deviation, and we conclude that no further deviations can occur. Based on the above, $\Omega^{\Phi}$ is not a CPNE.

$$
\Omega^{a b} \equiv\left\{\sigma_{a}=\{b, \varnothing\}, \sigma_{b}=\{a, \varnothing\}, \sigma_{c}=\{\varnothing, \varnothing\}\right\}
$$

$\Omega^{a b}$ is a Nash Equilibria if pollution is local and $\lambda \varepsilon(0,0.027]$.

\section{PROOF:}

country a $=\{b, \varnothing\} \stackrel{\text { change }}{\longrightarrow}\{b, c\} \stackrel{\text { result }}{\longrightarrow}$ no change in $a$ 's welfare

country $\mathrm{a}=\{b, \varnothing\} \stackrel{\text { change }}{\longrightarrow}\{\varnothing, c\} /\left\{\varnothing, c^{u}\right\} /\left\{b^{u}, \varnothing\right\} /\{\varnothing, \varnothing\} /\left\{b^{u}, c^{u}\right\} \stackrel{\text { result }}{\longrightarrow} W^{a}\left(a b_{l}\right)>W^{a}\left(N_{l}\right)$

We can conclude, that country $a$ has no incentive to change its announcement.

country $\mathrm{b}=\{a, \varnothing\} \stackrel{\text { change }}{\longrightarrow}\{a, c\} \stackrel{\text { result }}{\longrightarrow}$ no change in $b$ 's welfare

country $\mathrm{b}=\{a, \varnothing\} \stackrel{\text { change }}{\longrightarrow}\{\varnothing, c\} /\left\{\varnothing, c^{u}\right\} /\left\{a^{u}, \varnothing\right\} /\{\varnothing, \varnothing\} /\left\{a^{u}, c^{u}\right\} \stackrel{\text { result }}{\longrightarrow} W^{b}\left(a b_{l}\right)>W^{b}\left(N_{l}\right) \& \lambda \varepsilon(0,0.027]$

We can conclude, that country $b$ has no incentive to change its announcement.

country $\mathrm{c}=\{\varnothing, \varnothing\} \stackrel{\text { change }}{\longrightarrow}\{a, \varnothing\} /\left\{a^{u}, \varnothing\right\} /\{\varnothing, b\} /\left\{\varnothing, b^{u}\right\} /\{a, b\} /\left\{a^{u}, b^{u}\right\} \stackrel{\text { result }}{\longrightarrow}$ no change in $c^{\prime} s$ welfare

We can conclude, that country $c$ has no incentive to change its announcement.

Based on the above, we conclude that $\Omega^{a b}$ is a Nash Equilibria if pollution is local and $\lambda \varepsilon(0,0.027]$. $\Omega^{a b}$ is not a Nash Equilibria if pollution is local and $\lambda \varepsilon(0.027,0.1]$.

\section{ProOF:}


country $\mathrm{b}=\{a, \varnothing\} \stackrel{\text { change }}{\longrightarrow}\{\varnothing, c\} /\left\{\varnothing, c^{u}\right\} /\left\{a^{u}, \varnothing\right\} /\{\varnothing, \varnothing\} /\left\{a^{u}, c^{u}\right\} \stackrel{\text { result }}{\longrightarrow} W^{b}\left(a b_{l}\right)>W^{b}\left(N_{l}\right) \& \lambda \varepsilon(0.027,0.1]$

We can conclude, that country $b$ can improve its welfare by unilaterally changing its announcement and deviating into no agreement scenario, and based on that, we conclude that $\Omega^{a b}$ is not a Nash Equilibria if pollution is local and $\lambda \varepsilon(0.027,0.1]$.

$\Omega^{a b}$ is not a Nash Equilibria if pollution is global.

PROOF:

country a $=\{b, \varnothing\} \stackrel{\text { change }}{\longrightarrow}\{\varnothing, c\} /\left\{\varnothing, c^{u}\right\} /\left\{b^{u}, \varnothing\right\} /\{\varnothing, \varnothing\} /\left\{b^{u}, c^{u}\right\} \stackrel{\text { result }}{\longrightarrow} W^{a}\left(a b_{g}\right)<W^{a}\left(N_{g}\right)$

We can conclude, that country $a$ can improve its welfare by unilaterally changing its announcement and deviating into no agreement scenario, and based on that, we conclude that $\Omega^{a b}$ is not a Nash Equilibria if pollution is global.

$\Omega^{a b}$ is not a CPNE if pollution is local and $\lambda \varepsilon(0,0.027]$.

PROOF:

We prove the above by examining the coalitional deviation of two dirty countries in the form of a customs union. In this case, the announcement profile would be altered as follows: $\Omega \equiv\left\{\sigma_{a}=\right.$ $\left.\{b, \varnothing\}, \sigma_{b}^{u}=\left\{\varnothing, c^{u}\right\}, \sigma_{c}^{u}=\left\{\varnothing, b^{u}\right\}\right\}$, and as a result, we observe the increase in members' welfare levels, $W^{b}\left(b c_{l}^{u}\right)>W^{b}\left(a b_{l}\right)$ and $W^{c}\left(b c_{l}^{u}\right)>W^{c}\left(a b_{l}\right)$. Though both members have an incentive to announce $a$ as well, and consequently, turn into a hub, the nature of customs unions prevent this deviation, and we conclude that no further deviations can occur. Based on the above, $\Omega^{a b}$ is not a CPNE if pollution is local and $\lambda \varepsilon(0,0.027]$.

$$
\Omega^{a b u} \equiv\left\{\sigma_{a}^{u}=\left\{b^{u}, \varnothing\right\}, \sigma_{b}^{u}=\left\{a^{u}, \varnothing\right\}, \sigma_{c}^{u}=\{\varnothing, \varnothing\}\right\}
$$

$\Omega^{a b u}$ is a Nash Equilibria if pollution is local.

PROOF:

country a $=\left\{b^{u}, \varnothing\right\} \stackrel{\text { change }}{\longrightarrow}\left\{b^{u}, c^{u}\right\} \stackrel{\text { result }}{\longrightarrow}$ no change in $a$ 's welfare

country a $=\left\{b^{u}, \varnothing\right\} \stackrel{\text { change }}{\longrightarrow}\{\varnothing, c\} /\left\{\varnothing, c^{u}\right\} /\{\varnothing, \varnothing\} /\{b, c\} /\{b, \varnothing\} \stackrel{\text { result }}{\longrightarrow} W^{a}\left(a b_{l}^{u}\right)>W^{a}\left(N_{l}\right)$

We can conclude, that country $a$ has no incentive to change its announcement.

country $\mathrm{b}=\left\{a^{u}, \varnothing\right\} \stackrel{\text { change }}{\longrightarrow}\left\{a^{u}, c^{u}\right\} \stackrel{\text { result }}{\longrightarrow}$ no change in $b$ 's welfare 
country $\mathrm{b}=\left\{a^{u}, \varnothing\right\} \stackrel{\text { change }}{\longrightarrow}\{\varnothing, c\} /\left\{\varnothing, c^{u}\right\} /\{\varnothing, \varnothing\} /\{a, c\} /\{a, \varnothing\} \stackrel{\text { result }}{\longrightarrow} W^{b}\left(a b_{l}^{u}\right)>W^{b}\left(N_{l}\right)$

We can conclude, that country $b$ has no incentive to change its announcement.

country $\mathrm{c}=\{\varnothing, \varnothing\} \stackrel{\text { change }}{\longrightarrow}\{a, \varnothing\} /\left\{a^{u}, \varnothing\right\} /\{\varnothing, b\} /\left\{\varnothing, b^{u}\right\} /\{a, b\} /\left\{a^{u}, b^{u}\right\} \stackrel{\text { result }}{\longrightarrow}$ no change in $c^{\prime} s$ welfare

We can conclude, that country $c$ has no incentive to change its announcement.

Based on the above, $\Omega^{a b u}$ is a Nash Equilibria if pollution is local.

$\Omega^{a b u}$ is not a Nash Equilibria if pollution is global.

PROOF:

country a $=\left\{b^{u}, \varnothing\right\} \stackrel{\text { change }}{\longrightarrow}\{\varnothing, c\} /\left\{\varnothing, c^{u}\right\} /\{\varnothing, \varnothing\} /\{b, c\} /\{b, \varnothing\} \stackrel{\text { result }}{\longrightarrow} W^{a}\left(a b_{g}^{u}\right)>W^{a}\left(N_{g}\right)$

We can conclude, that country the clean country $a$ would deviate to improve its welfare. Based on that, $\Omega^{a b u}$ is not a Nash Equilibria if pollution is global.

$\Omega^{a b u}$ is not a CPNE if pollution is local.

PROOF:

We prove the above by examining the coalitional deviation of two dirty countries, country $b$ and country $c$, in the form of a customs union. In this case, the announcement profile would be altered as follows: $\Omega \equiv\left\{\sigma_{a}^{u}=\left\{b^{u}, \varnothing\right\}, \sigma_{b}^{u}=\left\{\varnothing, c^{u}\right\}, \sigma_{c}^{u}=\left\{\varnothing, b^{u}\right\}\right\}$, and as a result, we observe the increase in members' welfare levels, $W^{b}\left(b c_{l}^{u}\right)>W^{b}\left(a b_{l}^{u}\right)$ and $W^{c}\left(b c_{l}^{u}\right)>W^{c}\left(a b_{l}^{u}\right)$. Though both members have an incentive to announce $a$ as well, and consequently, become a hub, the nature of customs unions prevent this deviation, and we conclude that no further deviations can occur. Based on the above, $\Omega^{a b u}$ is not a CPNE if pollution is local.

$$
\Omega^{b c} \equiv\left\{\sigma_{a}=\{\varnothing, \varnothing\}, \sigma_{b}=\{\varnothing, c\}, \sigma_{c}=\{\varnothing, b\}\right\}
$$

$\Omega^{b c}$ is a Nash Equilibria for both local and global levels of pollution.

PROOF:

country a $=\{\varnothing, \varnothing\} \stackrel{\text { change }}{\longrightarrow}\{b, \varnothing\} /\left\{b^{u}, \varnothing\right\} /\{\varnothing, c\} /\left\{\varnothing, c^{u}\right\} /\{b, c\} /\left\{b^{u}, c^{u}\right\} \stackrel{\text { result }}{\longrightarrow}$ no change in $a$ 's welfare

We can conclude, that country $a$ has no incentive to change its announcement. 
country $\mathrm{b}=\{\varnothing, c\} \stackrel{\text { change }}{\longrightarrow}\{a, c\} \stackrel{\text { result }}{\longrightarrow}$ no change in $b$ 's welfare

country $\mathrm{b}=\{\varnothing, c\} \stackrel{\text { change }}{\longrightarrow}\{a, \varnothing\} /\left\{a^{u}, \varnothing\right\} /\{\varnothing, \varnothing\} /\left\{\varnothing, c^{u}\right\} /\left\{a^{u}, c^{u}\right\} \stackrel{\text { result }}{\longrightarrow} W^{b}\left(b c_{\theta}\right)>W^{b}\left(N_{\theta}\right)$

We can conclude, that country $b$ has no incentive to change its announcement.

country $\mathrm{c}=\{\varnothing, b\} \stackrel{\text { change }}{\longrightarrow}\{a, b\} \stackrel{\text { result }}{\longrightarrow}$ no change in $c$ 's welfare

country $\mathrm{c}=\{\varnothing, b\} \stackrel{\text { change }}{\longrightarrow}\{a, \varnothing\} /\left\{a^{u}, \varnothing\right\} /\{\varnothing, \varnothing\} /\left\{\varnothing, b^{u}\right\} /\left\{a^{u}, b^{u}\right\} \stackrel{\text { result }}{\longrightarrow} W^{c}\left(b c_{\theta}\right)>W^{c}\left(N_{\theta}\right)$

We can conclude, that country $c$ has no incentive to change its announcement.

Based on the above, we conclude that $\Omega^{b c}$ is a Nash Equilibria for both local and global levels of pollution.

$\Omega^{b c}$ is not a CPNE for both local and global levels of pollution.

PROOF:

Members of this bilateral trade agreement, countries $b$ and $c$, can form a coalition to sign a different PTA, then $\Omega \equiv\left\{\sigma_{a}=\{\varnothing, \varnothing\}, \sigma_{b}^{u}=\left\{\varnothing, c^{u}\right\}, \sigma_{c}^{u}=\left\{\varnothing, b^{u}\right\}\right\}$, and $W^{b}\left(b c_{\theta}^{u}\right)=W^{c}\left(b c_{\theta}^{u}\right)>$ $W^{b}\left(b c_{\theta}\right)=W^{c}\left(b c_{\theta}\right)$. No further deviation can occur, because the nature of customs union prevents hub-and-spoke trade regimes. We can conclude that $\Omega^{b c}$ is not a CPNE for both local and global levels of pollution.

$$
\Omega^{b c u} \equiv\left\{\sigma_{a}^{u}=\{\varnothing, \varnothing\}, \sigma_{b}^{u}=\left\{\varnothing, c^{u}\right\}, \sigma_{c}^{u}=\left\{\varnothing, b^{u}\right\}\right\}
$$

$\Omega^{\text {bcu }}$ is a Nash Equilibria for both local and global levels of pollution.

\section{PROOF:}

country a $=\{\varnothing, \varnothing\} \stackrel{\text { change }}{\longrightarrow}\{b, \varnothing\} /\left\{b^{u}, \varnothing\right\} /\{\varnothing, c\} /\left\{\varnothing, c^{u}\right\} /\{b, c\} /\left\{b^{u}, c^{u}\right\} \stackrel{\text { result }}{\longrightarrow}$ no change in $a$ 's welfare

We can conclude, that country $a$ has no incentive to change its announcement.

country $\mathrm{b}=\left\{\varnothing, c^{u}\right\} \stackrel{\text { change }}{\longrightarrow}\left\{a^{u}, c^{u}\right\} \stackrel{\text { result }}{\longrightarrow}$ no change in $b$ 's welfare

country $\mathrm{b}=\left\{\varnothing, c^{u}\right\} \stackrel{\text { change }}{\longrightarrow}\{a, \varnothing\} /\left\{a^{u}, \varnothing\right\} /\{\varnothing, \varnothing\} /\{a, c\} /\{\varnothing, c\} \stackrel{\text { result }}{\longrightarrow} W^{b}\left(b c_{\theta}^{u}\right)>W^{b}\left(N_{\theta}\right)$

We can conclude, that country $b$ has no incentive to change its announcement.

country $\mathrm{c}=\left\{\varnothing, b^{u}\right\} \stackrel{\text { change }}{\longrightarrow}\left\{a^{u}, b^{u}\right\} \stackrel{\text { result }}{\longrightarrow}$ no change in $c^{\prime}$ 's welfare

country $\mathrm{c}=\left\{\varnothing, b^{u}\right\} \stackrel{\text { change }}{\longrightarrow}\{a, \varnothing\} /\left\{a^{u}, \varnothing\right\} /\{\varnothing, \varnothing\} /\{a, b\} /\{\varnothing, b\} \stackrel{\text { result }}{\longrightarrow} W^{c}\left(b c_{\theta}^{u}\right)>W^{c}\left(N_{\theta}\right)$ 
We can conclude, that country $c$ has no incentive to change its announcement.

Based on the above, $\Omega^{b c u}$ is a Nash Equilibria for both local and global levels of pollution.

$\Omega^{b c u}$ is a CPNE for both local and global levels of pollution.

PROOF:

We prove the above by examining every possible meaningful deviation:

- first, we consider a coalitional deviation of one dirty and one clean country, countries a and $\mathrm{b}$, in the form of either FTA or CU, and as a result, we observe that neither of these deviations is meaningful: $W^{b}\left(b c_{\theta}^{u}\right)>W^{b}\left(a b_{\theta}^{u}\right)>W^{b}\left(a b_{\theta}\right)$;

- second, we consider a coalitional deviation of two dirty countries, country b and country c, into a different PTA, and again we find that this deviation is not meaningful as well: $W^{j}\left(b c_{\theta}^{u}\right)>W^{j}\left(b c_{\theta}\right)$, where $j \neq a$;

- now, we examine the grand coalition, and again, we observe that this deviation is not meaningful, too: $W^{j}\left(b c_{\theta}^{u}\right)>W^{j}\left(a b c_{\theta}\right)$, where $j \neq a$;

- finally, we acknowledge that though both members of this coalition would benefit from signing a side deal with the clean country a, and consequently, become a hub, the nature of customs unions prevents hub-and-spoke trade regimes from arising.

Based on the above, we conclude that $\Omega^{b c u}$ survives all coalition-proof Nash equilibria refinements.

$$
\Omega^{a h} \equiv\left\{\sigma_{a}=\{b, c\}, \sigma_{b}=\{a, \varnothing\}, \sigma_{c}=\{a, \varnothing\}\right\}
$$

$\Omega^{\text {ah }}$ is not a Nash Equilibria if pollution is local.

PROOF:

country c $=\{a, \varnothing\} \stackrel{\text { change }}{\longrightarrow}\{\varnothing, \varnothing\} /\left\{a^{u}, b^{u}\right\} /\{\varnothing, b\} /\left\{\varnothing, b^{u}\right\} /\left\{a^{u}, \varnothing\right\} \stackrel{\text { result }}{\longrightarrow} W^{c}\left(a_{l}^{h}\right)<W^{c}\left(a b_{l}\right)$

We can conclude, that country $c$ has an incentive to self-exclude itself.

Based on the above, we can conclude that $\Omega^{a h}$ is not a Nash Equilibria if pollution is local. $\Omega^{a h}$ is not a Nash Equilibria if pollution is global.

PROOF: 
country a $=\{b, c\} \stackrel{\text { change }}{\longrightarrow}\{\varnothing, \varnothing\} /\left\{b^{u}, c^{u}\right\} /\left\{b^{u}, \varnothing\right\} /\left\{\varnothing, c^{u}\right\} \stackrel{\text { result }}{\longrightarrow} W^{a}\left(a_{g}^{h}\right)<W^{a}\left(N_{g}\right)$

We can conclude, that country $a$ has an incentive to self-exclude itself.

Based on the above, we can conclude that $\Omega^{a h}$ is not a Nash Equilibria if pollution is global.

$$
\Omega^{b h} \equiv\left\{\sigma_{a}=\{b, \varnothing\}, \sigma_{b}=\{a, c\}, \sigma_{c}=\{\varnothing, b\}\right\}
$$

$\Omega^{\text {bh }}$ is not a Nash Equilibria if pollution is local.

PROOF:

country $\mathrm{c}=\{\varnothing, b\} \stackrel{\text { change }}{\longrightarrow}\{\varnothing, \varnothing\} /\left\{a^{u}, b^{u}\right\} /\{a, \varnothing\} /\left\{a^{u}, \varnothing\right\} /\left\{\varnothing, b^{u}\right\} \stackrel{\text { result }}{\longrightarrow} W^{c}\left(b_{l}^{h}\right)<W^{c}\left(a b_{l}\right)$

We can conclude, that country $c$ has an incentive to self-exclude itself.

Based on the above, we conclude that $\Omega^{b h}$ is not a Nash Equilibria if pollution is local.

$\Omega^{\text {bh }}$ is not a Nash Equilibria if pollution is global.

PROOF:

country a $=\{b, \varnothing\} \stackrel{\text { change }}{\longrightarrow}\{\varnothing, \varnothing\} /\left\{b^{u}, c^{u}\right\} /\{\varnothing, c\} /\left\{\varnothing, c^{u}\right\} /\left\{a^{u}, \varnothing\right\} \stackrel{\text { result }}{\longrightarrow} W^{a}\left(b_{g}^{h}\right)<W^{a}\left(b c_{g}\right)$

We can conclude, that country $a$ has an incentive to self-exclude itself.

Based on the above, we can conclude that $\Omega^{b h}$ is not a Nash Equilibria if pollution is global.

$$
\Omega^{F} \equiv\left\{\sigma_{a}=\{b, c\}, \sigma_{b}=\{a, c\}, \sigma_{c}=\{a, b\}\right\}
$$

$\Omega^{\digamma}$ is a Nash Equilibria if pollution is local and $\lambda \varepsilon(0,0.043]$.

PROOF:

country a $=\{b, c\} \stackrel{\text { change }}{\longrightarrow}\{b, \varnothing\} /\{\varnothing, c\} \stackrel{\text { result }}{\longrightarrow} W^{a}\left(a b c_{l}\right)>W^{a}\left(b_{l}^{h}\right)=W^{a}\left(c_{l}^{h}\right)$

country $\mathrm{a}=\{b, c\} \stackrel{\text { change }}{\longrightarrow}\{\varnothing, \varnothing\} /\left\{b^{u}, c^{u}\right\} /\left\{b^{u}, \varnothing\right\} /\left\{\varnothing, c^{u}\right\} \stackrel{\text { result }}{\longrightarrow} W^{a}\left(a b c_{l}\right)>W^{a}\left(b c_{l}\right)$

We can conclude, that country $a$ has no incentive to change its announcement.

country $\mathrm{b}=\{a, c\} \stackrel{\text { change }}{\longrightarrow}\{a, \varnothing\} \stackrel{\text { result }}{\longrightarrow} W^{b}\left(a b c_{l}\right)>W^{b}\left(a_{l}^{h}\right)$

country $\mathrm{b}=\{a, c\} \stackrel{\text { change }}{\longrightarrow}\{\varnothing, c\} \stackrel{\text { result }}{\longrightarrow} W^{b}\left(a b c_{l}\right)>W^{b}\left(c_{l}^{h}\right)$

country $\mathrm{b}=\{a, c\} \stackrel{\text { change }}{\longrightarrow}\{\varnothing, \varnothing\} /\left\{a^{u}, c^{u}\right\} /\left\{a^{u}, \varnothing\right\} /\left\{\varnothing, c^{u}\right\} \stackrel{\text { result }}{\longrightarrow} W^{b}\left(a b c_{l}\right)>W^{b}\left(a c_{l}\right) \& \lambda \varepsilon(0,0.043]$.

We can conclude, that country $b$ has no incentive to change its announcement.

country $\mathrm{c}=\{a, b\} \stackrel{\text { change }}{\longrightarrow}\{\varnothing, b\} \stackrel{\text { result }}{\longrightarrow} W^{c}\left(a b c_{l}\right)>W^{c}\left(b_{l}^{h}\right)$

country $\mathrm{c}=\{a, b\} \stackrel{\text { change }}{\longrightarrow}\{a, \varnothing\} \stackrel{\text { result }}{\longrightarrow} W^{c}\left(a b c_{l}\right)>W^{c}\left(a_{l}^{h}\right)$ 
country $\mathrm{c}=\{a, b\} \stackrel{\text { change }}{\longrightarrow}\{\varnothing, \varnothing\} /\left\{a^{u}, b^{u}\right\} /\left\{a^{u}, \varnothing\right\} /\left\{\varnothing, b^{u}\right\} \stackrel{\text { result }}{\longrightarrow} W^{c}\left(a b c_{l}\right)>W^{c}\left(a b_{l}\right) \& \lambda \varepsilon(0,0.043]$

We can conclude, that country $c$ has no incentive to change its announcement.

Based on the above, we conclude that $\Omega^{\digamma}$ is a Nash Equilibria if pollution is local and $\& \lambda \varepsilon(0,0.043]$. $\Omega^{\digamma}$ is not a Nash Equilibria if pollution is local and $\lambda \varepsilon(0.043,0.1]$.

PROOF:

country $\mathrm{c}=\{a, b\} \stackrel{\text { change }}{\longrightarrow}\{\varnothing, \varnothing\} /\left\{a^{u}, b^{u}\right\} /\left\{a^{u}, \varnothing\right\} /\left\{\varnothing, b^{u}\right\} \stackrel{\text { result }}{\longrightarrow} W^{c}\left(a b c_{l}\right)<W^{c}\left(a b_{l}\right) \& \lambda \varepsilon(0.043,0.1]$

We can conclude, that country $c$ has an incentive to self-exclude itself.

Based on the above, we conclude that $\Omega^{\digamma}$ is not a Nash Equilibria if pollution is local and \& $\lambda \varepsilon(0.043,0.1]$

$\Omega^{\digamma}$ is not a Nash Equilibria if pollution is global.

PROOF:

country a $=\{b, c\} \stackrel{\text { change }}{\longrightarrow}\{\varnothing, \varnothing\} /\left\{b^{u}, c^{u}\right\} /\left\{b^{u}, \varnothing\right\} /\left\{\varnothing, c^{u}\right\} \stackrel{\text { result }}{\longrightarrow} W^{a}\left(a b c_{g}\right)<W^{a}\left(b c_{g}\right)$

We can conclude, that country $a$ has an incentive to self-exclude itself.

Based on the above, we conclude that $\Omega^{\digamma}$ is not a Nash Equilibria if pollution is global.

$\Omega^{\digamma}$ is not a CPNE if pollution is local and $\lambda \varepsilon(0,0.043]$.

\section{PROOF:}

We prove the above by examining the coalitional deviation of two dirty countries, country $b$ and country $c$, in the form of a customs union. In this case, the announcement profile would be altered as follows: $\Omega \equiv\left\{\sigma_{a}=\{b, c\}, \sigma_{b}^{u}=\left\{\varnothing, c^{u}\right\}, \sigma_{c}^{u}=\left\{\varnothing, b^{u}\right\}\right\}$, and as a result, we observe the increase in members' welfare levels, $W^{j}\left(b c_{l}^{u}\right)>W^{j}\left(a b c_{l}\right)$ where $j \neq a$. Though both members have an incentive to announce $a$ as well, and consequently, become a hub, the nature of customs unions prevent this deviation, and we conclude that no further deviations can occur. Based on the above, $\Omega^{F}$ is not a CPNE if pollution is local.

$$
\Omega^{F^{u}} \equiv\left\{\sigma_{a}^{u}=\left\{b^{u}, c^{u}\right\}, \sigma_{b}^{u}=\left\{a^{u}, c^{u}\right\}, \sigma_{c}^{u}=\left\{a^{u}, b^{u}\right\}\right\}
$$

$\Omega^{\digamma^{u}}$ is not a Nash Equilibria for both local and global levels of pollution.

PROOF: 
Either dirty country can improve their welfare by excluding the clean country $a$ :

country $\mathrm{b}=\left\{a^{u}, c^{u}\right\} \stackrel{\text { change }}{\longrightarrow}\left\{\varnothing, c^{u}\right\} \stackrel{\text { result }}{\longrightarrow} W^{b}\left(b c_{\theta}^{u}\right)>W^{b}\left(a b c_{\theta}\right)$

country $\mathrm{c}=\left\{a^{u}, b^{u}\right\} \stackrel{\text { change }}{\longrightarrow}\left\{\varnothing, b^{u}\right\} \stackrel{\text { result }}{\longrightarrow} W^{c}\left(b c_{\theta}^{u}\right)>W^{c}\left(a b c_{\theta}\right)$

We can conclude, that either of the dirty countries can improve its welfare by calling another dirty country only. Dirty countries would prefer to exclude the clean partner for both local and global levels of pollution. Based on the above, we are confident to conclude that $\Omega^{\digamma^{u}}$ is not a Nash Equilibria for both local and global levels of pollution.

\section{A. 4.9.2.2 Deep Trade Agreements Game}

Welfare effects of various type of shallow trade agreements:

Country a, local pollution

$W^{a}\left(a_{l}^{h i}\right)>W^{a}\left(a b c_{l}^{i}\right)>W^{a}\left(b_{l}^{h i}\right) \stackrel{\lambda \in(0,0.009]}{>} W^{a}\left(a b_{l}^{i}\right)>W^{a}\left(a b_{l}^{i u}\right)>W^{a}\left(N_{l}\right)>W^{a}\left(b c_{l}^{i}\right)>W^{a}\left(b c_{l}^{i u}\right)$

$\lambda \in(0,0.009]$

$W^{a}\left(a_{l}^{h i}\right)>W^{a}\left(a b c_{l}^{i}\right)>W^{a}\left(a b_{l}^{i}\right) \stackrel{\lambda \in(0.009,0.1]}{>} W^{a}\left(b_{l}^{h i}\right)>W^{a}\left(a b_{l}^{i u}\right)>W^{a}\left(N_{l}\right)>W^{a}\left(b c_{l}^{i}\right)>W^{a}\left(b c_{l}^{i u}\right)$

$\lambda \in(0.009,0.1]$

Country a, global pollution

$W^{a}\left(a_{l}^{h i}\right)>W^{a}\left(a b c_{g}^{i}\right)>W^{a}\left(b_{g}^{h i}\right)>W^{a}\left(b c_{g}^{i}\right)>W^{a}\left(b c_{g}^{i u}\right)>W^{a}\left(a b_{g}^{i u}\right)>W^{a}\left(a b_{g}^{i}\right)>W^{a}\left(N_{g}\right)$

Country b, local pollution

$W^{b}\left(b c_{l}^{i u}\right)>W^{b}\left(b c_{l}^{i}\right) \stackrel{\lambda \in(0,0.008]}{>} W^{b}\left(b_{l}^{h i}\right)>W^{b}\left(a b_{l}^{i u}\right)>W^{b}\left(a b c_{l}^{i}\right)>W^{b}\left(N_{l}\right)>W^{b}\left(a_{l}^{h i}\right)>W^{b}\left(a b c_{l}^{i}\right)$

$\lambda \in(0,0.008]$

$W^{b}\left(b c_{l}^{i u}\right)>W^{b}\left(b_{l}^{h i}\right) \stackrel{\lambda \in(0.008,0.1]}{>} W^{b}\left(b c_{l}^{i}\right)>W^{b}\left(a b_{l}^{i u}\right)>W^{b}\left(a b c_{l}^{i}\right)>W^{b}\left(N_{l}\right)>W^{b}\left(a_{l}^{h i}\right)>W^{b}\left(a b c_{l}^{i}\right)$

$\lambda \in(0.008,0.1]$

Country b, global pollution

$W^{b}\left(b c_{g}^{i u}\right) \stackrel{\lambda \in(0,0.006]}{>} W^{b}\left(b_{g}^{h i}\right)>W^{b}\left(b c_{g}^{i}\right) \stackrel{\lambda \in(0,0.089]}{>} W\left(a b c_{g}^{i}\right)>W^{b}\left(a_{g}^{h i}\right)>W^{b}\left(a b_{g}^{i}\right)>W^{b}\left(N_{g}\right)>$

$W^{b}\left(a b_{g}^{i u}\right) \lambda \in(0,0.006]$

$W^{b}\left(b_{g}^{h i}\right) \stackrel{\lambda \in(0.006,0.1]}{>} W^{b}\left(b c_{g}^{i u}\right)>W^{b}\left(b c_{g}^{i}\right) \stackrel{\lambda \in(0,0.089]}{>} W\left(a b c_{g}^{i}\right)>W^{b}\left(a_{g}^{h i}\right)>W^{b}\left(a b_{g}^{i}\right)>W^{b}\left(N_{g}\right)>$

$W^{b}\left(a b_{g}^{i u}\right) \lambda \in(0.006,0.089]$ 
$W^{b}\left(b_{g}^{h i}\right) \stackrel{\lambda \in(0.006,0.1]}{>} W^{b}\left(b c_{g}^{i u}\right)>W^{b}\left(a b c_{g}^{i}\right) \stackrel{\lambda \in(0.089,0.1]}{>} W\left(b c_{g}^{i}\right)>W^{b}\left(a_{g}^{h i}\right)>W^{b}\left(a b_{g}^{i}\right)>W^{b}\left(N_{g}\right)>$ $W^{b}\left(a b_{g}^{i u}\right) \lambda \in(0.089,0.1]$

Country c, local pollution

$W^{c}\left(b c_{l}^{i u}\right)>W^{c}\left(b c_{l}^{i}\right)>W^{c}\left(a b_{l}^{i}\right)>W^{c}\left(a b c_{l}^{i}\right)>W^{c}\left(N_{l}\right)>W^{c}\left(b_{l}^{h i}\right)>W^{c}\left(a_{l}^{h i}\right)>W^{c}\left(a b_{l}^{i u}\right)$

Country c, global pollution

$W^{c}\left(b c_{g}^{i u}\right)>W^{c}\left(b c_{g}^{i}\right) \stackrel{\lambda \in(0,0.089]}{>} W^{c}\left(a b c_{g}^{i}\right)>W^{c}\left(a_{g}^{h i}\right)>W^{c}\left(a b_{g}^{i}\right)>W^{c}\left(a b_{g}^{i u}\right)>W^{c}\left(b_{g}^{h i}\right)>W^{c}\left(N_{g}\right)$

$\lambda \in(0,0.089]$

$W^{c}\left(b c_{g}^{i u}\right)>W^{c}\left(a b c_{g}^{i}\right) \stackrel{\lambda \in(0.089,0.1]}{>} W^{c}\left(b c_{g}^{i}\right)>W^{c}\left(a_{g}^{h i}\right)>W^{c}\left(a b_{g}^{i}\right)>W^{c}\left(a b_{g}^{i u}\right)>W^{c}\left(b_{g}^{h i}\right)>W^{c}\left(N_{g}\right)$

$\lambda \in(0,0.089]$

\begin{tabular}{|c|c|}
\hline Announcement Profiles & Shallow Trade Agreements \\
\hline \hline$\Omega^{\Phi^{i}} \equiv\left\{\sigma_{a}^{i}=\{\varnothing, \varnothing\}, \sigma_{b}^{i}=\{\varnothing, \varnothing\}, \sigma_{c}^{i}=\{\varnothing, \varnothing\}\right\}$ & $\left\langle\Phi^{i}\right\rangle$ \\
\hline$\Omega^{a b i} \equiv\left\{\sigma_{a}^{i}=\left\{b^{i}, \varnothing\right\}, \sigma_{b}^{i}=\left\{a^{i}, \varnothing\right\}, \sigma_{c}^{i}=\{\varnothing, \varnothing\}\right\}$ & $\langle$ abi $\rangle$ \\
\hline$\Omega^{a b i u} \equiv\left\{\sigma_{a}^{i u}=\left\{b^{i u}, \varnothing\right\}, \sigma_{b}^{i u}=\left\{a^{i u}, \varnothing\right\}, \sigma_{c}^{i u}=\{\varnothing, \varnothing\}\right\}$ & $\langle$ abiu $\rangle$ \\
\hline$\Omega^{b c i} \equiv\left\{\sigma_{a}^{i}=\{\varnothing, \varnothing\}, \sigma_{b}^{i}=\left\{\varnothing, c^{i}\right\}, \sigma_{c}^{i}=\left\{\varnothing, b^{i}\right\}\right\}$ & $\langle b c i\rangle$ \\
\hline$\Omega^{b c i u} \equiv\left\{\sigma_{a}^{i u}=\{\varnothing, \varnothing\}, \sigma_{b}^{i u}=\left\{\varnothing, c^{i u}\right\}, \sigma_{c}^{i u}=\left\{\varnothing, b^{i u}\right\}\right\}$ & $\langle$ bciu $\rangle$ \\
\hline$\Omega^{a h i} \equiv\left\{\sigma_{a}^{i}=\left\{b^{i}, c^{i}\right\}, \sigma_{b}^{i}=\left\{a^{i}, \varnothing\right\}, \sigma_{c}^{i}=\left\{a^{i}, \varnothing\right\}\right\}$ & $\langle$ ahi $\rangle$ \\
\hline$\Omega^{b h i} \equiv\left\{\sigma_{a}^{i}=\left\{b^{i}, \varnothing\right\}, \sigma_{b}^{i}=\left\{a^{i}, c^{i}\right\}, \sigma_{c}^{i}=\left\{\varnothing, b^{i}\right\}\right\}$ & $\left\langle F^{i}\right\rangle$ \\
\hline$\Omega^{F^{i}} \equiv\left\{\sigma_{a}^{i}=\left\{b^{i}, c^{i}\right\}, \sigma_{b}^{i}=\left\{a^{i}, c^{i}\right\}, \sigma_{c}^{i}=\left\{a^{i}, b^{i}\right\}\right\}$ & $\left\langle F^{i u}\right\rangle$ \\
\hline$\Omega^{F^{i u}} \equiv\left\{\sigma_{a}^{i u}=\left\{b^{i u}, c^{i u}\right\}, \sigma_{b}^{i u}=\left\{a^{i u}, c^{i u}\right\}, \sigma_{c}^{i u}=\left\{a^{i u}, b^{i u}\right\}\right\}$ & \\
\hline
\end{tabular}

$$
\Omega^{\Phi^{i}} \equiv\left\{\sigma_{a}^{i}=\{\varnothing, \varnothing\}, \sigma_{b}^{i}=\{\varnothing, \varnothing\}, \sigma_{c}^{i}=\{\varnothing, \varnothing\}\right\}
$$

$\Omega^{\Phi^{i}}$ is a Nash Equilibria for both local and global levels of pollution.

PROOF:

Countries cannot get better off by unilaterally changing the announcements; countries have no incentive to announce any other country unless they are going to be announced back.

$\Omega^{\Phi^{i}}$ is not a CPNE for both local and global levels of pollution.

PROOF:

We prove the above by examining the coalitional deviation of two dirty countries in the form of an integrated customs union. In this case, the announcement profile would be altered as follows: $\Omega \equiv\left\{\sigma_{a}^{i}=\{\varnothing, \varnothing\}, \sigma_{b}^{i u}=\left\{\varnothing, c^{i u}\right\}, \sigma_{c}^{i u}=\left\{\varnothing, b^{i u}\right\}\right\}$, and as a result, we observe the increase in 
members' welfare levels, $W^{b}\left(b c_{\theta}^{i u}\right)>W^{b}\left(N_{\theta}\right)$ and $W^{c}\left(b c_{\theta}^{i u}\right)>W^{c}\left(N_{\theta}\right)$. This deep trade union of two dirty countries brings its members the highest level of welfare in this game if pollution is local and if pollution is global and $\lambda \varepsilon(0,0.006]$, and though both members have an incentive to deviate and form a side deal with the clean country $a$ if pollution is global and $\lambda \varepsilon(0.006,0.1]$, the nature of customs unions prevents this deviation. We conclude that no further deviations can occur. Based on the above, $\Omega^{\Phi^{i}}$ is not a CPNE.

$$
\Omega^{a b i} \equiv\left\{\sigma_{a}^{i}=\left\{b^{i}, \varnothing\right\}, \sigma_{b}^{i}=\left\{a^{i}, \varnothing\right\}, \sigma_{c}^{i}=\{\varnothing, \varnothing\}\right\}
$$

$\Omega^{a b i}$ is not a Nash Equilibria if pollution is local.

\section{PROOF:}

country $\mathrm{b}=\left\{a^{i}, \varnothing\right\} \stackrel{\text { change }}{\longrightarrow}\left\{\varnothing, c^{i}\right\} /\left\{\varnothing, c^{i u}\right\} /\left\{a^{i u}, \varnothing\right\} /\{\varnothing, \varnothing\} /\left\{a^{i u}, c^{i u}\right\} \stackrel{\text { result }}{\longrightarrow} W^{b}\left(a b_{l}^{i}\right)<W^{b}\left(N_{l}\right)$

We can conclude, that country $b$ has an incentive to self-exclude itself.

Based on the above, we conclude $\Omega^{a b i}$ is not a Nash Equilibria if pollution is local.

$\Omega^{a b i}$ is a Nash Equilibria if pollution is global.

\section{PROOF:}

country $\mathrm{a}=\left\{b^{i}, \varnothing\right\} \stackrel{\text { change }}{\longrightarrow}\left\{b^{i}, c^{i}\right\} \stackrel{\text { result }}{\longrightarrow}$ no change in $a$ 's welfare

country $\mathrm{a}=\left\{b^{i}, \varnothing\right\} \stackrel{\text { change }}{\longrightarrow}\left\{\varnothing, c^{i}\right\} /\left\{\varnothing, c^{i u}\right\} /\left\{b^{i u}, \varnothing\right\} /\{\varnothing, \varnothing\} /\left\{b^{i u}, c^{i u}\right\} \stackrel{\text { result }}{\longrightarrow} W^{a}\left(a b_{g}^{i}\right)>W^{a}\left(N_{g}\right)$

We can conclude, that country $a$ has no incentive to change its announcement.

country $\mathrm{b}=\left\{a^{i}, \varnothing\right\} \stackrel{\text { change }}{\longrightarrow}\left\{a^{i}, c^{i}\right\} \stackrel{\text { result }}{\longrightarrow}$ no change in $b$ 's welfare

country $\mathrm{b}=\left\{a^{i}, \varnothing\right\} \stackrel{\text { change }}{\longrightarrow}\left\{\varnothing, c^{i}\right\} /\left\{\varnothing, c^{i u}\right\} /\left\{a^{i u}, \varnothing\right\} /\{\varnothing, \varnothing\} /\left\{a^{i u}, c^{i u}\right\} \stackrel{\text { result }}{\longrightarrow} W^{b}\left(a b_{g}^{i}\right)>W^{b}\left(N_{g}\right)$

We can conclude, that country $b$ has no incentive to change its announcement.

country $\mathrm{c}=\{\varnothing, \varnothing\} \stackrel{\text { change }}{\longrightarrow}\left\{a^{i}, \varnothing\right\} /\left\{a^{i u}, \varnothing\right\} /\left\{\varnothing, b^{i}\right\} /\left\{\varnothing, b^{i u}\right\} /\left\{a^{i}, b^{i}\right\} /\left\{a^{i u}, b^{i u}\right\} \stackrel{\text { result }}{\longrightarrow}$ no change in $c$ 's welfare

We can conclude, that country $c$ has no incentive to change its announcement.

Based on the above, we conclude $\Omega^{a b i}$ is a Nash Equilibria if pollution is global.

$\Omega^{a b i}$ is not a CPNE if pollution is global.

PROOF: 
We prove the above by examining the coalitional deviation of two dirty countries in the form of an integrated customs union. In this case, the announcement profile would be altered as follows: $\Omega \equiv\left\{\sigma_{a}^{i}=\left\{b^{i}, \varnothing\right\}, \sigma_{b}^{i u}=\left\{\varnothing, c^{i u}\right\}, \sigma_{c}^{i u}=\left\{\varnothing, b^{i u}\right\}\right\}$, and as a result, we observe the increase in members' welfare levels, $W^{j}\left(b c_{g}^{i u}\right)>W^{j}\left(a b_{g}^{i}\right)$ where $j \neq a$. This deep trade union of two dirty countries brings its members the highest level of welfare in this game if pollution is global and $\lambda \varepsilon(0,0.006]$, and though both members have an incentive to deviate and form a side deal with the clean country $a$ to become a hub if pollution is global and $\lambda \varepsilon(0.006,0.1]$, the nature of customs unions prevents this deviation. We conclude that no further deviations can occur. Based on the above, $\Omega^{a b i}$ is not a CPNE.

$\Omega^{a b i u} \equiv\left\{\sigma_{a}^{i u}=\left\{b^{i u}, \varnothing\right\}, \sigma_{b}^{i u}=\left\{a^{i u}, \varnothing\right\}, \sigma_{c}^{i u}=\{\varnothing, \varnothing\}\right\}$

$\Omega^{\text {abiu }}$ is a Nash Equilibria if pollution is local.

\section{PROOF:}

country $\mathrm{a}=\left\{b^{i u}, \varnothing\right\} \stackrel{\text { change }}{\longrightarrow}\left\{b^{i u}, c^{i u}\right\} \stackrel{\text { result }}{\longrightarrow}$ no change in $a$ 's welfare

country $\mathrm{a}=\left\{b^{i u}, \varnothing\right\} \stackrel{\text { change }}{\longrightarrow}\left\{\varnothing, c^{i}\right\} /\left\{\varnothing, c^{i u}\right\} /\{\varnothing, \varnothing\} /\left\{b^{i}, c^{i}\right\} /\left\{b^{i}, \varnothing\right\} \stackrel{\text { result }}{\longrightarrow} W^{a}\left(a b_{l}^{i u}\right)>W^{a}\left(N_{l}\right)$

We can conclude, that country $a$ has no incentive to change its announcement.

country $\mathrm{b}=\left\{a^{i u}, \varnothing\right\} \stackrel{\text { change }}{\longrightarrow}\left\{a^{i u}, c^{i u}\right\} \stackrel{\text { result }}{\longrightarrow}$ no change in $b$ 's welfare

country $\mathrm{b}=\left\{a^{i u}, \varnothing\right\} \stackrel{\text { change }}{\longrightarrow}\left\{\varnothing, c^{i}\right\} /\left\{\varnothing, c^{i u}\right\} /\{\varnothing, \varnothing\} /\left\{a^{i}, c^{i}\right\} /\left\{a^{i}, \varnothing\right\} \stackrel{\text { result }}{\longrightarrow} W^{b}\left(a b_{l}^{i u}\right)>W^{b}\left(N_{l}\right)$

We can conclude, that country $b$ has no incentive to change its announcement.

country $\mathrm{c}=\{\varnothing, \varnothing\} \stackrel{\text { change }}{\longrightarrow}\left\{a^{i}, \varnothing\right\} /\left\{a^{i u}, \varnothing\right\} /\left\{\varnothing, b^{i}\right\} /\left\{\varnothing, b^{i u}\right\} /\left\{a^{i}, b^{i}\right\} /\left\{a^{i u}, b^{i u}\right\} \stackrel{\text { result }}{\longrightarrow}$ no change in $c$ 's welfare

We can conclude, that country $c$ has no incentive to change its announcement.

Based on the above, we conclude that $\Omega^{a b i u}$ is a Nash Equilibria if pollution is local. $\Omega^{\text {abiu }}$ is not a Nash Equilibria if pollution is global.

PROOF:

country $\mathrm{b}=\left\{a^{i u}, \varnothing\right\} \stackrel{\text { change }}{\longrightarrow}\left\{\varnothing, c^{i}\right\} /\left\{\varnothing, c^{i u}\right\} /\{\varnothing, \varnothing\} /\left\{a^{i}, c^{i}\right\} /\left\{a^{i}, \varnothing\right\} \stackrel{\text { result }}{\longrightarrow} W^{b}\left(a b_{g}^{i u}\right)<W^{b}\left(N_{g}\right)$

We can conclude, that country $b$ has an incentive to self-exclude itself.

Based on the above, we conclude that $\Omega^{a b i u}$ is not a Nash Equilibria if pollution is global. 
$\Omega^{\text {abiu }}$ is not a CPNE if pollution is local.

PROOF:

We prove the above by examining the coalitional deviation of two dirty countries in the form of an integrated customs union. In this case, the announcement profile would be altered as follows: $\Omega \equiv\left\{\sigma_{a}^{i u}=\left\{b^{i u}, \varnothing\right\}, \sigma_{b}^{i u}=\left\{\varnothing, c^{i u}\right\}, \sigma_{c}^{i u}=\left\{\varnothing, b^{i u}\right\}\right\}$, and as a result, we observe the increase in members' welfare levels, $W^{b}\left(b c_{l}^{i u}\right)>W^{b}\left(a b_{l}^{i u}\right)$ and $W^{c}\left(b c_{l}^{i u}\right)>W^{c}\left(a b_{l}^{i u}\right)$. This deep trade union of two dirty countries brings its members the highest level of welfare in this game, and we conclude that no further deviations can occur. Based on the above, $\Omega^{a b i u}$ is not a CPNE.

$$
\Omega^{b c i} \equiv\left\{\sigma_{a}^{i}=\{\varnothing, \varnothing\}, \sigma_{b}^{i}=\left\{\varnothing, c^{i}\right\}, \sigma_{c}^{i}=\left\{\varnothing, b^{i}\right\}\right\}
$$

$\Omega^{b c i}$ is a Nash Equilibria for both local and global levels of pollution.

\section{PROOF:}

country a $=\{\varnothing, \varnothing\} \stackrel{\text { change }}{\longrightarrow}\left\{b^{i}, \varnothing\right\} /\left\{b^{i u}, \varnothing\right\} /\left\{\varnothing, c^{i}\right\} /\left\{\varnothing, c^{i u}\right\} /\left\{b^{i}, c^{i}\right\} /\left\{b^{i u}, c^{i u}\right\} \stackrel{\text { result }}{\longrightarrow}$ no change in $a$ 's welfare

We can conclude, that country $a$ has no incentive to change its announcement.

country $\mathrm{b}=\left\{\varnothing, c^{i}\right\} \stackrel{\text { change }}{\longrightarrow}\left\{a^{i}, c^{i}\right\} \stackrel{\text { result }}{\longrightarrow}$ no change in $b$ 's welfare

country $\mathrm{b}=\left\{\varnothing, c^{i}\right\} \stackrel{\text { change }}{\longrightarrow}\left\{a^{i}, \varnothing\right\} /\left\{a^{i u}, \varnothing\right\} /\{\varnothing, \varnothing\} /\left\{\varnothing, c^{i u}\right\} /\left\{a^{i u}, c^{i u}\right\} \stackrel{\text { result }}{\longrightarrow} W^{b}\left(b c_{\theta}^{i}\right)>W^{b}\left(N_{\theta}\right)$

We can conclude, that country $b$ has no incentive to change its announcement.

country $\mathrm{c}=\left\{\varnothing, b^{i}\right\} \stackrel{\text { change }}{\longrightarrow}\left\{a^{i}, b^{i}\right\} \stackrel{\text { result }}{\longrightarrow}$ no change in $c$ 's welfare country $\mathrm{c}=\left\{\varnothing, b^{i}\right\} \stackrel{\text { change }}{\longrightarrow}\left\{a^{i}, \varnothing\right\} /\left\{a^{i u}, \varnothing\right\} /\{\varnothing, \varnothing\} /\left\{\varnothing, b^{i u}\right\} /\left\{a^{i u}, b^{i u}\right\} \stackrel{\text { result }}{\longrightarrow} W^{c}\left(b c_{\theta}^{i}\right)>W^{c}\left(N_{\theta}\right)$

We can conclude, that country $c$ has no incentive to change its announcement.

Based on the above, we conclude that $\Omega^{b c i}$ is a Nash Equilibria for both local and global levels of pollution.

$\Omega^{b c i}$ is not a CPNE for both local and global levels of pollution.

PROOF:

Members can form a coalition to sign a different deep trade agreement, then $\Omega \equiv\left\{\sigma_{a}^{i}=\{\varnothing, \varnothing\}, \sigma_{b}^{i u}=\right.$ $\left.\left\{\varnothing, c^{i u}\right\}, \sigma_{c}^{i u}=\left\{\varnothing, b^{i u}\right\}\right\}$, and $W^{j}\left(b c_{\theta}^{i u}\right)>W^{j}\left(b c_{\theta}^{i}\right)$ where $j \neq a$. We can conclude that $\Omega^{b c i}$ is not a CPNE for both local and global levels of pollution. 


$$
\Omega^{b c i u} \equiv\left\{\sigma_{a}^{i u}=\{\varnothing, \varnothing\}, \sigma_{b}^{i u}=\left\{\varnothing, c^{i u}\right\}, \sigma_{c}^{i u}=\left\{\varnothing, b^{i u}\right\}\right\}
$$

$\Omega^{\text {bciu }}$ is a Nash Equilibria for both local and global levels of pollution.

PROOF:

country a $=\{\varnothing, \varnothing\} \stackrel{\text { change }}{\longrightarrow}\left\{b^{i}, \varnothing\right\} /\left\{b^{i u}, \varnothing\right\} /\left\{\varnothing, c^{i}\right\} /\left\{\varnothing, c^{i u}\right\} /\left\{b^{i}, c^{i}\right\} /\left\{b^{i u}, c^{i u}\right\} \stackrel{\text { result }}{\longrightarrow}$ no change in $a$ 's welfare

We can conclude, that country $a$ has no incentive to change its announcement.

country $\mathrm{b}=\left\{\varnothing, c^{i u}\right\} \stackrel{\text { change }}{\longrightarrow}\left\{a^{i u}, c^{i u}\right\} \stackrel{\text { result }}{\longrightarrow}$ no change in $b$ 's welfare

country $\mathrm{b}=\left\{\varnothing, c^{i u}\right\} \stackrel{\text { change }}{\longrightarrow}\left\{a^{i}, \varnothing\right\} /\left\{a^{i u}, \varnothing\right\} /\{\varnothing, \varnothing\} /\left\{a^{i}, c^{i}\right\} /\left\{\varnothing, c^{i}\right\} \stackrel{\text { result }}{\longrightarrow} W^{b}\left(b c_{\theta}^{i u}\right)>W^{b}\left(N_{\theta}\right)$

We can conclude, that country $b$ has no incentive to change its announcement.

country $\mathrm{c}=\left\{\varnothing, b^{i u}\right\} \stackrel{\text { change }}{\longrightarrow}\left\{a^{i u}, b^{i u}\right\} \stackrel{\text { result }}{\longrightarrow}$ no change in $c$ 's welfare

country $\mathrm{c}=\left\{\varnothing, b^{i u}\right\} \stackrel{\text { change }}{\longrightarrow}\left\{a^{i}, \varnothing\right\} /\left\{a^{i u}, \varnothing\right\} /\{\varnothing, \varnothing\} /\left\{a^{i}, b^{i}\right\} /\left\{\varnothing, b^{i}\right\} \stackrel{\text { result }}{\longrightarrow} W^{c}\left(b c_{\theta}^{i u}\right)>W^{c}\left(N_{\theta}\right)$

We can conclude, that country $c$ has no incentive to change its announcement.

Based on the above, $\Omega^{b c i u}$ is a Nash Equilibria for both local and global levels of pollution.

$\Omega^{\text {bciu }}$ is a CPNE for both local and global levels of pollution.

PROOF:

We prove the above by examining every possible meaningful deviation:

- first, we consider a coalitional deviation of one dirty and one clean country, countries $a$ and $b$, in the form of either FTA or CU, and as a result, we observe that neither of these deviations is meaningful: $W^{b}\left(b c_{l}^{i u}\right)>W^{b}\left(a b_{l}^{i u}\right)>W^{b}\left(a b_{l}\right)$ and $W^{b}\left(b c_{g}^{i u}\right)>W^{b}\left(a b_{g}^{i}\right)>W^{b}\left(a b_{g}^{i u}\right)$;

- second, we consider a coalitional deviation of two dirty countries, country $b$ and country $c$, into a different PTA, and again we find that this deviation is not meaningful as well: $W^{j}\left(b c_{\theta}^{i u}\right)>W^{j}\left(b c_{\theta}^{i}\right)$, where $j \neq a$;

- now, we examine the grand coalition, and again, we observe that this deviation is not meaningful, too: $W^{j}\left(b c_{\theta}^{i u}\right)>W^{j}\left(a b c_{\theta}^{i}\right)$, where $j \neq a$;

- finally, we acknowledge that though both members of this coalition would benefit from signing a side deal with the clean country $a$, if pollution is global and $\lambda \varepsilon(0.006,0.1]$, and conse- 
quently, become a hub, the nature of customs unions prevents hub-and-spoke trade regimes from arising.

Based on the above, we conclude that $\Omega^{b c i u}$ survives all coalition-proof Nash equilibria refinements.

$$
\Omega^{a h i} \equiv\left\{\sigma_{a}^{i}=\left\{b^{i}, c^{i}\right\}, \sigma_{b}^{i}=\left\{a^{i}, \varnothing\right\}, \sigma_{c}^{i}=\left\{a^{i}, \varnothing\right\}\right\}
$$

$\Omega^{\text {ahi }}$ is not a Nash Equilibria if pollution is local.

PROOF:

country $\mathrm{c}=\left\{a^{i}, \varnothing\right\} \stackrel{\text { change }}{\longrightarrow}\{\varnothing, \varnothing\} /\left\{a^{i u}, b^{i u}\right\} /\left\{\varnothing, b^{i}\right\} /\left\{\varnothing, b^{i u}\right\} /\left\{a^{i u}, \varnothing\right\} \stackrel{\text { result }}{\longrightarrow} W^{c}\left(a_{l}^{h i}\right)<W^{c}\left(a b_{l}^{i}\right)$

We can conclude, that country $c$ has an incentive to self-exclude itself.

Based on the above, we can conclude that $\Omega^{a h i}$ is not a Nash Equilibria if pollution is local. $\Omega^{\text {ahi }}$ is a Nash Equilibria if pollution is global.

PROOF:

country $\mathrm{a}=\left\{b^{i}, c^{i}\right\} \stackrel{\text { change }}{\longrightarrow}\left\{b^{i}, \varnothing\right\} /\left\{\varnothing, c^{i}\right\} \stackrel{\text { result }}{\longrightarrow} W^{a}\left(a_{g}^{h i}\right)>W^{a}\left(a b_{g}^{i}\right)=W^{a}\left(a c_{g}^{i}\right)$ country a $=\left\{b^{i}, c^{i}\right\} \stackrel{\text { change }}{\longrightarrow}\{\varnothing, \varnothing\} /\left\{b^{i u}, c^{i u}\right\} /\left\{b^{i u}, \varnothing\right\} /\left\{\varnothing, c^{i u}\right\} \stackrel{\text { result }}{\longrightarrow} W^{a}\left(a_{g}^{h i}\right)>W^{a}\left(N_{g}\right)$

We can conclude, that country $a$ has no incentive to change its announcement.

country $\mathrm{b}=\left\{a^{i}, \varnothing\right\} \stackrel{\text { change }}{\longrightarrow}\left\{a^{i}, c^{i}\right\} \stackrel{\text { result }}{\longrightarrow}$ no change in $b$ 's welfare

country $\mathrm{b}=\left\{a^{i}, \varnothing\right\} \stackrel{\text { change }}{\longrightarrow}\left\{\varnothing, c^{i}\right\} /\{\varnothing, \varnothing\} /\left\{a^{i u}, c^{i u}\right\} /\left\{a^{i u}, \varnothing\right\} /\left\{\varnothing, c^{i u}\right\} \stackrel{\text { result }}{\longrightarrow} W^{b}\left(a_{g}^{h i}\right)>W^{b}\left(a c_{g}^{i}\right)$

We can conclude, that country $b$ has no incentive to change its announcement.

country $\mathrm{c}=\left\{a^{i}, \varnothing\right\} \stackrel{\text { change }}{\longrightarrow}\left\{a^{i}, b^{i}\right\} \stackrel{\text { result }}{\longrightarrow}$ no change in $c^{\prime}$ 's welfare

country c $=\left\{a^{i}, \varnothing\right\} \stackrel{\text { change }}{\longrightarrow}\left\{\varnothing, b^{i}\right\} /\{\varnothing, \varnothing\} /\left\{a^{i u}, b^{i u}\right\} /\left\{a^{i u}, \varnothing\right\} /\left\{\varnothing, b^{i u}\right\} \stackrel{\text { result }}{\longrightarrow} W^{c}\left(a_{g}^{h i}\right)>W^{c}\left(a b_{g}^{i}\right)$

We can conclude, that country $c$ has no incentive to change its announcement.

Based on the above, we conclude that $\Omega^{a h i}$ is a Nash Equilibria if pollution is global.

$\Omega^{\text {ahi }}$ is not a CPNE if pollution is global.

PROOF:

We prove the above by examining the coalitional deviation of two dirty countries in the form of an integrated customs union. In this case, the announcement profile would be altered as follows: 
$\Omega \equiv\left\{\sigma_{a}^{i}=\left\{b^{i}, c^{i}\right\}, \sigma_{b}^{i u}=\left\{\varnothing, c^{i u}\right\}, \sigma_{c}^{i u}=\left\{\varnothing, b^{i u}\right\}\right\}$, and as a result, we observe the increase in members' welfare levels, $W^{b}\left(b c_{g}^{i u}\right)>W^{b}\left(a_{g}^{h i}\right)$ and $W^{c}\left(b c_{g}^{i u}\right)>W^{c}\left(a_{g}^{h i}\right)$. This deep trade union of two dirty countries brings its members the highest level of welfare in this game if pollution is global and $\lambda \varepsilon(0,0.006]$, and though both members have an incentive to deviate and form a side deal with the clean country $a$ if pollution is global and $\lambda \varepsilon(0.006,0.1]$, the nature of customs unions prevent this deviation. We conclude that no further deviations can occur. Based on the above, $\Omega^{a h i}$ is not a CPNE.

$$
\Omega^{b h i} \equiv\left\{\sigma_{a}^{i}=\left\{b^{i}, \varnothing\right\}, \sigma_{b}^{i}=\left\{a^{i}, c^{i}\right\}, \sigma_{c}^{i}=\left\{\varnothing, b^{i}\right\}\right\}
$$

$\Omega^{\text {bhi }}$ is not a Nash Equilibria for both local and global levels of pollution.

PROOF:

country $\mathrm{c}=\left\{\varnothing, b^{i}\right\} \stackrel{\text { change }}{\longrightarrow}\left\{a^{i}, \varnothing\right\} /\{\varnothing, \varnothing\} /\left\{a^{i u}, b^{i u}\right\} /\left\{a^{i u}, \varnothing\right\} /\left\{\varnothing, b^{i u}\right\} \stackrel{\text { result }}{\longrightarrow} W^{c}\left(b_{\theta}^{h i}\right)<W^{c}\left(a b_{\theta}^{i}\right)$

We can conclude, that country $c$ has an incentive to self-exclude itself.

Based on the above, we conclude that $\Omega^{b h i}$ is not a Nash Equilibria for both local and global levels of pollution.

$$
\Omega^{F^{i}} \equiv\left\{\sigma_{a}^{i}=\left\{b^{i}, c^{i}\right\}, \sigma_{b}^{i}=\left\{a^{i}, c^{i}\right\}, \sigma_{c}^{i}=\left\{a^{i}, b^{i}\right\}\right\}
$$

$\Omega^{\digamma^{i}}$ is not a Nash Equilibria if pollution is local.

PROOF:

country $\mathrm{c}=\left\{a^{i}, b^{i}\right\} \stackrel{\text { change }}{\longrightarrow}\{\varnothing, \varnothing\} /\left\{a^{i u}, b^{i u}\right\} /\left\{a^{i u}, \varnothing\right\} /\left\{\varnothing, b^{i u}\right\} \stackrel{\text { result }}{\longrightarrow} W^{c}\left(a b_{l}^{i}\right)>W^{c}\left(a b c_{l}^{i}\right)$

We can conclude, that country $c$ has an incentive to self-exclude itself.

Based on the above, we conclude $\Omega^{F^{i}}$ is not a Nash Equilibria if pollution is local.

$\Omega^{\digamma^{i}}$ is a Nash Equilibria if pollution is global.

PROOF:

country a $=\left\{b^{i}, c^{i}\right\} \stackrel{\text { change }}{\longrightarrow}\left\{b^{i}, \varnothing\right\} /\left\{\varnothing, c^{i}\right\} \stackrel{\text { result }}{\longrightarrow} W^{a}\left(a b c_{g}^{i}\right)>W^{a}\left(b_{g}^{h i}\right)=W^{a}\left(c_{g}^{h i}\right)$

country a $=\left\{b^{i}, c^{i}\right\} \stackrel{\text { change }}{\longrightarrow}\{\varnothing, \varnothing\} /\left\{b^{i u}, c^{i u}\right\} /\left\{b^{i u}, \varnothing\right\} /\left\{\varnothing, c^{i u}\right\} \stackrel{\text { result }}{\longrightarrow} W^{a}\left(a b c_{g}^{i}\right)>W^{a}\left(b c_{g}^{i}\right)$

We can conclude, that country $a$ has no incentive to change its announcement.

country $\mathrm{b}=\left\{a^{i}, c^{i}\right\} \stackrel{\text { change }}{\longrightarrow}\left\{a^{i}, \varnothing\right\} \stackrel{\text { result }}{\longrightarrow} W^{b}\left(a b c_{g}^{i}\right)>W^{b}\left(a_{g}^{h i}\right)$ 
country $\mathrm{b}=\left\{a^{i}, c^{i}\right\} \stackrel{\text { change }}{\longrightarrow}\left\{\varnothing, c^{i}\right\} \stackrel{\text { result }}{\longrightarrow} W^{b}\left(a b c_{g}^{i}\right)>W^{b}\left(c_{g}^{h i}\right)$

country $\mathrm{b}=\left\{a^{i}, c^{i}\right\} \stackrel{\text { change }}{\longrightarrow}\{\varnothing, \varnothing\} /\left\{a^{i u}, c^{i u}\right\} /\left\{a^{i u}, \varnothing\right\} /\left\{\varnothing, c^{i u}\right\} \stackrel{\text { result }}{\longrightarrow} W^{b}\left(a b c_{g}^{i}\right)>W^{b}\left(a c_{g}^{i}\right)$

We can conclude, that country $b$ has no incentive to change its announcement.

country $\mathrm{c}=\left\{a^{i}, b^{i}\right\} \stackrel{\text { change }}{\longrightarrow}\left\{a^{i}, \varnothing\right\} \stackrel{\text { result }}{\longrightarrow} W^{c}\left(a b c_{g}^{i}\right)>W^{c}\left(a_{g}^{h i}\right)$

country $\mathrm{c}=\left\{a^{i}, b^{i}\right\} \stackrel{\text { change }}{\longrightarrow}\left\{\varnothing, b^{i}\right\} \stackrel{\text { result }}{\longrightarrow} W^{c}\left(a b c_{g}^{i}\right)>W^{c}\left(b_{g}^{h i}\right)$

country $\mathrm{c}=\left\{a^{i}, b^{i}\right\} \stackrel{\text { change }}{\longrightarrow}\{\varnothing, \varnothing\} /\left\{a^{i u}, b^{i u}\right\} /\left\{a^{i u}, \varnothing\right\} /\left\{\varnothing, b^{i u}\right\} \stackrel{\text { result }}{\longrightarrow} W^{c}\left(a b c_{g}^{i}\right)>W^{c}\left(a b_{g}^{i}\right)$

We can conclude, that country $c$ has no incentive to change its announcement.

Based on the above, we conclude that $\Omega^{\digamma^{i}}$ is a Nash Equilibria if pollution is global.

$\Omega \digamma^{i}$ is not a CPNE if pollution is global.

\section{PROOF:}

We prove the above by examining the coalitional deviation of two dirty countries in the form of an integrated customs union. In this case, the announcement profile would be altered as follows: $\Omega \equiv\left\{\sigma_{a}^{i}=\left\{b^{i}, c^{i}\right\}, \sigma_{b}^{i u}=\left\{\varnothing, c^{i u}\right\}, \sigma_{c}^{i u}=\left\{\varnothing, b^{i u}\right\}\right\}$, and as a result, we observe the increase in members' welfare levels, $W^{b}\left(b c_{g}^{i u}\right)>W^{b}\left(a b c_{g}^{i}\right)$ and $W^{c}\left(b c_{g}^{i u}\right)>W^{c}\left(a b c_{g}^{i}\right)$. This deep trade union of two dirty countries brings its members the highest level of welfare in this game if pollution is global and $\lambda \varepsilon(0,0.006]$, and though both members have an incentive to deviate and form a side deal with the clean country $a$ if pollution is global and $\lambda \varepsilon(0.006,0.1]$, the nature of customs unions prevent this deviation. We conclude that no further deviations can occur. Based on the above, $\Omega^{F^{i}}$ is not a CPNE.

$$
\Omega^{F^{i u}} \equiv\left\{\sigma_{a}^{i u}=\left\{b^{i u}, c^{i u}\right\}, \sigma_{b}^{i u}=\left\{a^{i u}, c^{i u}\right\}, \sigma_{c}^{i u}=\left\{a^{i u}, b^{i u}\right\}\right\}
$$

$\Omega^{\digamma^{i u}}$ is not a Nash Equilibria for both local and global levels of pollution.

\section{ProOF:}

Either dirty country can improve their welfare by excluding the clean country $a$ :

country $\mathrm{b}=\left\{a^{i u}, c^{i u}\right\} \stackrel{\text { change }}{\longrightarrow}\left\{\varnothing, c^{i u}\right\} \stackrel{\text { result }}{\longrightarrow} W^{b}\left(b c_{\theta}^{i u}\right)>W^{b}\left(a b c_{\theta}^{i}\right)$

country $\mathrm{c}=\left\{a^{i u}, b^{i u}\right\} \stackrel{\text { change }}{\longrightarrow}\left\{\varnothing, b^{i u}\right\} \stackrel{\text { result }}{\longrightarrow} W^{c}\left(b c_{\theta}^{i u}\right)>W^{c}\left(a b c_{\theta}^{i}\right)$

We can conclude, that either of the dirty countries can improve its welfare by calling another dirty country only. Dirty countries would prefer to exclude the clean partner for both local and global 
levels of pollution. Based on the above, we are confident to conclude that $\Omega^{\digamma^{i u}}$ is not a Nash Equilibria for both local and global levels of pollution.

\section{A. 4.9.2.3 The Choice between Deep and Shallow Customs Unions}

Welfare effects of various type of deep and shallow trade agreements:

Country a, local pollution

$W^{a}\left(a b c_{l}^{i}\right)>W^{a}\left(a b_{l}^{i u}\right)>W^{a}\left(a b_{l}^{u}\right)>W^{a}\left(a b c_{l}\right)>W^{a}\left(N_{l}\right)>W^{a}\left(b c_{l}^{u}\right)>W^{a}\left(b c_{l}^{i u}\right)$

Country a, global pollution

$W^{a}\left(a b c_{g}^{i}\right)>W^{a}\left(b c_{g}^{i u}\right)>W^{a}\left(a b_{g}^{i u}\right)>W^{a}\left(N_{g}\right)>W^{a}\left(a b_{g}^{u}\right)>W^{a}\left(a b c_{g}\right) \stackrel{\lambda \in(0,0.089]}{>} W^{a}\left(b c_{g}^{u}\right) \lambda \in$ $(0,0.089]$

$W^{a}\left(a b c_{g}^{i}\right)>W^{a}\left(b c_{g}^{i u}\right)>W^{a}\left(a b_{g}^{i u}\right)>W^{a}\left(N_{g}\right)>W^{a}\left(a b_{g}^{u}\right)>W^{a}\left(b c_{g}^{u}\right) \stackrel{\lambda \in(0.089,0.1]}{>} W^{a}\left(a b c_{g}\right) \lambda \in$ $(0.089,0.1]$

Country b, local pollution

$W^{b}\left(b c_{l}^{i u}\right)>W^{b}\left(b c_{l}^{u}\right)>W^{b}\left(a b c_{l}\right)>W^{b}\left(a b_{l}^{u}\right)>W^{b}\left(a b_{l}^{i u}\right)>W^{b}\left(a b c_{l}^{i}\right)>W^{b}\left(N_{l}\right)$

Country b, global pollution

$W^{b}\left(b c_{g}^{i u}\right)>W^{b}\left(a b c_{g}^{i}\right)>W^{b}\left(b c_{g}^{u}\right)>W^{b}\left(a b_{g}^{u}\right)>W^{b}\left(N_{g}\right)>W^{b}\left(a b c_{g}\right)>W^{b}\left(a b_{g}^{i u}\right)$

Country c, local pollution

$W^{c}\left(b c_{l}^{i u}\right)>W^{c}\left(b c_{l}^{u}\right)>W^{c}\left(a b c_{l}\right)>W^{c}\left(a b c_{l}^{i}\right)>W^{c}\left(N_{l}\right)>W^{c}\left(a b_{l}^{i u}\right)>W^{c}\left(a b_{l}^{u}\right)$

Country c, global pollution

$W^{c}\left(b c_{g}^{i u}\right)>W^{c}\left(a b c_{g}^{i}\right)>W^{c}\left(a b_{g}^{i u}\right)>W^{c}\left(b c_{g}^{u}\right)>W^{c}\left(N_{g}\right)>W^{c}\left(a b c_{g}\right)>W^{c}\left(a b_{g}^{u}\right)$

\begin{tabular}{|c|c|}
\hline Announcement Profiles & Trade Agreements: CU vs. IU \\
\hline \hline$\Omega^{\Phi^{u}} \equiv\left\{\sigma_{a}^{u}=\{\varnothing, \varnothing\}, \sigma_{b}^{u}=\{\varnothing, \varnothing\}, \sigma_{c}^{u}=\{\varnothing, \varnothing\}\right\}$ & $\left\langle\Phi^{u}\right\rangle$ \\
\hline$\Omega^{a b u} \equiv\left\{\sigma_{a}^{u}=\left\{b^{u}, \varnothing\right\}, \sigma_{b}^{u}=\left\{a^{u}, \varnothing\right\}, \sigma_{c}^{u}=\{\varnothing, \varnothing\}\right\}$ & $\langle a b u\rangle$ \\
\hline$\Omega^{a b i u} \equiv\left\{\sigma_{a}^{i u}=\left\{b^{i u}, \varnothing\right\}, \sigma_{b}^{i u}=\left\{a^{i u}, \varnothing\right\}, \sigma_{c}^{i u}=\{\varnothing, \varnothing\}\right\}$ & $\langle a b i u\rangle$ \\
\hline$\Omega^{b c u} \equiv\left\{\sigma_{a}^{u}=\{\varnothing, \varnothing\}, \sigma_{b}^{u}=\left\{\varnothing, c^{u}\right\}, \sigma_{c}^{u}=\left\{\varnothing, b^{u}\right\}\right\}$ & $\langle b c u\rangle$ \\
\hline$\Omega^{b c i u} \equiv\left\{\sigma_{a}^{i u}=\{\varnothing, \varnothing\}, \sigma_{b}^{i u}=\left\{\varnothing, c^{i u}\right\}, \sigma_{c}^{i u}=\left\{\varnothing, b^{i u}\right\}\right\}$ & $\langle b c i u\rangle$ \\
\hline$\Omega^{F^{u}} \equiv\left\{\sigma_{a}^{u}=\left\{b^{u}, c^{u}\right\}, \sigma_{b}^{u}=\left\{a^{u}, c^{u}\right\}, \sigma_{c}^{u}=\left\{a^{u}, b^{u}\right\}\right\}$ & $\left\langle F^{u}\right\rangle$ \\
\hline$\Omega^{F^{i u}} \equiv\left\{\sigma_{a}^{i u}=\left\{b^{i u}, c^{i u}\right\}, \sigma_{b}^{i u}=\left\{a^{i u}, c^{i u}\right\}, \sigma_{c}^{i u}=\left\{a^{i u}, b^{i u}\right\}\right\}$ & $\left\langle F^{i u}\right\rangle$ \\
\hline
\end{tabular}




$$
\Omega^{\Phi^{u}} \equiv\left\{\sigma_{a}^{u}=\{\varnothing, \varnothing\}, \sigma_{b}^{u}=\{\varnothing, \varnothing\}, \sigma_{c}^{u}=\{\varnothing, \varnothing\}\right\}
$$

$\Omega^{\Phi^{u}}$ is a Nash Equilibria for both local and global levels of pollution.

\section{PROOF:}

Countries cannot get better off by unilaterally changing the announcements; countries have no incentive to announce any other country unless they are going to be announced back.

$\Omega^{\Phi^{i u}}$ is not a CPNE for both local and global levels of pollution.

\section{PROOF:}

We prove the above by considering a deep trade union of two symmetric dirty countries, $b$ and $c$. The trade union of two dirty countries brings its members the highest level of welfare in this game, so we can conclude that those counties can form a self-enforcing trade agreement for both levels of pollution, and no further deviations can occur. Based on the above, we conclude that $\Omega^{\Phi^{u}}$ is not a CPNE for both levels of pollution.

$$
\Omega^{a b u} \equiv\left\{\sigma_{a}^{u}=\left\{b^{u}, \varnothing\right\}, \sigma_{b}^{u}=\left\{a^{u}, \varnothing\right\}, \sigma_{c}^{u}=\{\varnothing, \varnothing\}\right\}
$$

$\Omega^{a b u}$ is a Nash Equilibria if pollution is local.

PROOF:

country a $=\left\{b^{u}, \varnothing\right\} \stackrel{\text { change }}{\longrightarrow}\left\{b^{u}, c^{u}\right\} \stackrel{\text { result }}{\longrightarrow}$ no change in $a$ 's welfare

country a $=\left\{b^{u}, \varnothing\right\} \stackrel{\text { change }}{\longrightarrow}\left\{\varnothing, c^{u}\right\} /\left\{\varnothing, c^{i u}\right\} /\{\varnothing, \varnothing\} /\left\{b^{i u}, \varnothing\right\} /\left\{b^{i u}, c^{i u}\right\} \stackrel{\text { result }}{\longrightarrow} W^{a}\left(a b_{l}^{u}\right)>W^{a}\left(N_{l}\right)$

We can conclude, that country $a$ has no incentive to change its announcement.

country $\mathrm{b}=\left\{a^{u}, \varnothing\right\} \stackrel{\text { change }}{\longrightarrow}\left\{a^{u}, c^{u}\right\} \stackrel{\text { result }}{\longrightarrow}$ no change in $b$ 's welfare

country $\mathrm{b}=\left\{a^{u}, \varnothing\right\} \stackrel{\text { change }}{\longrightarrow}\left\{\varnothing, c^{u}\right\} /\left\{\varnothing, c^{i u}\right\} /\{\varnothing, \varnothing\} /\left\{a^{i u}, c^{i u}\right\} /\left\{a^{i u}, \varnothing\right\} \stackrel{\text { result }}{\longrightarrow} W^{b}\left(a b_{l}^{u}\right)>W^{b}\left(N_{l}\right)$

We can conclude, that country $b$ has no incentive to change its announcement.

country $\mathrm{c}=\{\varnothing, \varnothing\} \stackrel{\text { change }}{\longrightarrow}\left\{a^{u}, \varnothing\right\} /\left\{a^{i u}, \varnothing\right\} /\left\{\varnothing, b^{u}\right\} /\left\{\varnothing, b^{i u}\right\} /\left\{a^{u}, b^{u}\right\} /\left\{a^{i u}, b^{i u}\right\} \stackrel{\text { result }}{\longrightarrow}$ no change in $c$ 's welfare

We can conclude, that country $c$ has no incentive to change its announcement.

Based on the above, $\Omega^{a b u}$ is a Nash Equilibria if pollution is local.

$\Omega^{a b u}$ is not a Nash Equilibria if pollution is global. 


\section{PROOF:}

country a $=\left\{b^{u}, \varnothing\right\} \stackrel{\text { change }}{\longrightarrow}\left\{\varnothing, c^{u}\right\} /\left\{\varnothing, c^{i u}\right\} /\{\varnothing, \varnothing\} /\left\{b^{i u}, \varnothing\right\} /\left\{b^{i u}, c^{i u}\right\} \stackrel{\text { result }}{\longrightarrow} W^{a}\left(a b_{g}^{u}\right)<W^{a}\left(N_{g}\right)$

We can conclude, that country the clean country $a$ would deviate to improve its welfare. Based on that, $\Omega^{a b u}$ is not a Nash Equilibria if pollution is global.

$\Omega^{a b u}$ is not a CPNE if pollution is local.

\section{PROOF:}

We prove the above by examining the coalitional deviation of two dirty countries, country $b$ and country $c$, in the form of a deep customs union. In this case, the announcement profile would be altered as follows: $\Omega \equiv\left\{\sigma_{a}^{u}=\left\{b^{u}, \varnothing\right\}, \sigma_{b}^{i u}=\left\{\varnothing, c^{i u}\right\}, \sigma_{c}^{i u}=\left\{\varnothing, b^{i u}\right\}\right\}$, and as a result, we observe the increase in members' welfare levels, $W^{b}\left(b c_{l}^{i u}\right)>W^{b}\left(a b_{l}^{u}\right)$ and $W^{c}\left(b c_{l}^{i u}\right)>W^{c}\left(a b_{l}^{u}\right)$. The level of welfare both members achieve is the highest in this game, and we conclude that no further deviations can occur. Based on the above, $\Omega^{a b u}$ is not a CPNE if pollution is local.

$$
\Omega^{a b i u} \equiv\left\{\sigma_{a}^{i u}=\left\{b^{i u}, \varnothing\right\}, \sigma_{b}^{i u}=\left\{a^{i u}, \varnothing\right\}, \sigma_{c}^{i u}=\{\varnothing, \varnothing\}\right\}
$$

$\Omega^{\text {abiu }}$ is a Nash Equilibria if pollution is local.

\section{PROOF:}

country $\mathrm{a}=\left\{b^{i u}, \varnothing\right\} \stackrel{\text { change }}{\longrightarrow}\left\{b^{i u}, c^{i u}\right\} \stackrel{\text { result }}{\longrightarrow}$ no change in $a$ 's welfare country a $=\left\{b^{i u}, \varnothing\right\} \stackrel{\text { change }}{\longrightarrow}\left\{\varnothing, c^{u}\right\} /\left\{\varnothing, c^{i u}\right\} /\{\varnothing, \varnothing\} /\left\{b^{u}, c^{u}\right\} /\left\{b^{u}, \varnothing\right\} \stackrel{\text { result }}{\longrightarrow} W^{a}\left(a b_{l}^{i u}\right)>W^{a}\left(N_{l}\right)$.

We can conclude, that country $a$ has no incentive to change its announcement.

country $\mathrm{b}=\left\{a^{i u}, \varnothing\right\} \stackrel{\text { change }}{\longrightarrow}\left\{a^{i u}, c^{i u}\right\} \stackrel{\text { result }}{\longrightarrow}$ no change in $b$ 's welfare country $\mathrm{b}=\left\{a^{i u}, \varnothing\right\} \stackrel{\text { change }}{\longrightarrow}\left\{\varnothing, c^{u}\right\} /\left\{\varnothing, c^{i u}\right\} /\{\varnothing, \varnothing\} /\left\{a^{u}, c^{u}\right\} /\left\{a^{u}, \varnothing\right\} \stackrel{\text { result }}{\longrightarrow} W^{b}\left(a b_{l}^{i u}\right)>W^{b}\left(N_{l}\right)$

We can conclude, that country $b$ has no incentive to change its announcement.

country $\mathrm{c}=\{\varnothing, \varnothing\} \stackrel{\text { change }}{\longrightarrow}\left\{a^{u}, \varnothing\right\} /\left\{a^{i u}, \varnothing\right\} /\left\{\varnothing, b^{u}\right\} /\left\{\varnothing, b^{i u}\right\} /\left\{a^{u}, b^{u}\right\} /\left\{a^{i u}, b^{i u}\right\} \stackrel{\text { result }}{\longrightarrow}$ no change in $c$ 's welfare

We can conclude, that country $c$ has no incentive to change its announcement.

Based on the above, we conclude that $\Omega^{a b i u}$ is a Nash Equilibria if pollution is local. $\Omega^{\text {abiu }}$ is not a Nash Equilibria if pollution is global.

\section{PROOF:}


country $\mathrm{b}=\left\{a^{i u}, \varnothing\right\} \stackrel{\text { change }}{\longrightarrow}\left\{\varnothing, c^{u}\right\} /\left\{\varnothing, c^{i u}\right\} /\{\varnothing, \varnothing\} /\left\{a^{u}, c^{u}\right\} /\left\{a^{u}, \varnothing\right\} \stackrel{\text { result }}{\longrightarrow} W^{b}\left(a b_{g}^{i u}\right)<W^{b}\left(N_{g}\right)$

We can conclude, that country $b$ has an incentive to self-exclude itself.

Based on the above, we conclude that $\Omega^{a b i u}$ is not a Nash Equilibria if pollution is global.

$\Omega^{\text {abiu }}$ is not a CPNE if pollution is local.

PROOF:

To prove the above, we consider a trade and environmental union between two symmetric dirty countries, $b$ and $c$, then $W^{b}\left(b c_{l}^{i u}\right)>W^{b}\left(a b_{l}^{i u}\right)$ and $W^{c}\left(b c_{l}^{i u}\right)>W^{c}\left(a b_{l}^{i u}\right)$. Also, the level of welfare countries $b$ and $c$ achieve from forming an integrated union is the highest in this game, so none of the members would deviate any further.

$$
\Omega^{b c u} \equiv\left\{\sigma_{a}^{u}=\{\varnothing, \varnothing\}, \sigma_{b}^{u}=\left\{\varnothing, c^{u}\right\}, \sigma_{c}^{u}=\left\{\varnothing, b^{u}\right\}\right\}
$$

$\Omega^{b c u}$ is a Nash Equilibria for both local and global levels of pollution.

\section{PROOF:}

country a $=\{\varnothing, \varnothing\} \stackrel{\text { change }}{\longrightarrow}\left\{b^{u}, \varnothing\right\} /\left\{b^{i u}, \varnothing\right\} /\left\{\varnothing, c^{u}\right\} /\left\{\varnothing, c^{i u}\right\} /\left\{b^{u}, c^{u}\right\} /\left\{b^{i u}, c^{i u}\right\} \stackrel{\text { result }}{\longrightarrow}$ no change in $a$ 's welfare

We can conclude, that country $a$ has no incentive to change its announcement.

country $\mathrm{b}=\left\{\varnothing, c^{u}\right\} \stackrel{\text { change }}{\longrightarrow}\left\{a^{u}, c^{u}\right\} \stackrel{\text { result }}{\longrightarrow}$ no change in $b$ 's welfare

country $\mathrm{b}=\left\{\varnothing, c^{u}\right\} \stackrel{\text { change }}{\longrightarrow}\left\{a^{u}, \varnothing\right\} /\left\{a^{i u}, \varnothing\right\} /\{\varnothing, \varnothing\} /\left\{a^{i u}, c^{i u}\right\} /\left\{\varnothing, c^{i u}\right\} \stackrel{\text { result }}{\longrightarrow} W^{b}\left(b c_{\theta}^{u}\right)>W^{b}\left(N_{\theta}\right)$

We can conclude, that country $b$ has no incentive to change its announcement.

country $\mathrm{c}=\left\{\varnothing, b^{u}\right\} \stackrel{\text { change }}{\longrightarrow}\left\{a^{u}, b^{u}\right\} \stackrel{\text { result }}{\longrightarrow}$ no change in $c$ 's welfare

country $\mathrm{c}=\left\{\varnothing, b^{u}\right\} \stackrel{\text { change }}{\longrightarrow}\left\{a^{u}, \varnothing\right\} /\left\{a^{i u}, \varnothing\right\} /\{\varnothing, \varnothing\} /\left\{a^{i u}, b^{i u}\right\} /\left\{\varnothing, b^{i u}\right\} \stackrel{\text { result }}{\longrightarrow} W^{c}\left(b c_{\theta}^{u}\right)>W^{c}\left(N_{\theta}\right)$

We can conclude, that country $c$ has no incentive to change its announcement.

Based on the above, $\Omega^{b c u}$ is a Nash Equilibria for both local and global levels of pollution.

$\Omega^{b c u}$ is not a CPNE for both local and global levels of pollution.

\section{PROOF:}

To prove the above we suppose, that members add an environmental clause to their agreement, then $W^{b}\left(b c_{\theta}^{i u}\right)=W^{c}\left(b c_{\theta}^{i u}\right)>W^{b}\left(b c_{\theta}^{u}\right)=W^{c}\left(b c_{\theta}^{u}\right)$, and no further deviations can occurs because 
this welfare level is highest in the entire game. Based on the above, we conclude that $\Omega^{b c u}$ is not a CPNE for both local and global levels of pollution.

$$
\Omega^{b c i u} \equiv\left\{\sigma_{a}^{i u}=\{\varnothing, \varnothing\}, \sigma_{b}^{i u}=\left\{\varnothing, c^{i u}\right\}, \sigma_{c}^{i u}=\left\{\varnothing, b^{i u}\right\}\right\}
$$

$\Omega^{\text {bciu }}$ is a Nash Equilibria for both local and global levels of pollution.

PROOF:

country a $=\{\varnothing, \varnothing\} \stackrel{\text { change }}{\longrightarrow}\left\{b^{u}, \varnothing\right\} /\left\{b^{i u}, \varnothing\right\} /\left\{\varnothing, c^{u}\right\} /\left\{\varnothing, c^{i u}\right\} /\left\{b^{u}, c^{u}\right\} /\left\{b^{i u}, c^{i u}\right\} \stackrel{\text { result }}{\longrightarrow}$ no change in $a$ 's welfare

We can conclude, that country $a$ has no incentive to change its announcement.

country $\mathrm{b}=\left\{\varnothing, c^{i u}\right\} \stackrel{\text { change }}{\longrightarrow}\left\{a^{i u}, c^{i u}\right\} \stackrel{\text { result }}{\longrightarrow}$ no change in $b$ 's welfare

country $\mathrm{b}=\left\{\varnothing, c^{i u}\right\} \stackrel{\text { change }}{\longrightarrow}\left\{a^{u}, \varnothing\right\} /\left\{a^{i u}, \varnothing\right\} /\{\varnothing, \varnothing\} /\left\{a^{u}, c^{u}\right\} /\left\{\varnothing, c^{u}\right\} \stackrel{\text { result }}{\longrightarrow} W^{b}\left(b c_{\theta}^{i u}\right)>W^{b}\left(N_{\theta}\right)$

We can conclude, that country $b$ has no incentive to change its announcement.

country $\mathrm{c}=\left\{\varnothing, b^{i u}\right\} \stackrel{\text { change }}{\longrightarrow}\left\{a^{i u}, b^{i u}\right\} \stackrel{\text { result }}{\longrightarrow}$ no change in $c$ 's welfare

country $\mathrm{c}=\left\{\varnothing, b^{i u}\right\} \stackrel{\text { change }}{\longrightarrow}\left\{a^{u}, \varnothing\right\} /\left\{a^{i u}, \varnothing\right\} /\{\varnothing, \varnothing\} /\left\{a^{u}, b^{u}\right\} /\left\{\varnothing, b^{u}\right\} \stackrel{\text { result }}{\longrightarrow} W^{c}\left(b c_{\theta}^{i u}\right)>W^{c}\left(N_{\theta}\right)$

We can conclude, that country $c$ has no incentive to change its announcement.

Based on the above, $\Omega^{b c i u}$ is a Nash Equilibria for both local and global levels of pollution.

$\Omega^{\text {bciu }}$ is a CPNE for both local and global levels of pollution.

PROOF:

We prove the above by examining every possible meaningful deviation:

- first, we consider a coalitional deviation of one dirty and one clean country, countries $a$ and $b$, in the form of either deep or shallow customs union, and as a result, we observe that neither of these deviations is meaningful: $W^{b}\left(b c_{\theta}^{i u}\right)>W^{b}\left(a b_{\theta}^{u}\right)>W^{b}\left(a b_{\theta}^{i u}\right)$;

- second, we examine whether two dirty countries, country $b$ and country $c$, are interested in removing an environmental clause and sign a shallow CU instead of a deep one, and again we find that this deviation is not meaningful as well: $W^{j}\left(b c_{\theta}^{i u}\right)>W^{j}\left(b c_{\theta}^{u}\right)$, where $j \neq a$;

- now, we examine two possible grand coalitions, shallow and deep free trade agreements, and 
again, we observe that neither of these deviations is meaningful: $W^{j}\left(b c_{l}^{i u}\right)>W^{j}\left(a b c_{l}\right)>$ $W^{j}\left(a b c_{l}^{i}\right)$ and $W^{j}\left(b c_{g}^{i u}\right)>W^{j}\left(a b c_{g}^{i}\right)>W^{j}\left(a b c_{g}\right)$, where $j \neq a$.

Based on the above, we conclude that $\Omega^{b c i u}$ survives all coalition-proof Nash equilibria refinements.

$$
\Omega^{F^{u}} \equiv\left\{\sigma_{a}^{u}=\left\{b^{u}, c^{u}\right\}, \sigma_{b}^{u}=\left\{a^{u}, c^{u}\right\}, \sigma_{c}^{u}=\left\{a^{u}, b^{u}\right\}\right\}
$$

$\Omega^{\digamma^{u}}$ is not a Nash Equilibria for both local and global levels of pollution.

\section{PROOF:}

Either dirty country can improve their welfare by excluding the clean country $a$ :

country $\mathrm{b}=\left\{a^{u}, c^{u}\right\} \stackrel{\text { change }}{\longrightarrow}\left\{\varnothing, c^{u}\right\} \stackrel{\text { result }}{\longrightarrow} W^{b}\left(b c_{\theta}^{u}\right)>W^{b}\left(a b c_{\theta}\right)$

country c $=\left\{a^{u}, b^{u}\right\} \stackrel{\text { change }}{\longrightarrow}\left\{\varnothing, b^{u}\right\} \stackrel{\text { result }}{\longrightarrow} W^{c}\left(b c_{\theta}^{u}\right)>W^{c}\left(a b c_{\theta}\right)$

We can conclude, that either of the dirty countries can improve its welfare by calling another dirty country only. Dirty countries would prefer to exclude the clean partner for both local and global levels of pollution. Based on the above, we are confident to conclude that $\Omega^{\digamma^{u}}$ is not a Nash Equilibria for both local and global levels of pollution.

$$
\Omega^{F^{i u}} \equiv\left\{\sigma_{a}^{i u}=\left\{b^{i u}, c^{i u}\right\}, \sigma_{b}^{i u}=\left\{a^{i u}, c^{i u}\right\}, \sigma_{c}^{i u}=\left\{a^{i u}, b^{i u}\right\}\right\}
$$

$\Omega^{\digamma^{i u}}$ is not a Nash Equilibria for both local and global levels of pollution.

PROOF:

Either dirty country can improve their welfare by excluding the clean country $a$ :

country $\mathrm{b}=\left\{a^{i u}, c^{i u}\right\} \stackrel{\text { change }}{\longrightarrow}\left\{\varnothing, c^{i u}\right\} \stackrel{\text { result }}{\longrightarrow} W^{b}\left(b c_{\theta}^{i u}\right)>W^{b}\left(a b c_{\theta}^{i}\right)$

country $\mathrm{c}=\left\{a^{i u}, b^{i u}\right\} \stackrel{\text { change }}{\longrightarrow}\left\{\varnothing, b^{i u}\right\} \stackrel{\text { result }}{\longrightarrow} W^{c}\left(b c_{\theta}^{i u}\right)>W^{c}\left(a b c_{\theta}^{i}\right)$

We can conclude, that either of the dirty countries can improve its welfare by calling another dirty country only. Dirty countries would prefer to exclude the clean partner for both local and global levels of pollution. Based on the above, we are confident to conclude that $\Omega^{\digamma^{i u}}$ is not a Nash Equilibria for both local and global levels of pollution. 


\section{A. 4.9.2.4 The Choice between Deep and Shallow FTAs}

Welfare effects of various type of deep and shallow trade agreements:

Country a, local pollution

$W^{a}\left(a_{l}^{h i}\right)>W^{a}\left(a b c_{l}^{i}\right)>W^{a}\left(a_{l}^{h}\right)>W^{a}\left(b_{l}^{h i}\right) \stackrel{\lambda \in(0,0.009]}{>} W^{a}\left(a b_{l}^{i}\right)>W^{a}\left(a b c_{l}\right)>W^{a}\left(a b_{l}\right)>W^{a}\left(b c_{l}\right) \stackrel{\lambda \in(0,0.023]}{>}$

$W^{a}\left(b_{l}^{h}\right)>W^{a}\left(N_{l}\right)>W^{a}\left(b c_{l}^{i}\right)$ if $\lambda \in(0,0.009]$

$W^{a}\left(a_{l}^{h i}\right)>W^{a}\left(a b c_{l}^{i}\right)>W^{a}\left(a_{l}^{h}\right)>W^{a}\left(a b_{l}^{i}\right) \stackrel{\lambda \in(0.009,0.1]}{>} W^{a}\left(b_{l}^{h i}\right)>W^{a}\left(a b c_{l}\right)>W^{a}\left(a b_{l}\right)>W^{a}\left(b c_{l}\right) \stackrel{\lambda \in(0,0.023]}{>}$

$W^{a}\left(b_{l}^{h}\right)>W^{a}\left(N_{l}\right)>W^{a}\left(b c_{l}^{i}\right)$ if $\lambda \in(0.009,0.023]$

$W^{a}\left(a_{l}^{h i}\right)>W^{a}\left(a b c_{l}^{i}\right)>W^{a}\left(a_{l}^{h}\right)>W^{a}\left(a b_{l}^{i}\right) \stackrel{\lambda \in(0.009,0.1]}{>} W^{a}\left(b_{l}^{h i}\right)>W^{a}\left(a b c_{l}\right)>W^{a}\left(a b_{l}\right)>W^{a}\left(b_{l}^{h}\right) \stackrel{\lambda \in(0.023,0.1]}{>}$

$W^{a}\left(b c_{l}\right)>W^{a}\left(N_{l}\right)>W^{a}\left(b c_{l}^{i}\right)$ if $\lambda \in(0.023,0.1]$

Country a, global pollution

$W^{a}\left(a_{g}^{h i}\right)>W^{a}\left(a b c_{g}^{i}\right)>W^{a}\left(b_{g}^{h i}\right)>W^{a}\left(b c_{g}^{i}\right)>W\left(a b_{g}^{i}\right)>W^{a}\left(b c_{g}\right)>W^{a}\left(N_{g}\right)>W^{a}\left(a_{g}^{h}\right)>W^{a}\left(a b c_{g}\right)>$

$W^{a}\left(a b_{g}\right)>W^{a}\left(b_{g}^{h}\right)$

Country $b$, local pollution

$W^{b}\left(b_{l}^{h}\right)>W^{b}\left(b c_{l}^{i}\right) \stackrel{\lambda \in(0,0.008]}{>} W^{b}\left(b_{l}^{h i}\right)>W^{b}\left(a b c_{l}\right)>W^{b}\left(b c_{l}\right)>W^{b}\left(a_{l}^{h}\right) \stackrel{\lambda \in(0,0.009]}{>} W^{b}\left(a b c_{l}^{i}\right)>$ $W^{b}\left(a b_{l}\right) \stackrel{\lambda \in(0,0.027]}{>} W^{b}\left(N_{l}\right)>W^{b}\left(a_{l}^{h i}\right)>W^{b}\left(a b_{l}^{i}\right){ }^{45}$ if $\lambda \in(0,0.008]$

$W^{b}\left(b_{l}^{h}\right)>W^{b}\left(b_{l}^{h i}\right) \stackrel{\lambda \in(0.008,0.1]}{>} W^{b}\left(b c_{l}^{i}\right)>W^{b}\left(a b c_{l}\right)>W^{b}\left(b c_{l}\right)>W^{b}\left(a_{l}^{h}\right) \stackrel{\lambda \in(0,0.009]}{>} W^{b}\left(a b c_{l}^{i}\right)>$ $W^{b}\left(a b_{l}\right) \stackrel{\lambda \in(0,0.027]}{>} W^{b}\left(N_{l}\right)>W^{b}\left(a_{l}^{h i}\right)>W^{b}\left(a b_{l}^{i}\right){ }^{46}$ if $\lambda \in(0.008,0.009]$

$W^{b}\left(b_{l}^{h}\right)>W^{b}\left(b_{l}^{h i}\right) \stackrel{\lambda \in(0.008,0.1]}{>} W^{b}\left(b c_{l}^{i}\right)>W^{b}\left(a b c_{l}\right)>W^{b}\left(b c_{l}\right)>W^{b}\left(a b c_{l}^{i}\right) \stackrel{\lambda \in(0.009,0.1]}{>} W^{b}\left(a_{l}^{h}\right)>$ $W^{b}\left(a b_{l}\right) \stackrel{\lambda \in(0,0.027]}{>} W^{b}\left(N_{l}\right)>W^{b}\left(a_{l}^{h i}\right)>W^{b}\left(a b_{l}^{i}\right){ }^{47}$ if $\lambda \in(0.009,0.027]$

$W^{b}\left(b_{l}^{h}\right)>W^{b}\left(b_{l}^{h i}\right) \stackrel{\lambda \in(0.008,0.1]}{>} W^{b}\left(b c_{l}^{i}\right)>W^{b}\left(a b c_{l}\right)>W^{b}\left(b c_{l}\right)>W^{b}\left(a b c_{l}^{i}\right) \stackrel{\lambda \in(0.009,0.1]}{>} W^{b}\left(a_{l}^{h}\right) \stackrel{\lambda \in(0,0.082]}{>}$

$W^{b}\left(N_{l}\right) \stackrel{\lambda \in(0.027,0.1]}{>} W^{b}\left(a b_{l}\right)>W^{b}\left(a_{l}^{h i}\right)>W^{b}\left(a b_{l}^{i}\right)$ if $\lambda \in(0.027,0.082]$

$W^{b}\left(b_{l}^{h}\right)>W^{b}\left(b_{l}^{h i}\right) \stackrel{\lambda \in(0.008,0.1]}{>} W^{b}\left(b c_{l}^{i}\right)>W^{b}\left(a b c_{l}\right)>W^{b}\left(b c_{l}\right)>W^{b}\left(a b c_{l}^{i}\right)>W^{b}\left(N_{l}\right) \stackrel{\lambda \in(0.082,0.1]}{>}$

$W^{b}\left(a_{l}^{h}\right)>W^{b}\left(a b_{l}\right)>W^{b}\left(a_{l}^{h i}\right)>W^{b}\left(a b_{l}^{i}\right){ }^{48}$ if $\lambda \in(0.082,0.1]$

\footnotetext{
${ }^{45} W^{b}\left(a_{l}^{h}\right) \stackrel{\lambda \in(0,0.082]}{>} W^{b}\left(N_{l}\right)$ holds as well

${ }^{46} W^{b}\left(a_{l}^{h}\right) \stackrel{\lambda \in(0,0.082]}{>} W^{b}\left(N_{l}\right)$ holds as well

${ }^{47} W^{b}\left(a_{l}^{h}\right) \stackrel{\lambda \in(0,0.082]}{>} W^{b}\left(N_{l}\right)$ holds as well

${ }^{48} W^{b}\left(a b c_{l}^{i}\right) \stackrel{\lambda \in(0.009,0.1]}{>} W^{b}\left(a_{l}^{h}\right)$ holds as well
} 
Country b, global pollution

$$
\begin{aligned}
& W^{b}\left(b_{g}^{h i}\right)>W^{b}\left(b c_{g}^{i}\right) \stackrel{\lambda \in(0,0.089]}{>} W^{b}\left(a b c_{g}^{i}\right)>W^{b}\left(a_{g}^{h i}\right)>W^{b}\left(b_{g}^{h}\right)>W^{b}\left(b c_{g}\right)>W^{b}\left(a b_{g}\right) \stackrel{\lambda \in(0,0.019]}{>} \\
& W^{b}\left(a b_{g}^{i}\right)>W^{b}\left(N_{g}\right)>W^{b}\left(a b c_{g}\right)>W^{b}\left(a_{g}^{h}\right){ }^{49} \text { if } \lambda \in(0,0.019] \\
& W^{b}\left(b_{g}^{h i}\right)>W^{b}\left(b c_{g}^{i}\right) \stackrel{\lambda \in(0,0.089]}{>} W^{b}\left(a b c_{g}^{i}\right)>W^{b}\left(a_{g}^{h i}\right)>W^{b}\left(b_{g}^{h}\right)>W^{b}\left(b c_{g}\right) \stackrel{\lambda \in(0,0.035]}{>} W^{b}\left(a b_{g}^{i}\right) \stackrel{\lambda \in(0.019,0.1]}{>} \\
& W^{b}\left(a b_{g}\right) \stackrel{\lambda \in(0,0.065]}{>} W^{b}\left(N_{g}\right)>W^{b}\left(a b c_{g}\right)>W^{b}\left(a_{g}^{h}\right){ }^{50} \text { if } \lambda \in(0.019,0.035] \\
& W^{b}\left(b_{g}^{h i}\right)>W^{b}\left(b c_{g}^{i}\right) \stackrel{\lambda \in(0,0.089]}{>} W^{b}\left(a b c_{g}^{i}\right)>W^{b}\left(a_{g}^{h i}\right)>W^{b}\left(b_{g}^{h}\right) \stackrel{\lambda \in(0,0.083]}{>} W^{b}\left(a b_{g}^{i}\right) \stackrel{\lambda \in(0.035,0.1]}{>} W^{b}\left(b c_{g}\right)> \\
& W^{b}\left(a b_{g}\right) \stackrel{\lambda \in(0,0.065]}{>} W^{b}\left(N_{g}\right)>W^{b}\left(a b c_{g}\right)>W^{b}\left(a_{g}^{h}\right) \text { if } \lambda \in(0.035,0.065] \\
& W^{b}\left(b_{g}^{h i}\right)>W^{b}\left(b c_{g}^{i}\right) \stackrel{\lambda \in(0,0.089]}{>} W^{b}\left(a b c_{g}^{i}\right)>W^{b}\left(a_{g}^{h i}\right)>W^{b}\left(b_{g}^{h}\right) \stackrel{\lambda \in(0,0.083]}{>} W^{b}\left(a b_{g}^{i}\right) \stackrel{\lambda \in(0.035,0.1]}{>} W^{b}\left(b c_{g}\right)> \\
& W^{b}\left(N_{g}\right) \stackrel{\lambda \in(0.065,0.1]}{>} W^{b}\left(a b_{g}\right)>W^{b}\left(a b c_{g}\right)>W^{b}\left(a_{g}^{h}\right) \text { if } \lambda \in(0.065,0.083] \\
& W^{b}\left(b_{g}^{h i}\right)>W^{b}\left(b c_{g}^{i}\right) \stackrel{\lambda \in(0,0.089]}{>} W^{b}\left(a b c_{g}^{i}\right)>W^{b}\left(a_{g}^{h i}\right)>W^{b}\left(a b_{g}^{i}\right) \stackrel{\lambda \in(0.083,0.1]}{>} W^{b}\left(b_{g}^{h}\right)>W^{b}\left(b c_{g}^{i}\right)> \\
& W^{b}\left(N_{g}\right) \stackrel{\lambda \in(0.065,0.1]}{>} W^{b}\left(a b_{g}\right)>W^{b}\left(a b c_{g}\right)>W^{b}\left(a_{g}^{h}\right) \\
& W^{b}\left(b_{g}^{h i}\right)>W^{b}\left(a b c_{g}^{i}\right) \stackrel{\lambda \in(0.089,0.1]}{>} W^{b}\left(b c_{g}^{i}\right)>W^{b}\left(a_{g}^{h i}\right)>W^{b}\left(a b_{g}^{i}\right) \stackrel{\lambda \in(0.083,0.1]}{>} W^{b}\left(b_{g}^{h}\right)>W^{b}\left(b c_{g}^{i}\right)> \\
& W^{b}\left(N_{g}\right) \stackrel{\lambda \in(0.065,0.1]}{>} W^{b}\left(a b_{g}\right)>W^{b}\left(a b c_{g}\right)>W^{b}\left(a_{g}^{h}\right) \\
& C^{52} \text { if } \lambda \in(0.089,0.1]
\end{aligned}
$$

Country c, local pollution

$W^{c}\left(b c_{l}^{i}\right)>W^{c}\left(a b c_{l}\right) \stackrel{\lambda \in(0,0.043]}{>} W^{c}\left(a b_{l}\right)>W^{c}\left(b c_{l}\right)>W^{c}\left(a b_{l}^{i}\right)>W^{c}\left(b_{l}^{h}\right)>W^{c}\left(a_{l}^{h}\right) \stackrel{\lambda \in(0,0.009]}{>} W^{c}\left(a b c_{l}^{i}\right)>$$$
W^{c}\left(N_{l}\right)>W^{c}\left(b_{l}^{h i}\right)>W^{c}\left(a_{l}^{h i}\right)^{53} \text { if } \lambda \in(0,0.009]
$$$$
W^{c}\left(b c_{l}^{i}\right)>W^{c}\left(a b c_{l}\right) \stackrel{\lambda \in(0,0.043]}{>} W^{c}\left(a b_{l}\right)>W^{c}\left(b c_{l}\right)>W^{c}\left(a b_{l}^{i}\right)>W^{c}\left(b_{l}^{h}\right)>W^{c}\left(a b c_{l}^{i}\right) \stackrel{\lambda \in(0.009,0.1]}{>}
$$$$
W^{c}\left(a_{l}^{h}\right) \stackrel{\lambda \in(0,0.082]}{>} W^{c}\left(N_{l}\right)>W^{c}\left(b_{l}^{h i}\right)>W^{c}\left(a_{l}^{h i}\right) \text { if } \lambda \in(0.009,0.043]
$$$$
W^{c}\left(b c_{l}^{i}\right)>W^{c}\left(a b_{l}\right) \stackrel{\lambda \in(0.043,0.1]}{>} W^{c}\left(a b c_{l}\right)>W^{c}\left(b c_{l}\right)>W^{c}\left(a b_{l}^{i}\right)>W^{c}\left(b_{l}^{h}\right)>W^{c}\left(a b c_{l}^{i}\right) \stackrel{\lambda \in(0.009,0.1]}{>}
$$$$
W^{c}\left(a_{l}^{h}\right) \stackrel{\lambda \in(0,0.082]}{>} W^{c}\left(N_{l}\right)>W^{c}\left(b_{l}^{h i}\right)>W^{c}\left(a_{l}^{h i}\right) \text { if } \lambda \in(0.043,0.082]
$$$$
W^{c}\left(b c_{l}^{i}\right)>W^{c}\left(a b_{l}\right) \stackrel{\lambda \in(0.043,0.1]}{>} W^{c}\left(a b c_{l}\right)>W^{c}\left(b c_{l}\right)>W^{c}\left(a b_{l}^{i}\right)>W^{c}\left(b_{l}^{h}\right)>W^{c}\left(a b c_{l}^{i}\right)>W^{c}\left(N_{l}\right) \stackrel{\lambda \in(0.082,0.1]}{>}
$$$$
W^{c}\left(a_{l}^{h}\right)>W^{c}\left(b_{l}^{h i}\right)>W^{c}\left(a_{l}^{h i}\right)^{54} \text { if } \lambda \in(0.082,0.1]
$$

\footnotetext{
${ }^{49} W^{b}\left(b_{g}^{h}\right) \stackrel{\lambda \in(0,0.083]}{>} W^{b}\left(a b_{g}^{i}\right) \& W^{b}\left(b c_{g}\right) \stackrel{\lambda \in(0,0.035]}{>} W^{b}\left(a b_{g}^{i}\right) \& W^{b}\left(a b_{g}\right) \stackrel{\lambda \in(0,0.065]}{>} W^{b}\left(N_{g}\right)$ hold as well

${ }^{50} W^{b}\left(b_{g}^{h}\right) \stackrel{\lambda \in(0,0.083]}{>} W^{b}\left(a b_{g}^{i}\right)$ holds as well

${ }^{51} W^{b}\left(a b_{g}^{i}\right) \stackrel{\lambda \in(0.035,0.1]}{>} W^{b}\left(b c_{g}\right)$ holds as well

${ }^{52} W^{b}\left(a b_{g}^{i}\right) \stackrel{\lambda \in(0.035,0.1]}{>} W^{b}\left(b c_{g}\right)$ holds as well

${ }^{53} W^{c}\left(a_{l}^{h}\right) \stackrel{\lambda \in(0,0.082]}{>} W^{c}\left(N_{l}\right)$ holds as well

${ }^{54} W^{c}\left(a b c_{l}^{i}\right) \stackrel{\lambda \in(0.009,0.1]}{>} W^{b}\left(a_{l}^{h}\right)$ holds as well
} 
Country c, global pollution

$W^{c}\left(b c_{g}^{i}\right) \stackrel{\lambda \in(0,0.089]}{>} W^{c}\left(a b c_{g}^{i}\right)>W^{c}\left(a_{g}^{h i}\right)>W^{c}\left(a b_{g}^{i}\right)>W^{c}\left(b_{g}^{h i}\right)>W^{c}\left(b c_{g}\right)>W^{c}\left(N_{g}\right)>W^{c}\left(a b c_{g}\right)>$ $W^{c}\left(a_{g}^{h}\right)>W^{c}\left(a b_{g}\right)>W^{c}\left(b_{g}^{h}\right)$ if $\lambda \in(0,0.089]$

$W^{c}\left(a b c_{g}^{i}\right) \stackrel{\lambda \in(0.089,0.1]}{>} W^{c}\left(b c_{g}^{i}\right)>W^{c}\left(a_{g}^{h i}\right)>W^{c}\left(a b_{g}^{i}\right)>W^{c}\left(b_{g}^{h i}\right)>W^{c}\left(b c_{g}\right)>W^{c}\left(N_{g}\right)>W^{c}\left(a b c_{g}\right)>$ $W^{c}\left(a_{g}^{h}\right)>W^{c}\left(a b_{g}\right)>W^{c}\left(b_{g}^{h}\right)$ if $\lambda \in(0.089,0.1]$

\begin{tabular}{|c|c|}
\hline Announcement Profiles & Shallow \& Deep Trade Agreements \\
\hline \hline$\Omega^{\Phi} \equiv\left\{\sigma_{a}=\{\varnothing, \varnothing\}, \sigma_{b}=\{\varnothing, \varnothing\}, \sigma_{c}=\{\varnothing, \varnothing\}\right\}$ & $\langle\Phi\rangle$ \\
\hline$\Omega^{a b} \equiv\left\{\sigma_{a}=\{b, \varnothing\}, \sigma_{b}=\{a, \varnothing\}, \sigma_{c}=\{\varnothing, \varnothing\}\right\}$ & $\langle a b\rangle$ \\
\hline$\Omega^{a b i} \equiv\left\{\sigma_{a}^{i}=\left\{b^{i}, \varnothing\right\}, \sigma_{b}^{i}=\left\{a^{i}, \varnothing\right\}, \sigma_{c}^{i}=\{\varnothing, \varnothing\}\right\}$ & $\langle a b i\rangle$ \\
\hline$\Omega^{b c} \equiv\left\{\sigma_{a}=\{\varnothing, \varnothing\}, \sigma_{b}=\{\varnothing, c\}, \sigma_{c}=\{\varnothing, b\}\right\}$ & $\langle b c\rangle$ \\
\hline$\Omega^{b c i} \equiv\left\{\sigma_{a}^{i}=\{\varnothing, \varnothing\}, \sigma_{b}^{i}=\left\{\varnothing, c^{i}\right\}, \sigma_{c}^{i}=\left\{\varnothing, b^{i}\right\}\right\}$ & $\langle b c i\rangle$ \\
\hline$\Omega^{a h} \equiv\left\{\sigma_{a}=\{b, c\}, \sigma_{b}=\{a, \varnothing\}, \sigma_{c}=\{a, \varnothing\}\right\}$ & $\langle a h\rangle$ \\
\hline$\Omega^{a h i} \equiv\left\{\sigma_{a}^{i}=\left\{b^{i}, c^{i}\right\}, \sigma_{b}^{i}=\left\{a^{i}, \varnothing\right\}, \sigma_{c}^{i}=\left\{a^{i}, \varnothing\right\}\right\}$ & $\langle b h\rangle$ \\
\hline$\Omega^{b h} \equiv\left\{\sigma_{a}=\{b, \varnothing\}, \sigma_{b}=\{a, c\}, \sigma_{c}=\{\varnothing, b\}\right\}$ & $\langle b h i\rangle$ \\
\hline$\Omega^{b h i} \equiv\left\{\sigma_{a}^{i}=\left\{b^{i}, \varnothing\right\}, \sigma_{b}^{i}=\left\{a^{i}, c^{i}\right\}, \sigma_{c}^{i}=\left\{\varnothing, b^{i}\right\}\right\}$ & $\langle F\rangle$ \\
\hline$\Omega^{F} \equiv\left\{\sigma_{a}=\{b, c\}, \sigma_{b}=\{a, c\}, \sigma_{c}=\{a, b\}\right\}$ & $\left\langle F^{i}\right\rangle$ \\
\hline$\Omega^{F^{i}} \equiv\left\{\sigma_{a}^{i}=\left\{b^{i}, c^{i}\right\}, \sigma_{b}^{i}=\left\{a^{i}, c^{i}\right\}, \sigma_{c}^{i}=\left\{a^{i}, b^{i}\right\}\right\}$ &
\end{tabular}

$$
\Omega^{\Phi} \equiv\left\{\sigma_{a}=\{\varnothing, \varnothing\}, \sigma_{b}=\{\varnothing, \varnothing\}, \sigma_{c}=\{\varnothing, \varnothing\}\right\}
$$

$\Omega^{\Phi}$ is a Nash Equilibria for both local and global levels of pollution.

PROOF:

Countries cannot get better off by unilaterally changing the announcements; countries have no incentive to announce any other country unless they are going to be announced back.

$\Omega^{\Phi}$ is not a CPNE for both local and global levels of pollution.

PROOF:

To prove the above, we assume that two symmetric dirty countries, $b$ and $c$, form a deep bilateral free trade agreement, then their announcement profiles would be altered as follows: $\sigma_{b}^{i}=\left\{\varnothing, c^{i}\right\}$ and $\sigma_{c}^{i}=\left\{\varnothing, b^{i}\right\}$. As a result, we observe the increase in the members' welfares: $W^{j}\left(b c_{\theta}^{i}\right)>$ $W^{j}\left(N_{\theta}\right)$, where $j \neq a$. We are confident to conclude that $\Omega^{\Phi}$ is not a CPNE for both local and global levels of pollution. 


$$
\Omega^{a b} \equiv\left\{\sigma_{a}=\{b, \varnothing\}, \sigma_{b}=\{a, \varnothing\}, \sigma_{c}=\{\varnothing, \varnothing\}\right\}
$$

$\Omega^{a b}$ is a Nash Equilibria if pollution is local and $\lambda \varepsilon(0,0.027]$.

PROOF:

country a $=\{b, \varnothing\} \stackrel{\text { change }}{\longrightarrow}\{b, c\} \stackrel{\text { result }}{\longrightarrow}$ no change in $a$ 's welfare

country a $=\{b, \varnothing\} \stackrel{\text { change }}{\longrightarrow}\{\varnothing, c\} /\left\{\varnothing, c^{i}\right\} /\left\{b^{i}, \varnothing\right\} /\{\varnothing, \varnothing\} /\left\{b^{i}, c^{i}\right\} \stackrel{\text { result }}{\longrightarrow} W^{a}\left(a b_{l}\right)>W^{a}\left(N_{l}\right)$

We can conclude, that country $a$ has no incentive to change its announcement.

country $\mathrm{b}=\{a, \varnothing\} \stackrel{\text { change }}{\longrightarrow}\{a, c\} \stackrel{\text { result }}{\longrightarrow}$ no change in $b$ 's welfare

country $\mathrm{b}=\{a, \varnothing\} \stackrel{\text { change }}{\longrightarrow}\{\varnothing, c\} /\left\{\varnothing, c^{i}\right\} /\left\{a^{i}, \varnothing\right\} /\{\varnothing, \varnothing\} /\left\{a^{i}, c^{i}\right\} \stackrel{\text { result }}{\longrightarrow} W^{b}\left(a b_{l}\right)>W^{b}\left(N_{l}\right) \& \lambda \varepsilon(0,0.027]$

We can conclude, that country $b$ has no incentive to change its announcement.

country $\mathrm{c}=\{\varnothing, \varnothing\} \stackrel{\text { change }}{\longrightarrow}\{a, \varnothing\} /\left\{a^{i}, \varnothing\right\} /\{\varnothing, b\} /\left\{\varnothing, b^{i}\right\} /\{a, b\} /\left\{a^{i}, b^{i}\right\} \stackrel{\text { result }}{\longrightarrow}$ no change in $c^{\prime} s$ welfare

We can conclude, that country $c$ has no incentive to change its announcement.

Based on the above, we conclude that $\Omega^{a b}$ is a Nash Equilibria if pollution is local and $\lambda \varepsilon(0,0.027]$. $\Omega^{a b}$ is not a Nash Equilibria if pollution is local and $\lambda \varepsilon(0.027,0.1]$.

\section{PROOF:}

country $\mathrm{b}=\{a, \varnothing\} \stackrel{\text { change }}{\longrightarrow}\{\varnothing, c\} /\left\{\varnothing, c^{i}\right\} /\left\{a^{i}, \varnothing\right\} /\{\varnothing, \varnothing\} /\left\{a^{i}, c^{i}\right\} \stackrel{\text { result }}{\longrightarrow} W^{b}\left(a b_{l}\right)<W^{b}\left(N_{l}\right) \& \lambda \varepsilon(0.027,0.1]$

We can conclude, that country $b$ can improve its welfare by unilaterally changing its announcement and deviating into no agreement scenario, and based on that, we conclude that $\Omega^{a b}$ is not a Nash Equilibria if pollution is local and $\lambda \varepsilon(0.027,0.1]$.

$\Omega^{a b}$ is not a Nash Equilibria if pollution is global.

\section{PROOF:}

country a $=\{b, \varnothing\} \stackrel{\text { change }}{\longrightarrow}\{\varnothing, c\} /\left\{\varnothing, c^{i}\right\} /\left\{b^{i}, \varnothing\right\} /\{\varnothing, \varnothing\} /\left\{b^{i}, c^{i}\right\} \stackrel{\text { result }}{\longrightarrow} W^{a}\left(a b_{g}\right)<W^{a}\left(N_{g}\right)$

We can conclude, that country $a$ can improve its welfare by unilaterally changing its announcement and deviating into the no agreement scenario, and based on that, we conclude that $\Omega^{a b}$ is not a Nash Equilibria if pollution is global.

$\Omega^{a b}$ is not a CPNE if pollution is local and $\lambda \varepsilon(0,0.027]$.

\section{PROOF:}


We prove the above by examining the coalitional deviation of two dirty countries in the form of a deep bilateral trade agreement. In this case, the announcement profile would be altered as follows: $\Omega \equiv\left\{\sigma_{a}=\{b, \varnothing\}, \sigma_{b}^{i}=\left\{\varnothing, c^{i}\right\}, \sigma_{c}^{i}=\left\{\varnothing, b^{i}\right\}\right\}$, and as a result, we observe the increase in members' welfare levels, $W^{b}\left(b c_{l}^{i}\right)>W^{b}\left(a b_{l}\right)$ and $W^{c}\left(b c_{l}^{i}\right)>W^{c}\left(a b_{l}\right)$. Though both members have an incentive to announce $a$ as well, and consequently, turn into a hub, the nature of their agreement prevents this deviation (announcements should match at both levels, the partner's name and the type of FTA), and we conclude that no further deviations can occur. Based on the above, $\Omega^{a b}$ is not a CPNE if pollution is local and $\lambda \varepsilon(0,0.027]$.

$$
\Omega^{a b i} \equiv\left\{\sigma_{a}^{i}=\left\{b^{i}, \varnothing\right\}, \sigma_{b}^{i}=\left\{a^{i}, \varnothing\right\}, \sigma_{c}^{i}=\{\varnothing, \varnothing\}\right\}
$$

$\Omega^{\text {abi }}$ is not a Nash Equilibria if pollution is local.

PROOF:

country $\mathrm{b}=\left\{a^{i}, \varnothing\right\} \stackrel{\text { change }}{\longrightarrow}\{\varnothing, c\} /\left\{\varnothing, c^{i}\right\} /\{a, \varnothing\} /\{\varnothing, \varnothing\} /\{a, c\} \stackrel{\text { result }}{\longrightarrow} W^{b}\left(a b_{l}^{i}\right)<W^{b}\left(N_{l}\right)$

We can conclude, that country $b$ has an incentive to self-exclude itself.

Based on the above, we conclude $\Omega^{a b i}$ is not a Nash Equilibria if pollution is local. $\Omega^{a b i}$ is a Nash Equilibria if pollution is global.

\section{PROOF:}

country a $=\left\{b^{i}, \varnothing\right\} \stackrel{\text { change }}{\longrightarrow}\left\{b^{i}, c^{i}\right\} \stackrel{\text { result }}{\longrightarrow}$ no change in $a$ 's welfare

country a $=\left\{b^{i}, \varnothing\right\} \stackrel{\text { change }}{\longrightarrow}\{\varnothing, c\} /\left\{\varnothing, c^{i}\right\} /\{b, \varnothing\} /\{\varnothing, \varnothing\} /\{b, c\} \stackrel{\text { result }}{\longrightarrow} W^{a}\left(a b_{g}^{i}\right)>W^{a}\left(N_{g}\right)$

We can conclude, that country $a$ has no incentive to change its announcement.

country $\mathrm{b}=\left\{a^{i}, \varnothing\right\} \stackrel{\text { change }}{\longrightarrow}\left\{a^{i}, c^{i}\right\} \stackrel{\text { result }}{\longrightarrow}$ no change in $b$ 's welfare

country $\mathrm{b}=\left\{a^{i}, \varnothing\right\} \stackrel{\text { change }}{\longrightarrow}\{\varnothing, c\} /\left\{\varnothing, c^{i}\right\} /\{a, \varnothing\} /\{\varnothing, \varnothing\} /\{a, c\} \stackrel{\text { result }}{\longrightarrow} W^{b}\left(a b_{g}^{i}\right)>W^{b}\left(N_{g}\right)$

We can conclude, that country $b$ has no incentive to change its announcement.

country $\mathrm{c}=\{\varnothing, \varnothing\} \stackrel{\text { change }}{\longrightarrow}\{a, \varnothing\} /\left\{a^{i}, \varnothing\right\} /\{\varnothing, b\} /\left\{\varnothing, b^{i}\right\} /\{a, b\} /\left\{a^{i}, b^{i}\right\} \stackrel{\text { result }}{\longrightarrow}$ no change in $c^{\prime} s$ welfare

We can conclude, that country $c$ has no incentive to change its announcement.

Based on the above, we conclude $\Omega^{a b i}$ is a Nash Equilibria if pollution is global. $\Omega^{a b i}$ is not a CPNE if pollution is global. 


\section{PROOF:}

We prove the above by examining the grand coalition. In this case, the announcement profile would be altered as follows: $\Omega \equiv\left\{\sigma_{a}^{i}=\left\{b^{i}, c^{i}\right\}, \sigma_{b}^{i}=\left\{a^{i}, c^{i}\right\}, \sigma_{c}^{i}=\left\{a^{i}, b^{i}\right\}\right\}$, and as a result, we observe the increase in members' welfare levels, $W^{a}\left(a b c_{g}^{i}\right)>W^{a}\left(a b_{g}^{i}\right) \& W^{b}\left(a b c_{g}^{i}\right)>W^{b}\left(a b_{g}^{i}\right)$ $\& W^{c}\left(a b c_{g}^{i}\right)>W^{c}\left(a b_{g}^{i}\right)$. Though for some levels of lambda, dirty countries would achieve higher welfare levels if they exclude the only clean country form the deep free trade agreement, country $\mathrm{c}$ would not agree to sign such agreement with $\mathrm{b}$, because $\mathrm{b}$ has an incentive to deviate further and still announce the clean country a, and by doing so, turn into a hub. Based on that, we conclude that no further deviations can occur. and $\Omega^{a b i}$ is not a CPNE.

$$
\Omega^{b c} \equiv\left\{\sigma_{a}=\{\varnothing, \varnothing\}, \sigma_{b}=\{\varnothing, c\}, \sigma_{c}=\{\varnothing, b\}\right\}
$$

$\Omega^{b c}$ is a Nash Equilibria for both local and global levels of pollution.

PROOF:

country $\mathrm{a}=\{\varnothing, \varnothing\} \stackrel{\text { change }}{\longrightarrow}\{b, \varnothing\} /\left\{b^{i}, \varnothing\right\} /\{\varnothing, c\} /\left\{\varnothing, c^{i}\right\} /\{b, c\} /\left\{b^{i}, c^{i}\right\} \stackrel{\text { result }}{\longrightarrow}$ no change in $a$ 's welfare

We can conclude, that country $a$ has no incentive to change its announcement.

country $\mathrm{b}=\{\varnothing, c\} \stackrel{\text { change }}{\longrightarrow}\{a, c\} \stackrel{\text { result }}{\longrightarrow}$ no change in $b$ 's welfare

country $\mathrm{b}=\{\varnothing, c\} \stackrel{\text { change }}{\longrightarrow}\{a, \varnothing\} /\left\{a^{i}, \varnothing\right\} /\{\varnothing, \varnothing\} /\left\{\varnothing, c^{i}\right\} /\left\{a^{i}, c^{i}\right\} \stackrel{\text { result }}{\longrightarrow} W^{b}\left(b c_{\theta}\right)>W^{b}\left(N_{\theta}\right)$

We can conclude, that country $b$ has no incentive to change its announcement.

country $\mathrm{c}=\{\varnothing, b\} \stackrel{\text { change }}{\longrightarrow}\{a, b\} \stackrel{\text { result }}{\longrightarrow}$ no change in $c$ 's welfare

country c $=\{\varnothing, b\} \stackrel{\text { change }}{\longrightarrow}\{a, \varnothing\} /\left\{a^{i}, \varnothing\right\} /\{\varnothing, \varnothing\} /\left\{\varnothing, b^{i}\right\} /\left\{a^{i}, b^{i}\right\} \stackrel{\text { result }}{\longrightarrow} W^{c}\left(b c_{\theta}\right)>W^{c}\left(N_{\theta}\right)$

We can conclude, that country $c$ has no incentive to change its announcement.

Based on the above, we conclude that $\Omega^{b c}$ is a Nash Equilibria for both local and global levels of pollution.

$\Omega^{b c}$ is not a CPNE for both local and global levels of pollution.

\section{PROOF:}

First, we consider the case of local pollution and relatively high lambda, $\lambda \varepsilon(0.023,0.1]$. In this case, the clean country $a$ is interested in forming a coalition with either dirty country, and welfare 
levels would be as follows: $W^{b}\left(b_{l}^{h}\right)=W^{c}\left(c_{l}^{h}\right)>W^{b}\left(b c_{l}\right)=W^{c}\left(b c_{l}\right)$ and $W^{a}\left(b_{l}^{h}\right)=W^{a}\left(c_{l}^{h}\right)>$ $W^{a}\left(b c_{l}\right)$ if $\lambda \varepsilon(0.023,0.1]$. We can conclude that $\Omega^{b c}$ is not a CPNE if pollution is local and $\lambda \varepsilon(0.023,0.1]$. Now, we examine two cases together, the case of local pollution and relatively low lambda, $\lambda \varepsilon(0.023,0.1]$, and the case of global pollution and any level of lambda, and we observe that though the clean country $a$ is not interested in the forming a trade union with either dirty country, those countries can simply add an environmental clause to their shallow trade agreement and gain higher levels of welfares, $W^{j}\left(b c_{\theta}^{i}\right)>W^{j}\left(b c_{\theta}\right)$. Based on the above, we conclude that $\Omega^{b c}$ is not a CPNE for both levels of pollution and any level of lambda.

$$
\Omega^{b c i} \equiv\left\{\sigma_{a}^{i}=\{\varnothing, \varnothing\}, \sigma_{b}^{i}=\left\{\varnothing, c^{i}\right\}, \sigma_{c}^{i}=\left\{\varnothing, b^{i}\right\}\right\}
$$

$\Omega^{\text {bci }}$ is a Nash Equilibria for both local and global levels of pollution.

PROOF:

country a $=\{\varnothing, \varnothing\} \stackrel{\text { change }}{\longrightarrow}\{b, \varnothing\} /\left\{b^{i}, \varnothing\right\} /\{\varnothing, c\} /\left\{\varnothing, c^{i}\right\} /\{b, c\} /\left\{b^{i u}, c^{i u}\right\} \stackrel{\text { result }}{\longrightarrow}$ no change in $a^{\prime} s$ welfare

We can conclude, that country $a$ has no incentive to change its announcement.

country $\mathrm{b}=\left\{\varnothing, c^{i}\right\} \stackrel{\text { change }}{\longrightarrow}\left\{a^{i}, c^{i}\right\} \stackrel{\text { result }}{\longrightarrow}$ no change in $b$ 's welfare

country $\mathrm{b}=\left\{\varnothing, c^{i}\right\} \stackrel{\text { change }}{\longrightarrow}\{a, \varnothing\} /\left\{a^{i}, \varnothing\right\} /\{\varnothing, \varnothing\} /\{\varnothing, c\} /\{a, c\} \stackrel{\text { result }}{\longrightarrow} W^{b}\left(b c_{\theta}^{i}\right)>W^{b}\left(N_{\theta}\right)$

We can conclude, that country $b$ has no incentive to change its announcement.

country $\mathrm{c}=\left\{\varnothing, b^{i}\right\} \stackrel{\text { change }}{\longrightarrow}\left\{a^{i}, b^{i}\right\} \stackrel{\text { result }}{\longrightarrow}$ no change in $c^{\prime}$ 's welfare

country $\mathrm{c}=\left\{\varnothing, b^{i}\right\} \stackrel{\text { change }}{\longrightarrow}\{a, \varnothing\} /\left\{a^{i}, \varnothing\right\} /\{\varnothing, \varnothing\} /\{\varnothing, b\} /\{a, b\} \stackrel{\text { result }}{\longrightarrow} W^{c}\left(b c_{\theta}^{i}\right)>W^{c}\left(N_{\theta}\right)$

We can conclude, that country $c$ has no incentive to change its announcement.

Based on the above, we conclude that $\Omega^{b c i}$ is a Nash Equilibria for both local and global levels of pollution.

$\Omega^{\text {bci }}$ is a CPNE if pollution is local \& $\lambda \varepsilon(0,0.008]$.

PROOF:

Though both members of this deep bilateral trade agreement would prefer to make a side deal with the clean country $a$, and consequently, assume the role of a hub in a shallow hub-and-spoke trade regime, this deviation is not possible due to the nature of the original agreement (announcements 
should match at both levels, the partner's name and the type of FTA). All other deviations are not meaningful, simply because they bring lower levels of welfares to their members. Based on that, we conclude that there are no coalitional deviations which can be meaningful for either member, and $\Omega^{b c i}$ is a CPNE if pollution is local and $\lambda \varepsilon(0,0.008]$.

$\Omega^{b c i}$ is not a CPNE if pollution is local \& $\lambda \varepsilon(0.008,0]$ or if pollution is global.

PROOF:

We prove the above by examining the coalitional deviation of one clean and one dirty country. Either member of this deep bilateral trade agreement is interested in making a side deal with the only clean member of the world, country $a$. Country $a$ would except this offer from either dirty country. The clean player is better of as a spoke than as an outsider of a deep FTA of two dirty countries.

$$
\Omega^{a h} \equiv\left\{\sigma_{a}=\{b, c\}, \sigma_{b}=\{a, \varnothing\}, \sigma_{c}=\{a, \varnothing\}\right\}
$$

$\Omega^{\text {ah }}$ is not a Nash Equilibria if pollution is local.

PROOF:

country $\mathrm{c}=\{a, \varnothing\} \stackrel{\text { change }}{\longrightarrow}\{\varnothing, \varnothing\} /\left\{a^{i}, b^{i}\right\} /\{\varnothing, b\} /\left\{\varnothing, b^{i}\right\} /\left\{a^{i}, \varnothing\right\} \stackrel{\text { result }}{\longrightarrow} W^{c}\left(a_{l}^{h}\right)<W^{c}\left(a b_{l}\right)$

We can conclude, that country $c$ has an incentive to self-exclude itself.

Based on the above, we can conclude that $\Omega^{a h}$ is not a Nash Equilibria if pollution is local. $\Omega^{a h}$ is not a Nash Equilibria if pollution is global.

PROOF:

country a $=\{b, c\} \stackrel{\text { change }}{\longrightarrow}\{\varnothing, \varnothing\} /\left\{b^{i}, c^{i}\right\} /\left\{b^{i}, \varnothing\right\} /\left\{\varnothing, c^{i}\right\} \stackrel{\text { result }}{\longrightarrow} W^{a}\left(a_{g}^{h}\right)<W^{a}\left(N_{g}\right)$

We can conclude, that country $a$ has an incentive to self-exclude itself.

Based on the above, we can conclude that $\Omega^{a h}$ is not a Nash Equilibria if pollution is global.

$$
\Omega^{a h i} \equiv\left\{\sigma_{a}^{i}=\left\{b^{i}, c^{i}\right\}, \sigma_{b}^{i}=\left\{a^{i}, \varnothing\right\}, \sigma_{c}^{i}=\left\{a^{i}, \varnothing\right\}\right\}
$$

$\Omega^{\text {ahi }}$ is not a Nash Equilibria if pollution is local.

PROOF:

country c $=\left\{a^{i}, \varnothing\right\} \stackrel{\text { change }}{\longrightarrow}\{\varnothing, \varnothing\} /\{a, b\} /\left\{\varnothing, b^{i}\right\} /\{\varnothing, b\} /\{a, \varnothing\} \stackrel{\text { result }}{\longrightarrow} W^{c}\left(a_{l}^{\text {hi }}\right)<W^{c}\left(a b_{l}^{i}\right)$ 
We can conclude, that country $c$ has an incentive to self-exclude itself.

Based on the above, we conclude that $\Omega^{a h i}$ is not a Nash Equilibria if pollution is local.

$\Omega^{\text {ahi }}$ is a Nash Equilibria if pollution is global.

PROOF:

country a $=\left\{b^{i}, c^{i}\right\} \stackrel{\text { change }}{\longrightarrow}\left\{b^{i}, \varnothing\right\} /\left\{\varnothing, c^{i}\right\} \stackrel{\text { result }}{\longrightarrow} W^{a}\left(a_{g}^{h i}\right)>W^{a}\left(a b_{g}^{i}\right)=W^{a}\left(a c_{g}^{i}\right)$

country $\mathrm{a}=\left\{b^{i}, c^{i}\right\} \stackrel{\text { change }}{\longrightarrow}\{\varnothing, \varnothing\} /\{b, c\} /\{b, \varnothing\} /\{\varnothing, c\} \stackrel{\text { result }}{\longrightarrow} W^{a}\left(a_{g}^{h i}\right)>W^{a}\left(N_{g}\right)$

We can conclude, that country $a$ has no incentive to change its announcement.

country $\mathrm{b}=\left\{a^{i}, \varnothing\right\} \stackrel{\text { change }}{\longrightarrow}\left\{a^{i}, c^{i}\right\} \stackrel{\text { result }}{\longrightarrow}$ no change in $b$ 's welfare

country $\mathrm{b}=\left\{a^{i}, \varnothing\right\} \stackrel{\text { change }}{\longrightarrow}\{\varnothing, \varnothing\} /\{a, c\} /\left\{\varnothing, c^{i}\right\} /\{\varnothing, c\} /\{a, \varnothing\} \stackrel{\text { result }}{\longrightarrow} W^{b}\left(a_{g}^{h i}\right)>W^{b}\left(a c_{g}^{i}\right)$

We can conclude, that country $b$ has no incentive to change its announcement.

country $\mathrm{c}=\left\{a^{i}, \varnothing\right\} \stackrel{\text { change }}{\longrightarrow}\left\{a^{i}, b^{i}\right\} \stackrel{\text { result }}{\longrightarrow}$ no change in $c^{\prime}$ 's welfare

country $\mathrm{c}=\left\{a^{i}, \varnothing\right\} \stackrel{\text { change }}{\longrightarrow}\{\varnothing, \varnothing\} /\{a, b\} /\left\{\varnothing, b^{i}\right\} /\{\varnothing, b\} /\{a, \varnothing\} \stackrel{\text { result }}{\longrightarrow} W^{c}\left(a_{g}^{h i}\right)>W^{c}\left(a b_{g}^{i}\right)$

We can conclude, that country $c$ has no incentive to change its announcement.

Based on the above, we conclude that $\Omega^{a h i}$ is a Nash Equilibria if pollution is global.

$\Omega^{\text {ahi }}$ is not a CPNE if pollution is global.

PROOF:

To prove the above, we consider a coalitional deviation of two dirty countries, country $b$ and country $c$. By forming this coalition these two players would "drive" the clean country into a deep free trade agreement, and improve their welfare levels. Dirty countries would prefer to live in a fully integrated world versus being spokes. Though for some levels of lambda, clean countries would achieve higher welfare levels if they exclude the only clean country form the deep free trade agreement, neither of them would agree to that, because in this case both members would have an incentive to keep country $a$ in their announcement and turn into a hub themselves. Based on the above, we conclude that $\Omega^{a h i}$ is not a CPNE if pollution is global.

$$
\Omega^{b h} \equiv\left\{\sigma_{a}=\{b, \varnothing\}, \sigma_{b}=\{a, c\}, \sigma_{c}=\{\varnothing, b\}\right\}
$$

$\Omega^{\text {bh }}$ is not a Nash Equilibria if pollution is local.

PROOF: 
country $\mathrm{c}=\{\varnothing, b\} \stackrel{\text { change }}{\longrightarrow}\{\varnothing, \varnothing\} /\left\{a^{i}, b^{i}\right\} /\{a, \varnothing\} /\left\{a^{i}, \varnothing\right\} /\left\{\varnothing, b^{i}\right\} \stackrel{\text { result }}{\longrightarrow} W^{c}\left(b_{l}^{h}\right)<W^{c}\left(a b_{l}\right)$

We can conclude, that country $c$ has an incentive to self-exclude itself.

Based on the above, we conclude that $\Omega^{b h}$ is not a Nash Equilibria if pollution is local. $\Omega^{\text {bh }}$ is not a Nash Equilibria if pollution is global.

PROOF:

country a $=\{b, \varnothing\} \stackrel{\text { change }}{\longrightarrow}\{\varnothing, \varnothing\} /\left\{b^{i}, c^{i}\right\} /\{\varnothing, c\} /\left\{\varnothing, c^{i}\right\} /\left\{a^{i}, \varnothing\right\} \stackrel{\text { result }}{\longrightarrow} W^{a}\left(b_{g}^{h}\right)<W^{a}\left(b c_{g}\right)$

We can conclude, that country $a$ has an incentive to self-exclude itself.

Based on the above, we can conclude that $\Omega^{b h}$ is not a Nash Equilibria if pollution is global.

$$
\Omega^{b h i} \equiv\left\{\sigma_{a}^{i}=\left\{b^{i}, \varnothing\right\}, \sigma_{b}^{i}=\left\{a^{i}, c^{i}\right\}, \sigma_{c}^{i}=\left\{\varnothing, b^{i}\right\}\right\}
$$

$\Omega^{\text {bhi }}$ is not a Nash Equilibria for both local and global levels of pollution.

PROOF:

country $\mathrm{c}=\left\{\varnothing, b^{i}\right\} \stackrel{\text { change }}{\longrightarrow}\{\varnothing, \varnothing\} /\{a, b\} /\left\{a^{i}, \varnothing\right\} /\{a, \varnothing\} /\{\varnothing, b\} \stackrel{\text { result }}{\longrightarrow} W^{c}\left(b_{\theta}^{h i}\right)<W^{c}\left(a b_{\theta}^{i}\right)$

We can conclude, that country $c$ has an incentive to self-exclude itself.

Based on the above, we conclude that $\Omega^{b h i}$ is not a Nash Equilibria for both local and global levels of pollution.

$$
\Omega^{F} \equiv\left\{\sigma_{a}=\{b, c\}, \sigma_{b}=\{a, c\}, \sigma_{c}=\{a, b\}\right\}
$$

$\Omega^{\digamma}$ is a Nash Equilibria if pollution is local and $\lambda \varepsilon(0,0.043]$.

PROOF:

country a $=\{b, c\} \stackrel{\text { change }}{\longrightarrow}\{b, \varnothing\} /\{\varnothing, c\} \stackrel{\text { result }}{\longrightarrow} W^{a}\left(a b c_{l}\right)>W^{a}\left(b_{l}^{h}\right)=W^{a}\left(c_{l}^{h}\right)$

country a $=\{b, c\} \stackrel{\text { change }}{\longrightarrow}\{\varnothing, \varnothing\} /\left\{b^{i}, c^{i}\right\} /\left\{b^{i}, \varnothing\right\} /\left\{\varnothing, c^{i}\right\} \stackrel{\text { result }}{\longrightarrow} W^{a}\left(a b c_{l}\right)>W^{a}\left(b c_{l}\right)$

We can conclude, that country $a$ has no incentive to change its announcement.

country $\mathrm{b}=\{a, c\} \stackrel{\text { change }}{\longrightarrow}\{a, \varnothing\} \stackrel{\text { result }}{\longrightarrow} W^{b}\left(a b c_{l}\right)>W^{b}\left(a_{l}^{h}\right)$

country $\mathrm{b}=\{a, c\} \stackrel{\text { change }}{\longrightarrow}\{\varnothing, c\} \stackrel{\text { result }}{\longrightarrow} W^{b}\left(a b c_{l}\right)>W^{b}\left(c_{l}^{h}\right)$

country $\mathrm{b}=\{a, c\} \stackrel{\text { change }}{\longrightarrow}\{\varnothing, \varnothing\} /\left\{a^{i}, c^{i}\right\} /\left\{a^{i}, \varnothing\right\} /\left\{\varnothing, c^{i}\right\} \stackrel{\text { result }}{\longrightarrow} W^{b}\left(a b c_{l}\right)>W^{b}\left(a c_{l}\right) \& \lambda \varepsilon(0,0.043]$

We can conclude, that country $b$ has no incentive to change its announcement.

country $\mathrm{c}=\{a, b\} \stackrel{\text { change }}{\longrightarrow}\{a, \varnothing\} \stackrel{\text { result }}{\longrightarrow} W^{c}\left(a b c_{l}\right)>W^{c}\left(a_{l}^{h}\right)$ 
country $\mathrm{c}=\{a, b\} \stackrel{\text { change }}{\longrightarrow}\{\varnothing, b\} \stackrel{\text { result }}{\longrightarrow} W^{c}\left(a b c_{l}\right)>W^{c}\left(b_{l}^{h}\right)$

country $\mathrm{c}=\{a, b\} \stackrel{\text { change }}{\longrightarrow}\{\varnothing, \varnothing\} /\left\{a^{i}, b^{i}\right\} /\left\{a^{i}, \varnothing\right\} /\left\{\varnothing, b^{i}\right\} \stackrel{\text { result }}{\longrightarrow} W^{c}\left(a b c_{l}\right)>W^{c}\left(a b_{l}\right) \& \lambda \varepsilon(0,0.043]$

We can conclude, that country $c$ has no incentive to change its announcement.

Based on the above, we conclude that $\Omega^{\digamma}$ is a Nash Equilibria if pollution is local and $\lambda \varepsilon(0,0.043]$.

$\Omega^{\digamma}$ is not a Nash Equilibria if pollution is local and $\lambda \varepsilon(0.043,0.1]$.

PROOF:

country $\mathrm{c}=\{a, b\} \stackrel{\text { change }}{\longrightarrow}\{\varnothing, \varnothing\} /\left\{a^{i}, b^{i}\right\} /\left\{a^{i}, \varnothing\right\} /\left\{\varnothing, b^{i}\right\} \stackrel{\text { result }}{\longrightarrow} W^{c}\left(a b c_{l}\right)<W^{c}\left(a b_{l}\right) \& \lambda \varepsilon(0.043,0.1]$

We can conclude, that country $c$ has an incentive to self-exclude itself.

Based on the above, we conclude that $\Omega^{\digamma}$ is not a Nash Equilibria if pollution is local and \& $\lambda \varepsilon(0.043,0.1]$.

$\Omega^{\digamma}$ is not a Nash Equilibria if pollution is global.

PROOF:

country a $=\{b, c\} \stackrel{\text { change }}{\longrightarrow}\{\varnothing, \varnothing\} /\left\{b^{i}, c^{i}\right\} /\left\{b^{i}, \varnothing\right\} /\left\{\varnothing, c^{i}\right\} \stackrel{\text { result }}{\longrightarrow} W^{a}\left(a b c_{l}\right)<W^{a}\left(b c_{l}\right)$

We can conclude, that country $a$ has an incentive to self-exclude itself.

Based on the above, we conclude that $\Omega^{\digamma}$ is not a Nash Equilibria if pollution is global.

$\Omega^{\digamma}$ is not a CPNE if pollution is local and $\lambda \varepsilon(0,0.043]$.

PROOF:

We prove the above by examining the coalitional deviation of two clean countries, country $b$ and country $c$, in the form of a deep bilateral free trade agreement, then $W^{b}\left(b c_{g}^{i}\right)=W^{c}\left(b c_{g}^{i}\right)>$ $W^{b}\left(a b c_{g}\right)=W^{c}\left(a b c_{g}\right)$. There cannot be any further deviations, because an outsider of this agreement does not announce an environmental clause. Based on the above, we can conclude that the announcement profile $\Omega^{\digamma}$ does not survive a coalition-proof Nash equilibria refinement.

$$
\Omega^{F^{i}} \equiv\left\{\sigma_{a}^{i}=\left\{b^{i}, c^{i}\right\}, \sigma_{b}^{i}=\left\{a^{i}, c^{i}\right\}, \sigma_{c}^{i}=\left\{a^{i}, b^{i}\right\}\right\}
$$

$\Omega^{\digamma^{i}}$ is not a Nash Equilibria if pollution is local.

PROOF:

country $\mathrm{c}=\left\{a^{i}, b^{i}\right\} \stackrel{\text { change }}{\longrightarrow}\{\varnothing, \varnothing\} /\{a, b\} /\{a, \varnothing\} /\{\varnothing, b\} \stackrel{\text { result }}{\longrightarrow} W^{c}\left(a b_{l}^{i}\right)>W^{c}\left(a b c_{l}^{i}\right)$ 
We can conclude, that country $c$ has an incentive to self-exclude itself.

Based on the above, we conclude $\Omega^{F^{i}}$ is not a Nash Equilibria if pollution is local.

$\Omega^{\digamma^{i}}$ is a Nash Equilibria if pollution is global.

PROOF:

country a $=\left\{b^{i}, c^{i}\right\} \stackrel{\text { change }}{\longrightarrow}\left\{b^{i}, \varnothing\right\} /\left\{\varnothing, c^{i}\right\} \stackrel{\text { result }}{\longrightarrow} W^{a}\left(a b c_{g}^{i}\right)>W^{a}\left(b_{g}^{h i}\right)=W^{a}\left(c_{g}^{h i}\right)$

country $\mathrm{a}=\left\{b^{i}, c^{i}\right\} \stackrel{\text { change }}{\longrightarrow}\{\varnothing, \varnothing\} /\{b, c\} /\{b, \varnothing\} /\{\varnothing, c\} \stackrel{\text { result }}{\longrightarrow} W^{a}\left(a b c_{g}^{i}\right)>W^{a}\left(b c_{g}^{i}\right)$

We can conclude, that country $a$ has no incentive to change its announcement.

country $\mathrm{b}=\left\{a^{i}, c^{i}\right\} \stackrel{\text { change }}{\longrightarrow}\left\{a^{i}, \varnothing\right\} \stackrel{\text { result }}{\longrightarrow} W^{b}\left(a b c_{g}^{i}\right)>W^{b}\left(a_{g}^{h i}\right)$

country $\mathrm{b}=\left\{a^{i}, c^{i}\right\} \stackrel{\text { change }}{\longrightarrow}\left\{\varnothing, c^{i}\right\} \stackrel{\text { result }}{\longrightarrow} W^{b}\left(a b c_{g}^{i}\right)>W^{b}\left(c_{g}^{h i}\right)$

country $\mathrm{b}=\left\{a^{i}, c^{i}\right\} \stackrel{\text { change }}{\longrightarrow}\{\varnothing, \varnothing\} /\{a, c\} /\{a, \varnothing\} /\{\varnothing, c\} \stackrel{\text { result }}{\longrightarrow} W^{b}\left(a b c_{g}^{i}\right)>W^{b}\left(a c_{g}^{i}\right)$

We can conclude, that country $b$ has no incentive to change its announcement.

country $\mathrm{c}=\left\{a^{i}, b^{i}\right\} \stackrel{\text { change }}{\longrightarrow}\left\{a^{i}, \varnothing\right\} \stackrel{\text { result }}{\longrightarrow} W^{c}\left(a b c_{g}^{i}\right)>W^{c}\left(a_{g}^{h i}\right)$

country $\mathrm{c}=\left\{a^{i}, b^{i}\right\} \stackrel{\text { change }}{\longrightarrow}\left\{\varnothing, b^{i}\right\} \stackrel{\text { result }}{\longrightarrow} W^{c}\left(a b c_{g}^{i}\right)>W^{c}\left(b_{g}^{h i}\right)$

country $\mathrm{c}=\left\{a^{i}, b^{i}\right\} \stackrel{\text { change }}{\longrightarrow}\{\varnothing, \varnothing\} /\{a, b\} /\{a, \varnothing\} /\{\varnothing, b\} \stackrel{\text { result }}{\longrightarrow} W^{c}\left(a b c_{g}^{i}\right)>W^{c}\left(a b_{g}^{i}\right)$

We can conclude, that country $c$ has no incentive to change its announcement.

Based on the above, we conclude that $\Omega^{\digamma^{i}}$ is a Nash Equilibria if pollution is local.

$\Omega^{\digamma^{i}}$ is a CPNE if pollution is global.

PROOF:

To prove the above, we consider every possible deviation in the following six steps:

First, we assume that one clean and one dirty country deviate in the form of a shallow bilateral trade agreement, then $W^{a}\left(a b_{g}\right)=W^{a}\left(a c_{g}\right)<W^{a}\left(a b c_{g}^{i}\right)$. We can see that this deviation is not meaningful.

Second, we assume that one clean and one dirty country deviate in the form of a deep bilateral trade agreement, then $W^{a}\left(a b_{g}^{i}\right)=W^{a}\left(a c_{g}^{i}\right)<W^{a}\left(a b c_{g}^{i}\right)$, and again, we observe that this deviation is not meaningful.

Next, we consider the coalitional deviation of two symmetric dirty countries in the form of a shallow bilateral trade agreement, then $W^{j}\left(b c_{g}\right)<W^{j}\left(a b c_{g}^{i}\right)$ where $j \neq a$. We can see that this devia- 
tion is not meaningful as well.

Now, we consider the coalitional deviation of two symmetric dirty countries in the form of a deep bilateral trade agreement and $\lambda \varepsilon(0,0.089]$, and as a result of this agreement, we have the following levels of welfares $W^{j}\left(b c_{g}^{i}\right)>W^{j}\left(a b c_{g}^{i}\right)$ where $j \neq a$. However, both countries have an incentive to deviate further and become a hub: $W^{j}\left(j_{g}^{h i}\right)>W^{j}\left(b c_{g}^{i}\right)$. We conclude that this deviation is not self-enforcing.

In this step, we consider the coalitional deviation of two symmetric dirty countries in the form of a deep bilateral trade agreement and $\lambda \varepsilon(0.089,0.1]$, and we observe that the only reason dirty countries would form this agreement is a further deviation to become a hub: $W^{j}\left(j_{g}^{i}\right)>W^{j}\left(a b c_{j}^{i}\right)>$ $W^{j}\left(b c_{g}^{i}\right)$ where $j \neq a$.

Finally, we consider a grand coalition in the form of free trade world, and again we observe that this deviation cannot be meaningful.

Based on the above, we can conclude that $\Omega^{\digamma^{i}}$ is a CPNE if pollution is global. 


\section{References}

Antweiler, W., Copeland, B.R., Taylor, M.S., 2001. Is free trade good for the environment?, Amer. Econ. Rev. 91, 877-908.

Bagwell, K., Staiger, R.W., 1997. Multilateral Tariff cooperation during the formation of customs unions. J. Int. Econ. 42, 91-123 (Elsevier).

Bagwell, K., Staiger, R.W., 1998. Regionalism and multilateral tariff cooperation. In: Piggott, John, Woodland, Alan (Eds.), International Trade Policy and the Pacific Rim. MacMillan, London. Barrett, S. (1994) “Strategic environmental policy and international trade,” Journal of Public Economics 54(3), 325-38

Bernheim, D. B., Peleg, B.,Whinston, M.D.,, 1987. Coalition-proof Nash equilibria I. Concepts. Journal of Economic Theory 42, 1-12.

Bernheim, D. B., B.,Whinston, M.D.,, 1987. Coalition-proof Nash equilibria II. Applications. Journal of Economic Theory 42, 13-29.

Bond, E.W., Constantinos S., 1996. The size of trading blocs: market power and world welfare effects. J. Int. Econ. 40, 411-437.

Broda, C., Limao, N., Weinstein, D.E., 2008. Optimal tariffs and market power: the evidence. Am. Econ. Rev. 98 (5), 2032-2065.

Copeland, B.R., Taylor, M.S., (1994) North-South trade and the environment, Quart. J. Econ. 438, $755-787$.

Diamantoudi, E., Sartzetakis, E., Strantza, S., 2018. International Environmental Agreements - The Impact of Heterogeneity among Countries on Stability. Working Paper, retrieved from https://papers.ssrn.com/sol3/papers.cfm?abstract_id=3209170, 34 pages.

Feenstra, R., 2004, Advanced International Trade. Princeton University Press.

Ferrara, I., Missios, P., Yildiz, H.M, 2009. Trading rules and the environment: Does equal treatment lead to a cleaner world? Journal of Environmental Economics and Management 58, 206-225. Ferrara, I., Missios, P., Yildiz, H.M, 2011. Inter-regional competition, comparative advantage and environmental federalism. Working Papers 027, Ryerson University, Department of Economics. 
Grossman, G.M., McCalman, P., Staiger, R.W., The "NEW" economics of trade agreements: from trade liberalization to regulatory convergence? Working Paper 26132, retrieved from http://www.nber.org/papers/w26132

Horn, H., Maggi, G., Staiger, R.W., 2010. Trade agreements as endogenously incomplete contracts. Am. Econ. Rev. 100 (1), 394-419.

Lawrence, R., Z., 1996. Regionalism, Multilateralism, and Deeper Integration. Washington, DC: Brookings Institution.

Limão, N., 2016. 2016. Preferential Trade Agreements. NBER Working Paper 22138, March.

Missios, P., Saggi, K., Yildiz, H.M, 2016. External trade diversion, exclusion incentives and the nature of preferential trade agreements. Journal of International Economics 99, 105-119.

Moreno, D., Wooders, J., 1996. Coalition-Proof Equilibrium. Games and Economic Behavior 17, 80-112.

Morin, J.F., Brandi, C., Berger, A., 2018. The Multilateralization of PTA Environmental Clauses Scenarios for the Future? Working Paper, retrieved from http://www.academia.edu/35633107/

Morin, J.F., Dür, A., Lechner, L., 2018. Mapping the trade and environment nexus: Insights from a new dataset, Global Environmental Politics, vol. 18(1).

Rodrik, D., 2018. What Do Trade Agreements Really Do? Journal of Economic Perspectives, Volume 32, Number 2, Spring 2018, 73-90

Saggi, K., Yildiz, H. M., 2010. Bilateralism, multilateralism, and the quest for global free trade. J. Int. Econ. 81, 26-37. 